UNIVERSIDAD NACIONAL DE LA PLATA

FACULTAD DE HUMANIDADES Y CIENCIAS DE LA EDUCACION SECRETARIA DE POSGRADO

\title{
Identidad personal, ipseidad, alteridad y lenguaje en la obra de Martin Heidegger
}

\author{
Luis Fernando Butierrez \\ (IdIHSC,FaHCE,UNLP)
}

Tesis para optar por el grado de Doctor en Filosofía

Director : Dr. Oscar Esquisabel

(UNLP-Conicet)

Co director : Dr. Mario Presas

(UNLP-Conicet)

La Plata , 4 de septiembre 2017 


\section{Resumen}

La siguiente investigación tiene como objetivo analizar pormenorizadamente las elaboraciones en torno a la ipseidad, la alteridad y el lenguaje en el pensamiento y discurso de Martin Heidegger, atendiendo desplazamientos y proyecciones en el despliegue de su propia obra y en determinadas recepciones contemporáneas, así como también su articulación en el marco de la tradición con la que dialoga, en especial, con los desarrollos de su maestro Edmund Husserl. Con ello, buscaremos circunscribir un horizonte dialógico en los actuales abordajes respecto a la condición humana y los procesos socio-políticos de subjetivación e identificación, en el ineludible marco de sus relaciones con la alteridad, con la intención de contribuir para la profundización, despliegue y continuación del alcance de tales debates contemporáneos. En ese sentido, consideramos que la experiencia del pensar de Heidegger se halla implícita en las bases de numerosos abordajes temáticos afines, indefectiblemente ligados también a sus perspectivas sobre el lenguaje.

En efecto, las consideraciones sobre la autoconciencia y la identidad, con sus respectivas tensiones y reelaboraciones, representan un trayecto significativo del pensamiento occidental en el siglo XX y el nuestro. Específicamente, el desplazamiento desde las perspectivas existencialistas, al marxismo posterior a la segunda guerra mundial, pasando por el estructuralismo de la década del '60, hasta arribar a la hermenéutica y al posestructuralismo de los últimos años, señalan un singular desplazamiento comprensivo en occidente. Enfoques que, a través del abandono de la conceptualización de la metafísica de la subjetividad y los supuestos de unidad de la conciencia trascendental, centralistas y jerárquicos, permiten reelaborar y articular las filosofías del sujeto con las del lenguaje, atendiendo un carácter escindido, mediado y diferido en su configuración sociohistórica.

En ese contexto, los desarrollos de Heidegger han contribuido a reelaborar el discurso y el pensar respectivo, a partir de su replanteamiento del método fenomenológico y de la comprensión en torno al Dasein y sus relaciones mediadas con su sí-mismo, en el marco de su constelación entramada de estructuras. Así, la reconstrucción, análisis e interpretación de tales desarrollos, atendiendo minuciosamente sus variaciones y desplazamientos enunciativo-discursivos, en el contexto de su singular recepción de la tradición metafísica, articulado con las continuidades, rupturas y derivas de su recepción contemporánea, indican las diferentes paradas de nuestro recorrido por este tramo fundamental del pensamiento filosófico del siglo XX.

Palabras clave: IPSEIDAD, ALTERIDAD, LENGUAJE, PENSAMIENTO 


\section{Agradecimientos}

A Oscar Esquisabel, por su apoyo y orientación incondicional.

A Mario Presas, por su generosidad.

A Pablo Fernández, por acompañar un proceso de escritura para hacerlo vida y experiencia.

A Luciana Carrera, por su amistad e impulso hecho de fuego y Logos.

A Analía Melamed, por alentar este recorrido.

A mi familia: a mi padre, a mi madre, a mis hermanos, Maia, Fede, Paty; a mi abuela. A este conjunto preciado de vidas y luchas que me constituye y que late implícito en cada movimiento de estas páginas.

A mis amigas y amigos, por nuestro cruce vital en la existencia que confluye en este recorrido de investigación.

A todas y todos aquellos que ya no están, por su presencia-ausencia que también a movilizado este camino del pensar.

Finalmente, a una mujer sin igual, por su lucha abnegada, valiente y ejemplar que ha sido condición de posibilidad y oportunidad para este trabajo y recorrido.

En suma, a todas estas personas y experiencias que no solo han acompañado este proyecto y escrito, sino que constituyen, en definitiva, su Dasein propio. 


\section{Lista de abreviaturas utilizadas}

a) Obra de Heidegger

\begin{tabular}{|c|c|}
\hline A & Aletheia (Heraklit, Fragment 16) (1954b) \\
\hline AED & Aus der Erfahrung des Denkens (1947) \\
\hline AJPW & Anmerkungen zu Karl Jaspers »Psychologie der Weltanschauungen« (1919-1921) \\
\hline B & Besinnung (1938-1939a), \\
\hline $\mathrm{BH}$ & Brief über den Humanismus (1946) \\
\hline BP & $\begin{array}{l}\text { Zur Bestimmung der Philosophie. 1. Die Idee der Philosophie und das } \\
\text { Weltanschaunngsproblem (1919) }\end{array}$ \\
\hline BPE & Beiträge zur Philosophie (Vom Ereignis) (1936-1938) \\
\hline BwA & Briefe 1925-1975 (Briefwechsel mit Hannah Arendt) (1998) \\
\hline BwJ & Briefwechsel mit Karl Jaspers (1920-1963) \\
\hline BwR & Briefe 1912-1933(Briefwechsel mit Heinrich Rickert) (2002) \\
\hline $\mathrm{BZ}$ & Der Begriff der Zeit (1924) \\
\hline DGPh & Die Grundprobleme der Phänomenologie (1927b) \\
\hline DR & Der Rektorat 1933/34. (1945a) \\
\hline ED & Aus der Erfahrung des Denkens, (1910-1976) \\
\hline EHD & Erläuterungen zu Hölderlins Dichtung (1936-1968) \\
\hline EM & Einführung in die Metaphysik (1935) \\
\hline EP & Einleitung in die Philosophie (1928-1929) \\
\hline $\mathrm{EPhF}$ & Einführung in die phänomenologische Forschung (1923-1924) \\
\hline FT & Die Frage nach der Technik (1953) \\
\hline G & Gelassenheit (1959) \\
\hline GbaP & Die Grundbegriffe der antiken Philosophie (1926) \\
\hline GbM & Die Grundbegriffe der Metaphysik. Welt - Endlichkeit - Einsamkeit (1929-30) \\
\hline GfF & Grundfragen der Philosophie. Ausgewählte "Probleme" der "Logik" (1937-1938) \\
\hline $\mathrm{GPh}$ & Grundprobleme der Phänomenologie (1919-1920) \\
\hline $\mathrm{H}$ & $\begin{array}{l}\text { Heraklit. 1. Der Anfang des abendländischen Denkens (summer semester 1943) / } 2 . \\
\text { Logik. Heraklits Lehre vom Logos (1943-1944) }\end{array}$ \\
\hline Hw & Holzwege $(1936-1946)$ \\
\hline ID & Identität und Differenz (1955-1957) \\
\hline KBS & Die Kategorien und Bedeutungslehre des Duns Scotus, (1915) \\
\hline KPM & Kant und das Problem der Metaphysik (1929a) \\
\hline KV & $\begin{array}{l}\text { Wilhelm Diltheys Forschungsarbeit und der gegenwärtige Kampft um eine historische } \\
\text { Weltanschauung (Kasseler Vorträge) (1925) }\end{array}$ \\
\hline LFW & Logik. Die Frage nach der Wahrheit (1925-6) \\
\hline MAgL & Metaphysische Anfangsgründe der Logik im Ausgang von Leibniz (1928) \\
\hline MWPh & Mein Weg in die Phänomenologie (1963) \\
\hline N I & Nietzsche I (1936-1939) \\
\hline N II & Nietzsche II (1939-1946), \\
\hline $\mathrm{OHF}$ & Ontologie. Hermeneutik der Factizität (1923) \\
\hline
\end{tabular}


P Parménides (1942-3)

PhAA Phänomenologie der Anschauung und des Ausdrucks. Theorie der philosophischen Begriffsbildung (1920)

PhIA Phänomenologische Interpretationen zu Aristoteles zu Ontologie (Anzeige der hermeneutischen Situation) (1921-1922)

PRL Phänomenologie des religiösen Lebens. 1. Einleitung in die Phänomenologie der Religion (1920-1921)

SGH Spiegel-Gesprächt mit Martin Heidegger (1966)

SuZ Sein und Zeit (1927a)

SvG Der Satz vom Grund (1955-1956)

U II U Überlegungen II-VI (Schwarze Hefte) (1931-1938)

US Unterwegs zur Sprache (1950-1959)

UStS Überlieferte Sprache und technische Sprache (1962b)

U VII Überlegungen VII-XI (Schwarze Hefte) (1938-1939c)

U XII Überlegungen XII-XV (Schwarze Hefte) (1939-1941)

VA Vorträge und Aufsätze (1936-1953)

VWG Vom Wesen des Grundes (1929b)

WhD Was heisst Denken? (1951-1952)

WiM Was ist Metaphysik? (1929c)

WM Wegmarken,(1919-1961)

WP Was ist das - die Philosophie? (1955)

WS Das Wesen der Sprache (1957-1958)

WW Vom Wesen der Wahrheit (1930b)

ZEG Zur Erörterung der Gelassenheit. Aus einem Feldweggespräch über das Denken, (1944-1945)

ZS Zollikoner Seminare (1959-69)

ZSD Zur Sache des Denkens (1962-1964)

$\mathrm{ZuS} \quad$ Zeit und Sein, (1962a)

b. - Obra de Husserl:

BwF $\quad$ Briefwechsel. Vol. III: Die Freiburger Schule (1994)

CM Cartesianische Meditationen (1973[1931])

DL Die Lebenswelt. Auslegungen der vorgegebenen Welt und ihrer Konstitution (2008 [1916-37])

FTL Formale und Transzendentale Logik. Versuch einer Kritik der Logischen Vernunft, (1974[1929])

Ideen I Ideen zu einer reinen Phänomenologie und phänomenologischen Philosophie I: Allgemeine Einfuhrung in die reine Phänomenologie (1988 [1913])

Ideen II Ideen zur einer reinen Phänomenologie und phänomenologischen Philosophie II:

Phänomenologische Untersuchungen zur Konstitution (1952[1913])

KW Die Krisis der europäischen Wissenschaften und die transzendentale Phänomenologie (1954[1936])

LUI Logische Untersuchungen. I. Prolegomena zur reinen Logik (1975 [1900-1901])

LUII Logische Untersuchungen. II. Untersuchungen zur Phänomenologie und Theorie der Erkenntnis (1984 [1900-1901])

PhP Phänomenologische Psychologie (1968[1925]) 
Las citas de estas obras se realizarán a partir de las abreviaturas, especificando el nombre completo de una obra o bien al inicio del capítulo, o bien cuando su referencia sea en el marco de un análisis más detallado. Estas también se consignan en la bibliografía final, a partir del año que figura entre paréntesis en la lista precedente. 


\section{Contenido}

$\begin{array}{lr}\text { Agradecimientos } & 4\end{array}$

$\begin{array}{lr}\text { Contenido } & 8\end{array}$

$\begin{array}{ll}\text { Introducción } & 13\end{array}$

Capitulo 1. ¿Cómo abordar la cuestión del Dasein? Discusiones y diferencias con el método fenomenológico de Husserl en el pensamiento de Heidegger hasta 1927.

1.- La fenomenología en Husserl: la reducción eidética y el concepto de intencionalidad. 30

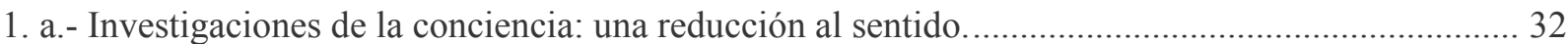

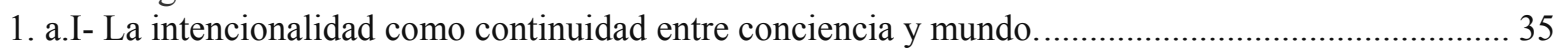

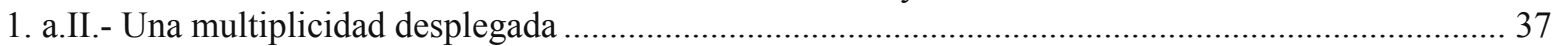

1. b.- Aproximaciones históricas al vínculo con Heidegger. ...................................................................... 39

2.- Primeros abordajes de Heidegger a la fenomenología. Límites e influencias en sus vínculos con el horizonte de la cientificidad.

2. a. Acta de nacimiento para el concepto de fenomenología: recorridos y derivas. ............................. 42

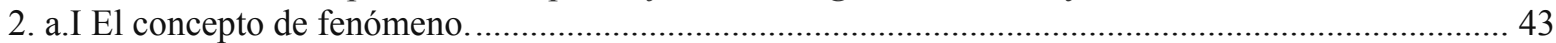

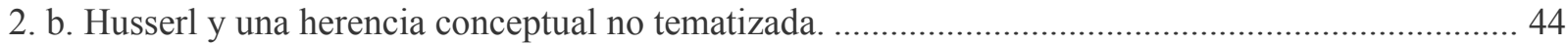

2. c.- La desfiguración de la fenomenología y la reformulación de Heidegger....................................... 46

3.- Aproximaciones metodológicas a la analítica del Dasein. $\quad 50$

Capitulo 2. El Dasein como cuestionamiento de la noción moderna de sujeto. $\quad 55$

$\begin{array}{ll}\text { 1.- En camino para la significación del Dasein. } & 57\end{array}$

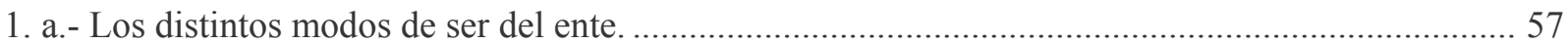

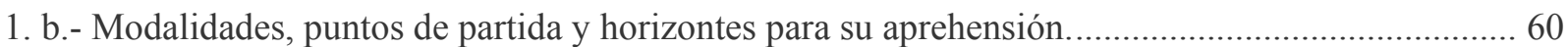

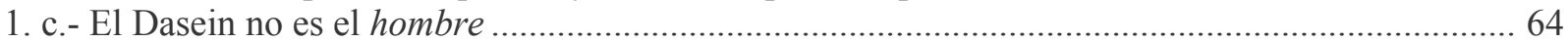

1. d.- Hacia la aprehensión de sus estructuras: la consideración del límite............................................. 66

2.- Algunas críticas a la comprensión moderna: ni yo puro, ni sujeto. $\quad 68$

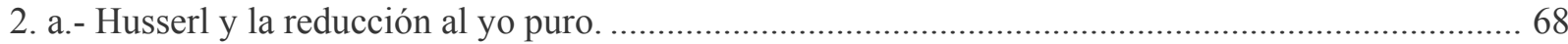

2. b- Heidegger y la imposibilidad de la reducción del yo. ……............................................................. 73

2. c.- Cuestionamientos al sujeto moderno: tensiones en el marco categorial....................................... 74

2. d.- La desubjetivacion del concepto de intencionalidad ..................................................................... 76 
3. La cuestión de la preeminencia para el análisis y algunas estructuras fundamentales. 77

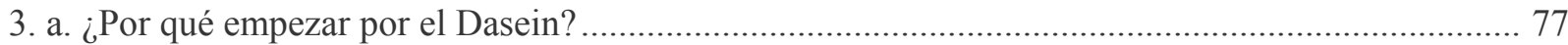

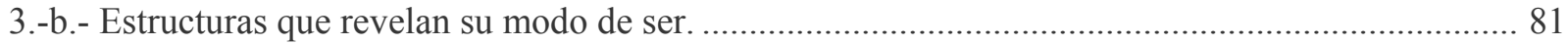

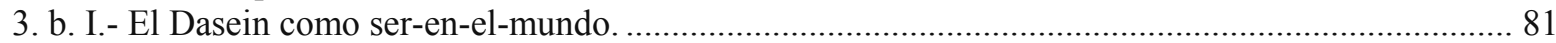

3. b.II.- La originariedad ontológica del comprender, el cuidado y la temporeidad ................................. 82

4.- La comprensión heideggeriana del Dasein y su significación: ¿continuidad, ruptura o $\begin{array}{ll}\text { transición con la modernidad? } & \mathbf{8 6}\end{array}$

Capitulo 3 .Retorno y comprensión de sí: análisis y articulaciones respecto a la ipseidad.92

1.- Abordajes tempranos de la mismidad: hacia un pliegue del uno-mismo y sus

$\begin{array}{ll}\text { significaciones. } & 95\end{array}$

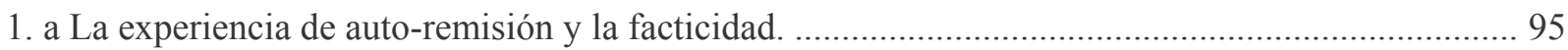

1. b. El uno-mismo y su encubrimiento en las interpretaciones de su época.........................................97

1. c.- Ampliación fenomenológica de la intencionalidad: los fenómenos de retorcimiento y extrañamiento.

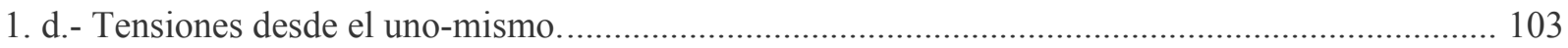

2.- La mismidad e ipseidad en $S u Z$ : relaciones con el lenguaje y la alteridad. 106

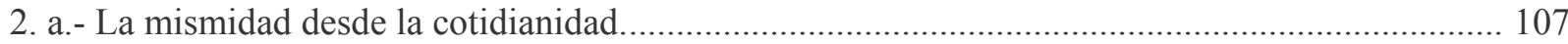

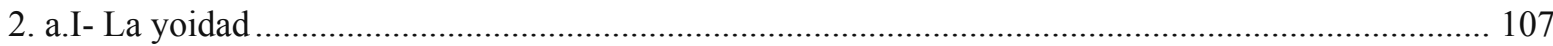

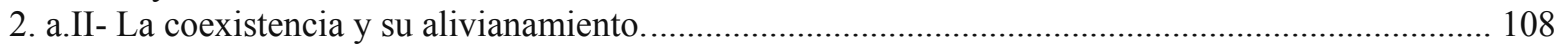

2. b.- La importancia de la disposición afectiva para el pliegue del sí-mismo. ..................................... 111

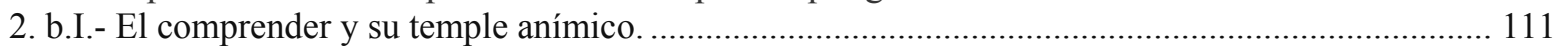

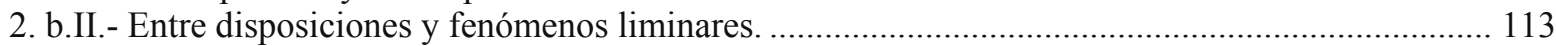

2. c.- Un fundamento no racional para el retorno a sí: la voz de la conciencia y su consecuente resolución

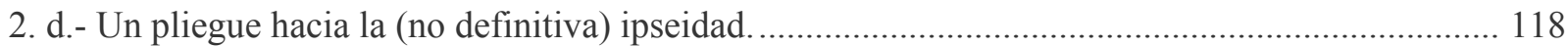

3.- En camino a la consideración de la alteridad. $\quad 120$

Capitulo 4. Desde la alteridad. Hacia un horizonte de la eticidad en las elaboraciones de la época de $S u Z$.

$\begin{array}{ll}\text { 1.- Husserl y la alteridad a partir del ego. } & 125\end{array}$

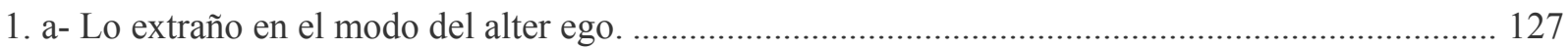

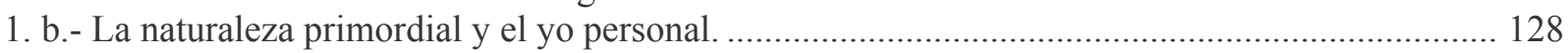

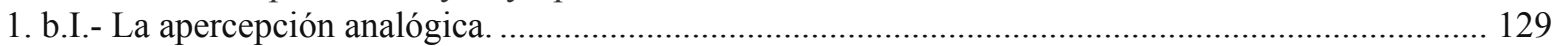

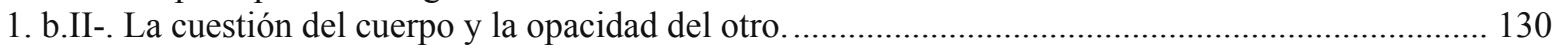

1. c.- Paralelos con la comunidad monádica...................................................................................... 133

2.- Heidegger y el ser-con como otro punto de partida. 135

2. a.- La consideración de la identidad del ser-en-el-mundo.......................................................... 136

2. b.- La temporeidad en el proceso de individuación: el instante, la espera....................................... 138

3.- El mantenimiento de sí. $\quad 140$

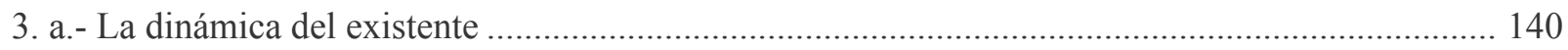

3. b.- La estabilidad desde la resolución: temporeidad propia y acontecer histórico............................. 141 
3. c.- El destino del Dasein.

4.- La irreductibilidad del ser-con: de la neutralidad del Dasein a las visiones del mundo.

4. a.I Lo Mismo desde el mundo común.

4. a.II.- El carácter derivado de la sexualización y la corporeidad.

4. b.- Visiones del mundo como sostén.

4. b.I. El carácter de arrojado y la dispersión.

4. b.II.- Desplazamientos del mito a la filosofía

4. b.III- Retomar el camino de la pregunta por el ser.

5.- La alteridad y las relaciones con los otros: ¿es posible delimitar una ética en estas elaboraciones?

Capitulo 5. Perspectivas y derivas desde 1930: la co-pertenencia Dasein-ser en su mismidad mediada.

1.- La pregunta por el ser: hacia un decir y pensar posmetafísico.

1. a.- De superación a torsión de la metafísica

1. b.- Aproximaciones al planteamiento tradicional.

1. c.- Consideraciones en torno al claro y la donación del ser.

2.- La co-pertenencia hombre-ser con sus modalidades de pensamiento 175

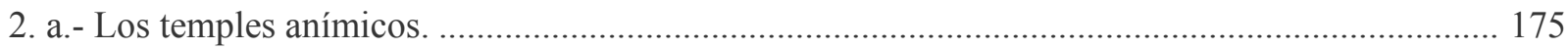

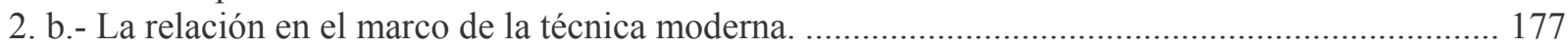

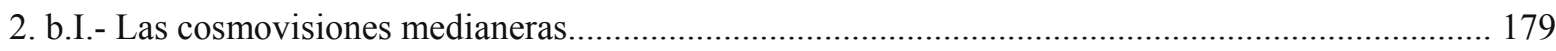

2. b.II.- La ciencia en la modernidad: un diagnóstico de época. .............................................................. 180

2. c.- El pensamiento de Nietzsche como metafísica consumada...................................................... 183

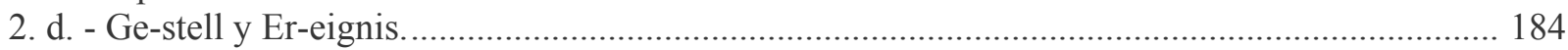

3.- Mismidad en las modalidades de co-pertenencia. $\quad 187$

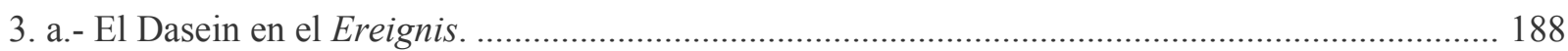

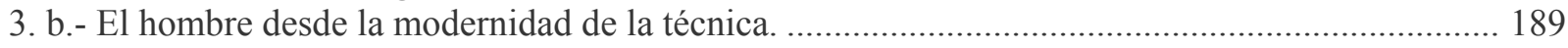

4.- El carácter mediado de la mismidad en su carácter dinámico. 192

Capitulo 6. Consideraciones prácticas, éticas y políticas (Hacia la alteridad y la ipseidad $\begin{array}{ll}\text { del Dasein como discurso) } & 194\end{array}$

$\begin{array}{ll}\text { 1.-Heidegger y sus implicaciones políticas. } & 197\end{array}$

1. a.- Trabajos y comunicaciones en la época del Nacional Socialismo............................................. 198

1. b.- En torno a la publicación de los Schwarze Hefte ......................................................................... 202

2. Perspectivas sobre la participación práctica y posicionamiento del Dasein con vistas a una transición. $\quad 205$

2. a.- Dificultades y posibles desplazamientos del mundo técnico...................................................... 206

2. b.- La relevancia del pensar para una posible filosofía práctica. ................................................... 207

2. c.- El ámbito decisional: los roles del Dasein en la historia del ser................................................ 209 
3.-El Ethos y la ética originaria bajo el supuesto de alteridad. 215

3. a.- Hacia un Ethos posmetafísico.................................................................................................. 216

3. b.- Disposición afectiva y Ethos desde el destino del ser. ............................................................... 219

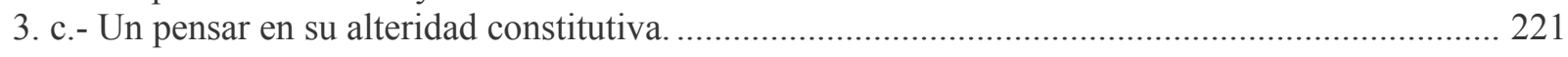

4.- Aproximaciones a la ipseidad y la alteridad $e n$ el lenguaje. 222

Capitulo 7 .Elaboraciones sobre el lenguaje en el pensamiento de Heidegger 225

$\begin{array}{ll}\text { 1.- El lenguaje en la época de } S u Z \text {. } & 227\end{array}$

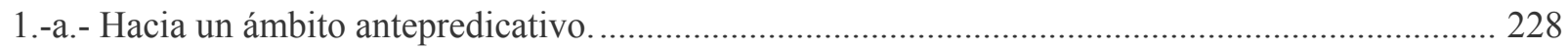

1. a.I- La perspectiva instrumental de la tradición metafísica................................................................ 229

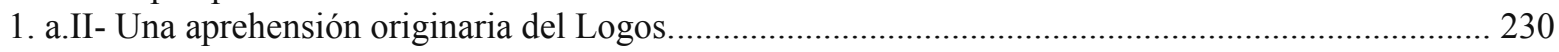

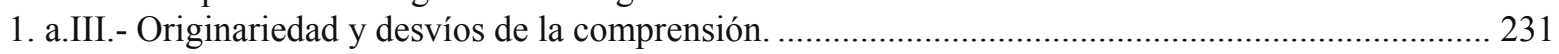

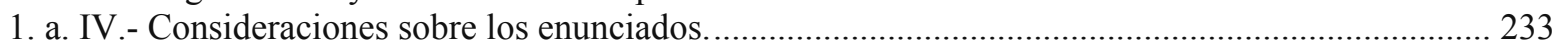

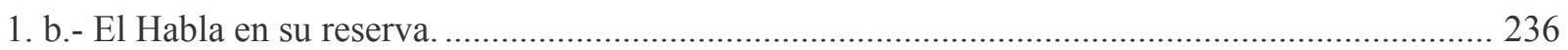

1. b. I- El carácter inagotable del ámbito prelingüístico: límites y horizontes........................................ 238

1. b.II.-- En torno al carácter dinámico de las significaciones. ................................................................ 240

2.- Tras la esencia del lenguaje como casa del ser.

2. a.- De las limitaciones del decir a la alteridad del silencio ......................................................... 243

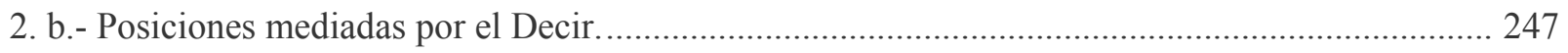

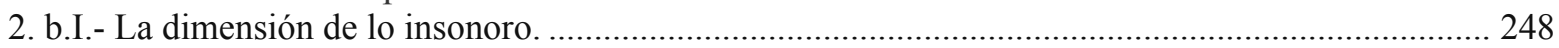

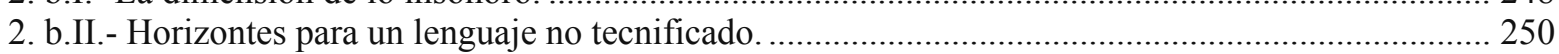

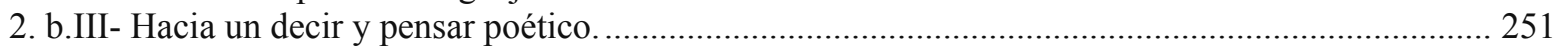

2. b. IV. La pregunta por la mismidad en su dinámica de tránsito............................................................... 255

3.-La modalización discursiva de Heidegger. $\quad 256$

4.- Vínculos entre discurso e ipseidad. $\quad 261$

Capitulo 8. Proyecciones, continuidades y rupturas en el pensamiento contemporáneo. 265

1.- La consideración de la autodeterminación y la mismidad desde la perspectiva analítica

$\begin{array}{ll}\text { de Tugendhat. } & \mathbf{2 6 8}\end{array}$

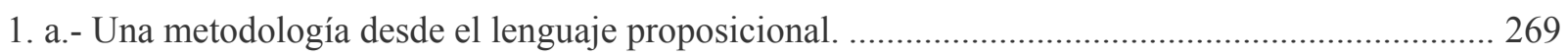

1. b.- El comportamiento práctico en el marco de un sentido constatable del ser. ............................... 270

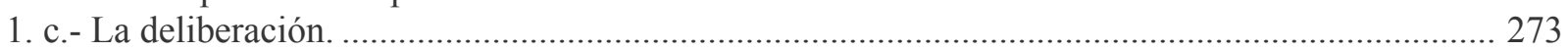

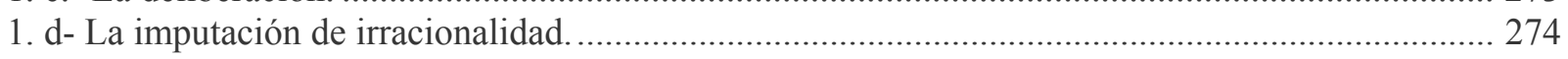

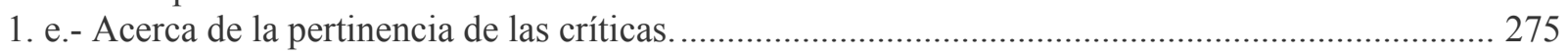

2.- Perspectivas sobre la mediación alteridad-ipseidad en la recepción europea. $\quad 277$

2. a La alteridad del dialogo y la tradición en las elaboraciones de Gadamer. .................................... 278

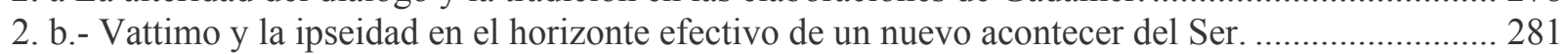

2. c.- Relaciones entre lo indecidible y el por-venir en el pensamiento de Derrida.............................. 284

3.- Hacia una heterología ética en la consideración metafísica del sí-mismo en Levinas. 289

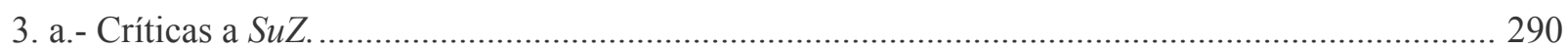

3. b.- Un pensar de lo Mismo; un pensar de lo Otro............................................................................... 291 


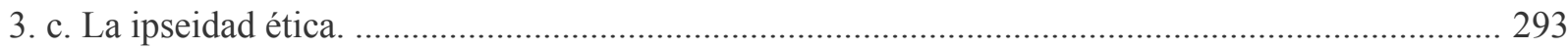

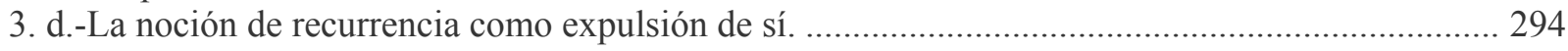

4.- Análisis posheideggerianos de la identidad: Paul Ricoeur y la hermenéutica de sí. 296

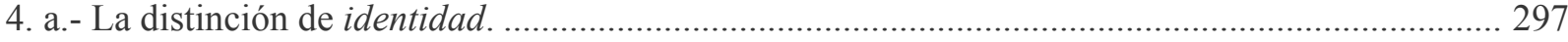

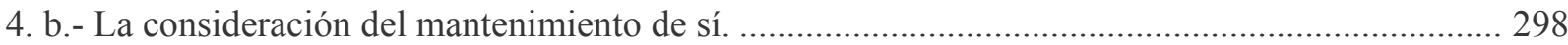

4. c.- La ipseidad en la hermenéutica del texto y la narración de sí. .................................................. 299

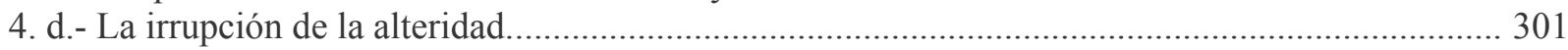

\section{5.- Ipseidad, interculturalidad y lenguaje como primeras orientaciones en la recepción} regional.

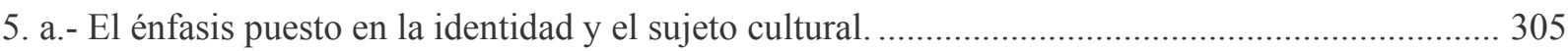

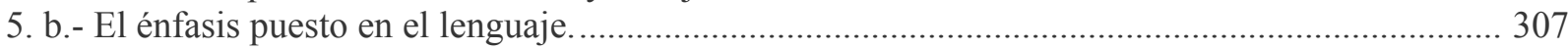

$\begin{array}{ll}\text { Conclusiones } & 310\end{array}$

Referencias Bibliográficas $\quad 339$

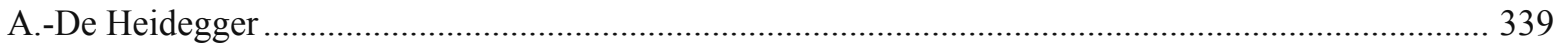

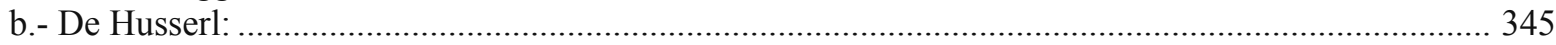

c.- Diálogos y resonancias respecto a cuestiones consideradas en Heidegger. .......................................... 347

d.- Sobre Filosofía del lenguaje, Fenomenología, Semiótica y Hermenéutica. ........................................ 369 


\section{Introducción}

En el siguiente trabajo nos proponemos desplegar un análisis, reconstrucción e interpretación de las elaboraciones en torno a la ipseidad, la alteridad y el lenguaje en el pensamiento de Martin Heidegger, atendiendo vínculos, desplazamientos y proyecciones tanto en el despliegue de su propia obra, como también en determinadas recepciones contemporáneas, sin descuidar la articulación de tales perspectivas en el marco de la tradición del pensamiento filosófico en la que se inscribe.

En efecto, entre los innumerables caminos del pensar, las consideraciones sobre la autoconciencia y la identidad, con sus respectivas tensiones y reelaboraciones, representan un trayecto significativo del pensamiento occidental en el siglo XX y el nuestro. Específicamente, el desplazamiento desde las perspectivas existencialistas, al marxismo posterior a la segunda guerra mundial, pasando por el estructuralismo de la década del '60 hasta arribar a la hermenéutica y al posestructuralismo de los últimos años, señalan algo más que meras modas intelectuales: emergentes de un contexto histórico determinado, dan cuenta de un giro en el centro de análisis que , a través del abandono progresivo de la conceptualización de la metafísica de la subjetividad, reelaboran y articulan las filosofías del sujeto con la(s) filosofia(s) del lenguaje.

Así, el pensamiento fundacional anclado en el cogito cartesiano o el sujeto trascendental pierden preeminencia hegemónica en sus fundamentos para ceder terreno a la relevancia del lenguaje y la palabra. En el plano de la ontología este desplazamiento se vio encarnado en el tránsito de la metafísica moderna a su destrucción o torsión (Pöggeler, 1963). La emergencia de un pensamiento no-fundacional, que exalta la contingencia, la multiplicidad y la diferencia, se distingue por un modo singular de abordar la historia y la temporalidad, el lenguaje formal e informal y, por supuesto, en una nueva manera de comprender y abordar la condición humana.

En este contexto, las perspectivas en los análisis de la identidad personal e ipseidad, posteriores al debate del antiesencialismo y los discursos filosóficos adscriptos al método 
estructuralista, por un lado, evidencian un desplazamiento comprensivo en torno a la noción de autoconciencia, respecto a sus ligazones con el cogito y la preeminencia del valor de la certeza en la perspectiva científica, entre cuyos supuestos principales se halla el concepto de verdad como adaequatio. Por otro lado, aquellos enfoques enfatizan las condiciones intersubjetivas y simbólicas de su constitución, así como las implicancias de su conformación a través del lenguaje , tal y como puede plasmarse en la noción de identidad narrativa ( MacIntyre, 1981 ; Ricoeur , 1985/1990 ), de modo tal que desplazan la vigencia de las comprensiones segregacionistas, aisladas o fragmentarias de la auto-remisión del existente humano, para poner de manifiesto el complejo social, situacional e histórico en el que se inscriben, cuyo correlato es la reelaboración de las tradicionales consideraciones sobre el saber, el conocimiento, la verdad y la ética.

En los capítulos que siguen abordaremos dicho camino, considerando como punto de partida uno de los escritos filosóficos que funciona como catalizador de este trayecto del pensamiento occidental: Martin Heidegger y su escrito de 1927, Sein und Zeit (SuZ). Tanto en esta obra como en sus cursos de la época, analizaremos y reconstruiremos la perspectiva que desarrolla en torno a las relaciones entre ipseidad, alteridad y sus posibles vinculaciones con el lenguaje, analizando diversos trayectos de su pensamiento. Consideramos que, insertos en un debate con la fenomenología trascendental de Husserl, se desarrollan desde allí modalidades del pensar singulares que sembraron las bases para las actuales perspectivas y debates en torno a la identidad personal, la ipseidad y la alteridad, funcionando como precursoras de orientaciones en perspectivas tales como la Hermenéutica, la filosofía del lenguaje, la antropología estructural y el psicoanálisis, entre otros. Por ello, entendemos que allí puede circunscribirse un escenario para un giro en el análisis del subjetivismo moderno al lenguaje, cuyos fundamentos demandan una revisión.

En general, una historia del abordaje y la crítica al pensamiento de Heidegger puede separarse en dos grandes etapas: un pensamiento anterior y otro posterior a la denominada Kehre heideggeriana. Entre las obras más comentadas en dichos períodos se destaca por un lado, una referencia casi exclusiva a $S u Z$ a partir de 1930 y, por otro, desde la publicación de Brief über den Humanismus (1947), los análisis donde predomina la problemática ontológica a partir de la cual el autor rechaza su vinculación con las temáticas de raigambre existencialista y con las respectivas conceptualizaciones de la metafísica moderna de la subjetividad. Luego de la segunda guerra mundial con la denominada Kehre, esta perspectiva logra afianzar sus fundamentos: la concepción del lenguaje como casa del ser (Heidegger, 1947) junto al acento puesto en la ontología hermenéutica y relacional de sus últimos escritos, consolidan esta segunda etapa de interpretación y crítica enmarcada en los caminos de la filosofía hermenéutica (Gadamer, 1960; Pöggeler, 1994). 
En aquel primer período de su pensamiento, la identidad es reelaborada en su relación con el concepto de ipseidad, perspectiva que tendrá un desplazamiento en el período de Heidegger después de la Kehre, donde ya tal contraste no es considerado de un modo unilateral sino mas bien a partir de la co-pertenencia pos-metafísica de hombre y ser (Zugehörigkeit) tal y como lo expone , por ejemplo, en Identität und Differenz ( 1955) y en Zur Sache des Denkens (1962).De este modo, puede considerarse su obra de 1927 como el punto de bisagra de estas dos corrientes interpretativas , así como también el terreno desde donde Heidegger plantará los fundamentos de su siguiente camino del pensar, los cuales permiten distinguir un trayecto de continuidades y transformaciones desde los primeros hasta los últimos escritos del autor. Análogamente, este umbral también se manifiesta como una figura de los desplazamientos generales de las perspectivas sobre el sujeto y la condición humana desde el siglo pasado.

Heidegger escribe $S u Z$ intentando el abandono y superación de la metafísica de la subjetividad y sus categorías, distinguiendo que las elaboraciones de Husserl continuaban ancladas a la ontología tradicional y, en especial, a los fundamentos cartesianos. Así, nuestro autor desarrolla una ontología fundamental del Dasein, a partir de la explicitación de una modalidad de comprensión singular: el modo de ser del existente humano es distinto al de todo otro ente. En ello se inscribe un viraje fundamental: si la comprensión es previa al despliegue articulado de toda perspectiva, entonces un desplazamiento en aquella impacta en la orientación del enfoque. No obstante, tanto el propio Heidegger como los primeros interpretes de su obra, destacan que este escrito aun se muestra condicionado por el lenguaje de la metafísica de la subjetividad, de lo cual buscó liberarse progresivamente en sus elaboraciones posteriores a 1930, donde la comprensión tradicional del sujeto-centro de la representación del ente (en el sentido de lo objetivo) para considerar al hombre de un modo relacional y mediado con y por el ser.

Ahora bien, el estatuto de tal condicionamiento sobre la base del lenguaje y la modalidad del pensamiento por él articulado, dista de presentar una explicitación suficiente en los análisis posteriores. En una primera aproximación a $S u Z$, encontramos que la sustancialidad y trascendencia del sujeto ceden terreno a la resignificación del concepto de Dasein. Con él, Heidegger pone en primer plano la estructura interrelacionada del ser-en-el-mundo (in-der-Welt-sein) y el ser-con (Mitsein). No hay anterioridad, ni fundamento previo: el Dasein es en ese ensamblaje de relaciones. 
La dinámica inherente a este complejo estructural se pone de manifiesto pormenorizadamente en la investigación fenomenológica de la mismidad (Selbigkeit) e ipseidad (Selbstheit) del Dasein, sobre el trasfondo de su indagación ontológica.

En efecto, por medio de una singular reelaboración de la fenomenología, Heidegger se posiciona frente a la concepción moderna del yo como subjectum (caracterizada por un yo que se mantiene igual en medio de la multiplicidad de las vivencias), la cual vincula con la mismidad de un modo inauténtico y establece una perspectiva que no ha permitido dar cuenta de la ipseidad de símismo. Frente a ello, la ipseidad es caracterizada desde el carácter proyectivo y temporal del Dasein, cuyas notas impactan en la modalización comprensiva de tal concepto. Como resultado de su analítica distingue que solo podemos acceder al Dasein que somos en cada caso(Jemeinigkeit) existiendo fácticamente, pudiendo así dar cuenta de una estabilidad o mantenimiento de sí mismo ( Selbständigkeit) proyectivo y no sustancial, en su propia temporalidad. Esta estabilidad de sí es articulada de un modo diferente que la mismidad idéntica- sustancial de la modernidad. Sin embargo, en la vinculación de sus consideraciones respecto al método fenomenológico con las elaboraciones respectivas de Husserl, encontramos diversas interpretaciones sobre posibles continuidades y rupturas entre ambos, por lo cual pueden distinguirse allí resonancias del pensar de la modernidad.

No obstante, los propios análisis sobre la articulación de la mismidad en sus elaboraciones de 1920, manifiestan ciertas tensiones. Nuestro autor destaca que el Dasein, debido a su ser-con, presenta dos modos o determinaciones posibles. Por un lado, el modo de ser que representa habitualmente la constancia del Dasein: el "uno" (das Man) mismo que inicialmente, en su cotidianeidad, señala la mismidad que no le es propia, caracterizándose por la dependencia y la inestabilidad. De este modo, absorto en las ocupaciones, surge un yo vacío que expresa un sí mismo impropio que le permite mantener una identidad al modo del sujeto-sustancia. Pero por otro lado, el Dasein puede asumir su sí mismo de modo propio. Logrará dicha determinación haciéndose cargo de su propia existencia por medio de su ser-hasta-la-muerte (Sein zum Tode), así como también reconociendo su poder ser propio por medio de la angustia y de la voz de su conciencia (Stimme des Gewissens) junto a su llamado. Por medio de este llamado el Dasein capta la constancia y firmeza de un estado contrapuesto a la inestabilidad en el "uno". Este mantenimiento de sí, como esbozamos más arriba, lo alcanza en la resolución (Entschlossenheit) precursora hacia la muerte, al asumirla como la posibilidad más propia.

De este modo, en el modo de la propiedad el Dasein elige por fuera de la interpretación mediana del "uno" el cual, a partir de la resolución, trae al Dasein hacia su destino (por medio del cual la tradición logra trasmitirse de sí a sí mismo).Así, la resolución del Dasein contrapone a la 
dispersión del uno y su inconstancia (Unselbständigkeit), el modo de una constancia prolongada (erstreckte Stätigkeit) manteniéndose en el seno de la existencia, asumidos nacimiento , muerte y el trayecto entre ambos, alcanzando así la propiedad del mantenimiento de sí en un proyecto donde la herencia de las posibilidades pasadas y su re-asunción como posibilidades futuras se insertan en el horizonte de su proyección. Esta reapropiación de la tradición se renovará fácticamente proyectando nuevos sentidos y usos en sus posibilidades heredadas, abandonando la comprensión de un yo idéntico e invariable a través de su existencia.

Así, en $S u Z$, serán posibles diferentes modos en que la existencia del Dasein despliega su temporalidad más propia por medio de un proyecto, cuyo impulso o exhortación no se vincula con ámbitos racionales o trascendentales, sino mas bien con límites, diferencias y alteridades, que precisan una delimitación en la analítica de Heidegger, debido a la constelación múltiple en la que se inscriben. Por otra parte, el campo semántico desde el que articula la determinación propia de la mismidad sigue vigente en las determinaciones lingüísticas por oposición con las que describe las estructuras o existenciales, por lo cual se torna necesario un examen de la operación discursiva heideggeriana en tales elaboraciones. Finalmente, se evidencian tensiones implícitas en la comprensión del proceso de resolución: ¿cuál es el ámbito de retorno para la propiedad de sí? ¿Logra nuestro autor esquivar las resonancias sustancialistas del cógito o el polo-yo husserliano? De todos modos, estos desarrollos y tensiones establecen las bases para la importancia que cobrará luego el lenguaje en el período posterior a la Kehre.

Específicamente, en escritos y clases posteriores a 1930, Heidegger desarrolló diferentes aspectos profundizando en su desvinculación con la metafísica moderna de la subjetividad y su lenguaje: por un lado, rechazando la centralidad atribuida al hombre en dicha metafísica y por otro, comprendiendo a la ipseidad del Dasein en una determinada relación con el ser y el lenguaje en su preeminencia originaria. En efecto, con el abandono de toda comprensión del hombre como sujeto (es decir, como sustancia) profundizó en su esencia ex-tática y temporal, destacando la ipseidad del Dasein en un modo auténtico a partir de la relación con el ser. Algunas críticas a la filosofía de la historia y el surgimiento de un pensamiento de la diferencia en la generación francesa de 1960 (Descombes, 1979) encuentra en estos fundamentos el suelo fértil para sus discusiones.

En ese marco, la preeminencia del lenguaje se torna cada vez más evidente en lo que respecta a la vinculación entre el Dasein y el ser. Desde allí profundiza por un lado, en su anterioridad originaria respecto al hombre y, por otro, en la comprensión pre-conceptual sobre la que se devela todo ente, al mismo tiempo que antecede toda comprensión de la naturaleza, la historia, el mundo y esencia del hombre (1927/1958). Analizando la decadencia del lenguaje bajo la influencia de la metafísica de la subjetividad, contrapuso a la centralidad del sujeto de la 
modernidad, el auténtico lugar del hombre como pastor del ser (1947) y la modalización poética del lenguaje como su correlato específico. En suma, del componente óntico de la ontología heideggeriana (el Dasein como el ente que requiere para su fundamentación) nuestro autor fue desplazando su análisis al ser y al lenguaje anticipando giros y perspectivas que se proyectarán luego en los principales fundamentos de algunos enfoques estructuralistas y lingüísticos de diversas áreas, entre las cuales podemos situar trayectorias del pensamiento de Derrida, Deleuze, Levi Strauss, Rorty, Lacan, Vattimo, Ricoeur, entre otros.

El entramado complejo de su analítica de 1920, y la reelaboración modal de y en su discurso posterior a 1930, han dado lugar a numerosas interpretaciones y análisis desarrollados en debates contemporáneos, orientados en torno a conexiones entre fenomenología, ipseidad y lenguaje en el pensamiento de Heidegger y la tradición con la que discute. En primer lugar, ligados con la tradición fenomenológica, podemos encontrar análisis de algunas continuidades y diferencias teóricas entre Husserl y Heidegger. Si SuZ de hecho "fue escrito contra Husserl" (Heidegger, 2003) entonces puede contraponerse parte de su fenomenología hermenéutica a ciertos aspectos de la fenomenología trascendental husserliana. Intérpretes contemporáneos han indagado en tal contraposición refiriéndose a la reducción fenomenológica del yo trascendental desprendida de la facticidad en Husserl, frente al análisis del sí mismo en Heidegger, el cual permanece imbricado en la facticidad del ser-en-el-mundo del Dasein (Walton, 2001/ 2009; Xolocotzi, 2004/2008). Por otra parte, algunos trabajos críticos destacan el paso de la egología de Husserl a una egocronía que se afianza con Heidegger (Cruz Velez , 1970), subrayando continuidades del último tramo del pensamiento de Husserl respecto a la indeclinabilidad de la reducción eidética que llega al yo originario (Ur-Ich) destacando su carácter temporal ( Husserl 1962/1974), cuestión que prefigura un final para la discusión moderna que parte de categorías de la metafísica de la subjetividad ( sustancialista, objetivante y presentificante) estableciendo algunas bases para el abordaje centrado en la temporalidad del sí mismo, a partir de su inacabamiento y su apertura en el horizonte de sus posibilidades, propio de la perspectiva de Heidegger y Ricoeur, entre otros (Presas , 2009).

En segundo lugar, en referencia a la identidad y la ipseidad en el período de $S u Z$, podemos encontrar análisis que hacen hincapié en tres áreas fundamentales : 1) En las figuras de la 
identidad y la ipseidad en la fenomenología posthusserliana contrastando y vinculando las posiciones de Heidegger, Ricoeur, Henry y Zubiri en lo que respecta al mantenimiento de sí y a la temporalidad como propias de la ipseidad ( Presas , 2002 ; Naishtat , 2007 ; Walton , 2001) . 2) Diferentes análisis del lenguaje en Heidegger vinculados con la comprensión y la ipseidad del Dasein, entre ellos : acerca de la comprensión de sí implícita en toda mismidad y la necesidad de una mediación discursiva ( Sáez Rueda , 1998 ; Castellanos , 2006); en relación a los cambios en los contextos de significación en SuZ ( Fuenmayor , 1994) y en torno al sentido en tanto carácter prepredicativo de la comprensión del ente ( Rodríguez Suarez , 2005) . 3) Finalmente, encontramos las críticas de irracionalismo en el pensamiento de Heidegger que proponen partir del análisis del mantenimiento-de-sí en SuZ, para elaborar una síntesis entre mismidad e ipseidad a través del concepto de identidad narrativa ( MacIntyre , 1981 ; Ricoeur, 1990) o desarrollar una teoría de la elección racional a partir de las premisas fundamentales del pensamiento de Heidegger (Ferrer , 1995 ; Tugendhat ,2002), así como también la consideración de algunas discusiones éticas : por un lado , las interpretaciones divergentes sobre el enfoque netamente individualista de $S u Z$ y , por otro , las interpretaciones del ser-con ( Mit-sein) como fenómeno o bien originario o bien derivado de la mismidad, las cuales conducen a las críticas y análisis de Karl Löwith (1984), Paul Ricoeur (1990) y Emanuel Levinas (2000/2002), entre otros.

En el marco de este estado de interpretación podemos distinguir tres ejes que orientan tales debates: por un lado, las vinculaciones de estas elaboraciones de Heidegger y las respectivas de Husserl, en el contexto de las discusiones respecto a la tradición metafísica en lo que respecta a la mismidad y la alteridad. Por otro, las reconstrucciones e interpretaciones de la analítica de Heidegger, que atienden aspectos descuidados, énfasis implícitos u orientaciones pre-esbozadas por la articulación lingüística, que aplican reflexivamente la perspectiva de nuestro autor a sus propias elaboraciones articuladas. Finalmente, desarrollos posteriores que parten de los resultados de tales elaboraciones, para ampliar significaciones o reelaborar consideraciones sobre el lenguaje, aspectos éticos, sociales, etc. Precisamente desde estas tres orientaciones desplegaremos nuestros análisis e interpretaciones en la vía de los ejes ipseidad-alteridad-lenguaje, las cuales mantendremos con un diálogo contemporáneo, en el margen paratextual de los próximos capítulos. 
En efecto, la distribución de los siguientes capítulos se realizará en dos partes: la primera, en relación a cursos y escritos de la década de 1920 y, la segunda, en sus elaboraciones posteriores a 1930. Allí buscaremos inscribir sus diálogos respectivos: en el primer caso, respecto a Husserl y otros pensadores de la tradición metafísica; en el segundo caso, circunscribiendo las proyecciones inmediatas de la obra heideggeriana. Por medio de citas y capítulos específicos, proponemos poner en evidencia el estado de las lecturas e interpretaciones que se hallan en debate con las elaboraciones de nuestro autor.

Primeramente, analizaremos e interpretaremos la ipseidad del Dasein y su relación con los otros en una vinculación posible con las consideraciones del lenguaje y la tensión racionalidad/irracionalidad a lo largo de sus obras fundamentales. Luego, confrontaremos con los desarrollos desde la perspectiva del ser y del lenguaje, atendiendo la modalización discursiva y del pensar de Heidegger. En ambos casos, articularemos el recorrido con las contribuciones de los análisis e interpretaciones de la obra heideggeriana y de los estudios vinculados al nexo ipseidadlenguaje en nuestra región (Presas, 2009; Naishtat ,2007; Blanco 1lari, 2000, entre otros).

Los tres ejes que organizan este recorrido, acompañan nuestras tres hipótesis principales:

a) Es posible circunscribir con claridad los elementos de una perspectiva del lenguaje vinculados con una teoría de la ipseidad, en la obra de Heidegger. En tales articulaciones, reconocemos la distinción de planos ontológicos originarios, como un criterio regulador para las modificaciones posibles en la comprensión de sí. En efecto, en sus primeros trabajos, la relación del Dasein con el sí-mismo y con el mundo, se abre a partir de la comprensión de los nexos de significación que articulan la facticidad. Entendemos que aquella distinción supone pliegues, intersticios, tensiones y fallas en tal entramado primario de articulación. Esto es correlativo a un enfoque sobre el lenguaje que rechaza implícitamente la consideración de un campo semántico susceptible de plenificacion, trascendental o clausurable.

Pues bien, sostenemos que esta perspectiva con su criterio regulador, es condición de posibilidad para el pliegue de la ipseidad en su modo auténtico, así como también para la producción de distorsiones /modificaciones del sentido y de las comprensión histórica del ser. Tales caracterizaciones y supuestos se mantienen tanto en el desarrollo de su pensamiento posterior a la época de SuZ, como en la matriz de su propio estilo filosófico-discursivo.

Asimismo, este enfoque también supone una alteridad constitutiva e irreductible del lenguaje. Ello se pone en evidencia en un conjunto de tensiones en sus desarrollos, los cuales mantienen parte de su discurso, aún en vinculación con el campo semántico moderno al que se 
opone. Entre otras, podemos especificar cierta orientación semántica, jerárquica o axiológica en tal despliegue discursivo, que bien puede vincularse con una modalizacion del pensamiento derivada de su articulación primaria en dicho campo.

b) Partiendo de las consideraciones de la comprensión del ser en la estructura del Dasein y de su carácter ante-predicativo, consideramos que el ámbito del lenguaje, la mediación discursiva y la interpretación son elementos para el escenario apropiado (e históricamente limitado) desde el cual poder desplegar la asunción de la propia ipseidad, razón por la cual no es posible comprenderla como una alternativa entre opuestos, sino como una dinámica de pliegue variable , manifestándose así correlativa a la significación y comprensión del Dasein.

Desde aquí, como segunda hipótesis postulamos tres argumentos articulados. En primer lugar que el sentido y el decir poético-literario necesariamente deben ocupar un lugar relevante en la consideración pos-metafísica de la co-pertenencia del Dasein y el ser (Heidegger, 1950-1959), no solo para las elaboraciones de nuestro autor, sino también para las articulaciones filosóficas posheideggerianas sobre la condición humana. En segundo lugar, a partir de aquel carácter mediado, relacional y dinámico de la ipseidad por la vía del lenguaje, interpretamos que los desarrollos respectivos en sus elaboraciones posteriores a 1930 se hallan implícitos en el propio discurso de nuestro autor, al cual puede entenderse como una figura correlativa que deriva de los resultados obtenidos en la analítica de 1920. Como tercera argumentación sostenemos que una complementación con el abordaje de las relaciones entre el proceso de significación, la intersubjetividad y la tradición (en $S u Z$ y a lo largo de la obra y biografía de Heidegger ${ }^{1}$ ) desde la cual se da cuenta del carácter originario y no derivado del ser-con en la estructura del Dasein, permite extraer posibles consecuencias tanto éticas como políticas de y en el discurso del autor.

c) Considerando el despliegue discursivo de Heidegger, su modalización y tratamiento respectivo, en vinculación con sus enunciados sobre la ipseidad, la alteridad y su teoría del lenguaje, sostenemos como tercera hipótesis que puede entenderse una necesariedad inherente de cada período de su pensamiento para la reelaboración posterior, de modo tal que las limitaciones halladas en la analítica de $\mathrm{SuZ}$, la tematización centralista del Dasein, las tensiones con la fenomenología husserliana, los sesgos metafísicos que atraviesan sus articulaciones y la insuficiencia de lenguaje que se evidencia en su recorrido, entre otras cuestiones, operan retrospectivamente como condiciones de posibilidad para la dinámica de transición que evidencia su

\footnotetext{
${ }^{1}$ Las vinculaciones de Heidegger con el nazismo pueden insertarse en el marco de esta caracterización.
} 
pensamiento en el siglo XX, la cual no sería posible si no llevase al límite las tensiones del campo semántico en el que se inscribe.

En tercer lugar sostenemos que también aquí es probable distinguir una tensión sostenida ( e irrebasable ) en su intento de transición o superación de la metafísica del sujeto, en diversos tramos del análisis de la ipseidad: I) en el campo semántico, respecto a la significación del Dasein , así como también en la consideración opuesta del significar y las significaciones en el das Man (rígidas e inflexibles) y en el Dasein propio (contingentes, no clausurables ni plenas); II) en su elaboración teórica, enfoque y articulación discursiva, respecto al ámbito para retorno a sí y a la dinámica del uno-mismo (en su posible pliegue como sí-mismo), el cual debe evitar recaer en comprensiones sustancialistas o cósicas del ser entendido como presencia; III) en sus elaboraciones de madurez, respecto a las consideraciones del Habla y el Decir en sus irreductibles mediaciones con el Dasein, con lo cual se propone radicalizar la puesta en cuestión y Destruktion de la conceptualización de la metafísica moderna y su lógica subyacente. Entendemos que dicha tensión irreductible pre-condiciona las orientaciones de recepciones e interpretaciones ulteriores de su obra.

Por lo dicho, abordaremos y desplegaremos un recorrido para analizar, argumentar y desarrollar tales hipótesis, del siguiente modo articulado:

Los primeros dos capítulos oficiarán de un modo preliminar respecto a la tematización de la ipseidad en la obra de nuestro autor. En el capítulo 1, estableceremos un contraste entre el pensamiento de Heidegger y Husserl a partir de consideraciones del método fenomenológico, revisando su pertinencia para las investigaciones de la conciencia o la analítica del existente humano, respecto al método científico. Por medio de un desarrollo del concepto de intencionalidad, evidencia y del método de reducción eidética, pondremos de relieve el imperativo de cientificidad que subyace al programa husserliano, que supone para Heidegger una comprensión del ser específica y un concepto tradicional de verdad. Frente a ello, desplegaremos los principales aspectos en la reelaboración que propone en vistas de la pregunta por el ser en general. En ese marco, analizaremos la pertinencia general de este método para el abordaje de la existencia humana, en el marco de una interpretación de continuidad entre las perspectivas de ambos pensadores, 
atendiendo relaciones con el lenguaje. En efecto, buscaremos dar cuenta del modo como la relación con y en el lenguaje de la tradición, con su motivación critico-destructiva respectiva, se mantiene vigente en ambos abordajes de la fenomenología, de modo tal que interpretar una continuidad a este respecto implica correlativamente una ruptura o reelaboración posterior del método, pues este impacta y modaliza la propia articulación lingüística que se fue construyendo en ese recorrido. En otras palabras: argumentaremos que extremar el método en su relación al lenguaje, pone de manifiesto el paradójico carácter necesario y provisorio de cada tramo de su despliegue, incluso, de su abandono posterior.

En el capítulo 2, abordaremos el modo singular en que Heidegger reelabora el término Dasein en el marco de la consideración fenomenológica de la existencia humana, en su intento de apartarse de las limitaciones de la comprensión implícita en los abordajes de la modernidad, es decir, aquellas que ponen en un plano central y anterior al hombre, el sujeto o el ego trascendental. Así, frente a las perspectivas sustancialistas que comprenden al ser como presencia, analizaremos sus elaboraciones respecto al modo propio de ser del Dasein, con las estructuras situacionales y dinámicas puestas de manifiesto en su analítica elaborada hacia finales de la década de 1920, sin descuidar un vínculo respectivo con las elaboraciones de Husserl. Asimismo, desplegaremos algunos de los escollos que distingue de las tematizaciones tradicionales de la conciencia, evidenciando también las tensiones que presenta su despliegue de significaciones dinámicas para el término Dasein. Desde allí, nuestra interpretación pondrá el énfasis en la cuestión de la articulación lingüística de esta reelaboración, en su carácter proyectivo y dinámico, así como también en el contexto o campo semántico en el que se inserta. En este marco, buscaremos dar cuenta del modo en que en sus propios desarrollos se mantiene aún inscrito en la metafísica de la subjetividad, al menos en ciertas modalidades de articulación lingüística y semántica del pensamiento. También aquí buscaremos evidenciar la inevitabilidad y necesariedad de esta trabazón debido a la alteridad irrebasable y constitutiva del lenguaje.

Los siguientes dos capítulos nos introducirán de lleno en las cuestiones de la ipseidad y alteridad en este primer período. En efecto, en el capítulo 3, desde los resultados de aquellos recorridos, delimitaremos sus elaboraciones de la mismidad y la ipseidad en trabajos y clases de la década de 1920, atendiendo al énfasis puesto en el carácter de complejo simultáneo del Dasein en su analítica existenciaria. A partir de las consideraciones sobre el yo de la metafísica entendido sustancialmente, analizaremos los abordajes de Heidegger que parecen tener como un paso obligado la facticidad, la cotidianidad y la caída en el Uno impersonal, que determina el uno-mismo y desde el cual es posible un desplazamiento hacia el propio sí-mismo. Pondremos especial atención a las condiciones de posibilidad de tales desplazamientos, con sus modalidades respectivas, evidenciando 
sus estrechos vínculos simétricos con el tratamiento del lenguaje desde el cual dinamiza su pensar. Asimismo, indagaremos en algunos alcances de la originariedad del ser-con en la estructura unitaria del ser-en-el-mundo del Dasein, en lo que respecta a las tensiones y posibilidades que esto permite para la asunción resolutiva del sí-mismo propio, reconociendo los esfuerzos que realiza para no retomar un polo-yo de partida o en el retorno a sí .Desde allí, distinguiremos continuidades o diferencias con sus primeros tratamientos y relaciones respecto a su propia articulación discursiva. Con ello, no solo continuaremos poniendo de manifiesto la matriz de lenguaje y pensamiento que aún lo mantienen en el mismo ámbito semántico de la metafísica, sino también buscaremos circunscribir ámbitos problematizables de estas dinámicas, en los cuales se articulan algunas discusiones y recepciones contemporáneas.

En el capítulo 4, analizaremos e interpretaremos la consideración de la constancia, estabilidad y mantenimiento de sí en la ipseidad del Dasein en su relación con la alteridad y el prójimo, en vistas de las tensiones que esto manifiesta en el marco de la articulación desde el lenguaje y de la comprensión propia del modo de ser del Dasein. Para dar cuenta de ello, desarrollaremos un recorrido que parte de una exanimación de la reducción al ego puro de Husserl para la manifestación de la intersubjetividad, considerando diferentes resultados de tal reducción , para luego abordar, en contraposición, el punto de partida desde el ser-con como ámbito cooriginario con el ser-en-el-mundo del Dasein, donde nuestro autor considera la cuestión de la ipseidad articulada con la temporeidad, el proceso de individuación y tres momentos del mantenimiento de sí desde su resolución anticipadora. Luego, evidenciando relaciones que este tratamiento aún mantiene con la metafísica de la subjetividad, analizaremos su elaboración de las cosmovisiones hacia finales de la década de 1920, en tanto preludio explícito para el desplazamiento posterior de la perspectiva de análisis, en este caso, desde las modalidades de los discursos o perspectivas de la época. Desde allí, distinguiremos una vía por la cual Heidegger busca retomar la pregunta por el ser en general, cuyo camino se veía cada vez más obstaculizado por la analítica del Dasein. De esta manera, demarcaremos fronteras y umbrales de este período, para aquel desplazamiento posterior hacia el tratamiento de la ipseidad y la alteridad desde la perspectiva de las relaciones con el ser.

Los dos capítulos siguientes desplegaran un tratamiento de aquellas tematizaciones desde su enfoque posterior. Específicamente, en el capítulo 5 retomaremos estas cuestiones a partir de las elaboraciones de 1930. Desde allí propondremos delimitar su desplazamiento hacia un abordaje marcadamente relacional, que le permiten elaborar la consideración del carácter mediado de la ipseidad, aspectos que lo obligan a cambiar su perspectiva de análisis. Para ello, examinaremos sus consideraciones de la cuestión del ser en este período, junto a la tematización de un pensar 
posmetafísico en su discusión con la modalidad del decir y pensar del mundo de la técnica. En este marco, articularemos con precisión las dos modalidades de co-pertenencia entre hombre y ser que distingue, con las modalidades de mismidad respectivas. Con ello, evaluaremos la relevancia de la consideración inescindible entre ipseidad, alteridad y lenguaje, así como también la correlación con el despliegue del propio discurso de Heidegger en sus desplazamientos graduales hacia un decir y pensar poético-literario. De esta manera, proponemos articular desplazamientos respecto a los tratamientos anteriores, con sus tensiones inherentes, con lo cual respaldar nuestra interpretación de la necesariedad inexorable de tales tratamientos para las elaboraciones posteriores. Asimismo, distinguiremos un modo de entender la articulación entre la primera y segunda orientación en sus elaboraciones, en el marco de la recepción de la obra heideggeriana y el estado de las interpretaciones. Finalmente, el encuadre de este carácter dinámico, relacional y mediado de la ipseidad, en contraste con sus tratamientos anteriores, nos permitirá evidenciar elementos para abordar la consideración de la alteridad y las cuestiones éticas, así como también las correlaciones con su despliegue discursivo.

En el capítulo 6, precisaremos tales enfoques de la alteridad y de la ética en cursos y escritos de aquel período. A partir del abordaje de las notas relacionales y mediadas de la mismidad presentaremos argumentos e interpretaciones que vinculen estos tratamientos con el discurso de nuestro autor, desarrollando nuestra hipótesis sobre la homogeneidad de su discurso respecto a la teoría que enuncia. Para ello, atendiendo la oscilación entre lo enunciado y su posición de enunciación, abordaremos en primer lugar, algunas tensiones y controversias en torno a su participación política de 1933-1934, en vistas a su perspectiva o teoría del cambio y la transformación histórica desde un pensar y decir posmetafísico. En este contexto, pondremos en evidencia la doble dimensión activa-pasiva en las posiciones prácticas y mediadas del Dasein, así como también el énfasis estratégico puesto por Heidegger, en vistas al horizonte hacia el cual proyecta sus elaboraciones. Luego, retomaremos la consideración de las disposiciones afectivas del otro comienzo del pensar, precisando la función relacional de los co-partícipes en tal dinámica. Por último, propondremos un análisis sobre sus consideraciones acerca de una ética y Ethos originario, como modos correlativos de articular las relaciones con los otros, el entorno, el ser y el lenguaje, desde su enfoque dinámico, relacional y mediado de la ipseidad. Con estos análisis, buscaremos evidenciar el estatuto y función de las consideraciones del lenguaje y el discurso en su pensamiento.

Para circunscribir un tratamiento específico de algunas puntualizaciones dispersas en los capítulos anteriores, dedicaremos el capítulo 7 a examinar y sistematizar diversas elaboraciones de Heidegger respecto a la tematización del lenguaje. Por un lado, aquellas que desarrolla en el período de $S u Z$ con su distinción de planos originarios en sus dinámicas y, por otro, aquellas que articula 
después de 1930, en el horizonte de una posible aprehensión intuitiva de un Decir originario, ya por fuera de la perspectiva de la analítica o los existenciarios del Dasein. Con ello, evidenciaremos un desplazamiento en su perspectiva, al tiempo que evaluaremos sus ligazones con la consideración de la relación del hombre y la ipseidad, en el marco de las relaciones dinámicas y epocales con el ser. A partir de esto, confrontaremos con el estilo y despliegue del propio discurso de nuestro autor, atendiendo a las relaciones manifiestas con términos, conceptos, campos semánticos, modulaciones y resonancias, cotejando los vínculos respectivos. De esta manera nos proponemos desplegar los elementos que fuimos recabando en nuestro recorrido, para argumentar en torno a la continuidad entre la elaboración heideggeriana de la ipseidad mediada-articulada en el lenguaje y el correlato respectivo en su enunciación y discurso, de modo tal que permita distinguir entre la exanimación del tratamiento explícito en sus primeras elaboraciones, y aquella que remite a un despliegue implícito en su dinámica discursiva, para extraer de ello consecuencias en relación a interpretaciones, recepciones y lecturas de estas cuestiones en su obra.

Finalmente, en el capítulo 8 analizaremos algunas críticas, proyecciones, continuidades y rupturas respectivas, en el pensamiento filosófico contemporáneo. Atendiendo el marco de discusión en nuestra región, nos enfocaremos sobre las interpretaciones posteriores relacionadas a los tres ejes antes mencionados, a las tensiones de racionalidad/irracionalidad e ipseidad/alteridad en su obra y las cuestiones relacionadas con el lenguaje, la ontología y la política. Específicamente, confrontaremos aquellas elaboraciones con las críticas analíticas de Tugendhat en torno a la deliberación racional en el marco de la autodeterminación y la ipseidad en SuZ. Luego, demarcaremos un contraste con recepciones que comparten determinados supuestos sobre el lenguaje de nuestro autor, examinando algunos trabajos de Vattimo, Derrida y Gadamer, para evidenciar los énfasis respectivos del carácter no clausurable del lenguaje y sus diferencias respecto al alcance de la irrupción de la alteridad en las dinámicas constitutivas de la ipseidad. En tercer lugar, analizaremos vínculos entre las consideraciones sobre el carácter ético-metafísico de las relaciones con la alteridad en la teoría de Levinas y la noción de identidad narrativa y la hermenéutica de sí en Ricoeur, desde las consideraciones sobre el lenguaje y el ser-con heideggeriano. Por último, realizaremos un análisis y circunscripción de tales consideraciones en la recepción regional, demarcando desplazamientos desde los análisis que atienden la cuestión de la subjetividad y la cultura, hacia aquellos que abordan las cuestiones de la alteridad y el lenguaje.

Con el despliegue y vinculación de estas proyecciones proponemos por un lado, cotejar la pertinencia de críticas e interpretaciones atendiendo al ámbito comprensivo y teoría del lenguaje desde donde se efectúan y, por otro, seguir vías de diálogo con el estado de investigación e interpretación de la obra de Heidegger en estas cuestiones, de tal modo que permitan dinamizar y 
continuar recorridos. Ello se efectivizará no solo en el despliegue de los apartados, sino también en la inclusión de comentarios y argumentos de otros pensadores en notas a pie de página o citas marginales, con lo cual proponemos evidenciar que el pensamiento de nuestro autor se halla hoy atravesado no solo por la alteridad con la que discute y de su época, sino también por una polifonía que deriva de su recepción contemporánea. 
"La tradición no se hereda, se forja"

(Malraux, La condición humana)

\section{Capitulo 1. ¿Cómo abordar la cuestión del Dasein? Discusiones y diferencias con el método fenomenológico de Husserl en el pensamiento de Heidegger hasta 1927.}

En este capítulo realizaremos un abordaje del método fenomenológico en el marco de ciertas relaciones entre las perspectivas de Husserl y Heidegger en lo que respecta a su tratamiento y alcance. Consideramos relevante detenernos en estas vinculaciones debido a que la indagación heideggeriana del Dasein, su ipseidad y los vínculos con la perspectiva sobre el lenguaje, encuentran en dicho método una vía fundamental de acceso a tal campo temático. Ahora bien, con Heidegger es posible circunscribir una transición en lo que respecta a la modalidad y comprensión de la fenomenología, tal y como la había desarrollado Husserl desde comienzos del siglo XX.

En líneas generales proponemos indagar en torno a la validez de esta modalidad de investigación para el campo temático estipulado, luego de circunscribir el modo singular del procedimiento de Heidegger, especialmente en sus clases y escritos a lo largo de la década de 1920 (hasta la publicación de Ser y tiempo en 1927), en contraste con aquel realizado por Husserl a partir de sus Investigaciones lógicas e Ideas atendiendo , en especial, los desplazamientos y torsiones que 
son articulados desde el lenguaje . Específicamente, planteamos un recorrido en vistas de las siguientes preguntas y problematizaciones:

- ¿En qué sentido puede sostenerse la originariedad o primacía del método fenomenológico respecto al método científico, en lo que remite a una investigación que se ocupe del existente humano?

- ¿De qué manera puede inscribirse la reelaboración heideggeriana del método fenomenológico en el marco de una posible transición o umbral respecto al pensamiento filosófico moderno?

- Atendiendo a que los resultados de una investigación fenomenológica se articulan en un entramado conceptual y de lenguaje, ¿es posible arribar a resultados definitivos bajo la égida de este método?

En el camino de estas problematizaciones abordaremos las siguientes cuestiones : a) A partir de algunas puntualizaciones del vínculo histórico entre ambos pensadores, desarrollaremos la consideración de la reducción y la intencionalidad en las investigaciones de las obras de Husserl ,especialmente desde sus elaboraciones desde 1913, en el marco del horizonte de cientificidad hacia el cual se orienta ; b)luego, distinguiremos las aproximaciones singulares de Heidegger a la fenomenología en sus primeros trabajos : su consideración del legado de Husserl, la cuestión de las influencias ,la relevancia de la comprensión en su distinción metódica respecto al planteamiento de su maestro, entre otras cuestiones; c) finalmente, abordaremos el programa fenomenológico de Ser y tiempo (SuZ), el cual entendemos como una cristalización de este recorrido para su reformulación. Este último apartado nos remitirá: por un lado, a sus críticas en el marco de su denominada destrucción fenomenológica, desde donde podremos dar cuenta de sus razones para retomar la pregunta por el ser en general y por qué parte de la analítica del Dasein para ello. Por otro, permitirá establecer algunas distinciones en el marco de las problematizaciones antes mencionadas.

En este marco, interpretamos que la reelaboración de la fenomenología en Heidegger, con base en la cuestión del comprender y en relación con el concepto de intencionalidad, no solo implica otra modalidad para el tratamiento del Dasein sino que correlativamente también modaliza la propia relación con el lenguaje

De este modo, podremos articular una transición entre ambas perspectivas, con el objeto de poder distinguir con claridad las diferencias y desplazamientos en los procesos de pensamiento, la comprensión y la articulación conceptual, que entendemos relevantes para adentrarnos a la analítica del Dasein. 


\section{1.- La fenomenología en Husserl: la reducción eidética y el concepto de intencionalidad.}

La trayectoria teórica de Husserl manifiesta una continuidad en clara sintonía con su campo de estudio $^{2}$. En su fase fundacional, aproximadamente hacia el año 1901, la fenomenología de Husserl se desarrolló en un ambiente académico con marcada influencia del neokantismo, donde la filosofía no solo había perdido autonomía sino también su importancia para la vida.

En sus inicios, este pensador se dedicó al estudio de la matemática, doctorándose en $1883^{3}$. Luego, se formó filosóficamente bajo la influencia de Brentano, enmarcado en la tradición aristotélica, tomando con ello cierta distancia de la perspectiva neokantiana de Marburgo, predominante en la época. En este contexto, su pensamiento fue desarrollando una creciente independencia, articulando aquella formación matemática, con el estudio de una tradición moderna que recorre la filosofía kantiana a partir de las elaboraciones de Descartes.

En general, tal desarrollo se orienta por oposición el escepticismo resultante del positivismo de finales del siglo XIX. Específicamente, el modelo epocal de la ciencia, se encuadra en la expansión del racionalismo el cual, apoyándose en la precisión de los estudios matemáticos, se propone reducir la pluralidad/contingencia de la experiencia y las sensaciones, a estructuras o “esencias" atemporales, necesarias y universales, es decir, susceptibles de sistematización y

\footnotetext{
${ }^{2}$ A este respecto véase Waldenfels (1997): 11-12; quien distingue una motivación fundamental que se despliega a lo largo de toda la obra de Husserl.

${ }^{3}$ En esta década, Husserl escribe varios trabajos sobre matemática y filosofía de la matemática: luego de su tesis doctoral Beiträge zur Variationsrechnung (1883), escribe bajo la tutela de Carl Stumpf (discípulo de Brentano), Über den Begriff der Zahl (1887) y más adelante Philosophie der Arithmetik (1891). Entre otras cuestiones, en estas obras se aboca a consideraciones aritméticas sobre los números o las variaciones, desde perspectivas tanto psicológicas (experiencial e intuitiva) como lógicas (objetivas), articulándolas así, como veremos, en algunas discusiones fundamentales de su época.
} 
conocimiento certificable. Con evidente orientación cartesiana, la epistemología trascendental del neokantismo de la escuela de Marburgo, distingue como insuficiente abordar el campo de las sensaciones para tal aspiración de la ciencia, destacando las consideraciones en torno a la actividad constituyente de la conciencia, como un modo relevante para circunscribir un ámbito de anterioridad al carácter fluctuante y variable de dicho campo. Así, aquella rigurosidad que solo atiende lo susceptible de articulación bajo leyes universales y necesarias, co-implica una desatención y escepticismo cada vez mayor respecto del mundo y la vida, en lo que respecta a la búsqueda de sus fundamentos o aspectos universales.

En tal marco, Husserl desarrolla sus trabajos de fenomenología aceptando las precauciones metodológicas del positivismo, pero buscando recomponer o distinguir una orientación necesaria y universal a las elaboraciones respecto a la vida. Retomando el ámbito de la conciencia para sus desarrollos, plantea en sus primeros trabajos un conjunto de discusiones con las perspectivas psicologistas tradicionales.

En efecto, en sus LU de 1901, se inscribe en los debates entre las perspectivas psicologistas y logicistas, en el contexto de las consideraciones del carácter normativo de la lógica para alcanzar un pensamiento verdadero y cierto. Por un lado, las perspectivas psicologistas, ocupándose del pensamiento en su totalidad, entienden de un modo derivado los estudios de la lógica. Por otro, los logicistas distinguen en la lógica pura las condiciones del pensar para toda teoría, destacando que las aspiraciones científicas de la Piscología, necesariamente la requieren para sus desarrollos. En esta discusión, Husserl se posiciona por fuera de toda consideración general sobre principios, abordando proposiciones específicas de la ciencia, con el objeto de develar sus estructuras y cotejar su validez, distanciándose del logicismo platónico que se conformaba con la mera validez de valores o verdades en sí.

Específicamente, se propone superar algunas consecuencias relativistas y exceptivas de la perspectiva psicologista, poniendo en evidencia las conclusiones absurdas o con falta de sentido de supuestos y premisas ${ }^{4}$. Desde allí, distingue como un error del psicologismo, entender los principios de la lógica como meras normas modales del pensar. Frente a ello, destaca que más bien estos indican las condiciones necesarias de lo universal, o bien, tomando un término que atraviesa toda su obra, las esencias de aquello que se investiga. Así, también para este pensador la contingencia y fugacidad de los hechos, en su articulación temporal fluida, se opone al reino de las esencias y el sentido de las cosas. Por ello, ve necesario distinguir entre los hechos (contingentes) y las verdades

\footnotetext{
${ }^{4}$ Véase LU I: 9-191 [39-163].Para un desarrollo y análisis contextual de estas discusiones con el psicologismo en IL, véase Xirau (1966):34ss.
} 
enunciadas sobre ellos (universales y necesarias) ${ }^{5}$. De esta manera, la fenomenología de Husserl no abandona la intuición sino que la articula con el rigor lógico: la intuición eidética implica una doctrina de la verdad que busca ser tanto intuitiva como rigurosa, es decir, que parte de la evidencia y de la vivencia, pero de un modo apodíctico, reconociendo sus leyes ideales.

No obstante, sus análisis fenomenológicos han sido variables en lo que respecta a su perspectiva u enfoque. Sin descuidar la valoración positiva que Heidegger manifiesta respecto a las IL, nuestro abordaje a continuación, y a lo largo de los próximos capítulos, se limitará mayoritariamente a las elaboraciones a partir de Ideas I (1913), pues desde allí podremos distinguir sus desarrollos de una fenomenología egológica y constitutiva, que nos permitirán plantear un diálogo y discusión con las reelaboraciones y críticas de Heidegger, especialmente en torno al Dasein y la ipseidad ${ }^{6}$.

\section{1. a.- Investigaciones de la conciencia: una reducción al sentido.}

En efecto, uno de los puntos de partida para la investigación fenomenológica en su obra de 1913, se halla en los actos intencionales de la conciencia .Desde este enfoque, no hay diferencia entre el objeto que el pensamiento mienta y el objeto a cuya presencia aspira, por lo cual más que una peculiaridad que se halle en la naturaleza del objeto, distingue la manera de referirse la conciencia a él. De este modo, no se trata de investigar la relación entre dos realidades externas e independientes (pensamiento y mundo/sujeto y objeto), sino de determinar el sentido de la

\footnotetext{
${ }^{5}$ Como veremos, para Husserl los sentidos de las palabras implican las esencias.

${ }^{6}$ Wilhelm Szilasi desarrolla la consideración de tres periodos en los análisis de la fenomenología de Husserl: el descriptivo, el trascendental y el constitutivo, destacando continuidades y conexiones entre ellos. En el primer periodo, circunscribe su culminación con las LU I, donde se desarrollan los principales pilares de la fenomenología descriptiva, como las reelaboraciones de la intencionalidad, entre otros. Luego, en el periodo de la fenomenología trascendental, reconoce las cuestiones referidas a la evidencia en el horizonte de la fundamentación apodíctica donde Husserl, a lo largo de 15 años, elabora en detalle las consideraciones respecto a los estratos del yo, pasando de los anteriores abordajes de la conciencia trascendental a los análisis y reducciones al ego puro. Ello comienza a desarrollarse en sus obras Die Idee der Phänomenologie (1907); Ideen zu einer reinen Phänomenologie und phänomenologischen Philosophie I-III (1913), y alcanza su epítome en Formale und Transzendentale Logik. Versuch einer Kritik der Logischen Vernunft (1929) y en Méditations Cartésiennes (1931). Finalmente, su trabajo parcialmente publicado en vida, Die Krisis der Europäischen Wissenschaften und die Transzentale Phänomenologie: Eine Einleitung in die Phänomenologische Philosophie (1936), inaugura otro recorrido de 15 años, en el que puede articularse el período de la fenomenología egológica, genética o constitutiva, que complementa las elaboraciones de las últimas dos obras mencionadas. En este marco, los análisis se centran principalmente en la experiencia constitutiva de mundo, enfatizando la fenomenología genética: allí se abordan las efectuaciones del ego puro y sus experiencias constitutivas y trascendentales, las consideraciones de la intersubjetividad y del mundo de la vida (Lebenswelt). No obstante, estos tres periodos no manifiestan una separación tajante en el desarrollo de aquellas obras. Para un análisis detallado de cada uno de ellos, véase, Szilasi (1959):23-144.
} 
trascendencia en la inmanencia que constituye la vida de la conciencia ${ }^{7}$, la cual se funda en la intuición sensible, pero aspira a un rigor de fundamentación al desplazarse hacia la intuición de las esencias o eidos, en tanto configuraciones invariantes, universales y necesarias que un estado de cosas o fenómeno (entre todas sus variaciones) muestra mediante la reducción eidética ${ }^{8}$.

Específicamente, parte de una correlatividad entre fenómeno y conciencia, entendiendo que toda conciencia es conciencia de algo y, simultáneamente, que ese algo es el fenómeno que se da en aquella conciencia, de modo que lo mundanal cobra su sentido solo desde las efectuaciones de la conciencia. Una reducción fenomenológica consiste en reducir toda realidad a la condición de lo que es manifiesto, donde todos los actos de conciencia y los objetos de esos actos pueden ser puestos entre paréntesis.

Tal reducción invierte la relación habitual del hombre con el mundo, donde vivir naturalmente es estar soportado por una protocreencia (Urglaube) en la realidad de todo. La operación fenomenológica consiste en desconectar o suspender esta tesis de la actitud natural que implica continuar con las creencias y ejecutando actos, pero poniéndola entre paréntesis (Einklammerung), en pura abstención de su vigencia real, quedando reducida a puro fenómeno como lo que aparece (y en tanto que me aparece) a mi conciencia (Ideen I: 48-50[65-69]) ${ }^{9}$. De esta manera, el ser del ego puro, que se halla en las bases de dichas reducciones, precede al ser natural del mundo: es un ámbito trascendental que el método fenomenológico reconduce por la vía de lo que denomina reducción fenomenológica trascendental (CM: 61[60] $)^{10}$.

A partir de estas reducciones, entiende aquellas esencias como dimensiones del ser irreductibles a la experiencia empírica ( aunque anterior o posterior a ella ), las cuales permiten una visión precisa de lo que son las cosas, pues los fenómenos impregnados de ellas tienen un una

\footnotetext{
${ }^{7}$ Puede establecerse una clasificación de las trascendencias a las que se aboca Husserl : de los hechos (reales, físicos y psíquicos) ; de lo eidético ; de Dios ; de los sujetos en tanto yoes puros ajenos ; del yo puro respecto a su misma corriente de vivencias ; el del propio porvenir puro y el del propio pasado puro. Desde aquí comprendemos que lo trascendente remite a lo objetual a que se dirigen los actos intencionales primarios (lo cual se pone entre paréntesis para evidenciar, en su peculiaridad, los actos de la conciencia). Como veremos, la consideración del ámbito de lo no-objetual será una de los desplazamientos propuestos por Heidegger.

${ }^{8}$ Esta búsqueda de invariables y constantes también podemos hallarla en el abordaje de Heidegger en relación a las estructuras fundamentales de la analítica del Dasein. Como es evidente, el peso del rigor cientificista se halla en el horizonte de estas búsquedas, lo cual se mantendrá vigente, por ejemplo, en los horizontes de los pensadores enmarcados en la corriente estructuralista, entre otros.

${ }^{9}$ A partir de aquí en las citas presentadas de Husserl, se consignará una doble paginación: en primer lugar, la que corresponde a la publicación en idioma original, principalmente en Husserliana (HUA) y, en segundo, a la traducción castellana disponible y especificada en la bibliografía final. En caso que no hubiese versión castellana, solo se indicará la paginación de la obra en idioma original.

${ }^{10}$ En el marco de discusiones actuales en fenomenología, encontramos distinciones entre la reducción y la epojé en los textos de Husserl, que permiten destacar la manifestación de casos de epojé (puesta entre paréntesis de una tesis de la actitud natural en el mundo) donde no fuesen necesarias reducciones y, por tanto, dar cuenta del carácter contingente en tomar las cogitaciones del ego puro (y lo teorético) como base para los análisis. Véase Patočka, J. (1988):260 y ss. Cf. Carlson (2014):241-246.
} 
sentido inequívoco y unitario para la conciencia , buscando de este modo que el mundo recobre una estructura determinada, cuya condición de posibilidad se halla en tales especies ideales, es decir, condicionan la posibilidad misma de un mundo con sentido. Así, entiende que tales fenómenos no son dados (gegebenes) según el modelo de la intuición sensible, con su temporalidad y flujo inherentes, sino que la realidad dada en la conciencia inmediata está encuadrada en aquella trama de formas o esencias intemporales, vigente para todos sus dominios.

Por esta vía, Husserl hace explicita su intención de alcanzar una fundamentación absoluta para las ciencias, en el marco de una época donde el escepticismo y el relativismo volvían a socavar el suelo del pensamiento científico. En especial, hacia mediados de 1930, Husserl distingue el avance del irracionalismo de la filosofía de la vida, por lo cual articula una suerte de "destrucción de la historia", entendida como un llamamiento a adoptar una actitud escéptica antidogmatica que logre penetrar en la teleología oculta de los hechos (KW: 14-6[60-2]).

Tal actitud busca reactivar los conceptos sedimentados, evidenciando la formación originaria y sedimentación de sentido, que asumidos sin critica terminaron convirtiéndose en prejuicios. Desde aquí explica la crisis de las ciencias y de la humanidad europea, consistente en la separación y automatización de sus adquisiciones sedimentadas en conceptos y en formas de vida asumidos de modo mecánico. El pensar formalizado y tecnificado olvida el proceso por el cual transformo las experiencias de la vida corriente en "cosas en sí", admitiendo como natural la existencia de objetos y verdades en sí que reemplaza nuestro mundo inmediato vivido (Lebenswelt). Precisamente tal olvido condujo a la crisis de las ciencias, las cuales ya no se manifiestan capaces de dar sentido a la existencia humana, debido a que han perdido el sentido de su procedencia (Ibíd. :48-51[92-4]). Estas preocupaciones relacionadas con la herencia conceptual no tematizada tendrán un singular relevo en el pensamiento de Heidegger.

Ahora bien, antes de abordar de lleno tal articulación, se torna necesario explicitar adecuadamente la modalidad de su indagación fenomenológica en los actos intencionales de la conciencia, en vistas a la reformulación que plantea Heidegger. Por ello, continuaremos con su perspectiva de la cuestión del mundo objetivo, tal y como figura en torno a dos de sus conceptos fundamentales: intencionalidad y evidencia. 


\section{1. a.I- La intencionalidad como continuidad entre conciencia y mundo.}

La fenomenología como descripción de vivencias intencionales se aplica a las cogitaciones particulares en sus dos direcciones: la del objeto intencional como tal, considerando las determinaciones atribuidas en los correspondientes modos de conciencia (modos de ser tales como ser-cierto, ser-posible, etc.); y por otra parte a la dirección que atañe a los modos de conciencia, la percepción, etc. (CM: 75 ss. [81 ss.]).

Por esta doble vía, la estructura intencional de la conciencia da cuenta de un nuevo concepto de objetividad que permite reconocer la consistencia objetiva de las esencias. Específicamente, el concepto de intencionalidad que toma de su formación con Brentano (aunque cambiándole radicalmente su contenido ${ }^{11}$ ), le permiten comprender que el acto de conciencia y el objeto no pueden darse el uno sin el otro, circunscribiendo en un lugar fundamental la mediación del sentido en dicho acto.

En efecto, en un análisis pormenorizado en la $\mathrm{V}$ de sus Investigaciones Lógicas, distingue que el objeto ${ }^{12}$ es el mismo en la alternancia de modos factuales e intencionales, al ser percibido, recordado, deseado, etc. La característica fundamental del "algo como algo", su diferencia significativa $^{13}$, se enmarca en la forma en que Husserl trata el sentido o significado (entendiendo la significación como lo propiamente mentado en configuraciones lingüísticas): una intención de significado indica el objeto en cuestión y eventualmente lo hace cognoscible como objeto real, de modo tal que lo mentado se da de modo propio y cumplido, es decir, intuitivamente.

Por un lado, la aprehensión más originaria en la experiencia es el estado de cosas (Sachverhalt), donde la experiencia se manifiesta en un ensamblaje de conciencia-objeto-mundo. Por otro, el acto elemental de la aprehensión cognoscitiva es el acto intencional, comprendiendo con ello a la conciencia como efectuante (leistend), es decir, desde un acto de reunión orientado por un interés unitario o efectuación sintética. En este sentido los actos, como vivencias intencionales, pueden aprehender los significados en tanto unidad ideal, al traer a la conciencia las vivencias donde se dan las significaciones ideales.Allí , Husserl distingue una doble estructura fundamental

\footnotetext{
11 A este respecto véase el análisis y comparación a partir del realismo gnoseológico que subyace al concepto de intencionalidad de Brentano, en Landgrebe (1968): 16-22.

${ }^{12}$ El término objeto tiene en los desarrollos de Husserl una importante distinción. Como su empeño teórico incluye la pregunta por la condición de posibilidad del conocimiento en general, cabe diferenciar lo cognoscible según dos modalidades: a) Gegenstand, al cual Szilasi traduce como "lo enfrentado", en referencia a aquello con que nos encontramos en el mundo y b) Objekt, en referencia al objeto de conocimiento de las ciencias, es decir, a los primeros en tanto configurados según las exigencias de las ciencias. En continuidad con lo desarrollado anteriormente, en este apartado nos referimos a la segunda modalidad.

${ }^{13}$ Es decir, de "algo", su modo de conciencia respectivo y la significación o sentido que permite identificarlo (es decir, los conceptos o categorías que subsumen lo múltiple de la percepción sensible). Cabe aclarar también que la situación entrecomillada de estas expresiones remite precisamente al carácter enunciativo de las mismas y, con ello, señala el campo del lenguaje en los análisis de Husserl.
} 
que remiten a las dos direcciones antes mencionadas (de los modos de conciencia y del objeto intencional ) : la dualidad de noesis y noema ${ }^{14}$, en el marco de una pura teoría del significado ${ }^{15}$, con la cual no remite a una característica objetiva ( es decir , un "que") ni componente real de un acto , sino más bien a una delimitación espacial, temporal, modal, del acto intencional .

De esta manera el concepto de intencionalidad, entendido como un mentar (Vermeinen), atiende el recorrido hacia los procesos de conciencia, concibiéndolo como un intendere (Intendieren), es decir, como una tendencia dinámica orientada hacia la elaboración de la representación propia, hacia el proceso de producción que une un signo o forma simbólica con una representación plena o cumplida que lo indica. Desde la perspectiva de la intencionalidad, los objetos se determinan como lo idénticamente mentado en una multiplicidad de actos efectivos o posibles referidos a ellos, siendo la cuestión del ser real de tales objetos una referencia a las efectuaciones intencionales, en las que ellos se dan a la conciencia como "presentes ahí mismo".

En este marco entendemos que toda explicitación que Husserl realiza no puede asimilarse a una construcción metafísica, pues explicita el sentido que este mundo objetivo tiene para nosotros en la estructura intencional de la conciencia y que, por ello, es anterior a todo filosofar e incluso a un abordaje o investigación de cuño científico:"un sentido que puede ser descubierto pero jamás alterado por la filosofía" (CM: 174[226]). Por medio de esta reducción al sentido, esta teoría abandona el dualismo interior-exterior, al tiempo que deja de comprender a la conciencia como cosa o substancia, distinguiendo su hecho permanente y primario de trascenderse: la conciencia es una realidad fuera de sí. . Esta desustancialización de la conciencia se apoya en el carácter dinámico y múltiple que se revela en su proceso intencional, que se torna manifiesto si nos detenemos en el proceso mismo de tal reducción.

\footnotetext{
${ }^{14}$ En el acto intencional o de significación Husserl distingue estos dos elementos: el acto intencional o noesis (en el que se co-efectúan también las intuiciones del marco apriorístico) y el contenido objetivo al cual el acto se refiere o formas determinadas en las cuales se da lo sensible, en tanto estados de cosas plenamente aprehendidos en el acto intencional, es decir, el noema. Por la noesis surge de lo sensible amorfo el sentido intencional, donde las sensaciones son interpretadas como modos de aparición de un objeto y adquieren mediante ello un sentido y una significación, otorgando al acto una referencia al objeto. Por su parte, a través de las múltiples noemas el objeto permanece idéntico centro de referencia de predicados y mantiene una unidad a pesar de todas las perspectivas perceptivas. La noema se halla constituido por un núcleo de cualidades predicativas (como color, forma, etc.) ordenadas alrededor de una unidad objetiva: precisamente por medio de este núcleo la conciencia se refiere a una $\mathrm{X}$ unitaria. De este modo podemos entender la relación intencional como referencia de un acto a un objeto, a través de un núcleo noemático. Para un análisis más detallado, véase Ideen I: 179-273[210-315].

${ }^{15}$ Waldenfels sostiene que este aspecto de la significación ha quedado desdibujado en la obra de Husserl (Waldenfels, 1997:18). En esta línea de pensamiento, los tratamientos posteriores de Wittgenstein ( especialmente en sus Investigaciones filosóficas), por ejemplo, pueden entenderse como una indagación noematica para comprender hasta qué punto el significado de expresiones y acciones se atribuye a intenciones subjetivas (aunque sin reducir el sentido a vivencias interiores) o más bien a normas socio-históricas (sin reducirlo a vivencias exteriores).
} 


\section{1. a.II.- Una multiplicidad desplegada}

En primer lugar, lo percibido en la percepción, que denomina cosa del mundo circundante, puede variar su dirección aprehensiva. En efecto, si prescindo de mí en la percepción, aquello es una cosa del mundo en general. Del mismo modo, puedo percibirlo como cosa natural por rodeo de caracteres de cosas previamente dadas del mundo circundante ${ }^{16}$. También se dan nexos entre caracteres generales, es decir, como estructuras que se pueden advertir en lo dado. Con estas distinciones se vuelve evidente que el campo de la aprehensión abarca mucho más de lo que se puede verificar con una teoría positivista de la percepción, atenida a la mera sensibilidad.

Asimismo, se dan posibilidades diversas de ser-intentado o captado (ser percibido, imaginado, deseado, pensado, por ejemplo), diferencias que corresponden a la intuición. Es decir, si bien la presencialidad (Leibhaftigkeit) es el modo sobresaliente en que las cosas se dan, también lo hacen estructuras que no corresponden a las cosas ni a los hechos, sino a la intención actual ligada a la situación: el objeto es siempre el mismo, pero lo objetual en la captación es distinto pues se adecua a la modificación de la intención (puedo mentar el objeto, o representarlo, etc.).

Por otra parte, la percepción va desplegando diversos horizontes en torno a lo percibido , hacia : a) la multiplicidad de sus perfiles o perspectivas ; b) el fondo-mundo en el que se destaca ; c) un horizonte temporal donde se incluyen las sedimentaciones de sentido y d) un horizonte intersubjetivo, que lo inscribe en una trama histórica de relaciones humanas.

A partir de esta diversidad, Husserl distingue que la determinación de la conciencia procede de una concreta situación vital y cambia con el cambio de esta. Con la intencionalidad se hace visible la multiplicidad de posibilidades en las cuales un mismo estar-dirigido-a varía y se transforma, subrayando así que la percepción más que un mero fijar la mirada, está inmersa en la corriente natural (y múltiple) de nuestras vivencias, entrelazada en la trama de las $\operatorname{cosas}^{17}$.

Finalmente, las consideraciones respecto a la evidencia son aquí una cuestión central. Si la evidencia perceptiva no es la única forma de aquella, entonces en el conocimiento del mundo cancela las verdades definitivas, apartándose así del fundamento tradicional que vincula directamente la evidencia y la verdad. Esto se debe a que lo decisivo en la explicitación

\footnotetext{
${ }_{17}^{16}$ Por ejemplo, en lugar de una "mesa", puedo percibir "madera".

${ }^{17}$ Una de las críticas que ha recibido la concepción de la conciencia de Husserl es que puede entenderse como ahistorica: las críticas de Heidegger se orientan en este sentido. Frente a ello, Szilasi interpreta que en el bosquejo husserliano la conciencia debe hacer su historia, quedando predispuesta a ello luego de las reducciones y explicitaciones realizadas. Sin embargo, esta historia de la conciencia convendrá precisarla dialécticamente según el propio acaecer fáctico, pues enfrenta aspectos contradictorios que no remiten al pensar sino a las cosas en su ambigüedad e imprecisión por lo cual enfrentan a la conciencia, por ello subraya que "Justamente el que el pensar haga frente a esa ambigua imprecisión muestra su aptitud trascendente. El medio propio de su confirmación es la historia biográfica de la conciencia, es decir, la historia de lo experimentado en la experiencia, de lo pensado en el pensar", Szilasi (1959):178179.Esto manifiesta ciertas resonancias de las elaboraciones heideggerianas.
} 
fenomenológica reside en poner de manifiesto que la experiencia está configurada en horizontes que señalan otras posibles experiencias, o bien confirmatorias o bien antagónicas, las cuales conduzcan a correcciones en diversos modos. Por ello, ninguna experiencia puede darse como conclusiva.

La cuestión fundamental es que la conciencia empírica trabaja siempre con actos intencionales y sus implicaciones, pero el yo empírico con sus acciones permite una multiplicidad de descripciones del mundo que resultan insuficientes para garantizar la certeza del cogitatum y para fundamentar sus acciones empíricas. Precisamente en este marco, Husserl busca alcanzar el ego constituyente, el cual se encuentra en la base de aquel yo empírico, reduciendo todas las posiciones respecto al mundo, para conservar así el ámbito de la actividad propio de este ego puro.

No obstante, en dicho marco se torna necesario establecer ciertas distinciones. El punto de partida o a priori de la correlación conciencia-mundo, desde el que aborda sus análisis, remiten a las reducciones teoréticas o reflexivas de la conciencia, en vistas al horizonte de cientificidad hacia el que se despliega su método ${ }^{18}$.Específicamente, la conciencia originaria (Urbewußtsein) es notemática, previa a todo posicionamiento reflexivo respecto a si, solo evidenciable de un modo retroactivo a partir de la conciencia reflexiva o temática ${ }^{19}$. Desde aquí, es posible distinguir la vertiente teorético-reflexiva en la fenomenología de Husserl la cual, como veremos, se distingue de la fenomenología hermenéutica de Heidegger en su consideración de la correlación concienciamundo desde su ámbito prerreflexivo ${ }^{20}$.

En suma, el método fenomenológico de análisis de la conciencia intencional le permitió a Husserl dar cuenta de estructuras correlativas, simultáneas y múltiples, en contraposición a la tradición moderna en un sesgo dualista y sucesivo que derivó en la distinción de falsos problemas filosóficos y el despliegue de problematizaciones estériles. Heidegger, uno de sus más reconocidos discípulos, parte de estos resultados pero radicalizando la investigación fenomenológica al punto de reelaborar el propio método. La reducción al ego puro, su comprensión de base y el programa husserliano en el marco de un horizonte de cientificidad son los aspectos más relevantes para dicha reelaboración.

\footnotetext{
${ }^{18}$ En el marco de las críticas a la primacía de la reflexión para su metodología, con una (supuesta) vertiente solipsista, encontramos, a partir de la perspectiva de Heidegger, textos de Habermas (1985); McIntyre (1986); Herrmann FW von (2000); entre otros.

${ }^{19}$ Sartre ha realizado un célebre ensayo en torno a esta distinción, con el objeto de destacar la variedad en la espontaneidad de la conciencia-mundo respecto a la unidad del ego en su función de fascinación y enmascaramiento. Véase, Sartre (1936/1943/1960).

${ }^{20}$ En esta vertiente, Richir también destaca la posibilidad de radicalizar la epojé hasta el abandono de la egología para evidenciar el fenómeno de mundo preteorético (donde el a priori de la correlación conciencia-mundo se considera desde lo ya-acontecido del mundo circundante) en su originaria multiplicidad, donde el darse de tales fenómenos desbordan la unidad de sentido para la conciencia, véase Richir (1992): 191 y ss. Así, dar cuenta de esta esfera preteorética y las limitaciones en el análisis de Husserl a este respecto (quien aborda el a priori de tal correlación a partir de la experiencia de la reducción), distinguen el pensamiento de Heidegger, abriendo un camino para las reelaboraciones en la fenomenología contemporánea. Para un desarrollo de esta distinción, Cf. Posada Varela (2015):27-42.
} 
Sus críticas se guiaron por la interpretación de que tal descripción fenomenológica aún manifiesta una correlación estática entre las unidades objetivas y los modos subjetivos de la intencionalidad, ignorando la temporalidad y dejando sin examinar el ser de lo constituyente ${ }^{21}$ $(\text { SuZ: 6[29] })^{22}$. Por esta vía, comienza a desplegar una modalidad autónoma de relacionarse con la enseñanza recibida, que también se manifestó en sus vínculos personales y profesionales.

\section{1. b.- Aproximaciones históricas al vínculo con Heidegger.}

Los inicios de la relación con Husserl, han manifestado una continuidad y dependencia tal y como puede constatarse en su tesis doctoral y de habilitación (1913/1915). Pueden fecharse tales inicios en 1909 en la facultad de Teología, a partir de sus indagaciones en $L U$. Luego de un período en el estudio matemático y algebraico, previo abandono de la teología a partir de una crisis personal hacia 1911, se encamina hacia la filosofía de la mano de Arthur Schneider, su director de tesis doctoral. En 1915, a partir de un proyecto de habilitación centrado en la historia de la filosofía sobre Duns Scoto, sus primeras lecciones y seminarios se manifiestan en la línea teórica del neokantismo, contexto de pensamiento que, como vimos, también influyó en su maestro ${ }^{23}$. Por medio de vínculos

\footnotetext{
${ }^{21}$ No obstante, en sus Meditaciones cartesianas, Husserl no considera los actos como unidades inmóviles sino como inmanentes en la duración, que en su devenir se conectan dentro de la totalidad concreta de la corriente vivencial de la conciencia, de modo que el análisis fenomenológico alcanza las cuestiones de la génesis universal y de la estructura genética del ego (CM: 110[132]). El análisis genético persigue el devenir vivo de la intencionalidad. Con esto se pone al descubierto la propia historia (las referencias intencionales que corresponden a la situación del que percibe, juzga, etc.) de toda vivencia intencional de la conciencia, es decir, su génesis temporal. El enfoque genético parte del análisis estático de las cosas ya acabadas, para traer a la luz la génesis pasiva que posibilita esas cosas, retrocediendo también a la temporalidad inmanente que permite comprender esta preconstitucion e instauración originaria, que al sedimentarse provee de materia a las "actividades superiores " del yo que comienzan con la percepción activa. Abordando el tiempo como forma universal de toda génesis egologica, la fenomenología aspira así a comprender el mundo mismo en su origen (Ibíd.: 109[130-1]). Para un análisis de las relaciones entre el método genético y las habitualidades del ego, véase Walton (2009):46-62.Cf. Patočka J. (1988), passim.

${ }^{22}$ Complementando lo especificado en la nota 9 de este capítulo, destacamos que las citas de obras y cursos de Heidegger remitirán en primer lugar a la paginación de la edición alemana agrupada principalmente en la Gesamtausgabe (GA); en segundo lugar, a las traducciones al castellano más relevantes. En caso que no hubiese alguna de estas fuentes, se indicará en el anexo bibliográfico. Asimismo, los términos alemanes fundamentales para nuestros recorridos se colocarán entre paréntesis al lado de sus traducciones, en las primeras menciones respectivas.

${ }^{23}$ Específicamente, las obras y trabajos de Heidegger, son: su tesis doctoral, Die Lehre vom Urteil im Psychologismus. Ein kritisch-positiver Beitrag zur Logik (1913); la tesis de habilitación, Die Kategorien und Bedeutungslehre des Duns Scotus (1915) (ambas publicadas en GA 1). Entre las primeras lecciones y seminarios en la Universidad de Friburgo hasta 1917, destacamos: Über Kant, Prolegomena (1915-6); Übungen über Texte aus den logischen Schriften des Aristoteles (1916); Kant und die Deutsche Philosophie des 19. Jahrhunderts (1916); Grundfragen der Logik (1916-7); Wahrheit und Wirklichkeit: Über Fichtes Wissenschaftslehre von 1794 (1916-7), entre otros. A este respecto, véase la investigación del archivo de dicha Universidad, en Xolocotzi Yañez (2008):17-9.
} 
académicos $^{24}$ comienza a transitar por los caminos de la fenomenología: a partir de 1914, efectiviza un contacto epistolar con Husserl ${ }^{25}$.

Luego de su habilitación como profesor no numerario en la Universidad de Friburgo en el período de 1915-1922, continúa con investigaciones y enseñanzas, las cuales distan de un pleno acuerdo con aquellos enfoques: en sus primeros escritos manifiesta sus diferencias con el punto de partida fenomenológico, especialmente con el ámbito de comprensión que le subyace. Aun así, su incorporación a la docencia se establece con el apoyo de Husserl, vinculándose no solo como alumno sino también como su asistente. En este período de formación, mantiene sus diferencias, repitiendo la misma relación filosófica que tuvo Husserl con su maestro Franz Brentano.

A partir de sus primeras lecciones, Heidegger profundiza su crítica a la estrechez del horizonte de comprensión de la fenomenología, a partir de lo cual tomará distancia de Husserl, cuestión que le permitirá desarrollar su propia perspectiva con mayor libertad. Ya en 1920 presenta su lección Grundprobleme der Phänomenologie, donde despliega pormenorizadamente sus críticas al horizonte cientificista hacia el cual se orienta la comprensión de Husserl. Junto a este distanciamiento, se acrecienta su número de alumnos y asistentes, así como también crece su notoriedad institucional por la originalidad de procedimiento, de modo tal que le permite incrementar su autonomía institucional y de pensamiento.

Luego radicaliza cada vez más sus diferencias con la fenomenología de Husserl, las cuales se cristalizan en un distanciamiento en sus respectivas relaciones personales en tensión dentro del ámbito laboral universitario: la preservación de su puesto como docente lo enmarca en una cierta dependencia, ambivalencia que se manifiesta entre los comentarios privados y públicos sobre Husserl $^{26}$.

En el período de 1923-1928 se desempeña como profesor titular en la universidad de Marburgo, al tiempo que Husserl sostiene una defensa de la tentativa fenomenológica de Heidegger, subrayando incluso su interés de que este fuese el sucesor de su cátedra en Friburgo. Finalmente, por la vía de su mediación, Heidegger logra dicha sucesión luego de su publicación de Ser y tiempo

\footnotetext{
${ }^{24}$ En especial, por mediación de Emil Lask, discípulo de Husserl, en el marco de las relaciones docentes y de investigación que Heidegger tiene con Heinrich Rickert. Para un desarrollo de las influencias y relaciones en estos primeros pasos académicos de Heidegger, véase Xolocotzi Yañez (2008):15 ss.

${ }^{25}$ La correspondencia con Husserl que puede consultarse, se halla publicada en BwF. No obstante, algunos comentarios en los contactos epistolares Heidegger-Husserl de 1914, al momento solo pueden cotejarse por medio de la correspondencia con su maestro Heinrich Rickert. Al respecto, véase BwR: 16-21.

${ }^{26}$ En las cartas y cuadernos de Karl Lowith, uno de sus alumnos destacados, pueden encontrarse testimonios del descrédito filosófico que Heidegger le imputa a su maestro, a este respecto véase Xolocotzi Yañez (2007b).No obstante, en sus lecciones de 1923 afirma que "Mentor en la busca fue el Lutero joven; modelo, Aristóteles, a quién aquel odiaba. Impulsos me los dio Kierkegaard, y los ojos me los puso Husserl” (OHF: 5[22]). Nuestra interpretación es que tal ambivalencia es una de las figuras de la tensión irreductible e inherente entre las elaboraciones singulares de Heidegger y la articulación en el lenguaje de la tradición con el que discute.
} 
en $1927^{27}$, consagrándose como pensador y docente en el período 1928-1944, aunque poniendo de manifiesto la tensión latente en su relación con Husserl en un distanciamiento que se torna definitivo. Años más tarde, Husserl también reconoce la radical distancia metodológica y temática del tratamiento de la fenomenología de Heidegger, en una vía de a-cientificidad que se aparta de su horizonte fundamental ${ }^{28}$.

Precisamente esta cuestión del horizonte de cientificidad es uno de los aspectos más relevantes en la consideración de la cuestión de la comprensibilidad de base que Heidegger le critica al método de su maestro, lo cual orienta el pasaje de aquella fenomenología de tipo trascendental a lo que Heidegger entiende como una fenomenología hermenéutica.

\section{2.- Primeros abordajes de Heidegger a la fenomenología. Límites e influencias en sus vínculos con el horizonte de la cientificidad.}

Entre los primeros años de la década de 1920, cuando Heidegger comienza a destacarse como profesor en la Universidad de Marburgo, encontramos los lineamientos principales de la posición crítica respecto al método fenomenológico husserliano ${ }^{29}$. Allí, reelabora el método fenomenológico a partir de una indagación en el marco conceptual y categorial en su tradición respectiva, poniendo en evidencia el horizonte de comprensión en el que dicha articulación en el lenguaje se proyecta.

En efecto, en sus lecciones de 1922 distingue la fenomenología como un modo apropiado de investigar, pues permite hablar de algo solo en la medida como ese algo se muestra, es decir , una modalidad de la investigación que actualiza los objetos en la intuición y habla de ellos en la medida en que están en la intuición. Aquí, además del concepto de intencionalidad que se liga con dicho ámbito de la intuición, podemos encontrar el subrayado que realiza Heidegger de la cuestión del fenómeno (del que se habla) y del decir mismo en tanta articulación de aquello que se investiga.

\footnotetext{
${ }^{27}$ Del cual afirma, en su correspondencia con Jaspers el 29/12/1926, que si el tratado está escrito 'contra' alguien, es contra Husserl (BwJ: 71[58]).

${ }^{28}$ El quiebre definitivo de sus vínculos personales se cristaliza cuando Heidegger asume la rectoría de la Universidad Alberto-Ludoviciana en Friburgo (1933), en el marco de su pronunciación en el partido nacionalsocialista, a partir de lo que Husserl entiende como un antisemitismo creciente. Véase la entrevista a Hermann Heidegger en Xolocotzi Yañez (2007b).

${ }^{29}$.Aquí, nos detendremos especialmente en los cursos entre: Einführung in die phänomenologische Forschung (19231924) (EPhF) y Die Grundprobleme der Phänomenologie (1927b) (DGPh), este último es el sucesor inmediato de la publicación de $S u Z$. No obstante, también pueden encontrarse otros cursos y trabajos de esta época donde plantea explícitamente su posicionamiento crítico respecto a Husserl, véase MAgL; EP.
} 
Con ello, y en línea con su maestro, se manifiesta atento a los pormenores de la articulación en el lenguaje, a la carga semántica y originaria de los conceptos desde y con los que discute, sin descuidar la consideración propia del concepto de fenómeno, por la vía de una indagación que confluye en $S u Z$ con la distinción de un concepto fenomenológico de fenómeno, entre otras.

\section{2. a. Acta de nacimiento para el concepto de fenomenología: recorridos y derivas.}

En el marco de la historia de la significación del concepto fenomenología, nuestro autor distingue que, en las elaboraciones de Husserl, aquel quedó circunscripto al campo temático de la conciencia como flujo de vivencias. En tal contexto, destaca que el horizonte de cuestionamiento respectivo se orientó a partir de una triple herencia tradicional: por un lado, el cuestionamiento epistemológico de Descartes; por otro, en vistas a la fundamentación de las ciencias del espíritu, en continuidad con los desarrollos de Dilthey y, finalmente, a partir de la comprensión de ser como presencia, que caracteriza las bases del pensamiento griego. En esta cristalización la modalidad recibe influencias desde la obra de Hegel, implementándose el modelo de la lógica, mientras crece el afán de sistema. Heidegger entiende que estas herencias no tematizadas de la fenomenología la desvían de su origen, imputándole a su maestro el mismo tipo de críticas que este dirigió al pensamiento tecnificado y sedimentado de la ciencia de su época, como explicita en este fragmento:

“...la contaminación de la fenomenología con la terminología de la tradición redunda en una indefinición general. Resultan patentes las afinidades mutuas. La investigación fenomenológica, que debía ser la base del trabajo científico, se hunde en la indefinición, la irreflexión y la ligereza, convirtiéndose en la moda filosófica del momento, moda un tanto ruidosa, un escándalo público de la filosofía” (OHF: 73[97 s.])

Aquí se pone en evidencia su crítica a la comprensión de base de la tentativa de Husserl, dirigiéndole a su tratamiento conceptual sus propias críticas. Por ello, interpretamos esta tentativa como una radicalización de la perspectiva husserliana, es decir, el mismo tratamiento del lenguaje frente su aspecto dogmático que halla en la remisión crítica al método e investigación de partida, un principio de continuidad y profundización.

En dicha línea, realiza una indagación del concepto de fenómeno en un recorrido que también toma como referencia las obras de Aristóteles, Descartes y Kant con el objeto de plantear un punto de partida más apropiado para el campo temático de investigación. Esto se debe a que encuentra un hiato, un sesgo entre el campo terminológico y semántico utilizado y el campo temático de la conciencia, tal y como se articula en las obras de aquellos pensadores. Una 
consecuencia de esta indagación en la historia de la significación es que, a partir de la respectiva reelaboración y la problematización de los análisis en torno a la conciencia en la filosofía moderna, Heidegger logra distinguir la necesidad y supremacía de retomar la pregunta por el ser, a la luz de los escollos de los anteriores caminos del pensar.

\section{2. a.I El concepto de fenómeno.}

En efecto, rastrea las primeras apariciones de la expresión fenomenología en el siglo XVIII en el Nuevo Organon de Lambert, cuyo significado se enmarca en una teoría que busca evitar la apariencia ilusoria. Una significación similar encuentra en la obra de Kant, Hegel, en la teología protestante del siglo XIX; en las lecciones de metafísica de Franz Brentano y en la obra de Husserl (EPhF: 5-7[26 s.]).

Ahora bien, subraya que estas consideraciones de la apariencia ilusoria solo pueden establecerse sobre el supuesto de una manifestación cierta o plena, que se vincula con conceptos de verdad y certeza, entre otros. Así, se ve remontado hacia tradiciones antiguas pues dicha significación, al estar articulada de una manera negativa, deja al descubierto un suelo más originario (desde donde puede plantearse tal enunciación negativa): accede a la etapa del pensamiento filosófico en que se articulo esta dualidad entre la manifestación plena y el posible error o apariencia ilusoria de tal manifestación.

En ese trayecto retoma el concepto griego respectivo, en la obra de Aristóteles: fenómeno en tanto algo que se muestra, por sí mismo a la conciencia ${ }^{30}$. Esta conceptualización supone la comprensión griega del Logos apofántico, que fundamentalmente significa hacer patente lo que se habla en el decir. En este contexto de significación, el ser verdadero del Logos implica sacar del ocultamiento el ente del que se habla y hacerlo ver como desoculto. Como contrapartida, lo falso remite a un encubrir o poner una cosa delante de otra en tal decir. El horizonte sobre el que se proyecta esta significación es la ousía, la cual fundamentalmente comprende el ser en el sentido de la presencia.

De esta manera, la función del Logos es hacer que algo sea visto o percibido. Desde esta mediación, en tanto fundamento para entender posibles desvíos en el acceso al ente, Heidegger

\footnotetext{
${ }^{30}$ Aquí aborda el tratamiento que Aristóteles realiza de la cuestión de percibir el mundo (en el modo de ver) en su tratado Sobre el alma.
} 
retoma la exigencia de certeza implícita en los pensadores modernos abordados y en la investigación de Husserl, la cual articula aquella herencia griega en su concepto respectivo ${ }^{31}$.

\section{2. b. Husserl y una herencia conceptual no tematizada.}

Pöggeler, en sus interpretaciones, circunscribe la diferencia general del abordaje de Husserl y Heidegger, en un paso que va de la fenomenología trascendental y descriptiva a una fenomenología hermenéutica de la facticidad. Para ello, destaca que el estadio del que parte la fenomenología de Husserl se mueve bajo la exigencia de ir a las cosas mismas, en tanta descripción imparcial de fenómenos, sin desecharlos. Como vimos más arriba la reducción al eidos convierte a la fenomenología descriptiva en descripción eidética, regresando a la conciencia trascendental en cuyos actos viene constituido el ente en tanto ente. Por su parte, el punto de partida radical fenomenológico para Heidegger es la vida fáctica, donde la descripción no debe ser en referencia a algo objetivo o cósico sino que debe estar guiada por la comprensión como punto de partida (Pöggeler, 1993: 81-5). Siguiendo esta distinción entre ambos autores en vistas del círculo de comprensión en el horizonte de sus investigaciones, nuestra interpretación pone de relieve los vínculos estrechos en lo que respecta a la consideración de la herencia conceptual y terminológica de la tradición. En este sentido, entendemos que la motivación de partida es la misma, siendo una la radicalización de la anterior.

En efecto, en sus cursos sobre fenomenología Heidegger insiste en que el pensamiento de Husserl manifiesta ciertas ligaciones no solo con la idea de certeza y evidencia del marco categorial científico, sino también con el horizonte de comprensión del ser que se halla en el pensamiento griego. Para Heidegger, el método fenomenológico apropiado debe surgir de una confrontación con la cosa, prescindiendo de aquella orientación científica, la cual mantiene con el pensamiento griego la caracterización quiditativa de la existencia y el fenómeno, es decir, con determinaciones propias del ser entendido como presencia, propio de la comprensión implícita en la ousía griega ${ }^{32}$.

Específicamente, Heidegger distingue que en sus obras fundacionales la fenomenología es entendida como ciencia eidética descriptiva en sus vínculos con la lógica, pues busca que los objetos de la lógica sean traídos a una intuición que los muestre. En este sentido, el "ir a las cosas

\footnotetext{
${ }^{31}$ En especial, véase las comparaciones que desarrolla entre Descartes y Husserl en EPhF: 42-6[60-75]; 247-70[248$68]$.

${ }^{32}$ A estas determinaciones que remiten al ser de la presencia, propios del ámbito natural, Heidegger las distingue como determinaciones-qué (Was-Bestimungen) (Ibíd.:45[62]). Por otra parte , sus primeros análisis de las significaciones de la ousía en Aristóteles, respecto a la comprensión de ser que le subyace, pueden encontrarse en el informe de sus investigaciones, que confecciona para los comités de selección universitaria , a pedido de Natorp en PhIA:367-375[ 50$60]$.
} 
mismas" tiene como horizonte el rigor matemático de la cientificidad de su época. Incluso, le reprocha a su maestro que las determinaciones que establece en su indagación de los actos intencionales de la conciencia son meramente verbales (es decir, no provenientes de la experiencia con el ente que se investiga), por medio de lo cual se evidencia una sucesión no tematizada de tales conceptualizaciones heredadas (EPhF: 56[71]).

En este marco, su preocupación por el conocimiento reconocido, en sus pretensiones de cientificidad, lo conduce a una comprensión de la conciencia como naturaleza, utilizando categorías cósicas respectivas. De este modo, la conciencia es tomada en el sentido de una ejemplificación de un universal y el hombre es comprendido como un caso de esa posibilidad general de ser conciencia. Frente a ello, Heidegger reconoce la necesidad de tematizar nuevamente, abordando adecuadamente estas cuestiones.

Articula esta trasposición categorial en aquel lema de la fenomenología y el campo de comprensión que supone, puesto que las cosas vienen a nuestro encuentro primero como problemas, los cuales se hallan siempre prefigurados de un modo especifico. En este sentido, Husserl prefigura la problematización a partir de una idea de ciencia con vínculos y compromisos con la matemática y la lógica. Esto repercute y media la experiencia de acceso al ente en su investigación y, consecuentemente, repercute en una postergación de la pregunta específica por el ser específico de la conciencia. Esta trabazón, se mantiene en la misma línea que el tratamiento cartesiano del cogito, que nuestro autor entiende como etapa fundacional del pensamiento filosófico, donde se revela la conciencia como campo de investigación bajo la égida del marco comprensivo y categorial cósico.

Esto se debe a que Descartes se mantuvo en la preocupación por el conocimiento fundado y certificado, con lo cual terminó por nivelar el carácter del ser, al mantener el mismo suelo de la escolástica, desde un concepto de verdad como certeza (lo certum), por lo cual el cogito funciona como un fundamento para alcanzar el conocimiento indubitable. Así, prefigura el movimiento comprensivo del pensar de Husserl, al entender como secundario la cuestión del ser específico de la res cogitans, solo predicando de esta su carácter cierto y formal.

Así , en este recorrido Heidegger le imputa a su maestro pasar por alto un cuestionamiento y discusión con el cogito sum de Descartes, aceptándolo como comprensible de suyo, desde el mismo suelo de la certeza que es, al fin y al cabo, el que subyace a la preocupación por el desarrollo de la ciencia. Entre las distintas manifestaciones de ello, destaca ciertas tergiversaciones que se hallan en el concepto de intencionalidad, donde distingue resonancias de un subjetivismo como corolario del punto de partida: la comprensión del ser como subsistencia. 


\section{2. c.- La desfiguración de la fenomenología y la reformulación de Heidegger.}

La interpretación de partida de nuestro autor es que el conocimiento trascendental en Husserl parte de un objeto pensado cósicamente desde donde se regresa a un sujeto en el análisis de la intencionalidad, dejando en desatención la vida en su facticidad, es decir, la vida originaria en la conexión de significatividad del mundo ${ }^{33}$. En lugar del yo trascendental, Heidegger pone la vida en su carácter factual, la cual es vida en un mundo y es históricamente como se comprende a sí. De este modo, la historia acontecida se convierte en hilo conductor de su investigación fenomenológica: de la vida en su facticidad a la vida en su historicidad ${ }^{34}$.

La puesta entre paréntesis de la historia en Husserl implica para nuestro autor un encubrimiento de los prejuicios que operan en toda descripción que se vale de conceptos, los cuales se hallan impregnados por la tradición y la comprensión. Asimismo, como vimos, la orientación teorética y reflexiva de su método, deja sin consideración suficiente las implicancias factuales de la conciencia originaria. Frente a ello, Heidegger denomina interpretación a un nuevo desarrollo de la comprensión, que se apropia de lo comprendido al hacerlo explícito. Precisamente desde esta consideración es donde destacamos la continuidad con motivaciones de Husserl, así como también, la necesariedad de posicionarse críticamente con su perspectiva y la consecuencia posterior del abandono del método en cuestión.

Desde sus primeras lecciones de Friburgo, nuestro autor indaga en torno al método apropiado para aprehender las remisiones de significado en que se da primaria y preteoréticamente la vida fáctica. Específicamente, Heidegger destaca que el nexo de significados es aquello a partir de lo cual comprendemos y es hacia lo cual se proyecta el existente humano y, como tal, es una estructura de este y no algo ideal o inscripto en los entes. En tal dirigirse a, esta dado de antemano lo comprendido, de modo que lo interpretado se halla ya sesgado por una cierta conceptualización. De esta manera, la interpretación se mueve en un círculo, pues está dentro de lo ya comprendido: se trata de un círculo hermenéutico el cual, ineludible, demanda un modo apropiado de entrar en él ${ }^{35}$.

\footnotetext{
${ }^{33}$ Diversas exégesis subrayan que la reducción de Husserl no debe comprenderse como una tentativa de aislamiento de la conciencia y el mundo, lo cual puede ser una de las derivaciones de tal desatención. En este contexto, Tugendhat subraya que la reducción husserliana evidencia más bien el fenómeno trascendental de mundo haciendo epojé del mundo natural supuesto, lo cual permite más bien evidenciar la profunda correlación conciencia-mundo. Véase, Tugendhat (1970):263 y ss.

34 Lo cual también torna relevante el carácter sedimentado de la experiencia. En este marco, además de las consideraciones de Gadamer en torno a la tradición, encontramos numerosas elaboraciones del fenomenólogo checo Patočka quien propuso cierta fenomenología de la historia humana correlativa al análisis de la originariedad de la vida fáctica en el mundo: específicamente, aborda relaciones entre el darse de los fenómenos y el carácter histórico de la apertura del mundo. Véase Patočka J. (1988 [ 1974-75] )

${ }^{35}$ Este precomprensión de las cosas produce una circularidad natural e inevitable en la comprensión y el conocimiento, que va de lo incomprendido a lo comprendido y viceversa, por ello se ha denominado como círculo hermenéutico (por
} 
Para nuestro autor, esto se logra si la interpretación se desprende prioritariamente de las cosas mismas. La tarea propuesta es no permitir que la manera previa y sedimentadas de ver y entender, que denomina haber previo (Vorhabe), sean dadas por el trato y la experiencia en lo cotidiano y el entorno del existente humano la cual, más que apuntar a un conocimiento teorético, denota un elemento anterior: remite siempre a elementos pre teoréticos y a-reflexivos, de los cuales la fenomenología puede proporcionar una genuina intuición categorial $^{36}$. Desde allí, se pone de manifiesto un mundo significativamente articulado en el cual ya siempre nos hallamos inmersos de un modo comprensivo. El modo de acceso, por tanto, es hermenéutico-comprensivo y no meramente reflexivo como en el caso de Husserl. De este modo, la fenomenología es comprendida como una ciencia preteorética originaria (BP: 59[70-71] $)^{37}$.

Así, al fundarla en la comprensión la reformula como una fenomenología hermenéutica, donde el interpretar es tomado en el sentido de determinar la esencia de la exégesis a partir de lo hermenéutico ${ }^{38}$. Así, Heidegger busca descubrir cómo nos comportamos en cada caso en el mundo y no ir tras contenidos eidéticos universalmente válidos ${ }^{39}$.Desde allí todo nos resulta accesible desde el horizonte de precomprension del mundo de la vida ${ }^{40}$.

Frente a las perspectivas que ponen en relieve un aspecto intencional en la reformulación heideggeriana, distinguimos aquí que es la singular puesta al límite de un modo de tratamiento del

ejemplo: ¿cómo puede conocerse la parte si no se comprende el todo? Y, correlativamente ¿cómo puede conocerse el todo si no reconozco las partes? ).Para un análisis de estas cuestiones, véase Vattimo (1985):34-35.

${ }^{36} \mathrm{El}$ ser, por ejemplo, no es accesible por medio de una intuición sensible sino por una intuición categorial. A este respecto, véase un análisis en KV: 161[69 s.].En su trabajo posterior, reflexionando sobre su camino por la fenomenología, destaca el influjo que recibió de la sexta investigación lógica de Husserl, respecto a las consideraciones sobre la intuición categorial (MWPh: 98[99]).En el capítulo 7 desarrollaremos estas distinciones.

${ }^{37}$ Para un abordaje pormenorizado del contrapunto y desplazamiento desde la fenomenología teorética y reflexiva en Husserl hacia la fenomenología a-teorética, prerreflexiva y hermenéutica en Heidegger, véase Herrmann, F.W (1990/2000); Zahavi (2003) y Xolocotzi (2002). A partir de ello, Adrian distingue 4 fases del giro hermenéutico heideggeriano a partir de los cursos de Friburgo hasta la publicación de SuZ, donde va explicitando su apropiación de la concepción husserliana de la intencionalidad de la conciencia, pero rechazando la comprensión de la subjetividad a partir de cogito cartesiano, véase Adrian (2011):212-230.

${ }_{38}^{3}$ Para una distinción y especificación de esta modalización de la interpretación, véase Pöggeler (1993):84.

${ }^{39}$ En este marco , encontramos en sus primeras lecciones de juventud la distinción entre la capacidad de apropiarse comprensivamente del mundo que circunda la vida (Ereignis), frente al proceso de privación de la vida (Entlebnis) que responde a procesos de objetivación (Vorgang) propio de perspectivas con pretensiones cientificistas. Aquel acontecimiento apropiador designa el sumergirse y apropiarse (en actitud a-teorética y prerreflexiva) de la corriente significativa en la que estamos inmersos, en contraposición al intento objetivador y teorético de las ciencias (BP: $75 \mathrm{~s}$. [91 s.]). En su período posterior de pensamiento, como veremos, el término Ereignis designa más bien la co-pertenecia entre ser y Dasein.

${ }^{40}$ De este modo el significado no es algo posterior al encuentro sujeto-objeto (de conocimiento), sino mas bien comprendemos ya a partir y desde nuestra familiaridad con horizontes de significatividad, desde el mundo (como todo de significaciones) en que estamos inmersos. Tales horizontes, entonces, son anteriores a todo conocimiento teorético: este siempre ya los presupone. 
lenguaje, sobre su herencia conceptual y comprensiva, aquello que desplaza y renueva la puesta en cuestión de la existencia humana en el horizonte de la pregunta por el ser que desarrolla en $\mathrm{SuZ}^{41}$.

En efecto, Heidegger encuentra necesario liberarse de aquella tradición y su terminología, que tuvo el descuido de no preguntar primero por el ente respecto a su constitución peculiar. El modo de realizarlo es mediante una desconstrucción : retroceder al sentido originario de las categorías puestas en juego ( conciencia , persona , sujeto, etc. ) para llegar a su suelo originario en la experiencia del ser, es decir, retrotraer los conceptos a su auténtico origen, haciendo visible lo positivo de tal pasado, revelando nuevamente el tema de la existencia, tal y como vimos, por ejemplo, con el concepto de fenómeno.

En ese sentido entiende que la fenomenología se ha visto obturada en una suerte de deriva que se manifiesta en las desfiguraciones de significación que mencionamos anteriormente. No obstante, propone retomar la fenomenología en su posibilidad pero distinguiendo su modo propio de asumirse como concepto y configurarse en su ser ${ }^{42}$. Este planteamiento originario lo conduce a subrayar que los objetos deben tomarse tal y como aparecen en un determinado mirar, lo cual surge de un estar orientado a ellos, es decir, estando ya familiarizado con el ente al que se dirige.

En este desmontaje crítico de la tradición, propone un retorno a la filosofía griega para dar cuenta como aquel suelo originario decae y queda encubierto. Esta operación del pensamiento heideggeriano remite a una hermenéutica de la facticidad que se orienta, mediante la interpretación, al haber previo que hay que interpretar desde la trama de los objetos en su manifestación, en un apartarse de lo más próximo hacia lo que se encuentra en su fondo. En pocas palabras: este recorrido hacia atrás es el trayecto y sentido que persigue el método fenomenológico en la reelaboración que plantea.

Por contraste, entiende que en la investigación de Husserl se cuela previamente una dirección de la mirada para todo análisis intencional: con la reducción eidética de la conciencia trascendental, la división metódica se halla guiada por categorías ${ }^{43}$ que no corresponden al ser especifico de la conciencia. Desde aquí Heidegger inscribe lo que entiende como destrucción fenomenológica (phanomenologische Destruktion) en tanto operación en el lenguaje, remitiéndose a la investigación histórica del origen de tales categorías.

En sus lecciones en Marburgo de 1927, insiste en la comprensión previa del ser que se despliega antes de que nos comportemos con todo ente, señalando con ello la relevancia de

\footnotetext{
${ }^{41}$ Asimismo, en $S u Z$ sintetiza y consolida estas reelaboraciones en torno al concepto de fenómeno, la fenomenología hermeneútica, el programa de aquella ciencia preteorética (cristalizándose en la analítica existenciaria del Dasein) y el método de la interpretación, como el adecuado para esta labor. Véase, SuZ: 27-40[50-62].

${ }^{42}$ Sostiene que la fenomenología es el único tipo para la investigación ontológica, pues permite mostrar a sí mismo el ente y ser nombrado tal y como se muestra (BZ: 4[12]).

${ }^{43}$ Entre ellas distingue: género, especie, singularidad eidética, diferencia específica, entre otras (EPhF:274[273])
} 
establecer una distinción ontológica. La modalidad puede distinguirse pues se halla articulada en el lenguaje, tal y como se evidencia en este parágrafo:

“Debemos comprender'efectividad','realidad','vitalidad','existencialidad', 'consistencia' para poder comportarnos de manera positiva respecto de un determinado ente efectivo, respecto de algo real, con relación a algo vivo, respecto de algo existente o algo consistente. Debemos comprender el ser para estar en disposición de que se nos dé un mundo que es, para existir en él y para que nuestro propio Dasein que es pueda ser. Debemos entender la efectividad antes de toda experiencia de lo efectivo. Respecto de la experiencia del ente , la comprensión de la efectividad o del ser en el más amplio sentido es, en un determinado sentido, anterior a dicha experiencia(...) no quiere decir, claro está , que tengamos que tener antes un concepto explícito de ser para experimentar teórica o prácticamente el ente. Debemos comprender el ser, ser que no puede ser ya denominado ente, ser que no puede aparecer como un ente entre los demás entes, pero que, sin embargo, debe darse y de hecho se da en la comprensión del ser.”(DGPh: 14[35 s.])

En suma, entendemos que esta anterioridad, que oscila entre lo conceptual y lo preconceptual, se torna irreductible en su reformulación de la fenomenología. En este marco, subraya que para Husserl la reducción fenomenológica derivó en un método de reconducción de la mirada, desde la actitud natural del hombre en el mundo de las cosas y personas, hasta la vida trascendental de la conciencia y sus vivencias noéticas-noemáticas, que tornó de importancia tomar como punto de partida la neutralidad de la existencia, es decir, la suspensión del juicio respecto de la existencia de las cosas y de los hechos de la conciencia para entregarse rigurosamente a examinar su estructura y su modo de aparición ante la conciencia trascendental. En cambio, para Heidegger la reducción fenomenológica significa la reconducción de la mirada fenomenológica desde la comprensión concreta de un ente articulada en el lenguaje hasta la comprensión del ser de ese ente, por lo cual rechaza aquel nivel de universalidad en la descripción ${ }^{44}$.

La indagación conceptual que realiza, que evidencia la comprensión de base en la investigación fenomenológica de su maestro, se manifiesta frente al extravío de la pregunta por el ser de lo tematizado en su reemplazo por el ser-objeto para la ciencia, cuestión que lo conduce a una nueva problematización : para ampliar el círculo de la comprensión que se articula en un marco conceptual, se torna necesario como condición aclarar previamente la diferencia ontológica entre ente natural y existencia, distinguiendo las terminologías y conceptos propios para cada caso, por lo cual un abordaje del existente humano se torna ineludible. Asimismo, tal articulación y

\footnotetext{
${ }^{44}$ En este contrapunto, Thurnher analizó algunas modificaciones que Heidegger desplegó en SuZ, a partir de las elaboraciones de Husserl en sus Ideen. Entre ellas, destaca la diferencia en la concepción de realidad en Husserl (lo representable y dable en actos intencionales de la conciencia) y en Heidegger (quien comprende no solo la representación objetal sino también al ente no abierto a la contemplación teórica y solo comprensible en la "ejecución" de la existencia del Dasein) .Véase, Thurnher (2004):437-454.
} 
reelaboración pone en evidencia que la fenomenología y sus resultados desplegados en una trama de lenguaje, en última instancia, se ven modificados de acuerdo con los progresos en los temas investigados ${ }^{45}$.

\section{3.- Aproximaciones metodológicas a la analítica del Dasein.}

Tomando distancia de líneas interpretativas o abordajes de mediados del siglo pasado, que ponen el acento en la figura del autor y sus motivaciones de fondo, las interpretaciones en las que aquí nos articulamos, en cambio, proponen dar cuenta también de las dinámicas, umbrales y desplazamientos que se manifiestan en el ámbito del lenguaje en un campo de articulaciones específicas. Por ello, sostenemos que la consideración del fundamento y el campo semántico afín, implícitos en estas primeras reelaboraciones de Heidegger, evidencian tensiones entre los sedimentos conceptuales y de sentido tradicionales, con el pliegue interno correlativo a la consideración diacrónica de estas perspectivas que atienden al carácter no clausurable del lenguaje.

En esta perspectiva, podemos distinguir que la posición de Heidegger dista de enunciarse como definitiva. Sus marchas y contramarchas en el entramado del lenguaje de la filosofía occidental remiten a una investigación en diferentes procesos y etapas más que al despliegue de una doctrina constituida. Por ello, entendemos los resultados de esta etapa de la investigación heideggeriana como elaboraciones provisorias con recorridos necesarios, cuya sistematización específica y confluencia podemos encontrar en $1927^{46}$.Asimismo, distinguimos que su articulación

\footnotetext{
${ }^{45}$ Por ello la terminología que utiliza, en el campo de análisis propuesto, se aparta de un mero carácter denotativo, óntico y acabado. Incluso tal campo impacta en forma correlativa en la relación que establece con el lenguaje, atendiendo su aspecto diacrónico, en su despliegue temporal. A este respecto, sostiene un intérprete: "El hilo conductor de la mirada hermenéutica lo constituye lo que Heidegger llama indicación formal (formale Anzeige), concepto que usó mucho antes de Ser y tiempo, aunque las referencias temáticas son escasas. La indicación formal es un concepto que no tiene un contenido material. Su modo de remitir a algo no está determinado por un conjunto de rasgos ónticos de la cosa que designa. No es un concepto susceptible de ser llenado por la presencia del objeto mentado, mediante una intuición impletiva, según la terminología de Husserl. Pero tampoco significa vaciedad completa, sino una exigencia de ejecución. Tenemos que recorrer un camino para que la indicación formal se llene de sentido. Solo es inteligible en los comportamientos mediante los cuales se ejerce. En la indicación formal hay un llamado a ejercer el concepto como condición del proceso hermenéutico de interpretación o de explicitación del contenido posible. No se trata simplemente de un método que el filósofo adopta en forma libre. La vida fáctica impone este procedimiento desde sí misma, y no mediante un artificio metódico, como la epojé de Husserl. Por eso Heidegger reemplaza la epojé por la disposición afectiva, como la angustia, que rompe con toda objetivación.” (León 2009:.7-8). Cf. con la consideración de la indicación formal como un instrumento metódico y un metaconcepto, al dar cuenta de la modalidad de aquellos conceptos que ponen de manifiesto la facticidad en su abordaje fenomenológico, en Rodríguez (2012):157 y ss.

${ }^{46}$ Tal consideración la realizamos en vistas a nuestras tesis y argumentos respectivos. Las interpretaciones actuales en torno a las primeras lecciones de Heidegger, entre las cuales inscribimos esta perspectiva, pueden agruparse en :a) aquellas que consideran que principalmente ofician como prolegómenos para las consideraciones de SuZ (Xolocotzi , Adrián Escudero; Kisiel, Van Buren, entre otros) ; b)las que destacan las cuestiones consideradas en las lecciones a partir de su valor para estudios autónomos, sin direccionarlos necesariamente a las elaboraciones ontológicas de SuZ ( Grondin; Gadamer, entre otros); c) las perspectivas que sostienen la relevancia de estas elaboraciones enmarcadas en la
} 
lingüística es co-extensiva con una modalizacion y orientación del pensamiento, tal y como en este caso figuran en el ordenamiento y las jerarquías implícitas de sus análisis. En este marco, entendemos conveniente recapitular algunas consideraciones anteriores.

Específicamente, aquellos recorridos e investigaciones que Heidegger realiza y que presenta en los cursos, seminarios y tratados en su etapa de la Universidad de Marburgo, se configuran de un modo consistente en su ya célebre escrito, Ser y tiempo. Allí, adopta explícitamente la concepción metodológica de la fenomenología en su confrontación con las cosas mismas, aunque sus recorridos previos le permiten esquivar parcialmente las desfiguraciones respecto a su suelo originario de emergencia en el pensamiento filosófico, buscando apartarse de la manipulación técnica que subyace al método científico y su orientación, tal y como se halla implícitamente en el recorrido de Descartes y en Husserl.

El objeto temático de la investigación que propone en su opus magnum es el ser del ente y su correlato, el sentido del ser en general. Esta es la tarea de la ontología, que se vio enturbiada por legados tradicionales sin examen previo. A partir de las necesidades objetivas de la pregunta por el sentido del ser y del tratamiento que exige un más adecuado "ir a las cosas mismas", encuentra en la fenomenología la forma más apropiada forma de tratar esta pregunta. Asimismo, funciona como la metodología más pertinente para la investigación de la existencia humana, al contrastar, por ejemplo, con el método científico. Dicha pertinencia reside en su originariedad, es decir, su anterioridad respecto a los prejuicios y desviaciones semánticas y conceptuales que se hallan implícitas en las metodologías de las ciencias naturales y humanas.

No obstante, la destrucción fenomenológica que propone Heidegger no toma el concepto de fenomenología para dejarlo intacto: parte de su concepto formal y vulgar, entendido como mostración del ente tal como se muestra en sí mismo, pero con el objeto de desformalizarlo y convertirlo en un concepto fenomenológico. Para ello, distingue lo que necesariamente debe ser tema de una mostración explícita, aquello que de un modo inmediato y regular no se muestra, lo que queda oculto en lo que inmediatamente se muestra y que pertenece a ello, al punto de constituir su sentido y fundamento: el ser del ente, aquello que se devela como oculto en el suelo originario. Y precisamente ello es lo que la fenomenología debe tomar como objeto.

De esta manera, entiende que una ontología solo es posible como fenomenología. Su método se torna necesario al momento en que puede permanecer oculto aquello que debe convertirse en fenómeno. En este marco, primariamente se debe hacer una adecuada presentación del ente mismo, en el modo de acceso que corresponde a su propia condición. Esto remite a una ontología 
fundamental que tiene como tema el ente de carácter óntico-ontológico privilegiado, el Dasein, desde donde puede plantearse la pregunta por el sentido del ser.

Así, la ontología fenomenológica parte de la hermenéutica del Dasein la cual, como analítica de la existencia, fija el término del hilo conductor de todo cuestionamiento filosófico. En este sentido tal analítica abre el horizonte para toda ulterior investigación ontológica de entes que no son el Dasein ${ }^{47}$. En este recorrido pone particular atención a la consideración del lenguaje, puesto que su herencia terminológica y conceptual, como vimos, pierde el arraigo en su propio fundamento y por ello lo encubre. De todos modos, subraya que el descubrimiento realizado en el lenguaje no garantiza que quien lo comprende re-ejecute el acto descubridor originario, es decir, puede entenderse un concepto sin que se lo vea en su surgir desde las cosas mismas. Así, pone en evidencia un saber hacer respecto al lenguaje cuya modalidad abre una brecha en el campo del lenguaje desde el cual despliega su investigación, lo cual le permite establecer planteamientos más originarios y adecuados a los ámbitos tematizados. El método fenomenológico y la reformulación que propone son los apropiados para este emprendimiento ${ }^{48}$.

Como vimos, la fenomenología no debe partir de la intuición entendida en referencia a objetos sino del comprender: contra los prejuicios que llevaron al olvido de la pregunta por el ser, distingue que vivimos siempre en una pre comprensión del ser cuyo sentido permanece oscuro, al tiempo que permanece articulado en conceptos y categorías de una ontología tradicional. Por ello, entendemos que la pregunta por el ser y la tematización del lenguaje de la tradición se tornan inseparables, en este sentido sostiene:

"Si se quiere que la pregunta misma por el ser se haga transparente en su propia historia, será necesario alcanzar una fluidez de la tradición endurecida, y deshacerse de los encubrimientos producidos por ella. Esta tarea es lo que comprendemos como la destrucción, hecha al hilo de la pregunta por el ser, del contenido tradicional de la ontología antigua, en busca de las experiencias originarias en las que se alcanzaron las primeras determinaciones del ser, que serían en adelante las decisivas"(SuZ: 22[46]).

Específicamente, la investigación fenomenológica que lleva a cabo Heidegger consiste en tomar un ente (en este caso el Dasein) y dividirlo en sus regiones esenciales. Luego establecer los conceptos fundamentales, los cuales se justifican con la previa investigación de esta región del ente.

\footnotetext{
${ }^{47}$ En este contexto, Grondin destaca que la hermenéutica de Heidegger puede distinguirse en tres grandes abordajes: a) de la facticidad; b) del Dasein y c) de la historia de la metafísica, lo cual marca los diversos recorridos en sus elaboraciones. Véase Grondin (2011):140 y ss.

${ }^{48}$ Tambien subraya que la tarea es lograr un acceso de forma originaria, para luego aprehenderlo conceptualmente (KV:154[58])
} 
A partir de allí, interpreta el ente en función de la constitución fundamental de su ser. Este modo de preguntar ontológico es más originario que el preguntar óntico de las ciencias positivas ${ }^{49}$.

De esta manera, el pensamiento de Heidegger se propone como transicional respecto a la filosofía moderna con la que discute, cuya operación es realizada desde el entramado de significaciones y conceptos de los sedimentos de lenguaje desde los que se posiciona. No obstante, aún atento al suelo originario y la comprensión que subyace a toda articulación, Heidegger va presentando los resultados de sus investigaciones lingüísticamente. Esta tensión impacta de modo manifiesto en su modalidad móvil: algunos conceptos y categorías que serán relevantes en una etapa ya no lo serán en la siguiente; un modo de acceso y una comprensión determinadas serán abandonadas una vez que se traspase el umbral hacia comprensiones más originarias. Por ello, las relaciones entre la cuestión del ser y el acceso por la vía del lenguaje se muestran necesariamente con cierta opacidad, tal y como sostiene en este pasaje:

“Con respecto a la pesadez y 'falta de belleza' de la expresión en los análisis que habrán de seguir, permítaseme añadir la siguiente observación: una cosa es hablar en forma narrativa sobre el ente y otra, captar el ente en su ser. Para este último cometido con frecuencia faltan no sólo palabras, sino sobre todo la 'gramática'." (SuZ: 38 s. [61])

En efecto, en sus reflexiones de 1963 en torno a su adopción y reelaboración del método fenomenológico de sus primeros trabajos, destaca el camino de la pregunta por el ser por sobre el método mismo. Un camino que solo puede recorrer de modo indirecto, y en el que la vía de la fenomenología ofició como el modo más propicio para dinamizar el pensar que las cristalizaciones conceptuales no tematizadas tienden a obturar, es decir : un método provisoriamente abordado con el objeto de dinamizar los caminos del pensar ${ }^{50}$. Desde aquí, podemos sostener que en estas elaboraciones no hay significaciones ni métodos definitivos sino más bien un recorrido, un tránsito, desde y en el lenguaje.

Finalmente, por medio de este rodeo histórico-descriptivo, llegamos a la consideración del Dasein bajo estas premisas metodológicas. En los capítulos siguientes proponemos invertir en parte

\footnotetext{
${ }^{49}$ En este sentido, Pöggeler destaca que el sentido de la fenomenología hermenéutica propuesta por Heidegger es interpretación de la vida fáctica, donde la vida factico-histórica es "origen" en el sentido del lugar que ocupaba el yo trascendental en Husserl, que no es el yo sino, más bien, es siempre vida en el mundo. Véase Pöggeler (1993):33.

${ }^{50}$ Tal y como indica en este fragmento: “ $¿ Y$ hoy? El tiempo de la fenomenología parece haberse acabado... en lo que tiene de más intimo, la fenomenología no es dirección alguna, sino que es la posibilidad del pensar que , llegados los tiempos, reaparece de nuevo, variada, y que solo por ello es la permanente posibilidad del pensar, para corresponder al requerimiento de aquello que hay que pensar. Cuando la fenomenología viene así experimentada y conservada, puede entonces desaparecer como rótulo a favor de la Cosa por pensar, cuya revelabilidad sigue siendo un misterio" (MWPh: 101[102]). En el marco de nuestras interpretaciones, este fragmento evidencia una modalidad de relación no clausurable con el lenguaje, que entendemos como una de las consecuencias de su experiencia en el lenguaje. En otras palabras: la fenomenología solo puede desaparecer como rótulo, luego de asumirse propiamente.
} 
el recorrido heideggeriano por el cual encuentra, en la indagación de las estructuras fundamentales del Dasein, el acceso más apropiado a la consideración de la pregunta por el ser en general. Sin descuidar algunos de sus resultados en lo que respecta a esta cuestión, nuestro abordaje consiste en indagar en torno a tal consideración, donde recorridos anteriores y ulteriores nos permitan clarificar y circunscribir las variaciones en sus consideraciones respectivas. En este sentido, no planteamos la consideración de la existencia humana como un estadio necesario para una pregunta más originaria, sino que nos detendremos en diversos tramos de este trabajo en el mismo campo temático, sin los imperativos de una progresión en el pensamiento. Por ello, retomamos a continuación la clarificación necesaria de un término en sus elaboraciones que ya hemos introducido en estas páginas: ¿Qué entiende Heidegger por Dasein?

"Era él, pero hasta ahora nunca había creído que él fuese él. Tenía la sensación de que ella y yo y todas las personas que tuve que mezclar en este asunto, solo éramos palabras, detrás de las cuales no había nada, que nosotros ni siquiera éramos nosotros, mientras que lo que éramos seguía siendo, seguía siendo siempre, sin que ni siquiera lamentásemos que no hubiera palabras para designarnos"

(William Faulkner, Luz de agosto) 


\section{Capitulo 2. El Dasein como cuestionamiento de la noción moderna de sujeto.}

En el presente capítulo, continuaremos con la indagación de las consideraciones de Heidegger en los trabajos de su primera etapa, esta vez deteniéndonos en el abordaje específico del Dasein. La discusión en lo que respecta al método fenomenológico de su maestro Husserl, lo llevó a posicionarse en un planteo singular, atendiendo a las categorías y conceptos de una tradición que se remonta hacia Aristóteles, pasando por el pensamiento medieval, Kant y Descartes, en lo que respecta a las perspectivas en torno a la conciencia articuladas con el concepto moderno de sujeto, así como también con la relación entre verdad y representación. También se posiciona de un modo transicional, retomando la voz alemana Dasein, aunque reelaborando la significación respectiva.

Si buscamos dar cuenta de la modalizacion en el lenguaje y en el pensar que la obra de Heidegger realiza, tanto en sus escritos tempranos como en los de su madurez, a partir de la consideración del Dasein, su ipseidad y sus vínculos con la alteridad, entonces se torna necesaria una pormenorización de qué entiende por dicho término, así como también las estructuras fundamentales que le reconoce en el marco de aquella significación. Asimismo, puesto que mantiene una posición modal respecto al lenguaje y al pensamiento que asume como tradición, se torna relevante: a) presentar sus análisis de algunos escollos con los que se encontraron Descartes y Husserl en sus tematizaciones de la conciencia o del sujeto trascendental, entre otros y b) poner de manifiesto tensiones, ambivalencias y obstáculos, a partir de los propios términos que utiliza en el campo semántico respectivo. En este sentido, subrayaremos el modo singular en que el pensamiento de Heidegger opera como un umbral respecto al pensamiento filosófico moderno, en lo referente a la comprensión y problematización de la existencia humana.

No obstante, estos desarrollos no pretenden reducirse a una mera recopilación descriptiva de estas obras de Heidegger. Al hilo de los resultados de nuestras elaboraciones del capítulo anterior, proponemos plantear este recorrido desde un conjunto de problematizaciones:

- ¿Cuáles son los puntos de apoyo y horizontes para los análisis por los cuales puede sostenerse la primacía del Dasein y en qué sentido esto puede considerarse distinto a la tradición moderna del sujeto como fundamento? 
- ¿De qué manera los resultados estructurales de la analítica existenciaria pueden comprenderse para todo existente humano en su cotidianidad? ¿Son posibles planteamientos de tipo universal en el enfoque, métodos y modalidades propuestas?

- ¿Es posible plantear una distinción auténticamente radical respecto de la noción moderna de sujeto, atendiendo no solo al campo de asociaciones conceptual y categorial, sino también a la modalizacion de la significación y del pensamiento que acompaña la articulación lingüística de Heidegger en esta etapa?

- En definitiva ¿Presenta aspectos problemáticos esta noción, en el marco de su discusión con/en la tradición? ¿Puede representar, sin más, un nuevo punto de partida para los análisis y consideraciones sobre la subjetividad y la mismidad en el pensamiento contemporáneo?

En este contexto, nos detendremos en cursos y obras de Heidegger en su período temprano de pensamiento, articulado entre 1920-1930, pues allí va dinamizando y delimitando significaciones singulares para el término Dasein, de un modo correlativo al programa fenomenológico que despliega. Atenderemos diferentes consideraciones : a) en primer lugar, desarrollaremos la distinción que realiza del Dasein respecto al resto de los entes, a su modalidad y horizonte de aprehensión especifica, junto a las significaciones o conceptos de la herencia antropológica que rechaza ; b) en la misma línea, nos detendremos brevemente, en sus consideraciones sobre el ego en Husserl y el sujeto en Kant y Descartes, desde las cuales también plantea su reelaboración ; c) finalmente, presentaremos algunas interpretaciones y análisis del modo de comprensión y articulación de Heidegger respecto al Dasein y sus estructuras de ser-en-el-mundo, comprensión y temporeidad, distinguiendo ciertas tensiones, escollos y obstáculos, por los cuales entendemos que se encuentra parcialmente sometido a la perspectiva de la modernidad con la que discute.

En este marco , nuestra hipótesis es que, por un lado, la tematización del Dasein , o mejor, la emergencia de tal positividad y su significación dinámica en el marco del pensamiento heideggeriano, son el corolario de una articulación en el lenguaje en vistas a tres frentes simultáneos : en primer lugar, el marco conceptual utilizado; luego, el contexto de discusión en el que se inserta y, finalmente, la modalizacion del pensamiento como consecuencia de los aspectos antes mencionados. Entendemos que tal corolario es un paso ineludible en vistas a un posterior abandono o ruptura respecto de la consideración central o eminente del Dasein, debido a dicha serie de tensiones, rémoras y ambivalencias en el ámbito del lenguaje desde donde pretende articular una transición. En este sentido, interpretamos que tales tensiones no solo son irreductibles, sino también 
irrebasables para estos recorridos, tal y como figura de modo evidente en sus consideraciones sobre el sí mismo.

\section{1.- En camino para la significación del Dasein.}

\section{1. a.- Los distintos modos de ser del ente.}

Para comprender el uso de la voz alemana Dasein en la obra de Heidegger, es necesario establecer algunas especificaciones: por un lado, el marco de significaciones desde las que establece sus distinciones; por otro, el sentido en que usa el término y finalmente, especificar por qué lo usa en el sentido que lo aplica.

En general encontramos, a lo largo de sus elaboraciones en la década de 1920, una significación que en lugar de presentarse acabada, se manifiesta como una construcción dinámica. En esta línea, va perfilándose un singular modo de despliegue de conceptos y existenciales en sintonía con el ente considerado : si el carácter proyectivo y móvil del Dasein lo distingue del ente dado ahí como presente, los marcos lingüísticos con los que se busca aprehenderlo necesariamente se hallan dotados del mismo carácter.

En efecto, el significado de existencia, que usualmente más se aproxima a la traducción de este término, no en todos los casos permite hacer referencia al Dasein en el uso que le va dando Heidegger, en referencia al ente que somos nosotros mismos ${ }^{51}$. Específicamente, el infinitivo sustantivado del verbo respectivo (dasein) tradicionalmente designa en alemán la existencia de cualquier cosa (como sol, Dios, etc.), razón por lo cual nuestro autor desarrolla algunas diferenciaciones fundamentales ${ }^{52}$.

\footnotetext{
${ }^{\mathbf{5 1}}$ El significado clásico fue canonizado en los trabajos de Christian Wolff, donde equivale a existencia (Existenz), en el sentido de realidad efectiva (Wirklichkeit) y subsistencia, estar- ahí-delante (Vorhandensein).Para un abordaje de la historia de este término, véase Adrian (2009):63-5.

${ }^{52}$ La carga semántica que presenta esta voz alemana manifiesta ciertas dificultades en la traducción. En efecto, la traducción al castellano más pertinente de Dasein es, entre otras, existencia humana. El verbo correspondiente significa existir (que remite a un estar aquí en una situación determinada), aunque también el haber (en el sentido de hay), además de denotar el estar en un lugar y momentos determinados. Como vimos, en el uso corriente del término alemán significa existencia. El $d a$ es un deíctico que especifica el modo de ser (sein): puede significar aquí, ahí, allí, señalando el momento del tiempo que se actualiza en un relato. Por esta variedad inherente al termino, algunos traductores encuentran imposible verterlo justamente: mientras unos lo traducen por existir o existencia (como Jaime Azpiunza, Manuel Redondo, Zubiri, Jiménez Redondo, etc.). Otros lo dejan sin traducción al considerarlo como término técnico (.Juan García Norro, Rivera, Gaos, Adrián, Berciano, etc.). El existir al que se refiere Heidegger es siempre el propio, aquello en lo que uno mismo está, es decir, el aquí (en relación a la primera persona del singular). En el presente trabajo
} 
Frente a ello, en sus cursos entre 1923-1927, nuestro autor reiteradamente destaca tres palabras de uso corriente en la lengua alemana para designar existencia: Dasein, Vorhandenheit, Existenz. Su distinción y uso revela un punto de partida propio, respecto a la indagación fenomenológica que desarrolla. Mientras que con el primero designa el ente que somos en cada caso, los otros dos remiten a modalidades de ser: el modo de ser de los entes naturales y el del mismo Dasein.

Asimismo, junto a aquella especificación correspondiente a los entes que no son el Dasein, reconoce e incluye otra modalidad de ser. En efecto, por un lado las expresiones Vorhandenheit (carácter de simple-estar-ante) y Vorhandensein (estar-ahí-delante) tradicionalmente remiten al modo de ser de lo subsistente (vorhanden) ${ }^{53}$. Por otro, la significación de los términos Zuhandenheit; Zuhandensein designan, respectivamente: el carácter de aquello que está a disponibilidad o a la mano (zuhanden) (solo aprehensibles en la práctica a la que pertenecen); el modo de ser del útil (Zeug). Cuando los útiles circunstancialmente dejan de serlo y pierden su ligazón de significación con el entorno del Dasein (por ejemplo, por que se estropean), entonces retoman la modalidad de ser del ente subsistente que reflejan las anteriores expresiones ${ }^{54}$.

Ahora bien, Heidegger destaca que la tradición metafísica no entendió cabalmente la diferencia del Dasein respecto a estos modos de ser. Su carácter proyectivo lo distingue de la existencia del ente que simplemente está presente. Pero también se diferencia por su constitución ontológica de mayor originariedad: el fenómeno de mundo donde los entes intramundanos (en sus remisiones) se dan, ya se halla abierto previamente, y tal apertura se articula comprensivamente desde las estructuras y el modo de ser del Dasein (SuZ: 71-4 [98-101]).

Por ello, usa el término Dasein tomando distancia de tales significaciones reducidas a lo subsistente, especificando que su modo de ser se caracteriza por la apertura $(D a)$ al ser (sein). En este sentido, el Dasein no se cierra sobre si como lo meramente presente o como el útil, sino que su existir consiste en mantenerse abierto hacia el mundo, en relación dinámica y proyectiva con su entorno, topándose con las cosas, pero sin reducirse a ello. Tal irreductibilidad remite a la constitución ontológica de la existencia humana, es decir, permite distinguir aquella constitutiva apertura y la capacidad propia para cuestionarse sobre el sentido del ser.

Ahora bien, este uso y sentido del término se despliega de un modo procesual en sus trabajos tempranos. Un rastreo diacrónico permite inscribir su carácter y uso técnico como ente que se

nos inscribimos en la tradición que mantiene el término Dasein sin traducción específica. Para una discusión respecto a la traducción castellana de este término, véase Azpiunza (2001):71.

${ }^{53}$ Así, ambos términos remiten a la mera presencia. Aquí, para sus traducciones, hemos utilizado términos diferentes para evitar conflictos con Anwesen y Präsenz, pues usualmente también se traducen como "presencia".

${ }^{54}$ Los prefijos de ambos términos permiten significar tal distinción: Vor significa ante la mano; $z u$ significa a la mano, en el sentido de cosas con las que nos las habemos en la práctica. 
pregunta por su ser, a partir de su informe de $1922^{55}$. No obstante, en sus cursos hasta 1923 el sentido de Dasein no está fijado en forma definitiva, pues no evidencia una separación radical de aquél significado tradicional que lo vincula con la existencia en un sentido más bien general. Esta ambigüedad en la significación se va desplazando hacia 1924, con su tratado sobre el tiempo, donde el término designa el ente cuyo ser consiste en el ahí del ser, consolidándose en tal sentido en su opus magnum: $S u Z^{56}$.

En todos los casos, la ligazón Dasein-facticidad se manifiesta inescindible desde la comprensión de base que distingue. No obstante, esta significación dinámica se va tornando irreductible tanto a la concepción tradicional del hombre (comprendido individualmente o aislado), como a comprensiones que lo ciñen a situaciones espacio-temporales determinadas, pues también abarca el ser del mundo histórico, es decir, el mundo como significatividad y apertura ${ }^{57}$. Así, el sentido en que va aplicando Heidegger este término abre un campo de significación que manifiesta una tensión sostenida entre dos dimensiones: aquella vinculada a lo concreto-fáctico (en su ligazón ineludible) y aquella que da cuenta de su carácter originario-complejo (en su constitución ontológicamente anterior y entramada de facticidad-mundo-apertura al ser).

En este marco, entendemos que Heidegger usa y aplica tal sentido dinámico, no solo para distinguirlo en su modalidad especifica de ser respecto a los entes naturales, sino también como un paso necesario y previo a toda dilucidación científica o filosófica respectiva, pues el carácter originario de su modo especifico de ser, permite evidenciar la originariedad de la comprensión y la apertura de mundo, en lo que respecta al modo en que los entes intramundanos son aprehendidos.

En suma, en contraste con significaciones que remiten al ámbito del ente natural o cósico, Heidegger caracteriza al Dasein por cierta inesencialidad. Con ello, pone énfasis en que su originariedad da cuenta de una falta de subsistencia o suelo, por lo cual se procura una consistencia en el despliegue de su existir ${ }^{58}$.Ahora bien, esta dimensión constitutiva del Dasein, también vinculada a su carácter de no estar meramente ahí presente, parece radicalizar el problema del yo trascendental, al tiempo que exige una particularización de las modalidades de aprehensión del mismo. Veamos cómo va circunscribiendo estas cuestiones.

\footnotetext{
${ }^{55}$ Véase, PhIA: $14[43 \mathrm{~s}$.

${ }^{56}$ Puede encontrarse una distinción más detallada de las significaciones y usos que este término va teniendo en sus trabajos tempranos hasta SuZ, en Berciano (1992):435-7.

${ }^{57}$ Desde allí puede distinguirse la escritura guionada (Da-sein), utilizada para destacar con el $D a$ su aperturidad en/del mundo más originaria, la cual es constitutiva y anterior a todo aquí (hier) o allí (dort) determinados (es decir, a todas las figuraciones o determinaciones concretas de aquella apertura originaria). Luego de $S u Z$, aquella será distinguida como claro (Lichtung) del ser.

${ }^{58}$ Véase, EP: 336-38[352-54]. En los capítulos siguientes retomaremos esta consideración de la nihilidad de la existencia, en tanto carencia de suelo o sostén que entendemos capital al momento de abordar su consideración de la ipseidad del Dasein.
} 


\section{1. b.- Modalidades, puntos de partida y horizontes para su aprehensión.}

Ya en el conjunto de lecciones impartidas en Friburgo , con un sesgo motivacional de cuño husserliano, Heidegger se manifiesta proclive a la búsqueda de una filosofía auténtica y genuina no afectada por los prejuicios de la tradición, la cual inicialmente denomina como ciencia originaria de la vida (Urwissenschaft), orientada al estudio del fenómeno primario de la vida en su inmediatez (BP:15[19]), perspectiva que luego se proyecta hacia una incipiente hermenéutica de la facticidad, como preludio de la ontología fundamental de $S u Z$. En tal perspectiva la filosofía debe ocuparse de la vida, pero este programa lo conduce a toparse una y otra vez con rémoras y limitaciones a partir de los sedimentos conceptuales y comprensivos del lenguaje desde el que lo articula ${ }^{59}$.

Como vimos anteriormente, ello se debe a que la tarea que se propone en estas elaboraciones es expresar conceptualmente, por medio del desarrollo de una fenomenología hermenéutica, la comprensión desde su existencia inmediata en el mundo de la vida fáctica ${ }^{60}$. De esta manera, en sus obras y lecciones de la etapa preparatoria para SuZ, Heidegger se empeñó en articular tal (pre) ciencia originaria para señalar cómo se da la realidad, antes de toda consideración desde una concepción del mundo (Weltanschauung) o perspectiva determinada, cuyo punto de partida es la vivencia directa del mundo circundante $^{61}$. En el vivenciar, la vida se manifiesta rodeada de significados en una trama, de modo tal que Heidegger se propone revelar primariamente lo significativo como tal, sin buscar captar lo aislado.

De este modo, en trabajos y seminarios tempranos, va enfatizando las relaciones entre significatividad y mundo: lo circundante se manifiesta como ámbito preteorético, desde donde

\footnotetext{
${ }^{59}$ En sus GPh establece la primera articulación de esta ciencia originaria. Luego, en PhIA, lo que se conoce como el Informe Natorp, y las lecciones de 1923, comienza a exponer detalladamente las estructuras ontológicas del Dasein sobre dicha base.

${ }^{60}$ Esta tarea se va articulando con diversos nombres, connotando con ello la singular relación que establece Heidegger con el lenguaje. En sus lecciones de 1919, como vimos, se llama ciencia originaria de la vida; en 1922, la articula como ontología fenomenológica; en 1923, como hermenéutica de la facticidad y en 1927 se cristaliza en la analítica existencial de SuZ.

${ }^{61}$ Incluso ya en su trabajo a encargo de Husserl sobre una fenomenología de la religión, donde explora el cristianismo primitivo, toma como punto de partida la experiencia fáctica de la vida (PRL: 10[45]). Allí puede rastrearse las similitudes entre la interpretación agustiniana de la vida humana y aquella que incorpora en $S u Z$. Como veremos luego, los seminarios y trabajos tempranos de Heidegger insisten en que la labor filosófica no consiste en suministrar una concepción del mundo (totalidad de perspectivas de la vida y valores que se aceptan en una cultura determinada y ofrecen una visión de la realidad cultural, histórica y natural), sino comprender el ámbito originario desde donde puede surgir. Por esta vía plantea una de las críticas que le realiza a Jaspers, a la filosofía de la vida de Dilthey y a Rickert. Sus primeros tratamientos respectivos también se desarrollan en el mismo sentido, en los seminarios de BP:10-29[10-35] ;GPh:24;41 ;AJPW:1-7[15-20];PhIA:6:43[34s.,76 s.];DGPh: 4-16 [27-37] y en SuZ: 110; 391 s [135,406s.].
} 
puede ser conocido lo ente. Luego, estas consideraciones se consolidan en $\mathrm{SuZ}$ en el marco de la ontología del Dasein $^{62}$. Interpretamos que este énfasis puesto en las tramas significativas de la vida y lo circundante, ponen de manifiesto una doble herencia en sus análisis: por un lado, a través de una continuidad con la matriz de la investigación fenomenológica de Husserl que remite a sus intentos por conjurar los prejuicios cristalizados en la comprensión y lenguaje tradicional; por otro, en consonancia con el proceder critico-destructivo de la tradición fenomenológica (respecto al abordaje de tales prejuicios), lo cual Heidegger se propone radicalizar ${ }^{63}$.

Tanto en sus últimas lecciones de Friburgo en 1923, como en las primeras de Marburgo, Heidegger propone una investigación fenomenológica de esta pre-ciencia (Vorwissenschaft), en un análisis desde una modalidad o cómo situacional del Dasein. En este contexto de investigación pone de manifiesto su intención de apartarse de las pretensiones universalistas que entiende implícitas en las reducciones eidéticas del ego en las obras de Husserl. En el mismo sentido, toma distancia de cierta orientación del pensamiento al cálculo y la cuantificación, pues las reconoce como modalidades del proceder cognoscitivo propias de tales pretensiones con rigor cientificista ${ }^{64}$. Por ello, aquella pre-ciencia rechaza saberes objetivos y universales de todo Dasein, aunque se despliega en pos de un saber de tipo objetivador, es decir, susceptible de describir características determinantes y estructuras originarias, las cuales destaca en su anterioridad a toda investigación científica.

Ahora bien, hacia sus elaboraciones de 1927 la investigación de este ámbito de originariedad pre-científico se articula explícitamente con el programa de una ontología

\footnotetext{
${ }^{62}$ Asimismo, esto supone una crítica: lo teorético está determinado por lo cósico, por lo cual se torna necesario aprender el entorno en cuanto significativo, a partir de una intuición hermenéutica. La consideración del carácter primario de lo significativo (que indica el horizonte de sentido en el que nos hallamos inmersos y donde los significados se entraman en una totalidad remisional), ya se halla expuesta en sus lecciones de 1919 (BP: 70-73[84-8]); en su seminario GPh: 104-16 y en PRL: 13-6[47-50]. Progresivamente va relacionando la cuestión de la significatividad como la condición y el modo donde se da o articula el mundo, en sus cursos y seminarios OHF: 86-104[110-32]; LFW: 134-71; 370-76[11241,291-5] y DGPh: 280,370[242,315], entre otros. Finalmente su perspectiva del significado se consolida en la ontología del Dasein, a través de su estructura de ser-en-el-mundo en SuZ: 161-66, 186,192[184-9, 208,213s.].En el capítulo 7, analizaremos específicamente estas elaboraciones.

${ }^{63}$ En esta línea, Adrián sostiene que en este recorrido previo a $S u Z$, Heidegger toma una decisión metodológica, la cual:"...ya en los cursos universitarios de 1919 le lleva a un desmontaje crítico de la historia de la metafísica y a una transformación hermenéutica de la fenomenología de Husserl. Dos momentos imprescindibles de su método filosófico: un momento destructivo y otro momento constructivo. El primero destapa el intrincado mapa conceptual de la filosofía y retrotrae el fenómeno de la vida a su estado originario. El segundo propone un análisis formal de los diversos modos de realizarse la vida en su proceso de gestación histórica. Sin ellos resulta vano aventurarse en la senda de una articulación categorial del ámbito de donación inmediato de la vida fáctica y de su carácter ontológico" (Adrián, 2010b:19). Entendemos que la necesidad de estos pares: marco conceptual/estado originario; análisis formal/vida fáctica y destrucción /construcción, dan cuenta de una tensión ineludible e irrebasable al poner en evidencia el campo del lenguaje en que estos se dinamizan.

${ }^{64}$ Para un análisis que relaciona la Vorwissenschaft a una propedéutica existencial del Dasein, véase Ordoñez García (2014):159. Este intérprete traduce Dasein desde el verbo estar (para poner de manifiesto su carácter relativo y no absoluto propio del objeto de este pre ciencia) como extante, para destacar su singular modo de estancia proyectiva en el tiempo (ibíd.: 168).
} 
fundamental ${ }^{65}$. En efecto, nuestro autor reconoce la primacía ontológica de la pregunta por el ser, como condición del preguntar ontico de las ciencias positivas. Ello se debe a que, en toda investigación científica o disciplinar, siempre se haya abierta una comprensión y un acuerdo previo sobre lo que es el ser del ente que se investiga. Por esta razón, se torna necesaria una indagación que coteje y revise los presupuestos comprensivos de toda ciencia, abandonando así su estado ingenuo respecto a las regiones que investiga (SuZ: 10[33]).

Como horizonte de este programa, nuestro autor se propone plantear la pregunta por el sentido del ser en general, a partir de la pregunta por el ser del Dasein. En efecto, el preguntarse por el sentido del ser en aquella esfera a-reflexiva de la vida fáctica, a partir de su analítica existenciaria (existenciale Analytik), lo encamina hacia una ontología fundamental: primero, poniendo de manifiesto las estructuras ontológicas constitutivas del Dasein; desde allí, buscando aprehender el sentido de su ser a partir del horizonte de la temporeidad y la historicidad; finalmente, desplazándose desde allí a la pregunta por el ser en general, en su carácter filosófico primario , es decir, como condición previa a toda ciencia o investigación regional.

En este marco, la primera tarea de la hermenéutica es investigar el Dasein propio. Como vimos con la doble dimensión o tensión de significaciones, a partir de su diferenciación de modalidades de ser, el Dasein es proyecto y devenir: su ser consiste en poder-ser (Seinkönen) ${ }^{66}$. Así, puesto que la existencia a investigar está en marcha, el vivir de tal ente solo se deja aclarar de un modo definitivo cuando se ha vivido ${ }^{67}$ : mientras exista se despliega hacia un resto pendiente de lo que puede ser, resistiéndose con ello a ser aprehendido como un ente acabado y determinado, comprensión que se halla implícita en definiciones tales como la 'esencia' del Dasein consiste en su existencia $^{68}$, entre otras ${ }^{69}$.

\footnotetext{
${ }^{65}$ La ontología fundamental (Fundamentalontologie) remite a la aclaración o la pregunta por el sentido del ser en general, que luego adquiere la forma de una indagación por la forma del ser del Dasein, por medio del establecimiento de sus existenciarios. A diferencia de ello, las ontologías regionales despliegan las categorías de cada ciencia, al tiempo que suponen y se basan en una ontología fundamental. Así, hacia 1927 Heidegger se encamina hacia una indagación de mayor originariedad respecto a las determinaciones y perspectivas regionales. Véase SuZ:11-15[34-7]

${ }^{66}$ Este existenciario del Dasein, en ligazón con su carácter proyectivo y la noción de posibilidad, es el que permite articular sus consideraciones sobre la posibilidad propia e impropia de ser sí mismo. Por otra parte, destaca que el Dasein despliega en el tiempo tal proyección y poder-ser, por medio de un proyecto de realización. Así, mientras exista siempre está en camino (unterwegs), de modo dinámico y abierto. Podemos encontrar una de las primeras elaboraciones de este existenciario en BZ: 79 ss. [102 ss.], donde se vincula con la posibilidad de muerte. Luego, en su relación con la estructura del comprender en Heidegger DGPh: 391-410[331-46]. Finalmente, en 1927, se enmarca en su carácter estructural proyectivo, por ejemplo en SuZ: 38-40,143-48,168-80,259-77[60-3,166-71,190-202,278-96], entre otros.

${ }^{67}$ Nuestro autor sigue con esta expresión, una cita de Kierkegaard, véase OHF: 16 s. $/ 35$.

${ }^{68}$ Véase SuZ: 42 [67] .El uso entrecomillado del término esencia, también nos remite a la problemática de lenguaje en la que se inscribe Heidegger: en el campo semántico de dicho término se encuentra eidos, que supone la comprensión del ser como presencia. En un reciente análisis de esta cuestión terminológica en el término esencia, un intérprete sostiene que la trama semántica respectiva, lleva implícito una interpretación del Dasein en términos de sujeto, lo que conduce a Heidegger a plantear un número de precauciones iniciales en torno al uso de estos términos, véase Cataldo Sanguinetti (2013): 33 s. Las dificultades y tensiones en el lenguaje se tornan aquí evidentes.
} 
Considerando este aspecto para su aprehensión, la investigación debe enfrentar la compleja tarea de tomar al Dasein sin evitarlo ni manipularlo , considerándolo en el adelantarse y su aquí ocasional, es decir, sin llegar a término (cuestión que lo haría equivalente a un ente subsistente , clausurando sus posibles) ni tomando en cuenta el mero estar en marcha, sino más bien en un análisis que conserve el ser-posible que lo distingue ontológicamente del resto de los otros entes, es decir, como apertura respecto a aquello que no es aún.

A primera vista esta tarea puede presentarse como inaprehensible para una metodología y lenguaje de cuño metafísico y científico, afín a lo sustancial, presente y corpóreo ${ }^{70}$. Frente a esto, la noción de posibilidad (Möglichkeit) de la que parte Heidegger, es distintiva en la especificación de las estructuras del Dasein respecto al carácter de ser de los entes ${ }^{71}$.

Esta modalidad diferencial manifiesta cierta co-relación entre el ahí del estar y dicho adelantarse, la cual articula en su seminario de 1924, a partir de la consideración de la facticidad, aunque en estos cursos y trabajos previos a SuZ, esta noción se liga mayormente a consideraciones de índole práctica ${ }^{72}$. Destacamos que con las elaboraciones en el uso de este término, se propone en definitiva articular la tensión dinámica y oscilante del Dasein en su situacionalidad, su carácter proyectivo y temporalidad ${ }^{73}$, tal y como interpretamos desde la siguiente definición:

“...este estar-presente que un Dasein es en cada caso el suyo propio (uno lo es o bien yo lo soy), lo definimos como facticidad. Esta facticidad es, a su vez, la condición ontológica de posibilidad que permite

\footnotetext{
${ }^{69}$ Precisamente por este carácter posible y proyectivo del Dasein , se ha interpretado SuZ (bajo el influjo de los trabajos de Franco Volpi ) como un tratado de filosofía práctica, véase Adrián (2010b):20

${ }^{70}$ En este contexto, Pintos Peñaranda realiza un abordaje de la constitución del yo en la fenomenología heideggeriana interpretando que, en un contraste con la concepción husserliana, en Heidegger existir designa al ser en el mundo y el proyectarse a partir de ese mundo, perspectiva que lo conduce a desplegar un mínimo desarrollo de la cuestión de la corporalidad. Véase, Pintos Peñaranda (1982):.110 ss. En este contexto, interpretamos que el énfasis de la vía proyectiva por sobre la corporalidad puede inscribirse en el contexto semántico de discusión, desde donde Heidegger busca distinguir su analítica de todas las notas estáticas y sustancialistas de la comprensión moderna del sujeto.

${ }^{71}$ En el marco de un abordaje y análisis de esta estructura del Dasein y de las resonancias semánticas implícitas en el termino posibilidad, un intérprete argumenta que la critica a la subjetividad moderna no remite a una abolición del término subjectum, sino mas bien a un desplazamiento comprensivo, véase Cataldo Sanguinetti (2013):34-6. Cf. Santiesteban (2005): $100 \mathrm{~s}$.

${ }^{72}$ La noción de Dasein como posibilidad es central en SuZ, a la luz de las distinciones entre los modos de ser del ente natural o cósico. Destaca allí su carácter ontológicamente primario respecto a la realidad (Wirklichkeit), mayormente ligada a la modalidad teorética de la ciencia que da prioridad al ente meramente presente (SuZ: 38 s. [60s.]). En seminarios y lecciones anteriores, Heidegger presenta elaboraciones que anticipan la centralidad de esta noción. Por ejemplo, en su seminario de 1926, articula este sentido a partir de una distinción con los conceptos aristotélicos de potencia y acto. En ese contexto, distingue un sentido negativo y otro positivo: en el primer caso, en referencia a la posibilidad puramente lógica; en el segundo, en el sentido de poder-hacer, ser capaz-de (Vermögen) (GbaP: 172-5; 182 Ss. [203-6; 215 ss.]) . En esta línea, también encontramos algunos tratamientos preparatorios afines en PRL: 246-9; OHF: 15-20[33-40]; LFW: 219-28,235[177-85,189s.]; GbaP: 186 ss. [217ss]. Finalmente, se consolida como una estructura ontológica primaria del Dasein en SuZ: 36-8,42s., 143s, 147-51; 191-5; 266 s.; 383-92[58-60,67s, 166s, 1705,212-6,285s, 399-407], entre otros.

${ }^{73}$ Para el desarrollo de una interpretación en torno a la bidimensionalidad (Zweidimensionalität) estructural del Dasein y de su tensión (Spannung) y escisión (Spaltung) de origen ontológico que lo determina en tal bidimensionalidad, posicionándolo en un entrelugar estructural, como correlato o efecto de la donación del ser, véase Basso (2014):278-82.
} 
referirse a un Dasein como algo que también está mundanamente ahí; aunque solo se pueda referir a él en el modo de la aprehensión abstracta que constata el vacío tener-ahí-presente”(BZ:43[59]).

Así, la facticidad del Dasein queda referido aquí a su ser-posible, poniendo de relieve el carácter inesencial y en construcción en su adelantarse, así como también sugiriendo una intuición de tipo categorial para dicha aprehensión en vacío. Esta modalidad de abordaje, lleva a Heidegger a la problematización de la articulación lingüística o conceptual de los resultados de la investigación, tornando necesario retomar la posición desde la cual se pregunta, la cual también se manifiesta tensionada por la comprensión implícita en la idea tradicional de hombre.

\section{1. c.- El Dasein no es el hombre}

Heidegger encuentra que aquel termino y su campo semántico correlativo, presente en las categorizaciones respectivas de la modernidad, está impregnado por la metafísica de la presencia que entiende el ser en el sentido cósico. Vimos que caracteriza esta perspectiva por una modalidad de pensamiento preferentemente basada en el cálculo, en el marco de un razonamiento de orientación cientificista y universal, lo cual se contrapone con la comprensión y los resultados del análisis de la facticidad del Dasein. Especialmente en el curso de 1923 , aborda y analiza las acepciones tradicionales del concepto de hombre, en tanto ser vivo dotado de razón y personalidad, cuya perspectiva y comprensión viene dada de antemano de un modo determinado. Es decir, tales caracterizaciones suponen algo dado que, en función de elementos posteriores en la experiencia, se le atribuye un modo de ser. Estos conceptos están presentes en las perspectivas usuales de hombre, tal y como rastrea en la idea de persona en Kant, en exponentes del idealismo alemán y en la teología medieval.

Por el contrario, Heidegger busca evitar dar un nombre a esta región de ser en dicha línea categorial, con lo cual interpretamos la necesariedad de recurrir al término Dasein y modalizarlo dinámicamente en su significación no-clausurable, como intento singular de desplazamiento semántico ante estas limitaciones en el lenguaje heredado y asumido. De hecho, destaca que aquel concepto tradicional imposibilita poner al descubierto la facticidad, pues:

“ Al llamar hombre al existente que se va a investigar se le pone ya de antemano dentro de una determinada concepción categorial, puesto que el examen se lleva a cabo siguiendo la pauta de la definición tradicional de 'animal rationale'. Con tal definición por pauta viene prescrita la descripción de una perspectiva 
determinada, sin que con ella se recuperen activamente, haciéndolos propios, los motivos originarios de tal perspectiva" (OHF: 26[46]).

Encontramos aquí nuevamente un rastreo terminológico que propone recuperar el suelo desde el cual se articulo tal significación, al que supone móvil y dinámico. En el marco del derrotero del concepto de hombre, que cubrió de opacidad la diferencia ontológica que Heidegger propone retomar, la vía de la destrucción fenomenológica es la escogida para abordar tal deriva de su significación ${ }^{74}$. Distingamos brevemente esta vía para evidenciar su relación con tal lenguaje.

En efecto, aquella definición aristotélica de animal rationale, circunscribe al Dasein dentro del ámbito de los entes que existen en el modo de lo viviente (plantas, animales), con la sola distinción del ente que posee lenguaje, más específicamente, Logos. No obstante, las definiciones posteriores que adscribieron al sentido literal de hombre como ser vivo racional terminaron de encubrir el terreno intuitivo en el que se originó esta determinación del ser.

De un modo similar, en el marco del despliegue de su método de destrucción fenomenológica, distingue la determinación teológica con la cual se ligó aquella comprensión y significación, cuyo énfasis fue puesto en la vinculación del carácter cognoscente humano con las Escrituras, es decir, la comprensión del ser del hombre se articuló con la originariedad o no de la relación con Dios, por medio de aquél legado bíblico. No obstante, nuestro autor subraya que este campo de significaciones, en el que se asienta y consolida la antropología teológico-cristiana, se desplazó parcialmente desde su recepción en la modernidad, con respectivas re-elaboraciones filosóficas.

En efecto, distingue que allí la idea de ser persona neutraliza la relación constitutiva con Dios, para convertirse en un campo de significación que remite a la conciencia de las normas y los valores. Posteriormente, representantes del pensamiento filosófico moderno llegaron a mencionar la yoidad como acto fundamental originario y centro de los actos, en ligazón con este trayecto comprensivo. Frente a esto, nuestro autor propone prescindir de esta modalidad del pensamiento habituada a orientarse por dichas ideas determinadas de lo que es ser hombre, pues se hallan todas orientadas por la misma comprensión del ser como presencia.

Por tales recorridos y derivas, Heidegger subraya que el término hombre resulta inadecuado para comprender al Dasein. Mas bien, este excede lo concreto espacial, temporal e individual (incluyéndolo), en una apertura fáctica que también abarca la sucesión temporal e histórica. Es por

\footnotetext{
${ }^{74}$ En el marco de un análisis del deslinde que Heidegger realiza del concepto de hombre de la tradición aristotélica y agustiniana , por medio de la comprensión del Dasein, un trabajo reciente distingue una ambivalencia en los desarrollos de Heidegger respecto a la antropología , que consiste en un movimiento o vaivén de aproximación y distancia, véase Santiesteban(2005):74-102.
} 
esta significación, que al Dasein le pertenece como estructura sobrepasar su concretez y proyectarse desde ella a sus posibilidades.

No obstante, estas distinciones de ámbitos originarios, correlativas al desarrollo de significaciones más complejas y abarcativas, no suponen la posibilidad de distinguir un a priori en esta analítica, pues su punto de partida es el Dasein de los existentes, desde donde se propone dar cuenta de estructuras propias en cada caso. De este modo, podemos circunscribir aquí una bidimensionalidad de significación, al replantear una relación singular entre lo general (pues no se reduce a individuos aislados, al tiempo que evidencia estructuras originarias) y lo individual ( pues no remite a una esencia abstracta para todo individuo) : el Dasein como apertura donde se da el existente concreto $^{75}$.Ahora bien, esta consideración nos conduce a preguntarnos nuevamente por al problema de la aprehensión del Dasein, aunque ahora en su aspecto estructural y de contenido .

1. d.- Hacia la aprehensión de sus estructuras: la consideración del límite.

Vemos que Heidegger planeta un estilo particular en sus desarrollos para dar cuenta de estructuras o totalizaciones posibles en sus investigaciones, debido a que enfrenta la difícil tarea de analizar este ente que se muestra en su fugacidad y devenir. Uno de sus recursos característicos consiste en un contrabalanceo por medio de la ausencia, la falla, lo negativo, lo opuesto, lo que oficia de límite y, por supuesto, lo más cercano en su facticidad, entre otras formas que representan fronteras para tales totalizaciones ${ }^{76}$.

En efecto, entiende que para determinar el ser del Dasein hay que aprehenderlo en su totalidad, la cual puede circunscribirse a partir de sus límites inherentes y de un modo regresivo, tal como resulta de su análisis de la posibilidad de muerte (KV: 168[82]).En el marco de esta modalidad liminar de determinación, también plantea partir del Dasein en sus relaciones de alteridad y alienación con los otros Dasein ${ }^{77}$.

\footnotetext{
${ }^{75}$ En el capítulo 5 veremos cómo esta referencia del Dasein como acaecer prefigura la consideración del Ereignis. A este respecto, puede encontrarse un análisis en Berciano (1991a):91 ss.

${ }^{76}$ Por ejemplo, cuando despliega la pregunta metafísica por la nada, el punto de partida es el Dasein de la comunidad de investigadores la cual, proyectada hacia el horizonte de la ciencia, le deja a la cosa misma la primera y la última palabra. En contrapartida, Heidegger parte de la negación de la totalidad del ente: la nada. Por ello, en este contexto de elaboración distingue al hombre como lugarteniente de la nada (Platzhalter des Nichts) (WiM: 115-118[102-105]).

${ }^{77}$ Un conjunto de estudios recientes de psicoanálisis y psiquiatría proponen partir de esta caracterización heideggeriana, poniendo énfasis en el carácter singular del Dasein, los cuales remiten en especial al desarrollo de lo que Heidegger entiende por Daseinanalyse clínica en sus ZS (1959-69), Véase, Cardinalli (2015):254-56. En este contexto de discusiones, respecto a la consideración del Dasein para una crítica al modelo biomédico en psicología, enfatizando que la sola consideración del cuerpo no es suficiente para una comprensión de la salud humana, teniendo en cuenta la multidimensionalidad de su ser-en-el-mundo, Cf. Roehe \& Dutra, (2014):112 s. La tradición de discusión en la que tales estudios se inscriben, remite a los desarrollos de Medard Boss en medicina y psiquiatría, a partir de una recepción de estas elaboraciones de Heidegger, los cuales mantuvieron amistad desde 1950 y cuya presencia podemos encontrar en
} 
En todo caso, debido a la significación y estructura dinámica, constelada y de despliegue funcional simultáneo, entiende que la vida fáctica del Dasein no puede ser agotada por medio de una reconstrucción que la abarque temáticamente por completo, pero puede ofrecerse indicaciones formales al respecto, es decir, orientaciones de las formas puestas en juego en la facticidad, cuyo punto de partida es su cotidianidad ${ }^{78}$.

Tomemos un ejemplo o figuración de tal recurso: en el seminario de 1924 parte de un análisis de lo ya interpretado y público de la actualidad cotidiana del Dasein, es decir, del modo como comprenden el existir, en la historia y filosofía de su época ${ }^{79}$. A partir de allí, mediante una interpretación en retroceso, busca llegar a cierto carácter de ser de tal facticidad: destaca lo que permanece invariable en este fenómeno de cotidianidad, aunque distinguiendo un suelo fecundo y olvidado en tal fenómeno. Luego, propone convertir en concepto dicho carácter de ser puesto de manifiesto, pero aclarándolo en cuanto existenciario, es decir, sin los matices ni la comprensión de lo dado y acabado ( propios del ámbito de lo cósico o lo subsistente).Podemos distinguir que en esta figuración busca poner a la vista el existir, configurando un primer acceso ontológico a la facticidad y así destacar los rasgos fundamentales de su ser, insistiendo en que el existir: "no es cosa alguna ni algo compuesto de vivencias, ni mucho menos el sujeto o yo que esta frente al objeto o no yo" ${ }^{\prime 80}$.

Ahora bien, el despliegue fenomenológico de tales rasgos y su atención al lenguaje, lo conducen una y otra vez a revisar el marco categorial con el cual articula los resultados de tales investigaciones ${ }^{81}$.En este marco, se torna relevante especificar sus discusiones con los esquemas y

dichos seminarios de 1959-69: junto a un grupo de psiquiatras, Boss también asiste a una de las clases. Para un abordaje de los desarrollos y articulaciones del Daseinanalyse de este autor, véase Boss (1963) y (1979), este último escrito bajo la supervisión de Heidegger. El intercambio epistolar entre ambos, está prevista en la edición de Briefausgabe para BA II.10.

${ }^{78}$ La analítica del Dasein requiere detenerse en estructuras y modalidades pero sin descuidar el carácter simultáneo de su despliegue. Es decir, si tales estructuras son co-originarias y se manifiestan u operan al mismo tiempo en la facticidad, la pretensión metafísica de una aprehensión acabada del Dasein fáctico se torna imposible. Asimismo, tal complejidad simultánea requiere retomar desde diversos encuadres las estructuras del Dasein, lo cual explica las reiteraciones manifiestas en las diversas exposiciones respectivas.

${ }^{79}$ Para un despliegue del análisis de lo ya interpretado en la conciencia histórica y la filosofía en su actualidad, véase OHF: $35-43[56-63]$.

${ }^{80} \mathrm{Y}$ agrega, en un párrafo tachado posteriormente por el mismo Heidegger, un comentario que podemos entender como una prefiguración de su posicionamiento respecto al movimiento existencial sartreano : " No se trata de agenciarse una serie de frases y de dogmas acerca de ese existir, y de exponerlos; ni de hacer con ello o sobre ello una filosofía ; ni tampoco, lo que para la mayoría es más importante, de montar, de poner en escena una nueva escuela dentro de la fenomenología y así amplificar aún más el escándalo y el jaleo actuales, ya de por sí bastante sospechosos “(Ibid.:47[68]). En este fragmento subyace un posicionamiento respecto a las cristalizaciones en el pensar y el lenguaje, que mantiene luego respecto a la recepción y análisis de sus propias elaboraciones.

${ }^{81}$ En este sentido, a partir de esta vía metodológica de Heidegger podemos encontrar una interpretación del Dasein como un sujeto de enunciación complejo (Bertorello, 2006:41 ss.) y a partir de los componentes semánticos del Da y sein, inscribe la dinámica inherente al Dasein de ciertos procesos que describen la apertura de su ser y la estructura resultante (Bertorello, 2011:11 ss.). En el capítulo 7 desarrollaremos una posible teoría de la producción del sentido en 
comprensiones tradicionales más relevantes, los cuales entendemos que no solo ofician de límite para sus elaboraciones, sino que también establecen los contornos del campo discursivo en el que estas se desplazan. Con estas especificaciones buscamos evidenciar con mayor claridad las tensiones en el campo semántico en el que se articulan las estructuras fundamentales del Dasein. Atendiendo a las discusiones epocales que mantuvo con su maestro, proponemos comenzar con la cuestión de la reducción egológica desde las elaboraciones de Husserl.

\section{2.- Algunas críticas a la comprensión moderna: ni yo puro, ni sujeto.}

\section{2. a.- Husserl y la reducción al yo puro.}

Hemos visto que proyectándose hacia el horizonte de la cientificidad, Husserl realiza reducciones eidéticas para obtener esencias invariables de los fenómenos, punto de partida fundamental en vistas a su meta de fundamentación absoluta de las ciencias. El modo en que obtiene y explicita el yo puro como estructura total y primera, es un claro ejemplo de ello ${ }^{82}$.

Este pensador no parte de la conciencia como premisa para posteriores deducciones sino como campo ilimitado de investigación, abierto a una descripción analítica de sus estructuras intencionales: un campo de experiencia trascendental. La operación que realiza pone al descubierto un ego que no puede presentarse como tema (téticamente) en el mundo, siendo así un ego desmundanizado (entweltlichte): el ego trascendental o puro en su carácter necesario e idéntico en medio de los cambios de las vivencias (Ideen I:109[132]).Proponiéndose aclarar la subjetividad sin intromisión de conceptos objetivantes, también podemos considerar que finalmente "Husserl precisamente fracasa en este intento de 'descosificar' el sujeto trascendental” (Presas, 2009:38). Veamos en qué sentido.

Antes que nada, entiende que el retroceso hasta la subjetividad constituyente no puede ser determinado por las mismas categorías de los entes mundanales. En la epojé libera el sentido auténtico del mundo natural y circundante en el que nos encontramos, al referirlo constitutivamente

Heidegger, donde el Dasein no puede ser comprendido como artífice directo de tal producción, aunque distinguiremos ciertas singularidades discursivas de nuestro autor que bien pueden plantearse como una teoría de enunciación.

${ }^{82}$ A este respecto, véase Ideen I: 65-7,108-10,159-61,253-5[83-5,131-3,189-91,292-94]. Cf. Con sus desarrollos posteriores, en Ideen II: 97-120; 311; 321-7[133-157; 361; 372-9] y en sus últimas elaboraciones, CM: 48-65; 91120[41-68; 105-148].En este apartado tomaremos especialmente la reducción a una egología trascendental de Ideen I, texto anterior a SuZ, al cual Heidegger se opone. Asimismo, presentaremos algunas elaboraciones posteriores de Husserl, con el objeto de una mayor especificación de los estratos del yo y las reducciones que distingue en sus análisis, en vistas de nuestros próximos desarrollos. 
a la conciencia pura, de modo tal que se da una liberación que va desde una enajenación (Bindung) a una esfera autónoma donadora de sentido. La reducción a la conciencia pura conduce luego de lo dado a lo constituido en el ego.

En efecto, en esta explicitación pueden observarse en el yo en tanto fenómeno central , tres estratos : a) el yo actual o empírico, como polo de las experiencias naturales y punto de partida del fenomenólogo ; b) el yo trascendental ( también denominado o bien sujeto trascendental o bien ego trascendental, en sus elaboraciones posteriores), cuyas acciones hacen comprensible la legitimidad de los procesos empíricos de la experiencia y c) el ego puro que se distingue al quedar al descubierto la subjetividad trascendental, haciendo comprensible su efectuación. Siempre se trata del yo único en la realidad total, donde el polo-yo y el polo-cosa son entendidas como partes puestas en una unidad, funcionando como una distinción establecida a los fines de la descripción y no de una fundamentación. El paso del yo empírico al sujeto trascendental se realiza por medio del método de la epojé o puesta entre paréntesis. Veamos en qué consiste este pasaje.

El yo empírico, en su experiencia, halla estados de cosas que no muestran diferencias respecto a las cosas del mundo en general. La totalidad de ese conjunto es el flujo individual del conocimiento o la experiencia, donde se encuentran las percepciones de objetos reales, el yo y los otros hombres. Como vimos, en cuanto nos orientamos directamente a esos objetos con enunciados acerca de la realidad, permanecemos en la actitud natural, sumergidos en los actos téticos. Ahora bien, si nos dirigimos sobre estos actos, en una actitud fenomenológica, estamos ante un nuevo acto intencional llamado reflexión, donde el acto y el hacia donde de ese acto pertenecen al mismo flujo de vivencias. Estamos aquí ante la inmanencia de la conciencia, es decir, la inclusión del objeto de la intención en la aprehensión misma y en la unidad de la misma realidad [Ideen I: 94s. [115s.]. Asimismo el flujo de la conciencia es en cada caso el mío propio, por lo cual no hay una conciencia trascendental a-subjetiva, ni conciencia pura que no pertenezca a nadie: es siempre actual, en un aquí y ahora. Al menos, como punto de partida de la reducción.

Ahora bien, en la epojé la reflexión considera el acto sin participar en él, es decir, no sigue su dirección temática (en cuanto al contenido), sino solo con referencia a la modalidad de la intencionalidad de la conciencia. La obtención de esta esfera de actos y de los objetos que se determinan en esta esfera es denominada reducción, la cual implica reconducir aquello que se muestra a la forma de cómo se muestra ${ }^{83}$.

\footnotetext{
${ }^{83}$ En continuidad con las consideraciones respecto a la intuición de las esencias que mencionamos en el capitulo anterior, cabe recordar que Husserl distingue la reducción eidética y la reducción trascendental. En el primer caso , remite a la reconducción de lo dado a su eidos o esencia, aquello que se impone como invariante en un proceso de variaciones imaginativas ( ensayando distintas condiciones y contextos de experiencia), permitiendo distinguir una identidad donde actúan procesos de idealización, formalización y generalización del sentido. En el segundo caso, la
} 
En líneas generales, el resultado de esta explicitación que abandona metodológicamente la actitud natural, es un mundo que se muestra haciéndose, incompleto, donde las indeterminaciones de la experiencia forman parte de ésta: la corriente de vivencias no alude a nada permanente, ni a una unidad de vivencias, más bien refiere a la unidad fáctica y fluyente de la conciencia, en su permanente estar en movimiento.

No obstante el resultado de esta reducción también marca el encuentro de sí mismo como unidad psicofísica y en esa unidad, con el yo actual que se sumerge en el mundo natural y padece su acción por medio del propio cuerpo orgánico. En su esfera primordial reducida, el fenomenólogo es el polo-yo idéntico de sus múltiples vivencias puras, las de la propia intencionalidad y de las habitualidades instituidas o por instituir en dichas vivencias. Asimismo, se percata de que el ego ya estaba ahí dado para sí, aunque en todos los casos con un horizonte abierto e infinito de propiedades interiores aun no descubiertas. Así, tomando especificaciones de elaboraciones posteriores de Husserl, puede distinguirse aquí cada vivencia del yo que la vivencia, precisamente en este sentido el yo es un "polo", es decir, un término de esta bilateralidad de los actos intencionales (CM: 99s. [117-9]; Ideen II: $105-7[141-3])^{84}$.

El yo del fenomenólogo transcurre en el presente viviente ${ }^{85}$ y la explicitación solo puede dar cuenta de una percepción que allí transcurre, descubriendo luego el pasado propio mediante recuerdos. Si bien varían los modos de implicancia en la corriente de vivencias, el yo se manifiesta como punto de origen o centro, en tales vivencias ${ }^{86}$. En otras palabras: la accesibilidad de las corrientes de vivencias para Husserl, en primer lugar es en sus actualidades y luego en sus

\footnotetext{
reducción no tematiza solo el cómo algo se presenta sino también cuestiona la aparición misma del "algo como algo", explicitando la diferencia significativa en su diferencia trascendental.

${ }^{84}$ En Ideas I encontramos elaboraciones preparatorias respecto a esta polarización yo-objeto, a partir de la distinción de la orientación subjetiva y objetiva de la esfera de las vivencias de la conciencia. Véase, Ideen I: $160 \mathrm{~s}$. [190 s.]

${ }^{85}$ En este presente viviente de la esfera primordial se hallan también las habitualidades, las cuales parten de actos que son propios del yo, instaurando dichas habitualidades y constituyéndose como permanentes, es decir, habitualidades por medio de las cuales el polo-yo obtiene determinaciones especificas del yo. Véase CM: 107-10[129-32]; Ideen II: 311[361]. Estas consideraciones se tornarán relevantes para comprender los análisis de la identidad que realiza Ricoeur, los cuales desarrollaremos en el capítulo 8.

${ }^{86}$ Walton desarrolla y analiza comparativamente, diversas perspectivas fenomenológicas actuales, donde "el yo centralizante ha quedado expuesto a las vicisitudes de un descentramiento por estar situado en una configuración que no puede dominar, o de una subordinación por estar sujeto a un origen o una respuesta”, Walton (1992):418 ss. En este marco comparativo, destaca elaboraciones posteriores que comprenden dinámicas en procesos vivenciales que se organizan sin la orientación de un polo específico. Sin embargo, subraya que en la etapa genética de las elaboraciones de Husserl, el yo se relaciona con habitualidades de una temporización articulada con la sedimentación de las vivencias pasadas, lo cual permite distinguir variedad de yoes, con sus historias respectivas. Con ello, este intérprete pone énfasis en que las elaboraciones posteriores de Husserl comprenden también una multiplicidad no idéntica en el curso de las vivencias, aunque correlativa a un centro de experiencia que le otorga a la vivencia permanencia y unicidad. Estos análisis se enmarcan en una corriente interpretativa reciente que pone en evidencia la presencia de elaboraciones de madurez de Husserl, en los trabajos de juventud de Heidegger.
} 
potencialidades propias (donde podría poner en marcha determinadas series de vivencias) ${ }^{87}$. Específicamente este yo remite a un centro que se vuelve hacia el mundo a la vez que recibe estímulos de él, es decir, de un polo idéntico del que irradian las vivencias.

Ahora bien, la cadena de reducciones y puesta entre paréntesis (cada epojé consta de estos dos momentos) se despliega sobre cuatro acciones sucesivas: a) la concerniente a la actitud de la experiencia ingenua o natural; b) la reducción trascendental que al poner entre paréntesis o desconectar los objetos mundanos, pone al descubierto las acciones puras de la conciencia y explicita la subjetividad trascendental ${ }^{88}$. Puesto que la subjetividad trascendental es en cada caso la mía propia (la del fenomenólogo) y posee aspectos concretos fijados de modo histórico-biográficos, no comparte con el yo trascendental la misma apodicticidad ${ }^{89}$, por ello: c) continúa luego la reducción donde aquellos aspectos se ponen entre paréntesis. Con ello, se evidencia la estructura de las acciones trascendentales de la conciencia, sin su carácter meramente individual. Específicamente, se plantea aquí una reducción a los objetos inmanentemente trascendentes de la conciencia (objetos de la reflexión que tiene la misma manera de ser que el flujo de las vivencias), al tiempo que se ponen entre paréntesis sus elementos trascendentemente trascendentes (aquellos que no se hallan en el flujo de las vivencias, lo cual implica que aún contienen elementos mundanos $)^{90}$. Con este doble movimiento, se establece una depuración en la vía de la reducción a la conciencia pura, obteniendo correlativamente el ámbito del ego puro en tanto centro funcional de toda constitución.

Este ego puro es un centro funcional sin explicitación de sí y pone en marcha la organización de la conciencia, vivificándola para el conocimiento del mundo y la fundamentación de la evidencia de lo conocido, revelándose como fuente prístina de todo acto tético (Ideen I: 253[292s.]. Finalmente, una cuarta reducción: d) aquella que descubre la intuición de esencias,

\footnotetext{
${ }^{87}$ Por ello sostiene: "Toda explicitación de datos egologicos singulares (...) participa del a priori apodíctico universal con su generalidad indeterminada pero determinable" (CM.:133[167]). Entendemos que el énfasis de Heidegger mayormente puesto en este sesgo proyectivo remite a una comprensión diferente, aunque en el mismo campo semántico que su maestro.

${ }^{88}$ El término trascendental remite aquí a la unidad entre los actos de conciencia de esta reducción y los actos intencionales de la primera reducción.

${ }^{89}$ Específicamente: el olvidarse, el engañarse, etc., propios de la subjetividad trascendental menoscaban su pureza. Precisamente estos aspectos concretos son los fijados de modo histórico-biográfico y son la razón por la cual Husserl realizará una nueva reducción hacia el ego puro. Asimismo, otra de las razones tal y como subraya Presas consiste en que "esta tarea se ve enormemente dificultada por el uso del lenguaje que ya siempre remite a los otros", Presas (1983):48.

${ }^{90}$ En el primer caso, la reducción se efectiviza hacia el ego puro; en el segundo, esencias trascendentes tales como "persona", "cosa", "carácter", etc., se revelan extrañas al flujo de vivencias de la conciencia, por lo cual son puestas entre paréntesis. Para Husserl, el carácter inmanente remite a la conjunción entre la reflexión y lo reflexionado. En cambio, lo trascendental remite a la conciencia prescindiendo de los contenidos mundanos de sus actos, mientras que trascendente significa lo objetual hacia los que se dirigen los actos intencionales. Al poner entre paréntesis los objetos trascendentes, se ponen de manifiesto en su singularidad los actos de la conciencia. Para sus primeras elaboraciones de la distinción entre trascendencia e inmanencia en el flujo de las vivencias, véase ,Ideen I:76-83[94-103]
} 
siempre correlativa a todo acto total de la conciencia. De todos modos no perdamos de vista que estas reducciones son estructuras estratificadas de una misma conciencia.

En este estrato irreductible, el yo originario $(U r-i c h)$ no nos permite saltar por detrás de él ${ }^{91}$. Aquí se pone de manifiesto la intersubjetividad como fenómeno dado a mi subjetividad. Esta modalidad indeclinable y temporal del yo preocupó a Husserl en sus últimos años (Presas ,2009:43), aspecto que comparte con las motivaciones de Heidegger en sus primeras elaboraciones ${ }^{92}$.

De esta manera, el problema del yo parecería evitar ser discutido con las categorías de la metafísica de la subjetividad. Sin embargo, esta reducción impide la clara captación de la temporalidad al dirigirse al yo que ejecutó los actos, descuidando la dimensión del futuro y devenir que Heidegger distingue como fundamental.

En este marco, Landgrebe muestra que la reflexión en Husserl se basa en un modelo de constitución de la unidad objetiva, a través de sus maneras especificas de darse en los fenómenos, la cual interpreta como objetivante y presentificante, lo que hace que tales elaboraciones se mantengan adheridas al concepto de sustancia de la metafísica moderna (Landgrebe, 1968b:309), es decir, a la tradición de la que se quiere distinguir. Asimismo, subraya que al tematizar el tiempo como marco para determinar el ego, no es posible para el método de Husserl recurrir nuevamente a la reflexión (debido a dicho desplazamiento), como tampoco puede ya sostenerse la identificación entre ser y ser-objeto que se hallaba implícita. Esta tensión entre aquel modelo y la dimensión temporal del ego, figura en el marco categorial respectivo, como este interprete distingue implícitamente en el siguiente fragmento: “...también caduca la categoría de identidad, toda vez que al yo le es esencial su apertura, su inacabamiento, la dimensión del todavía no o sea del futuro como posibilidad. Este horizonte del futuro corresponde a lo que Husserl denomina 'yo puedo' y, consecuentemente, es el horizonte práctico de la libertad" (Ibid.:44) ${ }^{93}$.

\footnotetext{
${ }^{91}$ En este caso, la referencia a un yo originario es a las condiciones de posibilidad de los actos. Por otra parte, cuando la referencia se dirige a la génesis del yo, Husserl distingue al pre-yo (Vor-Ich).En ambos casos el acto intencional no está constituido aún, es decir, no hay conciencia de objetos constituida, poniéndose en evidencia la función de una dimensión afectiva previa a la intencionalidad. Para un desarrollo y análisis respectivo, comparándolo con la fenomenología actual, véase Walton (1992):438-41.

${ }^{92}$ En esta línea interpretativa Cruz Velez entiende que la definición para este ego en Husserl puede articularse de la siguiente manera: "el yo es un llegar a ser desde lo que ha sido proyectándose en lo que será. Su haber sido corresponde a su facticidad, su ir a ser a su poder ser. El es, pues, actualmente proyectándose hacia sus posibilidades y apoyándose para ello en lo que ha sido ya fácticamente" (Cruz Velez 1970:.84) Con ello, puede conjeturarse una influencia de Heidegger en el ultimo Husserl, donde ya no cabria hablar de egologia sino egocronía (Ibid.:43).

${ }^{93}$ A este respecto, sostiene Presas: "Husserl, en definitiva, fracasa en su intento de establecer las bases de una nueva ciencia filosófica fundamental que tenga por objeto el ego trascendental en su dimensión temporal” (Presas 2009:44). De esta manera el fracaso de Husserl presenta elementos para un nuevo pensar, que dan cuenta de una sucesión: al establecer la intelección de la indeclinabilidad y la facticidad de la constitución del mundo, mostrando la radical dependencia de la subjetividad trascendental, abre el camino y ofrece elementos para que Heidegger afronte un intento más radical de superación de la metafísica de la subjetividad desenmascarando sus conceptos operativos, en tránsito hacia un nuevo tipo de pensar. Por ello, a nuestro entender todo "fracaso", tanto en Husserl como en Heidegger, se torna condición necesaria e ineludible para una transición respectiva.
} 
Ahora bien, la confluencia del carácter situacional y actual de la conciencia (en el mundo de la vida circundante) con la reducción al ego puro es el punto de mayor relevancia en las críticas que le realiza Heidegger, quien encuentra una aporía ineludible en los planteos de Husserl, pues: ¿cómo es posible sostener la pertenecía del yo al mundo y la simultánea constitución del mundo por obra del yo?

\section{2. b- Heidegger y la imposibilidad de la reducción del yo.}

Heidegger manifiesta sus discrepancias, respecto a las consideraciones del yo puro, en tanto origen y principio trascendental/constituyente de todo objeto ${ }^{94}$. Este yo puro dado a priori, sostiene Heidegger, es en realidad un yo-en-el-mundo, aunque este estar en el mundo es diferente de la simple presencia (Vorhandensein) dentro del mundo. Mientras Husserl propone una universal voluntad teorética frente a toda actitud ingenua/natural, que debe mantener en suspenso todas nuestras vivencias; Heidegger, por su parte, pone en duda la voluntad de reducción no tematizada en aquél método, es decir, la entiende como un punto de partida que implica un querer-decir, una decisión metodológica previa a la reducción, de modo tal que interpreta la reducción del yo humano a yo puro, en última instancia, como injustificada e imposible.

Específicamente, subraya que para Husserl el yo reducido ya no es un yo humano, sino una pureza que es excepción de lo empírico y positivo. A partir de esto, Heidegger sostiene que la reducción no es una posibilidad del hombre: es imposible porque éste no es una realidad simplemente ya dada, sino que como vimos, es un comportamiento (Verhalten) que se hace y se pone a sí mismo, aunque no como las cosas ni su tipo de positividad. Como destacamos con la distinción de Landgrebe, las limitaciones de aquella reducción consisten en un reducirse a pura presencia de un objeto, quedando fuera de su verdadera facticidad: la realidad humana es un ente no meramente presente ahí (vorhanden).

Por otra parte, lo que Husserl llama mundo, como conjunto de entes, no puede explicarse basándose en otro ente (como el hombre). Para este pensador, el lugar de la constitución de los entes debe estar por encima de ellos, es en este sentido que debe ser trascendental: entiende que puede haber un ente que sea el lugar de la trascendencia misma. Frente a ello, Heidegger insiste en que este "lugar" es el Dasein aunque su ser consiste en no ser un mero estar ahí.

\footnotetext{
${ }^{94}$ Pueden encontrarse algunas discrepancias de Heidegger en algunas especificaciones o notas al pie en las lecciones de Husserl de 1925. En especial, véase PhP: 272-275.
} 
De esta manera, las críticas de Heidegger evidencian la imposibilidad de un análisis universal y absoluto que nivele al yo al modo de ser dado y acabado de los objetos. El Dasein en su significación dinámica y en su carácter de poder-ser, rechaza la posibilidad de alcanzar tal reducción. La cuestión de fondo, para nuestro autor, reside en el enraizamiento no tematizado por Husserl en la comprensión de ser como presencia, la cual se remonta a la ousía griega, tal y como la encuentra también en ciertas perspectivas y elaboraciones de Descartes y Kant.

\section{2. c.- Cuestionamientos al sujeto moderno: tensiones en el marco categorial.}

Precisamente circunscribe al pensamiento de Descartes, Kant y Hegel la cristalización de esta orientación al sujeto, con la comprensión del ser que subyace al pensamiento griego, en las respectivas pérdidas u olvidos del suelo originario. Las consideraciones modernas del yo y del sujeto, así como las categorías y conceptos empleados en tales comprensiones, son también el objeto de la destrucción heideggeriana ${ }^{95}$.

En efecto, como hemos visto en sus análisis del pensamiento de Descartes, allí se destaca que el cógito es lo único cierto a conocer, tomando como punto de partida al yo sin tematizar el modo de ser del sujeto y aceptando la ontología tradicional. Entre los extremos de esta comprensión moderna (Descartes-Hegel) ubica la posición intermedia de Kant, que oficia de transición entre ambas.

Según su interpretación, la distinción de Kant entre el yo y el objeto , representa esa modalidad comprensiva: el yo es entendido como unificante y siempre co-pensado en cada representación, es decir, apercibimos nuestro yo simultáneamente con el pensar de lo particular, sin remitir con tal distinción una representación, sino más bien el fundamento de toda posibilidad de representar. El yo de la apercepción trascendental (que subyace a todo pensar y es idéntico en todo

\footnotetext{
${ }^{95}$ Esta consideración no tematizada de los conceptos ya recibe un tratamiento temprano en un trabajo de 1921, cuando analiza algunas indagaciones que realiza Jaspers en torno a que sea el hombre. Heidegger discute la anticipación que le sirve de guía a Jaspers, para saber lo que se pretende y cómo se pretende. En este contexto, sostiene que la experiencia fundamental relativa al yo es decisiva su facticidad, en tanto fenómeno que se cumple históricamente. La propia experiencia de la vida fáctica tiene tendencia a caer en significaciones entendidas como objetivas del entorno experimentable. Por medio de la destrucción de la tradición es posible llegar a los fenómenos existenciales explicándolos en una conceptualización genuina, con la mirada puesta en modos y medios de explicación de la experiencia de la realidad propia. En Jaspers su método se sitúa en contra de la tendencia de su anticipación que se dirigen hacia los fenómenos de la existencia, caracterizándola como pura observación : lo que está aquí no está incluido en el contexto de comprensión, no dejando en claro el sentido de esa observación, en tanto interpretación , que es histórica, y subraya : "en la medida en que la vida es un todo infinito que fluye pero los conceptos son formas que paralizan la vida, se torna imposible captar auténticamente la vida”(AJPW:39[44]).
} 
sujeto fáctico) es indeterminable, no se opone como otro yo al psíquico subsistente, aunque tampoco sostiene que no sea un ente.

En este marco, Kant no aclara el modo de ser del yo, solo destaca que las categorías no son aplicables a este, razón por la cual queda indeterminado. Específicamente, si el yo co-pensado es el fundamento de las categorías, entonces estas no pueden aplicarse a él. Asimismo, las categorías se aplican a lo unible, mientras el yo se aparta de tal carácter, aunque articulado como algo no-múltiple que hace posible toda experiencia. Por tanto, para Kant no hay conocimiento óntico del yo trascendental ni se puede determinar ontológicamente por medio de categorías, al tiempo que lo distingue como condición de toda representación. Así, junto con la exigencia de las categorías aplicable a tal campo temático y de la distinción de un yo o conciencia trascendental, Heidegger destaca que no consigue quitarse de encima la ontología tradicional.

Precisamente en este contexto de la tradición, Heidegger insiste en la necesidad de determinar el Dasein de un modo ontológicamente adecuado, partiendo como vimos de la facticidad. No obstante, entendemos que este punto de partida manifiesta en lo inmediato huellas de alteridad y tensiones en el ámbito de la mismidad, que lo apartan de aquellas pretensiones puristas y universales de las reducciones fenomenológicas. Esto puede evidenciarse en este análisis desde la intencionalidad, donde el Dasein:

"Se encuentra primaria y constantemente en las cosas, porque tendiendo a ellas o repelido por ellas, siempre descansa en ellas de alguna manera. Cada uno de nosotros es aquello que persigue y aquello por lo que se preocupa. En cada momento nos comprendemos a nosotros mismos y a nuestra experiencia a partir de lo que perseguimos y de lo que nos ocupamos. Nos comprendemos a nosotros mismos partiendo de ahí porque el Dasein se encuentra primariamente en las cosas (...) .al darse de forma inmediata y apasionada al mundo mismo, el propio yo del Dasein se refleja en las cosas “(DGPh: 126 s. [201])

En este fragmento queda manifiesta la modalizacion primaria o inicial de la comprensión de nuestro yo, de carácter cósico, que Heidegger distingue en su analítica. Ello es una prueba del carácter ineludible de las herencias y limitaciones tradicionales, en su sedimentación comprensiva y conceptual. Por ello, el término sujeto en Heidegger debe entenderse en el sentido del Dasein, como un ente singular que es en el mundo (Ibíd.: 308[265]). Esta labor preparatoria de una ontología fundamental hace frente a interpretaciones meramente antropocéntricas o subjetivo-idealistas ${ }^{96}$.Así,

\footnotetext{
${ }^{96}$ En este sentido afirma: "Que el Dasein sea el tema de la ontología fundamental no es un capricho nuestro, sino que, por el contrario, surge de la necesidad y del contenido quiditativo de la idea de ser en general” (DGPh: 320[273-74]).Es decir, remite a una necesidad inherente a las tensiones en el lenguaje y el pensar de la metafísica.
} 
comprender el yo en el marco de la intencionalidad implica para Heidegger una reelaboración de los análisis y enfoques de Husserl.

\section{2. d.- La desubjetivacion del concepto de intencionalidad}

Aquel rastreo histórico por la comprensión del ser en su tradición, lo conducen a distinguir el pensamiento de Husserl y Kant bajo el mismo suelo de comprensión en línea con la escolástica, que refieren al modo de ser de las cosas naturales (Vorhandenheit). Asimismo, allí enmarca la comprensión de Husserl del concepto de intencionalidad, a la cual le subyace cierto subjetivismo en sintonía con el resto de sus investigaciones.

Si bien Heidegger subraya que el comportamiento intencional del Dasein es una de sus estructuras fundamentales, pues designa el modo en que está ya siempre confrontado con algo subsistente (vorhanden), distingue también un conjunto de desvíos o inadecuaciones comprensivas. Una de ellas consiste en que la intencionalidad en su comprensión tradicional fue entendida como una relación entre dos entes subsistentes, sujeto y objeto; frente a ello la comprende como una estructura que constituye el carácter de relación del comportarse del Dasein. En este sentido, la estructura intencional de los comportamientos no es algo inmanente a un sujeto que este necesitada de trascendencia hacia los objetos, más bien la constitución ontológica de los comportamientos del Dasein es la condición ontológica de la posibilidad de toda trascendencia. De esta manera, la exposición adecuada de la intencionalidad en su carácter de condición comprensiva vuelve discutibles los conceptos derivados de sujeto y subjetividad, tal y como sostiene en este pasaje:

“También esta insuficientemente definido el concepto filosófico tradicional de sujeto con respecto a la constitución fundamental de la intencionalidad. Partiendo del concepto de sujeto no se puede decidir nada de la intencionalidad por que la intencionalidad es la estructura esencial, aunque no la más original, del sujeto mismo" (Ibíd.: 92[95]).

En suma, la carga semántica del concepto de sujeto remite, en última instancia, a la comprensión griega implícita en el término ousía, la cual como vimos, implica una comprensión del 
ser no tematizada ${ }^{97}$. Heidegger encuentra en las perspectivas de Descartes, Kant, Hegel y Husserl una tendencia a la búsqueda de un suelo firme para todo problema filosófico a partir del esclarecimiento suficiente del "sujeto". Ahora bien, si el carácter insubstancial y no universal es la distinción ontológica originaria del Dasein, que contrapone Heidegger como resultado de su analítica y su atención puesta a la diferencia ontológica, lo cual oficia como distinción en el campo semántico dentro de la tradición en la que se inscribe, ¿en qué sentido plantea la eminencia del Dasein para la pregunta por el ser en general, como horizonte último de su investigación fenomenológica?

En el próximo apartado abordaremos el estatuto de tal preeminencia en su propuesta, el cual se torna problemático a partir de su consonancia con la centralidad del sujeto o el ego puro en aquellas perspectivas de la modernidad. Luego, analizaremos tres estructuras fundamentales del Dasein ( el ser-en-el-mundo, la comprensión y la temporeidad ), a la luz de la modalidad de ser que distingue nuestro autor y su comprensión correlativa, con el objeto de circunscribir un marco para plantear el alcance del cuestionamiento a la noción moderna de sujeto que implica esta comprensión y significación dinámica del término Dasein, lo cual nos ofrecerá los elementos necesarios para indagar en torno a sus consideraciones respectivas sobre el sí mismo.

\section{La cuestión de la preeminencia para el análisis y algunas estructuras fundamentales.}

\section{3. a. ¿Por qué empezar por el Dasein?}

En su curso de 1927, que continua a la publicación de $S u Z$, insiste en la importancia de la comprensión la cual, como vimos, es condición para desplazamientos respecto a las sedimentaciones semánticas y conceptuales de la modernidad. En este marco, subraya que debido a que la comprensión del ser es anterior a la experiencia del ente, el Dasein presenta cierta preeminencia pues aquella le pertenece como pregunta ${ }^{98}$. Como vimos, si el Dasein es el sitial del

\footnotetext{
${ }^{97}$ En esta misma línea, en su último curso en la Universidad de Marburgo, realiza algunas aproximaciones a la monadología de Leibniz. Encuentra ciertas similitudes de este con Descartes en tanto poner en el mismo plano ser y subjetividad., entendiendo el auto certeza del yo como la certeza primaria viendo en el ego la dimensión desde la cual poder extraer todos los conceptos metafísicos fundamentales. Allí el problema del ser se intenta resolver volviendo al sujeto. Véase, MAgL: 72-99[72-93].

${ }^{98}$ En este marco, un intérprete analiza e historiza el camino de la pregunta por el sentido del ser desde los trabajos tempranos de Heidegger, distinguiendo un inicial abandono y posterior recuperación (como pregunta) de tal problemática, a partir de un rastreo que se aparta de las consideraciones unitarias del pensamiento de Heidegger, propias de la recepción clásica de su obra, véase Vigo (2006):97-100. Entendemos que esta comprensión no lineal y multiple del pensamiento de Heidegger, en el marco de la pregunta por el ser, también es un correlato de la tensión en el marco
} 
sentido y posee una comprensión del ser, entonces se torna necesario empezar por un abordaje existencial del Dasein y su respectivo sentido de ser, para plantear de allí un horizonte hacia el sentido del ser en general . En el contexto de nuestras interpretaciones tal preeminencia por un lado, busca apartarse de las connotaciones antropocéntricas, al articularse con el carácter dinámico y proyectivo del lenguaje correlativo a la estructura proyectiva del Dasein y, por otro, el carácter regresivo de su modalidad de análisis lo mantiene en vinculación con ellas. En este sentido sostiene:

“La comprensión del ser tiene ella misma el modo de ser del Dasein humano. Cuanto más originaria y adecuadamente determinemos este ente respecto de la estructura de su ser, es decir, lo determinemos ontológicamente, con mayor seguridad estaremos en disposición de captar, en su estructura, la comprensión del ser que pertenece al Dasein, y con mayor claridad se podrá entonces plantear la cuestión: ¿qué es lo que hace posible esta comprensión del ser en general?’(DGPh: 21[41])

Es por ello que se ve en la necesidad de poner de relieve la constitución fundamental del Dasein humano, caracterizando su singular sentido del ser. Distingue que si hay comprensión del ser, hay ser, y esto se debe a que existe el Dasein, ente preeminente para la cuestión acerca de la pregunta por el ser en general, aunque desde una modalidad de preguntar, comprender y existir en dinámica esquiva frente a las cristalizaciones. En este marco, Von Hermann argumenta y desarrolla en torno a la interpretación del término Dasein y su carga de significación, tomando el prefijo $D a$ en dicho término: tal y como Heidegger lo especifica, este lleva implícito en su significación un direccionamiento a la pregunta por el sentido del ser en general, además de dar cuenta de estructuras ontológicas de la existencia humana ${ }^{99}$.

Por ello, se vuelve necesario aprehender el conjunto de estructuras del Dasein, en vistas a tal carácter comprensivo. En este marco, denomina existencialidad a la trama de estructuras donde se da la exposición analítica de la existencia, remitiendo con ello a la constitución del ser del ente que existe: si la existencia determina al Dasein, la analítica ontológica requiere una visualización de tal existencialidad $^{100}$.

del lenguaje heredado. Tambien podemos encontrar la tesis de continuidad en el pensamiento de Heidegger en el trayecto hacia los desarrollos de SuZ: Cf. Adrian (2010b):16 ss. Vemos con esta discusión, una muestra del interés creciente, en los estudios actuales de su pensamiento, en el abordaje de textos, cursos y seminarios del joven Heidegger, es decir, previos a la publicación de $S u Z$.

${ }^{99}$ Véase, von Hermann (2002):48 ss.

${ }^{100}$ En SuZ, el término Existenz , remite al modo de ser propio del Dasein , a su apertura y salir fuera de sí mismo( que luego de 1927 busca significarlo con la grafía Ek-sistenz), que aquí articulamos con el término existencia. Con ello se separa de la significación de la ontología tradicional que remite al mero subsistir en la realidad efectiva. Los conceptos Existenzial (existencial) y existenziell (existentiva), le permiten a Heidegger distinguir en general los existenciarios (Existenzialien) (indicación formal de los caracteres ontológicos del Dasein) de las categorías (conceptos en relación a estructuras de los entes que no son el Dasein). En particular, el existenzial designa las determinaciones ontológicas constitutivas de todos los modos de ser de la existencia del Dasein; el existenziell, se circunscribe al nivel ontico- 
Desde aquí, desarrolla con mayor precisión los aspectos por los cuales es preeminente el Dasein para su analítica, en tres niveles complementarios : a) ónticamente, pues está determinado en su ser por la existencia ; b) ontológicamente, pues tiene en su ser una relación (de ser) con su ser : el comprender el ser (en general) es una de sus determinaciones específicas ${ }^{101}$; c) finalmente , es condición óntico-ontológica y fáctica de todas las ontologías, pues en el marco de su comprensión de la existencia, le pertenece también una comprensión de los entes que no tienen su propio modo de ser .Precisamente debido a esta orientación ontológica de su analítica, aun en la etapa de elaboración de $S u Z$ no se manifiesta completa sino mas bien en proceso. Con ello, distinguimos otro intento de desmarcarse de toda tentativa antropológica con sus notas estáticas, tal y como hallamos implícito en este fragmento:

“...el análisis del Dasein no solo es incompleto, sino que, por lo pronto, también es provisional. En su primer momento se contentará con sacar a la luz el ser de este ente, sin dar una interpretación de su sentido. En cambio, deberá preparar la puesta al descubierto del horizonte para la interpretación más originaria de ese ser. Una vez que haya sido alcanzado este horizonte, el análisis preparatorio del Dasein exigirá ser repetido sobre una base más alta, la propiamente ontológica. La temporeidad se nos mostrará como el sentido de ser de ese ente que llamamos Dasein”. (SuZ: 17[41])

Es decir, que aquello desde donde el Dasein comprende e interpreta el ser es el horizonte del tiempo. En continuidad con su modalidad de análisis, este deberá ser sacado a la luz en una comprensión genuina en tanto horizonte de toda comprensión del ser y de todo modo de interpretarlo.

La propuesta de Heidegger, como vimos, consiste en alcanzar la tradición y deshacerse de sus encubrimientos., un desmontaje en pos de los fundamentos que lo constituyen, para mostrar los elementos vivos y fecundos. En este marco, la analítica existencial, sus estructuras y los existenciales necesarios para su aprehensión se hallan en un campo de análisis anterior a toda descripción óntica del hombre en la psicología, antropología y biología, así como de cualquier perspectiva o disciplina regional que parta de un yo dado. En esta línea, también se propone evitar el punto de partida cartesiano de la conciencia, por medio de un direccionamiento de la pregunta ontológica, como un ámbito anterior y de mayor originariedad respecto a estos supuestos y perspectivas. A partir de aquí entendemos que la preeminencia de una analítica del Dasein se halla

existencial de la vida de cada Dasein .Por su parte, la Existencialität (existencialidad), remite al conjunto de estructuras que dan cuenta de la constitución ontológica del Dasein.

${ }^{101}$ Más aún, la comprensión del ser en general es condición de la comprensión que posee de su ser. Por ello, en relación a la significación tradicional de ontología, Heidegger especifica el ser-ontológico del Dasein, como pre-ontológico (SuZ: 12 s [35 s.]) 
motivada por una oposición con aquella preeminencia de tipo antropocéntrica y sustancialista, un imperativo que lleva a modalizar la tematización respectiva, tal como específica en este parágrafo:

“Toda idea de 'sujeto'-si no está depurada por una previa determinación ontológica fundamental-

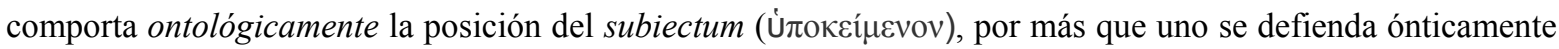
en la forma más enfática contra la 'sustancializacion del alma' o la 'cosificación de la conciencia'. La coseidad misma tiene que ser previamente aclarada en su procedencia ontológica, para que se pueda preguntar qué es lo que debe entenderse positivamente por el ser no cosificado del sujeto, del alma, de la conciencia, del espíritu y de la persona. (.......su empleo va siempre unido a una curiosa no necesidad de preguntar por el ser del ente así designado" (Ibíd.:46[71]).

En suma, Heidegger retoma el preguntar por el modo de ser del Dasein, en una modalidad que no fue explicitada en la antropología, psicología y biología: aquellos fundamentos ontológicos están en la base de toda investigación positiva pero no han sido puestos en cuestión ${ }^{102}$. Por estas razones que aluden, más que a un sesgo determinante o sustancial, a un carácter mediado y relacional, entiende que el Dasein debe ser interrogado con prioridad a todo otro ente. El cuestionamiento que propone es correlativo a la visualización de la existencialidad antes mencionada: sin agotar su análisis, el Dasein pone al descubierto algunas estructuras en sus modalidades de existir en el mundo.

A continuación, a partir del carácter proyectivo del Dasein, en el marco del programa heideggeriano de una ontología fundamental, analizaremos algunas de estas estructuras, no solo para dar cuenta de las totalizaciones y unidades que propone la analítica en esta indagación ontológica, sino también para delimitar el campo estructural que nos permita un abordaje e indagación de la cuestión de la mismidad e identidad del Dasein.

\footnotetext{
${ }^{102}$ En 1930 insiste en el abandono de todo tipo de antropología y toda subjetividad del hombre como sujeto, buscando la verdad del ser como el fundamento de la posición histórica fundamental. En esta lección distingue el ser-aquí como nuevo modo de plantear un punto de partida, aunque reconoce que la progresión del preguntar, en el marco de sus investigaciones, va marcando el camino de un pensar que experimenta como transformación de la relación con el ser. Con esto pone de manifiesto la transitoriedad de la analítica del Dasein y del método fenomenológico, en el marco de su camino de la pregunta por el ser. Véase, WW: 202[170 s.]
} 


\section{3.-b.- Estructuras que revelan su modo de ser.}

\section{3. b. I.- El Dasein como ser-en-el-mundo.}

Especialmente en sus elaboraciones en torno a $S u Z$, la analítica existencial expresa el ser del Dasein en estructuras cada vez más unitarias como la de ser-en-el-mundo (in-der-Welt-sein), entre otras. En efecto, hay una regresión analítica que va del ser-en a la temporeidad, en el marco del planteamiento de la pregunta del ser en general. Desde allí se revela que tal horizonte del tiempo es el que permite plantear una totalización adecuada del Dasein, en vistas a tal preguntar primario. El despliegue de la analítica descubre el siguiente orden (regresivo) de originariedad de estructuras: el ser-en-el-mundo, la disposición afectiva (Befindlichkeit), la comprensión (Verstehen), el cuidado (Sorge) y la temporeidad (Zeitlichkeit).

Asimismo, hemos visto que distingue respecto al Dasein , cuatro determinaciones de ser: a) como aquél que le va en su ser ese mismo ser (es geht um), es decir, que proyecta su ser y que correlativamente éste lo determina ;b) como aquél que mantiene una relación de ser con su ser (das Seinsverhältnis), involucrando su ser en la misma relación con él, cuya constitución estructural lo diferencia de los otros entes que no son como el Dasein ; c) aquél que se comprende en su ser (das Sich-verstehen) y sus posibilidades de ser; d) finalmente, como el que se encuentra en una apertura de ser (die Erschlossenheit), donde toda posibilidad, modalidad o comprensión está abierta en su $a h i^{103}$.

En el marco de estas determinaciones, el mundo se manifiesta constitutivo del ser-en-elmundo, es decir, perteneciente al Dasein como tal. Esta estructura le permite distinguir sus análisis de aquellos esquemas tradicionales que diferencian: sujeto y objeto; conciencia y ser; el ser como objeto del conocimiento; la conciencia como el "yo pienso" y la persona como centro de los actos, entre otros. Tales perspectivas son inherentes a la teoría moderna del conocimiento, impidiendo el acceso a la vida fáctica.

Al igual que en $S u Z$, encontramos en sus cursos de 1928-1929 la distinción de las estructuras originarias del trato con los entes, entre las que se encuentra lo que denomina como el ser-cabe

\footnotetext{
${ }^{103}$ En esta línea, puede sostenerse que en $S u Z$ se despliega una teoría de la iluminación del ser, por medio de la consideración del Dasein como sitial donde acontece la iluminación para abrir el sentido de la palabra ser, es decir, la forma en que el Dasein está en apertura por su contingencia asumida y su estructura de ser-en-el-mundo. No obstante en estos primeros trabajos de Heidegger, tal iluminación no depende de una voluntad sino que remite a un estado de apertura del mundo, donada por el ser y dada a la existencia del Dasein. Un intérprete destaca una ambigüedad en SuZ, respecto a su participación en dicha apertura, dando cuenta de un residuo subjetivista que se pone de manifiesto en ciertos análisis o conceptos desarrollados en esta obra, Véase Garrido Periñán (2014):214 s.
} 
$(\text { Sein-bei })^{104}$, en tanto estructura más originaria que el ocuparse de las $\operatorname{cosas}^{105}$ : refiere al entregarse a las cosas a-temáticamente, para que estas puedan mostrarse como son. En este contexto, menciona que el sujeto de la tradición es una mala subjetividad, al cual parece no pertenecerle esta estructura constitutiva.

Asimismo, la estructura del ser-en-el-mundo también se revela en sus análisis como ser-con (Mitsein), en el tomar a su cuidado o procurar (Fürsorge) a los otros y en el ser sí mismo en la forma del Uno (Man). Dejando la consideración de estas cuestiones relativas a la alteridad para capítulos posteriores, destaquemos que el análisis desde la facticidad del Dasein, da como resultado esta estructura entramada y originaria, que se evidencia afín no solo a su modalidad de análisis, sino también al punto de partida en la aprehensión del Dasein. Por medio de ella, Heidegger evidencia el constitutivo demorarse y cuidarse en lo en-torno del mundo del Dasein, además de un situarse a sí mismo junto con aquello en lo que se demora. Es precisamente en tal sentido y contra las imputaciones de Husserl, que sostiene que la ontología fundamental no es antropológica. En este contexto retoma sus críticas a la egología por partir de la conciencia, la cual supone el concepto tradicional de sujeto y prescinde de estas estructuras en su concepción de la conciencia intencional $^{106}$.

Como veremos, el fenómeno del cuidado desde el trato en el mundo circundante, en el marco de la estructura de ser-en-el-mundo, se manifiesta correlativo a la consideración y problematización del ser como el carácter distintivo del Dasein respecto al resto de los entes.

\section{3. b.II.- La originariedad ontológica del comprender, el cuidado y la temporeidad}

Con el análisis de aquella estructura, Heidegger también insiste en que la analítica del Dasein debe perseverar en su diferencia ontológica, al momento de analizar sus estructuras unitarias, aspecto que han descuidado una y otra vez aquellas perspectivas modernas. Parte de estas estructuras las destaca por su anterioridad ontológica: la compresión y la temporeidad, en su relación con el carácter unitario del cuidado.

\footnotetext{
${ }^{104}$ En sus trabajos de 1927 esta estructura se encuentra como parte constitutiva de la Sorge. Tal expresión designa el involucrarse y formar parte del mundo del Dasein, es decir, como el estar-en-medio-de. Ahora bien, en tanto parte de la estructura de la Sorge ( como anticiparse-a-sí-estando-ya-en-el-mundo en-medio-de ), Sein-bei expresa la tendencia del Dasein a la caída (Verfallen), con la cual queda cautivo del mundo entorno, olvidando su sí mismo propio. Véase , SuZ:54-6[80-2]

${ }^{105}$ Para un análisis respectivo y sus distinciones respecto al concepto moderno de sujeto, véase EP: 72-75[81-84].

${ }^{106}$ En este contexto, subraya respecto a la facticidad: "Husserl redujo a la esfera egológica como pura captación de cosas y datos, sin tomar referencias de la existencia” (Ibid.:140-41[152-53])
} 
Por una parte, hemos visto que Heidegger caracteriza al Dasein siempre delante de si, lanzado en y a un proyecto en su poder-ser. Al ocuparse de su propio poder ser, se proyecta en una posibilidad que se hace existente en el proyecto, develándose a sí mismo como poder-ser. Dicho proyecto se especifica en el modo en que es la posibilidad en el proyectarse ${ }^{107}$. Que el Dasein se ocupa de su ser implica un comprender no solo su ser, sino también el de los demás entes, pues es en medio de y con ellos.

Esta cuestión de la comprensión (Verstehen) es necesario distinguirla como fundamental: si la inesencialidad del proyectarse del Dasein cancela la nivelación de su ser con lo objetual o lo cósico, el carácter modal que se desprende de la comprensión del ser y de sí, va a determinar el propio proyectarse y encontrarse entre los entes, es decir, el modo de comprensión es correlativo al modo en que se proyecta fácticamente. En este sentido, también distingue el carácter preontológico de tal comprensión, pues su horizonte y dirección modaliza la manifestación histórica de las estructuras de cada Dasein fáctico: el cómo se articulan y determinan, se halla pre-orientado por la comprensión ya abierta. Por ello, Heidegger ve la necesidad de un análisis de la estructura total del Dasein, para que de allí se desprenda el sentido de esa comprensión del ser, la cual se encuentra situada histórica y temporalmente ${ }^{108}$.

En particular, este análisis de la comprensión se despliega también a partir del modo específico de ser del Dasein. En efecto, dar cuenta de tal estructura co-implica una remisión ni cósica ni objetal, al momento de desarrollar la aprehensión del Dasein como ente singular. Es por ello que, en este marco, el Dasein no puede remitir propiamente a un qué (en referencia a la constitución quiditativa, es decir, a la esencia de la cosa) sino a quién, con el carácter dinámico y abierto que ello implica ${ }^{109}$.

\footnotetext{
${ }^{107}$ En este contexto , sostiene que este es el modo en que el Dasein existe libremente (DGPh:395[335])

${ }^{108}$ De este modo, la comprensión en SuZ se encuentra ligada al proyectarse activo del Dasein. Lo cual, junto a su condición de arrojado (Geworfenheit), permite determinar al Dasein como proyecto arrojado (geworfener Enwurf), enfatizando así el carácter determinado de las posibilidades sobre las que se proyecta. Ahora bien, en sus trabajos y cursos previos a SuZ, va deslindando la concepción tradicional que liga dicho término con el ámbito cognoscitivoteorético, ligándolo a una habilidad o saber-hacer que entiende más primario que la diferenciación entre pensamiento y acción. Luego, insiste en destacar se apertura previa y originariedad. Específicamente, en sus lecciones de 1919 , introduce este término en relación con la intuición hermenéutica (hermeneutische Intuition), en tanto experiencia noreflexiva capaz de aprehender la vida en el carácter familiar en el que ya nos hallamos inmersos, previamente a toda conceptualización (BP:65-70,117[79-84,141s.]). En 1923, la comprensión se torna central terminológicamente, en su carácter de originariedad, pero aún no definitivamente ligado al carácter proyectivo del Dasein (OHF: 5-18[21-36). Posteriormente destaca su carácter previo y primario, a partir de un rastreo desde las elaboraciones de Aristóteles (LFW: 143-53[119-27]; GbaP: 207-12[243-7]). Ya en su seminario de 1927, desarrolla el existenciario originario del comprender en relación al poder-ser del Dasein (DGPh: 391-6,409-18[331-6]. Finalmente, en SuZ se consolida la relación entre la comprensión y la proyección sobre las posibilidades, en SuZ: 86 ss. , 143-53,262-7[112ss, 166-77,2816], y en relación a la temporalidad del comprender en SuZ: 337-40[354-6].

${ }_{109}$ Esta distinción es tomada directamente por Hannah Arendt en la articulación que realiza de la identidad en Arendt (1993):201-205.
} 
De esta manera, en lugar de estar constituido por una quididad (Wasgehalt), subraya que lo está por una quisidad (Werheit) (DGPh: 169[155 s.]), en relación a su singular carácter de ser proyectivo $^{110}$. Así, el concepto originario del comprender no se relaciona con un yo (más bien es inasible en tanto yo-objeto), sino que remite a un ser posible en el mundo, implicando el ámbito de posibilidades libres.

Por tales caracterizaciones, la estructura del comprender presenta diversos niveles de análisis, de tal modo que permitan poner de manifiesto estructuras fundamentales desde las cuales sea posible acceder a sus condiciones primarias, revelando sus respectivos niveles de originariedad : el poder-ser (en el proyectarse del Dasein); el ser-con (en sus vínculos constitutivos con los otros Dasein) y el trato con los entes (que impacta y orienta, en principio, en la comprensión de sí y de los otros entes). En los tres casos, nuestro autor subraya el carácter temporal de la comprensión ya abierta.

Específicamente: ¿cómo distingue Heidegger la apertura de la comprensión en tales niveles o estratos de análisis? En primer lugar, entiende que se comprende el ser en la medida en que es proyectado hacia algo: de un modo originario al ente queda proyectado hacia el ser y este último hacia "algo". Cada una de estas proyecciones se establece sobre una modalizacion de la comprensión. Ahora bien, este algo último de tal comprensión es pre-conceptual, sin un Logos: una comprensión preontológica del ser que tiene un carácter y estatuto temporal. En otras palabras, destacando el orden regresivo de mayor originariedad, podemos especificar estos estratos sucesivos que articulan el comprender y la temporeidad: a) la comprensión del ser se mueve en un horizonte de mundo (pues primeramente parte Heidegger del ser-en-el-mundo); b) mas originariamente descubre el comprender al cual proyectamos el ser; c) aún más originariamente, la temporeidad como condición primera de tales proyecciones y estructuras ${ }^{111}$.

Ahora bien, los diversos análisis sobre la temporeidad le permiten también dar cuenta de la modalidad específica de ser propia del Dasein., así como también acceder a totalizaciones en vistas a su programa ontológico.

\footnotetext{
${ }^{110}$ La cuestión de la quididad se enmarca en la distinción que realiza de las significaciones de ousia que subyacen en la comprensión moderna. En efecto, por un lado designa el ser presencial y por otro el ser-que, la quididad, aquello que hace de algo lo que es .Destaca que ambas significaciones están orientadas al tema del tiempo como duración constante ,es decir, en tanto presencia (Anwesenheit). A este respecto véase, MAgL: $183 \mathrm{~s}$. [170 s.]

111 Distinguimos aquí la temporeidad (Zeitlichkeit), como determinación del ser del Dasein por el tiempo y la temporalidad (Temporalität), en tanto determinación del ser mismo por el tiempo. En esta línea, diferenciamos algunos términos afines : temporal (zeitlich); temporalizar (zeitigen) o producir en el tiempo ; temporalización (Zeitigung) o proceso de despliegue-maduración de las dimensiones temporales que se distinguen en la temporeidad ( con sus respectivas modalizaciones : propia e impropia) ; temporáneo (temporal) y la temporalidad intramundana (Innerzeitigkeit), como determinación del tiempo del ente intramundano, sobre la cual que se funda el concepto vulgar y tradicional de tiempo.
} 
En efecto, en los fragmentos en que considera tal horizonte como estructura, retoma la cotidianidad como punto de partida para el análisis. Hemos visto que, la consideración de la temporeidad le permite encontrar un ámbito para totalizar las estructuras ontológicas del Dasein, en el marco de la pregunta por su ser especifico ${ }^{112}$. Tal análisis se revela como condición de posibilidad de la comprensión del ser.

Allí, destaca una tendencia histórica del Dasein de comprenderse a sí mismo como un ser meramente presente ahí-adelante (Vorhandensein), a partir de su trato cotidiano con los entes, comprensión que se proyecta al interpretar al tiempo del mismo modo, al cual conoce inicialmente como una serie de ahoras. Esta modalizacion es lo que denomina como concepto vulgar de tiempo.

Frente a ello, distingue que su carácter de arrojado lo conduce a tomar su presente concreto desde sus posibles, es decir, aceptando y asumiendo lo que era el Dasein en cada caso (arrojado, proyectivo, inesencial), puede ser propiamente futuro. Y solo así, puede ser propiamente pasado. Este singular modo de temporeidad del Dasein es lo que Heidegger pone de manifiesto distinguiéndola de aquel concepto vulgar: su proyectarse hacia el futuro modaliza su pasado (y de alguna manera, deriva de aquel). En este retorno a sí como futuro, donde se constituye a sí mismo como sido, emerge el presente. He aquí, entonces, la estructura de la temporeidad del Dasein, constituyente de su ser: el fenómeno unitario de futuro que haciendo presente va siendo y constituyendo su pasado. Y desde allí se concretiza su historicidad ${ }^{113}$. Por ello, la temporeidad e historicidad del Dasein tampoco se reducen a las situaciones históricas o individuos concretos, sino que, manteniéndolos en su campo semántico, también los supera en un tejido dinámico o unidad circular-relacional.

En este contexto, el sentido ontológico primario de la estructura del cuidado es el de la temporeidad, revelando así otro nexo fundamental del tiempo en relación con las estructuras del Dasein $^{114}$. En efecto, en la temporeidad del Dasein se fundan de modo unitario tres

\footnotetext{
${ }^{112}$ Ahora bien, el tratamiento de la temporeidad en la etapa preparatoria a SuZ, va manifestando progresivamente vinculaciones en tanto significado último de la facticidad y la vida, hacia el carácter especifico del tiempo en relación al Dasein. Las elaboraciones históricas de este término como necesidad de tomar conciencia de la dimensión históricotemporal de la vida fáctica en las comunidades anteriores al cristianismo, puede encontrarse en PRL:31-54[63-83]; entre las primeras elaboraciones que desarrollan la temporeidad especifica del Dasein, destacamos : OHF:101ss[128ss];su tratamiento desde el horizonte de la muerte, manifiesta los primeros desarrollos en BZ:93 ss.[119ss.]. Luego, los desarrollos empiezan a ceñirse sobre el ser del Dasein, en EPhF: 282 ss. [279ss.], entre otros. Finalmente, en 1927 se desarrolla la concepción de la temporeidad como sentido ontológico del cuidado, así como también su relación con el comprender (SuZ: 302-50[321-66]).

${ }^{113}$ Véase, SuZ: 325 ss. [342 ss.]

${ }^{114}$ Las elaboraciones sobre el cuidado, encuentra los primeros esbozos en el tratamiento que realiza en 1920-21 a propósito del pensamiento de San Agustín y las epístolas paulinas, en relación a modos de comportamiento que prefiguran sus consideraciones posteriores sobre la propiedad e impropiedad (PRL:68 ss.[97ss.]), que luego desarrolla respecto al Dasein en LFW:220-43[178-96]. En 1923-4, destaca la dimensión práctica de la relación con el mundo en torno. (EPhF: 58 ss.; 105-119,277-91[72ss., 112-26,275-86]). La consolidación del cuidado como estructura ontológica
} 
determinaciones constitutivas del cuidado: la facticidad (Faktizität), la existencialidad (Existenzialität) y la caída (Verfallen ${ }^{115}$. Esto se debe a que cada uno de estos momentos estructurales remiten correlativamente a una dimensión de la temporeidad: a) al pasado, pues la facticidad da cuenta de la condición de arrojado (Geworfenheit) en un mundo con posibilidades y significaciones determinadas; b) al futuro, en lo que respecta al poder-ser o capacidad proyectiva a la que remite la existencialidad y c) al presente, en el marco de la caída en la cotidianidad como condición de partida ineludible ${ }^{116}$. Por ello, la temporeidad también se revela en su sentido unitario $\mathrm{y}$ anterior respecto del cuidado.

Aún así, desde esta búsqueda de totalizaciones ontológicas, Heidegger insiste que el esclarecimiento del Dasein en relación a la comprensión, la temporeidad y el fenómeno del cuidado, en vistas de la diferencia ontológica, solo prepara el suelo para pensar la pregunta por el ser en general. No obstante, este programa de una ontología fundamental no prosperó después de 1927, al no elaborar la tercera parte estipulada de SuZ. En parte, ello se debe a que nuestro autor se topa con la imposibilidad de poder pensar y articular adecuadamente la temporalidad del ser, desde el horizonte de la temporeidad del Dasein. Como veremos en los próximos capítulos, esta tensión y límite lo conducen a un giro de perspectiva que va desde esta consideración de la temporeidad extático-horizontal, hacia la temporalidad epocal del ser en su emergencia como acontecimiento (Ereignis).

Para terminar, con el objeto de argumentar en relación a las hipótesis e interpretaciones con las que iniciamos este capítulo, clarificando y sistematizando los resultados del recorrido, dedicaremos el próximo apartado a una recapitulación respectiva.

\section{4.- La comprensión heideggeriana del Dasein y su significación: ¿continuidad, ruptura o transición con la modernidad?}

La significación y comprensión del Dasein en esta época del pensamiento de Heidegger parte de un modo singular de retomar la tradición de lenguaje y pensamiento en la que está inscripto. La destrucción fenomenológica que realiza de conceptos y categorías modernas, como el

fundamental del Dasein se cristaliza en SuZ: 191-206[212-27], en relación a la temporeidad como sentido ontológico del cuidado, SuZ: 302-34[321-50], entre otras.

${ }^{115}$ Tal y como son articulados en la definición formal del cuidado en Ibíd.: 192 s. [214 s.].Por otra parte, recordemos que Heidegger distingue entre el ocuparse de los entes en el mundo circundante (Besorge) y el cuidado de los otros en el modo propio de la solicitud (Fürsorge).

${ }^{116}$ Como veremos, esta temporeidad se realiza escuchando la voz de la conciencia (modalidad propia) o manteniéndose en el Uno en su carácter impersonal (modalidad impropia). 
caso de hombre o sujeto, da cuenta del estilo propio de Heidegger en su relación con el campo conceptual heredado, lo cual supone previamente un desplazamiento de sentido y comprensión ontológica.

En efecto, la modalidad con la que propone una transición respecto a la perspectiva moderna reside en una revisión de la comprensión subyacente a los términos utilizados en el horizonte de la pregunta por el ser. Las conexiones no tematizadas con el ser como presencia, que se remontan a la consideración de la ousía en la Grecia clásica, colocan bajo la misma corriente comprensiva a Descartes, Kant, Hegel y al mismo Husserl. Este último, aunque partiendo apropiadamente desde el concepto de intencionalidad, parece no lograr sortear los escollos del subjetivismo con los que se topa, por articulaciones lingüísticas no suficientemente tematizadas y por las modalizaciones respectivas del pensamiento. El carácter cósico que impregna el uso categorial en la tematización de la existencia humana, así como la consideración trascendental, universal y aislada de la conciencia, develan las exigencias proyectadas desde un horizonte de cientificidad, que de algún modo obstruyen la pregunta por el ser del ente, sobre el cual y desde el cual despliegan sus análisis y elaboraciones.

La reelaboración del método fenomenológico que realiza es una de las razones por las que se orienta con las exigencias de no manipulación y tergiversación de conceptos y términos aplicables a la analítica de la existencia. La especificación de existenciales y la distinción ontológica y estructural del Dasein le permiten un desplazamiento respecto de aquellas significaciones y cargas semánticas. Precisamente en la línea de esta reelaboración que incluye, por un lado , su reconsideración del concepto de fenómeno y de aquello oculto/olvidado en el suelo del pensar, así como también, por otra parte, la preeminencia del Dasein en tanto tematización necesaria en la marcha a la pregunta por el ser en general, le permiten dar cuenta de estructuras unitarias y con niveles cada vez más amplios de originariedad, en el marco de una comprensión que da cuenta de horizontes no clausurables, como en el caso de su consideración de la temporeidad que remite a una totalización dinámica y no cerrada, correlativa al Dasein en su determinación como poder-ser.

Así, debido a que estas estructuras se develan en la analítica y que remiten, en última instancia, a una ampliación del circulo de la comprensión respecto al de la tradición y a especificar la diferencia ontológica respecto al ente subsistente, en lugar de unidades y totalidades primeras, denotan más bien estructuras ontológicas que pueden dar cuenta con mayor propiedad de la variabilidad óntica del Dasein, en su condición fáctica e histórica. Específicamente, evidencian un entramado correlativo y co-originario que incluye, entre otros: el carácter fáctico, situacional e histórico del ente existente; su comprensión del ser, de los entes, de los otros Dasein y de sí mismo; su carácter proyectivo; su remisión constitutiva y constituyente en el trato con los entes, etc. En 
suma, estructuras que se apartan de aquellas concepciones tradicionales que comprenden al sujeto o al hombre de modo primario e independiente respecto al entorno, o bien de las que parten de enfoques modernos universales y centralistas, especialmente a partir de las elaboraciones de Descartes.

En este contexto, Gadamer interpreta que cuando Heidegger se refirió en esta época al Dasein no se trataba solo de poner una palabra nueva de una fuerza nominadora más elemental en el lugar de la subjetividad, la autoconciencia y el ego trascendental. Entiende que al elevar al rango de concepto el horizonte temporal del existente humano, que se sabe como finito y que tiene la certeza de su fin, sobrepasó la comprensión del ser subyacente en la metafísica griega y de los conceptos conductores de la moderna filosofía de la conciencia. No obstante, sostiene que su estructura de exposición aun sigue dentro del pensamiento de fundamentación trascendental que Husserl compartía con el neokantismo ${ }^{117}$.

En esta misma línea interpretamos que la propuesta de Heidegger se encuentra imposibilitada de un radical desprendimiento de la articulación moderna. Ello deriva en una dinamización creciente de su discursividad, para hacer frente a los obstáculos emergentes en sus recorridos del pensar. Específicamente, la modalización que realiza de las articulaciones modernas, a partir de una comprensión de ser adecuada al Dasein, debe elaborarla siempre en y desde la misma cadena de significaciones en la que se inserta: sea por oposición semántica, desplazamiento o transformación. En general, entendemos que esta es una de las condiciones fundamentales de todo pensamiento y del uso del lenguaje, siempre sedimentado y circunscripto socio-históricamente, lo cual torna ineludible compartir una base semántico-conceptual, con sus respectivas orientaciones al momento de traducir expresiones de un contexto semántico anterior al nuevo, como en este caso: parte de la significación del Dasein que elabora nuestro autor, se halla ligada al campo del término sujeto.

Sin embargo, el campo conceptual y los significados que Heidegger se propone superar se muestran condicionantes para sus análisis y su programa general, tal y como lo evidencian algunas de las tensiones a las que nos hemos referido .Es decir, tales significados presentan obstáculos para sus intentos de superar las limitaciones teórico-comprensivas de un pensamiento que se muestra caduco. Y estas rémoras solo se tornan tangibles en el despliegue discursivo de sus elaboraciones.

Como vimos, esto impacta en sus análisis desde varios frentes: por un lado, su pensamiento se halla en una situación delimitada por los interlocutores con los que discute y sus articulaciones lingüísticas. Las temáticas abordadas, los giros y torsiones posibles se encuentran en parte pre-

\footnotetext{
${ }^{117}$ Véase Gadamer (2002): 111-114.
} 
determinadas por el campo en el que está circunscripto. En este contexto, distinguimos que las posibles modalizaciones y desplazamientos que propone en la significación y analítica del Dasein, desde otra base comprensiva y sentido ontológico, se encuentran con un conjunto de obstáculos que inhiben toda pretensión de ruptura o superación radical y definitiva. Estas limitaciones revelan para nuestro autor la necesidad de modificar el enfoque de su recorrido.

En este marco interpretativo, Carrera Aizpitarte especifica que, en aquella etapa de su pensamiento, el Dasein aun conserva el carácter de fundamento, como el ente que debe ser interrogado por la pregunta por el ser. En este sentido, conserva notas de la noción de sujeto, donde el individuo humano es aun comprendido como aquel que sigue siendo responsable de la elaboración del sentido $^{118}$. En la misma línea, Jean Luc Marion interpreta que la analítica del Dasein no alcanza para suceder al sujeto de la metafísica puesto que aún se hallan vigentes las figuras del polo yo y de la reflexividad de la auto-fundamentación del sujeto trascendental ${ }^{119}$.

De este modo, el marco conceptual y el contexto de discusión del programa de investigación de aquél período, dan cuenta de limitaciones en el pensar y las elaboraciones respectivas. Asimismo, nuestro autor se topa con dificultades para expresar o circunscribir determinadas cuestiones, lo cual complica más aún tales desarrollos, aspecto que él mismo advierte al sostener que el abandono de la continuación del proyecto de $S u Z$ se debe a una insuficiencia del lenguaje, condicionado y dificultado por el lenguaje de la metafísica tradicional ${ }^{120}$. Es por ello que insiste en una tentativa para una transición, cuyo margen posible, inicialmente se encuentra circunscripta a la articulación de lenguaje en la que se inscribe. Sin embargo, no pierde de vista la disyunción de fondo, al suelo olvidado y no tematizado del ser, que fue tergiversado, oculto y olvidado en las diversas derivas del pensar, desde donde replanteará las teorías del fundamento, como veremos en próximos capítulos.

Es en aquél contexto que entendemos la influencia de estas articulaciones no solo en las conceptualizaciones y estructuras que propone Heidegger en esta etapa, sino también con la modalizacion del pensamiento respectivo. En efecto, en el tramo de su pensar que llega hasta $S u Z$ y sus cursos sucesivos, la consideración del Dasein se presenta como un medio para la pregunta por el ser en general, pero sin evitar la tematización primaria en el pensar que caracterizó los recorridos

\footnotetext{
${ }^{118}$ Véase Carrera Aizpitarte L. (2014): 14 ss. En contraste con el período siguiente de su pensar, agrega que en el segundo Heidegger la pregunta por el ser no requiere aclarar estructuras existenciales del Dasein: el ser se dirige al hombre en el espacio del habla., reservado solo para poetas, donde el ser dirige la palabra a unos pocos individuos capaces de escucharlo. Entendemos que este sesgo selectivo responde a una matriz de lenguaje y pensamiento, cuestión que desarrollaremos detenidamente en el capítulo 7.

${ }^{119} \mathrm{La}$ hipótesis que sostiene es que la analítica del Dasein no implica una sucesión del sujeto de la modernidad sino su último heredero, es decir, tan solo logra señalar una vía para el abandono de tal comprensión. Véase, Marion (1990):91 S.

${ }^{120}$ Véase, BH: 327 s.; $343[269$ s.; 282].
} 
de Descartes y Husserl, entre otros. Si bien nuestro autor cambia la modalidad de dicha (pre) eminencia, conserva notas fundamentales de la herencia moderna con la que discute: por allí se empieza y desde allí se elaboran las significaciones y los desplazamientos del pensar. Su programa de una ontología fundamental, que comienza con la analítica del Dasein, se manifiesta como una versión hermenéutica de la pregunta moderna por el sujeto, llevándolo a toparse con diversos escollos.

El ímpetu de los análisis de Heidegger lo conducirán progresivamente al abandono de este lugar de fundamento del Dasein hacia una segunda etapa que, como veremos, destaca una singular dinámica de actividad-pasividad, en el marco de la co-pertenencia con el ser. En tales elaboraciones, más afines a la orientación griega que comenzó por la pregunta por el ser y luego por el hombre (incluido en un modo de darse el ser), la problemática del ser desplazará la analítica del Dasein como temática primaria, intentando desprenderse de los sedimentos conceptualeslingüísticos-comprensivos de la tradición, que obstaculizan su recorrido del pensar.

Sin perder de vista que el estilo de su pensar mantiene una continuidad con movimientos jerárquicos y centralistas del pensar moderno (por medio de preeminencias, anterioridades, condiciones, articulaciones conceptuales cristalizadas, etc.) , destacamos que la estrategia conceptual que empezó a esbozar en $S u Z$ y sus cursos inmediatamente posteriores, fue vincular al Dasein términos que logren connotar procesos y movimientos, más afines al carácter de poder-ser en el horizonte de la temporeidad, que al ámbito categorial de lo cósico, demostrando con ello que no podría desplegar su potencialidad propia si no estableciera también giros y desplazamientos en la propia articulación conceptual y significativa de lo que se expone. En este sentido, la tensión y doble dimensión en estas elaboraciones se manifiestan como irrebasables, al momento de presentar este vaivén significante y comprensivo (que busca desplazar el eje de la discusión y la argumentación) como una transición respecto a la conceptualización moderna.

De todos modos, nuestras interpretaciones rechazan todo posicionamiento crítico frente a estas tensiones que suponga la posibilidad de una modalidad de aprehensión o significación plena, que lograse un rompimiento radical y definitivo. Frente a ello, insistimos en el carácter no solo ineludible sino también irrebasable de estas tensiones en la superficie del lenguaje, puesto que suponer lo contrario, como veremos, implicaría la supresión de toda alteridad en el lenguaje (de la cual son figuras los conceptos de la tradición, los campos semánticos de discusión, entre otros).

Por otra parte, entendemos relevante enfocarnos en un intento por proyectar los resultados de las elaboraciones de nuestro autor, en las propias modalidades de lectura e interpretación de su obra, pues ello no solo supone un despliegue y desarrollo de tales resultados, sino también implica la posibilidad de una experiencia aprehensiva desde ellos. 
En suma, el carácter no-esencial, complejo, dinámico de la significación del Dasein en la comprensión heideggeriana, en su multiple dimensionalidad, manifiesta simetrías con la modalidad del lenguaje con el que se propone aprehenderlo (significaciones no clausurables, dinámicas, etc.).

En este contexto, las elaboraciones respecto a las modalidades de relación con el sí mismo del Dasein, ofrecen mayores muestras de tales simetrías, al tiempo que revelan nuevos obstáculos en su recorrido. Entendemos que tales cuestiones son relevantes para entender las tensiones dentro del concepto heideggeriano de Dasein pues, al desplegar sus análisis en torno a la mismidad e ipseidad, se especifican nuevos puntos en tensión y condicionamientos derivados del campo conceptual de partida. Por ello, en el marco de las reelaboraciones en la significación del término Dasein, tales desarrollos se revelan como uno de los principales motivos para los giros y cambios de enfoque en su programa de investigación posterior a 1930. Para argumentar interpretaciones en este marco, proponemos un abordaje respectivo en aquella etapa temprana de su pensamiento.

“ ¡Por Dios santo! ¿Quién dispone de todo ese tiempo?'. Hans Castorp rió tranquila y brevemente, alzando la cabeza hacia las estrellas. ;Ah, el tiempo! Antes de opinar sobre este punto en concreto, sobre el tiempo humano, James debería comenzar por revisar los conceptos que había traído consigo de allá abajo."

(Thomas Mann, La montaña mágica) 


\section{Capitulo 3 .Retorno y comprensión de sí: análisis y articulaciones respecto a la ipseidad.}

En el presente capitulo abordaremos, en una primera etapa de discusión, la mismidad del Dasein y algunas relaciones con los otros, en una articulación posible con las consideraciones del lenguaje. Hemos visto que Heidegger escribe $S u Z$ intentando el abandono y superación de la metafísica de la subjetividad y sus categorías, teniendo en cuenta que si bien Husserl y Scheler, entre otros, se resistían al uso de categorías objetivantes para referirse al yo y a sus actos, de todos modos seguían aferrados a la ontología tradicional y, en especial, a los fundamentos cartesianos.

Así, nuestro autor desarrolla una ontología fundamental del Dasein subrayando que el modo de ser del existente humano es distinto al de todo otro ente y, por ello, aquél tiene la posibilidad de una constitución trascendental. Si bien en este primer período Heidegger aun se muestra condicionado por el lenguaje de la metafísica de la subjetividad, irá progresivamente liberándose de sus restricciones en el denominado giro (Kehre) de su pensamiento, donde abandona las resonancias semánticas del sujeto como el centro de la representación del ente (en el sentido de lo objetivo) para considerar al hombre como el pastor del ser. Específicamente ¿cómo aborda la cuestión del sí mismo del Dasein en esta etapa? A continuación desarrollaremos estas consideraciones en articulación con nuestro recorrido.

En efecto, en capítulos anteriores subrayamos que en la resignificación del Dasein, Heidegger pone en primer plano una estructura interrelacionada donde originariamente el Dasein es tanto su apertura al mundo, los entes, a los demás, como también a sí mismo y al ser, comprendiendo así el complejo de totalidad simultánea que le es constitutivo. En sus modos de comprender (Verstehen), se autorremite a sí en relación con su estar-en-el-mundo y en su proyecto puede significar en relación a un todo de significatividad. Ahora bien, una remisión primaria a sí mismo desde tal estructura conlleva necesariamente notas y modalidades propias de las relaciones con las cosas del entorno y con los otros Dasein, pues no puede fundamentarse en un polo-yo dado o recuperado.

La dinámica inherente a esta estructura se pone de manifiesto en la investigación fenomenológica de la identidad y mismidad del Dasein, sobre el trasfondo de su indagación ontológica. Por medio de su análisis fenomenológico, Heidegger se posiciona frente a la concepción 
moderna del yo como subiectum (caracterizada por un yo que se mantiene igual en medio de la multiplicidad de las vivencias) que vincula con la mismidad (Selbigkeit) de un modo inauténtico, estableciendo una perspectiva que no permite dar cuenta de la ipseidad (Selbstheit) de sí mismo, en tanto carácter proyectivo y dinámico de remisión a sí mismo.

Como solo podemos acceder al Dasein que somos en cada caso (Jemeinigkeit) existiendo fácticamente, podemos dar cuenta de una estabilidad o mantenimiento de sí mismo (Selbständigkeit) en su propia temporalidad que incluye tal carácter proyectivo. Esta estabilidad de sí como fundamento diferente de la mismidad idéntica- sustancial en la perspectiva moderna, es el referente para la ipseidad en SuZ.

En el desarrollo de este capítulo analizaremos estas elaboraciones de Heidegger en sus primeras producciones, atendiendo las consideraciones de la mismidad en el marco de la cotidianidad fáctica del Dasein, en sus primarias relaciones con los otros. Además de describir estructuras, vínculos y modalidades en que se manifiesta el autoremisión del Dasein, retomando la multiplicidad inherente a su estructura de ser-en-el-mundo, proponemos dar cuenta de algunas tensiones y problematizaciones que no solo se articulan con nuestras hipótesis, sino también se insertan en algunas discusiones actuales y proyecciones posteriores de su obra. Por ello, nuestro recorrido se orienta a partir de las siguientes interrogaciones:

- ¿Cuáles son las condiciones de posibilidad para los desplazamientos del Dasein en relación a la comprensión del ser, de sí mismo y de los otros Dasein, en el pensamiento de Heidegger de este período?

- ¿En qué consisten tales desplazamientos en vistas a la significación dinámica del Dasein?

- ¿Qué consecuencias pueden extraerse de ello para continuar circunscribiendo su concepción ontológica del Dasein?

- ¿En el tratamiento y desarrollo de la mismidad hasta $S u Z$ está involucrado el lenguaje? ¿En qué medida?

- ¿Qué relaciones pueden establecerse respecto al lenguaje y comprensión heredado?

Estas problematizaciones son coextensivas a nuestras hipótesis que se inscriben en los tres ejes principales de las discusiones expuestas: ipseidad, alteridad y lenguaje. A saber: 
a) Es posible circunscribir con claridad los elementos de una perspectiva del lenguaje vinculados con una teoría de la ipseidad, en la obra de Heidegger. En tales articulaciones, reconocemos la distinción de planos ontológicos originarios, como un criterio regulador para las modificaciones posibles en la comprensión de sí. En efecto, en sus primeros trabajos, la relación del Dasein con el sí-mismo y con el mundo, se abre a partir de la comprensión de los nexos de significación que articulan la facticidad. Entendemos que aquella distinción supone pliegues, intersticios, tensiones y fallas en tal entramado primario de articulación. Esto es correlativo a un enfoque sobre el lenguaje que rechaza implícitamente la consideración de un campo semántico susceptible de plenificación, trascendental o clausurable.

Pues bien, sostenemos que esta perspectiva con su criterio regulador, es condición de posibilidad para el pliegue de la ipseidad en su modo auténtico, así como también para la producción de distorsiones /modificaciones del sentido y de las comprensión histórica del ser. Tales caracterizaciones y supuestos se mantienen tanto en el desarrollo de su pensamiento posterior a la época de SuZ, como en la matriz de su propio estilo filosófico-discursivo.

b) Partiendo de las consideraciones de la comprensión del ser en la estructura del Dasein y de su carácter ante-predicativo, consideramos que el ámbito del lenguaje, la mediación discursiva y la interpretación son elementos para un escenario apropiado (e históricamente limitado) desde el cual poder desplegar la asunción de la propia mismidad, razón por la cual no es posible comprenderla como alternativa entre opuestos, sino como una dinámica variable, manifestándose así correlativa a la significación y comprensión del Dasein.

c) En tercer lugar sostenemos que también aquí es probable distinguir una tensión sostenida ( e irrebasable ) en su intento de transición o superación de la metafísica del sujeto, en este tramo de su análisis de la ipseidad: I) en el campo semántico , respecto a la significación del Dasein ,así como también en la consideración opuesta del significar y las significaciones en el das Man (rígidas e inflexibles) y en el Dasein propio (contingentes, no clausurables ni plenas); II) en su elaboración teórica, enfoque y articulación discursiva , respecto al ámbito para retorno a sí y a la dinámica del uno-mismo (en su posible pliegue como si-mismo), el cual debe evitar recaer en comprensiones sustancialistas o cósicas del ser entendido como presencia.

Con estas consideraciones de partida, proponemos entonces un recorrido por estas elaboraciones sobre la mismidad. En una primera parte, nos detendremos en los respectivos análisis en sus primeros trabajos (entre 1923 y 1925), atendiendo su particular tratamiento del Dasein en su 
cotidianidad, a partir de la distinción que reconoce entre el uno-mismo y el sí-mismo. Luego, buscaremos abordar los elementos de su análisis que remiten al lenguaje y la comprensión en tales consideraciones. A continuación, estableceremos un recorrido por las elaboraciones respectivas en SuZ, caracterizando especialmente el concepto de ipseidad y el sí-mismo en sus condiciones de posibilidad de pliegue, con el objeto de atender diferencias y continuidades con sus primeros tratamientos. En ambos desarrollos, buscaremos dar cuenta de tensiones y ambigüedades respecto a las elaboraciones metafísicas y su lenguaje. Finalmente, retomaremos nuestras problematizaciones iniciales para dar cuenta de paralelos y relaciones entre estos análisis sobre la mismidad del Dasein y las articulaciones discursivas de Heidegger, que inicialmente nos ofrecerán un marco para la cuestión de la alteridad, la cual abordaremos con mayor precisión en el capítulo siguiente.

\section{1.- Abordajes tempranos de la mismidad: hacia un pliegue del uno-mismo y sus significaciones.}

\section{1. a La experiencia de auto-remisión y la facticidad.}

En sus primeros trabajos de la década de 1920, previos a sus elaboraciones de SuZ, encontramos abordajes donde destaca la primacía del carácter situacional y fáctico del Dasein para la consideración tanto de la mismidad (Selbstheit) como de los fenómenos existenciales en general, así como también ciertas distinciones, que entendemos parte de un programa que se propone evitar retomar las comprensiones implícitas en la metafísica del sujeto de la tradición. En este marco, las elaboraciones en torno a la mismidad e ipseidad se manifiestan como un umbral en tensión con las perspectivas de las que busca diferenciarse, el cual irá desplazándose hacia 1927, aunque sin superación.

En efecto, para sortear escollos de un polo-yo como punto de partida, en cursos de esta época considera la cuestión del cumplimiento activo del soy ${ }^{121}$, en su carácter proyectivo, donde el ser del sí-mismo remite a la experiencia en la que me encuentro a mi mismo como tal, al vivirla, y,

\footnotetext{
${ }^{121}$ La escritura en itálica que Heidegger utiliza en cursos y escritos remite a referencias de tipo lingüísticas, es decir, toma la articulación lingüística cotidiana de palabras o expresiones para luego dar cuenta de estructuras, fenómenos, condiciones de posibilidad, etc., en relación a ellas. En el presente trabajo mantendremos esta modalidad de escritura y análisis.
} 
de acuerdo con el sentido de tal vivenciar, en una segunda instancia puedo preguntar el sentido de mi yo soy. La extrañeza del yo respecto a regiones concretas anuncia que toda pretendida determinación regional o anticipación que se aferra a una conexión de vivencias, anula el sentido del soy y convierte al yo en un objeto constatable y clasificable de acuerdo con su posición presente. De esta manera pre-elabora el carácter del sentido proyectivo y dinámico del sí-mismo, en modo correlativo con la significación dinámica del Dasein, frente a toda anticipación regionalmente objetivadora y contra las conexiones conceptuales que de allí surgen.

Frente a tal presentificación, el yo es entendido en su sí-mismo en tanto históricamente fáctico, siempre desde una precomprensión del ser, de modo tal que cuando el yo soy puede ser particularizado como un él o ella es decir, en su diferencia de género, ya se está designando a tal existencia como un sentido o cómo del ser lo cual, como hemos visto en el capítulo anterior, puede indicar múltiples modalidades (en el sentido de estar presente, etc.) ${ }^{122}$. Por ello, entiende que el sentido del soy tiene que ser experimentado en una auténtica apropiación, en la plena concreción fáctica del yo y volver a apuntar hacia ella desde una modalidad determinada.

De este modo, lo decisivo en la experiencia de autoremisión relativa al yo es la facticidad, fenómeno esencialmente histórico de acuerdo con el cómo de su cumplimiento activo propio, es decir, se cumple históricamente y se experimenta de este modo a sí mismo ${ }^{123}$. Entendemos que esto se halla en correlación con una comprensión móvil de las significaciones y conceptualizaciones que aprehenden este fenómeno, puesto que Heidegger se empeña en utilizar términos con significaciones no clausurables y dinámicas, o conceptos en tensión respecto a su campo semántico, dando cuenta así de un paralelo entre la consideración de la mismidad y las cuestiones del lenguaje, como puede observarse en este fragmento donde destaca aquella primacía del carácter situacional:

"Puesto que hoy día no vemos propiamente los fenómenos existenciales, tampoco experimentamos el sentido de conciencia y responsabilidad que reside dentro de lo histórico mismo y que no es solo algo de lo que tenemos conocimiento y sobre lo que hay libros, sino que es lo que nosotros mismos somos y lo que nos

\footnotetext{
${ }^{122}$ Aquí destacamos el carácter derivado del género y la corporalidad, respecto a la facticidad y la comprensión del ser, que entendemos como paso necesario en elaboraciones que proponen tensar al límite la herencia conceptual y comprensiva de la tradición metafísica. Retomaremos en el capitulo siguiente sus desarrollos de la cuestión de la corporeidad y la sexualidad en este sentido.

${ }^{123}$ A partir de este carácter fáctico e histórico de la mismidad del Dasein se encuadra una singular recepción argentina de Heidegger, en un énfasis puesto en la inculturación: nos referimos a Rodolfo Kusch. Este autor, por la vía de una fenomenología de la cultura, articulo el ser-en-el-mundo en su carácter latinoamericano, enfatizando la consideración del estar. Sostiene que Heidegger, al no disponer de la diferencia de la lengua castellana entre el ser y el estar, protoontologiza el ahí cuando concibe como ser al ser-ahí (Dasein). Frente a ello, este autor reconoce en el estar-siendo, además de una estructura existencial, una decisión cultural latinoamericana. En este sentido, ve surgir en determinadas expresiones indígenas la categoría de aquel estar aquí que define una modalizacion de lo humano en América , contrapuesta al ser alguien tipificado en la comprensión y pensamiento europeo contemporáneo .Véase , Kusch (1975) :97 ss. ; y especialmente, Kusch (1973):575-9.En el capitulo 8, retomaremos esta vía de interpretación y recepción de Heidegger en nuestra región.
} 
soporta. Por eso, también los motivos para volver a lo histórico a través de la propia historia se hallan sin vida y escondidos" (...) "es lo que hace entender que el Mismo, en relación con su sentido del ser, sea fácilmente experimentado en una significación objetivada (la personalidad, la idea de humanidad) y que en semejante orientación de la experiencia llegue a ser captado teóricamente y alcance un significado filosófico...” (AJPW: $33-4[39])$.

Con los supuestos de una concepción no clausurable y no objetivante del lenguaje, articulada en simultáneo con el carácter proyectivo del sí-mismo del Dasein, destaca aquí una tendencia a la cristalización de las significaciones, la cual es un movimiento propio de la existencia cotidiana que experimenta el entorno como cósico y acabado, condensándolo luego atemáticamente en conceptos y significaciones. Precisamente desde esa cotidianidad de significaciones Heidegger modaliza, por oposición, sus elaboraciones y articulaciones ${ }^{124}$. Interpretamos que esta operación en el discurso de nuestro autor manifiesta también una figuración o transferencia semántico-discursiva de sus respectivas consideraciones del Uno (das Man), lo cual desarrolla sucesivamente a partir de los análisis fenomenológicos de la cotidianidad y facticidad del Dasein. Abordemos tales consideraciones.

\section{1. b. El uno-mismo y su encubrimiento en las interpretaciones de su época.}

En sus primeros tratamientos respectivos, toma un punto de partida que se repetirá en toda analítica del Dasein que realice posteriormente: una hermenéutica de la cotidianidad que aborda primariamente el Uno, en tanto estructura existentiva primaria del Dasein. Como primer acceso ontológico de la facticidad del Dasein, busca convertir estos análisis en conceptos y existenciarios, de modo tal que pueda dar cuenta de estructuras ontológicas y modalizaciones más que destacar variaciones, casos o fenómenos no relevantes para la ontología fundamental que propone.

Como vimos, la superficie desde donde aborda tales consideraciones es el lenguaje de la tradición que se inscriben en la comprensión subyacente en las disciplinas de su época, desde lo cual Heidegger modaliza su propia perspectiva. Tal es el caso, por ejemplo, de lo ya interpretado (Ausgelegtheit) y público que se revela en la conciencia histórica y la filosofía : contra una

\footnotetext{
124 En este sentido, Theunissen entiende que Heidegger parte de la caracterización de la cotidianidad del Uno, considerando malformaciones de la vida (missgeltatenes Leben) para reelaborar desde allí, por oposición, un conjunto de formaciones positivas de la vida. Para un análisis de esta interpretación, en comparación respecto a la obra de Kierkegaard, véase Theunissen (1993):47 ss.
} 
perspectiva tradicional de la filosofía que tipifica, ordena y clasifica en vistas a un orden como proceso universal parte, por ejemplo, de un análisis fenomenológico de la curiosidad (Neugier) en ambas disciplinas, lo que le permite dar cuenta del existir en su peculiar movilidad, anticipando con ello sus análisis posteriores del fenómeno fundamental del cuidado (Sorge), del cual aquél seria una de sus modalidades de manifestación.

Tal estructura ontológica en el trato con las meras cosas, se orienta a un conjunto de remisiones, a los otros, y al sí mismo del Dasein. A modo de contrabalanceo de tal fenómeno, y con el objeto de evidenciarlo con precisión, realiza allí un análisis de lo inhabitual (ungewöhnlich), en referencia a experiencias que despiertan el hábito de su indistinción (OHF: $100 \mathrm{~s}$ [127 s]). Con esto pone de manifiesto el carácter del aquí, que se destaca de la indistinción de lo sobreentendido del habito, al tiempo que nos permite nuevamente distinguir en su metodología de exposición el recurso relacional al límite o al opuesto en tensión, como tentativa para esquivar los análisis de fenómenos o procesos a partir de una fundamentación por y en sí mismos, lo cual es propio de la discursividad y comprensión de la tradición metafísica.

Ahora bien, en estos análisis de lo ya interpretado y público de su actualidad, ontológicamente se manifiesta el Uno, en el marco de una temporalidad común con los demás Dasein. Esta actualidad como modo de la facticidad cotidiana revela algunas características: la publicidad (Offentlichkeit), como estructura que caracteriza el ser del Uno, donde el existir cotidiano se mueve en el marco de las habladurías (das Gerede), lo cual designa el modo respectivo de hablar de sí mismo. Específicamente, ello remite a un decir sin fundamento, que es retomado, se propaga y adquiere consistencia solo por el hecho de que se dice. En tal decir, se desplaza el énfasis en la referencia al ente, hacia lo hablado en sí mismo (aquel queda invisibilizado detrás de la centralidad que toma el mero hablar). En este marco, Heidegger distingue una precomprensión de sí mismo desde el cual el existir se aborda y se habla a sí, es decir, la modalidad cristalizada en que una interpretación ya-hecha de sí mismo que está a disposición del existente en tales habladurías ${ }^{125}$.

Otra de sus características es el amplio campo de referencias de tal hablar, aunque con una modalidad específica para este: no manifiesta sensibilidad por las diferencias ni se dan sujetos de enunciación que se posicionen como responsables efectivos en el decir, figurando con esto una vacuidad en el contexto de esta auto-remisión primaria. Debido al carácter proyectivo y no dado del Dasein, nuestro autor parte de esta instancia de alteridad anterior, que constituye un campo diferido

\footnotetext{
${ }^{125}$ No obstante, nuestro autor no realiza estas distinciones en sentido peyorativo, puesto que designan existenciales por los cuales se constituye el Uno, es decir, del Dasein en su cotidianidad: aquel punto de partida estructural e ineludible para su indagación en camino hacia la pregunta por el ser. Es precisamente en este contexto la inscripción de nuestro argumento : en lugar de remitir a una cuestión de alternativas del habla o el sí-mismo, se trata más bien de pliegues modales, que no apuntan a los contenidos o estructuras, sino a la relación y posición respectiva. En el segundo apartado desarrollaremos este argumento.
} 
desde el cual plantear luego pliegues dinámicos, aunque insiste en su carácter ineludible, tal y como sostiene en este pasaje:

“ese 'uno' es el nadie que como un fantasma anda en el existir factico, un cómo de la fatalidad especifica de la facticidad, fatalidad a la que todo existir fáctico paga su tributo" (Ibíd.:32[52]).

Este "tributo" primariamente ineludible tiene vinculación con la caracterización ontológica del Dasein. En efecto, esta modalidad del Uno la entiende como una máscara estructural con la cual el Dasein se cubre para no espantarse de sí mismo, de su ausencia de fundamento. De este modo busca prevenirse de la angustia con que el existir factico puede encontrarse en este singular retorno a sí: con esta mascara de lo ya-interpretado publico se presenta el existir como actividad suma o ajetreo (Betrieb), modalidades del existir que se proponen obturar tal inconsistencia constitutiva.

En aquél análisis del fenómeno de la curiosidad, nuestro autor pone de manifiesto esta modalidad del tenerse-a-si-mismo que subyacen en lo ya interpretado y público de su actualidad, en sus dos versiones epocales: por un lado, la conciencia histórica (como un modo de tenerse a sí mismo, cuyo punto de consistencia reside en el haber sido) y, por otro, en la filosofía (que se comprende como un tenerse idéntico, en tanto ser siempre así). En ambos casos, la modalidad del actuar respectiva se caracteriza por un ánimo de determinar y conocer aquello hacia lo que se dirige, al tiempo que cosifica y objetiva al ente tematizado, lo cual se evidencia correlativo con la preocupación por la certeza del horizonte de la cientificidad moderna. De esta manera el cuidado del Dasein, en el marco del análisis de este fenómeno en sus dos articulaciones desde la cotidianidad de su época, se encubre constantemente a sí en lo que respecta a su estructura fundamental.

El interés de Heidegger por aquellos fenómenos en lo ya-interpretado, consiste en que permiten dar cuenta del Dasein, distinguiendo en qué sentido el existir es movilidad, y esa movilidad una modalización de la temporalidad ${ }^{126}$. Entendemos que aquel análisis del haber previo a partir de la cotidianidad, busca circunscribir y esquivar la comprensión de la conciencia como yo o desde la relación sujeto-objeto.

De todos modos, el análisis de estos fenómenos le permiten a Heidegger poner de manifiesto una estructura fundamental: la mismidad es inicialmente una en el mundo con los demás, y se determina a partir de este campo de alteridad. De modo específico, destaca que la Dasein tiene primariamente el existir mismo allí, por lo cual lo busca por la vía del escuchar a los demás

\footnotetext{
${ }^{126}$ Específicamente busca con ello evidenciar que la filosofía e historia epocales no lograron asimilar el existir en su modo específico de ser, convirtiéndose más bien en contra-posibilidades.
} 
respecto a lo que dicen de ello, es decir, atendiendo cómo resulta en los demás, lo que hacen respecto a sí. De esta manera, la mismidad se revela inicialmente como uno-misma.

En efecto, en estos análisis los otros Dasein aparecen en el mundo común llevando consigo su uno-mismo con/en aquello que hacen, con su posición, aspectos, logros, éxitos o fracasos. En línea comprensiva con el aquí estático de las meras cosas, nos encontramos inicialmente con este modo de mismidad, el cual se encuentra no destacado ni expreso: esta ya uno-mismo ahí, sin volver la mirada sobre el ámbito de diferimiento anterior, sin reflexión alguna.

En suma, el ser-en-el-mundo en el cuidado de lo en-torno pone de manifiesto el mundo común: aquello de lo que nos cuidamos en el aquí es el mundo común y de uno-mismo. El carácter fundamental de esta modalidad de mismidad consiste en situarse a sí mismo en el mismo modo de ser de lo que busca en el cuidado. Igualmente, como el cuidado tiene su lenguaje en cada ocasión, el Dasein se aborda mundanamente para hablar de sí. Por ello, en la costumbre y la publicidad de la cotidianidad se encubre la estructura del cuidado, de modo tal que el mundo y el uno-mismo aparecen como si simplemente estuvieran ahí, como dados, donde el cuidado dormita ${ }^{127}$.

En la línea de nuestras interpretaciones la relevancia de desplegar esta modalización del habla y la comprensión de sí en el Uno, consiste en que permite circunscribir un campo semántico de partida para su re-modalización: la articulación en el lenguaje del modo opuesto de la propiedad del sí-mismo deberá por consiguiente presentar los caracteres contrarios o, al menos, con una ambigüedad suficiente para que los ponga en tensión. Del mismo modo, la articulación enunciativa de estas elaboraciones de Heidegger manifiesta en sí misma una modalidad de relación con el lenguaje, opuesta a la tradición metafísica, al buscar sortear inmovilizaciones y cristalizaciones conceptuales, gramáticas y sintácticas. En ambos casos, se pone en evidencia el supuesto de una irrebasabilidad semántica, en sintonía con el carácter irreductible de aquella alteridad originaria que elabora en su analítica.

Ahora bien ¿Cómo articula el diferimiento de aquel modo primario de la mismidad, en un desplazamiento posible, desde el marco comprensivo del que parte?

\footnotetext{
${ }^{127}$ Entendemos que a Heidegger le interesa subrayar el encuentro con la diferencia más que un realizar un tradicional abordaje crítico: si el mundo es significativo y puede dormitar de ello, entonces se da la posibilidad que repentinamente se dé un agobio o urgencia, es decir, un pliegue o diferencia que permita un desplazamiento. Por ello, vemos relevante atender las dificultades de lecturas y recepciones de la obra de Heidegger que son realizadas desde el tamiz comprensivo del que este autor busca apartarse.
} 


\section{1. c.- Ampliación fenomenológica de la intencionalidad: los fenómenos de retorcimiento y extrañamiento.}

Encontramos en sus cursos de 1923-24, la explicitación de dos fenómenos que se proponen dar cuenta de las dinámicas en la mismidad, a partir del carácter proyectivo e inesencial del Dasein. En efecto, desde su consideración de la existencia como lo que está en fuga ante sí, subraya que esto también denota la mismidad: el Dasein siempre se preocupa de si, aunque sea como en el caso primario, en el modo de la huida, donde extravía la pregunta por el ser y la reemplaza por el ser objeto para la ciencia, propia del pensamiento moderno.

En el marco de esta huida de la mismidad, analiza el fenómeno de retorcimiento (Verdrehung), en tanto movimiento fundamental de la existencia que remite a una distinción respecto a las elaboraciones de Husserl : primariamente, la existencia no puede tomarse a sí desde el fenómeno de la intencionalidad, pues desde el comienzo está dirigida a ver algo en dirección a algo. A partir de esta estructura, la existencia, al estar puesta hacia el mundo, se co-preocupa de su propia existencia, que no necesariamente implica una reflexión tética sobre el yo, pues esta remisión no debe determinarse en el sentido de un ser que se tiene, sino como un ser que se es, es decir, que existe y lleva en sí la posibilidad de convertirse en yo soy. Destaquemos aquí, el doble pliegue necesario para acceder a esta enunciación en primera persona.

Heidegger distingue que el retorcimiento se origina precisamente en el ámbito de lo que tradicionalmente se ha entendido como reflexión. Sin reducirse a ella y a sus connotaciones de la metafísica de la subjetividad, se manifiesta como un fenómeno que opera como clave metódica y dinámica, al permitir recortar la intencionalidad y llevándola a los límites de su función de interpretación, de modo tal que lo ya-interpretado y pensado, mediante una torsión o pliegue aplicado a lo fáctico, puede ampliar la comprensión, es decir, puede y permite decir más al respecto $^{128}$

Por este fenómeno que manifiesta una modalidad reflexiva, pero sin la unilateralidad del cógito o la subjetividad trascendental, la mismidad amplia el campo fenomenológico de la intencionalidad, como base estructural sobre la que pueden hacerse visibles fenómenos y disposiciones afectivas de diferimiento respecto a la vida fáctica tales como la alegría, terror,

\footnotetext{
${ }^{128}$ Véase EPhF: 284 ss. [281 ss.]. Con la puesta en análisis de este fenómeno, Heidegger subraya una modalidad donde se evidencia que lo ya pensado, incluye siempre lo no pensado: aquí, lo pensado e interpretado retorna sobre la vida fáctica, para que esta hable. De esta manera, se pone al descubierto plano originarios de alteridad y diferimiento constitutivo que son condición de toda reflexividad y dinámica, frente al fundamento trascendental, binario y estático de la metafísica de la subjetividad.
} 
tristeza, angustia, etc., los cuales entiende como inadecuados si se determinan como intencionalidad.

Ahora bien, el retorcimiento se manifiesta de diversos modos entre los cuales se halla aquel fenómeno de la huida de la existencia, el cual se da en el modo del encubrir, es decir, como ser que tiene que desaparecer para tranquilizarse, tal y como figura en la motivación tras la preocupación por la certeza de la perspectiva moderna. Este modo de defenderse es una determinación de su ser: la existencia se defiende de sí misma, pues la amenaza el hecho de que $e^{129}$. Tal defensa se articula modalmente en el fenómeno de extrañamiento (Entfremdung).

En efecto, en tal auto-defensa Heidegger inscribe lo que entiende como existencia asegurada, la cual se preocupa por conocer, buscando con ello no volverse extraña ante el ente en su cotidianidad. Por ello, huye ante tal extrañamiento, que es la autentica amenaza para la existencia, orientándose hacia lo familiar y tranquilizador. Entendemos que tal aseguramiento es correlativo con el modo primario de mismidad en la cotidianidad del Uno.

No obstante, el fenómeno del extrañamiento es también condición de posibilidad para que en la existencia se encuentre algo como el ser-descubierto. Esto lo distingue con un análisis del fenómeno de la preocupación, que consiste en salir en pos de algo que viene a nuestro encuentro en el mundo, lo cual implica un modo de salir del extrañamiento. Precisamente con esta dinámica , evidencia que bajo al extrañamiento subyace el fenómeno de retorcimiento, sobre el cual puede la intencionalidad ser llevada nuevamente al suelo al que pertenece, permitiéndole a nuestro autor explicitar un modo de dirigirse al mundo de la ocupación, aunque inicialmente en el modo de la huida del sí-mismo (EPhF:318[306]).

En suma, en estas primeras elaboraciones de la mismidad, Heidegger analiza la estructura del ser- en-el-mundo que implica de algún modo un estar al descubierto, visible en el mundo, aspecto que el fenómeno del extrañamiento favorece e intensifica. Este carácter es ante todo aquello de lo que la preocupación esta en huida. En este marco, el retorcimiento es una peculiar inclusión del auténtico ser de la preocupación en aquello de lo que se preocupa, pues se hace visible que aquello de lo que se ocupa es de ella misma. Asimismo, desde la cotidianidad, se manifiesta una huida de la existencia ante sí misma y del extrañamiento, en busca de tranquilidad en la familiaridad y estabilidad de lo cósico ${ }^{130}$. De esta manera, nuestro autor propone explicitar un diferimiento de

\footnotetext{
${ }^{129}$ En este sentido, en el marco de la comprensión de sí sumida en el Uno, sostiene que el Dasein es un ser que busca desaparecer para tranquilizarse (ibid.:289-90[285-6]).

${ }^{130}$ Frente a ello, el carácter proyectivo del Dasein, además de la intranquilidad que lo caracteriza, manifiesta ciertas dificultades de lenguaje derivadas de su carácter ante-predicativo: un ser que se es, es el ente que lleva en sí la posibilidad de convertirse en yo soy, es decir, de articularse luego en el lenguaje desde estos fenómenos considerados. Con esta distinción, que implica una teoría del lenguaje, nuestro autor destaca el carácter derivado y contingente de la articulación sintagmática yo, que fue el punto de partida en la tradición metafísica moderna.
} 
base, un pliegue posible donde el Dasein se relacione en su mismidad propia, evitando el recurso comprensivo de la autoconciencia.

Sin embargo, algunos matices en estos fenómenos quedan sin explicitarse, manifestando ciertas tensiones: ¿cómo es posible una intuición del ámbito que se manifiesta en este fenómeno de retorcimiento que esquive toda nota sustancialista? ¿En qué consiste este retorno sobre sí de la preocupación, la intencionalidad y la mismidad, si se halla primariamente diferida? Y de un modo más general: ¿son acaso estas tensiones consecuencias directas del modo de abordaje que propone Heidegger?

Con el objeto de indagar en estas cuestiones, se torna necesario abordar su consideración de esta ampliación de la estructura de la intencionalidad por la vía del retorcimiento, desde la perspectiva del Dasein, de modo tal que logremos precisar el campo de estas tensiones. Para ello, detengámonos brevemente en sus primeras elaboraciones en torno a la disposición afectiva, la cual, vimos que explicita a partir del fenómeno del retorcimiento.

\section{1. d.- Tensiones desde el uno-mismo.}

Estos análisis de la constitución ontológica fundamental del Dasein, son presentados como un medio para una investigación más profunda, modalidad que nuestro filósofo repetirá hasta sus escritos de finales de la década ${ }^{131}$. En este marco, los existenciales fundamentales del Dasein son : mundo , tiempo , Uno, habla, comprensión, cuidado, disposición afectiva, ser-para-la-muerte . La analítica existencial que va presentando en estos primeros cursos consiste en el desarrollo de tal conjunto, los cuales se cristalizaran de un modo articulado en su obra de 1927. Recordemos aquí, que tal constelación estructural es co-originaria, dinámica y se despliega de modo simultáneo, lo que imposibilita una aprehensión acabada de la facticidad del Dasein. No obstante, Heidegger busca plantear totalizaciones poniendo de manifiesto aspectos formales, estructurales y originarios, para dar cuenta de horizontes para el planteo ontológico fundamental ${ }^{132}$.

\footnotetext{
${ }^{131}$ Lo cual evidencia el carácter siempre mediado, relacional y lateral de su enfoque. En su trabajo sobre el concepto de tiempo, por ejemplo, propone una interpretación pormenorizada del Dasein sino, pero buscando tan solo hacer visible el tiempo. Véase, BZ: 19 ss. [29 ss.].

${ }^{132}$ En este sentido, un intérprete destaca el modo singular en que se da el principio de funcionamiento en el Dasein, el cual:" es una totalidad estructural en la que cada uno de sus constituyentes funciona, por decirlo así, simultáneamente, como un sistema de relaciones cuyo principio de funcionamiento no está en una relación determinada, sino en la
} 
En efecto, estas determinaciones evidencian que los análisis desplegados son formales, pues tales estructuras del Dasein son anteriores a todo comportamiento fáctico. Es en este sentido que evita plantear directrices para la existencia, pues esta solo se define mediante el existir desde tales determinaciones, de modo tal que excluye toda formula general para el caso concreto ${ }^{133}$.Entre las primeras determinaciones que analiza, en el marco de su abordaje de la mismidad, se encuentra el mundo y el trato con los útiles, a partir de la cotidianidad fáctica, lo cual revela notas de alteridad irreductibles.

En el trato con cada cosa en el mundo común, se devela el estar el uno con el otro, en tanto plano co originario del Dasein. Del mismo modo, se manifiesta el sí mismo a partir del mundo circundante, destacando con ello el carácter originario y ante-predicativo de tal fenómeno, desplazando con ello el punto de partida que caracterizó a la tradición metafísica. Esta anterioridad no unitaria se evidencia en este pasaje:

“...uno también se encuentra a sí mismo en aquello que uno hace, en aquello que uno espera, en aquello que uno evita, en aquello en lo que uno permanece mientras está ocupado en algo. Y este encontrarse a sí mismo a partir del mundo circundante se produce sin necesidad de recurrir a una introspección dirigida al yo o a una percepción reflexiva de vivencias y actos 'internos'", (BZ: 25[36])

Aquí también reconoce la significatividad desde donde se comprende el mundo compartido y el propio. El estado interpretativo queda delimitado por el campo de la ocupación y se ratifica/devela con otros, como veremos con más detenimiento en el próximo capítulo. Precisamente en este contexto reconoce la estructura de la disposición afectiva, por la cual el Dasein es puesto al descubierto para sí mismo, a partir de la estructura primaria del Uno.

Si la habladuría habla en términos medios sobre el mundo, entonces desde allí se solidifica un estado interpretativo: desde estas bases se autointerpreta y toma el cómo debe comportarse, alejándolo de una interpretación y confrontación originaria (que es el conocer primario para Heidegger), pues, la publicidad y la tradición no tematizada encubre al Dasein y lo arrastra al modo de ser de lo Uno: encubre el sí mismo propio, ocultándose la disposición afectiva que lo caracteriza.

totalidad. La temporalidad designa precisamente la captación de esa estructura desde el punto de vista de la totalidad"(Bertorello, 2011:120)

${ }^{133}$ En esta línea manifiesta vínculos con la ética de Aristóteles, para quien vivir es un arte que solo se aprende viviendo. El Dasein sólo puede actuar responsablemente y de manera autónoma cuando no dispone de reglas, valores, normas o procedimientos que deban ser aplicados al caso particular a fin de obtener resultados previsibles. Si la conciencia -tal y como la piensa Heidegger- no ofrece indicaciones prácticas, se debe a que, bajo la luz de máximas bien calculadas, la "conciencia rehusaría a la existencia nada menos que la posibilidad de actuar". Para un análisis comparativo respectivo, véase Volpi (2006a): 137 ss. y Santiesteban (2009):96 ss. En los capítulos siguientes abordaremos las implicancias éticas de estas consideraciones. 
Sin embargo, tal encubrimiento no alude a un contenido oculto, alternativo y superador sino, más bien, a la falta de contenido o consistencia definitiva, a la ausencia de significaciones últimas, por lo cual distinguimos una tensión y diferimiento de fondo que estructura una doble dimensión en la estructuración de la mismidad del Dasein a partir de la cotidianidad. Tal diferimiento y dimensionalidad permite que distingamos pliegues en lugar de alternativas entre modalidades de la mismidad.

De aquella manera, el Dasein habla de si desde el lenguaje del mundo, huyendo de sí y refugiándose en el Uno. Entendemos que esta huida de sí, semánticamente no remite a un polo-yo de partida, sino más bien a su determinación proyectiva y de alteridad cuyo ámbito de auto-remisión se constituye relacionalmente y retroactivamente, aunque estos primeros análisis elaborados desde el Dasein sugieren precisamente lo contrario. En el siguiente fragmento podemos encontrar indicios del singular modo en que Heidegger concibe este ámbito de mismidad en dinámica tensiva con la alteridad:

\footnotetext{
"Incluso cuando habla de sí mismo, el Dasein habla el lenguaje del mundo, en cuyo aspecto se ha perdido. En la curiosidad, pues, el Dasein huye de sí mismo. En esta huida se opone a posibles situaciones que impliquen una confrontación, una obligación, un compromiso, una elección. En esta huida el Dasein encuentra su refugio en la habladuría ; la publicidad prescribe y sanciona 'las cosas que deben haberse visto y leído', alimenta nuevas necesidades del ver y descubre las cosas que proporcionan a ese ver una adecuada satisfacción” (...) “...contra el peligro de encubrimiento implícito en la publicidad y contra el dominio del estado interpretativo consagrado por el uso, el Dasein tiene que recurrir siempre y cada vez de nuevo a la crítica para apropiarse las posibilidades de una adecuada experiencia originaria" (Ibid.:38[53]).
}

Esta descripción es lo que entiende como caída (Verfall), desde donde el Dasein crea posibilidades idealizantes de tomarse a la ligera y perderse. El margen, la diferencia para los desplazamientos, torsiones y apropiaciones en tal huída parecen sugeridas en aquel recurso a la crítica, que entendemos como una diferencia de base que remite a la misma relación o dinámica con la alteridad originaria. Por ello, esta caída tienta y tranquiliza, empujándolo a la alienación, al tiempo que denotan el uno-mismo del Dasein en su particular modalizacion.

De esta manera, el Dasein puede definirse como algo que esta mundanamente ahí aunque en el modo singular del proyectarse. Precisamente por ello puede perderse o elegirse, es decir, someter toda ocupación a elección originaria, donde su inmediato estar-en se manifiesta como un ser posible. La consideración del lenguaje en la caída en el Uno se nos muestra aquí relevante para la distinción de la modalizacion conceptual y lingüística del sí-mismo propio del Dasein, al tiempo 
que tal consideración se manifiesta como una modalizacion que el propio Heidegger propone de elaboraciones tradicionales ${ }^{134}$.

Ahora bien, las articulaciones reflexivas implícitas en los términos utilizados (perder-se, elegir-se, etc.), así como también las resonancias respectivas en los fenómenos de extrañamiento y retorcimiento, tensan estas elaboraciones de Heidegger en el campo semántico de la comprensión y lenguaje de la metafísica. En este marco, distinguimos una continuidad progresiva hacia la analítica que despliega en SuZ, donde pone un mayor acento en fenómenos marginales, límites y relacionales, con el objeto de abandonar radicalmente tales resonancias.

En efecto, en la época de $S u Z$ desarrolla con mayor amplitud el fenómeno limite por el cual, cuando el Dasein propio se adelanta a su ser posible, descubre la muerte como posibilidad, colocándolo únicamente ante sí mismo. Precisamente por ello es temporal, en el modo de su ser posible. En este sentido, destaca la importancia que el Dasein se interprete en su constitución ontológica como temporalidad. Desde aquí, retoma la analítica desde sus estructuras fundamentales, así como también amplía el desarrollo de las condiciones para un pasaje del uno-mismo al (propio) sí-mismo.

En el siguiente apartado, pondremos especial atención a dicho pasaje, con el objeto de determinar el alcance de sus intentos de superar las tensiones en su elaboración de la ipseidad, en el marco de la comprensión del ser que le es correlativa.

\section{2.- La mismidad e ipseidad en $S u Z$ : relaciones con el lenguaje y la alteridad.}

En efecto, a continuación mostraremos que algunos tratamientos y elaboraciones presentadas en esta obra, que si bien retoman las consideraciones de sus escritos y cursos anteriores, enfatizan en una orientación diferente los fenómenos considerados, ampliando algunos desarrollos respecto de la mismidad ${ }^{135}$. Por una parte, los analiza descentralizando en mayor grado la voluntad

\footnotetext{
${ }^{134}$ En este marco, Santiesteban desarrolla cierta permanencia del pensamiento y lenguaje griego en estos análisis de Heidegger, a partir de los trabajos de Franco Volpi, quien distinguió continuidades entre la analítica existenciaria y la filosofía práctica. En especial, distingue la consideración de las habladurías, en continuidad con las resistencias de Platon y Aristoteles a los influjos de la sofistica, así como también los análisis de la disposición afectiva, en sintonía con el $\pi \alpha \tau \eta$ aristotélico y sus intentos de conjurar las estrategias retoricas. Véase, Santiesteban (2005): 78-82.Cf. Adrian (2010 b):21 ss. ; (2011b):18-25, donde destaca la distinción heideggeriana de ontologizar los conceptos de la filosofía práctica, quitándoles su matriz práctica y convirtiéndolos en modos de ser del Dasein.

${ }^{135}$ Adrian Escudero propone una interpretación de la analítica del Dasein en su mismidad, en clave narrativa, en el marco del desasosiego en la cultura y espiritual de sociedad alemana de la época, que resulta pertinente como introducción para nuestro apartado, a saber: "la obra magna del joven Heidegger, Ser y tiempo, se puede leer en clave
} 
y la racionalidad en su enfoque, que va atravesado por el sesgo jerárquico propio de las perspectivas modernas del sujeto y la conciencia como centro de representaciones. Frente a ello, busca dar cuenta de fenómenos originarios que permiten dinámicas y articulaciones por fuera del carácter volitivo del yo del Dasein y de la comprensión tradicional del fundamento. Por otra parte, articula de un modo más consistente las referencias a la ipseidad en su modalidad propia, contrapuestas a las consideraciones estables de la identidad. Articulemos brevemente algunas de sus elaboraciones en vistas de estos vínculos y diferencias, retomando el punto de partida de sus análisis: la facticidad.

\section{2. a.- La mismidad desde la cotidianidad.}

\section{2. a.I- La yoidad}

En el análisis del Dasein en su cotidianidad desarrollado en $S u Z$, nuevamente destaca que la inmediata mismidad es el "sí" (das "Selbst"), como lo que se mantiene idéntico a través de los cambios de comportamiento y vivencias, que en cursos anteriores circunscribió al concepto tradicional de yo y hombre. Ontológicamente ligado a la idea de subiectum, se entiende como aquello que ya está siempre ahí “en cuanto es 'el mismo' en medio de la multiplicidad de las diferencias, el carácter de la mismisidad" (SuZ: 114[140]). Con esto Heidegger comienza a contraponer la sí-mismo del Dasein propio a la identidad del yo del uno-mismo, a partir de circunscribir este último al término mismidad. Aquí el Dasein queda concebido como algo que estaahí, más afín al modo de ser de un ente cósico. Frente a ello, la pregunta por el quién cancela la

de una novela filosófica de formación que, al igual que otras novelas de la época, reflexiona sobre el significado del ser humano en una era dominada por la ciencia y pone de relieve el sometimiento del individuo a fuerzas más poderosas que lo anulan, empequeñecen y manipulan hasta el punto de perder de vista el sentido de su propia existencia. En Ser y tiempo nos encontramos con el Dasein como protagonista de una trama que se estructura en tres actos: en un primer momento, hallamos a un Dasein cómodamente instalado en las certezas de la vida cotidiana, que sabe desenvolverse práctica y eficazmente con las normas de comportamiento colectivamente reconocidas, que comparte un mismo horizonte de valores y de expectativas con la gente que le rodea y que se siente protegido por la sociedad a la que pertenece; en un segundo momento, este mundo familiar en el que el Dasein se siente como en casa entra inesperada y repentinamente en crisis, lo cual provoca la desorientación y la perplejidad de un Dasein que se encuentra por primera vez en su vida colocado delante del mundo sin capacidad de respuesta, sin asideros donde agarrarse, flotando en un océano ignoto y sin rumbo, suspendido en la nada más absoluta y preso de la angustia; y en un tercer momento, ese Dasein toma conciencia de su situación errática, asume su condición de arrojado y decide retomar las riendas de su existencia proyectando un modelo de vida propio que lucha contra la fatal inercia a volver a caer preso de las anónimas redes de la cotidianidad" (Adrian, 2010b:13 s.). Cf. Steiner (1993):16. Dejando de lado el voluntarismo o subjetivismo implícito en esta articulación, interpretamos aquí un recurso a la modalización lingüístico-narrativa de estos desarrollos en SuZ, que es coextensivo a la consideración de la ipseidad y mismidad del Dasein .En pocas palabras: esta versión lleva implícita una comprensión de la ipseidad en dicha obra. 
posibilidad de partir de un yo, como polo de actos o ámbito para el retorno a sí, tal como explica en este pasaje:

"Pero la misma interpretación positiva que hasta aquí hemos hecho del Dasein impide partir del dato formal del yo cuando lo que se busca es una respuesta fenoménica suficiente a la pregunta por el quién. La aclaración del estar-en-el-mundo ha mostrado que no 'hay' inmediatamente, ni jamás esta dado un mero sujeto sin mundo. Y de igual modo, en definitiva, tampoco se da en forma inmediata un yo aislado sin los otros. " $\mathrm{Y}$ en una nota al pie agrega: ..." O también, justamente, autentica mismidad frente a la miserable 'yoidad' (Ichlichkeit)” (Ibíd.:116[141])

Esta miserabilidad ya connota el horizonte de la ipseidad como la modalidad propia de la mismidad del Dasein, lo cual bien puede interpretarse en relación inescindible con la alteridad: su diferencia requiere dar cuenta de aquella estructura específica de carácter primario. Asimismo, queda explicita aquí la tensión que encuentra Heidegger en la elaboración de estas cuestiones sin suponer un ámbito dado en la dimensión de partida ni en el retorno de tal mismidad, como aún podía asociarse desde la consideración fenomenológica del extrañamiento y el retorcimiento que vimos anteriormente.

Por ello, Heidegger insiste en aclarar fenoménicamente la índole de aquella coexistencia en la inmediata cotidianidad, como punto de partida ineludible para esta comprensión. Hemos visto que el análisis del mundo común, devela que el Dasein propio se “encuentra” a sí mismo y se comprende primariamente desde su mundo y la coexistencia de los otros. Recorramos algunas puntualizaciones que realiza al respecto.

\section{2. a.II- La coexistencia y su alivianamiento.}

Los otros son los que existen inmediata y regularmente en la vida cotidiana, que remiten en estos tratamientos al quién del impersonal, el sé. Aquí el Dasein propio esta disuelto en ese modo de ser, donde se despliega una presión de obligatoriedad (que designa como dictadura) caracterizada por el término medio (Durchschnittlichkeit), en el que se nivela todas las posibilidades de ser, donde toda interpretación del Dasein y del mundo queda regulada por la publicidad. Con esto se despoja al Dasein de su responsabilidad, anticipando todo juicio o decisión que manifiesta o emite 
lo cual, por el alivianamiento (Aufhellung) que esto produce, mantiene y refuerza su dominio sobre él ${ }^{136}$.

Al igual que en su obra temprana, la estructura co-originaria del ser-con revela una suerte de mismidad propia, diferida y no asumida, como punto de partida inexorable para la relación del Dasein con su sí: este despojamiento y diferimiento se manifiesta más originario y, por ello, necesario para una asunción propia de sí, como evidencia en este parágrafo:

"El sí mismo del Dasein cotidiano es el uno mismo (Man selbst), que nosotros distinguimos del sí mismo propio, es decir, del sí- mismo asumido expresamente. En cuanto uno-mismo, cada Dasein está disperso en el uno y debe llegar a encontrarse" (....) "Que el Dasein sea familiar a sí mismo en cuanto uno-mismo, significa que el uno bosqueja la interpretación inmediata del mundo y del estar-en-el-mundo.” (...) "Inmediatamente yo no 'soy' 'yo', en el sentido del propio si-mismo, sino que soy los otros a la manera del uno" (Ibíd.:129[153]).

Desde aquí extrae la interpretación pre-ontológica de su ser, comprendiéndolo y encontrándolo a partir del mundo común como un ente intramundano. Desde este punto de partida se hace dar también el sentido del ser-ente, en función del cual estos sujetos entitativos son comprendidos ${ }^{137}$. Específicamente, en la interpretación pública dominante el Dasein se da a conocer como cosa, por lo cual usa conceptos del mundo y no términos que le pertenecen originariamente $^{138}$.

\footnotetext{
${ }^{136}$ La caracterización que realiza Kierkegaard de la plebe (Plebs) o la masa (Massen) donde agrupa lo que denomina como lo numérico (das Numeriske) desde donde confronta lo singular con lo social, presenta muchos puntos en común con la caracterización del Uno en Heidegger. Para un análisis y desarrollo de tales caracterizaciones, véase García Martin (2009): 221 ss.

${ }^{137}$ Esta perspectiva ha suscitado diversas polémicas en la recepción inmediata de la obra de Heidegger. En efecto, la prioridad expositiva de la forma de ser de lo a la mano respecto al ser-con y el ser-ahí-con le parecen justificadas a nuestro autor, aun cuando subraya que estas dos son co-originarias. Esto implica ciertas consecuencias para la comprensión de las estructuras comunitarias del ser-ahí: ambos son analizados e interpretados desde la comprensión del ser en el mundo como el cuidado de lo a la mano, como trato activo con los útiles. Una de las consecuencias del proceder en el análisis del ser-con a partir de esta vía, es que la pregunta por el quién del ser ahí (en cuanto ser-con) se concreta en aquella comprensión cotidiana del ser ahí y en la manera inautentica del ser-con. Pero Heidegger insiste en que los otros y el ser ahí del Dasein no tienen la forma de ser de lo a la mano. En este marco, algunos intérpretes subrayan que el ocuparse por ellos termina siendo puramente formal y que la intersubjetividad en SuZ, porque parte del ser ahí perdido en el mundo, se halla obligada a llegar al ser ahí de la caída: porque interpreta la relación interpersonal desde la relación con las cosas, acaba en una clara cosificación del otro. Luego, en la analítica los otros quedan incluidos en la propia constitución del mundo, viéndose privados de su verdadera alteridad, aspecto que se halla en sintonía con el abordaje de Husserl de la intersubjetividad. En el marco de estas críticas podemos encontrar trabajos de Karl Löwith (1968/1984); Theunissen (1965); Josep Coll (1990); entre otros. Nuestra interpretación es que aquel énfasis en el comienzo del análisis no remite tanto a un posicionamiento ético implícito, sino más bien como un efecto de las tensiones que Heidegger encuentra entre la comprensión del Dasein que despliega en su analítica y las sedimentaciones en el lenguaje desde donde las articula, en particular, en estas elaboraciones en torno a la mismidad.

${ }^{138}$ Por ello afirma en un trabajo anterior: "el mundo de la ocupación da al Dasein el primer concepto" (KV: 165[78]). Distinguimos aquí un énfasis crítico puesto en el modo de conceptualización estática, que implica una modalidad correlativa de relación con/en el lenguaje, indicando asimismo por oposición, la modalización dinámica desde la que articula su propio pensamiento.
} 
Ahora bien, de algún modo Heidegger tiene que suponer, previo a este análisis, un desajuste o disparidad constitutiva que le permita sostener un ámbito de propiedad de la mismidad, debido a que el método fenomenológico comienza con el entramado de la cotidianidad del Dasein. Es decir, ¿por qué indagar en una modalidad del quién del Dasein que no sea la estructura primaria que revela la cotidianidad del Uno, sino se supone un yo o conciencia dados? ¿Responde a una ética de la mismidad o la autenticidad, a una axiomática implícita, a imperativos subyacentes de la metafísica moderna?

Pues bien, subrayamos que dicha disparidad viene articulada por un lado, con la consideración de la diferencia ontológica del ser del Dasein respecto al resto de los entes que no son el Dasein y, por otro, en su perspectiva respecto al lenguaje y las significaciones que retoma de la tradición.

En este marco, Heidegger insiste en que el modo propio de ser-sí-mismo no remite a un desprendimiento del Uno, que lo torne autónomo y nuevo, sino a una modificación existentiva de aquel, en tanto existencial esencial y estructural de base. En otras palabras : su diferencia no remite al contenido sino a la modalizacion respecto a estas estructuras que son constitutivas del Dasein, en vistas a su singularidad ontológica ${ }^{139}$, donde la existencia autentica puede entenderse como una especie de mella/grieta modal que es inherente al Uno en la cotidianidad, también distinguiendo de esta manera su irrebasabilidad ${ }^{140}$.

Así, por medio de esta diferencia y tensión puede sostener una inadecuación o diferimiento en el auto-remisión primaria del Dasein, desde su caída en el Uno. Por ello, insiste que la modificación existentiva de la mismidad dista de un desplazamiento de tipo volitivo o racional. Más

\footnotetext{
${ }^{139}$ A este respecto, Waelhens sostiene que los términos de esta descripción muestran que Heidegger no se mantiene en los límites de la fenomenología pura. Interpreta una jerarquía de los dos modos fundamentales: "esta pretendida neutralidad no se mantiene sino para velar la gratuidad de las apreciaciones presentándolas so color de descripciones puras". Este intérprete sostiene que el amor, el sentimiento del deber que cumplir, la fe religiosa son capaces de sellar y transformar existencias que se manifiestan en la actividad cotidiana más banal. Heidegger parece ignorarlo, pues confunde existencia y la expresión de ella elaborada por el existente. Sostiene que cuando estos seres traten de expresar su amor, su fe, etc. tendrán que servirse del único lenguaje del que disponen, con sus clisés correspondientes Por ello, entiende como fundamental, desde la analítica heideggeriana, distinguir el comprender y el expresar, en lo que respecta a la existencia y su comprensión. En este marco, señala que la autenticidad heideggeriana manifiesta cierta grandeza que parece reservada para un conjunto menor de existentes humanos. Véase Waelhens, (1952):78-80.A nuestro entender, la modalización jerárquica no se reduce a un término o expresión, sino a una modalización en la articulación en el lenguaje, en la que bien puede inscribirse también la propuesta de tal interpretación.

${ }^{140}$ Estas interpretaciones se articulan con diversas discusiones recientes a este respecto. Por ejemplo, Fernández Beites interpreta que las dos dimensiones para el Dasein (propiedad e impropiedad), en los desarrollos de SuZ, no remiten más que a un solo modo posible: la impropiedad, único modo de existencia posible y el nihilismo como la opción coextensiva a tal pensar (es decir, aquel que la reconoce, sin embagues ni encubrimientos, como la única opción). El carácter de alternativa en las interpretaciones clásicas, solo son una consecuencia de la ambigüedad controlada del discurso y la exposición de Heidegger. Véase Fernández Beites (2009):33-56.Cf. Dreyfuss (2002):41 ss.;336 ss., quien enfatiza y desarrolla la dimensión nihilista de la autenticidad, poniendo en evidencia la profunda falta de fundamento o vacuidad de la apertura existencial del Dasein ,es decir , la caída de la expectativa ante significados últimos para la vida fáctica, lo que ofrece un impulso estimulante como consecuencia.
} 
bien, intervienen tonalidades afectivas desde experiencias de singularización, que permiten al Dasein desarticularse de esta comprensión de sí en la cotidianidad del Uno.

\section{2. b.- La importancia de la disposición afectiva para el pliegue del sí-mismo.}

\section{2. b.I.- El comprender y su temple anímico.}

El Dasein al abrirse al mundo se abre a sí mismo, se comprende siendo. Se dan una multiplicidad cooriginaria de caracteres ontológicos constitutivos, entre ellas la disposición afectiva (Befindlichkeit) y el comprender (Verstehen), ambos co-originariamente determinados por el discurso, en la que ninguno de ellos puede dar cuenta autónomamente del todo de aperturidad, aunque si cierta primacía en tal o cual análisis de la cotidianidad ${ }^{141}$.

Con la disposición afectiva como existencial Heidegger refiere al estado de anímico (Stimmung) que pone al ser en su ahí., donde el Dasein ya está siempre afectivamente abierto en su ir siendo, la cual es anterior a todo abordaje de los sentimientos por parte de la psicología. El Dasein siempre ya esta dispuesto afectivamente de un modo u otro ${ }^{142}$. Con ello, Heidegger se aparta de la reducción racionalista del concepto moderno de hombre y sujeto, en el cual lo afectivo fue abordado de un modo derivado y secundario ${ }^{143}$. De esta manera, esta estructura no puede ya comprenderse

\footnotetext{
${ }^{141}$ Considerando esta matriz relacional como originariamente básica entre las estructuras del Dasein, se han planteado algunos análisis y discusiones. Entre los trabajos recientes, destacamos interpretaciones en torno al pasaje de la experiencia fáctica filosófica (en $S u Z$ ), la cual se desplaza superando la inicial comprensión de sí mismo, aquella que se constituye a través del rebote (Rückstrahlung) desde las categorías propias del ente hacia su ser. Un intérprete sostiene que el sí-mismo propio que logra deslindarse de la tendencia del uno-mismo en la vida fáctica, remite en definitiva a una modalidad de vida filosófica (Velez López, 2009:120 ss.) Cf Burlando (2015):376 s. En esta interpretación, en cambio, el sí-mismo del Dasein es distinguido como ontológico en primera instancia, desde cuya dimensión se basan los otros modos del sí mismo. En línea con las elaboraciones de Edith Stein, esta caracterización subraya críticamente un carácter unidimensional para el Dasein heideggeriano, en contraste con la potencial comprensión multidimensional del existente humano que se halla implícita en elaboraciones de Aristoteles y Santo Tomas. Entendemos que aquella caracterización y designación de la modalizacion heideggeriana, supone y enfatiza una alternancia, por sobre una tensión irrebasable en y de tales modalizaciones, mientras que la segunda parece rechazar la tensión que implica el carácter ineludible del Dasein en la cotidianidad, para la analítica de Heidegger.

${ }^{142}$ Heidegger refiere a diversos aspectos en torno a la disposición afectiva, hasta su elaboración en SuZ. Así, por ejemplo, se refiere al estado de ánimo; el temple anímico (Gestimmheit) y el plural, estados de ánimo (Stimmungen). A partir de sus lecciones de la década de 1930, especialmente en Beiträge zur Philosophie (BPE), considera lo que entiende como temple de ánimo fundamental (Grundstimmung), a partir de lo cual distingue temples como condición para determinados desplazamientos o situaciones fácticas. Para un análisis y distinción del estatuto de la disposición afectiva aquí y en su obra tardía, véase Santiesteban (2005):82-4.

${ }^{143}$ En lo referente a la consideración del fenómeno afectivo en el joven Heidegger, podemos distinguir claramente una tentativa para pensar a la existencia humana a partir de la afectividad, de modo tal que su racionalidad e inteligencia intervienen a posteriori del comprender, la interacción en el mundo y tal disposición. En un trabajo de discusión
} 
como mero fenómeno psicológico, pues remite a un existencial con un grado de mayor originariedad en la aperturidad del ser-en-el-mundo.

En este marco, subraya que el comprender es siempre afectivamente templado, en un saber de lo que pasa consigo mismo, un saber del propio ser como posible. Precisamente en el comprender se da existencialmente el poder ser, como modo de ser, es decir : porque siempre se comprende, el Dasein puede extraviarse y malentenderse, pues es el modo en que ese ser abre, en sí mismo, lo que pasa consigo mismo .El Dasein ya siempre se ha proyectado y es tal proyectarse mientras existe, al mismo tiempo que se ha comprendido desde posibilidades, pues el comprender co-capta temáticamente tales posibilidades: en el proyectar se despliegan las posibilidades y la hacen ser tales. Por ello, sostiene que el Dasein es lo que llega o no a ser, tal y como exhorta en esta nota al pie:

"Pero ¿Quién eres 'tu'? Ese que tu, liberándote de ti mismo, proyectas al lanzarte decididamente hacia adelante- el que devienes" (Ibid.:146[169]).

En esta línea proyectiva, aún aquí con resonancias voluntaristas, inscribe la asunción auténtica, cuando la interpretación comprende que su constante tarea es no dejar que la manera previa de ver y entender le sean dados por simples opiniones populares. El despliegue y el desarrollo del comprender en tal interpretación, se manifiesta así correlativa con la dimensión futura implícita en tal carácter proyectivo. Aun así, en un modo u otro se trata de las mismas posibilidades, siendo la variación una modalidad relacional con el conjunto de ellas, el cual esta históricamente determinado: relación con posibilidades comprendidas como plenas, trascendentales, últimas o una relación comprendiéndolas como históricas y contingentes.

Ahora bien, en el análisis de la caída del Dasein subraya que entre los aspectos alienantes del Uno se encuentra aquél que le oculta su más propio poder-ser: los engañosos autoanálisis que allí se proponen lo llevan a enredarse en sí mismo en un despeñamiento (Absturz), donde se precipita desde sí mismo en sí mismo (Ibid.:178[200]). En este marco, una disposición afectiva

reciente, encontramos un análisis y comparación con la consideración moderna de los afectos y sentimientos, la cual remite y reduce más bien al cómo de sus posibilidades fácticas, es decir, a su mera modalidad ontica y derivada de manifestación, además de circunscribirlo al ámbito irracional, a diferencia de la perspectiva de Heidegger, en la cual : "el modo pre-reflexivo de conocer el mundo determina toda comprensión de ser, incluyendo la racionalidad científica y el preguntar filosófico; gracias a este se hace posible el descubrimiento del mundo y la aprehensión de los entes como algo matizado afectivamente. Por ello, la vía afectiva representa un posible nuevo acceso al ser, que siempre escapa a cualquier intento de aprehensión puramente intelectiva" (Xolocotzi y Huerta ,2014:9). Cf. Hoffman (2002):319 ss. 
fundamental se manifiesta como signo para un retorno propio a sí mismo, un pliegue que tensiona su mismidad en la cotidianidad, acompañando aquél desarrollo de la interpretación: la angustia ${ }^{144}$.

\section{2. b.II.- Entre disposiciones y fenómenos liminares.}

La constitución fundamental del estar-en-el-mundo en esta analítica demostró que la totalidad del todo estructural es el cuidado. Partiendo de la cotidianidad, particularmente del Dasein en el tramo de su existir entre nacimiento y muerte, nuestro autor dio cuenta de que la esencia del Dasein reside en el poder-ser, cancelando con ello la posibilidad de ser aprehendido como un ente entero, es decir, mientras es se comporta en relación a su poder ser, develando con ello su permanente inconclusión, de modo que cuando no queda nada pendiente, se da un no-existir-más del Dasein.

En este caso, con el fenómeno de la muerte, Heidegger distingue un camino para la asunción propia de la mismidad y las posibilidades. En un determinado estar vuelto hacia la muerte se manifiesta un dirigirse hacia una posibilidad propia e insustituible, puesto que se articula con el carácter de en cada caso mío del Dasein. Debido a su carácter ineludible de inminencia, designa el mas propio poder ser, donde le va radicalmente su estar en el mundo: su muerte es la posibilidad de no-poder-existir-mas, que lo remite a su poder ser mas propio. De este modo, es la más propia, irrespectiva e insuperable de las posibilidades ${ }^{145}$.

\footnotetext{
${ }^{144}$ En este marco , Basso sostiene que la vía heideggeriana del temple de ánimo (Stimmung) ( en relación a la consideración de la angustia y al aburrimiento profundo -tiefe Langeweile - ) permite dar cuenta de una estructura bidimensional del Dasein ,es decir, de una escisión (Spaltung) onto-ontológica de modalidad tensiva, cuya función en la dinámica de donación del ser en el Dasein es de enlace pues, al posicionarlo en un entrelugar en la relación con el ser, se configura la condición de posibilidad para que pueda proyectarse o dinamizarse en los modos de propiedad e impropiedad como posibles ( es decir, acercándose o alejándose de sí mismo, en lo que respecta a la comprensión del ser). En este marco, esta interprete distingue que es la relación Dasein-ser aquella que explica la tensión constitutiva que empuja a la oscilación entre ocultación y desocultacion, en pocas palabras, sostiene que: "la dinámica tensiva de la estructura bidimensional del Dasein (...) es el efecto de la originaria donación sustraída del ser" Véase, Basso (2014):275-85. En este caso, entendemos tal caracterización bidimensional como un modo y distinción para dar cuenta del carácter pendular y ontológico de las modalidades de la mismidad del Dasein, lo cual se aparta de consideraciones de alternancia que puedan aún asociarse a una conciencia, polo-yo o voluntad. Asimismo, distinguimos un planteo que anticipa (o supone) la comprensión de fondo de la différance derrideana, la cual abordaremos en el último capítulo.

${ }^{145}$ En este contexto, en las primeras elaboraciones al respecto, destaca que considerar la vida ya realizada de los otros es estéril, no solo porque aquellos otros ya no están más en su allí, sino porque no pueden sustituir la propia vida De esta manera, elabora un límite-diferencia que también le permite, por contraste, denotar un ámbito de propiedad sin el recurso a un polo-yo o conciencia sustancial. Véase, KV: 165[77].
} 
Este inevitable estar arrojado hacia la muerte se le revela al Dasein con la angustia (Angst), que se manifiesta oculta en la cotidianidad debido al alivianamiento que provoca ${ }^{146}$. En este contexto de la analítica, Heidegger aborda primariamente al uno- mismo en la cotidianidad nuevamente articulado en la habladuría, distinguiendo esta modalidad discursiva como aquella que le da a conocer la manera común en que se interpreta el estar vuelto hacia la muerte: como algo indeterminado e impreciso que ocurre para el Uno en la respectiva mismidad, en lugar que para sí.

Frente a ello, el direccionamiento propio de este fenómeno que subraya Heidegger en este período de elaboraciones, no remite a una espera ni afán de ocuparse de la muerte, sino a comprenderla como posibilidad, interpretada y sobrellevada como tal, de modo que " $l a$ vida sería arreglárselas con la muerte en el presente" (KV: 166[80]), o bien, un adelantarse hacia la posibilidad como posibilidad de la inconmensurable imposibilidad de la existencia. Precisamente en ello es posible comprender el poder-ser mas propio y en este arreglárselas con ello, Heidegger articula la elección del Dasein ${ }^{147}$.

Como consecuencia este horizonte ineludible repercute en su poder ser, al tornar móviles y relativas las posibilidades en las que se proyecta, de modo que el ser-para-la-muerte impide su cosificación o reducción a mera presencia, dinamizando la historicidad del ser-ahí en esta relación, como una existencia dotada de múltiples sentidos, historicidad que muestra también su pertenencia a una época (Geworfenheit) ${ }^{148}$.

Asimismo, la muerte reivindica al Dasein en su singularidad, alistándolo hacia sí mismo (SuZ: 264[283]) y permitiéndole comprender y elegir por primera vez en forma propia las posibilidades fácticas que están antepuestas a esta posibilidad insuperable, sacándolo de la dependencia del Uno y volviéndolo existencialmente sobre sí mismo en un modo propio ${ }^{149}$. Con

${ }^{146}$ En el contexto de la distinción de resonancias y sedimentos semántico-discursivos de estas elaboraciones de Heidegger, un intérprete distingue, en el desarrollo de la angustia como disposición afectiva fundamental para la salida de la familiaridad del uno-mismo y la preparación o disposición para el sí-mismo, las huellas comprensivas y de lenguaje de lo que denomina como motivo cartesiano ( con su vertiente subjetivista), en referencia a la articulación de la siguiente dinámica : a) la inmersión del sujeto o existente humano en la familiaridad cotidiana , b) la consiguiente obstaculización de una visión plena en ella y c) la nueva disposición de distanciamiento (de las habitualidades) y transformación (de la mirada), movimiento discursivo y comprensivo que también distingue implícitamente en la epoché de Husserl. Véase, Caravedo Duran (2014):71-80.

${ }^{147}$ Sin embargo, esta consideración explícita de la elección solo se articula en sus primeras lecciones, lo cual abandonará en sus trabajos posteriores dado su énfasis volitivo. Para un análisis de la elección implícita en el estar resuelto, véase Ibid.:168 ss. [82 ss.].

${ }^{148}$ Asimismo, esta estructura permite distinguir un sesgo desde el cual dinamizar aquella mismidad primaria del Dasein en su cotidianidad. En este marco, Vattimo interpreta que el sentido fundamental de SuZ se juega en esta consideración del ser-para-la-muerte, donde figura el nexo fundamentación-desfundamentación que caracteriza el pensamiento de Heidegger en sus diversas épocas. Destaca que esta modalización de las posibilidades permite que la existencia se constituya como tejido-texto, como discurso continuo, permitiendo no absolutizar las posibilidades singulares, es decir , ninguna ya asumida como única y definitiva : el Dasein como un todo continuo solo en referencia a su propia nulificacion (Vattimo ,1992:54 s.).En el capítulo 8, desarrollaremos la recepción de este pensador italiano.

${ }^{149}$ En este marco, se torna relevante aclarar el estatuto de las posibilidades del Dasein en su vinculación con la autodeterminación, en vistas a este enfoque relacional de la ipseidad y las tensiones que Heidegger va encontrando en 
ello, el Dasein deja de estar rezagado respecto a sí, aunque tal direccionamiento dista de tonalidades afectivas de júbilo y consistencia, más bien se manifiesta en la angustia, como su disposición afectiva fundamental ${ }^{150}$.

En suma, libre de las ilusiones del Uno, cierta de sí y acosada por la angustia: la libertad del Dasein es, en este modo, una libertad para la muerte. Con esto, nuestro autor señala un aspecto no volitivo para el desplazamiento desde el uno-mismo hacia el horizonte de la propiedad. Esta consideración no sustancialista encuentra un refuerzo con el abordaje de la conciencia: encontramos aquí una desestimación fenomenológica de la eminencia de la racionalidad y la conciencia propias de la modernidad.

\section{2. c.- Un fundamento no racional para el retorno a sí: la voz de la conciencia y su consecuente resolución.}

En efecto, otro modo de dinamizar y diferir existentivamente el uno-mismo hacia el ser simismo propio en $S u Z$, es mediante una reparación de la falta de elección en la cotidianidad, decidiéndose por un poder ser desde el propio sí mismo (Selbst). Si la mismidad es formalmente

las articulaciones que elabora. Así, vistas a nuestros desarrollos posteriores, insistimos en que aquellas no surgen deliberadamente en la conciencia sino que emergen del mismo carácter proyectivo. En este marco Ferrer Santos realiza un análisis pormenorizado de la cuestión de la autodeterminación en SuZ, cuyas condiciones son el cuidado y la recaída en el Uno. Sostiene que para Heidegger, la autodeterminación es distinta a escoger entre alternativas dadas, el decidir es ante todo un decidirse con ocasión del término objetivo al que se dirige la decisión. El Dasein se comprende en sus posibilidades al proyectarlas, las posibilidades propias no son primeros proyectadas y después referidas al existente. Siguiendo a Fichte entiende que en la analítica no hay una disposición ilimitada de si, la autodeterminación se funda en la no autodeterminación de la caída en el Uno. El Dasein es determinado en la propia actividad auto determinante, pues lo primero no es la acción por la que se auto determina el yo en la medida en que ya sería antes de toda acción. De esta manera, para este intérprete convertir en objetiva la relación del Dasein consigo es enmascararla. El existente no hace emerger de si las posibilidades determinándolas, sino que, a la inversa, es la posibilidad existencial la que hace al existente existir como si mismo y volver a sí. Así, subraya que Heidegger no solo omite el término bueno, sino también la deliberación en la elección. Véase, Ferrer Santos (2001):179-193.

${ }^{150}$ Desde aquí también se inscriben las críticas a la concepción de la intersubjetividad en Heidegger, al que se le imputa un profundo individualismo en la estructura de la resolución. Coll sostiene que el análisis heideggeriano decepciona en lo que respecta a su consideración de la autenticidad del ser uno-con-otro pues encierra un profundo individualismo. Para salir de lo inauténtico en la caída en el Uno es la propia singularización aquella que nos dará la autenticidad a través de la experiencia de la angustia y de la resuelta aceptación de nuestro ser para la muerte. El individualismo se manifiesta con mayor nitidez con el ser para la muerte. Con esto se destaca la soledad de este quedar absolutamente referido a sí mismo como característica de la existencia humana autentica, que se presenta en Heidegger como esencial y permanente .Pues aunque el ser ahí auténtico debe siempre formalmente ser con otros esto no cuenta para nada en el acto en el que se decide su autenticidad. Deja claro que la autenticidad del ser con otros es consecuencia de la propia autenticidad. De este modo, al igual que el Ur-Ich de Husserl acaba en la soledad, pues es constituyente sin ser constituido. Entiende que al solipsismo trascendental le corresponde el solipsismo existencial propio de la singularización: la egologia se convierte en autologia .Véase Coll (1990):196 ss. A nuestro entender, estas interpretaciones llevan implícita una comprensión del Dasein más ligada al concepto individual de hombre, que a la significación constelada y simultánea que propone Heidegger. 
una manera de existir, pero no como un ente que está ahí, entonces tal decidir no puede articularse primariamente desde el ámbito de la voluntad, pues su analítica dio cuenta de que primariamente no soy yo mismo, sino el uno-mismo. Para una modificación existentiva primero el Dasein debe encontrarse, debe ser mostrado a sí mismo en cuanto posibilidad, y esto puede lograrlo por medio de la voz de la conciencia (Stimme des Gewissens), fenómeno que Heidegger aborda a nivel ontológico $^{151}$.

En el análisis existencial respectivo retoma su tendencia cotidiana autotranquilizadora: el Uno aligera de la carga de la existencia, con una tendencia a escamotearse la desazón (Unheimlichkeit) respectiva., por medio de la ilusión de ser soberana. Esta concepción cósica de la conciencia supone que el sujeto dispone de la vida a voluntad, pretendiendo administrarla como una posesión material .Para Heidegger la conciencia es una instancia en que se comunica la posibilidad de un poder ser propio, mediante lo cual el Dasein es sacudido de las tendencias de encubrimiento que primariamente lo dominan.

Ello se explica porque la conciencia hunde sus raíces en el cuidado: se manifiesta como un llamado del cuidado, que arranca del yugo de lo impersonal, para ser puesto súbitamente en la desazón de la existencia de la que huía ${ }^{152}$. No obstante, el llamado no es el resultado de una decisión ni expresión de la voluntad o deseo de una existencia propia: la conciencia abre, da a entender algo y se revela como una llamada $(R u f)$, es decir, como apelación modal del discurso a hacerse cargo de su mas propio poder ser sí mismo. A esta llamada corresponde luego el escuchar y la comprensión de ella es un querer-tener-conciencia, es decir, un pliegue volitivo (secundario) que repercute en la resolución (Entschlossenheit) como acto existentivo de hacer la elección del símismo. También es un modo de intimidación a despertar a su más propio ser-culpable.

La culpa, en tanto formal y ontológica, precede a todo acto o culpa concreta y, por ello, no puede sacudirse de forma ocasional. Esta idea existencial de ser-culpable remite a un carácter originario: en su existencia arrojada el Dasein no se ha puesto a sí mismo, está determinando como un poder-ser que se pertenece y que no se ha dado el mismo en propiedad .Por ello, no le está dado ser el soberano de su existencia ni crear sus posibilidades ex nihilo, sino que esta entregado a ellas en su facticidad, es decir, en y desde la situación y relaciones respectivas. No obstante, sin jamás poder adueñarse de su fundamento, puede sin embargo asumir existiendo el ser-fundamento en el poder-ser que está en juego con el cuidado ${ }^{153}$.

\footnotetext{
${ }^{151}$ Véase, SuZ: 268 ss. [288 ss.].

${ }^{152}$ Franco Volpi, siguiendo a Gadamer, argumenta que Heidegger recurrió al concepto de Phronesis de Aristóteles en esta elaboración del fenómeno de la conciencia, Véase, Volpi (2012):109 ss.

${ }^{153}$ En cursos anteriores articula el ser-culpable en la consideración del tiempo: distingue que llegar a ser culpable es mantener y hacer visible el pasado, formar parte del presente a través de sus acciones llevando consigo el pasado.
} 
Ahora bien , si el Dasein primariamente desoye su propio sí mismo hundido en el Uno , la llamada puede quebrantar esa "escucha" en la caída, en una modalidad silenciosa e inequívoca , que no da lugar a la curiosidad, sino que da a entender algo por medio de una repentina sacudida. De este modo, el mismo del uno-mismo queda privado de su escondite y es conducido hacia símismo, sin contenido específico sino tan solo como llamado a su más propio poder-ser.

Esto evidencia que las determinaciones de tal fenómeno son articuladas por nuestro autor de un modo contrapuesto a las que pertenecen al ámbito de lo Uno. En efecto, ese "algo" que llama no puede ser comunicado a otros ni discutido públicamente, tal y como ocurre con las habladurías. Asimismo, la llamada remite al Dasein hacia adelante, en su proyectarse ${ }^{154}$, mientras la ilusión de soberanía de la conciencia lo petrifica en un mero presente. En este marco, interpretamos que la comprensión fenomenológica de la conciencia mantiene simetrías con las consideraciones de las estructuras del ser-con del Dasein y de la relación con el lenguaje: en los tres casos, las notas de alteridad constitutivas ofician simultáneamente como su límite (se opone a tal o cual determinación) y su condición para el desplazamiento (desde tal diferimiento se articulan las dinámicas).

En suma, la cotidianidad comprende al Dasein como algo a la mano , algo de manejo y de cálculo soberano, frente a ello la conciencia, sin dar instrucciones prácticas, intima al Dasein a su más propio poder ser sí mismo. En este marco, la resolución remite a un callado proyectarse, en disposición de angustia, hacia el mas propio ser-culpable. Esta resolución es el primer proyectarse de la correspondiente posibilidad fáctica, en un dejarse despertar desde la pérdida en el Uno. Se abre en el ahí de la situación, a la cual nos intima a entrar la voz de la conciencia, de modo tal que pueden sobrevenir lo que usualmente se denomina como azares de la vida. Frente a ello, al Uno la situación le está cerrada, solo conoce la situación general. Con estos análisis, nuestro autor pone de manifiesto los sesgos de alteridad que operan en las dinámicas de la mismidad, de modo tal que reelabora la interpretación de tales dinámicas.

\footnotetext{
Sumado a que el estar resuelto está dirigido al futuro, esto le permite sostener otra forma de distinguir el carácter no sustancial del existente humano: el Dasein es fundamentalmente tiempo. Al respecto, agrega: "Resulta curioso que en el actuar orientado al futuro se vivifique el pasado y desaparezca el presente. En realidad actúan aquellos que viven a partir del futuro. Estos pueden vivir a partir del pasado y el presente se realiza por sí mismo. El tiempo constituye la totalidad de mi Dasein y también determina mi propio ser en cada instante. La vida humana no acontece en el tiempo, sino que es el tiempo mismo" Véase KV: 169[84-85]. Con ello subraya el singular horizonte ontológico de totalización del Dasein, desde el cual plantear la pregunta por el ser en general.

${ }^{154}$ Un intérprete distingue tensiones entre lo originario y lo auténtico en esta estructura, a partir de considerar que el proyecto de autenticidad choca y se opone al llamado de la conciencia, lo cual da como resultado un sí-mismo que parece habitado por una voz extranjera. Véase, Haar (1990):45 y ss. . Entendemos que esta tensión y alteridad funciona más bien como condición de posibilidad para el proyecto de autenticidad. A partir de tal anterioridad ontológica, distinguimos que aquella interpretación supone de cierta manera un punto de consistencia previo para el sí-mismo, apartándose así de la comprensión heideggeriana de base.
} 


\section{2. d.- Un pliegue hacia la (no definitiva) ipseidad.}

Tenemos de esta manera, los momentos estructurales que entendemos como fundamentales para marcar el periplo del Dasein desde la pérdida en el Uno hasta su resolución en vistas al propio sí-mismo. En el marco de la mismidad ¿es el yo el que designa la unidad o el polo del todo estructural?

Lo que une esta totalidad aparenta ser el yo. Pero vimos que inmediatamente no es él mismo, sino que se encuentra perdido en el Uno. Por ello, Heidegger distingue que cuando en la cotidianidad se designa como yo, lo hace comprendiéndose como el que permanece siempre siendo el mismo. En este marco, toma de Kant la consideración de que ónticamente es imposible reducir al yo a una sustancia., pero evitando volver a entender a ese yo como sujeto, con lo cual aquel caracterizó la identidad (Selbigkeit) y la permanencia de algo que ya está siempre ahí ${ }^{155}$.

En la cotidianidad, el Dasein que dice yo pone de manifiesto que aquél que lo dice es unomismo, el cual comprendido como algo simple y permanentemente idéntico, pero también indeterminado y vacio. Frente a ello, Heidegger distingue que el yo del estar-en-el-mundo remite más bien a un anticiparse a sí, que dista de articularse en una identidad.

Este es para nuestro autor el yo del cuidado, opuesto al Uno que insiste en un "yo, yo", debido a que no es propiamente el mismo, al recaer en una anulación de su carácter proyectivo ${ }^{156}$. Por ello, aquella insistencia puede entenderse como un intento de fijación. Por el contrario, la ipseidad no manifiesta tal insistencia, sino que, de un modo silencioso, el Dasein es el ente arrojado que él puede ser como propio. Entendemos que este recurso al silencio también remite a una re modalización por oposición, dentro del campo semántico desde el que se desplaza. Es decir, un silencio que oficia de contrafigura a un yo-concepto dado y estático, tal como señala en este fragmento:

"El sí-mismo revelado en la silenciosidad de la existencia resuelta es la base fenoménica originaria para la pregunta por el ser del 'yo'” (...) "La pregunta ontológica acerca del ser del sí-mismo debe ser

\footnotetext{
155 En este sentido, pueden articularse diversos modos de comprender la cuestión de la identidad, en lo que respecta a dicho aspecto de permanencia en la mismidad. Desde ello, Walton realiza un instructivo abordaje comparativo de figuras de la identidad en la fenomenología post-husserliana, entre los que distingue a Heidegger, en lo que respecta al mantenimiento de sí en la mismidad del Dasein; Levinas y Waldenfels, con sus respectivos énfasis puestos en las relaciones con el otro; Ricoeur, en su concepción de la identidad narrativa; Henry, desde su análisis de la auto afección y a Zubiri, respecto al sentido experiencial de la identidad. Véase, Walton (2001):9-49.

${ }^{156} \mathrm{Tal}$ como especifica en este fragmento: "Pero entonces el carácter de mismo del sí-mismo que existe en forma propia queda separado por un abismo ontológico de la identidad del yo que se mantiene invariable a través de la multiplicidad de vivencias" (SuZ: 130[154]).
} 
arrancada de la idea previa de un sí-mismo-cosa que perdura en su estar-ahí, idea constantemente sugerida por el uso predominante del decir 'yo'”' (Ibíd.:323[340 s.]).

En resumen, por medio de aquellas estructuras y fenómenos de alteridad, el Dasein se resuelve auto remitiéndose a su sí-mismo en su carácter proyectivo. Esta auto-remisión no supone sustancialidad alguna y cosificación del Dasein, sino una modalizacion existentiva o pliegue de las determinaciones en su caída en el Uno, que impactan en la relación consigo mismo en el horizonte de posibilidades de sí, que su carácter situado y estructural develan ${ }^{157}$. Tanto el yo como la identidad quedan del lado de esta experiencia constitutiva en la cotidianidad, mientras la ipseidad se ciñe a la propiedad del sí-mismo ${ }^{158}$. Asimismo, el carácter volitivo y racional que acompañan tales categorías de la modernidad, ceden sus prioridades ante fenómenos de alteridad develados por la angustia y al llamado de la conciencia, o de distanciamiento a partir de la disposición afectiva. Sin embargo, el uso de determinados términos o conceptos, así como también la modalidad y enfoque del análisis, aún revelan vinculaciones semánticas con la metafísica de la subjetividad, que circunscriben un vector de tensiones en estas elaboraciones de la mismidad e ipseidad.

En el próximo apartado proponemos algunas recapitulaciones de este recorrido en vistas de nuestras problematizaciones e hipótesis iniciales, orientándolas hacia las vinculaciones inescindibles entre la ipseidad y la alteridad en la analítica heideggeriana.

\footnotetext{
${ }^{157}$ De este modo, la auto-remisión propia ( de forma singular) corresponde a una ipseidad, que resulta en Heidegger el modo propio de la mismidad, pudiendo destacarse a partir de ello la puesta en valor de la auto-remisión narrativa de símismo, tal y como lo hace Ricoeur. Al respecto , Presas sostiene :"Podría suponerse en efecto, que un ineludible acompañante del hombre en la aventura de la existencia, la actividad narrativa, el relato, tanto en la crónica histórica como en la narrativa de ficción, no es un simple adorno de la vida, un entretenimiento, sino el modo más apropiado en que el existente humano da (se da) cuenta de su propia temporalidad e historicidad (...) la acción de contar, sobre todo si se manifiesta en una obra literaria de ficción, es una suerte de laboratorio experimental que reproduce y anticipar las opciones de la existencia real y de ese modo predispone para la decisión moral. Por otra parte sirve de modelo de la identidad propia, entendida no como la estabilidad de un carácter o la constancia de un ser substancial, sino más bien como ese modo de existir que se sostiene en el ser en virtud de la fidelidad." (Presas, 2002: 13 s.). En esta interpretación se manifiesta la intima ligazón entre ipseidad y lenguaje, la cual entendemos ineludible y ya vigente en estas elaboraciones de Heidegger.

${ }^{158}$ En un análisis específico de las dimensiones de la ipseidad, desde esta perspectiva, Sáez Rueda destaca que la ipseidad heideggeriana remite a una mediacion autorreferencial consigo mismo en tanto proyecto, puesto que el existente humano es historico, es decir, realiza una experiencia de sí en una trama de acontecimientos articulados temporariamente. Por tanto, entiende que la constitucion del sí mismo no coincide solo con la captacion de sí valida para todo el tiempo de una existencia, es decir, sin una referencia al devenir fáctico de quien ejecuta tal captacion de sí. Siempre se precomprende a sí mismo quien toma o rehusa una autocomprension determinada: el sí mismo implica una comprensión de sí presupuesta en toda toma de decisión, la cual es inexorable ontológicamente, aunque esto no excluye la responsabilidad de ganarse a sí mismo, de modo que en cierto pliegue del proceso la ipseidad ha de ser conquistada , asumida y ejercida en el horizonte del mundo de la vida.Esto supone una autonomía, pues al articularse en un proyecto le es inherente la facultad de fortalecerse o declinar.En este marco distingue dos ideas de proyecto, en cuyo horizonte se encuentra la identidad narrativa articulada desde los desarrollos de Ricoeur. Véase ,Saez Rueda (1998):84 y ss. En este marco, subrayamos que la especificación de la temporalidad en la cuestión de la ipseidad no debe perder de vista el carácter siempre relacional de tal mismidad, al poner énfasis en cuestiones de responsabilidad y autonomía, si pretende mantenerse en el marco de la analítica heideggeriana y en su singular significación dinámida para el Dasein.
} 


\section{3.- En camino a la consideración de la alteridad.}

Hemos visto que el Dasein en su mismidad, debido a su ser-con, presenta dos determinaciones posibles. Por un lado, el modo de ser que representa habitualmente la constancia del Dasein: el uno-mismo que en su cotidianeidad, señala estructuralmente la mismidad que no le es propia y por la cual el Dasein se pierde a sí mismo, caracterizándose en tal modalidad por la dependencia, la inestabilidad y la impropiedad en la constancia de sí. De este modo, absorto en las ocupaciones, surge un yo vacío que es correlativo a una identidad al modo del sujeto-sustancia.

Sin embargo, el Dasein puede asumir el pliegue de su sí mismo propio. Logrará dicha determinación haciéndose cargo de su propia existencia por medio de su ser-hasta-la-muerte (Sein zum Tode), en tanto su posibilidad más propia (de su más radical imposibilidad). Debido a las variables que se desprenden de ello (puede comprenderse a partir de los otros, de los útiles a la mano o también de su poder ser), es posible una comprensión respecto a sí, logrando convertirse en el fundamento arrojado de su propia finitud ${ }^{159}$. Desde aquí, se abre una modalizacion que atraviesa el complejo dinámico y simultáneo de las estructuras cooriginarias del Dasein: relaciones con los entes, con los otros Dasein, con las significaciones, con el lenguaje y consigo mismo, que ponen en tensión las estructuras de su cotidianidad y des-cubren una dimensión contingente, dinámica, no clausurable ni plenificable.

Específicamente, si de modo inmediato y cotidiano el Dasein ya se encuentra disperso en el Uno, ¿cómo es posible salir de dicha dispersión sin apelar al ímpetu voluntarista de la metafísica? : Ello es posible con una apertura a su poder ser propio, a través de la angustia y de la voz de su conciencia junto a su llamado. Esta última emerge desde las vivencias en su disparidad dimensional y llama hacia atrás (al ser-culpable del Dasein) y hacia delante (hacia la asunción de ese serculpable en el modo de la propiedad).Por medio de este llamado, el Dasein capta la constancia y firmeza de un estado contrapuesto a la inestabilidad en el Uno desde lo cual, inversamente, se

\footnotetext{
${ }^{159}$ En este marco, Carlos Astrada retoma la articulación del uno-mismo en su pasaje a la ipseidad, interpretando que también en este ser-fundamento se trata de una libertad vacía. En efecto, interpreta que el Dasein aquí carece de un querer determinado acerca de sí mismo ,es decir, de un carácter decisorio, además de no poder auto remitirse desde sí , lo que deriva en una pérdida inexorable de su ipseidad, lo cual se manifiesta en una libertad impotente para afirmarse en acto. Asimismo, la consideración de la praxis queda limitada al ámbito de lo singular, sin permitir un análisis de la praxis social en el marco de la transformación humana. Véase, Astrada (1952):79-103 y (1970):96 ss. Como veremos en próximos capítulos, esta interpretación junto a la anterior, insiste en el supuesto de un polo-yo al momento de analizar estas elaboraciones de Heidegger. Entendemos que esto es consecuencia, en parte, de las resonancias modernas que implican comenzar estos análisis desde la perspectiva del existente humano, tensión que advierte nuestro autor, en sus siguientes elaboraciones.
} 
modalizan los marcos relacionales : comprendidos con un carácter finito y provisional, en el primer caso y con la apariencia de rigidez o necesariedad, en el segundo.

No obstante, algunas tensiones se evidencian en estas articulaciones. Con la resolución precursora, el Dasein obtiene una autonomía radical, teniéndose a sí, en sí mismo. Este retorno a sí, en tanto ámbito, parece aun mantener vigentes figuraciones y resonancias del yo trascendental y del polo yo como sede de tal retorno, así como también la autenticidad alcanzada en la propiedad de sí puede sugerir en primera instancia, una posibilidad de superación de las determinaciones situacionales y de alteridad irreductibles. Entendemos que estas resonancias y asociaciones derivan de una analítica que parte y se orienta desde la perspectiva del Dasein, la cual mantiene en parte estas elaboraciones bajo el yugo de la articulación desde el lenguaje en el ámbito de la metafísica $^{160}$. Será por medio de un mayor desarrollo del enfoque relacional, desplegado en el siguiente período de sus elaboraciones, desde donde proponga esquivar estos resabios metafísicos.

Por otra parte, el singular recorrido de Heidegger en relación con la tradición con la que discute, evidencia articulaciones con los resultados de la investigación que realiza. Por ello se torna necesario revisar las continuidades entre sus elaboraciones y el despliegue de su propio discurso, tomando distancia de aquellas recepciones y análisis que interpretan deficitariamente discontinuidades, rupturas y transformaciones en las elaboraciones de nuestro autor.

En este sentido, las condiciones de posibilidad para los plegamientos modales de la mismidad y de las reelaboraciones conceptuales en el discurso de Heidegger, se articulan con el carácter inesencial tanto del Dasein como del lenguaje. En efecto, el carácter proyectivo e inacabado del Dasein y su finitud como posibilidad más propia, contrapuestas a la yoidad y la tranquilización de la caída en el Uno, permiten giros modales y dinámicas en la asunción de la mismidad. Por otra parte, la vía del análisis del lenguaje de la tradición, a partir del marco categorial y conceptual heredado, devela un suelo aun fértil del pensar, cuya problematización da cuenta de olvidos, encubrimientos y ocultamientos, que también permiten reelaboraciones, distinciones y giros. Por tanto, estas modalizaciones necesariamente deben inscribirse en el modo de pensamiento y articulación lingüística que utiliza: con la utilización de conceptos y categorías dinámicas, en formación, desplazables, etc., frente al carácter rígido e inflexible de las significaciones y conceptos en el habla de la cotidianidad del Uno.

\footnotetext{
${ }^{160}$ Es necesario insistir en que, tanto en SuZ como en sus trabajos anteriores, Heidegger insiste en la imposibilidad de superación definitiva de las estructuras del Dasein en su cotidianidad. Por ello, insistimos en que el carácter sugestivo se desprende de las modalidades y orientaciones que atraviesan el campo semántico de la discursividad en esta etapa. Con una lectura del opus magnum de Sartre, podemos circunscribir las resonancias posteriores de tales orientaciones. Véase, Sartre ,1972[1943].
} 
En suma, la resolución del Dasein emerge a partir de la dispersión del Uno y su inconstancia (Unselbständigkeit), alcanzando así la propiedad en un proyecto donde la herencia de las posibilidades pasadas y su re-asunción como posibilidades futuras no clausurables, se insertan en el horizonte de su proyección. Esta reapropiación de la tradición se renovará fácticamente proyectando nuevos usos y modalidades respectivas en sus posibilidades heredadas, abandonando la comprensión de un yo idéntico e invariable a través de su existencia.

Ahora bien, en sus trabajos posteriores, Heidegger manifiesta mayores reparos en la articulación lingüística en esta obra y cursos anteriores, la cual entiende aún bajo el influjo del lenguaje y el campo semántico con la que discute. Como vimos, esto se debe a la matriz del pensar y el lenguaje metafísico, es decir, más que a su gramática y sintaxis, a una modalidad de articulación y orientación relacional en dicho ámbito.

Aquellas dinámicas en tanto modalizacion existentiva del Uno, tornan impensable una perspectiva segregacionista en estas elaboraciones. En este sentido, la estructura co-originaria del ser-con, también se ve modalizada con esta resolución precursora. Entre sus consecuencias encontramos la problematización o consideración de cuestiones éticas, en el marco de vínculos entre la ipseidad y la alteridad, que a continuación analizaremos. 
“... me di cuenta por primera vez, según las metamorfosis que se habian producido en todas esas personas, del tiempo que habia pasado para ellas, lo que me trastornó por la revelación de que éste habia pasado también para mi”" (...) "De modo que si me restara bastante tiempo para cumplir mi obra, no dejaría ante todo de describir a los hombres, aunque ello debiera hacerlos parecer seres monstruosos, como si ocuparan un lugar enorme, comparado con el tan restringido que les está reservado en el espacio, un lugar por el contrario prolongado sin medida, puesto que como gigantes hundidos en los años, tocan al mismo tiempo épocas muy distantes que han vivido y entre las cuales han venido a colocarse tantos días. En el Tiempo.” (Marcel Proust, El tiempo recobrado)

Capitulo 4. Desde la alteridad. Hacia un horizonte de la eticidad en las elaboraciones de la época de $S u Z$.

En el presente capítulo desplegaremos algunos de los alcances y consecuencias de estos análisis de la mismidad del Dasein, en el modo de la ipseidad, que se articulan ineludiblemente con la alteridad, en el primer período del pensamiento de Heidegger. Dada la complejidad y multiplicidad inherente a esta analítica por parte de nuestro autor, retomaremos a continuación 
algunas de las estructuras fundamentales, enfatizando el carácter relacional entre la inconsistencia del Dasein y su situacionalidad con los otros Dasein.

En efecto, el carácter estructural y co-originario del ser-en-el-mundo y el ser-con del Dasein en su facticidad, requiere un desmontaje analítico de las piezas que conforman tal complejo, sin descuidar su enlazamiento, correlación y carácter simultáneo. Por esta razón, nuestros análisis se han desplazado en una secuencia que parte de la comprensión general del existente humano al enfoque particular de la mismidad, en un vaivén que retoma varias veces los mismos nexos. Si a esto le sumamos las distinciones modales que desarrolla Heidegger, parece necesario duplicar tales recorridos.

En este marco, retomaremos la consideración de la mismidad desde su elaboración en SuZ, cotejando con sus desarrollos inmediatamente posteriores. Especialmente indagaremos en torno al carácter permanente o consistente de la resolución precursora en la ipseidad del Dasein con sus tensiones respectivas. Es decir, si la insustancialidad y el carácter proyectivo son las notas más relevantes de esta autoremisión propia ¿cómo puede entenderse una propiedad que no sea una mera fugacidad, un punto lábil y precario en la temporalidad del Dasein en permanente desplazamiento?

Precisamente entre los últimos parágrafos de SuZ, Heidegger despliega un análisis de tal mantenimiento del sí mismo del Dasein, que interpretamos en línea con la comprensión y reelaboración que plantea a partir de su cuestionamiento del lenguaje y conceptualización de la tradición. Aun así, hemos visto que preserva el empuje y las resonancias volitivas de las perspectivas subjetivistas, cuestión que lo conduce a un replanteamiento de estas cuestiones en cursos posteriores, a partir de las cosmovisiones del mundo históricas, poniendo un mayor énfasis en el complejo del ser-con y las sedimentaciones del lenguaje, desde cuya exposición propone apartarse de las notas individualistas o aisladas.

De esta manera, distinguiremos su desplazamiento de análisis hacia el campo interrelacional originario del Dasein, de modo tal que nos permita articular sus elaboraciones respecto a la alteridad tanto en su exposición como en su modalidad de análisis. Por ello, la problematización que orientará nuestro recorrido puede articularse de la siguiente manera: ¿cuál es el desplazamiento que propone, respecto al enfoque fenomenológico de la intersubjetividad y la alteridad de su maestro Husserl? ; ¿cuál es el estatuto de una posible constancia o estabilidad en la ipseidad, tanto en la relación con su sí -mismo, como con los otros? ¿Cuáles son los límites y condiciones que estos abordajes ontológicos puede presentar en la indagación de las relaciones entre alteridad e ipseidad en proyección a cuestiones éticas?

Entonces, tomando como punto de partida la alteridad subyacente al discurso y a los caminos del pensar de nuestro autor, comenzaremos con una presentación y análisis de diversas 
elaboraciones de Husserl en torno a la intersubjetividad, la cual funcionará como un contrapunto para los desarrollos y distinciones de Heidegger, entendiendo que aquella es una de las principales perspectivas desde donde parte y con la que discute. Así, luego de delinear el estatuto fenomenológico del otro, la corporeidad y la comunidad monádica en relación con la esfera del yo, vincularemos con la concepción del mantenimiento de sí en la ipseidad que desarrolla Heidegger en textos y cursos de finales de la década de 1920, desplegando sus momentos constitutivos. A partir de allí, articularemos sus análisis históricos de las visiones del mundo, que van del mito a la emergencia de la filosofía, con el objeto de dar cuenta de su desplazamiento hacia consideraciones de la mismidad desde la estructura del ser-con. Finalmente, estableceremos puntualizaciones respecto a la alteridad y a las relaciones con los otros, en vistas de tensiones o consideraciones éticas.

\section{1.- Husserl y la alteridad a partir del ego.}

En capítulos anteriores hemos presentado una contraposición entre la reducción fenomenológica del yo trascendental desprendida de la facticidad, frente al análisis del sí mismo en Heidegger, el cual permanece imbricado en la facticidad del ser-en-el-mundo del Dasein. En este contexto, la temporalidad se torna de gran relevancia en los análisis fenomenológicos, destacando lo que algunos autores distinguen como el paso de la egología de Husserl a una egocronía que se afianza con Heidegger ${ }^{161}$, subrayando continuidades del último tramo del pensamiento de Husserl, respecto a la indeclinabilidad de la reducción eidética que llega al yo originario (Ur-Ich) aunque evidenciando su carácter temporal ${ }^{162}$. Pero más allá de las interpretaciones de continuidades o rupturas entre ambos pensadores, estas consideraciones establecen un umbral para la discusión moderna que parte de categorías de la metafísica de la subjetividad (objetivante y presentificante), al establecer bases para el abordaje centrado en la temporalidad del sí mismo a partir de su inacabamiento y apertura en el horizonte de sus posibilidades, propio de la perspectiva de Heidegger.

En este marco, la cuestión de la mismidad, articulada en transición con la metafísica de la presencia, presenta claras conexiones con la consideración de la alteridad y la intersubjetividad. Los

\footnotetext{
${ }^{161}$ Véase Cruz Velez, 1970:185. Ello lo distingue en el marco de las concepciones en torno al yo y en los argumentos de lo que interpreta como la superación heideggeriana de la metafísica de la subjetividad, véase Ibid.:158-214.

${ }^{162}$ Especialmente, en el contexto de sus elaboraciones en Husserl ,1956; 2014.
} 
respectivos desarrollos de Husserl se manifiestan como uno de los interlocutores fundamentales de nuestro autor, lo cual torna necesario establecer ciertas puntualizaciones.

En efecto, en Cartesianische Meditationen (CM) y sus Pariser Vorträge publicadas también en 1931, Husserl desarrolla más ampliamente la cuestión de la reducción a la "intersubjetividad"163, enmarcada desde una fenomenología estática hacia el horizonte de un abordaje de tipo genético ${ }^{164}$. Especialmente en la V meditación, busca explicitar en la esfera de lo propio, la experiencia que justifique todo discurso acerca de otra subjetividad y, con ello, toda enunciación de un mundo objetivo, válido para cada uno. La experiencia del otro ocupará así un lugar eminente, explicitándola como esfera del ser trascendental del ego dando cuenta, contra los escollos del solipsismo, que "no es posible que tenga sentido para nadie un mundo que se limite a ser el ámbito infinito de mi soledad personal" ${ }^{165}$.En esta línea encontramos análisis que se manifiesta parcialmente a distancia de consideraciones estáticas o cerradas del polo-yo.

Aquí , Husserl destaca que una reflexión desde el ego aislado corre el riesgo del yo solitario, distinguiendo que aquél es el medio para el descubrimiento de una intersubjetividad absoluta (FTL:241-4[283-6]): el yo de partida no es un género universal de yo sino algo que así denominamos por un equívoco, pues el yo es por principio indeclinable y único (por lo cual, no es posible partir desde la intersubjetividad trascendental en la epojé), escollo que busca sortear explicitando la esfera de la intersubjetividad a partir de aquél(KW:188[225]). No obstante, en el contexto del horizonte de cientificidad de su método, entiende necesario encontrar en uno mismo la experiencia que justifique todo discurso acerca del otro y de un mundo objetivo, válido para cada uno, es decir, desde la soledad egológica acceder a la necesidad de la presencia y significaciones de los otros, sin renunciar a la subjetividad absoluta, sino mas bien ahondando en su contenido de alteridad.

En estos análisis retoma como punto de partida la corriente de las puras vivencias de conciencia, desde la reducción trascendental, para penetrar en la intencionalidad donde otros egos se enuncian y verifican, teniendo como hilo conductor el darse óntico-noemático del otro.

Podemos esquematizar tal darse noemático del otro en estos análisis, de la siguiente manera: a) como alter ego en la esfera primordial del ego; b) como co-presencia del otro en el mundo

\footnotetext{
${ }^{163}$ En esta obra puede distinguirse una confluencia de sus primeras elaboraciones y análisis sobre la alteridad y corporalidad. Los respectivos antecedentes se encuentran en Logische Untersuchungen II e Ideen II. Para un análisis comparativo de este trayecto, véase Iribarne (1998).

${ }^{164}$ Como veremos, la fenomenología estática analiza situaciones de tipo terminal en el desarrollo de la vida del yo; por su parte la fenomenología genética tiene en cuenta las remisiones retrospectivas de la situación temporal en la que se encuentra el yo. La mención de tal horizonte, remite al giro genético de la fenomenología de Husserl, en sus trabajos de madurez. Para un análisis pormenorizado de este contraste en el marco de una fenomenología de la intersubjetividad en Husserl, véase Walton (2009).

${ }^{165}$ A este respecto véase el análisis de Xirau (1966):199.
} 
intersubjetivo común, en dos vertientes: I) en significaciones y sentidos culturales, en utensilios y herramientas, etc., II) Con su cuerpo físico apresentado como cuerpo orgánico; c) finalmente, por medio de la analogía, da cuenta una singular consideración de la comunidad monádica.

Presentemos brevemente cada una de estas modalidades con el objeto de argumentar que, si bien Husserl pone de manifiesto huellas del otro en la esfera del yo y el mundo común, aún continúa desplegando sus análisis en el marco de un dualismo no superado, con su correlativa comprensión del ser implícita en esta perspectiva con pretensión de fundamentación absoluta. Entendemos que el punto de partida del ego puro, en su metodología fenomenológica, le obstruye de determinada manera la posibilidad de superar tales escollos.

\section{1. a- Lo extraño en el modo del alter ego.}

Husserl distingue que, si la realidad del mundo físico se manifiesta en el fenómeno de la percepción, entonces aquella que corresponde a la psique ajena se revela primordialmente en el fenómeno de la empatía o introafeccion (Einfühlung). A partir de este, explicita la realidad mental que anima y da sentido a la realidad del prójimo, partiendo del sentido "sujetos extraños" antes que de los sujetos objetivos, existentes en el mundo, es decir, pone de manifiesto la alteridad, por medio de un desdoblamiento del ego.

En un primer momento de la reducción tenemos la esfera primordial o de la propiedad (Eigenheitssphäre), que comprende lo que pertenece al ego trascendental una vez reducido todo lo perteneciente a lo extraño: Husserl procede a realizar una epojé dentro de la esfera trascendental, abstrayendo las efectuaciones de la intencionalidad de la subjetividad extraña, reduciendo sólo a su esfera trascendental propia. Así, el ego empírico ("yo, este hombre") deja paso a una estructura esencial de la constitución universal en la que transcurre la vida del ego trascendental, que incluye toda intencionalidad, incluso la dirigida a lo extraño.

Precisamente allí se constituye un ego como reflejándose en el yo propio del fenomenólogo, pero se constituye como alter ego, es decir, como otro yo que remite al del fenomenólogo en tanto analogón de sí mismo, lo que implica que lo capto como aquel para el que también yo mismo soy otro (como él lo es para mí) y para el cual existe un mundo tal y como existe para mí. No obstante, esta captación de la alteridad y sus huellas en el ámbito de lo propio, no se da sin cierta diferencia irreductible revestida de alteridad, como queda expreso en este sintagma modulado en dos 
dimensiones: "El otro es reflejo de mí mismo y, sin embargo, no es estrictamente reflejo" (CM: $125[156])$.

De esta manera, se describe una experiencia de alteridad en la esfera primordial del ego, que da cuenta también de una separación, un lapso, una diferencia entre el ego y el alter-ego. Aún así, el resultado de esta reducción parece condicionar y direccionar los aspectos manifiestos de dicha alteridad, pues su campo queda ligado irremediablemente a la esfera primordial como sede de manifestación ${ }^{166}$. Distingamos estas cuestiones en otras manifestaciones noemáticas de la alteridad.

\section{1. b.- La naturaleza primordial y el yo personal.}

En esta esfera primordial lo extraño también se presenta co-determinando el sentido del mundo, y es aquí donde Husserl profundiza su abstracción en diferentes niveles : a) de lo que da su sentido a los seres del genero del yo, b) de todas las determinaciones del mundo fenomenal, los predicados culturales, herramientas, etc. , que remiten o presuponen ( por su sentido ) a otros yo , c) el carácter de pertenecer al mundo circundante de cada uno y que constituye su extrañeza (valoraciones, aspiraciones, etc.). Lo que queda revelado luego de esta triple abstracción es un estrato unitario del fenómeno "mundo" (en tanto correlato trascendental de la experiencia del mundo) que se manifiesta como condición de posibilidad de la experiencia de lo extraño y del sentido "mundo objetivo". En otras palabras: me encuentro siendo en una naturaleza en la esfera de mi propiedad, la cual es anterior a todo sentido de una naturaleza "objetiva", que permite dar cuenta del mundo circundante según la diversidad condicionada de los hombres, como otra de las manifestaciones noemáticas de alteridad.

Este Lebenswelt propio (cuya traducción usual es mundo de la vida), es decir, el que he constituido en mí a priori bajo la dirección del ego puro y transformado en cada cambio de mi

\footnotetext{
${ }^{166}$ En este sentido, interpretaciones recientes distinguen que ya la concepción de la intencionalidad de Husserl deja al otro en cierto campo especular o representativo del yo, de modo tal que la comunidad intersubjetiva resulta una suerte de yo ampliado. A este respecto, Rossi-Muñiz sostienen: "si lo que se trata es de demostrar como el otro es posible, es porque no puede mostrar la necesidad de su aparición. Así, el problema del otro termina siendo un problema exterior, innecesario para la experiencia fenomenológica pura. La que abre la puerta al otro es la suposición de su presencia, no su inevitabilidad. Convertida en mero dato fenoménico en las lindes del propio yo, la alteridad no resulta así más que una modificación del ego (...) el otro no dejará de ser más que un reflejo, un eco en las profundidades del propio yo. Sin embargo, esta premisa no dejará nunca de ser problemática. Pues lo que la vida natural constata no es armonía sino discordancia, no acuerdo sino lucha. El otro no es simplemente un análogo a mí, un igual: es Otro”. Véase, Rossi y Muñiz (2012):83. Con evidentes resonancias de Sartre y Levinas, estos autores ligan el supuesto de la armonía y la comprensión de lo otro, en un condicionamiento dado por el punto de partida del análisis. Dar cuenta propiamente de la alteridad, parece implicar un rompimiento radical con estas reducciones de partida.
} 
mismidad, contiene elementos trascendentales, pues el mundo objetivo propio solo puede obtener validez sobre la base del acuerdo general, es decir, sobre una base intersubjetiva. Sólo por medio de la constitución de la intersubjetividad se edifica este mundo experimentable, donde cooperan los egos puros en la constitución de un mundo común ${ }^{167}$.

Así, distingue en su experiencia de reducción fenomenológica un mundo intersubjetivo de sentidos, en el seno de la propia experiencia sintética del ego: las huellas de sentido presentificadas en objetos culturales, por ejemplo, dan cuenta de un mundo trascendental anterior al mundo fenoménicamente constituido.

De este modo, ha llevado a cabo lo que denomina como apercepción mundanizante de sí mismo (verweltlichende Selbstapperzeption), donde distingue todo lo incluido en su propiedad trascendentalmente, como condición de que algo entre en su psique como psíquico (Ibid.:130[163]). Esto se articula con aquella primera experiencia de lo extraño en el ego, al modo de un alter ego. Veamos como también aquí halla nexos de la experiencia de los otros.

\section{1. b.I.- La apercepción analógica.}

En efecto, si el fenomenólogo puede oponer otra cosa a su esencia en su esfera propia, ello presupone que no todos los modos de conciencia propios pertenecen a los modos de la autoconciencia. En otras palabras, frente a la experiencia de sí y al sistema de su concordancia, se ponen de manifiesto en su ego otras experiencias que forman sistemas de concordancia, por medio de lo cual el ego trasciende su propio ser hacia la alteridad, lo otro.

Entre los cuerpos físicos del estrato unitario de la naturaleza primordial, se destaca en su preeminencia mi cuerpo físico-orgánico $(L e i b)^{168}$. La posición del propio cuerpo determina una perspectiva en el mundo que es la base para la percepción de los demás cuerpos ${ }^{169}$. El cuerpo es orgánico pues lo comando de modo inmediato y le atribuyo campos de sensación, experimento la naturaleza y la propia corporalidad orgánica ${ }^{170}$.

\footnotetext{
${ }^{167}$ Para su desarrollo diacrónico en torno al Lebenswelt y las relaciones comunitarias, véase DL.

${ }^{168}$ Siguiendo la traducción y distinción que realiza Presas, comprendemos que este cuerpo en la esfera primordial tiene dos caras: es un cuerpo físico como cualquier otro (Körper), pero al mismo tiempo es un cuerpo orgánico (Leib) sentido y vivido "desde adentro". Presas (1983):.48, cfr. CM: 127-9[159-61].

${ }_{169}$ Para una distinción de las funciones del cuerpo propio, en las cuestiones de orientación, espacialidad y percepción véase Ideen II: 55 ss. [87 ss.]

${ }^{170}$ Podemos encontrar interpretaciones y análisis que abordan los aspectos activos del ego y otros que ponen énfasis en los aspectos pasivos en su constitución, para dar cuenta de la alteridad constitutiva y primaria. Por ejemplo, para el primer caso, Rabanaque desarrolla la consideración de Husserl del cuerpo y las cinestesias, en su función de la
} 
Si otro hombre entra en el campo de mi percepción, por medio de una apresentacion ${ }^{171} \mathrm{se}$ realiza, a partir de mi autopercepcion y la de mi propio cuerpo, una trasposición aperceptiva, ligando aquel cuerpo al mío en virtud de sus semejanzas. Esta trasposición nos es dada simultáneamente en el acto de percepción o apercepción dentro de la esfera primordial ${ }^{172}$, por lo cual no puede ser comprendida como una inferencia del pensamiento. Husserl pone de relieve que toda apercepción contiene una intencionalidad que nos remite a un objeto de un sentido análogo, que se constituyó ante mí por primera vez, y subraya: conocemos lo nuevo por medio de una referencia a lo antiguo ${ }^{173}$.

Así, con la apercepción analógica, Husserl también explicita un modo de funcionamiento intencional en lo que respecta al sentido: realizamos una anticipación del sentido con sede en una experiencia anterior, donde toda nueva creación de sentido objetivo lleva implícita esta aptitud de anticipación y asimilación, enriqueciendo gradualmente el caudal de la experiencia personal. Este funcionamiento de trasposición y anticipación figura también en la comprensión de sí y del otro a partir de la corporeidad.

\section{1. b.II-. La cuestión del cuerpo y la opacidad del otro.}

Por otra parte , subraya que no es necesario postular una armonía de tipo exterior para las relaciones entre conciencias, cuando sólo basta la co-presencia de unas a otras, donde se establece una comunidad armónica con la percepción de la personalidad ajena en tanto otro yo idéntico al mío , lo cual implica la aptitud para la comprobación intuitiva de los contenidos ideales implícitos en la significación y el sentido de sus menciones, en otras palabras, una armonía que es condición de posibilidad para una comunidad de sentido y de habla. De este modo, Husserl sostiene que a la constitución del mundo objetivo le corresponde esencialmente una armonía de las mónadas, es decir, una intersubjetividad con sujetos que tienen una constitución intencional mutuamente correspondiente y concordante (Ibid.:138[173] ). Esta armonía deriva de la constitución de cada una

\footnotetext{
constitución del cuerpo propio como estrato primigenio de alteridad, aunque atendiendo especialmente el carácter yoico de estas, es decir, su aspecto activo para la conciencia. Véase, Rabanaque (1998):2 ss.

${ }^{171}$ Término que refiere a la apercepción analógica y designa el estar co-presente un ser-también-ahí en el sustrato del mundo primordial. El término remite precisamente a esta co-presencia. Siguiendo el análisis que realiza Szilasi, podemos aplicar el término cuando: "Sobre lo presente se ha construido un estrato secundario trascendente", Véase Szilasi (1959):.142.

${ }^{172}$ Entre las apercepciones pueden distinguirse las que pertenecen por su génesis a la esfera primordial en la que aparece ante mí el mundo y las que se levantan sobre el mundo con el sentido específico de "otro yo".

${ }^{173}$ Husserl nos ofrece el ejemplo del niño que ve las tijeras una vez que ya comprende su sentido (CM: 141[177-8]).
} 
de las mónadas y de una génesis que se realiza armónicamente en la convivencia comunitaria ${ }^{174}$. Aclara que no refiere a una construcción metafísica de la armonía monádica, sino a la explicitación de los contenidos intencionales que yacen en el mundo de la experiencia que existe para nosotros, es decir, a partir de las huellas de alteridad que encuentra en las reducciones antes mencionadas en 1.b y 1.b.1. Sin embargo, pueden presentarse algunas dificultades para admitir que la armonía monádica se evidencia estructuralmente en esta explicitación intencional, más bien se manifiesta como un supuesto a priori ${ }^{175}$.

Hemos visto que por medio de la apercepción analógica percibimos el cuerpo físico extraño como cuerpo orgánico. Esta aprehensión analogizante indica que la instauración originaria es siempre presente y viviente (en el sentido de estar en marcha permanente), aspecto que señala que ego y alter ego son dados en un originario apareamiento (Paarung), es decir, presentándose configurados como par en esta actualidad viviente. Esto explica la coincidencia mutua de intercambio de sentidos: por aquel se efectúa una transferencia de sentido en los elementos apareados, lo cual remite a una asociación por medio de una síntesis pasiva ${ }^{176}$.

Asimismo lo apresentado por esta asociación (la unidad psicofísica del ego de aquel cuerpo percibido) no puede llegar efectivamente a la presencia, es decir, el yo ajeno no se manifiesta directamente como "el mismo ahí", pues es otro yo en el modo de alter ego y no una cosa constituida en mi subjetividad. Si lo percibiese directamente, su mundo pasaría a ser mi mundo y la analogía se convertiría en identidad en tanto constitución sintética de mi propio ego (Ibíd.: 1389[174]).

En efecto, esta apresentación tiene un estilo de verificación que difiere del caso de la percepción. Este modo queda aquí excluido puesto que el otro es apresentado como centro constituyente de su mundo y no puede aparecer como objeto constituido presente en mi mundo primordial. Aquel cuerpo se anuncia como orgánico solo en su comportamiento, cambiante pero concordante. De esta manera, distinguimos que, en parte, el otro se manifiesta aquí como reflejo

\footnotetext{
${ }^{174}$ Atiende al caso de las anomalías físicas como posible objeción. Ante ello sostiene que toda anomalía supone un contraste con una normalidad que le precede. Véase, Ibid.:154[195].

${ }^{175}$ En este sentido Celms desarrolla la interpretación de que esta hipótesis aparta a Husserl de su pretendida rigurosidad. e, incluso, que lo conduce de un solipsismo monista a un solipsismo pluralista. Véase, Celms (1931):162-172.

${ }^{176}$ Husserl entiende al apareamiento como una forma originaria de la síntesis pasiva en el modo de la asociación (es decir, respecto a la coincidencia mutua del intercambio de sentidos objetivos). La síntesis pasiva designa aquella síntesis de unidades fenomenológicas (fenómenos) que la conciencia encuentra ya hecha, es decir, que no procede de su actividad (como si lo es, la actividad lógica de juzgar; la búsqueda de estados de cosas-eidéticos mediante intenciones de significación, por ejemplo.). Este tipo de síntesis es pre-lógica y ante-predicativa y la actividad lógico-eidética de la conciencia puede analizarla de un modo posterior. Este concepto, si bien problemático en la teoría de Husserl, proporciona la posibilidad de reflexionar sin concepto las unidades fenomenológicas como tales, es decir, los fenómenos solo como fenómenos. Para un análisis de los aspectos problemáticos de este concepto, en sus vínculos con la temporalización, véase, Richir (2012): 665-692.
} 
(Spiegelung) del yo, en tanto modalidad de analogía (Analogon), dándose así una duplicidad entre el ego y lo ajeno, en una suerte de objetivación de sí.

Aquel aspecto es crucial para comprender la función del apareamiento y la empatía (o mejor, sus consecuencias): comprendo su cólera o alegría, por ejemplo, a partir de mi propio comportamiento en circunstancias similares. De este modo toda comprensión lograda del otro no solo abre nuevas posibilidades para su comprensión, sino también respecto a la propia vida anímica en su similitud y diferencia.

En suma, la empatía o experiencia introafectiva del cuerpo del otro, está constituida por dos estratos: el cuerpo físico (Körper) ajeno, como inmediato y originario dado en la intuición sensible y otro co-presente a él y fundado en él (cuerpo orgánico-físico - Leib -), que no puede ser intuído en su integridad: tan sólo podemos llegar a la cuasi-presencia del yo ajeno y, por ello, sin la apodicticidad del cuerpo propio ${ }^{177}$. Desde esta distinción es posible destacar la encarnación del ego en el mundo ${ }^{178}$.

Finalmente, la constitución del mundo común se efectúa también por medio de apresentaciones habituales comunes a los distintos egos; dicho brevemente: mi ego, dentro de la constitución del Lebenswelt propio, añade a las presentaciones intencionales, apresentaciones en las cuales se constituye la objetividad del mundo común. Estas designan el estrato del mundo objetivo que procede de las determinaciones que nos son comunes, relativas al ámbito de la actualidad ${ }^{179}$. Este mundo objetivo (objektiv) esta empobrecido en comparación con mi Lebenswelt puesto que, como vimos, me está cerrado el acceso directo del Lebenswelt propio del otro ${ }^{180}$.

En este contexto de análisis, abordar brevemente la consideración de la comunidad nos permitirá evidenciar que las remisiones a escalas mayores de relaciones entre mónadas, también

\footnotetext{
${ }^{177}$ Mario Presas articula una continuidad de estas consideraciones acerca de la experiencia del otro con los enfoques de Gabriel Marcel y Max Scheler. Subraya que el concepto de subjetividad que Husserl maneja remite a una dimensión gnoseológica. Tomado de otros tramos de la obra de Husserl y de los enfoques mencionados, Presas entiende esta experiencia como la confluencia de dos libertades (y no la mera suma de dos sujetos gnoseológicos), perspectiva que permite plantear estas cuestiones en términos ontológicos más adecuados. Así, la experiencia del otro percibida como presencia irreductible marca "el encuentro con un ser libre-con un tu- que me hace ser yo apelando a mi propia libertad. La mirada del otro, lejos de cosificarme - como pensaba Sartre- promueve mi propio ser". Presas (1983):50. En esta línea, Landgrebe analiza la motivación innatural que subyace al proceder fenomenológico en la epojé, la cual entiende como un acto de libertad en sí mismo. Véase, Landgrebe (1968): 302-315.

${ }^{178}$ Rabanaque interpreta que el Leib en la fenomenología de Husserl oficia de puente vinculante entre subjetividad y mundo, véase Rabanaque (2013):3-5.

${ }^{179}$ Sartre encontrará aquí un camino de análisis para la relación yo-prójimo, (con su tesis de antagonismo según la cual el infierno son los otros) que desarrolla ampliamente en su obra de 1943 (especialmente en la tercera parte).

180 En este marco es posible sostener y oponer a este empobrecimiento, el enriquecimiento que proporciona, por ejemplo, la experiencia literaria. A nuestro entender, la experiencia artística posiblemente sea un modo auténtico de acceso al Lebenswelt propio del otro, en contraposición a experiencias y relaciones de sometimiento, dominación y alienación, que conducen aquel empobrecimiento hasta la extinción de esta esfera del otro, tal y como desarrolla respectivamente Sartre en la obra citada anteriormente.
} 
presenta una articulación por la vía de la analogía o semejanza la cual, en última instancia, se mantiene ligada a la esfera primordial del ego y el campo comprensivo que le es correlativo.

\section{1. c.- Paralelos con la comunidad monádica.}

Como vimos, el mundo propio se aplica a un mundo objetivo por medio de aquel estrato de sentido descubierto en el ego, desde donde Husserl distingue la comunidad monádica (Monadengemeinschaft) $^{181}$. Esta puede ser comprendida como intersubjetividad trascendental, debido a las huellas que la remiten al ego en su fundamento, la cual permite dar cuenta de relaciones intermonádicas que son independientes y autónomas del mundo natural ${ }^{182}$. Abordemos brevemente algunas de estas consideraciones.

Específicamente, distingue tres estratos para el análisis de la relación entre conciencia y mundo: el estático (remite a la relación entre polo-yo y polo-objeto, en el horizonte indeterminado de mundo), genético (aborda la historia intencional del horizonte de mundo, donde el yo se determina como sustrato de habitualidades y el objeto como sustrato correlativo de sedimentaciones) y monadológico (articula los resultados de aquellos dos modos de abordaje) ${ }^{183}$. En el primero, el ego se da como vacio e idéntico al igual que el objeto; en el segundo, se ponen en evidencia su historia y el objeto se revela como perteneciente a un mundo circundante determinado. Es precisamente en el tercer caso donde se evidencian las relaciones intersubjetivas y las relaciones con el entorno: los objetos son aquí culturales y los sentidos son compartidos en un mundo común. Como vimos, el pasaje de la egologia genética a la intersubjetividad, se articula desde la

\footnotetext{
${ }^{181}$ En este apartado, abordaremos algunas consideraciones de la comunización (Vergemeinschaftung) de las monadas, principalmente en tres trabajos: Ideen II: 173-281[219-328]; CM: 159-66[189-211] y DL: 145-206.

${ }^{182}$ Una corriente de investigación reciente (en la recepción que destaca la dimensión pasiva de la remisión a sí) articula las ciencias cognitivas con la consideración de una intersubjetividad trascendental en Husserl, en su giro a la fenomenología genética: la denominada New Husserl, entre cuyos exponentes se encuentran Dan Zahavi y Osswald, entre otros. Específicamente, interpretan en tal intersubjetividad una cooriginariedad (Gleichursprünglichkeit) pasiva y pre-reflexiva de sujeto, mundo e intersubjetividad, los cuales se articulan en una equiprimordialidad (equiprimordiality) constitutiva. Para abordajes de esta corriente, véase, Zahavi (2003b); Osswald (2014); Welton (2001). En este marco, un reciente trabajo comparativo parte de la hipótesis de un New Heidegger en los escritos de juventud, donde Heidegger rechaza una auto-donación del ego previo a la facticidad del ser-en-el-mundo, postulando una distancia o diferencia originaria, para subrayar : "En todo caso, antes que de reflexión (...)cabría hablar de una cierta reflexividad hermenéutica, entendida ésta como el oblicuo referir a sí desde el encontrarse (Sichbefinden) ya siempre fuera de sí viviendo en el mundo(...)Pues según constata Damasio cuando aborda el problema del yo, no hay un acceso inmediato a sí mismo desde sí mismo, según creía Descartes. Y es que, como afirma el neurocientífico portugués, el presente nunca está aquí, siempre llegamos demasiado tarde a la conciencia”, véase Garcés Ferer (2015):54. Entendemos que en esta última alusión kafkiana figuran los límites irrebasables que evidencia la analítica de Heidegger.

${ }^{183}$ Véase ,CM:100-3[118-22]
} 
consideración del cuerpo propio y también en la naturaleza primordial, por medio del recurso a la analogía, la semejanza, el apareamiento y la empatía.

En el análisis de estos estratos, el mundo común y compartido prefigura el mundo natural. Asimismo, allí se ponen de manifiesto participaciones en comunidades voluntarias o uniones de personas (Personenverbände), donde se adquieren nuevos sentidos y significaciones que implican motivaciones e intereses no reducidos a la esfera individual. Esta articulación de dos órdenes, también figura en sus tratamientos del cuerpo.

En efecto, Husserl articula el Leib de manera variable, dando cuenta con ello de paralelos y semejanzas con objetos y sentidos culturales/espirituales. (Ideen II: 236-47[283-95]). En ese marco, distingue unidades noemáticas a partir de multiplicidades de cuerpos reunidos en torno a obras o significaciones culturales, desde el despliegue de analogías entre el cuerpo individual y el cuerpo colectivo: considera la corporalidad colectiva (kollektive Leiblichkeit), como orden o unidad superior, la cual se caracteriza por prescribir sistemas de comportamiento posibles para sus miembros, que tienen como correlato un conjunto de objetos culturales y significaciones afines (DL: 180 ss.).

Con ello, encontramos un análisis de las instituciones sociales en su corporalidad colectiva y comportamientos característicos destacando, desde un punto de abordaje genético, habitualidades y sedimentaciones en el tiempo. El paso del Leib individual al colectivo, es decir, a unidades superiores, también se establece por medio de analogías ${ }^{184}$, lo cual representa como vimos, una de las modalidades de pasaje de la esfera de lo propio a la alteridad e intersubjetividad. Pero aun con esta escala gradual de esferas y estratos, entendemos que las manifestaciones analizadas siguen bajo la égida de la esfera del ego trascendental.

Más en detalle : en el marco de estas consideraciones podemos sostener por una parte , que el campo del sentido y las significaciones compartidas, así como el supuesto de una armonía monádica de tipo formalista, establecen un marco unitario para la correlación intersubjetiva, el cual se evidencia circunscripto y limitado a una dimensión gnoseológica: estas reducciones develan la intersubjetividad en campos ligados al conocimiento común, a los sentidos en objetos culturales afines y a la pertenencia a una comunidad de habla ${ }^{185}$. Por otra parte, interpretamos que tales entrelazamientos continúan suponiendo cierta externalidad y orientación comprensiva, considerando el punto de partida del análisis: aún como resultado de alteridad, el abordaje desde la

\footnotetext{
${ }^{184}$ Específicamente, la analogía se establece por medio de la expresión (Ausdruck) mediante el Leib, tanto en una monada individual (gestos, modos de manifestación, posturas, etc.) como en un objeto cultural (significaciones investidas colectivamente), véase, PhP: 110 ss.; Ideen II: 246s [293 s.].Para un desarrollo y análisis de estos paralelos de dos órdenes en Husserl, distinguiendo un escollo respecto a la empatía en el orden cultural, véase Rabanaque (2013):7 s. ${ }^{185}$ Véase nota 177.
} 
esfera de la propiedad atraviesa dicho resultado, proyectando su presencia y campo asociativo, tal y como podemos distinguir en la consideración de las cuestiones de la apodicticidad y de la armonía preestablecida, entre otras.

Finalmente, la consideración del carácter no apodíctico de estas experiencias de alteridad, supone una distancia u opacidad irreductible e inherente en el conocimiento relacional con el otro o la comunidad. No obstante, la analogía, la empatía y el apareamiento en la reducción a la esfera primordial, orientan la descripción hacia un horizonte que supone un borramiento de tensiones y conflictividades inherentes a las relaciones intersubjetivas, lo cual entendemos como una tensión en sus desarrollos derivada del propio método de análisis de la alteridad, que parte de la reducción a la esfera primordial del ego.

Frente a ello, Heidegger parte de la facticidad y la cotidianidad, ofreciendo así elementos para articular sus consideraciones desde la alteridad $a$ la mismidad: de cierto modo, el retorno a sí del Dasein presupone una estructura ontológica co-originaria de su relación con otros Dasein, cuestión que se imprime en tal auto-remisión como también en la modalidad de permanencia y mantenimiento de sí. Varias consecuencias siguen a esta modalidad u enfoque, entre las cuales se halla el desplazamiento de las presiones de un horizonte de cientificidad para el análisis. En este marco, los análisis que realiza de estos aspectos de la ipseidad pueden comprenderse como un intento de superar los sesgos externalistas, duales y limitados de aquella fenomenología de la intersubjetividad. Es los próximos apartados indagaremos en qué medida ello es o no posible.

\section{2.- Heidegger y el ser-con como otro punto de partida.}

En términos generales, tanto para Husserl como para Heidegger, el yo puede retomarse a sí mismo desde la dispersión en la multitud, reposicionándose respecto a la tradición. De este modo, la relación intersubjetiva remite a una valoración implícita del proceso de singularización en la esfera de la mismidad.

Para Husserl, vimos que aún cuando se revela las huellas trascendentes del otro en la esfera propia del ego, el yo parece poder esquivar la pasividad propia de la multitud: aquella se obtiene a través de la completa extradición de los prejuicios en la actitud natural, lo que le confiere cierta separación o externalidad respecto al ámbito colectivo. En cambio, para Heidegger la tradición nunca puede dejarse definitivamente atrás, la pasividad no es nunca totalmente superada por la resolución precursora: un Dasein resuelto no remite a un yo por fuera de la facticidad y la 
cotidianidad, sino más bien connota una ipseidad que determina qué es fácticamente posible en su propio proyectarse. Este cambio de punto de partida se evidencia como propuesta de superación de los análisis de su maestro.

En efecto, en $S u Z$ subraya que la existencia auténtica consiste en asumir sus propias posibilidades, siempre fácticamente circunscriptas. No obstante, esta aparente autarquía y auto determinación dista de aquella a la que apunta Husserl cuando supone la entera posesión propia del ego trascendental absoluto, que al parecer implica cierto saber prerrefelxivo de su identidad en su diferencia con el yo natural o mundano. Frente a ello, el júbilo o empuje subjetivista-voluntarista, con su anclaje en la comprensión moderna, pierden aquí sus credenciales: para Heidegger la vida en el olvido, la caída y los dictados del Uno, no logran ser totalmente superados en una existencia que fuese auténtica de modo definitivo ${ }^{186}$. El carácter co-originario del ser-con y el ser-en-el-mundo, se encuentran en las bases ontológicas de tal imposibilidad totalizadora.

Ahora bien, ¿cómo puede sostenerse aquella resolución que subyace a la mismidad propia del Dasein, teniendo en cuenta no solo su insustancialidad, sino también esta provisionalidad de la conquista del sí-mismo? Dos son los caracteres que proponemos retomar para abordar esta cuestión: la identidad e ipseidad del Dasein y la consideración del proceso de individuación.

Hemos visto que en su cotidianidad el Dasein se comprende y habitúa a una determinada interpretación del existir, comprensión que abre las posibilidades de su ser y las regula ${ }^{187}$. En este sentido, queda inicialmente a merced de su propia tradición, pero no de modo ineludible: puede develarla en tanto Dasein cuestionante, debido a su caracterización como el ser que es cada vez mío (en una u otra manera de ser), en el sentido de que cada vez, en cada situación, el Dasein es su posibilidad pues puede escogerse, ganarse o perderse a sí mismo en su ser.

\section{2. a.- La consideración de la identidad del ser-en-el-mundo.}

Vimos que en el análisis genético de Husserl, el yo mundano se constituye como sustrato de habitualidades, en virtud de que emergen en él disposiciones como resultado de la sedimentación de la experiencia pasada. A la unidad de cada yo frente a la multiplicidad de sus vivencias, se añade la

\footnotetext{
${ }^{186}$ Un conjunto de argumentos que vincula y distingue una teoría del Mitsein en Heidegger en su inspiración con la determinación del animal político en Aristoteles son desplegados en Santiesteban (2005):77 ss.

${ }^{187}$ Para un abordaje de esta relación entre la comprensión de sí implícita en toda mismidad y la necesidad de una mediación discursiva de la misma, véase Sáez Rueda (1998) y Castellanos (2006). En este marco, también puede articularse con un instructivo análisis en torno al sentido en tanto carácter pre-predicativo de la comprensión del ente y de sí, en Rodríguez Suarez (2005).
} 
correspondiente a las habitualidades y su mundo correlativo. De este modo, supone una exigencia de centramiento, respecto a tal sedimentación y habitualidades, que bien puede articularse como cierta concepción husserliana de la identidad ligada al polo-yo, una suerte de identidad-mismidad que se articula en una comprensión del ser como presencia ${ }^{188}$.

En lo que respecta a Heidegger, en el período de $S u Z$, la consideración de la identidad se distancia de tal exigencia de centramiento, al inscribirse en su analítica de la facticidad. Como vimos, en su cotidianidad el Dasein se encuentra impropiamente entre las cosas. No obstante, la comprensión de si impropia no es necesariamente inautentica, más bien expresa su efectividad cotidiana de un modo genuino pues es, primariamente, un factum del Dasein en su cotidianidad. En este sentido, primariamente es una comprensión autentica, efectiva e impropia, donde el yo se efectúa en su existencia diaria reflejándose a sí mismo en aquello en lo que se da.

Para aclarar la comprensión cotidiana del uno-mismo, Heidegger plantea una interpretación más radical de la intencionalidad, destacando la estructura unitaria del Dasein que existe a la manera de ser-en-el-mundo. Por esta razón, la primera vía que aborda es la indagación del trato con los útiles, pues es la relación más cercana en el complejo en las que estamos inmersos. Allí revela el entramado de remisiones en el que se inscribe; luego, en un movimiento análogo al de Husserl, a partir de la pre comprensión que tenemos de la totalidad funcional de los útiles, subraya el develamiento fenomenológico del mundo, manifiesto antes de cualquier determinación por el pensamiento; finalmente, la significatividad que en última instancia remite al Dasein, comprendido en dicha estructura que subyace a la intencionalidad. Es precisamente en este marco, donde establece distinciones respecto al concepto de identidad.

En efecto, como ser-en-el-mundo el Dasein es en vista de sí mismo, es decir, no se limita meramente a ser, pues también es un ser que le va su propio poder-ser .Por ello, este ente en cada caso mío (Jemeines) no es solo idéntico consigo mismo ontológico-formalmente, ni meramente consciente de su identidad, pues a diferencia de la esfera trascendental de Husserl, aquella remisión al Dasein supone una alteridad de partida , un diferimiento o distancia que abre la alternativa entre una reflexividad propia o impropia, tal como expone en este parágrafo, subrayando una tensión o ambivalencia respecto a la posesión de sí:

"el Dasein tiene una peculiar identidad consigo mismo en el sentido de un ensimismamiento (Selbstheit). Es de tal modo que, en cierta manera, se posee en propiedad, se tiene a sí mismo, y solo por esto puede perderse. A causa de que el ensimismamiento, o sea el 'poseerse' en cierto modo, pertenece a la existencia, el Dasein existente puede escogerse a sí mismo de un modo propio y determinar su existencia

\footnotetext{
${ }^{188}$ Para un tratamiento de esta cuestión de la mismidad-identidad del polo-yo, véase Walton (2001): 9 ss.
} 
primariamente a partir de esta elección, dicho de otra forma, puede existir propiamente. Pero puede también dejarse determinar en su ser por otros y existir de modo impropio por existir primariamente en total olvido de sí mismo" (DGPh: 242-3[214]).

Esta impropiedad pertenece a la esencia del Dasein fáctico y es un punto de partida irreductible, que, a diferencia del ego trascendental, cancela toda pretensión de autoposesión completa y de fundamentación absoluta. Ello es así, por que la propiedad es tan solo una modificación nunca definitiva de la impropiedad. Así, la comprensión cotidiana de sí no depende de la extensión de nuestro conocimiento de las cosas, sino más bien de la inmediatez de nuestro ser-enel-mundo ${ }^{189}$ : tal comprensión de sí varía con cada uno de los modos de ser del Dasein y de las formas de la propiedad e impropiedad. En pocas palabras, la consideración de la identidad remite en Heidegger a un modo singular de posesión de sí, que más que resonancias positivas o sustancialistas, remiten a consideraciones de carácter modal y a un diferimiento constitutivo. Para comprenderlo, retomemos brevemente el aspecto proyectivo y resolutorio del sí-mismo del Dasein, atendiendo otras articulaciones.

\section{2. b.- La temporeidad en el proceso de individuación: el instante, la espera.}

En su proyectarse, el Dasein también retorna a sí en el horizonte del tiempo. En efecto, en su análisis de la temporeidad, Heidegger se detiene en la observación metodológica del proyecto del Dasein. Como vimos, se comprende en tanto proyectarse en una posibilidad que se hace existente en el proyecto, develando el poder ser y develándose como tal. Este análisis formal diluye el carácter racional y deliberativo implícito en la comprensión moderna: en tanto insustancial las posibilidades articuladas en el proyecto se despliegan en el propio despliegue y no en el ámbito primario de una conciencia encapsulada. Con esto, manifiesta su modo de articular tal proyectividad sin recaer en fundamentos de partida.

La interpretación radical de los éxtasis temporales se vincula con aquél estado de resuelto, puesto que, en el venir hacia sí-mismo desde la posibilidad propia surge el instante (Augenblick). Esta modalidad temporal devela la situación donde el estar-resuelto se efectiviza ${ }^{190}$. Pero este

\footnotetext{
${ }^{189}$ En este marco remite al poeta como aquel capaz de llevar a la palabra la existencia como ser-en-el-mundo, capaz de ver este mundo originario, tal y como el caso de Rilke (DGPh: 247[217]).

190 Pueden encontrarse análisis pormenorizados de una vinculación de la temporeidad propia del Dasein y el mantenimiento de sí en su ipseidad, en los trabajos de Presas (2009); Naishtat, (2007) y Walton (2001), entre otros.
} 
proceso de individuación (Individuationsprozess), donde el Dasein queda singularizado (vereinzelt) no debe interpretarse de un modo aislado: como al mismo tiempo es ser-con, debe determinarse el auténtico ser en convivencia, a partir del estar-resuelto de cada uno, es decir, un pliegue o modalizacion repercute correlativamente en toda la constelación co-originaria del Dasein. Por ello, el análisis de la individuación resuelta, no deja de remitir a un proceso formal y modal de su analítica, con el cual busca esquivar todo escollo de mismidad -identidad, tal y como distingue la individuación de un correlato ontico:

”El existir en convivencia y junto con otro se funda en la auténtica individuación de lo individual que está determinada por el presentificar en el sentido del instante. Individuación no quiere decir aferrarse a los deseos privados sino ser libre para las posibilidades fácticas de cada existencia” (Ibíd.: 408[345])

Del mismo modo, el análisis de la resolución es formal en tanto estructura que sirve de base de la resolución concreta. Es decir, esta recibe un contenido y determinación concreta en el momento de resolverse, en simultaneo con su proyectarse en posibilidades. Así como le permite esquivar los escollos de la subjetividad trascendental, este formalismo en la analítica de Heidegger es fundamental para comprender aquella insistencia en que tal abordaje no da instrucciones en relación con la situación fáctica concreta. Es decir, el acto resolutorio abre en el instante la situación fáctica, por lo cual es anterior a todo comportamiento efectivo. Por ello, no remite a un acto de voluntad sino que se caracteriza por su pasividad en su constitución, aspecto de su analítica que irá tomando dimensiones cada vez más claras en sus trabajos posteriores a la Khere ${ }^{191}$.

Frente a la caracterización del instante, nuestro autor revela el modo inauténtico de mismidad desde la temporalidad: la espera (erwarten $)^{192}$. Este modo de comprenderse a sí a partir de las cosas tiene el carácter de llegar hacia sí mismo del futuro inauténtico, por medio de la anticipación (Gewärtigen) que abre el ámbito para la espera. Así, quedando a merced de su poderser a partir de las cosas, el Dasein espera algo de estas o atiende el modo en que transcurren a partir de la factibilidad o infactibilidad de las cosas por las que se preocupa, siendo estas las que

\footnotetext{
${ }^{191}$ Heidegger parece evitar la utilización del término actuar (Handeln). En sus cursos de finales de la década de 1920 utiliza la palabra decisión (Entscheidung), buscando con ello contrarrestar las resonancias subjetivistas, poniendo reparos en su pretensión de soberanía que opaca la verdad del ser. A este respecto, sostiene un intérprete contemporáneo:" Es característico del pensar de Heidegger que el hombre no es enteramente soberano de su historia y de su existencia, y que solo puede vivir de manera humana en el reconocimiento de que hay algo más grande o más profundo que la vida del hombre y que no es asible bajo ningún concepto" Santiesteban (2009): 95. En los próximos capítulos desarrollaremos estas consideraciones sobre el estatuto y alcance del accionar del Dasein, especialmente en sus trabajos a partir de la década de 1930.

${ }^{192}$ Aquí el Dasein proyecta su poder-ser a partir de las cosas y desde allí se comprende, quedando de este modo determinado por el éxito o fracaso, factibilidad o infactibilidad del trato con las cosas.
} 
proyectan su poder-ser, sin regresar a sí en una autentica proyección, ni asumirse en su facticidad $^{193}$.

Ahora bien, estos puntos de apoyo situacionales y de despliegue de la resolución del Dasein presentan un modo singular de "permanencia" o estabilidad en tal estado, que Heidegger busca elaborar sin descuidar aquel estatus dinámico y relacional co-originario. Con ello propone modalizar otras asociaciones en el campo semántico que en la tradición metafísica remiten a la subjetividad, la autoconciencia y la identidad.

\section{3.- El mantenimiento de sí.}

\section{3. a.- La dinámica del existente}

Anteriormente distinguimos que el concepto moderno de sujeto no caracteriza para nuestro autor a la ipseidad (Selbstheit) del sí-mismo, sino a la mismidad (Selbigkeit) y perduración (Beständigkeit) de algo que meramente está ahí adelante. En este sentido, considerar al sí-mismo como sujeto, implica destacar un carácter cósico en tanto fundamento de vivencias, y no como lo que somos en cada caso.

El Dasein es su sí-mismo en cada caso existiendo, por lo cual solo a través de la existencia se puede dar cuenta de un mantenimiento del sí-mismo (Ständigkeit des Selbst). En este sentido, si puede hablarse de consistencia (Bestand), esta no puede significarse desde la sustancialidad, sino en el mantenimiento de sí (Selbständigkeit) ${ }^{194}$ del existente en tanto ipseidad que, como veremos, se articula comprensivamente de un modo singular.

Precisamente en estas elaboraciones de 1927 y cursos posteriores de la misma década, podemos encontrar un contrapunto de la exigencia de centramiento del polo-yo en Husserl: en lugar de la mismidad que nos sale al encuentro como el mismo (ein Selbiges) en medio de la multiplicidad de las vivencias, el Dasein se caracteriza por una ipseidad que es determinada por su manera de existir y solo en relación con ella ${ }^{195}$.

\footnotetext{
${ }^{193} \mathrm{Y}$ agrega, en una remisión no sustancial, en vista de la diferencia ontológica:"Lo que somos, y en esto está siempre implicado lo que hemos sido, se encuentra, en cierto modo, detrás de nosotros, olvidado." (DGPh: 411[347]).

${ }^{194}$ Aquí nos inscribimos en una tradición de traducción, entre cuyos exponentes se encuentran Martineau; Ricoeur y Walton.

${ }^{195}$ Véase SuZ: 130-131[155]. Anteriormente, subrayando el uso que realiza de la referencia al "yo", sostiene: "El 'yo' debe ser entendido solamente en el sentido de un índice formal (formale Anzeige), sin compromiso (unverbindlich) de algo que en el contexto fenoménico de ser en que él se inserta, quizás se revele como su contrario".
} 
Específicamente, la exposición respectiva en $S u Z$ comienza con el análisis del modo de ser de la constancia (Ständigkeit) del Dasein en las relaciones del ser-uno-con-otro de la cotidianidad, caracterizado por la impropiedad (Uneigentlichkeit) ${ }^{196}$. Teniendo en cuenta las tensiones ineludibles entre esta tematización y el lenguaje en el que Heidegger la elabora: ¿En qué consiste tal constancia de sí con el carácter de propiedad?

\section{3. b.- La estabilidad desde la resolución: temporeidad propia y acontecer histórico.}

La ipseidad solo puede ser existencialmente descubierta en el modo propio del poder-ser sí mismo del Dasein en tanto cuidado. Aquí se da la estabilidad del sí-mismo, en el sentido de haber alcanzado un cierto estado y no como presunta persistencia del sujeto. Esta estabilidad, en el doble sentido de constancia y de firmeza de estado en la diferencia, se opone semánticamente y comprensivamente a la inestabilidad del sí-mismo en la caída. Es importante distinguir aquí que el campo asociativo de tal estabilidad no incluye la identidad y permanencia sino más bien las excluye. La estabilidad del sí-mismo remite a la resolución precursora ${ }^{197}$. Así, a la dependencia (Unselbständigkeit) de la absorción en el entorno, se contrapone esta modalización de la constancia/estabilidad y solidez/firmeza en ese estado alcanzado en la resolución, vuelta hacia su muerte para asumirla como la posibilidad más propia.

En este marco singular de comprensión, el mantenimiento del sí-mismo presenta tres modos o momentos singulares de ser-ahí respecto a su ipseidad. El primero concierne a la posibilidad de salir de la dispersión en el entorno, remitiéndose a la temporalidad propia del instante, en un prolongarse que asume su situación, es decir, en un mirar lo entorno a la luz de una existencia que se asume como arrojada en su ser-para-la-muerte, manteniéndose así en su posibilidad más propia correlativamente a su condición de arrojado. Esto se distingue del presente impropio donde el

(Ibid.:116[141]).Entendemos que tal índice revela el carácter dinámico de la relación con el lenguaje y la conceptualización que mantiene nuestro autor.

${ }^{196}$ Walton sostiene que en este caso se relaciona con el término Unselbständigkeit, que tiene las connotaciones de dependencia, inestabilidad y no (Un-) constancia o mantenimiento (Ständigkeit) de sí (Selbst). Walton (2001):15.

${ }^{197}$ En este sentido subraya: "El mantenimiento de sí (Selbst-ständigkeit) no significa existenciariamente otra cosa que la resolución precursora. La estructura ontológica de la resolución precursora revela la existencialidad de la mismidad del sí-mismo" (SuZ: 322[340]). 
Dasein modifica sus propias posibilidades en función de las circunstancias que lo rodean. En este modo, al permanecer junto a los entes sin comprenderlos, se manifiesta en la cotidianidad impropia una imposibilidad de quedarse (Unverweilen), la cual se caracteriza por la modalidad de estar en todas partes y en ninguna propiamente.

Como segundo momento, en relación con la prolongación de la existencia, respecto al ser total (Ganzsein) del Dasein, destaca la importancia no solo de la muerte en lo que respecta a la resolución, sino también en la consideración del nacimiento como comienzo ${ }^{198}$. Específicamente, entiende necesario considerar la extensión de la existencia del Dasein entre nacimiento y muerte, es decir, incluir la consideración de la trama de la vida (Zusammenhang des Lebens) ${ }^{199}$ en el que está envuelto, que le permite alcanzar el ser total del Dasein : tal prolongación es la que debe ser alcanzada como un todo ${ }^{200}$. A partir de esta consideración, interpretamos una remisión a un contenido pero al modo de relación, dicho con más detalle: una relación con una dinámica y diferencia, no ya de determinación en determinación, sino con (y a partir de) una distancia constitutiva e irreductible. En este marco, respecto a la caracterización particular de esta trama o urdimbre, y lo insustancial de las vivencias pasadas o futuras, afirma:

"El Dasein recorre el lapso de tiempo que le ha sido concedido entre el nacimiento y la muerte en tal forma que, siendo cada vez 'real' solo en el ahora, atraviesa a saltos, por así decirlo, la secuencia de ahoras de su 'tiempo'. Por eso se dice que el Dasein es 'temporal' En este continuo cambio de vivencias, el sí-mismo se mantiene en una cierta identidad. En la determinación de lo que permanece y de su posible relación con el cambio de las vivencias, las opiniones discrepan. El ser de esta trama cambiante y permanente de las vivencias queda indeterminado. Pero, en el fondo en esta caracterización de la trama de la vida se afirma-quiera o no reconocérselo- un ente que está ahí `en el tiempo', aunque, por supuesto, un ente 'no cósico'” (SuZ: 373[390]).

Por ello, por el carácter insustancial de lo pasado o futuro vivencial y el cambio incesante de vivencias, el sí-mismo se mantiene perdurable en relación con tal cambio de vivencias ${ }^{201}$. Destacamos una ambigüedad en la articulación lingüística, especialmente manifiesta en la oscilación del par indeterminación/darse en el tiempo, que remite no solo al complejo diferido co-

\footnotetext{
${ }^{198}$ Recordemos que mientras es, al Dasein algo le falta y cuando alcanza su ser total en la muerte, ya no es más. Respecto a la totalidad del Dasein, Heidegger destaca el desarrollo de una totalidad existencial, desde un modelo de totalidad diferente al de suma de accidentes. Para ello, parte de la distinción griega de totalidad como Holón (en el sentido de entera) y como Pan (como una suma). En el Dasein, el todo remite a la extensión entre nacimiento y muerte, cuya significación no admite la preexistencia de un sí-mismo.

${ }_{199}$ Entre otras cosas Zusammenhang significa continuidad, cohesión y coherencia.

${ }^{200}$ Heidegger critica esta expresión que toma de Dilthey, en lo que respecta a la "coherencia" de las vivencias de tal trama, en tanto secuencia en el tiempo.

${ }^{201}$ A partir de esto, un intérprete establece conexiones entre la unidad de orden y temporalidad con sentido (que interpreta implícita en esta perduración) en su proyección contemporánea con el concepto de identidad narrativa de una vida, véase Cataldo Sanguinetti (2015):39 s.
} 
originario, sino a un intento de elaborar un ámbito no sustancialista para la comprensión de la constancia.

Pues bien, entre estos extremos de su existencia el Dasein se prolonga envolviendo su propio comienzo y su propio fin, desplegándose desde la temporalización, en lugar de un mero e impropio llenado del trayecto. Tal prolongarse o extenderse (erstrecken) es lo que denomina acontecer, gestarse o devenir histórico del Dasein $\left(\right.$ Geschehen ${ }^{202}$, el cual incluye esta particular movilidad (Bewegtheit), de carácter ontológico, contrapuesta al movimiento (Bewegung) como cambio de lugar de los entes que no son como el Dasein ${ }^{203}$. Precisamente allí se inscribe la persistencia (Beharrlichkeit) como constancia en asumir la resolución anticipadora y no como la perduración (Beständigkeit) de lo dado del entorno: desde un comienzo es extensión temporal y no un sí-mismo estático o dado. Al mismo tiempo, la puesta en evidencia de la estructura de tal devenir, en el marco de la necesidad que halla en poner de manifiesto el todo de la vida del Dasein, permite una comprensión ontológica adecuada de la historicidad (Geschichtlichkeit), entendida como el carácter de acontecimiento de tal prolongarse del Dasein ${ }^{204}$.

\section{3. c.- El destino del Dasein.}

Finalmente, un tercer momento del mantenimiento del sí-mismo parte de esta temporalidad propia de la resolución y del acontecer del Dasein, introduciendo la noción de herencia (Erbe) y de destino (Geschick), abordando así la dimensión respectiva articulada desde el ser-con. En efecto, por la estructura del acontecer histórico, el Dasein se transmite posibilidades de ser que han sido, asumiéndolas en forma implícita o articulada. Este vínculo con la tradición, en tanto formal, no remite al contenido sino a la modalización: en la cotidianidad impropia, la elección entre

\footnotetext{
${ }^{202}$ Cuando este acontecer queda referido como una estructura del Dasein lo denomina Geschehensstruktur.

${ }^{203}$ Véase, SuZ: 375[391].

${ }^{204}$ Nuevamente aquí, este término se diferencia de Historie, el cual remite al saber o ciencia histórica. En el caso del Dasein, se trata del tiempo como temporalización y no como sucesión de secuencias de los ahora. En este marco, un intérprete aborda la consideración del tiempo como auto-afección pura, donde la formación del sí-mismo no se regula por un enlace extra-temporal, lo que requiere una modalizacion relacional singular: el retiro y la demora de si, para liberar lo que viene. En tal auto-remisión, se da correlativamente un lapso o distancia que permite la apertura al espacio del afecto. Así, el ahora se comprende como la no co-existencia consigo, con una separación inherente a la estructura de remisión, sugiriendo que Heidegger propone un descentramiento de la estructura del sí-mismo: "precisamente al hacer coexistir con ella un éxtasis que para ser el mismo no puede coexistir consigo, sino reconocer su transferencia en el apartarse-a-un-lado que posibilita el encuentro. Precisamente debido a que el sí-mismo siempre se despliega en dicha retirada o en dicha demora (en su 'apartarse-a-un-lado'), se abandona a sí en el lapso que permite la imposibilidad de coexistir consigo como reconocimiento de su alteración y de su irrecuperabilidad.”Véase Duran Rojas (2015):60-2. Es en este contexto comprensivo, que más arriba nos referimos a la modalidad relacional del Dasein con/desde una diferencia y distancia irreductible.
} 
posibilidades heredadas se establece en el marco del Uno; en la propiedad, el Dasein se aparta de aquella interpretación y elige desde la resolución. Esta modalización propia repercute en el campo de posibles: se desplaza de la liviandad a la firmeza resuelta y de una atención que primariamente se pone en lo primero que se ofrece, para dirigirse ahora hacia lo oculto, olvidado o devaluado. Con ello, la unidad del Dasein se separa de remisiones de tipo trascendental para articularse, en cambio, con una temporalidad de sentido, donde se constituye temporalmente como acontecer (Geschehen). En este contexto, destacamos que el horizonte y el camino del pensar del propio Heidegger en $S u Z$, en su vinculación con las elaboraciones de Husserl y de la tradición metafísica, pueden entenderse como correlativos a este modo de mantenimiento de sí.

Tambien allí es donde despliega su análisis y consideración del destino ${ }^{205}$.Brevemente : con este término remite al acontecer por medio del cual, en el singular modo de relación con la tradición antes expuesto, el Dasein se trasmite una tradición heredada a la vez que elegida. De esta manera, con la resolución el Dasein hace tradición de sí, cuya modalización matiza también al resto de las posibilidades heredadas, desarticulando de cierto modo sus contingencias. En este sentido interviene lo destinal: ya no es cualquier posibilidad, sino la asumida propiamente como "mía". Heidegger contrapone a esto el Dasein impropio de la cotidianidad que se dispersa en el entorno, a la espera y expectativa de situaciones de ocasión, lo cual retrospectivamente opera como (simulacro de) destino.

En este contexto podemos entender que la exigencia husserliana de centramiento del poloyo, como una figuración de consistencia o permanencia bajo otra comprensión, en parte supone una dispersión del Dasein en el entorno desde una temporalidad impropia, considerando una mismidad desde allí. Frente a ello, Heidegger comprende en el acontecer o gestarse histórico del Dasein la prolongación, movilidad y la temporalidad propia, las cuales no tornan necesario el imperativo de la conexión imperturbable entre vivencias de la trama de la vida (asociado más bien con aquella mismidad-identidad), aunque desde aquí ineludiblemente se articula esa modalización diferida. En este sentido, sostiene:

“ La resolución de sí-mismo en contra de la inestabilidad de la dispersión constituye como tal la continuidad extendida (erstreckte Stätigkeit) en la que el Dasein en cuanto destino mantiene 'incorporados', dentro de su existencia , tanto el nacimiento y la muerte , como su 'entre', de tal manera que en esta estabilidad el Dasein se ha hecho 'instantáneo' para lo mundi-histórico de su situación concreta” (...) “La resolución

\footnotetext{
${ }^{205}$ Véase, SuZ: 384-7[.400-3].Aquí se vuelve necesario establecer una distinción: Cuando Heidegger utiliza el término Geschick, alude al destino considerando que el Dasein forma parte de una comunidad o colectivo y, en el marco de esta interrelación y sedimentación, tiene o asume un destino. En cambio, la referencia al destino individual se halla significada en el término Schicksal, el cual dejará de tener relevancia a partir de la perspectiva que despliega en sus elaboraciones desde 1930 .
} 
constituye la fidelidad de la existencia a su propio sí-mismo"(...) "La temporeidad de la historicidad propia es , en cuanto instante precursor y repitente, una des-presentación del hoy y un des acostumbramiento (Entwöhnung) de las conductas usuales del Uno"(Ibid.:390-1[406]).

En suma, con estos tres tiempos o momentos se alcanza el mantenimiento de sí-mismo del Dasein resuelto. La estabilidad alcanzada, en tanto modal, no reside en los hechos, decisiones o situaciones concretas, sino en el instante, por ello puede abandonarse una decisión o cambiar una posibilidad por otra y seguir en la senda de esta estabilidad, siempre que se instale en esta apertura de la temporeidad propia. Asimismo, los instantes no se manifiestan acumulables desde un horizonte volitivo, lo que supondría un sí-mismo anterior a este acontecer, sino que emergen de la temporeidad de una mismidad propia. De todos modos, Heidegger busca pensar la unidad del Dasein, no en su dispersión o disolución, sino como unidad histórico acontecida desde la dispersión en la cotidianidad, es decir, una unidad no dada que se alcanza en un modo singular y relacional de la temporalidad del Dasein ${ }^{206}$.

No obstante este análisis formal y ontológico, que se despliega desde el horizonte de la temporeidad y la comprensión del Dasein, aún presenta ciertas tensiones. Como vimos en capítulos anteriores, distinguimos una coexistencia de dimensiones y ambigüedades semánticas y terminológicas, las cuales entendemos derivadas de una metodología que realiza la analítica desde el Dasein en su cotidianidad, tal y como se manifiesta en la metodología de Husserl, cuando halla las huellas de alteridad desde la esfera primordial del ego. Es decir, destacamos aquí un condicionamiento del análisis a partir de la base semántico-conceptual compartida con la tradición y de una metodología cuyo enfoque la mantiene en cierta continuidad con la perspectiva moderna que comprende al sujeto como fundamento. Tal punto de partida modula/orienta la aprehensión, comprensión y articulación del cuerpo del otro, la comunidad monádica y las relaciones intersubjetivas. En pocas palabras, subrayamos que en ambos casos, las tensiones y ambigüedades

\footnotetext{
${ }^{206}$ En el marco de estas caracterizaciones y desde la tradición que articula nuestra analítica con la psicopatología, encontramos resonancias respectivas. En efecto, Dastur destaca que la cuestión de la alteridad irreductible, la consideración de la temporalidad, el inacabamiento constitutivo y la búsqueda singular de coherencia o sentido de vida , es decir, de constituirse a sí mismo a través de la duración hacia lo imprevisible , forman el núcleo duro de la comprensión psicoanalítica del sujeto en análisis. Esta apertura del mantenimiento de sí a la contingencia del acontecimiento se distingue respecto de las determinaciones psicopatológicas. Específicamente: dicha cohesión no se reduce al mero acontecimiento contingente e inasimilable que se repite (propio de la neurosis traumática) debido a la síntesis de lo heterogéneo e imprevisible que es necesaria para el reconocimiento de un sí-mismo. Asimismo, la huida de la melancolía ante la imprevisibilidad del porvenir (cristalizada en apegos intensos a personas u ocupaciones al trabajo como intento de resistencia y obstrucción del porvenir, ante el flujo incesante del tiempo y a su experiencia de vacio), remite al refugio en una identidad sustancial. . Desde allí, destaca una perturbación de la posibilidad de la realización de su propia ipseidad, frente a la capacidad de acogida de lo imprevisible. Finalmente, en la esquizofrenia, distingue una pérdida del suelo de la cotidianidad del Uno, quedando a merced del acontecimiento sin posibilidad de un principio de unificación. Para un mayor desarrollo de estas articulaciones, véase Dastur (2015):262-6. Destacamos en esta perspectiva, la puesta en valor de la cuestión del porvenir en el marco de la ipseidad lo cual, como veremos en el último capítulo, forma parte del desarrollo de numerosas recepciones y análisis contemporáneos.
} 
son derivadas de una modalidad articulatoria y orientación del análisis, lo cual implica dificultades para superar las limitaciones del pensamiento y la comprensión moderna ${ }^{207}$.

Por ello esta perspectiva, en el fondo, sigue respondiendo a la exigencia de auto-fundación del sujeto trascendental de la metafísica. Precisamente a partir de estas distinciones y condicionamientos, interpretamos los desplazamientos que Heidegger realiza en sus cursos inmediatamente posteriores a $S u Z$, donde propone abordajes que vinculan la mismidad y el mantenimiento de sí a partir de las cosmologías o visiones del mundo, por medio de lo cual busca retomar la eminencia de la pregunta por el ser, poniendo un énfasis radical en la estructura cooriginaria del ser-con.

\section{4.- La irreductibilidad del ser-con: de la neutralidad del Dasein a las visiones del mundo.}

\section{4. a.I Lo Mismo desde el mundo común.}

En los cursos de esta época retoma la consideración de la cotidianidad fáctica del Dasein abordando desde la cuestión del ser-con: al tener la misma forma ontológica del Dasein se manifiestan intuiciones puestas hacia lo mismo $^{208}$. Si bien, esta modalidad se halla en línea con los análisis de Husserl, insiste en poner de relieve la inexorabilidad de la originariedad del ser-con. En este sentido, también mismidad e identidad implican una distinción en lo que respecta a su campo de significación.

En efecto, la mismidad en el papel que cumple en el ser-unos-con-otros, debe distinguirse respecto del término identidad (Identität), el cual no es suficiente para designar el factum de que varios Dasein se comportan respecto a lo mismo, de modo que ese comportamiento sea un ser-unoscon-otros de tipo estructural. Por ello, este concepto corriente es aquí insuficiente.

Lo mismo (Selbiges) no significa ausencia de cambios, ni tampoco la permanencia de una substancia ni la identidad formal del ente consigo mismo ${ }^{209}$. No es una mismidad que sea propia del

\footnotetext{
${ }^{207}$ En la misma línea, un intérprete contemporáneo también destaca ciertas tensiones o paralogismos que pueden explicar el desplazamiento de los análisis de nuestro autor después de 1930: si el Dasein es neutral ontológicamente, por ser en cada caso mío, entonces la autarquía que deriva de este proceso de mantenimiento de si lo aparta radicalmente de la cuestión del ser en general. Esto se debe a que tal acceso no puede establecerse como sí mismo autárquico, pues este solo se invoca a sí mismo. Véase, Marion (1990): 92-93.

${ }^{208}$ Desde esta perspectiva Gadamer desarrollará sus consideraciones respecto a la importancia moral de la tradición. Véase, Gadamer (1992): 195-283.

${ }^{209}$ En este marco, sostiene: “(...) nos comportamos también respecto a lo mismo cuando vemos pasar un coche, cuando vemos, pues, algo ahí adelante que en cada instante está cambiando de lugar. El cambio-por ejemplo, el de un coche que
} 
Dasein atendiendo a él mismo. Más bien, en la relación con otros, en el mundo común y las significaciones compartidas, debe hacerse referencia a una mismidad que alude al ente que es idéntico a sí y que como tal entra en una relación de aprehensión por varios. En este sentido, es lo mismo en tanto que común para el ser-unos-con-otros: la mismidad pone de manifiesto la anterioridad de una relación co-originaria entre varios Dasein, a partir de la cual se aprehenden los entes como idénticos a sí mismos en el mundo común.

En este marco, la existencia trae consigo un ámbito de patencia, un desocultamiento de las cosas y puede encontrarse a sí misma en esta apertura, la cual no parte de un Dasein comprendido en forma aislada. Por ello, también la auto-aprehensión del yo se realiza sobre el suelo de los unoscon-otros (Mit-einander), que no es lo mismo que una mera relación yo-tú, que podría suponer como vimos en el caso de Husserl, un vínculo externo e independiente ${ }^{210}$.

\section{4. a.II.- El carácter derivado de la sexualización y la corporeidad.}

En este contexto, en lugar de aquella metodología husserliana que parte del cuerpo propio, para arribar a la corporalidad de los otros y revelar la opacidad en el conocimiento respectivo, con las interrelaciones respecto al conocimiento de sí, nuestro autor intenta desarticular resonancias solipsistas o dualistas que puedan desprenderse de tal método expositivo del análisis. Por ello, la estructura co-originaria del ser-con se mantiene en las bases tanto del punto de partida como del resultado ${ }^{211}$.

Este carácter co-originario e irreductible del ser-con figura en diversos abordajes, como por ejemplo, en la consideración de la sexualidad y corporalidad como cuestiones derivadas. En efecto, entiende que originariamente el Dasein es neutro. En cuanto existe fácticamente y desarrolla su

\footnotetext{
pasa- no excluye identidad, sino que la incluye. El cambio implica siempre algo permanente, algo idéntico que se mantiene o queda" EP: $93[102]$.

${ }^{210}$ Es en este contexto donde insiste en el carácter ontológico, formal y neutral de sus elaboraciones. El Dasein existe en consideración a sí mismo, que es condición de posibilidad de que se pueda conducir el hombre en el modo egoísta o altruista o cualquier otra determinación respecto a los otros. En el marco de la cuestión de la mismidad en relación a una alteridad originaria, sostiene:'Es precisamente porque el Dasein como tal está determinado por la mismidad por lo que un yo-mismo puede actuar ateniéndose a un tu-mismo. La mismidad es el presupuesto para la posibilidad del yo, que se abre siempre y únicamente en el tu. Pero la mismidad nunca está referida al tu, sino que (en la medida en que es lo que hace posible todo esto) permanece neutral respecto al Ser-yo o Ser-tu y, sobre todo, respecto a la 'sexualidad"' (VWG: 157-8[135]). Entendemos que esta neutralidad de la mismidad, en tanto no sustancial, remite a un diferimiento, distancia o alteridad radical de base.

${ }^{211}$ Nuestro filósofo utiliza diversos términos que remiten a esta estructura de alteridad. El Mitsein, designa el ser en común como existencial; el Mitdasein, refiere a un Dasein concreto que no es el mío. El carácter interrelacional de los otros lo designa como mit-da, que puede significar conmigo. En cuanto al mundo común, lo designa como Mitwelt, es decir, co-mundo. Finalmente, Mit-einander designa el carácter de ser unos-con-otros desde donde se desprenden los análisis de la sexualidad y la corporalidad, como también de la amistad y el amor .Véase, respectivamente, EP: 147; $327[159 ; 342]$.
} 
existir, necesariamente rompe su neutralidad y, en tanto ser-ahí, es fácticamente o varón o mujer, es decir, un ser sexuado, lo cual se manifiestan como determinaciones posteriores de dicha estructura originaria.

Así, para Heidegger las posibilidades de la existencia humana no vienen determinadas por relación de sexo o genero, las cuales son estructuralmente derivadas. Más bien esto se debe a que el Dasein en su neutralidad metafísica viene ya determinado por y como el uno-con-otro ${ }^{212}$. En este marco, sostiene que la existencia del Dasein existe como corporal, es decir, el ser unos-con-otros no solo determina relaciones concretas, sino también el cuerpo. De este modo el ser sí misma de la existencia del Dasein no comienza con una reflexión sobre sí, sino que el sumergirse sin reflexión en algo es un ser-sí-mismo, siempre ya cooriginariamente ser-cabe (Sein-bei), con-ser (Mit-sein) y ser-sí-mismo (Selbst-sein), lo cual habrá de ser explicitado posteriormente por una modalidad reflexiva.

Ahora bien, la consideración de la neutralidad y la corporalidad de Heidegger promovió numerosas discusiones, por un lado en lo que respecta a la escueta tematización en $\mathrm{SuZ}^{213} \mathrm{y}$, por otro, a su posterior negativa a desarrollar una fenomenología del cuerpo sin antes determinar con claridad la comprensión adecuada al Dasein que ella requiere, es decir, en su respectiva diferencia ontológica $^{214}$. La tematización del cuerpo en su aspecto físico, es decir, en su dimensión óntica, se presenta secundaria para estos análisis, así como también debido a los aspectos complejos de la significación del Dasein desarrollados en capítulos anteriores.

En lugar de ello, esboza una suerte de sentido existencial del cuerpo, en su modalidad de articularse en las estructuras originarias del Dasein. De esta manera, lo que distingue como la corporalidad viva (Leiblichkeit) requiere una aprehensión ontológica que advierte como ausente en

\footnotetext{
${ }^{212}$ La consideración de la neutralidad metafísica remite a la "originaria positividad y ponderosidad de su esencia (...) interna posibilidad que mana en cada existir y que posibilita la existencia”. Esto designa cierta singularidad (Einzelke) en tanto aislamiento (Isolierum) metafísico del hombre. Sobre esta consideración de la analítica de la neutralidad metafísica previa a la corporeidad y la sexualidad, véase el despliegue pormenorizado que realiza en MAgL: 171-4[160$2]$.

${ }^{213}$ A este respecto, véase Greisch, 1994b.

${ }^{214}$ En una articulación respecto a estas referencias sobre la corporalidad, Johnson sostiene: "Se trata de una consideración eminentemente metódica, a saber, que una investigación sobre nuestro cuerpo puede desplegarse en sentido estricto si aprendemos por vez primera a conocerlo en el horizonte de una consideración genuina del Hombre. Ambas prescriben, entonces, aprender a mirarnos desde la radicalidad del existir y, por tanto, invitan a ganar una comprensión de su modo fáctico de ser. Ambas se traducen, en definitiva, en un llamado a llevar a cabo un traslado del pensar, a ensayar una modificación radical de nuestro acceso a nosotros mismos en cuanto corporales (...) las advertencias de Heidegger tienen un genuino sentido filosófico, y, por lo mismo, no se trata con ellas de obstaculizar una comprensión del cuerpo, sino más bien de ganar una orientación previa que evite emprender estudios apresurados que terminen ocultando el asunto auténtico en juego, enceguecidos por privilegiar el progreso sólo por el progreso" (Johnson,2016:144). Esta interpretación de la modalidad de tematización heideggeriana que insiste en no descuidar la diferencia ontológica, ya la hemos distinguido en su reelaboración del término Dasein, como necesariamente previa a las discusiones sobre el hombre o sujeto. Nos volveremos a encontrar con ello en sus consideraciones de una ética originaria anteriores a toda tematización ética determinada, en el capítulo 6.
} 
la tradición metafísica, centrada principalmente en la corporalidad cósica (Körperlichkeit). En pocas palabras, en línea con todas sus investigaciones, tematizar el modo de ser del Dasein tiene como correlato una reelaboración de la tematización existencial del cuerpo propio $^{215}$.

Aún con estos análisis insiste en que sus desarrollos no pueden agotar la interpretación de la esencia del ser unos-con-otros. Sin embargo, su carácter provisional está orientado al todo estructural que le permitirá establecer las posibilidades para retomar la pregunta por el ser. Precisamente en este sentido, presenta elaboraciones respecto a perspectivas o concepciones que emergen de los modos de mismidad, desplazando el análisis hacia ámbitos discursivos, lo cual entendemos como un preludio para el abandono definitivo de una analítica desde el Dasein (como punto de partida), y también para las primeras elaboraciones en torno al mundo de la técnica y su comprensión subyacente. Desarrollemos estas consideraciones, en vistas a tal desplazamiento.

\section{4. b.- Visiones del mundo como sostén.}

Toda elección y decisión trasciende el ente en su conjunto, por ello puede escoger dentro del ente. El Dasein existe desde la comprensión del ser, esta entregado a sí mismo, desde lo cual puede comportarse respecto de otros entes. Sin poder eludir esta tarea, debe decidirse acerca de las posibilidades de ser que le pertenecen y se dispersan en las distintas estructuras del cuidado respecto a su entorno. Pero su vacuidad de base, con su disposición afectiva y comprensión correlativas, también lo han conducido a sostenerse en cosmovisiones o visiones unitarias del mundo. Como veremos a continuación, en elaboraciones de cursos y seminarios posteriores a $\mathrm{SuZ}$, la consideración de la cosmovisión remite directamente a la mismidad del Dasein, pero enfatizando su estructura originaria de ser-con, en cuanto modo correlativo de lograr cierta tranquilidad o sostén ante la insustancialidad que lo constituye, lo cual entendemos como una reelaboración de aquellas modalidades de caída en el Uno de la cotidianidad en SuZ, afín a las discusiones e interpretaciones vigentes en su época ${ }^{216}$.

\footnotetext{
${ }^{215} \mathrm{Si}$ bien esta dimensión no aparece explícitamente en SuZ, podemos encontrar un desarrollo respectivo especialmente en sus Zollikoner Seminare, véase , ZS:111-20;202;231-5;243-7;292-6[145-54;240s;272-6;285-9;337-41], entre otras.Asimismo, para un análisis de esta distinción de la corporalidad, véase Johnson(2016):135-8.

${ }^{216}$ Podemos encontrar sus primeros abordajes respecto a las cosmovisiones en BP y en AJPW. Sin embargo, este giro respecto de las concepciones del mundo, en su relación con la estructura co-originaria del ser-con, lo encontramos en un conjunto de lecciones posteriores a SuZ: EP (1928-9). En el siguiente apartado analizaremos sus respectivas elaboraciones, con el objeto de dar cuenta de tal desplazamiento en su perspectiva de análisis.
} 


\section{4. b.I. El carácter de arrojado y la dispersión.}

Específicamente, hemos visto que a la comprensión le pertenece un temple y un encontrarse. El pesimismo y el optimismo, por ejemplo, incluyen tomas de postura respecto a la existencia fáctica. Por su parte, el temple (Stimmung) deprimido implica no sentirse en casa en sí mismo. Los desajustes o inconsistencias en tales disposiciones orientan al Dasein en el camino de la propiedad y la pregunta por el ser.

En el marco de estas disposiciones, retoma el ser-culpable originario del Dasein y su inconsistencia constitutiva, destacando que la facticidad y el venir arrojada de la existencia devela el absurdo de base y la finitud: sin siquiera haber decidido su venir a existencia, no hay fundamento de por qué existe o no el Dasein ${ }^{217}$. Este factum del Dasein lo denomina condición de ser arrojado (Geworfenheit), cuyo temple anímico correlativo es la desazón (Unheimlichkeit) (propia de la angustia), la cual se contrabalancea con la nihilidad, es decir, con aquella que denota la fuerza peculiar del existir del Dasein al emerger de la existencia, con su manifiesto "carácter de no", aún sabiéndose impotente frente al factum de que ella existe. Y esta emergencia establece una impronta propia desde la dispersión en su entorno.

En efecto, vimos que la existencia está dispersa en tres momentos de su estructura relacional de ser-en-el-mundo: en las cosas, en los otros, en sí mismo. Tal dispersión es condición para que el Dasein se disipe o pierda de sí. Desde aquí, mediante compromisos, equilibrios y compensaciones se decide por una u otra de ellas. Con esto, el Dasein se individua en una situación, aunque también acarrea una restricción interna de la verdad de la existencia, por ejemplo, con su caída en el Uno.

Debido a tal carácter de arrojado-idad y dispersión, el ser-en-el-mundo se encuentra sin apoyo, sostén o consistencia (halt-losigkeit). Con esa base y en tanto nihilidad, precisa tomar decisiones. Este vaivén o contrabalanceo y sus dos momentos, Heidegger los distingue como estructurales: toda existencia, en tanto que existe, se ha buscado ya una consistencia o apoyo. Esta suerte de reacción ineludible frente a tal estructura de vacuidad, representa un posicionamiento modal del Dasein, que es lo que denota con el cómo (Wie) de la existencia, evitando con ello pronunciarse por fuera de las estructuras formales que describe, lo cual distinguimos como un énfasis puesto en el carácter irrebasable de tales estructuras, más que en un mero análisis con resonancias peyorativas o axiológicas, tal y como podemos distinguir en el siguiente pasaje:

\footnotetext{
${ }^{217}$ Por ello, sin poder fundamentar su factum de ser, el Dasein puede oscilar de la oscuridad (inevitable) de su origen a la proyección resuelta de sus posibilidades de ser.
} 
”El cómo en el que en cada caso la existencia existe es algo a lo que esa existencia se ha visto llevada de una u otra forma por sí misma, por los otros, por las circunstancias, por la causalidad, por casualidades , o por todo ello a la vez. También aquello que no nace de la decisión expresa de uno , como es la mayor parte de lo que ocurre en la existencia del hombre, se lo tiene uno que apropiar retrospectivamente de una u otra manera, tiene uno retrospectivamente que hacerlo suyo, aunque solo sea en el modo de arreglárselas con ello, o de conformarse con ello, o de tratar de escabullirse de ello; aun cuando en rigor no esté sujeto a nuestra libertad, como puede ser una enfermedad, como puede ser una determinada disposición o propensión, nunca es algo que este simplemente ahí adelante, sino algo que de una u otra forma tiene que ser asumido o rechazado en el cómo de la existencia. Es decir, se mire por donde se mire, el ser-en-el-mundo es la estructura del ser dentro de la cual nos mantenemos, nos damos y cobramos puntos de apoyo, contenido o consistencia , y sostén" (EP:337[353-4])

Entre tales puntos de apoyo, en estas lecciones, circunscribe lo que denomina como visiones del mundo (Weltanschauung). Estas cosmovisiones, teñidas por la comprensión del ser y de sí del Dasein, manifiestan para Heidegger un carácter epocal, es decir, una sucesión histórica. Ya en sus primeras lecciones de comienzo de la década de 1920, mostró su empeño en distinguir estas cosmovisiones de la filosofía donde, siguiendo a Husserl, subrayó que su validez epocal va contra las pretensiones de la fenomenología: para Heidegger la filosofía no debe reducirse a producir una visión o concepción del mundo, puesto que la hermenéutica de la facticidad no busca orientar la acción del hombre. Más bien, busca comprender el ámbito originario desde donde emerge una concepción del mundo concreta.

Desde las consideraciones del mito y la cosmovisión científica, hasta la visión filosófica que retoma la pregunta por el ser, encuentra diversas modalizaciones de este intento de consistencia frente al carácter de arrojado del Dasein. El despliegue o el cambio de una visión a otra se produce cuando se rompe una cosmovisión unitaria, lo cual confronta nuevamente con tal carácter estructural de falta ${ }^{218}$. Para terminar este apartado, abordemos el tratamiento que realiza con algunas de ellas en sus lecciones de EP, atendiendo sus triples variaciones de configuración/desviación/desplazamiento, para dar cuenta del modo en que retoma la pregunta por el ser a partir de esta figuración de aquella estructura co-originaria.

\footnotetext{
${ }^{218}$ Como veremos, Heidegger realiza aquí una distinción diacrónica del surgimiento de la filosofía a partir de los desajustes e inconsistencias de las cosmovisiones. Sin embargo, en sus elaboraciones anteriores, insistió en que la filosofía puede relativizar y trascender la cosmovisión imperante, al poner en evidencia sus conceptos inadecuados y su fundamento en la libertad. Cfr.BP:9-13[9-4]; AJPW: 39-43[43-6]; VWG: 127-37; 163-75[112-19; 139-49].
} 


\section{4. b.II.- Desplazamientos del mito a la filosofía}

En efecto, para Heidegger cada formación de visiones del mundo ha presentado históricamente degeneraciones o desviaciones en su función de sutura. Entre estos desplazamientos inscribe la antropologización moderna del hombre y también, la tendencia a retomar la pregunta por el ser de la filosofía, en la que articula su propio camino del pensar. En ambos casos, se trata de derivaciones de un posicionamiento del Dasein respecto a sí mismo, en el marco del carácter originario del ser-con.

Específicamente, el circuito consiste en tomar un sostén o apoyo (Halt) y su posterior decaimiento al perder su carácter unitario. El mito inaugura este circuito de las cosmovisiones: en primer lugar, Heidegger distingue la visión del mundo del cobijo y la protección (Bergung) (EP: 354-6[375-81]).

Allí, cuando el Dasein queda dominado por el ente, se manifiesta a sí mismo como algo extraño, pues se agota en tal dominio. El surgimiento del mito y su cosmovisión, responde a esta ausencia de sostén, la cual se manifiesta como una falta de cobijo y protección que busca sosiego en el ente. En este caso, entonces, la mismidad se asume en (y desde) el ente.

Pero esta cosmovisión comienza a degenerarse, en lo que denomina como empresa o negocio (Betrieb), es decir, se convierte en una rutina que se impone, desde la cual el medio de protección comienza a presentarse como el ente mismo, lo cósico y, con ello, se tapa y oculta la ausencia de cobijo que le subyace a esta cosmovisión. Como resultado de ello, el apoyo de la existencia se desplaza a un posicionamiento en el mismo sostenerse, desde donde aquella se asume a si en el estar arrojada, co-gestionándose dentro del posicionamiento y enfrentándose con el ente: en esta derivación, el peso de la existencia recae en el comportarse, en su tomar posición, en su actuar, lo cual constituye un fin en sí dentro del sostenerse mismo y no ya en el ente ${ }^{219}$. En pocas palabras, se produce un desplazamiento de sostenerse en el ente hacia un posicionarse en y desde el mismo sostenerse. Esta nueva posición y el empuje que en ella se imprime, impactan correlativamente en la comprensión del ente: este se muestra ahora como aquello que hay que dominar, someter y dirigir (EP: 366-70[386-92]).

Con esta modalizacion, la cosmovisión resultante presupone una legalidad y orden en el ámbito del ente, perspectiva que también cambia el carácter de la verdad y el posicionamiento respecto a $\operatorname{este}^{220}$. Precisamente aquí comienza a desarrollarse la visión científica, surgiendo la

\footnotetext{
219 Precisamente, Heidegger llama a esta visión del mundo o forma básica de cosmovisión como postura o posicionamiento (Haltung)

${ }^{220}$ Más específicamente, subraya aquí que los cambios respecto de la verdad abren un espacio para un cambio en las formas de la existencia. Véase, EP: 370-1[392].
} 
técnica como nueva articulación y orden de la sociedad. De esta manera, entiende que con cada cambio de visión del mundo, correlativamente cambia el ser-en-el-mundo, pues ello impacta en la totalidad de la dispersión del Dasein, es decir, en cómo se comporta respecto a sí, a los otros y a los entes.

Pero también esta visión manifiesta formas de desviación, entre las que se encuentra la consideración central del hombre (propia de la modernidad), con su primacía respecto al ente, prefigurada en la desviación de la cosmovisión anterior. En este caso, el hombre queda reducido a una empresa o negocio que une antropologismo y autocomplacencia ${ }^{221}$. Heidegger subraya varios aspectos de esta desviación de la visión científica y técnica del mundo: por lado, cobra primacía la mera acumulación de conocimiento sin selección, aspecto que conduce a la barbarie. Por otro, el cómo de la acción se entiende como lo más relevante, por lo cual se cuida el gesto (Gebärde), en detrimento de aquella. Algunas de las consecuencias de ello son: la preponderancia de un cierto esteticismo; la autocomplacencia y prolijidad (Betulichkeit) en la indagación psicológica del hombre; el papel eminente de la libre elección; la preferencia por la reflexión, el culto a la interioridad (Innerlichkeit) y seriedad en la reflexión sobre sí, que Heidegger no solo asocia al cristianismo sino al subjetivismo y sus variables epocales.

Ahora bien, destaca que en estas degeneraciones donde el Dasein se pone en primacía, también se vuelve esencial el sí-mismo, aunque en el siguiente sentido: se torna relevante lograr la posibilidad de provocar que este suceda, que tenga lugar, como derivado de un acto de constitución voluntaria. En este marco, en todas estas formas de posicionamiento, la vida humana es entendida en el fondo como un negocio $(G e s c h \ddot{a} f)^{222}$, que ha de ser mantenido en marcha permanente por medio de la autocomplacencia y los neo-humanismos o pensamientos existenciales, por ejemplo.

Aquí distingue de base que la estructura de la existencia radica en la trascendencia, y en esta visión del mundo se vuelve más esencial el ser-en-el-mundo como tal. El trascender al que se refiere remite a que la existencia asume el comportarse respecto al ente en su conjunto, se da entonces un trascender expreso que se desplaza a la filosofía. En otras palabras, con el desenvolvimiento del posicionamiento (Haltung) se forma y desarrolla también una visión filosófica del mundo.

\footnotetext{
${ }^{221}$ Esta relación reflexiva de mismidad remite a que, por medio de perspectivas diversas busca sostener su primacía frente a los entes, buscando esquivar con ello su vacuidad constitutiva de base.

222 Distingue dos sentidos de negocio: mientras en la anterior visión del mundo utiliza Betrieb, como empresa, actividad, taller, explotación; aquí utiliza Geschäft, como ocupación, negocio.
} 


\section{4. b.III- Retomar el camino de la pregunta por el ser.}

En aquella segunda forma básica de cosmovisión destaca lo positivo que sale a la luz en sus formas respectivas de degeneración o desviación: se manifiesta un recogimiento (Sammlung) de la existencia, en el sentido del enfocarse de la existencia sobre sí, que puede entenderse como una modalidad de la mismidad, aunque esta vez remitida a los tres momentos del cuidado del ser-en-elmundo.

En efecto , si a la existencia cotidiana le pertenece una dispersión o diseminación en tres dimensiones distintas (relación con los objetos, con la co-existencia y consigo misma), así como también la tendencia a perderse, agotarse o absolutizar algunas de estas relaciones, entonces lo esencial de esta visión del mundo consiste en permitir un acceso al todo del ente conforme a estas tres direcciones, manteniéndolas recogidas, es decir, retomadas o plegadas desde su dispersión y enlace múltiple para lograr una aprehensión de conjunto. Tal recogimiento tiene cierta primacía, pues es lo que luego deriva en las formas de degeneración mencionadas.

Ahora bien, la modalidad de este recogimiento no es unificante pues lo que mantiene recogida es la dispersión, en su carácter mismo de dispersión: esta modalidad es propia de la estructura del Dasein, la cual se pone de manifiesto tanto en el posicionamiento como en la visión del mundo perteneciente a la existencia mítica. Precisamente aquí se inscribe la filosofía y su práctica, de modo tal que la visión del mundo como posicionamiento es condición para ella.

Recapitulemos los desplazamientos: en la visión del mundo como protección y cobijo, el Dasein se desplaza al todo del ente y encuentra en él su cobijo y protección; en su conjunto, el ente lo sostiene. En el posicionamiento, en cambio, el sostén y apoyo reside en la existencia misma, en tanto diseminada, esparcida, donde la existencia busca aquella protección en sí misma. Por ello, entra en juego la discusión con el ente, superándose la sobrepotencia (Übermacht) del ente, hacia el intento de dominio de este. Pero tal dominio remite al todo del ente en conjunto: este se convierte en cuestión en lo que respecta a qué es el ente, y desde esta pregunta también se plantea expresamente el problema del ser, un retorno que Heidegger distingue como ineludible ${ }^{223}$.

Aun así, la visión del mundo del posicionamiento no se agota en la filosofar. Esto se debe a que la eminencia del lenguaje del posicionamiento hace crecer el conocimiento conceptual, la diferenciación de los significados, el logos se vuelve el representante del ente y el posicionamiento

\footnotetext{
${ }^{223}$ En este marco sostiene que “...en la discusión con el ente, se produce necesariamente un despertar del problema del ser, es decir, un despertar de eso que más arriba llamamos el filosofar” (Ibid.:382[405]). Así, equipara la esencia de la filosofía con el camino de la pregunta por el ser.
} 
se torna una confrontación y discusión con este: las ciencias y la lógica se consolidan desde estas consecuencias $^{224}$.

En el desarrollo de esta visión del mundo y las modalizaciones que ha tomado la filosofía, Heidegger destaca que esta no puede aspirar a ser ejemplar y eminente, sino que remite más bien a la pasividad de un dejar suceder la trascendencia desde su base, la cual se manifiesta correlativa al carácter proyectivo y arrojado del Dasein, tal y como articula en este pasaje:

"Filosofar significa precisamente la formación de aquella trascendencia de la existencia que llamamos libertad, en la cual trascendencia todo lo esencial pasa a depender de la libertad. La esencia de la filosofía consiste en constituir un espacio de irrupción para la existencia histórica concreta determinada por su posicionamiento, postura o Haltung; pero con ello la filosofía es futura o advenidera en un sentido original y bien preciso" (Ibid.:398[422]).

En suma, en el marco de estas elaboraciones, la filosofía se inscribe en una relación histórica e irruptiva respecto al momento histórico de la visión del mundo como posicionamiento, desde la cual la existencia se remite de un modo singular a sí misma. En este marco, la mismidad y su insustancialidad de base permiten desplegar sucesivos modos históricos de intentos de consistencia o sostén, aunque esta vez articulados no tanto con el carácter singular y proyectivo del Dasein, sino implícitamente con el co-gestionarse histórico del ser-con, sobre la base de la comprensión de sí y su relación con el carácter heredado del lenguaje.

Con ello, Heidegger busca retomar el camino a la pregunta por el ser en general, sin abandonar los resultados obtenidos en su analítica anterior, aunque desde puntos de apoyo para su exposición que logren esquivar los escollos subjetivistas del lenguaje y la comprensión moderna respectiva. En este caso, el Dasein desde su estructura de ser-con, junto a las comprensiones y significaciones históricamente compartidas, le permite reelaborar, o mejor, retomar su programa ontológico. Tal retomar marcha de la mano, aquí, con un intento de quitar el enfoque desde el Dasein, con sus resonancias de aislamiento en su analítica, para abordar las dinámicas desde ámbitos de alteridad, como en este caso de las cosmovisiones o visiones del mundo. Desde aquí, profundizará tal cambio de perspectiva, incluso para las elaboraciones posteriores de la ipseidad y en la propia relación que establece con el lenguaje.

Para terminar, en el último apartado nos detendremos en breves puntualizaciones y recapitulaciones respectivas, a la luz de tensiones o problematizaciones posibles que remitan a

\footnotetext{
${ }^{224}$ Véase, Ibid.:387[.410-1].
} 
proyecciones éticas en estas elaboraciones tempranas de nuestro autor, con el objeto de distinguir el estatuto y las condiciones para tales proyecciones.

\section{5.- La alteridad y las relaciones con los otros: ¿es posible delimitar una ética en estas elaboraciones?}

En su abordaje del reconocimiento ontológico originario del ser-con, Heidegger deja ya de preguntarse por el fundamento epistemológico garante de la unidad esencial intersubjetiva entre dos conciencias lindantes, aisladas entre sí en el mundo. En la analítica ontológica de la existencia, el otro deja de ser aprehendido teóricamente como un alter ego en la esfera primordial de un ego puro. De esta manera, supone que la alteridad ya se encuentra radicada estructuralmente en la misma estructura del Dasein y su ipseidad, rechazando por tanto la definición del sí-mismo (Selbst), basada en el plano conceptual de la identidad (Identität), que supone un yo o un mundo común entendidos desde la permanencia de la mismidad, de la mera presencia y de lo idéntico en el tiempo ${ }^{225}$.

Hemos abordado algunos desarrollos de estas consideraciones tanto en su escrito de 1927 como en sus cursos de 1928-9. Mientras en SuZ analiza el co-estar en el contexto de la condición respectiva (Bewandtnisganzheit), en dichas lecciones lo hace al filo del ser-cabe es decir, desde el estar en medio de del Dasein. El enfoque y tratamiento del ser-con le permite remitirse a consideraciones del cuerpo y la sexualidad (como derivados), a distinguir estratos en la singular estabilidad o mantenimiento de sí, así como también dar cuenta de visiones históricas del mundo. Asimismo, ello le posibilita desplegar análisis específicos que remiten a las relaciones con los otros.

En efecto, por razones metódicas, en $S u Z$ limitó el análisis de la mundaneidad del mundo al estar-a-la-mano, reservando el ser-con para un momento posterior en la exposición, aunque insistiendo en su carácter de estructuras co-originarias que se hallan en el mismo claro (Lichtung) de comprensión y apertura del ser. Específicamente, desde el análisis de los útiles y la condición respectiva, en el marco de su comprensión, evidencia un mecanismo relacional en la base del coestar desde la cotidianidad, con una modalidad correlativa al ámbito de análisis: primariamente se

\footnotetext{
${ }^{225}$ Aquí seguimos la interpretación de Paul Ricoeur quien ha desarrollado tal concepción heideggeriana al afirmar que "la alteridad no se añade desde el exterior a la ipseidad, como para prevenir su derivación solipsista, sino que pertenece al tenor de sentido y a la constitución ontológica de la ipseidad”. Ricoeur (1990):352.En el capítulo 8 desarrollaremos esta recepción.
} 
da un medirse con el otro, cuyo móvil es una indiferencia mutua y cuya preocupación apunta a suprimirla o mantenerla para ejercer dominio sobre los demás.

En este contexto, aborda la estructura del cuidado para profundizar y precisar su planeamiento, introduciendo un término propio de esta estructura en dicho marco relacional: la solicitud (Fürsorge) ${ }^{226}$. De esta modalización del cuidado distingue, a su vez, dos formas: por un lado, aquella que descarga al otro del cuidado, reemplazándolo (Einspringen), la cual denomina como solicitud sustitutiva, en tanto forma que puede adoptar el matiz de la dependencia y el dominio (inscribiéndose en aquel medirse el uno al otro al que nos referimos). Por otro, la forma auténtica de la solicitud que consiste en promover la instalación de los otros en su cuidado auténtico, para que así puedan asumir sus posibilidades fácticas, buscando anteponerse (Vorauspringen) al otro para desarrollar con él su cuidado: la denominada solicitud anticipadora. La visión que remite a estas relaciones interpersonales de la solicitud son la consideración y la indulgencia $^{227}$. Pero estas dos formas de solicitud son modos extremos. También reconoce algunas intermedias 228 .

De todos modos, el tratamiento que propone de las relaciones entre los Dasein en este período, no le interesa como problema ético sino ontológico: busca destacar su carácter de estructura originaria, simultánea con el mundo, estableciendo las bases en vistas de la pregunta por el ser en general ${ }^{229}$. En este marco, destaca que tan solo la metontología (Metontologie), en tanto problemática del ente en su totalidad, necesaria para establecer unidades y totalidades en una

\footnotetext{
${ }^{226}$ Muñoz distingue que el tratamiento de esta estructura, en su modo propio , así como también las criticas que permite la descripción del Dasein en su cotidianidad y la práctica política sucesiva de Heidegger ( que supone la consideración de la resolución, en tanto decisión ), son los tres frentes en los planteos contemporáneos de una posible ética en $S u Z$. Sin embargo, destaca que la falta de fundamentos para la decisión y práctica, así como el escaso desarrollo de la estructura del Mitsein, apartan estas vertientes de una consistente propuesta ética, aunque si la propuesta de una fundamentación ontológica respectiva. Muñoz (2010)102 ss. Cf. Luckner (2001):166 ss. , quien pone de relieve el papel de la Fürsorge para las derivaciones éticas de $S u Z$.

${ }^{227}$ Lo cual se halla en contraste con la circunspección (Umsicht), en tanta visión que pertenece al trato con los entes a la mano de la ocupación (Besorgen), es decir, de la modalidad del cuidado del trato con los entes intramundanos.

${ }^{228}$ Respecto a las relaciones entre existentes, Martínez retoma estas consideraciones de Heidegger en contraposición con la perspectiva de Levinas (1988), para subrayar la importancia de una ética de la responsabilidad solidaria que apunte a una teoría de la alteridad ética en las consideraciones de la mismidad, perspectiva que distingue ausente en la obra de nuestro autor. Por ello, sostiene en línea con Levinas, la inseparabilidad de la problemática de la eticidad de la acción de la cuestión del prójimo. Véase Agut I Martínez (2001):112 ss.

${ }^{229}$ Asimismo irá gradualmente abandonando aquellos puntos de partida para el análisis. Diversas son las interpretaciones de estos desplazamientos ; por ejemplo, sostiene Vattimo: "En Heidegger, el paso del plano de la analítica existencial (Ser y tiempo) al de la historia de la metafísica como historia del ser (el sentido del «giro» de su pensamiento a partir de los años treinta) tiene lugar precisamente en referencia al hacerse cargo de que en un mundo como el nuestro y el suyo, de grandes potencias históricas, tendencialmente totalizantes y totalitarias, la esencia del hombre no puede pensarse (menos de lo que pudiera nunca) en términos de estructuras individuales o de definiciones suprahistóricas." Vattimo (1991):136.
} 
analítica en vistas a la dimensión problemática del ser, se presenta como el único ámbito donde pueden situarse las cuestiones de la ética (MAgL: 199[184]) ${ }^{230}$.

Aun así, no es conveniente reducir la estructura originaria de ser-con a estos análisis de relaciones entre los Dasein, pues Heidegger insiste en plantear condiciones para reelaborar las discusiones sobre los aspectos comunitarios e intersubjetivos a partir de su recorrido de la analítica ontológica del Dasein pues entiende, por ejemplo, que la ipseidad modaliza también tal estructura, reorientando las consideraciones afines ${ }^{231}$.

No obstante, si acaso pudiese sostenerse una ética de la autenticidad en estos trabajos (como modalidad relacional del Dasein respecto a su mortalidad propia), no lo sería con una base prescriptiva para la acción, ni tendría el obrar un análisis necesariamente correlativo a la estructura del ser-con, puesto que ello no se adecua a la propuesta de Heidegger, quien entiende que de tal modo se dejaría a la ética sin un auténtico y apropiado desarrollo ${ }^{232}$. En este sentido, sus trabajos buscan abandonar el horizonte teórico de los actos de pensamiento y voluntad subjetivista, sesgados por el cálculo y la deliberación de un querer y hacer auto complaciente, para poner de relieve, en cambio, una figura de la existencia humana marcada por la máxima pasividad y humildad, comprensión que también se halla implícita en estos abordajes de las relación entre los Dasein, que

\footnotetext{
${ }^{230}$ En estas lecciones de Marburgo de 1928, Heidegger despliega algunas especificaciones sobre la metontología, en el marco de su caracterización de una ontología fundamental. Allí, destaca que la comprensión del ente en su totalidad ya se encuentra abierta en la comprensión del ser del Dasein, por lo cual, en el marco de la pregunta por el ser en general, reconoce la necesidad de abordar la problemática del ente en su totalidad. En este sentido, la metontología no se reduce a una óntica sumaria de entes, propia de una ciencia general, sino que es derivada y complementaria de una radicalización de la ontología fundamental (junto a la cual debería formar una unidad metafísica), subrayando que: “(...) ella es, primero, analítica del Dasein y, segundo, analítica de la temporaneidad del ser. Pero esta analítica temporánea es a la vez el giro en la que la ontología misma da marcha atrás expresamente hacia la óntica metafísica en la que de modo implícito siempre ha permanecido. Conviene, mediante el movimiento de la radicalización y la universalización, llevar la ontología a la conversión en ella latente. Allí se lleva a cabo el giro y tiene lugar su conversión en metontología". Véase, MAgL: 196-202[182-6]. De esta manera, la metontología permite abordar problemas ónticos que han sido descuidados en la tarea de la delimitación de la ontología fundamental, como por ejemplo: las cuestiones éticas. Sin embargo, esta propuesta no presenta mayores desarrollos ni continuidad en sus trabajos posteriores.

231 En este sentido, solo cabria la objeción de una falta de desarrollo de esta estructuras ontológica en estas orientaciones, una vez constituido el pliegue de la ipseidad. Para un análisis que insiste en no descuidar la comprensión constelada y dinámica para el Mitsein en SuZ, véase, Dávila (2004):133-5. Por su parte, Burlando, subraya que las implicaciones del Mit-sein en este período han dejando en suspenso preguntas capitales, como por ejemplo: ¿es posible una comunidad auténtica?; ¿el ser también puede rebelarse a una comunidad intersubjetiva de Daseins?, etc., Véase, Burlando (2015):378-9. En este marco, las (re) consideraciones del concepto de comunidad a partir de estas elaboraciones de Heidegger, presentan fructíferos desarrollos en Nancy ,2001; 2003 y Blanchot ,2002.

${ }^{232}$ Plantear una ética de la autenticidad en SuZ implica una empresa compleja, considerando el camino del pensar de Heidegger. Un intérprete desarrolla una articulación entre la angustia, el ser-para-la-muerte y la voz de la conciencia como tres estadios para plantear una ética no-normativa, en tanto plegamiento que modaliza la mismidad del Dasein abriendo y desarrollando una disposición singular. Véase Arrese Igor (2011): 119 ss. A nuestro entender, una interpretación de este tipo pone énfasis en el Dasein, cuya significación es más bien deudora de recepciones existencialistas de esta obra. Sin embargo, bien pueden distinguirse elementos en SuZ para discusiones éticas desplegables en otros marcos discursivos tal y como lo realiza, por ejemplo, Charles Taylor (1994). Cf. Adrian (2012):76-79 en su planteo de interpretar dicha obra como una propuesta (de carácter indicativo-formal) para una ética del cuidado de sí en el marco de la cuestión de la mismidad.
} 
buscan articularse por fuera de las discusiones éticas tradicionales ${ }^{233}$. En trabajos posteriores propone un abandono explícito de la comprensión ética en la tradición filosófica, en vistas de una ética originaria, con el objeto de profundizar una transición desde las sedimentaciones y orientaciones subjetivistas $^{234}$.

En este marco: ¿cuáles son las orientaciones y los desplazamientos específicos, en sus elaboraciones posteriores a 1930, que permiten circunscribir dicha transición? Nuestro próximo capítulo se abre a partir de estas cuestiones.

\footnotetext{
${ }^{233}$ Sin embargo, la dimensión práctica que se desprende del análisis heideggeriano del carácter proyectivo del Dasein ha suscitado discusiones en torno al carácter implícito o sugerido de la dimensión ética en este primer período. Entre ellos encontramos los análisis de Volpi (1994/1996) y de Villarroel, quien sostiene sobre una ética en Heidegger: “(...) no escribió nunca acerca de algo semejante, sino que, además, enfatizó su rechazo a cualquier posible proyecto de esta naturaleza y criticó de dura manera a todos aquellos que han buscado reanimar valores en la era técnica. Sin embargo, no deja de sorprendernos que una buena parte de sus más conspicuos discípulos (Gadamer, Arendt, Jonas, entre otros) corresponda a quienes más han contribuido -directa o indirectamente- a la reflexión ética en nuestro tiempo, manteniendo en su particular deriva, cada uno por su propio camino, las categorías prácticas aristotélicas. Ello, por sí mismo, parece ser un hecho al que no se le puede dejar de prestar atención, un particular llamado que se desprende de esta dimensión práctica de la existencia que los pensadores señalados han insistido en explorar hasta sus más profundas consecuencias"(Villarroel 2006: 97). En continuidad con esta interpretación, sostenemos que las recepciones posteriores abordan la obra de Heidegger desde los resultados de su propia analítica.

${ }^{234}$ En este marco, Habermas afirma que, aun cuando a Heidegger no se le pueda considerar discípulo y continuador de la fenomenología de Husserl, no habría dejado sin embargo de quedar cautivo de las aporías de la filosofía de la conciencia y de la subjetividad, también en lo que referente a las perspectivas éticas. Tal aspecto se haría evidente en su rígida e insoluble contraposición entre el aislamiento solipsista del sí-mismo auténtico y la pérdida de sí-mismo en la impropiedad de la dispersión cotidiana. Al no considerar las estructuras lingüísticas intersubjetivas del mundo de la vida, llevándolas al ámbito de la vida cotidiana decaída del sí-mismo inauténtico, contrapuesta a lo en-cada-caso-mío del Dasein, Heidegger se habría cortado la posibilidad de repensar la ética en clave postmetafísica. Véase los argumentos respectivos en Habermas (1985):133; 166; 169; 171; 182-4. En el próximo capítulo plantearemos un recorrido que sugiere cierta inadecuación de esta crítica.
} 


\section{Capitulo 5. Perspectivas y derivas desde 1930: la co-pertenencia Dasein-ser en su mismidad mediada.}

Si las elaboraciones sobre los puntos de apoyo y el mantenimiento de sí, en la ipseidad y el proyecto arrojado del Dasein, podíamos distinguir tensiones, se debía no solo al direccionamiento del método que comenzaba por la analítica del Dasein para un acceso a la pregunta por el ser en general, sino también a las sedimentaciones y articulaciones del pensamiento desde la matriz del lenguaje heredada de Platon a Husserl, semántica, conceptual y comprensivamente, que 
interpretamos también como direccionante de los trabajos de nuestro autor en la década de 1920 . Por un lado, los resultados de la analítica conducen gradualmente a Heidegger a poner énfasis en el carácter relacional y dinámico, en vistas al horizonte para su pensar. Por otro, los resultados de nuestro recorrido nos plantean atender con mayor precisión, no solo las relaciones entre ipseidad y lenguaje en las elaboraciones posteriores, sino también a las correlaciones y simetrías que estas manifiestan respecto al despliegue y modalidad del propio discurso de Heidegger, a lo cual nos remitiremos en los siguientes capítulos.

En el presente caso buscaremos circunscribir estos desplazamientos, en el marco de las consideraciones heideggerianas de la ipseidad en su carácter mediado distinguiendo, específicamente, el estatuto de tal mediación. En efecto, en los cursos y escritos de Heidegger a partir de 1930, encontramos una profundización en los análisis del Dasein en el marco de las dinámicas de su co-determinación con el ser, es decir, con un énfasis puesto en esta dinámica en la que se halla configurado el existente humano, dejando de lado definitivamente abordajes que resalten notas de aislamiento, segregación o reducción, respecto a tal horizonte fundamental.

Correlativamente, esta etapa de su pensamiento se caracteriza por la articulación desde un lenguaje que oscila gradualmente hacia un decir poético-literario, es decir, con mayor predominio de alusiones, metáforas, acuñaciones terminológicas que se orientan a otros campos semánticos, con asociaciones que se desplazan por resonancias, que insinúan nuevos horizontes de significación e, incluso, que no tienen antecedente en la propia lengua alemana. Esta relación con el lenguaje está vinculada con una exhortación que se desprende de la búsqueda de Heidegger: sus anteriores trayectos pusieron de manifiesto un conjunto de limitaciones relacionadas al lenguaje, la conceptualización respectiva de la metafísica y al alcance propio de un pensar de tipo representativo, a partir de las cuales nuestro autor se ve impulsado a ensayar nuevos recorridos y modalidades del pensar.

Probablemente esta sea una de las razones por las cuales se ha canonizado en determinada recepción heideggeriana la distinción discontinua entre un primer y segundo período, circunscribiendo este último a partir de la época que abordaremos. Con el recorrido que aquí plantearemos, nos articulamos con otras interpretaciones que distinguen vínculos entre dichos períodos, atendiendo la modalidad de correlación entre ambos, lo cual entendemos pertinente respecto al pensamiento de Heidegger : hacia finales de la década de 1960 él mismo rechaza aquella distinción, al vincularla con una modalidad historicista de recepción de su obra, que se aparta de sus propios desarrollos en torno a la temporalización y la historia acontecida (Geschichte).

Para estas consideraciones nos remitiremos a diversos escritos, aunque centraremos nuestra atención en un conjunto de trabajos pertenecientes al período que va de 1930 a 1960 los cuales, a 
nuestro entender, catalizan su perspectiva en torno a la ipseidad del Dasein en el marco de la constelación que se articula con el ser y el lenguaje $\mathrm{e}^{235}$. Estas elaboraciones posteriores a $S u Z$ obstaculizan de un modo creciente todo abordaje que no atienda a cierta estructura holista en los análisis de Heidegger. De este modo, evitaremos eludir algunas cuestiones también entretejidas con la temática de la ipseidad: la modalización del pensar posmetafísico; las perspectivas en torno al mundo moderno de la técnica; la consideración dinámica del lenguaje; las respectivas relaciones del Dasein con el mundo circundante desde el punto de partida fáctico; los temples anímicos correlativos y sus funciones en el marco del otro inicio del pensar, entre otras.

No obstante, la temporalidad conceptual y terminológica en los trabajos de Heidegger (es decir, el tiempo en el despliegue de su camino del pensar), demanda retomar de modos renovados los puntos de partida y las paradas en tal camino, con el objeto de atender los cierres y aperturas en los campos semánticos respectivos, las conexiones y re-conexiones que se establecen, los modos en que los resultados de un tramo en el recorrido repercuten retroactivamente en el trayecto realizado y en el que luego realiza. Por la misma razón, se torna necesario distinguir las articulaciones en el lenguaje, a fin de comprender no solo qué sostiene sino también cómo lo hace, pues no siempre resulta evidente de suyo.

En este contexto, algunas preguntas oficiarán de guía para el presente recorrido, así como también permitirán articular nuestros desarrollos anteriores:

- ¿Cuáles son las reformulaciones que plantea en su camino a la pregunta por el ser y sobre la metafísica?

- ¿Qué relaciones posibles pueden establecerse entre la co-pertenecia del Dasein y el ser, respecto al lenguaje?

- En este marco, la mismidad e ipseidad ¿manifiestan diferentes determinaciones o desplazamientos significativos respecto a sus elaboraciones anteriores?

- Teniendo en cuenta la consideración de la alteridad como irreductible ¿En qué medida los posicionamientos respecto a la modernidad técnica y el pensar representativo permiten el develamiento y/o condicionan los ámbitos de mayor originariedad y los horizontes hacia los que se dirige el pensar y el discurso de Heidegger?

\footnotetext{
${ }^{235}$ Específicamente nos referimos a: Was ist Metaphysik? (1929) (WiM) ;Einführung in die Metaphysik (1935) (EM); Beiträge zur Philosophie (Vom Ereignis) (1936-8)(BPE); Nietzsche I (1936-1939) (N I); Holzwege (1936-1946)(Hw); Vorträge und Aufsätze (1936-1953)(VA);Besinnung (1938-9a)(B); Nietzsche II (1939-1946)(N II); Parménides (19423)(P); Brief über den Humanismus (1946)(BH); Die Frage nach der Technik (1953)(FT); Wissenschaft und Besinnung (1954)(WV); Identität und Differenz (1955-7)(ID); Gelassenheit (1959)(G) y Zeit und Sein (1962a)(ZuS).
} 
Desde ellas en primer lugar, desarrollaremos la cuestión del ser y las críticas a la metafísica en este período de sus elaboraciones, de modo tal que nos permita circunscribir las determinaciones correlativas del Dasein. Luego, distinguiremos el relieve cada vez mayor que toman las consideraciones respecto a la técnica moderna en sus vínculos con la consumación de la metafísica y la comprensión del ser como presencia. Finalmente, dedicaremos los últimos apartados al tratamiento de sus consideraciones en torno al otro pensar para el Dasein, en lo que respecta a sus relaciones con su mismidad. Con ello, en el marco de nuestras hipótesis de partida, obtendremos elementos para: a) delinear los alcances y limitaciones de la función del Dasein y su ipseidad, en el marco de las modalidades que distingue en la co-pertenencia con el ser; b) distinguir tensiones y umbrales de continuidad/desplazamiento en el pensamiento de Heidegger y c) comenzar a circunscribir un campo posible de correlaciones entre tales elaboraciones y el propio discurso de nuestro autor.

\section{1.- La pregunta por el ser: hacia un decir y pensar posmetafísico.}

Comencemos entonces con un abordaje a las elaboraciones sobre la cuestión del ser en este período, en vistas al desplazamiento desde el enfoque de la analítica del Dasein hacia una perspectiva relacional con el ser. Hemos visto que aquella analítica se despliega como un trayecto en su camino de la pregunta por el sentido del ser en general. Allí, el acceso al ser solo se logra al ponerse en juego en su singularidad, en su Dasein en cada caso suyo (Je meines): alcanza su ser solo proyectándose hacia él. Pero este punto de parida reveló ciertos escollos y direccionamientos temáticos que lo apartaban de su programa ontológico.

En efecto, en los capítulos anteriores distinguimos que las conexiones no tematizadas de un pensamiento de fundamentación trascendental, que subyace en la analítica del Dasein como punto de partida primario (en vistas de la ontología fundamental), pueden ser entendidas como una versión hermenéutica de la perspectiva moderna del sujeto, incluso con sus limitaciones respectivas. En este marco, las elaboraciones en torno a la resolución precursora y la mismidad del Dasein suponen, en parte, un retorno a sí mismo que presenta continuidades con el yo trascendental y el polo yo de los análisis de Husserl. En esta misma línea, las consideraciones sobre la autenticidad en la analítica presentan algunas tensiones en relación a la comprensión del carácter originario e 
irreductible de la alteridad del Dasein. Finalmente, siendo el tiempo la constitución fundamental y originaria del Dasein, la comprensión del ser y su proyección en el horizonte de la temporeidad pueden condicionar el camino de la pregunta por el sentido del ser en general.

No obstante, una vez desplegada la mismidad fundamental del Dasein, cuyos resultados desde la comprensión propia permitieron distinguir, a partir de estructuras y existenciales, su carácter inesencial, proyectivo y situacional, Heidegger se orienta al abandono de esta dirección para atender la dinámica relacional. Así, aquél énfasis de la analítica pasa primero a establecerse desde la perspectiva del ser ( buscando desplazarse de la comprensión tradicional del ser como fundamento del ente), abordando la dirección que va del ser (en su donación) al Dasein, para finalmente consolidarse en la relación inescindible de Ser-Dasein, es decir, en su pertenencia reciproca (Zusammengehorigkeit) ${ }^{236}$.Recorramos estos desplazamientos, atendiendo sus reformulaciones y las tensiones implícitas en ellas, en vistas de circunscribir la cuestión de la mismidad en el marco de tal mediación.

\section{1. a.- De superación a torsión de la metafísica.}

En SuZ, la pregunta por el ser estaba articulada a partir de su sentido, es decir, Heidegger planteaba un recorrido hacia el horizonte del sentido del ser de los entes, en el marco específico de la diferencia ontológica respecto al ser del Dasein, en su apertura y proyección ${ }^{237}$. En este contexto de análisis se presentan algunas tensiones: si el tiempo es la constitución fundamental del Dasein, ¿cómo podemos analizar el sentido del ser sin proyectar su comprensión en el horizonte de la temporeidad ${ }^{238}$

Específicamente, en sus elaboraciones posteriores, aún en su manifestación desde sentidos determinados, el ser deja ya de articularse en su discurso como equivalente o reductible al

\footnotetext{
${ }^{236}$ En este marco Cruz Velez destaca que el hombre en el pensamiento de Heidegger, por la separación con los supuestos de la filosofía del sujeto y la teoría del fundamento, solo puede considerarse en y como una relación. El ser del Dasein se halla en una comprensión y relación con el ser, constituyéndose en esa relación, siendo "el protofenómeno en el ser humano" (Cruz Velez 1970:201), por lo cual no puede determinárselo en relación con los entes: el ser del hombre es en relación. Entendemos que desde allí Heidegger propone una transición respecto a sus articulaciones en la analítica hacia finales de 1920, lo cual desarrollaremos y argumentaremos a lo largo de este capítulo.

${ }^{237}$ En un análisis lingüístico de la pregunta por el sentido del ser en esta obra, Tugendhat la distingue e interpreta como pregunta por el sentido de lo mentado al hablar del sentido del ser. Para este análisis, véase Tugendhat (1994):4-8.

${ }^{238}$ En el marco de esta línea de análisis y tensiones pueden cotejarse sus elaboraciones de finales de la década de 1920, en torno a la diferencia ontológica. Allí, Heidegger intenta realizar el paso de la Zeitlichkeit a la Temporalität como tiempo originario y también como problema (en el marco del programa de una ontología fundamental), distinguiendo que de esta última depende la comprensión del ser: desde allí se funda, se proyecta y se determina su posibilidad de comprensión temática (DGPh: 323s. [278]; 429-31[361s.]). Asimismo, para un abordaje respecto a las determinaciones epocales de esta proyección de la comprensión del ser, es decir, aquellas que temporalizan la distinción entre ser y ente, véase Ibíd.: 453-68[379-90].
} 
sentido $^{239}$ : desplaza el énfasis meramente circunscripto a la mediación elaborada en su analítica, donde el sentido del ser se enmarcó en el horizonte de un ente determinado (el Dasein) para revelarse finalmente en el horizonte del tiempo ${ }^{240}$. En estos desarrollos las tensiones resultantes son consecuencia de una analítica que se mueve siempre en el dominio del ser del ente, marco en el cual se aborda la cuestión del sentido del ser. Sin embargo, si la pregunta metafísica remite a la cuestión del ser en cuanto tal y su programa ontológico se orienta a la pregunta por el ser en general , entonces la consideración del ser del ente debe trascender toda proyección del Dasein hacia el ser en cuanto tal , para evitar quedar reducido al mero dominio del ente. Los problemas y escollos derivados de esta perspectiva lo conducen a tratamientos cada vez más específicos del ser, en el marco de la diferencia ontológica.

En primer lugar, el análisis de la diferencia entre ser y ente tiene desarrollos más precisos en 1929, en el contexto de la pregunta metafísica por la nada (en tanto negación de la totalidad del ente). Por esta vía, aborda el carácter originario de la angustia, como aquél estado de ánimo del Dasein que pone de manifiesto la nada, revelando la oculta extrañeza de lo ente y la apertura originaria en su diferencia (WiM: 112-5[100-2]). Desde estas elaboraciones, donde el análisis del Dasein presenta un carácter secundario, Heidegger retoma la orientación de la metafísica en su preguntar más allá del ente en cuanto tal (Ibíd.: 118s. [105]) ${ }^{241}$. Es precisamente cuando retoma dicha pregunta a partir de 1930, donde distinguimos de un modo más evidente un cambio de perspectiva en el camino de la pregunta por el ser.

En efecto, especialmente desde su Einführung in die Metaphysik, encontramos un desplazamiento hasta la consideración específica del sentido del ser enfatizando su carácter epocal: entiende el ser como aquello por lo que un ente es (en definitiva, supone que siempre el ser lo es del ente) pero aproximándose a la cuestión de su verdad (en su movilidad o dinámica propia de desocultamiento-ocultamiento) y no ya solo desde su sentido. Más en detalle: en estas elaboraciones el ser ya no queda circunscripto al marco del sentido del ente en relación al Dasein, sino que es considerado en su originariedad respecto a la cual un ente es, distinguiendo su variabilidad de

\footnotetext{
${ }^{239}$ Respecto a la pregunta por el sentido del ser (del Dasein), véase SuZ: 5-15[28-37]. Para aquella (re)consideración del ser del ente, en su aspecto dinámico-donante, véase, EM: 63-8; 80-99[61-5; 74-89] y ZuS, passim.

${ }^{240}$ Es decir, Heidegger despliega allí una elaboración respecto a la cual el sentido del ser es (y se da en) el tiempo (comprendido tal sentido como tal). Ello le permite distinguir que, desde la tradición griega, aquél se ha comprendido como presente/presencia. Desde la consideración dinámica y móvil de la temporeidad del Dasein en $S u Z$, diferenciada de la concepción vulgar de tiempo, establecerá otro marco para (re)pensar el sentido del ser, lo cual le posibilita transitar hacia una posible aprehensión (no representativa) de la movilidad dinámica del ser. Respecto a un intento de refutación del análisis heideggeriano de la comprensión griega del ser y del desplazamiento especular entre la movilidad temporal del Dasein y la del ser, Cf. Tugendhat (1994):21-4; 24-6, respectivamente.

${ }^{241}$ En este marco, distingue que la pregunta metafísica necesariamente debe formularse con anterioridad al proceder científico y sus elaboraciones, especificando que : "Solo cuando la ciencia vive de la metafísica es capaz de volver a lograr una y otra vez su tarea esencial (...) volver a abrir siempre de nuevo el espacio completo de la verdad de la naturaleza y de la historia "(WiM: 121[107])
} 
acceso histórico al hombre. Esto permite destacar la anterioridad del ser respecto a la determinación del sentido, lo cual remite a una suerte de radicalización del desocultamiento del ser respecto a su elaboración en la época de SuZ.

En esta perspectiva, el ser del ente se desoculta y oculta en el manifestarse en la presencia, desde/hacia una reserva fluyente e inagotable. Asimismo, el ser remite al surgir y estar presente del ente por medio de lo cual el hombre puede advenir a su encuentro, siendo el sentido aquello derivado de tal apertura y advenir ${ }^{242}$.Precisamente esta distinción le permite enfocar sus análisis posteriores en el darse, en el manifestarse del ser del ente en esta singular movilidad de desocultamiento y retracción, abriendo una perspectiva en torno a la historia del ser. Como veremos en próximos apartados, tal originariedad también impacta en el modo de relación del hombre respecto al ser, quitando las notas de centralidad o eminencia que aún mantenía en la analítica.

Desde esta orientación, propone elaborar la diferencia entre ser y ente desde la perspectiva del Ereignis. Para ello, enfatiza en su enunciación o articulación lingüística la equivalencia y simultaneidad del genitivo objetivo y el subjetivo para $\operatorname{comprenderlos}^{243}$, de modo tal que le permita evidenciar una diferencia más originaria que presupone tal relación, la cual debe ser mantenida por el pensar como anterior e inherente tanto al ser como al ente, es decir, no como algo añadido por nuestro capacidad representativa. Para aprehenderla en su modo dinámico y no objetivable, desarrolla un desplazamiento hacia la consideración desde el ser en su donación, desocultamiento y ocultamiento ${ }^{244}$.

En este marco, el Dasein ahora es analizado como el que descubre y preserva tal manifestación, invirtiendo aquel énfasis relacional al destacar su carácter pasivo y receptivo, aspecto que no obtuvo un suficiente tratamiento debido al enfoque y articulación del análisis, el cual podía connotar cierta injerencia activa en la determinación del ser como sentido del ente. En

\footnotetext{
${ }^{242}$ Respecto a estas consideraciones sobre la comprensión del ser y el carácter derivado del sentido y la significación del ser, lo cual es correlativo a un enfoque que ya no precisa de referencia al ente o al hombre para la pregunta por el ser, véase EM: 3s.[13s.];63s.[81s.];156 [184s.].Allí, nuestro autor subraya que las diferentes significaciones históricas del ser tienen en común rasgos que dan el horizonte epocal para su comprensión, por ejemplo: el marco de la presencia temporal y local, el perdurar, la consistencia, el demorar y el ad-venir. De este horizonte, la comprensión toma la uniformidad y determinación del sentido, la cual se halla ligada a la comprensión griega, que representa para Heidegger nuestra historia oculta (Ibíd.:69s. [88s.]).

${ }^{243}$ Es decir, el ser del ente en su uso como: a) genitivo objetivo: en tanto el ser constituye al ente y b) genitivo subjetivo: en tanto el ente tiene ser, es decir, el ser le pertenece, le corresponde. Para este último giro en la perspectiva y enunciación de Heidegger, véase Patočka (1991):610 ss.

${ }^{244}$ Un tratamiento especifico de la comprensión de esta diferencia desde el Ereignis, se encuentra en Heidegger (195557). Puede encontrarse un análisis proyectivo, de la diferencia ontológica, en contraste con una noción no metafísica (y heideggeriana) de diferencia en Deleuze, en Esperón (2016)146-155. Asimismo, para la reelaboración de tal diferencia a partir de los Beiträge, Cf. Berciano (1991b):375-80.
} 
definitiva: la pregunta por el ser ya no es elaborada solo en el marco del ser-en-el-mundo del Dasein, sino que Heidegger se encamina a pensarla desde el ser mismo ${ }^{245}$.

En el contexto de estos desarrollos, distingue la metafísica desde dos perspectivas: a) como aquella que considera el ser del ente (donde el ser se oculta ante cada manifestación determinada) y b) como aquella que intenta acceder al ser, más allá de lo óntico, es decir, del ser ligado a sectores del ente ${ }^{246}$. Es precisamente desde esta segunda perspectiva donde Heidegger insiste en el olvido (epocal) del pensar del ser y su sentido. Y aquí también despliega un matiz crítico: el desenvolvimiento histórico de la metafísica ha incurrido en su olvido, respecto a su diferencia específica $^{247}$.

Por ello, la pregunta por el ser debe articularse buscando esquivar todo intento de hacerlo por la vía de lo cósico y del ente, teniendo en cuenta que la tradición metafísica y su modo de pensar, direccionaron sus planteamientos y respuestas en el orden del ente, con sus respectivas limitaciones. Desde aquí es donde Heidegger plantea su tentativa de superación de la metafísica (Überwindung der Metaphysik ${ }^{248}$, expresión que luego se desplaza hacia una torsión (Verwindung), con lo cual entendemos que se propone eludir las connotaciones voluntaristas, aún implícitas en el término Überwindung ${ }^{249}$. Junto a ello, el recurso terminológico de método se abandona por el de

\footnotetext{
${ }^{245}$ Esto va acompañado con una modalizacion de la escritura en los Beiträge, cuando distingue: a) Sein, para referir a la relación ser-ente y b) Seyn, cuando considera el ser desde sí mismo.

${ }^{246}$ En el contexto de estas distinciones, pueden distinguirse elaboraciones preliminares, por ejemplo : a) en su análisis del rechazo de la ciencia por investigar la nada más allá de lo ente, en WiM:104-6[94s.] ; b) en sus desarrollos de la perspectiva de la metafísica que aborda la cuestión del ser como determinante de toda relación con lo ente y respecto a la superación de la metafísica como un rememorar el ser (por fuera del preguntar causal y representativo ligado a lo ente ) ,en WM:367-9;381s.[301s;311s. ].

${ }^{247}$ Desde aquí, Vattimo plantea dos orientaciones en tales tratamientos heideggerianos, no necesariamente opuestas : por un lado, hacia la rememoración del ser, en transición hacia un nuevo pensar y relación en el marco de una suerte de ontología mística, en un acceso dinámico y oscilante del ser contrapuesto a la metafísica, entendida como aquella que ha recaído en su olvido y, por otro, la que sugiere pensar el ser como huella, ya no contrapuesto sino interno a la metafísica, en el marco de un proceso no conclusivo de debilitamiento y declinar del ser que ya no podrá manifestarse presente, sino tan solo fugazmente en sus oscilantes determinaciones epocales .Véase, Vattimo (1991): 94. Frente a esta última orientación, una intérprete distingue un campo singular e inagotable para el pensar y la articulación respectivos destacando, en clave derrideana, una significación trascendental para el Ser: "el Sein heideggeriano no se disuelve en una cadena significante, ni en una sucesión de a prioris (sic) lingüísticos sin fin. El Sein no se debilita, ni declina, ni se fuga en un interminable diferir, sino que conserva toda su enigmática pero potente capacidad de desocultar el ente y mantenerlo en su presencia (más o menos estable o efímera), haciéndolo simplemente ser. Heidegger insiste y permanece en la diferencia ontológica no por temor a desprenderse nihilísticamente de la metafísica (...) El ser heideggeriano no se debilita, no puede hacerlo porque él no es ni fuerte ni débil; sólo las cosas pueden serlo, o nuestras concepciones sobre las cosas y sobre el ser. Heidegger y los pensadores posmodernos hablan sobre dos cuestiones distintas: la diferencia ontológica entre el ser y el ente, permanece más olvidada y oscurecida que nunca antes "(Filippi ,2006:90).

${ }^{248}$ En este contexto, Steiner entiende que la tentativa de Heidegger ,más que una superación de la metafísica, se orienta hacia una superación de la teología, desde su presencia no evidente en la filosofía occidental Ello debido a cierta tensión manifiesta en sus articulaciones sobre el Ser, las cuales suelen orientarse hacia un sentido teológico, véase Steiner(1993):23-6.

${ }^{249}$ Volpi distingue aquél intento de superación en el marco del movimiento del pensar en la filosofía continental. Para un análisis comparativo, respecto a la misma tentativa en la filosofía analítica (circunscripta solo al ámbito enunciativo y discursivo), Véase Volpi (2006):202 ss.
} 
camino, desde el cual la mención del encuentro establece un parámetro relacional-simultáneo, ya no unilateral ni externo.

Desde esta tentativa, desarrolla diacrónicamente los aspectos de la metafísica en línea con el carácter epocal del destino del ser, en su dinámica donante. Entre ellos, veremos que la técnica preludia la consumación de la metafísica, en un sentido singular: permite que esta época tense su campo comprensivo alcanzando así su propio límite, sin intervención directa ni voluntaria, ni tampoco la suposición de una externalidad o salida radical ${ }^{250}$.En el marco de estos planteamientos, nuestro autor destaca que dicha pregunta demanda un ámbito específico de elaboración, pero luego y a partir de una demarcación suficiente del planteamiento tradicional. Así, remonta al pensamiento de Platón este desvío que no atiende la diferencia ontológica, contrariamente a como se manifestó en el pensamiento presocrático con Heráclito y Parménides, entre otros.

\section{1. b.- Aproximaciones al planteamiento tradicional.}

En efecto, distingue que Platón ha interpretado que el ser es la Idea, en tanto aquello que hace posible que cada cosa sea, consumando y desplegando la comprensión griega desde sus orígenes (EM: 190 s. [165]). Con ello, desplaza aquella diferencia originaria a la relación entre las Ideas y las cosas, articulada como la distinción entre lo que es o no verdaderamente ente. Desde aquí, consolidándose con la comprensión que subyace a la ousía en Aristóteles, comienza a desplegarse y cristalizarse un olvido de la diferencia ontológica, circunscribiendo la verdad a uno de los dos lados de aquella diferencia desplazada: el ámbito suprasensible de las Ideas, que establece el marco de lo general y común para la aprehensión de lo ente (Ibíd.: 192-7[166-71]).

Consecuente con este desplazamiento, la verdad así comprendida se articula en ideas cada vez más generales correlativas a la división de todo aquello que es, considerado solo desde su carácter de presencia. Como luego desarrollaremos, por esta vía surgen las ciencias con sus campos respectivos y su determinación correlativa del ser de las cosas, que se cristaliza en un creciente

\footnotetext{
${ }^{250}$ Así describe Volpi esta concepción de torsión de la metafísica: "la metafísica está efectiva y definitivamente superada sólo cuando se la abandona a sí misma sin pretender cambiar nada en ella, cuando se sale de ella como se sale de una enfermedad o como se supera una crisis, asumiéndola y abandonándola a sí misma”. Y luego de plantear un conjunto de resonancias posteriores, sostiene: "Hay que reconocer que en nuestros días (...) no es posible ya más emplear la palabra "metafísica" sin incurrir en lo discutible. No tenemos más una relación directa con lo que la metafísica ha sido, ni es posible una relación de simple repetición con ella. Únicamente podemos tener una relación crítica. Esto significa, entre otras cosas, que debemos distinguir la realidad histórica de la metafísica de sus posibilidades. Y reconocer que más alto que la posibilidad contemporánea de la metafísica se tiene su realidad histórica (...) la metafísica, como todos los verdaderos problemas filosóficos, no tiene solución sino solo historia” ibid.:202; 230 s. A nuestro entender, este intérprete al poner coto al júbilo crítico enfatizando la irrebasabilidad del campo semántico de partida (el cual principalmente encuentra ligado al círculo histórico aristotélico) y en la necesaria distancia y escisión respecto al mismo, despliega una figura de la ipseidad heideggeriana.
} 
dominio calculado del ente, constituyendo un mundo que solo es conocido bajo tales perspectivas y métodos. De este modo, las nociones de ser como ontos on (presencia constante) y de la verdad como adecuación a esa presencia, marcan una línea directriz de la filosofía occidental. Para Heidegger, inscribirse de algún modo en esta línea, a partir de la comprensión del ser que le subyace, implica mantenerse en esta tradición, tal y como sucede con las tentativas de Nietzsche por lograr una inversión del platonismo e incluso en las interpretaciones contemporáneas de la filosofía de Platón (VA: 75[57]; P: 139s. [122]) ${ }^{251}$.

De esta manera, Heidegger entiende la metafísica como la historia de esta modalidad del conocimiento bajo el sesgo de la dominación, cuyo punto de partida es aquella orientación de la pregunta por el ser del ente. La historia (Historie) es el despliegue de este olvido de la diferencia ontológica. Vimos que su propuesta consiste en una destrucción de esta historia de la ontología, como un modo singular de develar aquello olvidado, por medio de una doble operación: a) desplegar el entramado semántico y comprensivo de la tradición metafísica; b) desde allí retomar la esencia de tal recorrido histórico en un camino hacia aquél inicio del pensar. Entendemos el carácter ineludible de la primera operación, implícita en su propuesta de torsión, como único medio de delimitación para orientar sus elaboraciones hacia otra modalidad del pensar y decir del ser ${ }^{252}$.

Esta orientación, entonces, se pliega respecto a la comprensión del ser como una presencia dotada de carácter atemporal y estático, evidenciando que la historia del pensar remite a una sucesión de épocas en las que las configuraciones del ser como fundamento ( Grund) se revelan en su carácter contingente, es decir, sin la condición absoluta que pretendía connotarle la metafísica. Más en detalle: en los Beiträge comienza a circunscribir con precisión dos orientaciones epocales del pensar: a) un primer comienzo (der erste Anfang) de la comprensión del ser, aquella de raigambre griega-metafísica y b) otro comienzo (der andere Anfang) que Heidegger sitúa temporalmente en el por-venir, donde el ser es/será pensado en su verdad como Ereignis, es decir, en una dinámica de co-pertenencia, apertura y donación. De este modo, el olvido resultante del primer comienzo impulsa la transición al otro, en la vía de dicha operación de destrucción ${ }^{253}$.

\footnotetext{
${ }^{251}$ Con ello , Heidegger insiste en la persistencia histórica de esta comprensión metafísica de base, distinguiendo elaboraciones y recepciones del platonismo que encubrieron aspectos abiertos del pensamiento de Platón, incluso interpretaciones posteriores que comparten sin tematizar los presupuestos fundamentales del platonismo(P: 138-44[1216]Cf. EM:154[182] ).Desde la misma distinción de fondo, Derrida recurre con frecuencia a la consideración de cierta complicidad en discursos contemporáneos que abogan por una superación o inversión de los esquemas occidentales metafísicos, no haciendo más que reforzar sus bases profundas. Véase, Derrida (1989 a [1967 a]): $32 ; 53$ s. y Derrida (2012):19; 175; 202.

${ }^{252}$ En torno a estas consideraciones véase, por ejemplo, EM: 155[183]; BPE: 33s. [43s.]; 73-8[73-7]; VA: 73-6[56-8].

${ }^{253}$ En este marco, nuestro autor desarrolla las consideraciones epocales e históricas en torno a la necesidad de abrir una perspectiva originaria, de otro comienzo para la pregunta por el ser que asuma "lo extraño, oscuro e inseguro que conlleva un comienzo verdadero", en EM: 28-30[43s.]; 155-7[183-6].
} 
Ahora bien, vimos que esta destrucción se encuentra con numerosos escollos. Para empezar, tanto el lenguaje con el que cuenta, como la modalidad del pensar respectiva, forman parte de esta historia del ser de la metafísica. Por ello, subraya que no es posible crear un lenguaje o articularse en un pensar ex nihilo, sino que debe transitar con el único que cuenta, para encontrar desde allí la diferencia sumida en el olvido. Aun así, el pensamiento aquí no se reduce al ente y al ámbito de partida, en camino hacia el horizonte no clausurable de aquello por pensar.

En suma, el camino del pensar será un arduo recorrido sin paradas definitivas, que atiende las dinámicas del lenguaje y el pensar, en un claro abandono por una modalización cósica o sustancial de los mismos aunque, por supuesto, se articulará a partir del campo semántico con el que discute, excluyendo así la posibilidad de abandonos definitivos ${ }^{254}$.

\section{1. c.- Consideraciones en torno al claro y la donación del ser.}

Efectivamente, la modalización en el lenguaje que encontramos a partir de estas elaboraciones, tienen como punto de partida la comprensión precedente y la conceptualización respectiva que, paradójicamente, impiden el acceso al ser en general ${ }^{255}$. En este contexto encontramos dos desplazamientos: por un lado, la consideración enfática o eminente del Dasein cede su ámbito a la indagación en sus relaciones desde el ser en su singular movilidad donante, y, por otro, el análisis crítico del Uno se desplaza hacia un abordaje crítico de la técnica moderna, la cual consuma en cierta medida la metafísica, consolidándose como uno de sus resultados. Precisamente en este contexto es donde plantea otro pensar, como nuevo horizonte para el camino hacia el sentido del ser.

Una de las notas características del campo semántico y la comprensión de la metafísica es la consideración del hombre como centro eminente entre los entes, en cuyo modelo se enfatiza la presencia y permanencia del objeto. Desde tales notas, Heidegger subraya el desterramiento (Heimatlosigkeit) del ser, cuyo abandono es consecuencia de aquel proceder planificador y

\footnotetext{
${ }^{254}$ En este marco, sostiene:'La rememoración (Andenken) en la historia del ser ha acontecido (ist ereignet) como un pensar preliminar al comienzo y ha acontecido desde el ser mismo. El acontecimiento (Ereignis) otorga cada vez el plazo desde el cual la historia toma la seguridad de un tiempo. Pero cada plazo, en el que el ser se entrega, no podrá jamás ser encontrado a partir del tiempo contado históricamente y con su medida. El plazo acordado solo se muestra a una reflexión que sea capaz de presentir la historia del ser, aun si esto solo pudiera lograrse en la forma de una indigencia (Not) esencial, la cual, sin ruido ni consecuencia, sacude todo lo que es verdadero y real"'(N II: 490[404]). En este fragmento queda manifiesto además el carácter intuitivo, derivado e involuntario de tal camino del pensar.

${ }^{255}$ En especial, diversos intérpretes sostienen que aquella modalizacion puede datarse a partir de sus Beiträge, entendida como su segunda obra capital después de los años 30. Tal distinción puede encontrarse en: Herrmann FW von ,1994; 1997, passim; Walton, 2012, passim; Veraza Tonda (2016):93, entre otros.
} 
calculante, cuya modalidad de pensamiento respectiva es la representación. Retomar un camino hacia un pensar no metafísico, implica pensar la metafísica en su esencia. Correlativamente, un pensar por fuera de la representación requiere necesariamente realizarse primariamente en el marco de la representación, atendiendo a las dinámicas que con ello se develan.

Es decir, en el marco de la necesidad del ocaso de la metafísica para el advenimiento de un nuevo comienzo, subraya que el despliegue y la puesta al límite del modo del pensar representativo (caracterizado por el poner-delante del representar que asegura y calcula, propio de la comprensión del ser de la metafísica de la subjetividad, su concepto correlativo de objeto y de la verdad como certeza $)^{256}$, se revela como una condición ineludible en el tránsito hacia la torsión de la metafísica ( VA : 68-72;81 [52-4;62]).

En elaboraciones posteriores, Heidegger precisa con más detalle esta dinámica que busca salir de tal modalidad metafísica desde la representación. Específicamente, utiliza dos términos o conceptos dinámicos para denominar este movimiento desde y en el pensar: el salto (Sprung) y el paso atrás (Schritt zurück), por medio de los cuales se dirige a un pensar no metafísico en pos de lo aún por pensar (de aquello ya pensado pero abandonado).Con el primero, denota un movimiento del pensar que conduce a un salto fuera de la metafísica y de la representación, que remite a la correlación del hombre y el ser regida por la técnica moderna; asimismo, conduce a un paso atrás hacia el comienzo de la metafísica. El salto se separa del ser como fundamento en tanto determinación de este por la metafísica, que fue finalmente sustituido por el ente en su modo comprensivo. El ser como ente, conduce a la idea de que este puede ser manejado, manipulado, entendido como algo técnico, como bajo nuestro dominio. Teniendo en cuenta esto, el salto no tiene una dirección o ámbito prefijado, sino que el punto donde se ha de saltar se abre a través del salto, de modo tal que la experiencia es condición de posibilidad de esta dinámica, tal y como articula la dimensión del proyecto en la resolución precursora e, incluso, como despliega las significaciones de términos tales como Dasein o Ereignis ${ }^{257}$.

\footnotetext{
${ }^{256}$ Al respecto, distingue sus límites: "Metido de este modo dentro de los límites de lo metafísico, el hombre queda adherido a la diferencia no experienciada entre el ente y el ser. El modo del representar humano, metafísicamente marcado, en ninguna parte encuentra otra cosa que no sea un mundo construido metafísicamente". Luego , en torno a las relaciones entre tal pensamiento representativo y el cogito cartesiano, agrega: "El ego cogito es para Descartes en todas las cogitaciones lo representado y producido, lo presente, lo que no está en cuestión, lo indubitable y lo que está puesto ya siempre en el saber, lo propiamente cierto , lo que está sólidamente establecido ante los demás, es decir, como aquello que lo pone todo en relación a sí y de este modo lo pone en el 'frente' a lo otro(...) El sujeto , en el ordenamiento de la génesis trascendental del objeto, es el primer objeto del representar ontológico" (VA: 70[53]).Cf. ID:40s.[77]).

${ }^{257}$ Respecto de aquellos conceptos dinámicos del pensar, como dos maneras de nombrar un mismo sentido, es decir, un mismo intento de pensar no-metafísico en y desde la metafísica, véase sus distinciones en VA: 174S. [133S.] .Cf. ID: 49s.; 58-61[95-7; 11-17].
} 
Con estos movimientos del pensar, en su estatuto dinámico y relacional, Heidegger subraya la co-pertenencia (Zusammengehören )del hombre y el ser, donde ninguno de ellos tienen preeminencia respecto al otro, sino que ambos precisan de un claro o despejamiento (Lichtung) para llegar a ser, o mejor, para venir a la presencia. Tal consideración la realiza a partir de la perspectiva y lenguaje de la verdad como Lichtung, lo cual co-implica un conjunto de tensiones en su campo semántico ${ }^{258}$. Tambien por ello, caracteriza este ámbito como claro del ocultarse (Lichtung des Sichverbergens), en referencia al ámbito abierto donde se manifiesta la retraccióndonación, lo cual acompaña un conjunto de términos afines, inscriptos en el horizonte comprensivo de este período ${ }^{259}$.

Más específicamente, distingue lo que mencionamos como las épocas del ser, con los diferentes modos de comprender su presencia, cuyo conjunto se articula en aquello que se usualmente se conoce como la historia de la filosofía. Así, la circunscripción a la presencia en el primer comienzo, condujo al olvido no solo del ser, sino también de aquello que posibilita la venida del ser: aquél ámbito del entre (das Zwischen). En esta dinámica y diferencia entre ser y ente, el ser se manifiesta en el propio salir o gestarse (Überkommnis) que culmina en una llegada (Ankunft). Precisamente la diferencia o dinámica entre aquél salir y su llegada en el ente, permiten designar este entre o claro, como ámbito más originario que el ser. Vemos aquí, con la aprehensión intuitiva de este ámbito intermedio, el énfasis puesto por nuestro autor en un pensar y decir relacional, que demandan conceptos o términos correlativos. Asimismo, nuevamente encontramos la puesta en relevancia de la verdad del ser y no ya solo de su sentido el cual, como vimos, se articulaba con la orientación anterior con sus matices voluntaristas ${ }^{260}$.

\footnotetext{
${ }^{258}$ La metáfora de la luz ha suscitado numerosas discusiones posteriores, especialmente enfocadas a las implicancias metafísicas y platónicas de la luz y en relación al ser entendido como presencia. En este marco, pueden consultarse (en línea descriptiva) respecto a SuZ y Brief über den Humanismus a Garrido Periñán (2014): 207 ss. Y Garrido Periñán (2015):307 ss., respectivamente, el cual argumenta una tesis de continuidad en el pensamiento de Heidegger. También puede hallarse un análisis crítico-deconstructivo de la metáfora fotológica heideggeriana, en Derrida (1993):35-75 y Derrida (2013):247-311.

${ }^{259}$ Un intérprete ofrece una lista instructiva de tales términos con sus desplazamientos respectivos: "Desde el «giro» en 1930, el filósofo se dedica a pensar la relación entre ocultamiento y desocultamiento, dentro de lo cual se vuelven sinónimos del desocultamiento: la mostración, la comprensión, el sentido y la verdad. Por otra parte, aparecen como sinónimos del ocultamiento la nada, el abismo, la sustracción, el silencio y el rehúso. Los nombres de la relación misma, propiamente la cosa del pensar o la cosa misma de la fenomenología, son: el claro del ocultarse (o simplemente claro), el ser (Seyn), el espacio-tiempo, el fundamento abismante, el entre, la esencia, la cuaternidad (Geviert), la contrada (Gegnet), el mundo, el acontecimiento (Ereignis) o la propiación (Eignis) “. Veraza Tonda (2016):102 s.

${ }^{260}$ De esta manera, el movimiento comprensivo de Heidegger se articula en este pasaje del sentido a la verdad del ser, es decir, como condición para el aparecer de todo ente y sentido. En estas elaboraciones, la verdad como desocultamiento $(\mathrm{A} \lambda \dot{\eta} \theta \varepsilon i \alpha)$ es anterior a toda presencia, manifestación o advenimiento del ente, es decir, con un carácter de mayor originariedad respecto a la comprensión desarrollada en SuZ. El movimiento de tal desocultamiento se caracteriza por dos facetas correlativas: a) la simultaneidad y la necesidad del ocultar, que mantiene la reserva en el ocultamiento; b) la necesaria capacidad de asombro, extrañamiento y entrega del Dasein. A este respecto, véase los análisis respectivos de los fragmentos de Heráclito en VA: 212s. [163); 251s. [192s.]; 271-4[206-8].Cf. WW.:18898[159-68].
} 
No obstante, aún con esta orientación Heidegger insiste en desarrollar enunciados en torno al ser sin referentes centrales para su apertura, desarrollando el enfoque hacia tales caracteres relacionales. Precisamente en aquel claro, ambos partenaires pueden apropiarse mutuamente y encontrarse. Esta apertura originaria (ursprüngliche Offenheit) permite distinguir que dicho claro del ente hace posible una experiencia del ocultarse como tal, de modo tal que reencontramos un mismo movimiento de pliegue tensivo: se torna necesario partir de la presencia para arribar a dicha experiencia histórica $^{261}$.

De este modo, el ser pone los horizontes y dona de un modo histórico, de modo tal que Heidegger figura allí una perspectiva dinámica de fundamentación-desfundamentación en su continua oscilación. Este distingo responde al intento de nuestro autor de esquivar un pensamiento del fundamento (Grund), desde el cual tradicionalmente se elaboran conexiones en pos de una totalidad que conduce finalmente a la pérdida de todo suelo (Boden) o abismo (Abgrund) inagotable de emanación del ser, fondo desde el cual algo puede nacer, aún en la situación del hombre moderno en la era atómica (SvG: 60-1[59-60]). Frente a ello, a partir de una perspectiva dinámica sin fundamento, se aparta de la comprensión metafísica y representativa del ser, para pensar el ser y el ente en su relación de diferencia, desfundamentándolos de toda pretensión de un carácter definitivo $^{262}$. En esta vía, el ser en su don (Gabe) se manifiesta por un enviar que, cuando dona, al mismo tiempo se retrae y sustrae a sí mismo, de modo tal que luego puede recibirse el don pero no tener experiencia del donar y el dar mismo.

Más en detalle, tal dinámica de donación manifiesta una oscilación en el marco de dimensiones o estratos coextensivos: claro-ser-Dasein-ente. Desde allí, solo a partir de lo que se manifiesta como presente es posible esbozar una aprehensión (siempre esquiva) del ser en su ocultamiento inmediato. Más aún, es precisamente lo que se sustrae u oculta lo que constituye aquello que se manifiesta o se presenta, pero consistiéndolo por el mismo movimiento de sustracción u ocultarse. Dar cuenta intuitivamente de esta singular dinámica de aprehensión del ocultarse-darse y del carácter epocal de tal consistir caracteriza el programa de esta perspectiva en torno al ser. Entendemos que por ello Heidegger enfatiza el aspecto relacional: el ámbito a

\footnotetext{
${ }^{261}$ En este marco podemos entender que el pensar metafísico y su lenguaje se circunscribió a uno de los momentos de esta dinámica, la presencia. La conceptualización de allí articulada no logró dar cuenta del momento de envío anterior, en su carácter de retraimiento-ocultamiento. Precisamente por ello, no se trata aquí de la oposición de un momento a otro o de un descarte y eliminación de la metafísica, sino de un tránsito a una dinámica no obturante o sustractiva.

${ }^{262}$ En el marco de esta distinción, vimos anteriormente que Vattimo inscribe lo que entiende como una ontología del declinar en Heidegger, la cual caracteriza como una teoría del ser débil que lo remonta al infinito respecto al fundamento, un fundamentación hermenéutica que incluye la desfundamentación y el ser del Dasein en relación a su ser-para-la-muerte. Aquí distingue una continuidad ontológica con SuZ, donde sustituye al ser como estabilidad y fuerza por el ser como vida y maduración. Con este desplazamiento el ser no es lo que permanece, sino lo que deviene, nace y muere, consideración desde la cual se coronaría lo que entiende como el nihilismo de Heidegger, correlativo a tal ontología del declinar. se, Vattimo (1992):66 ss.
} 
circunscribir en su fugacidad requiere de una singular relación entre los partenaires, sin reducirse a ellos ni a determinación alguna. Asimismo, aquel carácter de simultaneidad que subrayamos en las estructuras del Dasein encuentra aquí otra articulación, cuya función es rechazar puntos de partida externos o anteriores a la relación. En suma, tal lógica entramada, sustractiva, oscilante, esquiva, diferenciante y sin fundamento atraviesa estas elaboraciones, articulando la presencia en su carácter de proveniencia ${ }^{263}$.

Asimismo, estos recodos en el camino del pensar de Heidegger y su modalización, cancelan las pretensiones de articulaciones lingüísticas proposicionales definitivas o acabadas. Como estas se determinan en el marco de ciertas dinámicas, el paso obligado es desplegarlas, al menos en parte. Desde allí, sus puntos de llegada de tal despliegue, mantienen su recorrido y lo articulan retrospectivamente, por lo que se vuelve fundamental atender al vaivén de tales dinámicas, más que a las paradas en el recorrido ${ }^{264}$. Por otra parte, también sus recorridos precisan de tales paradas en el camino, de modo tal que en el movimiento de lo que se devela y oculta, se co-produzca el propio recorrido $^{265}$. Precisamente por ello, su anterior modalidad de análisis desde una metodología fenomenológica puede desplazarse sin mayores consecuencias en lo que respecta al horizonte de búsqueda.

Ahora bien, el "ahí del ser” del Dasein se ve ahora también modalizado: allí se dona esta sustracción, como entrelugar respecto al ente. Ello es lo que destaca como la instancia (Instāndigkeit), en tanto ámbito o dimensión donde la donación interpela al Dasein, en una invitación para corresponderle relacionalmente. Por ello, en el marco de esta elaboración en transición del pensar, se torna necesario especificar las determinaciones más relevantes de la copertenencia entre hombre y ser, atendiendo las consideraciones de la mismidad en esta etapa de su pensamiento pues, como veremos, también las modalizaciones y énfasis respectivos se articulan de modo correlativo.

\footnotetext{
${ }^{263}$ Desde aquí, Vattimo también articula una falta de desarrollo para una teoría de desalienación en Heidegger, pues desde estas elaboraciones esta no sería otra cosa que un darse del ser como presencia. Frente a una teoría tal, el pensamiento hermenéutico se despliega en el marco de la crítica de las ideologías y el psicoanálisis en lo que respecta al análisis infinito de fondos que sostienen todo contexto de significados. Véase, Vattimo (1998):124-7.Con esta interpretación se evidencia la relevancia de la consideración del lenguaje para este encuadre crítico en la obra heideggeriana.

${ }^{264}$ En este sentido, destaca el ámbito de despliegue en su carácter acontecimental, cuando sostiene la siguiente diferencia de orientación:"El opinar cotidiano busca lo verdadero en la diversidad múltiple de lo siempre nuevo que se dispersa ante él. No ve al callado resplandor (el oro) del misterio que brilla incesantemente en lo simple del despejamiento (...) no se deja tomar, porque no es nada que pueda tomarse sino que es el puro acaecer de un modo propio". (A: .273[208]).

${ }^{265}$ Por ello sostiene que en tal camino, dadas sus determinaciones singulares, el lugar se hace visible simultáneamente al momento en que se consuma el paso (ID: 58[117]). Asimismo, destaca que aquel consta de desvíos y rodeos, de modo tal que solo puede efectuarse de un modo indirecto (MWPh: 99[100]).
} 


\section{2.- La co-pertenencia hombre-ser con sus modalidades de pensamiento}

Recapitulemos: una transición en la época del ser implica el pasaje de la alusión primaria de cierta preeminencia del hombre respecto al ser, a una explícita subordinación del hombre respecto a este. No obstante mantener una preeminencia unilateral, no esquivaría la semántica del subjetivismo, sino tan solo desplazaría su inscripción. Por ello, nuestro autor destaca que, en tal dinámica, la comprensión del Dasein es derivada de la apertura del ser, incluso este en su especificidad, depende de la iluminación de ser para ser hombre. Con ello, la simultaneidad dinámica se desarrolla en un singular tratamiento de los aspectos o caracteres pasivos del Dasein.

A continuación abordaremos este enfoque relacional de un modo preliminar al abordaje respectivo de la ipseidad, con el objeto de delimitar o especificar aquél estatuto de simultaneidad en estos ámbitos dinámicos y relacionales. Por ello, puntualizaremos el lugar cada vez más eminente que manifiesta la consideración de los temples anímicos en vistas a la descentralización de los análisis desde la voluntad y la subjetividad. Asimismo, abordaremos la modalización respecto de la cotidianidad del Uno, que en este período puede asociarse a la consideración del mundo de la técnica, para luego cotejar el singular modo en que nuestro autor trata la dinámica no excluyente entre dos modalidades de relación de co-pertenencia: la del pensamiento técnico con la relación más originaria del otro inicio del pensar.

\section{2. a.- Los temples anímicos.}

Como mencionamos, Heidegger insiste aquí en la noción de tránsito (Ubergang), pues sus miras no le permiten un abandono radical del suelo lingüístico de la metafísica, en clara continuidad con las elaboraciones sobre la co-originariedad del Dasein con el Uno, en su irreductibilidad.

Ahora bien, del recorrido de estas elaboraciones y del campo semántico desde el que se desplaza se desprenden ciertas consecuencias que inciden retroactivamente sobre el suelo de lenguaje sobre el que transita. Su recorrido se enmarca así en la historia del ser, cuyo impulso primario lo toma del intento de abandono del pensamiento de lo ente como objetal y presente, para colaborar con el advenimiento de otra relación de co-pertenencia con el ser. Si bien como la 
exponemos esta transición puede aparentar ser un gesto voluntario, nuestro autor busca explicitar modos de articulación de tales dinámicas, por fuera de todo acto decidido o consciente.

En efecto, el horizonte calculable como meta de una voluntad consciente y obstinada no puede hallar un lugar pertinente en estas elaboraciones. La mismidad del Dasein se orienta en el seno de la pertenencia y a ella se confía. Para ello son necesarios como condición ciertos temples anímicos que resultan en tales pertenencias, determinados por oposición a la modalidad del hombre en la co- pertenencia de la técnica moderna, repercutiendo a su vez en la mismidad:'lo cual equivale un cambio de esencia del hombre desde el 'animal racional' hacia el Dasein” (BPE: 3[21])’

Las determinaciones del temple anímico que son correlativas a esta modalización se hallan en un campo de apertura y entrega que encuentran en aquella alteridad (sea el horizonte del ser, de la mismidad propia del Dasein, de la experiencia en el mundo circundante desde otra relación con el ser, etc.), las notas determinantes para tales estados. En estos trabajos, el encaminarse hacia el otro comienzo del pensar tiene como condición la apertura instituida por la disposición afectiva fundamental (Grundstimmung).Desde allí despliega el carácter pasivo del Dasein ${ }^{266}$, pues aquella sobreviene a partir del destino epocal del ser (Seinsgeschick) ${ }^{267}$.

En este marco, distingue algunos temples fundamentales que manifiestan tal vínculo con la diferencia en la modalización relacional, por ejemplo: asombro(Erstaunen), desasimiento (Sinchloslassen), serenidad (Gelassenheit), espera (Warten), tranquilidad (Ruhe), perseverancia (Ausdauer), insistencia (Beharrlichkeit), etc. ${ }^{268}$.Junto a ellos, entre los temples propios del otro inicio, también destaca: el espanto (das Erschrecken) (hacia lo que se oculta), la reserva (die Verhaltenheit) (en tanto desasirse para el despliegue del ser); el presentimiento (die Ahnung) y el recato o respeto (die Scheu), en los cuales nos detendremos en el próximo capítulo.

Desde estas disposiciones de ánimo, Heidegger encuentra la modalidad propia para el despliegue hacia el ser, al cual se encamina no en un sentido denotativo de un ir hacia un eso

\footnotetext{
${ }^{266}$ A partir de estas distinciones, Santiesteban subraya una doble dimensión en la comprensión del Dasein en el marco de estos procesos: “(...) Acaso con ello nos quiere dar a entender, en contraposición a la metafísica moderna, que el destino del hombre no depende por completo de su voluntad. Igualmente decisivo en este respecto es el hecho que el Dasein no se define tanto por el yo pienso, sino por el ser afectado por una disposición afectiva (Stimmung), es decir, por su pasividad. Heidegger reconoce en el hombre un componente activo, pero con igual originariedad una pasividad" Santiesteban (2005):83.

${ }^{267}$ Un intérprete distingue resonancias de estas tesis que preludian perspectivas posteriores, por ejemplo: "Según este nuevo enfoque de su pensamiento, es el ser el que, a través de la historia, determina los modos en que el hombre comprende el ser. La comprensión del ser por el hombre está determinada por la verdad del ser. Estas tesis heideggerianas constituyen formulaciones abstractas que prefiguran las teorías acerca de la existencia de estructuras inconscientes de carácter antropológico, social o histórico, tales como las epistemes de Foucault" Fidalgo Benayas (2013): 121 .

${ }^{268}$ Diferentes estaciones en este tramo del pensar de Heidegger retoman, desde 1936, las consideraciones de los temples anímicos fundamentales en esta modalidad de pertenecia al ser. Incluso algunos términos reelaborados, como Gelassenheit, por ejemplo, buscan dar cuenta de un campo semántico que incluye un número considerable de ellos .A este respecto, véase especialmente, BPE: 4-36[22-46]; B: 307-30[265-82], entre otros.
} 
consistente y definido, sino más bien un señalar que prolonga un acto de direccionamiento por la cual se encamina (Ibid.:4[22]), evitando así toda sustancializacion desplazada al ámbito del ser. En este marco, la disposición es de escucha para la exhortación que proviene del ser, tal y como en la etapa anterior provenía del llamado de la conciencia.

Finalmente, destaca que la consideración del tránsito subyacente a estas determinaciones conlleva una comprensión del tiempo correlativa. El señalamiento de un despliegue hacia un otro inicio del pensar no remite hacia adelante desde una consideración vulgar del tiempo (lo que supone ya expectativa y cálculo), sino en el marco de la historia acontecida (Geschichte), la cual se despliega en el marco despejado del olvido del ser (FT: 26[21]) $)^{269}$.

Tal marco señala hacia aquello que en el pensamiento sufrió un desvío y que nuestro autor puntualiza en el pensamiento griego presocrático: el ser desde su diferencia ontológica respecto al ente, la cual impacta inexorablemente en el modo de pensarlo y en sus posibilidades o modalidades de aprehensión verbal ${ }^{270}$.

No obstante, tales determinaciones son dinámicas y ellas no pueden comprenderse por fuera de las determinaciones del pensar, del decir y de los temples anímicos propios de la co-pertenencia del hombre y el ser en lo que denomina como la era atómica (Atomzeitalter) (ID:42[79]). Esta situación fáctica y epocal de partida es precisamente la que articula con la técnica moderna.

\section{2. b.- La relación en el marco de la técnica moderna.}

Para nuestro autor es necesario reelaborar la consideración del pensamiento, en vistas de su relación con el ser y las dinámicas relacionales. Las singularidades de aquello a pensar implican correlativamente una modalidad singular del pensar. Su propuesta se orienta a la donación del ser: si el mostrarse de los entes remite a la donación y lo mostrado es lo dado, entonces será precisamente la diferencia entre ambos aquello a lo que apunte el pensar en sus elaboraciones, en tanto modalidad

\footnotetext{
${ }^{269}$ Walton traza una sugerente continuidad entre los manuscritos tardíos de Husserl sobre el tiempo y la concepción heideggeriana del Ereignis (en el marco de dicho tránsito), precisamente en tal punto de contacto: en ambos casos se plantea una temporalidad primigenia, sea en la modalidad de abismo en Heidegger o en la de horizonte originario pretemporal anterior a las operaciones del yo, en Husserl. Véase Walton (2012):91-111.

${ }^{270}$ Es precisamente en este sentido desde donde repite las palabras de Ortega, cuando subraya que son necesarios despensadores (Zerdenker) ante la impotencia que experimenta el pensar frente a los poderes contemporáneos Véase, Begegnungen mit Ortega y Gasset, en ED: 127-8[89-90].
} 
de plantear la diferencia ontológica, es decir, entre el ser (mostrarse) y el ente (lo dado como presente), donde la donación se sustrae. Aquí es donde toma distancia con el método científico, por su tendencia a subordinar lo dado al método, en el marco de la exactitud y el dominio, en el marco del paradigma rector de la realidad reducida a lo efectivo y presente, en vistas al horizonte de cientificidad y de la comprensión metafísica de la verdad como correspondencia.

Frente a este marco, Heidegger distingue la región (Gegend) o claro como ámbito de lo abierto en donde se manifiesta lo dado del ente en la donación del ser. Lo dado, se manifiesta en el venir al encuentro (gegnet) de la dinámica de donación, por ello es desde tal región donde emerge el impulso o se abre lo pensable y todo horizonte posible, es decir, la dinámica de donación es aquí la que indica, abre, orienta. Este camino transicional al otro comienzo del pensar, remite a una comunidad por-venir, pues requiere una profundización o apertura mayor ${ }^{271}$.

Por su parte, una de las consecuencias de la consideración del ser en tanto presencia del primer comienzo, es lo que Heidegger denomina como antroporfismo incondicionado (unbedingten Anthropomorphismus), refiriéndose al dominio devastador de la tierra por parte del hombre (N II: 20[21]). Esto marca para nuestro autor no solo la época del ser desde la que articula sus elaboraciones, sino también el ámbito desde y contra el cual distingue una transición relacional. En este contexto ¿cuáles han sido las condiciones de posibilidad en el despliegue de esta relación del hombre con el mundo circundante?

En principio, es condición la modalización del pensar que aquella comprensión conlleva: la entidad es entendida desde el cálculo (Berechnung), la planificación y la institución ${ }^{272}$. Las relaciones entre la comprensión, la palabra, el concepto y la modalización del pensamiento son aquí fundamentales: condicionan las variaciones, cadencias, contenidos y perspectivas del pensar. Ahora bien, debido al ensamble complejo, su estructura múltiple y el carácter originario de la comprensión y el lenguaje, los desplazamientos o variaciones respecto a tal modalización no pueden explicarse desde la intervención humana, al menos, no de un modo directo. Adentrémonos

\footnotetext{
${ }^{271}$ En el marco de tal profundización, Veraza destaca el aspecto proliferante y renovable de la fenomenología y subraya: "La fenomenalización no puede ser monopolizada o agotada por ningún pensamiento, sino que cuando es llevada a la palabra prepara o anticipa un diálogo que otro puede retomar. En este sentido, el pensamiento del ser propicia una comunidad futura como su espacio tanto de permanencia y reconocimiento como de superación de sí (...) hay que escuchar y esperar a otros interlocutores, recuperar radicalmente el gesto de la herencia a los venideros que se apunta al final de los Beiträge, dentro de lo cual se puede contar también al Husserl de los póstumos que Heidegger no quiso o no pudo reconocer (...) el albergue la esencia de la verdad tiene que propiciarse en obras de diversa índole y la recepción ha de atender a lo irreductible en cada intento, a lo que no se puede ver como presente absoluto ni como ausencia, para decirlo en el espíritu de Derrida, pues es por-venir pero el inicio solo puede tener lugar efectivamente integrando la comunidad con otros, los superadores de sí mismos, donde el pensar heideggeriano quede resguardado en la proveniencia y el porvenir común y se supere en nombre de lo por pensar” Veraza Tonda (2016):111-3.

${ }^{272}$ Dentro de este proceso cobran primacía lo gigantesco (der Riese) ( en las cifras de la física atómica, de las distancias hechas por los aviones, etc.) en el marco de una pasión por la exageración y la superación que representan para nuestro autor una :" huida a la tradición, entremezclada de humanidad y prepotencia , no es capaz de nada por sí misma y se limita a ser una manera de cerrar los ojos y cegarse frente al momento histórico"(Hw:88[78])
} 
en estas consideraciones con el objeto de aprehender claramente estas articulaciones desde su caracterización general de las cosmovisiones de la época y, en particular, de la modalización relacional subyacente a la visión científica.

\section{2. b.I.- Las cosmovisiones medianeras.}

Dicha modalidad y comprensión epocal la caracteriza como una maquinación (Machenschaft), término con el que destaca la sustitución de la interrogación hacia la verdad del ser, por la elucubración e imposición de fines o valores (Ibíd.:21[22]). Precisamente desde allí puede explicarse el auge epocal de la imposición de cosmovisiones, como formas derivadas y extremas de aquellas desmesuras del representar y el producir calculante. Por esas vías se auto instaura el hombre dentro del ente, segregando valores culturales e ideas del pueblo (völkische). Con esta tematización, Heidegger radicaliza las consideraciones respectivas que elaboró en la década anterior, que distinguió en el marco de la consideración de la filosofía en su tarea respecto a la pregunta por el ser. Aquí, continúa a sus desarrollos sobre la falta de sostén, siguiendo la vía aún vigente de las desviaciones del posicionamiento y la visión científica.

Entre las cosmovisiones epocales que articula con ello se encuentran el comunismo, el cristianismo y la fe, la política y el culturalismo (que pretende significar toda la acción del hombre en sociedad), las cuales coinciden en determinar al hombre como aquel ente que se conoce en esencia, con el consecuente abandono del $\operatorname{ser}^{273}$.

Estas cosmovisiones inhiben una experiencia autentica al reducir el saber y el conocimiento a mera erudición escolar ${ }^{274}$. En tanto visiones totalizantes del actuar y pensar, tales perspectivas tienen como corolario la percepción de hostilidad en lo otro, con lo cual se cierran a la apertura del otro inicio del pensar (BPE: 40[49]).Entre sus correlatos, el pensar y proceder científico moderno hallan mayor relevancia en sus análisis, con sus respectivas modalidades en relación al ente y al mundo circundante en general.

\footnotetext{
${ }^{273}$ Entendemos relevante distinguir aquí estas especificaciones en el marco histórico del ascenso del nazismo, desde el cual escribe. En el próximo capítulo retomaremos estas consideraciones.

${ }^{274}$ En este marco también inscribe el predominio de época de las iglesias, a las que entiende como cosmovisiones para las masas (BPE:39[48])
} 


\section{2. b.II.- La ciencia en la modernidad: un diagnóstico de época.}

Heidegger distingue que el hombre asignado como centro de referencia del ente en su totalidad caracteriza la época moderna y su maquinación, donde el ente deviene imagen del mundo (Weltbildes), es decir, como representación y producción de lo objetivo en un mundo pre comprendido en el horizonte calculable de la cientificidad. Específicamente, utilizar, estatuir, calcular y delimitar horizontes caracterizan este modo de articular lo perceptible para su consecuente utilización, dotando al ente de cierta consistencia, cuya certeza en el marco del saber y el conocimiento adquiere valor de preeminencia.

Esto se debe a que el proceder anticipador del conocimiento requiere un ámbito ya abierto en el cual instalarse, es decir, un sector de objetos que se hallen dentro del ámbito del ser entendido como presencia. Esto manifiesta un imperialismo de la exactitud y certeza, pues tal ordenamiento permite fijar los hechos y la constancia de su variación, estableciendo una circularidad por la cual se fundamenta lo desconocido por medio de lo conocido (es decir, garantizando aquél por medio de este), al tiempo que motiva la proliferación de especializaciones. De esta manera, toda alteridad propia y su misterio inabarcable, quedan invisibilizados en tal ámbito y su apertura ${ }^{275}$. Respecto a estas reducciones sostiene:

"El conocimiento, en tanto que investigación, le pide cuentas a lo ente acerca de cómo y hasta qué punto está a disposición de la representación...dispone de lo ente cuando consigue calcularlo por adelantado (...) Solo aquello que se convierte de esta manera en objeto es, vale como algo que es .La ciencia solo llega a ser investigación desde el momento en que se busca el ser de lo ente en dicha objetividad" (Hw: 80[71 s.])

En este fragmento podemos encontrar en las menciones de manipulación y cálculo, que aluden a modalidades relacionales del hombre con el ser y el mundo, que son correlativas a las comprensiones implícitas de la metafísica de la subjetividad, tal y como vimos en capítulos anteriores.

En este marco, en diversos trabajos y cursos remite con el término obstancia (Gegenständigkeit) ${ }^{276}$ a esta modalización del ente, así como también utiliza para referirse al ímpetu

\footnotetext{
${ }^{275}$ Desde esta base distingue entre los fenómenos de la modernidad técnica más relevantes el auge de la ciencia y su corolario: la pérdida de los dioses (Hw: 70[64]).

${ }^{276}$ Aquí lo real remite a una región de objetos que marca de antemano posibilidades de cuestionamiento, asimismo designa el fondo desde donde se establecen los ámbitos objetivos: "la naturaleza se presenta al representar como una trama espacio-temporal calculable de un modo u otro" (VA: 54[41]). Por ejemplo, sostiene que tal obstancia se halla en la psiquiatría cuando ésta, en el marco de sus elucubraciones., comprende ya presente la existencia humana.
} 
que rige la mismidad del hombre correlativa. En efecto, la obstancia connota esta comprensión y apertura objetal de la presencia por medio de lo cual la teoría concibe lo real desde el aspecto objetal y presente, disponiéndolo de ese modo para la representación. Junto a ello, Heidegger distingue aquello que es desechado de la investigación y el pensar científico: lo irrodeable $o$ intratable (Unumgängliche) (VA: 56s [45s]). Mientras en el primer caso se trata siempre de un modo de la presencia calculable, lo irrodeable, en cambio, no permite cercar la plenitud de su esencia pues es lo inaprehensible por esta modalidad del pensar ${ }^{277}$. Con esta distinción articula un ámbito no conjurable del pensar y el lenguaje de la técnica, que se halla como fondo de toda relación entre el hombre y el ser, en sus elaboraciones de este período.

De aquella manera, el mundo queda convertido en imagen para disposición del hombre. La representación, como su modalidad respectiva de tal pensamiento, se caracteriza por traer ante si aquello que está ahí adelante. En vistas del dominio del ente en su totalidad., esto conduce al ente a la estabilidad como objeto, único modo en que esta modalidad del pensar lo concibe en su ser. En tanto designa una región de desocultamiento de lo ente, la técnica exige de la naturaleza energía para extraer y almacenar (Ibid.:18[15]). Esto es lo que denomina emplazamiento (Gestell) de la naturaleza, es decir, una estructura cuyo empuje consiste en forzarla a que dé: provocar, transformar, almacenar, distribuir, son algunas de las maneras de este hacer salir de lo oculto.

Correlativamente, la subjetividad se somete a este criterio de instaurabilidad de todo ente ${ }^{278}$, que dispone de aquel en el marco de la esencia de la técnica. Específicamente, cuando el mundo se convierte en imagen, el sujeto deviene subjectum dentro de lo ente.

En este sentido, en el mundo moderno de la técnica nuestro autor subraya que es el ser el que abandona al ente, entregándolo a sí mismo. No obstante, esta relación de abandono es posible experimentarla desde otro pensar, con su respectiva cuestionabilidad, lo que ya implica de algún modo un despejamiento del ser. Es decir, aquel despejamiento o claro (del vaivén del ocultarsedesocultarse y del contraste entre modalidades de co-pertenencia) ocurre desde las épocas del ser y no por el hombre, de modo tal que esta transición no se articula semánticamente con la idea moderna de progreso (Fortschritt), ni tampoco denota un desplazamiento que vaya de lo habido hasta lo nuevo, tal y como se articularía en un pensamiento representativo. En este contexto, se

\footnotetext{
${ }^{277}$ Respecto al límite no domesticable que representa esta dimensión para el pensamiento científico, que lo inscribe en una modalidad relacional ineludible, subraya : "el modo de representar científico,por su parte, no puede nunca decidir si la Naturaleza, por su obstancia, más que llevar a aparecer le oculta plenitud de su esencia, lo que hace es retirarse .La ciencia ni siquiera es capaz de preguntar esta pregunta; pues como teoría se ha asentado ya en la zona delimitada por la obstancia” (Ibid.:59[45]).

${ }^{278}$ En lo referente a esta modalidad de pertenencia en su impacto en la esencia misma del existente humano , subraya:"Lo decisivo no es que el hombre se haya liberado de las anteriores ataduras para encontrarse a sí mismo: lo importante es que la esencia del hombre se transforma desde el momento en que el hombre se convierte en sujeto(...) se convierte en aquel ente sobre el que se fundamenta todo ente en lo tocante a su modo de ser y su verdad"(Hw:81[72s.])
} 
instaura también uno de los mayores peligros para la esencia del hombre, al configurarse cósicamente dentro de aquella función de objetivación ${ }^{279}$.

En efecto, el hombre deviene un animal trabajador abandonado al vértigo de los artefactos, tornándose en su mismidad como un ente objetual. Es decir, se da una co-pertenencia de la representación, el objeto y la subjetividad, de modo que sólo puede concebirse un objeto donde hay un yo en su esencia de objeto como obstancia, de modo que se obstruye toda dinámica, por lo que sostiene:

“Los signos del último estado del abandono de ser son las proclamaciones de las 'ideas' y 'valores' , y el imprevisible vaivén de la proclamación de la 'acción' y de la imprescindibilidad del 'espíritu'(...)el consumo incluye el uso reglado del ente ,que se convierte en oportunidad y materia para realizaciones y para la intensificación de estas(...) En este proceso está implicado también el hombre , que no oculta por más tiempo su carácter de ser la materia prima más importante (...) El mundo se ha convertido en in-mundo en la medida en que el Ser, si bien esencia, lo hace sin su propio prevalecimiento ”(Ibíd.: 87-8[67-8]).

Con este fragmento no solo podemos cotejar la comprensión que Heidegger distingue a esta modalidad de la técnica, sino también inscribir la modalizacion subyacente a la analítica del Dasein de sus trabajos anteriores, que se desplaza a partir de estas elaboraciones. De aquella manera, el pensamiento representativo avanza con una única perspectiva. Este tránsito se enmarca en el largo período de finalización en el que ha entrado la metafísica, cuya superación solo puede darse como torsión, cuestión en las que nos detendremos especialmente en el próximo capítulo. Destacamos aquí que para nuestro autor, tanto el peligro para el hombre como aquello que puede desplazarlo se hallan en la misma superficie, que emerge por la pertenencia originaria del hombre respecto al ser. En ese sentido, sostiene:

"Lo que amenaza al hombre no viene en primer lugar de los efectos posiblemente mortales de las maquinas y los aparatos de la técnica. La autentica amenaza ha abordado ya al hombre en su esencia (...) Cuanto más nos acerquemos al peligro, con mayor claridad empezaran a surgir los caminos que llevan a lo que salva, más intenso será nuestro preguntar. Porque el preguntar es la piedad del pensar” (Ibíd.: 32-40[26-32])

\footnotetext{
${ }^{279}$ En este marco, el voluntarismo y la auto imposición constituyen los signos y el peligro de esta modalización, por ello sostiene:'El propio propósito de esta autoimposición desarrolla el ámbito del peligro consistente en que el hombre pierda su mismidad en la producción ilimitada. La amenaza que afecta a la esencia del hombre surge a partir de esa misma esencia" (...) "El hombre que se auto-impone vive de las apuestas de su querer. Vive esencialmente arriesgando su esencia en la vibración del dinero y el valer de los valores” (Ibíd.: 270- 289[218-233]).
} 
En suma, la técnica co-determina en el conocimiento qué resulta o no accesible: preproyecta la naturaleza como ámbito objetal, haciendo a dichos ámbitos susceptibles de cálculo. De esta manera dispone y fuerza a mostrarse a la naturaleza, exigiéndole y tornándola disponible para su regulación. ${ }^{280}$. Nuestro autor encuentra en las elaboraciones de Nietzsche una figuración de esta caracterización del mundo de la técnica, lo cual permite circunscribir un umbral en la metafísica y en la historia del ser.

\section{2. c.- El pensamiento de Nietzsche como metafísica consumada.}

En efecto, para Heidegger el pensamiento de este filósofo es una expresión de la etapa final de la metafísica, de su consumación, al destacarla como voluntad de poder. Tal expresión se halla implícita en el dominio y el conocimiento como posesión y autoafirmación. Es precisamente en diálogo con este pensador donde subraya, a partir de la década de 1930, que tal consumación permite al pensar direccionarse a un nuevo comienzo, retornando al origen de la metafísica occidental, es decir, a la filosofía griega y, en especial, el pensamiento presocrático cuyo sentido del ser es la phýsis. Así, este nuevo comienzo consiste en una repetición del comienzo de la metafísica, retomando la diferencia entre el ser y el ente que ha caído en el olvido. Sin intención de un abordaje específico, puntualizamos aquí algunas de estas consideraciones pues entendemos que constituyen un proemio para la concepción del ser como Ereignis.

Más en detalle: la voluntad de dominio es para Heidegger una figura histórica de la metafísica en occidente. En este contexto, se abandona la experiencia del ser para sumergirse en la totalidad del ente. El pensamiento nietzscheano representa un preludio para esta etapa de consumación de la metafísica, la cual es correlativa al dominio planetario de la técnica ${ }^{281}$. Como vimos, entiende que sus intentos de inversión del platonismo no solo se hallan aún dentro de los límites de la metafísica, sino que también extreman su olvido del ser característico (VA: 75s [57s.] Cf. Hw: 200[162]; EM: 29s. [44]). Ello se debe a que la voluntad de la voluntad se articulan con diversas notas y caracterizaciones que son propias del pensamiento metafísico: en el cálculo y la organización de lo ente, en la objetivación de la naturaleza y el hombre, en el pensar representativo y la extensión ilimitada de la razón calculadora. Más aún, destaca que el propio pensamiento y decir de Nietzsche se despliegan de un modo técnico y metafísico. No obstante, si bien con tal modalidad

\footnotetext{
${ }^{280}$ Para una interpretación y análisis en torno al carácter crítico y desemascarador del pensar del ser el cual, debido a su modalidad de pensamiento insondable (correlativa a lo pensado como huella insondable de un vacio), se ve orientado en el discurso heideggeriano a un decir siempre metafórico y dinámico, véase Chillón Lorenzo (2016):35-40.

${ }^{281}$ A este respecto, especifica: “(...) en la teoría de Nietzsche de la voluntad de poder en cuanto 'esencia' de todo lo efectivamente real, se consuma la moderna metafísica de la subjetividad” (Hw: 220[178] Cf. N II: 177-80[163-6]).
} 
no logra subvertir el suelo del platonismo con el que discute, su tentativa preludia el pasaje a un nuevo comienzo del pensar (VA: 78s. [59s]Cf. N I: 202-12[189-98]).

En esta línea, nuestro autor parte de la caracterización nietzscheana del nihilismo occidental (Hw: 194[158].Cf. N II: 68-71[70-4]; 77-82[79-83]), para pensar una superación y pasaje por la vía de la pregunta por el ser, de modo tal que permita experimentarlo desde el fondo de su origen histórico (EM: 155[183]). En este marco, analizando el pensamiento presocrático, destaca la experiencia del encubrimiento del ser en el desocultamiento de lo ente, insistiendo en que tal olvido es una parte del destino del ser en su historia (Hw: 310[250]) $)^{282}$.

En suma, el retorno hacia el origen, ante el dominio devastador del mundo de la técnica, consiste en retomar la diferencia ontológica, despojándose del modo de pensar representativo para interpretar el pensamiento antiguo. Frente a ello, Heidegger distingue otra modalidad de pensamiento que proyecta un camino dentro de la región del claro donde el ser se da, modalizando correlativamente la relación del existente humano.

\section{2. d. - Ge-stell y Er-eignis.}

Hemos visto que los movimientos del pensar propuesto por Heidegger en esta etapa distan de paradas definitivas. Subrayamos que ello se debe a que la superficie desde donde opera tal dinámica es la del lenguaje, en cuyo vaivén nuestro autor confía que se den develamientos parciales de aquello sumido en el olvido y hacia lo cual medita. En este sentido la co-pertenencia entre hombre y ser que se establecen en el marco de la técnica y aquella que señala en el otro inicio del pensar se inscriben en dicho vaivén y dinámica relacional. En el primer caso utiliza la denominación de Ge-stell y, en el segundo, lo señala con el término Er-eignis ${ }^{283}$.

En primer lugar, frente a dicha comprensión que encuentra en la voluntad del hombre el motor de la técnica, Heidegger insiste en que, en el darse epocal del ser, es más bien el hombre el que recibe la imposición de la técnica en una exhortación hacia el aseguramiento del mundo

\footnotetext{
${ }^{282}$ Respecto a lo cual, agrega: "Pero el olvido de la diferencia con que se inicia el destino del ser, para consumarse en él, tampoco es un defecto, sino el acontecimiento más rico y vasto en que la historia occidental del mundo llega a su resolución. Es el acontecimiento de la metafísica. Lo que ahora es, se encuentra bajo la sombra del destino del olvido del ser ya ocurrido previamente" (Hw: 336[271]). Vemos aquí la insistencia en una superación o torsión de tipo interna a la metafísica, que no oculta las limitaciones a las que constriñe el lenguaje y su herencia.

${ }^{283} \mathrm{El}$ guionado en el uso de tales términos remite a la intención de resaltar el verbo en referencia al campo semántico en el que se inscriben respectivame. Cuando los términos van sin guión continúan dentro del mismo campo, aunque cumpliendo la función de palabras conductoras del pensamiento, es decir, términos sin significación cerrada de modo tal que vayan abriendo surcos en el camino del pensar, en la dirección señalada de la pregunta por el ser. Tal es el caso de Ereignis, que por su distinción verbal construye un campo semántico que implica diversos sentidos: acontecimiento, instante, apropiación, rayo, mostrar, seña, etc.
} 
circundante bajo el dominio y el cálculo. De esta manera, tanto el hombre como el ser se develan bajo esta imposición que los dispone y empuja a comportarse de ese modo. Precisamente denomina a esta constelación de co-pertenencia y disposición como com-posicion $(G e-s t e l l)^{284}$, en tanto constelación/relación mutua de organización, automatización y cálculo, que expresa de un modo apropiado la esencia de la técnica, en referencia a la totalidad de los modos de poner técnico en esta relación. Destaca que este ensamble de los modos de poner (stellen) en esta constelación designa un destino (Ge-schick) del $\operatorname{ser}^{285}$, en el sentido de manifestarse como un modo histórico de enviarse el ser al hombre y de apropiarse.

Con esta relación y su modo relacional de articularla, nuestro autor insiste en la separación respecto a la comprensión tradicional de la metafísica: ya no es el hombre quien se vale de la técnica, por medio de su accionar y la voluntad, tal y como podía asociarse desde su analítica anterior, sino que aquella se vale de él y del ser. Específicamente, en la Ge-stell distingue una situación histórica del ser más originaria que la que situaba al existente humano en la metafísica, pues al hombre se le revela ahora su carácter de pertenencia ${ }^{286}$. De todos modos, tal pertenencia aún no adquiere un sesgo propio, lo cual le permite a Heidegger pensar por contraste otra modalidad de co-pertenencia.

En efecto, entiende esta disposición actual del mundo moderno de la técnica como el umbral/preludio hacia aquello que denomina como acontecimiento transapropiador (Er-eignis) ${ }^{287}$, cuyo ámbito representa una recuperación de la Ge-stell, con un consecuente deshacimiento de la técnica. Con ello remite a una co- pertenecia originaria, donde se revela la originariedad del mismo

\footnotetext{
${ }^{284}$ Con esta modalidad de escritura, Heidegger busca enfatizar en la significación del término Gestell (esqueleto o estructura interna de un objeto, etc.), el verbo stellen (colocar, etc.). Asimismo, el prefijo Ge remite a un conjunto o colectivo. De este modo, alude a la unidad de varias modalidades de puesta en posición de la visión científica, entre otras. Tanto en este caso, como en el anterior, utilizaremos ambos términos sin traducción.

${ }^{285}$ El uso del término destino permite enfatizar el abandono de toda nota que remita al subjetivismo. Para un análisis de las relaciones entre técnica y destino, en el marco de la consideración destinal del ser (seinsgeschicklich) en esta etapa del pensamiento de Heidegger, véase, Cerezo Galán (1997):59-92.

${ }^{286}$ A partir de esta elaboración de Heidegger, una intérprete (pre) esboza una relación contemporánea con la estructura de ser-en-el-mundo en la Gestell, a partir de lo que denomina como Dasein en-las-redes, es decir, en el marco de las tecnologías actuales. Véase, Cortés (2007):130-4.

${ }^{287}$ Como vimos, el término Ereignis tiene diversos significados: acontecimiento, evento, etc. En el análisis etimológico que Heidegger realiza en 1957, destaca su procedencia de significación desde Er-eignen en su vinculación de significación con Er-äugen, en tanto "asir con la mirada" (ID: 45[87]). Siguiendo un recorrido diacrónico en la lengua alemana, esto se debe a que Ereignen se remonta en el altoalemán medio (Mittelhochdeutsch) (entre los años 10501350) al verbo eräugen, que significa mostrar, poner ante los ojos. Desde allí, en el nuevo altoalemán temprano (Frühneuhochdeutsch) (entre los años 1350-1650) se desarrolló el verbo eräugnen. Finalmente, en el siglo XVIII se configuró la significación actual, en el marco de una aproximación con el verbo eignen (apropiar). Heidegger enfatiza esta resonancia verbal del término con el uso de guión, al tiempo que despliega esta dualidad etimológica e histórica del uso en una confluencia y resonancia de sentidos tales como: acontecimiento, instante (Augenblick), relámpago (BlickBlitz), apropiación, decir (sagen), mostrar (Zeigen), seña (en relación de significación con guiño) (Wink). En el contexto de esta riqueza de sentidos, seguimos aquí la traducción de acontecimiento transapropiador, con el objeto de enfatizar no solo el vaivén de apropiación mutua entre el ser y el hombre, sino también el desplazamiento de perspectiva en torno al ser, tal y como hemos desarrollado en los apartados anteriores. Para un análisis de la evolución de este concepto y la constelación de sentidos y significaciones que reúne, véase Berciano (2002):47-69.Cf. González (2004):140-50.
} 
pertenecer (Gehören) relacional que se pone en juego en ambos casos. En otras palabras: el Ereignis remite a un ámbito oscilante el cual, articulado en el lenguaje, dista de ser mero instrumento del hombre. De esta manera, piensa lo mutuo de la co-relación hombre-ser, a partir de tal pertenencia de fondo y no de la integración a partir de uno o del otro, es decir, sin un recurso que parta de alguno de ambos partenaires, con lo cual se propone saltar por fuera de la modalidad del pensar representativo, para señalar aquél fondo abierto que permite la pertenencia mutua de hombre-ser ${ }^{288}$. En este sentido, sostiene:

"Pero lo distintivo del hombre reside en que, como ser que piensa y que está abierto al ser, se encuentra ante éste, permanece relacionado con él, y de este modo, le corresponde. El hombre es propiamente esta relación de correspondencia y solo eso. 'Solo' no significa ninguna limitación, sino una sobreabundancia (...) ¿y el ser? Pensémoslo en su sentido inicial como presencia. El ser no se presenta en el hombre de modo ocasional no excepcional. El ser solo es y dura en tanto que llega hasta el hombre con su llamada. Pues el hombre es el primero que, abierto al ser, deja que éste venga a él como presencia. Tal llegada a la presencia necesita de lo abierto de un claro (...) Esto no quiere decir de ningún modo que el ser sea puesto sólo y en primer lugar por el hombre, por el contrario... el hombre y el ser han pasado a ser propios el uno del otro" (ID: 39s [75-7])

Reencontramos en este fragmento el fondo abismático que precede a esta relación y desde el cual Heidegger intenta esquivar la comprensión metafísica, el pensamiento representativo y una perspectiva de fundamentación. De esta manera, articula aquél término con su consideración del ser, donde lo que es no queda reducido a lo efectivamente presente, desmarcándose así del reduccionismo gnoseológico metafísico de la relación sujeto-objeto. Así, el pensamiento del Ereignis no es pensable en términos de presencia. Ahora bien ¿cómo enunciarlo o decirlo?

En principio, tal como la significación de Dasein, el decir respectivo no puede ser de ningún modo conclusivo, ni clausurable. Es una experiencia acontecimental no representable, preteorética, que abre un ámbito de propiedad y de significatividad. Como vemos, nuevamente aquí se plantea la cuestión liminar del decir y del discurso el cual, mientras se despliega, requiere cuestionarse a sí mismo. Tampoco remite en ningún momento a una voluntad o conciencia o instancia causal necesaria para su despliegue. El carácter simultaneo claro-ser-Dasein-ente para su acontecer, obtura toda remisiones o supuesto a priori, trascendental y de fundamento o principio. Es la relación simultánea y no el condicionamiento de uno sobre otro en particular, lo que da cuenta del Ereignis,

\footnotetext{
${ }^{288}$ Asimismo, puede rastrearse una continuidad terminológica en este término que lo vincula con el de autenticidad de la época de SuZ. En efecto, en el primer caso se trata de la elección de las posibilidades más propias y en el segundo supone un libre vínculo con la tradición. Ambos términos incluyen la raíz eigen (propio): Ereignis, Eigentlich. En este sentido, subraya que la existencia es propia si se deja expropiar por el Ereignis. Cf. Vattimo (1991):132-5.
} 
como acaecer en el marco de un entrelugar entre la presencia y lo que se oculta. Como vimos, se trata de una simultaneidad entre dinámicas que se modalizan mutuamente $\mathrm{y}$, en este caso, alcanzan cierto "equilibrio" de manifestación en el Ereignis: el ser dona y llama, el Dasein responde entregándose al llamado ${ }^{289}$.

En suma, la Ge-stell dispone mutuamente al hombre y al ser, en el modo de la presencia y ciñéndose sobre el cálculo. Más originario aun es el Ereignis, ámbito oscilante desde donde se despliega también la dinámica del habla ${ }^{290}$, el cual conlleva un retroceso del mundo técnico por fuera de la mera acción del hombre, abriendo experiencias más originarias del ente, el mundo técnico, la naturaleza, la historia y su ser. Ahora bien, estas puntualizaciones nos permiten circunscribir las consideraciones tanto implícitas como explicitas del la relación a sí del Dasein en esta etapa de sus elaboraciones y, más específicamente, en el contexto de estas dos modalidades de pertenencia mutua. Por lo cual, retomaremos estos análisis, enfocándonos y poniendo énfasis desde un pliegue específico: la mismidad e ipseidad.

\section{3.- Mismidad en las modalidades de co-pertenencia.}

Entre las referencias al existente humano en los trabajos de este período, encontramos la distinción entre hombre (Mensch) y Dasein, mediante el uso alternado de los términos. Mientras en el primer caso refiere al existente humano en el marco de las relaciones en el mundo de la técnica,

\footnotetext{
${ }^{289}$ Aquí seguimos la distinción del carácter simultáneo del Ereignis, que Rubín destaca también en el par llamadarespuesta de la modalizacion relacional del Dasein, con el objeto de argumentar en torno a la persistencia de cierta jerarquización, en efecto: "De acuerdo con esto hay una jerarquía presente de alguna forma en esa simultaneidad, no es simplemente un "pertenecer común", sino una transmisión vertical de estructura llamada-respuesta que sucede en un instante. Al prevalecer la identidad sobre la diferencia, se impide que haya un diferir que separe en dos momentos el dar-recibir, y también que haya más actores en juego, por ejemplo, dos seres humanos. Por el contrario, al ser una simultaneidad presente, su aparecer, su hacerse presente, es de algún modo lo que hace el acontecimiento (...) El performativo en Heidegger sería el de la autoridad, el performativo soberano: si hay una llamada y una respuesta inmediata, hay una orden, y esa orden implica una autoridad subyacente cuyos implicados asumen y aceptan como tal. Así, la performatividad toma la forma de lo simultáneo, ya que en el momento en el que la orden se da, se hace lo que ella implica por la asunción de la autoridad que la orden porta (...) Entonces el ser como Ereignis es la condición de posibilidad de mi ser, me hace ser lo que soy, y de paso, me hace poder decir (lo), mi decir (Sagen) es un mostrar (Zeigen). Y de este modo mi decir ya está mostrando -transfiriendo el "sentido" que he recibido- de forma inmediata. Por ello puede considerarse que es el pensador el que inicia el acontecimiento y que (...) el resto son "cuidadores". (Rubín, 2012:50 ss.). En línea con nuestras interpretaciones, distinguimos que esta jerarquía implícita es una derivación de esta articulación discursiva y, al mismo tiempo, un signo de la persistencia del campo semántico de la metafísica, es decir, de una alteridad en el discurso, la cual se explicita en una tensión dinámica dentro de su discurso.

${ }^{290}$ En este marco, sostiene:"habitamos el Ereignis en la medida en que nuestra esencia depende del lenguaje" (ID: 47[91]).
} 
en el segundo, en cambio, designa al existente que emerge del modo originario de co-pertenencia con el ser, es decir, del Ereignis en el singular contrabalanceamiento (Gegenschwingung) u oscilación co extensiva entre los partenaires $^{291}$. Más enfáticamente, desde 1936 escribe Da-sein, cuyo guionado busca enfatizar el carácter situado, relacional y derivado del ser del existente humano. Con ello, deja fuera toda comprensión de la mismidad e ipseidad que tengan sesgos voluntaristas o rectores tal y como puede desprenderse de un pensamiento orientado por el cálculo y la planificación ${ }^{292}$. Asimismo, distingue el carácter derivado en la ipseidad propia, en tanto dependiente de una dinámica anterior, histórica y acontecimental, aspecto que la analítica del Dasein y su enfoque no permitían distinguir con claridad.

\section{3. a.- EI Dasein en el Ereignis.}

En este marco, destaca que la aparente grandeza titánica del mundo moderno de la técnica, ha dejado sin fuerzas al hombre para el Dasein, estableciendo así aquella distinción terminológica en referencia a las modalidades relacionales del existente humano. Asimismo, la modalización del Dasein implica no solo determinados temples anímicos sino también disposiciones singulares en el camino que recorre y en el marco de una relación con el ser.

Tal fundación (y no creación) del Dasein en el Ereignis consiste en dejar-ser-fundamento por parte del hombre, en el sentido de modalidad singular de retorno y recuperación de su mismidad propia (Ibid.:31[43]). Desde aquí, entiende que la historia del Dasein es el despliegue del ser mismo el cual, fundado en aquél como ámbito de manifestación, el hombre deviene venidero ${ }^{293}$.

La voluntad aparente del sí mismo se separa del ajetreo anterior en el mundo de la técnica, apropiándose en el Ereignis, que se funda en un pertenecer a la verdad del ser. El empuje de tal fundación de un modo singular se dirige al hombre, implicando un sacrificio y abandono del cálculo y el resultado que pretende comprenderlo todo (Ibíd.: 47[54]) 294 . Así, la mismidad propia designa el

\footnotetext{
${ }^{291}$ Desde este carácter de contrabalanceo, von Herrmann distingue simetrías modales y de complemento en el entramado relacional: el acaecer del ser es coextensivo con un contrabalanceo proveniente de la proyección apropiadora del Dasein, en el marco de un requerimiento mutuo. Véase, Herrmann FW von (1994):90 ss. De esta manera, especifica y desarrolla el rechazo de todo a priori, implícito en el Ereignis heideggeriano.

${ }^{292}$ Lo cual no necesariamente se explicite en proposiciones o perspectivas teóricas, sino que puede desprenderse de la modalidad con la que se articula el lenguaje de uso tal y como, por ejemplo, puede encontrarse en ciertas recepciones del existencialismo sartreano de mitad del siglo pasado.

${ }^{293}$ Un intérprete argumenta a partir de posibles conexiones entre las elaboraciones respecto al Dasein en el Ereignis y un proyecto político de Heidegger, como figuras de su supuesto nacionalsocialismo privado (DR). Subraya que en tales elaboraciones insiste en la disolución del sujeto en su inserción en el devenir histórico y el énfasis puesto en poderes supraindividuales. Véase Llorente (2013):631-8. En el marco de los desarrollos en capítulos anteriores, entendemos que estas interpretaciones, en consonancia con las elaboraciones de Víctor Farías, al menos requieren una consideración mayor de las significaciones en torno al Dasein y al hombre en la obra de Heidegger.

${ }^{294}$ Desarrollaremos estas cuestiones en el apartado 2.d, del próximo capítulo.
} 
ámbito de aquel llamado y la pertenecia, que en lugar de un pensamiento planificador requiere de las tranquilas y profundas mediaciones de la meditación.

Con ello se aparta de todo culto a la personalidad, desplazándose en la dirección de un preguntar que evita toda pretendida certeza sobre el hombre .En tal camino no hay respuestas inmediatas, situándose en el umbral de aquella concepción de si del hombre bajo la modalidad de pensamiento metafísico ${ }^{295}$. Así, la mismidad del Dasein en el Ereignis acontece en el marco de la meditación de sí que no toma al hombre como dado desde las representaciones del yo, sino que lo entiende como corolario de una co-pertenencia originaria con el ser y su respectiva entrega.

\section{3. b.- El hombre desde la modernidad de la técnica.}

No obstante, Heidegger piensa y escribe en el marco de transición donde se manifiesta un rumbo contrario. Efectivamente, lo esencial de una posición metafísica fundamental reside en la manera en que el hombre es sí mismo, el tipo de esencia de esta mismidad que se determina como tal a partir de otra relación con el ser.

En el caso del mundo técnico, todo lo que tiene certeza a partir de si mismo tiene que asegurar la certeza del ente delante de sí, es decir, el hombre toma del objeto la consistencia que sostiene este proceso .Este juego de espejos se articula también con la preeminencia de la certeza en el marco del saber: por esta vía, el representar consiste en situar lo ente delante de si, a partir de sí mismo, asegurándolo como una forma de cálculo. De este modo, la consideración del hombre en el marco de estas relaciones, se halla atravesada por una consistencia especular, proyectada en el objeto, tomada de este y encapsulada en el saber y el pensamiento respectivo. Tal modalidad no se reduce a las dinámicas del conocimiento en la modernidad, sino que transversalizan diversas experiencias donde priman las posiciones fundamentales de la subjetividad, incluso en las perspectivas nacionalistas de su época, tal y como distingue en este fragmento:

"El hombre como ser con razón no es menos sujeto que el hombre que se comprende como nación , que se quiere como pueblo, se cría como raza y finalmente se otorga a si mismo poderes para convertirse en dueño y señor del planeta” (Hw:102 [89]).

\footnotetext{
${ }^{295}$ En este contexto subraya en un trabajo posterior un sesgo intuitivo para dicho umbral: "El pensar esencial está atento a los lentos signos de lo que es incalculable y reconoce en ellos la llegada, imprevisible, de lo ineluctable” (WM: 311[257]).
} 
En este contexto modal también inscribe la libertad moderna atribuida a la subjetividad, la cual entiende como el mero empuje de la objetividad que adecua a ella. Desde la perspectiva del otro pensar y su meditación correlativa, distingue otras modalidades para el hombre histórico que no necesariamente se reduzcan al ser-sujeto con sus dinámicas de objeto. Entre los textos más destacados de Heidegger en el marco de estos contrastes y análisis, encontramos su ya célebre trabajo de 1946, donde se propone compendiar sus análisis en torno al existente humano en el contexto de discusión de la primacía y crítica de los humanismos.

Allí, insiste en que la pregunta tradicional sobre qué es el hombre termina desplegando un punto de vista que busca encontrar o bien una persona o bien un objeto, impidiendo ver aquello esencial del existente humano en la historia del ser. Distingue además que previa a toda determinación de la esencia del hombre se halla implícita una interpretación de lo ente, que direcciona la pregunta para tal determinación ${ }^{296}$. En este marco, contrapone otra comprensión relacional en la que encontramos signos explícitos para sus consideraciones en torno al voluntarismo instrumental del hombre:

’La metafísica se cierra al sencillo hecho esencial de que el hombre solo se presenta en su esencia en la medida en que es interpelado por el ser. Solo por esa llamada 'ha' encontrado el hombre dónde habita su esencia. Solo por ese habitar 'tiene' el 'lenguaje' a modo de morada que preserva el carácter extático de su esencia. A estar en el claro del ser es a lo que yo llamo la ex-sistencia del hombre. Solo el hombre tiene ese modo de ser, solo de él es propio “(BH: 323 s [267]).

En este fragmento, hallamos la consideración del existente humano en su carácter extático, que articula bajo la acuñación modal del término ex-sistencia, lo cual se contrapone con aquellas comprensiones de consistencia especular. En efecto, dicha modalización se propone como epítome de la mismidad e ipseidad del Dasein tal y como elaboró en sus trabajos hasta $S u Z$, donde la temporalidad, la no-sustancialidad junto a su carácter arrojado y proyectivo, rechazan de plano toda certeza acabada sobre su ser.

En estas elaboraciones, tal carácter del existente humano remite a un modo de estar dentro y fuera en el claro del ser. En esta articulación lo esencial no es el hombre como ente sino como dimensión de lo extático de la ex-sistencia ${ }^{297}$, donde el ser le abre su claro al hombre en tal

\footnotetext{
${ }^{296}$ En este contexto, inscribe ciertas tendencias de los subjetivismos: "Todo nacionalismo es, metafísicamente, un antropologismo y, como tal, un subjetivismo. (...) Expulsado de la verdad del ser, el hombre no hace más que dar vuelta por todas partes alrededor de sí mismo en cuanto animal racionale. Pero la esencia del hombre consiste en ser más que el mero hombre entendido como ser vivo dotado de razón" (BH: 341s [280s.])

${ }^{297}$ Para evitar el giro idiomático de "el ser es", Heidegger sostiene que más bien, se da (es gibt) .Es decir, mientras el Dasein es, se da el ser., por ello cobra aquí una relevancia cada vez mayor el pensar de la historicidad del Dasein, tal y como comenzó a desplegarlo desde la época de $S u Z$.
} 
proyecto extático. De esta manera nuestro autor articula la consideración del existente humano con la modalidad del pensar posmetafísico que caracteriza este período, sorteando también los escollos de un pensamiento del fundamento. Incluso el impulso que dinamiza este carácter de arrojado lo especifica por fuera del ámbito de la subjetividad, cuya caracterización logra articularse por haber desplazado el punto de enfoque o perspectiva para sus análisis. En este marco, sostiene:

'El que arroja en este proyectar no es el hombre, sino el ser mismo, que destina al hombre a la exsistencia del ser-aquí en cuanto su esencia. Este destino acontece como claro del ser y éste solo es como tal. El claro garantiza y preserva la proximidad del ser. En dicha proximidad, en el claro del "aquí", habita el hombre en cuanto ex-sistente, sin que sea hoy capaz de experimentar ese habitar ni de asumirlo”. (Ibid.:337[277])

De esta manera, el hombre arrojado está en la apertura del ser, en el claro previamente abierto: aquél es el que resguarda la verdad del ser y el pensar del otro inicio, el no representativo, retomando el fundamento olvidado por la metafísica con su desplazamiento respectivo. Como queda manifiesto, las dinámicas relacionales que Heidegger articula en este trabajo atienden a las transformaciones del complejo articulado en tales dinámicas y no a momentos estáticos del mismo como podía asociarse con la analítica del Dasein en los trabajos de $1920^{298}$.

En suma, nuestro autor establece una continuidad singular con el pensar ensayado en $S u Z$, cuya analítica del Dasein como punto de partida, puede comprenderse en el camino al servicio de la verdad del ser. En la apertura donde la co-pertenencia originaria acontece, el ser se anuncia y se oculta, se ofrece y se sustrae, sin que su verdad se agote en el Dasein o se vuelva una con él: en estas elaboraciones es aquel ente cuyo ser está definido desde y en el ser, por medio de un abierto estar dentro del desocultamiento del ser.

En esta determinación dinámica, oscilante y no clausurable, la mismidad propia queda articulada con un conjunto de funciones y roles singulares, en las cuales nos detendremos en el próximo capítulo. Tal conjunto, por la vía de la meditación en transición hacia otro pensar, permite plantear un horizonte para cierto desplazamiento o disolución de la articulación múltiple de la comprensión, el pensar y el lenguaje del mundo moderno de la técnica, tal y como puede describirse la propia labor en la que Heidegger se inscribe.

Frente a ello, la esencia del hombre en la co-pertenencia de la Ge-stell es el fundamento para que pueda representarse al ente en cuanto tal y tener una conciencia de lo representado. En este caso, la conciencia no se manifiesta como determinada por el ser sí-mismo, pues como el pensar

\footnotetext{
${ }^{298}$ Dichas transformaciones relacionales se ponen en evidencia en este fragmento:’Lo que sí es posible es que si algún día el pensar consigue retornar al fundamento de la metafísica ocasione un cambio en la esencia del hombre que llevaría aparejada una metamorfosis de la metafísica" (WM: 368[301]).
} 
metafísico determina primariamente la mismidad del hombre a partir de la sustancia, el primer camino que lleva de la metafísica a la esencia extática del Dasein tiene que pasar necesariamente a través de la determinación metafísica de esta mismidad del hombre. En pocas palabras: el tránsito hacia una mismidad desde el Ereignis, la co-pertenencia originaria del hombre y el ser, requiere un paso obligado por la mismidad sustancial del hombre en el mundo moderno de la técnica.

Para finalizar este capítulo, proponemos retomar breves puntualizaciones del despliegue de estas dinámicas relacionales y simultaneas, con el objeto de despejar y circunscribir un campo de articulaciones en torno a la ipseidad en este período, en vistas a continuar con análisis e interpretaciones sobre las cuestiones prácticas, éticas y relativas a la alteridad, a partir de estas elaboraciones.

\section{4.- El carácter mediado de la mismidad en su carácter dinámico.}

Por medio de estos caminos del pensar y con sus articulaciones/modalizaciones respectivas , Heidegger busca poner en evidencia la necesidad de un nuevo inicio del pensar no ya en el marco de la pertenencia propia de la técnica sino en camino a una co-pertenencia originaria con el ser en las miras de este otro pensar. Y precisamente, intenta llevarlo a cabo por el salto y paso atrás, de modo tal que el dejar ser propio del pertenecer se desplace de la dimensión impropia que adquiere en la Ge-stell. No obstante, debido al énfasis puesto en el carácter relacional no se trata aquí de un cambio progresivo de estadios del pensar, sino de una transición y consumación que mantiene su estatus oscilante, sustractivo y dinámico.

En lo referente a la mismidad del hombre y el Dasein, encontramos un énfasis puesto en su carácter mediado en el marco de la relación de mutua pertenencia, cuyos lineamientos anteriores ofician de condición de posibilidad para esta elaboración. Así, la analítica del Dasein, respecto a la consideración de su carácter insustancial, arrojado y proyectivo, ha permitido continuar desde una perspectiva que atiende la relación en que tales determinaciones se inscriben. Sin aquel despejamiento resultante de la analítica, hubiesen quedado ocultas la caracterización y dinámicas de la relación misma, aún comprendidas y determinadas desde el mismo Dasein. Este modo de despejar el análisis permitió a Heidegger articular la relevancia no solo de los diversos modos históricos de relación mutua, sino también de la originariedad del claro/despejamiento como fondo para tal vinculación y de la modalidad de pensamiento correlativa. Por ello, estas elaboraciones 
presentan una modificación en el punto de enfoque que las tornan afines a la comprensión del ser del Dasein , lo cual no equivale a una ruptura con las consideraciones anteriores de la ipseidad y mismidad sino un desplazamiento que requiere de tales resultados para efectuarse, con sus respectivas tensiones y puestas al límite ${ }^{299}$.

En este marco, los desplazamientos en el decir y el pensar de Heidegger adquieren aquí mayor relevancia. En efecto, la modalidad no representativa del pensar que despliega requiere otra modalidad de articulación del lenguaje que oscile entre un decir conceptual-filosófico y un decir poético-literario que pueda dar cuenta de referencias sin contenido, de direcciones sin llegada, de ámbitos sin determinaciones precisas o acabadas, lo cual abre un campo de acceso hacia ámbitos originarios . No obstante, el punto de partida es el mismo pensar y decir metafísico-representativo, de modo tal que cada desplazamiento o umbral del recorrido, tendrá necesariamente que manifestar resonancias correlativas en las diferentes vías de la constelación Dasein-ser-lenguaje-pensar, en pocas palabras: un desplazamiento en una de ellas, repercute relacionalmente en las otras.

Desde tal perspectiva dinámica, entendemos que si en un primer momento las determinaciones están articuladas y ligadas por medio de la oposición al pensar representativo y al modo de relación del mundo de la modernidad técnica, luego del desocultamiento de ámbitos de mayor originariedad (como consecuencia de su recorrido del pensar y decir), tales determinaciones pueden verse desplazadas e incluso, abandonadas. Es decir, si la dirección del pensar se mantiene, el recorrido y las conexiones se ven modificadas en y por el propio trayecto emprendido por nuestro autor. Esto se debe en parte a que la relación con el lenguaje en tal dirección también se halla modalizada por los resultados del recorrido. Pero ello no debe entenderse como un accionar directo e intencional de nuestro autor.

En tal marco, estos análisis se hallan en tensión con perspectivas éticas que planteen manejar, dirigir o valorar la situación de los hombres, lo que más bien se encuadra en la

\footnotetext{
${ }^{299}$ En estos contextos de interpretación Marion distingue en estas elaboraciones de Heidegger lo que entiende como la figura del interpelado (interloqué) por el ser, en su reivindicación de sí mismo, en tanto figura superadora de la mismidad respecto de aquella que emerge de la resolución precursora en la analítica de SuZ Distingue que en las primeras elaboraciones, la resolución desemboca en una neutralidad ontológica que cancela la vía de la cuestión del ser en general, pero luego se posiciona desde la perspectiva del ser, a partir de una llamada que no efectúa ni decide , la llamada del ser (Anspruch des seines) que reivindica al Dasein, y a la cual este responde. Destaca que aquí el hombre se expone a esta reivindicación, ya no como resuelto sino en tanto interpelado. Esto cancela toda autonomía, pues el interpelado se descubre siempre en el marco de una relación. Asimismo, destaca la sorpresa inherente a esta reivindicación, donde el hombre se reconoce sin un yo, un sí mismo, sin un lugar que no sea solo la interpelación: antes del Dasein es necesaria la sorpresa de la reivindicación que convoca. De esta manera, el polo de esta instancia designa una instancia innombrable e imprevisible (la reivindicación), desde donde se experimenta como interpelado al sentirse como tal, de un modo singular:" experimento un me huérfano de todo yo trascendental" (Marion ,1990: 94 s.). De esta manera, subraya que el interpelado ofrece un camino para abolir el sujeto de la metafísica, debido a que el ámbito anterior a la constitución del yo es relacional: este se sorprende ya siempre interpelado. Desde este análisis e interpretación nos reencontramos con la puesta en evidencia de una transición respecto al pensamiento del fundamento, articulado en esta tematización heideggeriana de la ipseidad del existente humano.
} 
comprensión de la metafísica que entiende al Dasein como aquel que comanda o se encuentra por delante del mundo y el ente, en sus diversas vinculaciones. Desde este contexto, las derivaciones prácticas de los vínculos entre la mismidad del Dasein a partir de aquellas modalidades de pertenecia mutua, el empuje y desplazamiento en estas dinámicas junto a las consideraciones sobre la ética y el obrar como intervención posible, parecen demandar un abordaje específico.

"Menuda astucia haberme adaptado un lenguaje del que se imaginan que nunca podré servirme sin reconocerme de su tribu”.

(Samuel Beckett, El innombrable)

\section{Capitulo 6. Consideraciones prácticas, éticas y políticas (Hacia la alteridad y la ipseidad del Dasein como discurso)}

Nuestro recorrido nos ha conducido a una encrucijada entre alteridad, ética y lenguaje en el pensamiento de Heidegger, posterior a las elaboraciones de 1930. En efecto, las consideraciones de la mismidad e ipseidad del Dasein, en el marco de su relación de pertenencia mutua con el ser, puso al descubierto el énfasis en las notas de pasividad y entrega en las disposiciones para el otro 
comienzo del pensar. Aun así, el Dasein mantiene su doble dimensión activa y pasiva: Heidegger pone el acento mayormente en una de ellas, en consonancia con las disposiciones del otro comienzo y en contraste con aquellas que preponderan en el período de consumación de la metafísica. A la luz de tal bidimensionalidad se torna necesaria una indagación sobre estatuto específico de las cuestiones prácticas y dis-posicionales en el marco de esta modalidad relacional.

Por ello, dedicaremos este capítulo al desarrollo específico de las respectivas implicancias respecto al existente humano, en este caso enfatizando su trato con los entes y con los otros Dasein, sin descuidar ambas dimensiones. Si bien estas elaboraciones no presentan desarrollos explícitos referentes a la estructura originaria del ser-con, aún podemos articular una continuidad con sus anteriores planteos de la ipseidad, si atendemos la superficie del lenguaje en el cual se despliega, más específicamente, considerando el discurso del propio autor como una figura del Dasein propio. En esta figuración encontramos algunas correspondencias término a término: respecto al proyecto de la pregunta por el ser (a la que tal discurso se dirige); a su ineluctable articulación con los otros (en el lenguaje de la tradición) y en el carácter proyectivo del pensamiento desde y contra el que se despliega, entre otras.

Para fundamentar esta figuración entendemos necesario previamente dar cuenta de sus énfasis y discusiones respecto al papel activo o de intervención del hombre o Dasein, sus límites y condiciones en lo referente a la participación en estas dinámicas, así como también su rol y función en el marco de las variaciones históricas de las épocas del ser en sus modalidades respectivas de donación, retomando esta constelación de su discurso, pero abordándola desde nexos y perspectivas diferentes.

De esta manera, obtendremos mayores elementos para distinguir entre las elaboraciones específicas que articula y las que modaliza en el discurso, aquellas connotadas en la operación de pensamiento que allí se realiza. En pocas palabras: continuamos en nuestro camino de argumentación en torno a una interpretación del valor del discurso de Heidegger, el cual entendemos homogéneo respecto a la teoría que enuncia sobre la ipseidad en la co-relación respectiva con el ser. En este capítulo, ello se efectivizará a partir de las siguientes preguntas-guía:

a) ¿En qué consiste el margen o ámbito para la participación práctica del Dasein en las modalidades relacionales desarrolladas?

b) ¿Es posible plantear una orientación ética o política a partir de tal ámbito?

c) ¿Pueden establecerse vínculos, continuidades o diferencias específicas, respecto al discurrir teórico de Heidegger, en tanta modalidad enunciativa del obrar? ¿Y respecto de las polémicas biográfico-políticas suscitadas a partir de la década de 1930 ? 
En este marco, comenzaremos con breves consideraciones en torno a su participación política en el Nacionalsocialismo en el año 1933, y en algunos de sus escritos y discursos de época. Entendemos relevante esta descripción, vinculada con un conjunto de las polémicas posteriores, porque allí se plantean elementos en tensión desde los cuales Heidegger articula consideraciones sobre las injerencias históricas del Dasein , la perspectiva sobre la transformación y el cambio en el marco de la dimensión política de su pensamiento , así como también se delinean los primeros pasos hacia su abordaje en torno a la distinción entre una ética de tipo metafísica y lo que denomina como una ética originaria ( ursprüngliche Ethik), en la cual se articula la ipseidad del Dasein en el marco del Ereignis.

En segundo lugar, a partir de las notas que adquiere el abordaje del Dasein, profundizando la cuestión de la anterioridad de las disposiciones afectivas fundamentales para el tránsito hacia el otro comienzo del pensar, abordaremos la consideración filosófica en torno al cambio y los desplazamientos posibles, en el marco de la historia del ser. Aquí buscaremos precisar en qué consiste esta dinámica, si acaso es tal, cómo opera y qué función o roles específicos cumplen sus co-partícipes, en el contexto de aquellas elaboraciones desde 1930.

Finalmente, analizaremos sus consideraciones en torno a la ética, en su específica distinción de una ética originaria, especialmente desde sus desarrollos en el segundo seminario sobre Heráclito, que impartió en el semestre de verano de 1944. Articulado con ello, distinguiremos los vínculos con el Ethos originario, el cual se torna de relevancia para comprender la cuestión del Dasein en este período, en su relación con el ser y el mundo circundante ${ }^{300}$.

Por estas vías entonces, recabaremos los elementos que entendemos necesarios para distinguir la consideración de la mismidad, ipseidad y alteridad en este período, no solo con su carácter mediado, sino también en su articulación y despliegue necesario desde y en el lenguaje, lo cual nos permitirá destacar como una figura respectiva al mismo discurso que despliega Heidegger. En este sentido, insistimos en que tal tratamiento temático requiere una distinción del modo en que articula sus elaboraciones, luego de atender y retomar holísticamente el complejo relacional donde se dinamiza tal despliegue.

Comencemos desde una de las situaciones históricas más controversiales en las discusiones respecto a la biografía de Martin Heidegger: su adhesión al Nacionalsocialismo (NS).

\footnotetext{
${ }^{300}$ Abordaremos en especial textos de esta época que entendemos relevantes para los distintos desarrollos señalados: Beiträge zur Philosophie (Vom Ereignis) (1936-1938)(BPE); Holzwege (1936-46)(Hw); Vorträge und Aufsätze (193653)(VA);,Besinnung(1938-1939a)(B); Heraklit (1943-44)(H); Brief über den Humanismus (1946)(BH); Identität und Differenz (1955-1957)(ID); Gelassenheit(1959)(G) ; Überlieferte Sprache und technische Sprache (1962b)(UStS), entre otros.
} 


\section{1.-Heidegger y sus implicaciones políticas.}

Los hechos biográficos respectivos son hoy de circulación frecuente en los ámbitos académicos: Heidegger adhirió al Partido Nacionalsocialista obrero Alemán (NSDAP) en 1933 y obtuvo, por los favores del SS-Staat, el cargo de Rektor en la Universidad de Friburgo, además de la posibilidad de otros puestos, algunos de los cuales rechazó. En los meses en que se mantuvo en su puesto, previo a la renuncia en 1934, saco de su cargo a trece docentes no arios y quitó la dedicatoria a Husserl de las publicaciones de $S u Z$, entre otras cosas ${ }^{301}$.

Entre los documentos con los que se cuenta respecto a dicho período se encuentra el célebre discurso pronunciado a propósito de su asunción en la Universidad de Friburgo, una comunicación por radio motivada por la desestimación de un cargo en la Universidad de Berlín, su ensayo de 1945 El Rectorado 1933/1934 y su carta del mismo año enviada al Comité de la Universidad de Friburgo $^{302}$. Asimismo, son consideradas relevantes por un lado, algunas entrevistas posteriores, donde Heidegger hace referencia directa sobre estos hechos y, por otro, la reciente publicación de sus anotaciones en los denominados Schwarze Hefte.

Entendemos relevante para nuestro recorrido puntualizar dos flexiones en estas comunicaciones, entrevistas y manuscritos: por un lado, los aspectos distinguidos y valorados en tales discursos y, por otro, las estructuras o modalidades que subyacen a sus manifestaciones, los estilos que se presentan en ellas, etc. Es decir, detenernos en el referente de tales manifestaciones, atendiendo a su forma y articulación ${ }^{303}$, en vistas a distinguir el carácter de continuidad, ruptura y/o desplazamiento, respecto a sus elaboraciones anteriores y posteriores ${ }^{304}$.

\footnotetext{
301 Especialmente, aquí consideramos un conjunto de trabajos ya clásicos que abordan estos polémicos hechos biográfico-filosóficos de Heidegger: Farías (1998/2010); Pöggeler (1990); Ott (1992); Wolin (1990/1993); Thomä (2003); Faye (2009); Lyotard (1995); Nolte (1998); Young (1997) y Sluga (1993), entre otros.

${ }^{302}$ Asimismo en el volumen 16 de las GA podemos encontrar algunas reflexiones respectivas sobre el Estado, el Judaísmo y otros temas alusivos cercanos a sus Beiträge zur Philosophie (Vom Ereignis) de 1936-8.

${ }^{303}$ Una de las polémicas reside en considerar, o no, en términos políticos las afirmaciones de Heidegger en estos campos, debido a su insistencia en referir en términos de fenómenos onto-históricos, en el marco de la historia del ser , todas las manifestaciones sociales, culturales y políticas (entre ellas : el judaísmo, la democracia , el Nacionalsocialismo, el comunismo).Si bien el antijudaísmo y antisemitismo cultural-espiritual (no necesariamente de filiación Nacionalsocialista, es decir, en tanto racismo biológico) es hoy de presencia evidente en textos de Heidegger, el desarrollo de nuestro trabajo se ve excedido por el abordaje pormenorizado que requieren estas cuestiones : cotejar fuentes diversas, clasificar e inscribirse en debates, distinguir interpretaciones, articular con el contexto cultural y simbólico, etc. En este marco, nos resulta notorio el modo en que numerosas pronunciaciones contemporáneas al respecto descuidan y omiten tales requerimientos.

${ }^{304}$ En este marco, sostiene uno de sus interpretes:"El lenguaje de Heidegger, totalmente inseparable de su filosofía y de los problemas que esta plantea, debe verse como un fenómeno característico que brota de las circunstancias de
} 


\section{1. a.- Trabajos y comunicaciones en la época del Nacional Socialismo.}

En efecto, un breve análisis del discurso del rectorado puede poner de manifiesto una articulación jerárquica del pensar correlativa con una exhortación hacia temples anímicos de entrega, fidelidad, respeto y servicio. En dicho cargo público, Heidegger da cuerpo a la aplicación de la política de Gleichschaltung (nivelación y coordinación de los ámbitos alemanes al Führerprinzip), destacando la necesidad de una uniformización jerárquica. Dicha insistencia la enmarca en el horizonte de una dirección espiritual autónoma y reflexiva de la Universidad. En este sentido destaca la autoafirmación en la Universidad sostenida en una voluntad originaria y común.

Asimismo, en el marco de una crítica a la tendencia científica de su época, la cual persevera en su cercanía y planificación en el ámbito de lo ente, destaca la relevancia de retomar un inicio del pensar que encuentre sus raíces en la filosofía griega al direccionar el interés hacia lo oculto para el pensar tradicional. Y para un camino en tal dirección, resalta la selección de los mejores y más adecuados para tal emprendimiento junto a la importancia del deber, la vocación y la necesidad de guías, para todos los integrantes de la población universitaria.

Por un lado, exhorta al estudiantado a mantenerse firmes en el destino alemán, por medio de la vinculación con la comunidad nacional a través del servicio, lo cual se contrapone al auge de la libertad académica sin regulación, que entiende como inauténtica y caracterizada por la ausencia de preocupación e inclinaciones basadas en el mero capricho .Por otro, exhorta a los profesores a la administración adecuada del saber sedimentado en la tradición del pueblo alemán, en el marco de la comprensión de la metafísica y sus consecuencias. Para ello, también destaca como temples fundamentales la sencillez, entrega, austeridad y la perseverancia, que articula implícitamente en la frase de Platón con la que termina su discurso inaugural:"Todo lo grande esta en medio de la tempestad" (alles Grosse steht in Sturm) ${ }^{305}$.

En el mismo campo semántico puede leerse la exposición realizada en radio el año 1934. En primer lugar, teniendo en cuenta el uso político que el nazismo comenzó a darle a este medio, para

\footnotetext{
Alemania entre el cataclismo de 1918 y el ascenso del nacionalsocialismo al poder" (Steiner ,1999:9 s.). En este énfasis en el carácter situacional y contextual de las significaciones, encontramos también una atención puesta en las relaciones entre el discurso de Heidegger y sus elaboraciones respectivas.

${ }^{305}$ El texto griego originalmente dice "Todo lo grande está en peligro" (es decir, corre el riesgo de perecer), y pertenece a un pasaje de La República (497 d, 9), de Platón. La operación de Heidegger consiste en traducir poéticamente el sentido de la frase introduciendo Sturm, que significa tempestad, asalto, etc. Este desplazamiento, por un lado apunta al campo semántico en el que se inscribe la frase, en una operación de sustitución que bien puede tener fines estéticos. Pero tal término ha sido frecuentemente utilizado en el lenguaje y el discurso del NS, por ejemplo, en una de las principales organizaciones que participó en el ascenso al poder de Hitler, la cual fue conocida como Sturmabteilung (tropas de asalto). Por ello, también puede comprenderse aquí tal manifestación como una señal de pertenecia a tal discurso político.
} 
la promoción de escucha comunitaria y su consecuente influjo poblacional. Asimismo, en el texto Heidegger utiliza frecuentemente un campo de significaciones articuladas con el término Völkische, el cual remite a lo popular racial (o la cultura de lo popular) y al pueblo (Volk), que bien puede inscribirse en el marco del debate político en torno a la raza aria, a saber: ¿son ideales las condiciones del campesinado alemán para ello, debido a su carácter conservador a la vez que revolucionario? ${ }^{306}$ Pero estas probables articulaciones o conexiones semánticas no alcanzan el carácter de prueba definitiva.

En dicha alocución, valora su ambiente de trabajo inserto en un refugio de esquiadores en la Selva negra, en lo cual insistirá en varios escritos posteriores ${ }^{307}$. Describe el modo en que su trabajo abre el ámbito de la realidad de la montaña y viceversa, de modo tal que la marcha del trabajo permanece hundida en el acontecer del paisaje por ejemplo, al distinguir en el esfuerzo por acuñar palabras el reflejo simétrico de la resistencia de los abetos contra la tormenta. Destacando la vida del campesinado, elogia el silencio, las convenciones simples y la necesidad de mantenerse cercano a la naturaleza. Allí, el arraigo al suelo como pertenencia de su trabajo es valorado en primacía frente a las conferencias, gestiones y su actividad docente, lo cual se halla en consonancia con la tendencia identitaria histórica de Alemania que se articula con el arraigo (Bodenstandigkeit) en la tierra natal (Heimatland), establecido con su comunidad e historia ${ }^{308}$.

En ambos discursos encontramos continuidades con tramos anteriores en el camino del pensar de Heidegger: el carácter interrelacionado del ser-en-el-mundo del Dasein, la distinción entre autenticidad/inautenticidad, la mismidad propia frente al Uno mismo, la estratificación jerárquica del pensar que tiene como argumento el olvido de la diferencia ontológica desde la antigüedad griega, etc. No obstante, las acciones políticas concretas de Heidegger y su posición posterior, aun suscitan numerosas polémicas.

\footnotetext{
${ }^{306}$ Asimismo, pueden encontrarse en esta alocución otra serie de términos ligados al discurso del NS, que se articulan simbólicamente con la identidad alemana de la época, entre ellos el Boden (suelo), como terruño biológico y fundamento del Dasein alemán y algunos correlativos semánticos : Bodenständigkeit (arraigo al suelo); Zugehörigkeit (pertenencia) ; Heimat (Tierra). En este marco se establecieron también asociaciones entre su análisis de la calculabilidad como modalidad del pensar de la técnica y la caracterización de la cosmovisión judía, tal como figuraba en los estereotipos nazis. De todos modos, estas vinculaciones carecen de la validez de prueba unilateral: desde otras perspectivas también puede considerarse el énfasis en lo autóctono como una alusión negativa al régimen a partir del desplazamiento semántico del lenguaje heredado, tal y como opera con el lenguaje de la metafísica. Respecto a la unilateralidad y las interpretaciones politizadas de este período de Heidegger, véase Xolocotzi, A. (2013):104 ss.

${ }^{307}$ Por ejemplo, este elogio lo manifiesta en una poesía posterior donde da cuenta de la continuidad y pertenencia del pensar en el ambiente natural de la Selva negra. Allí, subraya que el reclamo del ser y su demanda, permite la emergencia del coraje del pensar y su lenguaje. En este marco, encontramos un verso que bien puede considerarse como alusión al período aquí considerado: “Quien piensa en grande debe errar en grande”. Véase, AED: 81[14].

${ }^{308}$ Un análisis pormenorizado de las etapas de su pensamiento durante el régimen puede encontrarse en Grosser (2011): 66 ss.
} 
En efecto, luego de su renuncia en 1934 no hubo pronunciamiento directo al respecto, actitud que fue sentenciada por numerosos intelectuales de su época ${ }^{309}$. Recién a partir de 1966, en el marco de una serie de entrevistas y conversaciones, podemos encontrar referencias explícitas no solo al contexto histórico en el que inscribió sus actos, sino también respecto a un conjunto de las críticas recibidas. Específicamente, reconoce el error de su apoyo al partido, al tiempo que agrega explicaciones que parecen buscar minimizar el impacto que tiene y ha tenido tal posicionamiento político.

En primer lugar, en una entrevista concedida a la revista Der Spiegel, afirma que en esa época estaba convencido de que el NS era la alternativa adecuada para la orientación nacional en la puesta en marcha de la autonomía ${ }^{310}$ y al cambio necesario ,aunque en referencia al significado filosófico y espiritual de tal movimiento, es decir, apuntando con ello a una ontología de lo político por medio de un significado ontológico de los términos, como modo de insistir en pensar un lugar propio para el habitar del Dasein del otro comienzo ${ }^{311}$.

Por ello, distingue que su asunción al Rectorado fue una ocasión, no la razón determinante. En ese marco, explica que haber retirado la dedicatoria a Husserl en $S u Z$ en dicha época se debió a una presión editorial y política, esgrimiendo que no modificó ni suprimió de ésta la nota 38, donde elogia y valora la obra de su maestro. Asimismo, afirma que mientras estuvo en su cargo, mantuvo docentes judíos en sus puestos a pesar de las presiones del Ministerio del NS, por las cuales se vio obligado a presentar su renuncia al cabo de diez meses ${ }^{312}$. En sus cursos posteriores, entre los cuales

\footnotetext{
${ }^{309}$ Tal y como puede ilustrarnos un intercambio epistolar, entre los años 1946-1948, con uno de sus discípulos: Herbert Marcuse .Este le imputa a Heidegger el hecho de nunca haberse retractado públicamente, ni haber denunciado los hechos e ideología del régimen. En respuesta a las defensas esgrimidas por Heidegger en este intercambio, sostiene que confundió la liquidación del Dasein occidental con su renovación, así como también circunscribe su propia autodefensa respecto a sus implicancias políticas de un modo esquivo y opaco, por fuera de la dimensión en que es posible un dialogo entre los hombres, es decir, fuera del Logos, Véase, Marcuse (1991):32[116].

${ }^{310}$ Al respecto sostiene: "Yo no veía entonces otra alternativa. En medio de la confusión general de las opiniones y de las tendencias políticas de veintidós partidos, había que encontrar una orientación nacional y sobre todo social." (SGH: 655[46]. En una entrevista posterior, en lo que respecta a las críticas recibidas, sostiene "El pensamiento está siempre un poco solitario. Cuando se lo compromete se lo puede desviar. Le diré una cosa. Lo aprendí en 1933 durante mi rectorado, en un momento trágico de la historia alemana. Me sentí engañado. ¿Un filósofo comprometido es aún filósofo? La manera como realmente la filosofía actúa sobre los hombres y la historia, el filósofo mismo ¿qué sabe de ello? La filosofía no se deja organizar.". Véase, Towarnicki-Palnier (1970) [1969]:92.

${ }^{311}$ Respecto a las consideraciones filosóficas y espirituales de una ontología de lo político en lo que respecta, por ejemplo, a la noción de pueblo, véase Zaborowski, H. (2010):414 ss.

${ }^{312}$ En este marco, un escrito de Arendt motivado por su 80 aniversario, entiende que Heidegger, al igual que Platón, recurrió a un tirano solo por deformación profesional., en el marco de un shock que no le permitió ubicar en su pensamiento lo ocurrido. En su defensa, distingue que su pensamiento se aparta de los pilares del nazismo, a diferencia de muchos intelectuales de su época que sacan del fango al nazismo vía Hegel o la historia de las ideas, al tiempo que destaca : “ el apartarse de la realidad se ha convertido en una profesión; pero el apartarse de la realidad, no para dirigirse hacia una intelectualidad, con la que el fango nunca tuvo nada que ver, sino hacia un reino fantasmal de representaciones e 'ideas' que, desde toda realidad experimentada o experimentable, va a parar de tal manera hacia lo meramente 'abstracto' que los grandes pensamientos de los pensadores pierden en él toda consistencia y se transforman unos en otros, como si fueran formaciones de nubes, en las que también de manera permanente una se convierte en
} 
señala los dedicados al pensamiento de Nietzsche en la década de 1930, distingue una explícita discusión con los principios ideológicos del NS.

En segundo lugar, en una conversación publicada en 1969 en la revista $L^{\prime}$ Express, Heidegger articula que su pretensión desde aquella época fue abrir una nueva manera de pensar, tanto en la Universidad como en la práctica de la filosofía. Sostiene, frente a sus críticos, que el pensamiento esencial desde donde surgieron las preguntas de la filosofía, atravesará intacto la muchedumbre de sus detractores (Towarnicki-Palnier ,1970 [1969]:90), subrayando así que las diatribas que le llegaron atacan al pensador y no al pensamiento. En ese sentido entiende que su nombre y su personalidad no son relevantes en lo que respecta al camino del pensar, por ello afirma: "es necesario, o bien prolongar mi problemática en otras direcciones o bien contradecirme" (Ibid.:93). Asimismo, articula el concepto sartreano de mala fe para las críticas recibidas, puesto que estos "olvidan la confusión trágica que existía en 1933, la miseria, la desesperanza, las ilusiones" (Ibíd.:94) en esa época política de Alemania ${ }^{313}$. Hacia el final de la entrevista, destaca su soledad asumida desde su trabajo aislado en la Selva negra en el marco de su intención de no entrar en las discusiones estériles del ambiente académico e intelectual de su época.

En estas maneras de asumir públicamente su participación en aquél régimen, que articulan también un alegato de autodefensa, quedan desdibujadas las injerencias de la voluntad y la conciencia bajo el influjo epocal del discurso y la política, en el seno de las tensiones sociales. Pero la modalización y estructura de dichos discursos nos ofrecen elementos para plantear algunas continuidades. En efecto, el planteamiento de un pensar jerárquico y segregacionista que se cristaliza en consideraciones nacionales, universitarias, de ámbitos de trabajo, de direcciones para el pensar, ya se hallan manifiestos en los seminarios y escritos de la década de 1920, como también en las elaboraciones de los años siguientes.

Ahora bien, recientemente se han publicado una serie de manuscritos personales y fragmentarios de Heidegger los cuales han proporcionado elementos para retomar la polémica no solo respecto de tales implicaciones políticas y probable antisemitismo, sino también del

otra"(Arendt ,1970 : 271). A partir de esta metáfora interpretamos un énfasis puesto en la matriz lingüística de ciertos pensamientos que aquí, en su separación del contexto, confluyen en las mismas vías del pensar totalitario.

${ }^{313}$ Las alocuciones, reflexiones y hechos biográficos de Heidegger entendemos que deben inscribirse también en el contexto de la caída de la República de Weimar (que antecede el ascenso del NS al poder), con su respectiva agitación política e inestabilidad económica, donde la consideración del desarraigo (Bodenlosigkeit), la constancia (Ständigkeit) en el suelo (Boden) y la marcha hacia las raíces alemanas y la tradición griega pueden acceder a una significación contextualizada. A este respecto véase ,Pöggeler (1984a):13-23.Mediante esta distinción buscamos subrayar la primacía de las significaciones (contextuales, históricas, sociales) no a modo de justificación para el obrar y el pensar político de Heidegger, sino que precisamente desde ellas, en el campo simbólico contemporáneo y actual, puede comprenderse la renovación del análisis político de su pensamiento, las respectivas condenas sociales y la re-tematización de las relaciones e implicancias entre filosofía y política, por sobre las intenciones o explicaciones individuales . 
interrogante sobre el posible correlato entre sus posicionamientos/convicciones políticas y el propio campo semántico y perspectiva en sus elaboraciones filosóficas.

\section{1. b.- En torno a la publicación de los Schwarze Hefte.}

En efecto, para terminar este apartado abordaremos brevemente la continuidad que ha tenido las consideraciones de las implicancias políticas de Heidegger en el marco de las polémicas en torno a sus obras y pensamiento, a partir de la publicación en 2014 de sus Cuadernos negros (Schwarze Hefte), en tres volúmenes de GA (94-6) y en 2015, el primer tomo de Observaciones (Anmerkungen I-V. Schwarze Hefte 1942-1948), todos editados por Peter Trawny ${ }^{314}$. Sin intención de desplegar un análisis minucioso, proponemos dar cuenta de algunas consideraciones que Heidegger apunta en dichos escritos, en el marco de estas puntualizaciones, con el objeto de plantear discusiones recientes, evidenciando aspectos enunciativo-discursivos en Heidegger. Tales debates se caracterizan por un énfasis puesto en lo dicho contextualmente, por sobre el despliegue del decir en sus elaboraciones, distinción que evaluamos de relevancia, en el marco de nuestras interpretaciones y argumentos.

Específicamente, estos diarios se distribuyen en 34 manuscritos filosóficos que escribió desde 1931 y cuya publicación debía realizarse, por su propio pedido, al cumplimentarse la publicación de los 102 tomos de la GA. Sin embargo, debido al interés creciente en los mismos y en la circulación intempestiva de fragmentos, recientemente ha comenzado su publicación oficial. Sin información específica del destino o la efectivizacion del primero de ellos, al momento se conocen las anotaciones de los cuadernos II a XV y de las observaciones I a V, entre las cuales sus Reflexiones (Überlegungen) de los años 1931-1941 (II-VI), nos proporcionan una articulación con los desarrollos anteriores respecto a sus comunicaciones en la etapa del Rectorado, por medio de elementos discursivos que permiten continuar evaluando su posición respecto al NS y la cuestión del judaísmo, al tiempo que han desarrollado los alcances de las discusiones y polémicas sobre las implicancias respectivas ${ }^{315}$.

\footnotetext{
314 Trawny ha desplegado en diversos trabajos y entrevistas, referencias en torno a estas cuestiones polémicas en Heidegger. Sus interpretaciones y tesis versan sobre cierto desplazamiento en el discurso de Heidegger después de 1930, en relación a su rechazo de un antisemitismo biológico, explicitado en los Beiträge, pero con una reformulación respectiva en el marco de sus elaboraciones sobre la historia del ser, es decir, en una modalización singular como seinsgeschichtliches Antisemitismus. Asimismo, distingue un maniqueísmo en sus distinciones binarias en tensión, que subrepticiamente llevan implícita una posible superación y valoración axiológica, la cual en definitiva orienta su discursividad y pensamiento .Véase, Trawny (2014b): 11; 22-6 y su entrevista Trawny- Guimarães (2014).Cf. Aurenque (2014):248.

${ }^{315} \mathrm{Al}$ respecto, pueden cotejarse algunos comentarios y discusiones en notas, entre las que destacamos: Jürg Altwerg (2013), respecto a su impacto en la filosofía francesa y los obstáculos para su publicación; Eric Aeschimann (2013), en
} 
De un modo sumario, algunas de las cuestiones en tales manuscritos que suscitan debates actuales, entre otras consideraciones, son: a) la singular valoración del Dasein alemán en el marco de la transición hacia una co-determinación propia del Ser y el Dasein, en lo que prefigura como el segundo comienzo del pensar ${ }^{316}$, articulado diacrónicamente con la consideración del pueblo o Dasein griego, como hito socio-histórico del primer comienzo del pensar lo cual ,como vimos en el capitulo anterior, es distinguido por nuestro autor en el marco de la cuestión de la verdad e historia del ser; b) la puesta en valor de la noción de pueblo, en estrecha vinculación con consideraciones de orden político, pues le permite establecer conexiones entre la orientación del pensar y la tierra o suelo natal (Heimat ; Heimatland) ${ }^{317}$; c) la afirmaciones o consideraciones respecto al pueblo judío o del judaísmo mundial (Weltjudentum), que si bien remiten a fenómenos onto-históricos, inscriptos en sus elaboraciones de las co-determinaciones del Dasein en el mundo de la técnica , aún así manifiestan una carga significativa de explicito antisemitismo ${ }^{318}$; d) la consideración de la metapolitica por sobre el proceder filosófico (en los intentos de su supresión ), en el marco transicional del pensar ${ }^{319}$.

En una entrevista del año 2014, el editor Peter Trawny analiza estas cuestiones en los Schwarze, ofreciendo algunas interpretaciones al respecto, las cuales consideramos pueden ofrecernos una muestra representativa de las orientaciones generales de los debates y discusiones respectivas. En primer lugar, distingue una valoración implícita de un modelo de irrupción revolucionaria para la transición relacional y del pensar respecto al Ser, lo cual subyace en su apoyo contextual al $\mathrm{NS}^{320}$. Asimismo, subraya las jerarquías implícitas y las connotaciones de privilegio

el marco de una polémica entre exégetas de los Cuadernos; el mismo Peter Trawny (2014) en discusión con Altwerg, a partir de lo cual plantea un dialogo Xolocotzi (2014). En el ámbito anglosajón, pueden confrontarse con las notas de Oltermann (2014) y Schuessler (2014).

${ }^{316}$ Como en el siguiente caso, con su cariz prescriptivo: “(...) No podemos regresar, y sobre todo no podemos sacarnos de apuros con apaños y remiendos de los que hayamos ido haciendo acopio (...)Ahí donde un pueblo se pone como objetivo para sí mismo, el egoísmo se ha ampliado adquiriendo dimensiones gigantescas, pero con ello no se ha ganado nada de ámbito ni de verdad: la ceguera de la diferencia de ser busca salvarse refugiándose en un 'biologismo' desangelado y burdo que fomenta una bravuconería con las palabras. Todo esto es, básicamente, no-alemán. U II:233[184s.] y luego, sostiene : No hay que seguir adelante por el cauce de la perdición, pero tampoco hay que echarse atrás hacia algo anterior, sino hay que salirse de todo este cauce hacia un segundo comienzo: hacia su cerramiento, su sencillez y su 'final'"(Ibid:236[187])

${ }^{317}$ Véase, Ibíd. : 188-97; 337 s.; 421; 521[154-60; 263 s.; 329; 408 s.], entre otros.

${ }^{318}$ Por ejemplo, véase U XII: 46-7; 261 s.; U VII: 97.En el marco de estas discusiones y polémicas, una intérprete entiende que el punto problemático en tales afirmaciones antisemitas, reside en la mezcla injustificada de prejuicios y convicciones personales con elaboraciones filosóficas (Aurenque, 2014:248 s.). Entendemos aquí una distinción entre la orientación del pensamiento y discurso, por un lado, y el registro de significación enunciativo, por otro. Esta diferenciación es una condición para poder enfatizar la posición enunciativa-situacional de Heidegger. Pues bien, tal distingo de estratos y posiciones también están supuestos en los desarrollos del presente capítulo.

${ }^{319}$ Por ejemplo, véase U II: 115 [97]; 225-7[179 s.]

${ }^{320}$ En este sentido, interpreta: “(...) yo diría que para Heidegger el tiempo necesario es el de la revolución. Esto quiere decir, que él no está tratando del mundo de una determinada comunidad sino que de una historicidad [Geschichtlichkeit]. Y la historia, para él, solamente es en cuanta situación de irrupción, de ruptura de algo que termina y comienza (...) Primero, él tiene hasta un punto de vista positivo sobre la Revolución del Nacionalsocialismo; pero 
para pueblos, disciplinas o posiciones, susceptibles de una inscripción propia en la codeterminación del Ereignis ${ }^{321}$. En el contexto de estas distinciones, entiende que lo más problemático en aquellas consideraciones son las infundadas vinculaciones entre el antisemitismo y la historia del ser, es decir, las conexiones entre sus consideraciones políticas-ideológicas y sus elaboraciones filosóficas .Trawny entiende que estas cuestiones problemáticas están fuertemente ligadas a cuestiones de comprensión y lenguaje : a partir de un maniqueísmo antagónico en la terminología y discurso de Heidegger ${ }^{322}$, se despliega una tensión sostenida que no resuelve , orientando sus manuscritos hacia valoraciones negativas respecto a la técnica y su época , o a una disposición emocional hostil frecuente en estos manuscritos, acompañadas por consideraciones segregacionistas de purificación del ser (Reinung des Seins) ${ }^{323}$, en el marco de la diferencia ontológica $^{324}$. En especial, interpreta que en las dualidades y contrarios, se halla implícita una valoración axiológica, que se repite en numerosos pasajes de los $S c h w a r z e^{325}$.

Desde estas perspectivas, las discusiones y polémicas en torno a las implicancias políticas de Heidegger en la década de 1930 y la evaluación del estatuto de estas en sus trabajos filosóficos, también requieren dilucidar el suelo discursivo y enunciativo de Heidegger, correlativamente con sus elaboraciones y desarrollos de la acción y las valoraciones en camino de transición hacia un nuevo comienzo del pensar.

En este caso, es relevante cotejar algunas consideraciones en sus trabajos de la época, respecto al Dasein y las cuestiones prácticas relacionadas a su situación y mundo circundante. Como

después, se vuelve más crítico al respecto. En todo caso, la Revolución del Nacionalsocialismo fue para él un indicio, una señal, el trazo de una determinada situación histórica, y esa situación histórica exigía una respuesta (...) Más tarde, él va a decir que el problema es que él entendió el otro comienzo, pero no el Nacionalsocialismo. Entonces, usted podría decir que en esa fase, él está pensando aquel segundo comienzo (...) presenta (o intenta) una filosofía para esa revolución, porque pensaba que esta revolución (y eso es una locura) podría ser un segundo comienzo" (TrawnyGuimarães, 2014:99-s.)

${ }^{321}$ Como se evidencia en este fragmento valorativo de los Schwarze:"Que bien que solo los menos (Wenigsten) intuyan tan raramente algo de la verdad de la diferencia del ser" U II: 277[217], entre otras.

${ }^{322}$ A este respecto, Aurenque entiende que el sitial de tal maniqueísmo está ocupado por una contradicción insalvable en el discurso de Heidegger, circunscripta entre su lucha contra la metafísica y la matriz metafísica en la cual se halla prisionero su discurso. Es tal matriz dualista metafísica y la intrusión de prejuicios personales, aquello que orientaría hacia sus posiciones antisemitas. Véase Aurenque (2014):245-8.

${ }^{323}$ Véase, U XII: 237 s.

${ }^{324}$ Véase, Trawny- Guimarães, 2014:105 s.

${ }^{325}$ En el marco de estas discusiones sobre las matrices o campos semánticos-comprensivos de la metafísica que orientan el discurso y el pensar, respecto a la polémica de los Schwarze, Jean- Luc Nancy, plantea una sugerente propuesta: "Una segunda pregunta nos interpela, independientemente de nuestra relación con Heidegger. No surge sólo de estos cuadernos, pero ellos la reactivan: ¿realmente tenemos en claro lo que está en juego en el antisemitismo?, entonces ¿sabemos realmente de qué error es culpable Heidegger? Porque él lo es, al igual que muchos otros, pero ¿de qué exactamente? ¿De qué se trata en el antisemitismo? Pregunta nunca suficientemente ni bien planteada, y que se dirige a todos, no sólo a Heidegger (ni sólo a los antisemitas visibles o declarados) (...) ¿Este límite todavía no es nuestro si pensamos poco o mal la constitución fundamental - "espiritual", dijo Lacoue-Labarthe - del antisemitismo en Occidente?” (Nancy, 2014). Este horizonte de búsqueda y elucidación, en clara resonancia con la irreductibilidad de la alteridad en el lenguaje que desarrollamos anteriormente, caracteriza la recepción francesa del pensamiento de Heidegger, especialmente en el caso de Nancy y Derrida. 
veremos, el rol y función que atribuye al existente humano en este período permite dilucidar derivaciones políticas, éticas en y de esta perspectiva, al momento de establecer vínculos con dicho período biográfico de Heidegger, ampliando el campo de discusión en torno a su decir contextualhistórico.

\section{Perspectivas sobre la participación práctica y posicionamiento del Dasein con vistas a una transición.}

Las comunicaciones y los manuscritos anteriores no dejan de presentar ambigüedades en el marco del despliegue de sus elaboraciones, que dificultan circunscribir la vertiente política de las mismas: luego de sus cursos de la década del 30, Heidegger arremete gradualmente contra principios fundamentales del NS, dirigiéndose especialmente a la comprensión del ser que le subyace y que redunda en un subjetivismo en los límites de la metafísica moderna. De esta manera, su embestida contra la comprensión e interpretación metafísica también se articula como un modo de posicionarse frente a políticas e ideologías del NS, al tiempo que circunscribe sus desmontajes a todas las resonancias directas e indirectas con el mundo de la técnica, como epítome de tal base comprensiva $^{326}$.

Sin embargo, la perspectiva que desarrolla también se contrapone al posicionamiento del hombre en el centro, propio de las perspectivas sobre el cambio y la transformación histórica y social, que bien puede articularse con el silencio posterior a su posicionamiento de 1933 o ante la embestida crítica de sus contemporáneos. Estas elaboraciones dan cuenta de dinámicas relacionales en cuya operatoria Heidegger rechaza de plano la reducción a uno de sus momentos o funciones, entre los cuales se halla el accionar y el comportamiento del hombre. En este marco, retomaremos a continuación algunos desarrollos del capítulo anterior, con el objeto de enfatizar y dilucidar con precisión el sitial del Dasein en esas dinámicas, atendiendo especialmente a consideraciones en torno al obrar, la praxis, la participación, es decir, relativas a una filosofía práctica. Abordemos en primer lugar una de estas derivaciones de la metafísica: el mundo de la técnica y la propuesta de una modalidad especifica de relación en el marco de la transición al otro comienzo.

\footnotetext{
${ }^{326}$ Como vimos en el capítulo anterior, en el marco de su interpretación del pensamiento de Nietzsche, sostiene: "Tenemos que concebir la filosofía de Nietzsche como metafísica de la subjetividad... metafísica de la subjetividad incondicionada de la voluntad de poder" (N II: 199 s. [163 s]). En este marco, la voluntad y los valores son modalidades últimas de la subjetividad y el dominio representacionista de la técnica, desde las cuales Heidegger también distingue las bases de la metafísica.
} 


\section{2. a.- Dificultades y posibles desplazamientos del mundo técnico.}

Pues bien, recapitulemos algunos recorridos: Heidegger destaca que la historia del ser se caracteriza por su olvido, en el repliegue de su diferencia respecto al ente. Este olvido es el acontecimiento propio de la metafísica. El impacto de ello se cristaliza en la historia de la metafísica que se corona en su consumación con la técnica moderna, con la pérdida de arraigo propia del hombre en la actualidad. La técnica conlleva una correlativa mismidad, una relación con lo que es: la posición respectiva del hombre comprende al mundo como objeto, dirigiendo un pensamiento calculador (G: 523s [23s]). Pero tal determinación es parte de una dinámica: la relación técnica con el mundo determina tales relaciones del hombre ${ }^{327}$. Y ello precisamente subyace a los subjetivismos modernos, en todas sus figuraciones históricas, tal y como explicita respecto a uno de los baluartes semánticos del NS y en sugestiva vinculación con el movimiento contemporáneo de la Internacional Comunista:

“Todo nacionalismo es, metafísicamente, un antropologismo y, como tal, un subjetivismo El nacionalismo no es superado por el mero internacionalismo, sino que simplemente se amplia y se eleva a sistema... Expulsado de la verdad del ser, el hombre no hace más que dar vuelta por todas partes alrededor de sí mismo en cuanto animal rationale" (BH: 341 s [280])

Del mismo modo, esta tendencia subyacente co-determina en el marco del conocimiento científico, pre-proyectando la naturaleza como ámbito objetal, para tornarla susceptible de cálculo. Vimos que aquella imposición es la que impulsa al hombre al desafío de la naturaleza en el marco de la Ge-stell, es decir, para nuestro autor la relación con el ser propia de la modernidad técnica no proviene primariamente del ámbito voluntario humano. En ella, el hombre se ve provocado y requerido por el poder de la técnica, motivado por una dinámica anterior y pre-subjetiva. Esto repercute y delimita el conjunto de posibles para el proyectarse del hombre, tal y como afirma en este pasaje:

“Lo más propio de la técnica moderna no es algo meramente hecho por el hombre ni que esté en poder del hombre. El propio hombre actual se ve él mismo provocado y desafiado por la pretensión de provocar y

\footnotetext{
327 Un intérprete distingue y argumenta que la pregunta por la esencia de la técnica, característica de estas elaboraciones, mantienen la misma estructura y orientación que (y a partir de) la pregunta epocal por el sentido del ser, especialmente en relación a la co-determinación de Ser-Dasein en la Ge-stell. Para esta continuidad semántica/comprensiva en Heidegger, véase Calle Zapata (2015):46 s.
} 
desafiar a la naturaleza a que le suministre energía. El hombre mismo se ve obligado, se ve solicitado a corresponder a la mencionada pretensión" (UStS: 19s [8])

Ahora bien, desde aquí subraya las dificultades históricas para poder detener el desarrollo de la técnica, puesto que también desborda la capacidad y la voluntad humanas. Así, opta por un modo transicional de relación : entiende que no es conveniente arremeter contra el mundo técnico , sino más bien que es posible un particular uso de los objetos técnicos, manteniéndonos a la vez libres de ellos, es decir ,dejándolos salir de nuestro dominio y manipulación permanentes .Por ello, la amenaza es la esencia humanística que subyace a la técnica, de la cual no se sale por remedios técnicos ni orientaciones éticas, sino por medio de una torsión (Verwindung) (sea por este trato con el mundo entorno o, como vimos, por el salto y el paso atrás) ${ }^{328}$.

De este modo, Heidegger distingue una co-posición que redefina la relación con las cosas, poniendo el énfasis en la modalización relacional, más que a los participes de estas. Tal redefinición se orienta aquí en una faz positiva del uso y negativa de la abstención, repercutiendo en el objeto técnico y en el hombre, puesto que al no reducir lo ente a pura domesticación, preservamos al mismo tiempo nuestra propia esencia (G: 527[27]). Esto implica lo que a finales de la década de 1950 denomina Gelassenheit, término con el cual remite a disposiciones de desasimiento que permitan poner en evidencia el misterio de aquello que se muestra, dona y simultáneamente se retira, dinámica que aquella primaria modalidad de relación obstruye. Tal disposición hacia un nuevo arraigo, se fortalece desde otro pensar que se distingue de aquél inscripto en la modalidad de la técnica.Solo por otro pensamiento, en su constelación compleja y simultánea, es posible un efecto indirecto y colateral para la liberación del hombre de la caída en el ente (SGH: 673[61]).

\section{2. b.- La relevancia del pensar para una posible filosofía práctica.}

Tales consideraciones del pensamiento se tornan fundamentales al momento de contraponerlas a la acción directa, pues las vincula al ámbito de originariedad que se corresponden con la dinámica entre comprensión e interpretación, que son previas al conocimiento y al fáctico

\footnotetext{
${ }^{328}$ En esta línea y contra toda interpretación dialéctica, destacamos que no se trata aquí de superación, sino de sobreponerse y reponerse en el marco de esta relación del hombre y el ser. Así , la técnica no es eliminada en una suerte de fuga romántica hacia otro ámbito o estadio , sino que Heidegger entiende necesario mirar hacia su fondo de misterio posibilitante, de tal modo que posibilite la cuaternidad (Geviert), término con el cual denomina la cuádruple relación irreductible que da cuenta del mundo del ser habitable por y para el hombre. Desde aquí precisamente se establece el preludio hacia el Ereignis.
} 
estar en el mundo ${ }^{329}$. En este marco, entiende la necesidad que motiva a preparar una región donde lo no pensado reclame un pensar, en tanto un señalamiento (no voluntario) de lo que sigue estando en lo sido del primer inicio, es decir, en el pensamiento del ser y su posterior olvido. Este remite a otro pensar no calculable, cuya vía más relevante es la meditación (Besinnung) que implica la serenidad para con lo digno de ser cuestionado. Así, tal distinción consiste en oponer a un pensar metafísico representativo, aquel pensar que se articula desde disposiciones afectivas fundamentales, correlativas al modo de relación con el mundo circundante. La relevancia del pensar se torna aquí fundamental ${ }^{330}$.

Específicamente, distingue la necesidad de un radical desplazamiento en el modo de pensar, aunque no ligado a la voluntad, sino más bien al influjo de aquello que interpela nuestra esencia, que la exhorta a dirigirse a aquello que está por pensar y se encuentra de espaldas al hombre (VA:126[97]). De esta manera, no podemos forzar al pensar al advenimiento, más bien se trata de una espera, hasta que se nos dirija dicha exhortación .Pero tal espera supone también un carácter proyectivo: la trasformación solo es posible en un ir a la reserva de su inicio en el pensar. Entendemos aquí implícita la constelación relacional-dinámica entre proyecto, ipseidad, ser y pensamiento que supone también relaciones con el lenguaje, como modo específico de articular tal complejo relacional.

Precisamente desde este marco levanta sus críticas contra el marxismo ortodoxo, al subrayar que antes que la transformación del mundo de modo práctico es indispensable una transformación del pensar (WM: 446 s [362]). Pues el pensamiento calculante, como una modalidad de huida epocal, se caracteriza por una velocidad que no se detiene a meditar. Por el contrario, la reflexión meditativa no se caracteriza por tal pensar espontáneo, sino que requiere un esfuerzo y un entendimiento superior capaz de esperar (G: 520[19]). Esta esencia del otro pensar se articula en un

\footnotetext{
${ }^{329}$ Un análisis pormenorizado del estatuto del obrar en el pensamiento de Heidegger puede encontrarse en elaboraciones de Reiner Schürmann. Este intérprete sostiene que no se establece una disociación entre ser y obrar en el pensamiento de nuestro autor sino una redefinición de sus vínculos. El planteo heideggeriano consiste en distinguir la ligazón de las filosofías prácticas con la filosofía primera o perspectivas que sostiene el arché y el thelos como constelaciones representativas para el obrar. El obrar pierde de esta manera toda conexión con doctrinas de fundamentos. Más bien se da una praxis sin porqué, un obrar múltiple:”... el obrar no se dejaría describir más que por un propósito concebido con anterioridad y ejecutado con la ayuda de medios apropiados. Heidegger sugiere así una abolición práctica de la finalidad, en el umbral de una economía no principal. El obrar correspondería a la manera múltiple en que, a cada momento, se ordena la presencia a nuestro alrededor" (Schürmann, 1983:362). De esta manera, liberando el pensamiento de representaciones de finalidad, podemos comprender un origen siempre nuevo y sin telos, en una "reencontrada inocencia de lo múltiple" (Ibíd.:365), que se articula en un obrar sin fondo y discontinuo en el marco del Ereignis. En esta caracterización e interpretación del obrar en estas elaboraciones de nuestro autor reencontramos las notas de aquellas articulaciones sobre la ipseidad mediada en su carácter dinámico, desde la perspectiva relacional y no representacionista.

${ }^{330}$ En esta línea, subraya: “es posible que después de siglos el hombre haya actuado demasiado y pensado muy poco. En un mundo que da cada vez más que pensar, el pensamiento no siempre existe” (Towarnicki-Palnier ,1970 [1969]:90).
} 
compromiso que no se dirige a un querer sino a un esperar sin objeto y en tránsito ${ }^{331}$, distinguiéndose de la expectativa propia del pensamiento representativo. Esta modalidad disposicional desplaza o dinamiza el pensar, a modo de manifestación última de la voluntad y el querer, es decir, un compromiso que requiere en un primer tiempo de una voluntad para, en segunda instancia, abandonarla desde el temple en la Gelassenheit. De esta manera la acción e intervención práctica humana son requeridas de un modo dinámico y lateral, en el marco de una transición a su abandono posterior.

A partir de estas puntualizaciones, podemos sostener que para Heidegger la historia del ser no se halla cerrada ni se despliega en vistas a un horizonte único e inexorable, pues el pensar puede cooperar a que se logre una relación satisfactoria con la esencia de la técnica. Ahora bien, esta modalización del pensar es correlativa a un modo de habitar del hombre en el mundo, en su respectiva relación con el ser.

\section{2. c.- El ámbito decisional: los roles del Dasein en la historia del ser.}

Un cambio terminológico de relevancia para las dinámicas de mismidad del Dasein va del uso de resolución (Entschlossenheit/Entschiedenheit) en SuZ, al de decisión (Entscheidung) a partir de sus trabajos de 1936. Desde aquí destaca la malinterpretación existencial de SuZ, en referencia a cierta recepción de su obra que, imbuida en el circuito representacionista moderno, ha puesto en primer plano al hombre, con su impacto correlativo en el decir y las palabras.

Específicamente, hemos visto que en $S u Z$ el acto resolutorio abre en cada caso la situación fáctica, revelándose desde allí una apertura ontológicamente anterior a todo comportamiento teórico y práctico. En pocas palabras, toda resolución y proyección solo es asumible en lo previamente abierto. Por ello, Heidegger parece evitar el uso del término actuar (Handeln) pues la resolución no queda ligada a un acto de voluntad, sino que la caracteriza por su pasividad en el marco de la posibilidad proyectiva ${ }^{332}$. No obstante, la preeminencia dada al Dasein, permitió distinguir cierto

\footnotetext{
${ }^{331}$ A este respecto y en el marco de un pensar por fuera de la sustancializacion del hombre, ilustra dicha orientación no calculable, en el contexto de un diálogo ficticio entre un Investigador (I), un Profesor (P) y un Erudito (E), en este pasaje:” I: Entonces ¿a qué debemos esperar? ¿y dónde debemos esperar? Dentro de poco no voy a saber dónde estoy ni quién soy. ; P: Esto ninguno de nosotros lo sabe ya, desde el momento en que dejamos (ablassen) de hacernos ilusiones sobre nosotros; E: Pero todavía nos queda nuestro camino, ¿no?; P: Desde luego. Mas, al olvidarlo demasiado pronto, abandonamos el pensar" (ZEG: 43[41]).

${ }^{332}$ Recordemos que las referencias allí son en relación a posibilidades de ser (Seinsmöglichkeiten), en lugar de remisiones al actuar u obrar, las cuales son afines al carácter proyectivo, insustancial, dinámico y simultáneo del Dasein en su significación.
} 
margen o comportamiento de apertura libre en relación al ente, implícito en el término resolución ${ }^{333}$.

Así, buscando esquivar las notas que aún lo mantengan en el campo semántico de la filosofía de la conciencia, luego de 1930 evita usar aquel término, sustituyéndolo por decisión, tratando así de captar su dinámica esencial no a partir del hombre sino desde la perspectiva del ser, en una relación de apertura y don, correlativa a un compromiso-entrega con tal apertura.

Frente a las consecuencias de las cosmovisiones medianeras y la cultura de la técnica, Heidegger insiste en señalar un tránsito desde un temple sin júbilo inmerso en el ente hacia una entrega a la pertenecia al ser (BPE: $99[92$ s]). Pero en tal desplazamiento la decisión tampoco implica una elección ni acto del hombre, sino que se inserta en una disyuntiva epocal: o bien pertenecer al ser o bien abandonarse en lo ente en el marco de la historia del ser, cuya base es el desarraigo en que el hombre contemporáneo se encuentra.

En el contexto de tal disyuntiva, el Dasein deviene en la cercanía guardada y vigilada para la venida de lo sagrado no ente, con el silenciamiento necesario y la soledad propia de los elegidos e insólitos (Wenigen und Seltenen) (Ibíd.:11[27s.]).Es decir, con estas consideraciones se evidencian también funciones y relevos para el Dasein en dicho marco relacional : en cuanto ex-sistente debe guardar la verdad del ser, tal y como articula en su célebre sintagma: el hombre es el pastor del ser (Hirt des Seins) (BH:342[281]), lo cual requiere también de un señalamiento de aquello que se retira, como función del guardián y vigía ${ }^{334}$.Esta relación opera como desplazamiento respecto del sesgo voluntarista con preeminencia de la conciencia ${ }^{335}$.

Del mismo modo, a partir de los temples anímicos fundamentales, otro de los roles para el Dasein es ser el custodio (Wächter) de la verdad del ser (BPE: 16s [32]). En ello su obrar fundamental consiste en preguntar y pensar, como radicalmente opuestos al modo intervencionista y manipulador del hombre en el marco de la técnica. Tambien por ello, ambos modos del obrar se despliegan destacando su carácter dinámico de tránsito, evitando así las cristalizaciones de los contenidos, los campos temáticos o regiones hacia los que se dirigen o señalan.

En tal contexto, reencontramos una misma operación discursiva: tales roles o posicionamientos del Dasein suponen una atención puesta por Heidegger al campo semántico y

\footnotetext{
${ }^{333}$ En este contexto, puede consultarse un análisis e interpretación sobre la herencia y recepción aristotélica de la praxis para la estructura del Dasein en $S u Z$, distinguiendo una retracción o desplazamiento respecto de la orientación éticopolítica aristotélica, en virtud de un planteamiento más originario. Véase, Rubio (2003):309-14.

${ }^{334}$ Respecto a la función de mostración del Dasein, Heidegger subraya que el hombre es un signo...que queda sin interpretación (VA: 130[100]). Y en el mismo sentido, en referencia a la comprensión de base en la metafísica, sostiene que el ser (en sentido verbal) del hombre, 'el Dasein en el hombre' (...) no es nada humano (WM: 397[322]).

${ }^{335}$ Un intérprete desarrolla esta modalidad de relación ser-Dasein, a partir de la singular consideración de la cercanía (Nähe) como la nota que la caracteriza, en Rocha de la Torre (2007):72-8.
} 
sintáctico metafísico, modalizándolo por oposición relacional ${ }^{336}$. El siguiente fragmento connota esta operación modal en el lenguaje:

"El hombre no es el señor de lo ente. El hombre es el pastor del ser. En este "menos" el hombre no solo no pierde nada, sino que gana, llega a la verdad del ser. Gana la esencial pobreza del pastor, cuya dignidad consiste en ser llamado por el propio ser para la guarda de su verdad" (BH: 342[281])

En efecto, aquí podemos distinguir una oposición sintáctica que tensiona la carga semántica del campo en el que se inscribe .Por un lado, frente al ser señor (que mantiene el subjetivismo de la voluntad de poder), el "menos" con el que se gana remite a resguardar el ser. Por otro lado, el uso entrecomillado sobre un término que alude al marco subjetivista y valorativo propio de la metafísica, se manifiesta como una operación de escritura que produce un efecto de distancia: a) tensando dichas alusiones en el límite de su campo semántico y, al mismo tiempo, b) demarcando un umbral o frontera en este campo (como consecuencia o efecto de tal puesta en tensión), en vistas a una transición o desplazamiento posible. En pocas palabras: un efecto de lenguaje que emerge lateralmente no por una acción voluntaria, sino por el despliegue de un modo de relación con/en este ámbito.

De este modo, podemos sostener que el carácter de pasividad del Dasein en estos posicionamientos, solo es tal si se la considera desde la perspectiva tradicional de intervención activa-directa en las dinámicas. Es decir, remite a un posicionamiento meramente pasivo, si se lo comprende en un horizonte de expectativas y comprensivo de tipo subjetivista. Pero aquí se trata más bien de una modalización de la actividad en su co-dimensión con la pasividad ${ }^{337}$, lo cual se manifiesta mediada, colateral, participe, colaboracionista, precursora, preparatoria, quedando inexorablemente separada de las notas de intervención directa que subyacen en aquella concepción, al hallarse articulada en una dinámica compleja y sin centro ${ }^{338}$.

\footnotetext{
${ }^{336}$ En esta línea, un intérprete distingue un desplazamiento terminológico y semántico en estas elaboraciones que remiten a la inacción del Dasein. Tal desplazamiento se ve impulsado a partir de la lectura de una tendencia nihilista epocal de globalización técnica como consumación de la metafísica, lo cual conduce al cierre (Verschlossenheit) de la aperturidad acontecimental en pos de un principio ontico, por sobre la diferencia ontológica, es decir, tensando el propio límite del campo metafísico. Para esta lectura de perspectiva escatológica en relación con el lenguaje, véase Garrido Periñán (2015): 317-9.

${ }^{337}$ Respecto a la singular reelaboración del concepto de pasividad, en relación al Dasein, véase un análisis en Santiesteban (2007):15-7.

${ }^{338}$ En este marco, Vattimo ofrece una interpretación sobre el papel del hombre en esta época de las elaboraciones de Heidegger, el cual se articula paradójicamente en un encontrarse en aperturas dadas, al tiempo que contribuye a determinarlas, pues la apertura del ser no es estructura trascendental sino acontecimiento histórico, por lo cual debe verificarse en los hechos que constituyen la historia: las decisiones y acciones del hombre, véase Vattimo (1998):101105. A nuestro entender esta interpretación se halla articulada mayormente desde un pensamiento representativo, pues el último sintagma manifiesta resonancias de autonomía y singularización respecto a la dinámica constelada en que tal verificación se inscribe.
} 
En ese sentido relacional irreductible subraya que, sin el hombre como receptor, el ser quedaría oculto y clausurado, y el hombre no sería hombre (ZuS: 17/288). Es decir, una dinámica relacional donde el ser se da y el sitial receptivo pertenece al hombre dispuesto a ello. Tal don no supone una potencia que pone en marcha el dar, pues esto implicaría desplazar el principio rector del hombre al ser, manteniéndose así bajo el mismo yugo del pensamiento representacionista y de aquél concepto de actividad. Por el contrario, remite a una donación cuyas determinaciones simultáneas son: el destinarse y la entrega en el seno de un múltiple desocultarse en el tiempo, en un ámbito ya dispuesto a su guarda ${ }^{339}$.

En suma, con estos énfasis y determinaciones para la pertenencia mutua del Dasein con el ser, pone un coto a las pretensiones del hombre de la técnica como señor del ente, el cual pone en riesgo su propia esencia y la de la vida en la tierra, lo que sin embargo tampoco puede reducirse a una pasividad en sentido metafísico tradicional.

\section{2. d.- Acerca de la posibilidad del cambio y la salvación.}

Frente a las malinterpretaciones que puedan haber surgido de su analítica de la década del 20, Heidegger amplía aquí sus elaboraciones e insiste en la consideración de que el Dasein, más que un ser autónomo que se autoproduce, es un ser situado, afectado, inmerso en dinámicas que lo preceden, condicionan y modalizan. Aún así, vimos que estas notas y consideraciones ya se hallaban manifiestas en la época de SuZ: allí articuló que su carácter proyectivo solo puede actuar sobre posibilidades arrojadas, así como también que la disposición afectiva es la que ilumina la comprensión, es decir, es anterior a la modalización fáctica del ser-en-el-mundo del Dasein. En estas elaboraciones posteriores desarrolla tales notas, poniendo de manifiesto las dinámicas relacionales, reorientando énfasis y sentidos.

Es a partir de estas consideraciones que insiste en que nadie puede plantear un a priori para lo concreto de la existencia fáctica, pues esta se define en el propio existir y en la época. Esto inmediatamente se vincula con la propia labor y discurso de nuestro autor, quien se manifiesta esquivo a una referencialidad directa y específica que oriente la práctica. A lo sumo, sostiene que un pensador tan solo puede esforzarse por construir la pasarela de un tránsito (SGH: 683[70]), tal y como se propone en su camino del pensar. Sus desarrollos en torno a dicha participación indirecta

\footnotetext{
${ }^{339}$ En dicha multiplicidad nuestro autor incluye la comprensión del ser como presencia y el tránsito hacia el otro inicio en la pregunta por el ser.
} 
buscan dar cuenta de un diferimiento de fondo, lo cual opera dinamizando el decir y el pensar, en un tránsito que va del ámbito en aquel camino hacia otro, el cual no es pre-visible (ni representable) sino que se efectúa en el propio desplegarse del tránsito. Esta suerte de horizontalidad simultánea o circularidad en sus elaboraciones sobre el cambio o el desplazamiento, evitan fundamentos primeros, centros, y teleologías, tres de los aspectos principales de la matriz del pensamiento y lenguaje metafísico. Lo cual se evidencia, por ejemplo, en este pasaje que destaca la figura del poeta para aquellos horizontes:

"No se produce nunca un cambio sin que lo anuncien heraldos .Pero ¿cómo pueden acercarse heraldos sin que se despeje el acaecimiento propio, este acaecimiento que, llamándola, usándola (y necesitándola), ojee, es decir, aviste la esencia del hombre, y en este avistar ponga a los mortales en camino del construir que piensa, que poetiza? (VA:95[73]).

En este fragmento, la primera significación se halla inmediatamente socavada en su sentido por la pregunta siguiente, de tal modo que la modalización del lenguaje respectiva se manifiesta correlativa a la modalidad relacional enunciada entre el ser y el hombre. Más en detalle: entendemos aquí que si bien mantiene ciertas resonancias de la metafísica de la subjetividad (la necesidad de heraldos para el cambio connota notas de eminencia o relevancia central del existente humano), no obstante la articulación semántica y sintáctica del fragmento acompaña con sus efectos las palabras o sintagmas que circunscriben un umbral dentro de este ámbito (los mortales, construir que poetiza, etc.).

Ahora bien, ¿bajo qué impulso inscribe tales necesidades? La posibilidad de salvación (Rettung) emerge del peligro en que se halla la esencia del hombre en el marco de la técnica, cuando el ser exhorta y permite la movilización de las dinámicas para el otro comienzo. Con esto reencontramos la consideración de la necesariedad de la modalidad epocal desde la que se posiciona su discurso, cancelando así toda interpretación que entienda en ello una sucesión o contraposición de alternativas, como queda ilustrado en este pasaje:

“Existe alguna posibilidad de salvación? Solo existe cuando está ahí el peligro. El peligro está cuando el propio ser camina hasta lo último e invierte el olvido que surge de sí mismo. ¿Pero qué ocurre si el ser usa en su esencia la esencia del hombre? ¿Qué ocurre si la esencia del hombre reside en pensar la verdad del ser? Entonces, el pensar tendrá que hablar poéticamente desde el enigma del ser. El pensar trae la aurora de lo pensado a la proximidad de lo que queda por pensar" (Hw: 343[277]). 
El impulso entonces, proviene del peligro inherente a la época de la técnica, pues de allí se dinamiza el tránsito. Asimismo destaca que también se ve movilizado y exhortado por la urgencia de lo otro, es decir, una alteridad que insiste en el pensar y en su primer inicio de la metafísica tradicional (BPE: 97[91]). Como pensador, la cuestión de fondo para Heidegger es la diferencia ontológica que en ello se revela, lo cual motiva y ciñe su tarea del pensar a una co-participación en los desplazamientos y tránsitos hacia otro pensar y un nuevo destino del $\operatorname{ser}^{340}$. Asimismo, las tensiones y limites de (y en) el ámbito de la metafísica y la técnica se revelan también como condición para la transición.

Desde aquí podemos comprender otras razones por las cuales Heidegger no escribió una ética específica o concreta. En primer lugar, debido a su rechazo a la fragmentación histórica de la filosofía en disciplinas, pues entiende que no puede diversificarse su tarea del pensar. En segundo lugar, por comprender que la prescripción de valores o sentidos se inscribe en una modalidad de subjetivación que remite al hombre como centro del ente y las relaciones respectivas, como una figuración más de aquel dominio calculante ${ }^{341}$. Aunque insiste en la relevancia de atender al vinculo ético en lo que respecta al hombre de la técnica ${ }^{342}$, pero ¿qué modalidad o plano de ética puede pensarse en el marco de sus elaboraciones?

En efecto, su desconfianza de las éticas modernas, incluso de las consideraciones políticas de posguerra que no discuten efectivamente con el mundo técnico y su consecuente desarraigo ${ }^{343}$, lo llevan a subrayar límites y funciones en las pretensiones humanas y en la filosofía ( con su base comprensiva tradicional y metafísica) cuando sostiene, por ejemplo:

"La filosofía no podrá operar ningún cambio inmediato en el actual estado de cosas del mundo. Esto vale no sólo para la filosofía, sino especialmente para todos los esfuerzos y afanes meramente humanos. Solo un dios puede aún salvarnos. La única posibilidad de salvación la veo en que preparemos, con el pensamiento y

\footnotetext{
${ }^{340}$ Por ello destaca que un desplazamiento en el pensar y en la actitud con el mundo circundante remite al advenimiento de nuevas perspectivas y no a la defensa de lo in-humano, e insiste desde cierta confianza intuitiva:"Las cosas importantes acaban por llegar a tiempo, aunque sea a última hora y aunque no estén destinadas a la eternidad" (BH: $344[282])$.

${ }^{341}$ En una interpretación del pensamiento de Heidegger como a-valórico, un autor subraya el carácter negativo de la ética, la epistemología y la teología en sus elaboraciones, que lo ligan a la tradición estoica: una negatividad en el sentido del retiro de nuestras valoraciones, nuestras representaciones en general y aquellas que nos forjamos de Dios, para el camino del pensar en el que se orienta. En este marco, el intérprete subraya que los valores como figura extrema de subjetivismo, no permiten que el ente y el ser sean, razón por la cual nuestro autor se aparta de toda ética ontica. Véase Hotzapfel (2000):99 ss. Entendemos dicha negatividad en el marco del campo semántico en tensión, desde el cual nuestro autor articula estas elaboraciones.

${ }^{342}$ Frente a ello sostiene que el pensar solo remite a rememorar el ser, sin resultado esperable. Lo deja ser al ser, pues el pensar no crea la casa del ser. Y esto modaliza una suerte de ética anterior, tal y como alude en este fragmento:" Solo en cuanto el hombre pertenece al ser ex-sistiendo en la verdad del ser, puede llegar del ser mismo la prescripción de esas normas que tiene que convertirse en ley y regla para el hombre" (BH: 360-1[294]).

${ }^{343}$ A ello opone el primer y único inicio : "en la experiencia e historia humanas... todo lo esencial y grande solo ha podido surgir cuando el hombre tenía una patria y estaba arraigado en una tradición”(SGH:670[59])
} 
la poesía, una disposición para la aparición del dios o para su ausencia en el ocaso; dicho toscamente, que no 'estiremos la pata', sino que, si desaparecemos, que desaparezcamos ante el rostro del dios ausente” (SGH: $671[59$ s.])

En este contexto, frente a la orientación hacia el nihilismo de la época y su ausencia de dios, destaca al disposición para aquello que denomina como el último dios (der letzte Gott), pensado sin las determinaciones del ser en cuanto presencia (tal y como conlleva la figura cristiana de Dios, por ejemplo), lo cual marca el comienzo de una nueva época del ser con su comprensión y apertura respectiva, es decir, mediada en el Ereignis ${ }^{344}$.En este sentido, la filosofía no puede aportar fuerzas o crear formas de acción y condiciones que susciten una acción histórica para salvarnos del peligro, pues: "la sola acción no cambiará el mundo sin primero interpretarlo" (Towarnicki-Palnier ,1970[1969]:89). Por ello, la ética entendida como doctrina de la acción supone pretensiones de totalización que difícilmente puedan esgrimirse para el pensamiento de posguerra ${ }^{345}$. Es decir, en tal contexto, se cuestiona ¿desde qué perspectiva puede arrogarse plantear una ética para el existente humano?

No obstante, propone un planteamiento lateral, anterior y ontológico, en vistas a un horizonte de posibilidad en general, al interior del cual un determinado posible no previsible puede emerger, a partir de su despliegue en torno a una ética originaria, desde la década de 1940.

\section{3.-El Ethos y la ética originaria bajo el supuesto de alteridad.}

\footnotetext{
${ }^{344}$ Para Heidegger, desde disposiciones afectivas fundamentales, pensar lo sagrado y lo divino implica deshacerse de la orientación representacionista de la metafísica y supone un ámbito de posibilidades históricas mayores e imprevisibles, así como también el advenimiento de los venideros o futuros (Die Zukiinftigen), es decir, una nueva comunidad humana desde una co-pertenencia con el Ser en el Ereignis .Véase, entre otros pasajes, BPE: 5-35;395-420[22-35;31736] y B:223-56[195-220]. Respecto a estas consideraciones, en su orientación y campo común con un reciente giro teológico en perspectivas fenomenológicas contemporáneas, las cuales articulan estas figuras o ámbitos de excedencia de posibilidades, pero en el marco de la consideración de la intersubjetividad o el mundo como horizontes, véase Walton (2010) :132 ss. Por otra parte, una lectura de la invocación del último dios , considerada como la propuesta critica de Heidegger en sus escritos de madurez, puede encontrarse en Santiesteban(2007):14 s.

${ }^{345}$ Un intérprete sostiene que el otro pensar de Heidegger ya es en sí mismo una realización, cuya eficacia consiste en el abandono de pensarlo en términos de efectuar un efecto, al cual describe del siguiente modo: "El pensamiento es unidad, síntesis, acuerdo, correspondencia, por consiguiente desde que existe, viene ya 'realizado'. Su 'realización' consiste en existir como pensamiento, no exige un ulterior paso a la acción" (Carrasco Pirard, 1996:86) En este sentido puede entenderse una homología entre las elaboraciones y el discurso de nuestro autor: tal realización del pensar es ya una perspectiva respecto a la filosofía práctica de la metafísica de la subjetividad.
} 
En efecto, en los trabajos de este período también encontramos desarrollos sobre las disposiciones afectivas del hombre, la función y rol en la co-pertenencia originaria con el ente y la modalidad de su ipseidad y trato circundante .En esta constelación puede articularse su elaboración acerca de una ética originaria y su respectivo Ethos. Especialmente desde su escrito sobre los humanismos podemos comenzar a datar la mención de una ética originaria ${ }^{346}$, que también desarrolla en una exposición en sus seminarios sobre Heráclito de 1943-44.

Como vimos, la crisis que impacta en la esencia del hombre y su mismidad en la época de la técnica delimita y prefigura toda ética, bajo la égida del cálculo y la dominación. Frente a ello, el pensar de la transición hacia el otro inicio , remite la consideración de un Ethos originario más allá de la tradición metafísica, a cuyo advenimiento el pensamiento de Heidegger busca contribuir de algún modo, entendiendo que este destino depende del ser y el claro que lo permite. Por ello, tan solo se propone dar cuenta de un sesgo en el seno del mundo de la técnica, un pliegue, una diferencia que colabore de modo indirecto con el desplazamiento histórico, incluso reconociendo que no puede producirlo de modo unilateral. Aquí reencontramos la modalidad dimensional ambigua del rol del Dasein, ahora figurando en su pensar y su discurso: no puede autogenerar sus modos (dimensión pasiva), pero el advenimiento requiere su colaboración (dimensión activa). La modalidad de este pensar consiste en interrumpir el cálculo, mediante un temple de espera, en rechazo de la precipitación en el accionar directo ${ }^{347}$.

La ética es aquí pensada desde su carácter originario y previo a toda ética concreta, remitiendo a la co-pertenecia con el ser en el Ereignis, de modo tal que despliega su pensar en torno a una ética exclusivamente en relación al ser. Dado que las disposiciones afectivas son condiciones de posibilidad para la comprensión que el Dasein tiene de sí, del ente y del ser, entendemos necesario retomar consideraciones a partir de la distinción de los temples fundamentales en sus implicancias relacionales, con el objeto de distinguir la perspectiva sobre el Ethos que juega en la consideración de la ética: aquí, la reserva (Verhaltenheit) cumple un rol determinante ${ }^{348}$.

\section{3. a.- Hacia un Ethos posmetafísico}

Para Heidegger la ética y ontología habituales forman parte de la metafísica. Frente a ello el otro pensar del ser no puede articularse desde allí, sino más bien señalar a una nueva dimensión no

\footnotetext{
${ }^{346}$ Véase BH:356[291]

${ }^{347}$ En este marco podemos comprender la negativa de Heidegger a las intervenciones directas en política, sus críticas al marxismo, su propio obrar sin cálculo pre-visible, etc.

${ }^{348}$ Desde Beiträge insiste en que esta es una disposición afectiva fundamental, como fundante del Ethos. Véase ,BPE: 15-36[30-46], y también WP: 7ss. [29 ss.].
} 
metafísica. En este marco, se torna de relevancia la consideración del Ethos como habitar del Dasein, pues desde allí se modaliza también la relación con el ente, los otros Dasein y, por supuesto, con el ser.

Retoma desde el pensamiento presocrático el sentido etimológico originario de la palabra Ethos, como lugar de estancia. Más específicamente, encuentra en el pensamiento griego dos acepciones: por un lado, la de hábito o comportamiento, que remite a la vía de comprensión en la que se inscribe Aristóteles ${ }^{349}$; por otro, el significado de lugar de habitación, de residencia del hombre, concepción que se remonta principalmente al pensamiento de Heráclito. Si en el primer caso Heidegger reconoce una continuidad con la tradición metafísica, en el segundo, distingue una comprensión apropiada para el otro comienzo del pensar que remite a aquél abismo o diferimiento que ha caído en el olvido. Esto se debe a que en la ética metafísica no se devela la consideración del Ethos, al quedar reducida su significación al tratamiento de la virtud y la costumbre. Por el contrario, un planteamiento más originario puede develar el sentido de tales valores, la orientación comprensiva desde la que emergen y el horizonte hacia el cual se proyectan. Desde aquí nuestro autor toma el término ética, en un singular modo de empleo que se superpone con un rechazo subrepticio del empleo tradicional del mismo: lo emplea desestimando sus relaciones y asociaciones sedimentadas, como evidencia este fragmento:

“Lo esencial en el $\eta \dot{\theta}$ os, en este permanecer, es el modo como el hombre se detiene en el ente y cómo

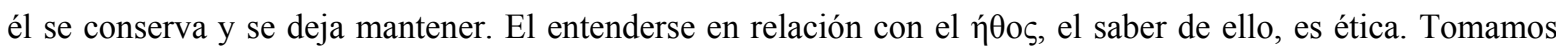
aquí la palabra en un sentido completamente amplio y esencial. La significación habitual como teoría de las costumbres, de la virtud o de los valores es sólo un resultado, variedad desviada y hasta aberración del oculto sentido originario”. (H: 206[230])

Esta mención al sentido originario se muestra aquí correlativa al rechazo del campo semántico en el que se inscribe tal palabra. Entendemos que tal rechazo no solo se enuncia aquí , sino que también se halla implícito en la tensión manifiesta en el empleo de un mismo término, que aquí funciona como otro, es decir, en el pliegue o diferimiento que implica decir una palabra, pero connotando otro sentido .

\footnotetext{
${ }^{349}$ Especialmente a partir del pensamiento de Aristóteles, Ethos tiene dos usos , según su escritura :a) Ethos con épsilon inicial , que remite a la significación de carácter (los hábitos sedimentados en la costumbre ) y b) Ethos con eta inicial , que remite al comportamiento y la conducta, al tiempo que se articula con el término ethikos (en referencia a la tendencia o disposición de hacer lo bueno). Frente a estas significaciones relacionadas por una comprensión común, Heidegger se remonta a la significación y sentido originario del término, para poner de manifiesto la comprensión metafísica del ser que subyace a estos usos, en vistas de una orientación de la ética desde su sentido originario, es decir, anterior a la ética de valores propia de la metafísica de la subjetividad.
} 
Precisamente en este marco retoma la vía de Heráclito, articulando aquél concepto como la forma de relacionarse el hombre con el ente en su totalidad, que varía según la destinación histórica del ser. De tal modo, subraya que esta dimensión está ya implícita en toda ética concreta, tornándose relevante una tematización adecuada a su carácter originario.

Específicamente, si el Ethos se configura o determina en su relación con el ente, entonces una modalidad de relación originaria se corresponde con su modo originario respectivo. En este marco, retoma la cuestión del papel relevante que ha tomado el Logos en la metafísica, considerándolo como lo más propio del hombre (determinado como animal racional), cuyo epítome ha sido el desplazamiento de esta comprensión al concepto de razón y su primacía. Frente a esto, Heidegger retoma la consideración del ámbito previo de la comprensión, que parte del don epocal del ser, desde la cual emerge la interpretación, en ambos casos se trata no solo de ámbitos anteriores sino también de las condiciones de posibilidad de aquellos. Tal anterioridad no implica un rechazo del Logos, sino más bien permite pensar un ámbito correlativo.

El Ethos de la técnica corresponde al Logos metafísico: este adquirió su papel dominante, separándose de aquél, lo que derivó en el desarraigo (Heimatlosigkeit) del hombre en la época del olvido del ser. Frente a esto, Heidegger destaca que el Ethos remite al ser del hombre en relación a su habitar, por lo cual toda interpretación del Dasein debe incluirlo (Ibid.:205 s. [229 s.]). También de esta manera, se propone colaborar con una torsión de esta vía de la metafísica, por medio de un pensar al ser del hombre en relación con su habitar o estancia en el mundo, entendido como el rasgo fundamental de su ser (VA: 155-6[119]). Nuevamente aquí, debe tomar el recodo de una problematización que no pone al hombre en el centro, pero en parte se vincula con aquél.

En efecto, el Ethos originario y posmetafísico se corresponde con el mencionado pastoreo del hombre respecto al $\operatorname{ser}^{350}$ : cuidando del ser, renuncia a la pretensión de señor y majestad del ente. La contraposición y distinción modal del hombre como señor del ente (en la Ge-stell) y como pastor del ser (en el Ereignis), suponen un Ethos disímil: mientras en el primer caso emerge el peligro para la esencia del hombre y su estancia sobre la tierra, en el segundo, en cambio, se preserva su esencia por medio del arraigo respectivo.

Como lugar de estancia, la transición y desplazamiento se dinamizan desde el ámbito ontológico, rechazando cualquier modo de articularse desde lo óntico, pues entiende que ello termina tan solo reinstalando lo vigente, es decir, sin lograr cambios sustanciales ${ }^{351}$. Aquél Ethos no

\footnotetext{
${ }^{350}$ Para un análisis contextual de esta expresión en Heidegger, véase Mörchen H. (1980):83-92.

${ }^{351}$ En parte, esto se debe a que se articulan en un lenguaje que los antecede, ligado a la tradición, en los casos en que ello prefigura el horizonte de llegada, sea por la matriz de lenguaje, sea por el campo semántico de inscripción. En este sentido podemos comprender la perspectiva de Heidegger en torno a la acción y la transformación directa en su camino del pensar: en todos los casos destaca el carácter provisional de sus estaciones y paradas.
} 
es sostenido por un ente cualquiera sino por el ser, es decir, por medio de su relación con el ser se determina correlativamente el vínculo respectivo con el ente. Con ello, impulsa la inauguración de una nueva relación con el ente y un nuevo modo de habitar en el mundo.

En suma, estas elaboraciones de Heidegger pueden entenderse como modos de seguir meditando el advenimiento de una nueva relación del hombre con el ser, el ente en su totalidad, con los otros hombres y consigo mismo, de modo tal que participe retroactivamente con el arribo de un nuevo Ethos. Aquí, su función de guardián es sede de los intentos de un pensar que, en colaboración, participan de las dinámicas para el advenimiento de un nuevo comienzo. No obstante, el carácter meramente transicional de estos intentos excluye toda propuesta de una ética concreta $u$ óntica.

Asimismo, la disposición afectiva fundamental que lo acompaña manifiesta la misma nota de entrega: nos referimos al respeto y la reserva, por los cuales se modula el proyectarse del Dasein, motivando una nueva relación con el ser. No obstante, el Ethos de respeto no remite a un disciplinamiento, referencia que lo tornaría ineficaz en una permanencia modal bajo una ética metafísica. En este marco, Heidegger entiende el Ethos fundado en una disposición afectiva, la cual modula las relaciones del hombre, de tal o cual modo, con el ente (GfF: 154[115]). Abordemos más en detalle este entramado.

\section{3. b.- Disposición afectiva y Ethos desde el destino del ser.}

Como hemos visto, en la transición hacia un nuevo comienzo del pensar el hombre debe experimentar, por el Ereignis, un cambio de esencia hacia el Dasein. En este marco, lo que importa para Heidegger no es tanto lo que se ha dicho sobre el ser, sino cómo se ha planteado la pregunta respectiva (cómo se trae al lenguaje el sentido del ser), y en esta modalidad el temple anímico se torna condición de posibilidad. Tal desplazamiento es posible a partir de la disposición afectiva fundamental, el respeto (Scheu) para luego articularse desde la reserva (Verhaltenheit).

No obstante, aquello que abre una disposición afectiva reside en el propio estar arrojado de modo tal que su apertura está confinada a la historia del ser y, en cierta medida, confiada al azar ( $Z u$-fall): no es un logro de la política ni del hombre, sino un favor del ser.

Podemos circunscribir aquí un desplazamiento: si en $S u Z$ la disposición afectiva o el encontrarse (Befindlichkeit) adquieren centralidad desde la analítica del Dasein, a partir de 1936 la considera desde del destino (epocal) del ser .La disposición afectiva fundamental sostendrá el otro 
comienzo, cuya preparación reside en la meditación sobre ello. Precisamente esto modula la nueva relación del Dasein con la totalidad del ente, que instaura un nuevo Ethos, determinando correlativamente el curso del actuar y el pensar.

Por un lado, subraya que las disposiciones fundamentales, en tanto modos de acomodarse nuestra conducta en relación al ente (en su ser), se destinan históricamente. A este respecto dedica parte de su escrito de 1955 donde indaga en la disposición de los inicios de la filosofía griega, el de la certeza cartesiana y el de la consumación de la filosofía moderna en el marco de la era atómica. Allí, destaca que el asombro dominó cada paso de la filosofía griega en el marco de una contención y retroceso ante el ente y su ser; luego, una nueva época se inaugura por medio de un temple ante la pregunta por el ser del ente: la duda cartesiana es desde donde se abre la disposición para el ente cierto, de modo tal que quede fijado para una subjetividad correlativa. Finalmente, la razón, la calculabilidad y planificación en la era de la técnica reciben su determinación (Be-stimmtheit) y disposición (Ge-stimmtheit) por el respeto ${ }^{352}$. Mientras las disposiciones del otro comienzo son soportadas por el ser, estas del primer comienzo, por su parte, son mantenidas por y desde el ente en la comprensión metafísica.

En estas elaboraciones subraya que las disposiciones se resisten a la articulación en el lenguaje debido a su carácter polivalente aunque, tal y como ocurre con su camino en la pregunta por el ser, pueden ser pensadas y exploradas sucesivamente en articulaciones provisorias. Puesto que su carácter de tránsito las torna indeterminadas, entiende necesario articularlas analíticamente. Entendemos que ello motiva las reelaboraciones terminológicas de tales disposiciones ${ }^{353}$.

En suma, con estas consideraciones de las disposiciones afectivas, poniendo el acento en la receptividad del Dasein, distingue que el Ethos se funda en ellas, lo que modula correlativamente el comportamiento del hombre respecto al ente. La reserva y el respeto forman principalmente la disposición unitaria fundamental del otro comienzo, con notas respectivas de humildad y recato, de un modo contrapuesto al Ethos de la devastación en la metafísica y la técnica. Estos aspectos que sus análisis develan, son anteriores al comportamiento ético-factico: actuar éticamente supone hacerlo desde y a partir de las disposiciones afectivas que orientan el Ethos respectivo. Por ello, estas se encuentran en la base y determinan la relación con el ser, siendo de este modo una parada ineludible en el camino del pensar transicional de Heidegger.

\footnotetext{
${ }^{352}$ Véase el análisis histórico de las disposiciones o temples anímicos en Heidegger (1955):22ss [57ss.].En este marco, por ejemplo, aquél que corresponde al estado de ánimo de la marcha por los caminos poéticos, es decir, el correlativo al pensar de transición: el respeto (Scheu), el cual es especificado en sus interpretaciones de Erläuterungen zu Hölderlins Dichtung (EHD:123 s. [145 s.]).

${ }^{353}$ En este marco, distingue entre disposiciones fundamentales y disposición rectora (Leitstimmung). (BPE: 395 s [317 s.]).
} 


\section{3. c.- Un pensar en su alteridad constitutiva.}

Con el abandono del apego al ente en pos de la verdad del ser, Heidegger caracteriza también la torsión (Verwindung) contra el desarraigo (Entwurzelung/Bodenlosigkeit) y falta de morada (Aufenthaltlosigkeit) que es lo característico del mundo de la técnica. Más específicamente, se trata aquí de dos torsiones: de la metafísica, respecto del olvido del ser, y de la ética, respecto al olvido y falta de reflexión respecto del $E t h o s^{354}$, desde lo cual es apropiado captar la esencia del ser del hombre, tal y como evidencian las torsiones de términos o palabras, como el caso de la ética:

"Hacer un juicio y afirmar no son, desde luego, comportamientos especiales del hombre, sólo algunos entre otros modos del comportamiento del hombre. Las formas de comportamiento del hombre desde su unidad en una actitud del hombre en el sentido del lugar de residencia en medio del ente, dicho sucintamente, el $\eta \dot{\eta}$ o $\varsigma$ del hombre, las analiza la ética. " (H: 222 s. [247 s.])

Así, cuanto más originaria se pone de manifiesto la esencia del habitar, más originario se revela el ser del hombre, de modo que una ética originaria remonta al lugar correlativo del habitar del hombre, mientras que una ética de valores aun se liga a su falta de morada.

En este marco, entendemos y distinguimos figuras de la alteridad que se hallan implícitas en esta ética originaria, lo cual manifiesta ciertas continuidades con la consideración del Dasein propio de sus primeros trabajos. Específicamente, hemos visto que la articulación y comprensión sobre la que se despliega, se encuentra siempre posicionada respecto a la ética en su vertiente metafísica y su campo semántico. Con ello, Heidegger evidencia mantenerse en la misma orientación respecto del carácter co-originario del ser-con y el Dasein, que aquí se torna explicito en su tratamiento del lenguaje articulado: un pensar y un decir que precisa hacerlo a partir de la ética metafísica para participar en el desocultamiento de un plano más originario, al cual se remite necesariamente desde tal punto de partida.

Asimismo, el otro como alteridad que toda ética supone (incluso originaria), podemos circunscribirlo aquí en el horizonte del otro comienzo, puesto que la transición remite a: otro pensar, otro modo de relacionarse con el ente, con el ser, con el sí-mismo y con el habitar en general, correlativo con otro horizonte de lo sagrado (el último dios) y otra comunidad de Dasein

\footnotetext{
${ }^{354}$ Aquí distingue una omisión estructural de la metafísica : "El habitar no experienciado como el ser del hombre ; el habitar no se piensa nunca plenamente como rasgo fundamental del ser del hombre" (VA:142[109])
} 
(los venideros). Es una alteridad en la preservación, en el respeto, la cual, sin descuidar el carácter proyectivo del Dasein, prepara un tránsito que repercute en la facticidad histórica.

Es por ello que también podemos articular relaciones entre estas elaboraciones y la consideración de la ipseidad, a partir de su articulación en y con el discurso. En esta línea, finalizaremos este capítulo, retomando algunos resultados de nuestro recorrido, para argumentar en torno al estatuto y posibilidad de tal figuración y articulación.

\section{4.- Aproximaciones a la ipseidad y la alteridad en el lenguaje.}

En este complejo múltiple que articula: claro-ser-disposición afectiva-Ethos-Logos-Dasein se torna evidente que el papel del existente humano en estas dinámicas de ningún modo puede ser determinante, sino más bien secundario y colateral. Incluso el retorno a sí del Dasein, su mismidad e ipseidad, ya no es posible asociarlo de modo encapsulado por fuera de esta constelación dinámica y simultánea.

Es decir, el carácter mediado de la mismidad pone en evidencia su co-dependencia dinámica, así como también borra toda nota voluntarista o propias de la filosofía de la conciencia que aún puedan interpretarse o desprenderse de la articulación en el lenguaje realizada en la analítica del Dasein de la época de $S u Z$.

En este marco, hemos retomado la constelación dinámica y simultánea de la co-pertenecia Ser-Dasein, a partir de los nexos prácticos y perspectivas éticas : el abordaje heideggeriano del mundo de la técnica con su diagnóstico de época ;las posiciones/roles en dinámicas de desplazamientos posibles o aperturas al por-venir; la ética originaria; la cuestión de la disposición afectiva fundamental; las modalizaciones del pensar en su matriz de alteridad, considerando previamente su posicionamiento político alrededor de 1933 y algunas polémicas respectivas, entre otras cuestiones.

En tal contexto de elaboraciones, por la vía de la meditación, del pensar y su articulación en el lenguaje el existente humano participa/colabora/se entrega de modo periférico y relacional en un nuevo destino del ser, cuyo tránsito mantiene una dirección hacia un horizonte no calculable. La singular bidimensionalidad en la comprensión de la actividad-pasividad en estas elaboraciones, nos permitió nuevamente dar cuenta del carácter de condición de la terminología y semántica de la tradición metafísica, para una transición posible al otro comienzo del pensar. 
En efecto, también aquí hemos argumentado que la dinámica que se manifiesta en las reflexiones de Heidegger es correlativa al modo en que se articula su discurso. Partiendo de un lenguaje no esencialista, su decir pivotea en dirección al otro comienzo, desde el lenguaje de la tradición hacia su torsión, sin paradas definitivas y con términos no clausurables, permitiendo delimitar umbrales en los campos semánticos, en una dinámica impulsada por y en la propia marcha del decir. Asimismo, si el lenguaje es la casa del ser y el habitar del hombre reside en él, entonces la atención a la vía del lenguaje se torna fundamental.

En este sentido, entendemos que el carácter mediado de la mismidad en esta etapa de sus elaboraciones, deriva en la consideración de una ipseidad en y por el lenguaje, de la que el discurso de Heidegger se ofrece como figura. Por ello sostenemos que el carácter co-originario del ser-con se halla figurado en la tensión entre el lenguaje de la metafísica y el horizonte del otro comienzo desde la superficie discursiva desplegada, de modo tal que Heidegger solo puede ensayar otro decir, desde el decir con el que cuenta ${ }^{355}$.

Específicamente, si la mismidad del Dasein no tiene consistencia definitiva, incluso su corporeidad y sexualidad son derivadas de su complejo co-originario, entonces se torna relevante desplazar su inscripción hacia un campo asociativo, aunque sin descuidar los caracteres implícitos de la metafísica de la subjetividad (cuando es asociado, por ejemplo, a cuerpos, grupos, posiciones subjetivas, etc.). Asimismo, si la mismidad se determina desde la copertenencia con el ser, en tanto mediada, y este se abre en el claro o fondo que se articula en un decir dinámico y no clausurable, entonces el más relevante (y siempre provisorio) sostén de la mismidad/ipseidad reside en su articulación en el lenguaje. Es decir, ¿desde donde retorna a sí el Dasein, en su proyectarse hacia el otro comienzo, si no es desde la meditación articulada y desplegada en un lenguaje? En este sentido, la otredad o alteridad que se manifiesta en el lenguaje es radical e irreductible.

Desde estas interpretaciones podemos comprender que todas las notas de los temples anímicos, el pensar y las modalidades del otro comienzo o el nuevo destino del ser, llevan inscriptas los trazos o marcas del lenguaje y las relaciones con el ser de la tradición: como vimos, son modalidades o notas contrapuestas, se inscriben por negación o contraposición en el mismo campo semántico. Esto plantea continuidades con la insuperabilidad definitiva del ser-con: aún en una

\footnotetext{
355 Desde estas elaboraciones y en una línea derrideana, interpretamos que una perspectiva y un discurso contemporáneo con orientaciones no-metafísicas, que no atienda suficientemente al lenguaje del que se opone , como punto de partida y superficie para estas dinámicas, incluso si lo rechaza de plano, probablemente termine deslizando la consistencia provisoria y precaria alcanzada en el lenguaje/discurso, hacia estratos o conceptos determinados e, incluso , hacia el hombre desde nuevas modalidades de centralismo (sea al yo de la enunciación, del enunciado o a la representación de sí) con lo cual reinstalaría su discurso con mayor profundidad en la comprensión de la metafísica de la subjetividad.
} 
nueva época del ser y sus modos de co-pertenencia con el hombre, se halla implícito el campo semántico de partida.

Por ello, entendemos que si bien después de 1930 Heidegger no tematiza explícitamente la cuestión de la ipseidad, su discurso la figura implícitamente: los desplazamientos y articulaciones en el marco político de 1933; su silencio inmediatamente posterior y su decir dinámico; las resonancias semánticas con la tradición e identidad alemana y sus re-elaboraciones ${ }^{356}$, pueden comprenderse en el marco de este tránsito de un sí-mismo que rechaza toda cristalización cósica o acabada, en una dinámica con filiaciones semánticas ineludibles.

En suma, una mismidad, o mejor, una ipseidad que se despliega en el lenguaje se manifiesta móvil y dinámica, más aun si su trasfondo originario es el habla (Rede) la cual, como veremos, no se halla reducida a las articulaciones lingüísticas, semánticas y sintácticas concretas. En el contexto de estas lecturas e interpretaciones, proponemos detenernos y sistematizar exclusivamente las reflexiones de Heidegger sobre el lenguaje, las cuales hemos puntualizado aisladamente a lo largo de estos capítulos. De un modo paralelo, buscaremos caracterizar las notas y modalidades especificas de su propia articulación en el lenguaje, cuestiones que nos conducen a nuestro próximo capítulo.

\footnotetext{
356 En esta línea interpretativa podemos inscribir algunos de los trabajos de Adorno en lo que respecta a las vinculaciones semánticas del pensamiento de Heidegger y la tradición alemana, en sus trabajos sobre el rastreo de manifestaciones excéntricas de su pensar. Entre otras, rastrea el concepto de fundamento o suelo en la situación alemana del período de entreguerras, desde donde distingue el origen agrario de los conceptos utilizados por Heidegger (especialmente en sus textos de 1933-1934) en el marco de la idealización de las figuras de la vida provinciana y la búsqueda del origen absoluto. El intérprete entiende que estas asociaciones le imponen juicios de valor sociales. De este modo, el autoctonismo se manifestó como una figura conductora de su pensar, en tanto representación que procede de la sociedad. Por ello , la base social se hallaría en el trasfondo de la tendencia segregacionista y jerárquica de su pensamiento, así como también el ideal del origen encubriría un subrepticio posicionamiento subjetivo, como argumenta en este fragmento : "Lo engañoso del ideal arcaico de los orígenes ... se confirma porque no podemos comportarnos con las cosas como si tuviéramos con ellas una inmediatez pura y antigua en un mundo totalmente mediado y con unas cosas mediadas hasta lo más intimo por este mundo(...)el pensamiento arcaico no es susceptible de reproducción . El engaño del origen como ideal radica en que algo, que según su sentido propio es irreproducible, algo que debe todo su pathos y su fuerza a su propia irreproductibilidad, es tratado como si procediera de modo inmediato de la subjetividad, la libertad, la nostalgia y la arbitrariedad del pensador."(Adorno, 1983:127 s.). En tal desplazamiento se hallaría este posicionamiento subjetivo pues entiende, en línea con las elaboraciones heideggerianas, que la mediación del mundo irrebasable es incompatible con la idea de un origen "puro". En la misma vía de interpretación elaboró un análisis respecto a la jerga de autenticidad en esta época, en tanto síntomas del fascismo en la lengua que precede a Heidegger y en la cual se inscribe su pensar, véase Adorno (2005): 424 ss. De este modo también supone inescindible el análisis de la constelación contexto-discurso-pensamiento en la obra de Heidegger.
} 


\section{Capitulo 7 .Elaboraciones sobre el lenguaje en el pensamiento de Heidegger}

En los capítulos anteriores hemos distinguido, de modo disperso, diversas características de la concepción sobre el lenguaje en el pensamiento de Heidegger, así como también comenzamos a delimitar la propia operatoria discursiva que este realiza, en el decurso de sus elaboraciones. Con ello quedó manifiesto el carácter dinámico del discurso y la enunciación para nuestro autor, tal y como figura en el desarrollo semántico de términos y estructuras correlacionadas, desplazamientos relacionales y del valor entre términos, etc.

Sin embargo, el conjunto de proposiciones conclusivas del capítulo precedente, en las cuales distinguimos conexiones entre la ipseidad y el lenguaje, permitió destacar que su propio discurrir discursivo se ofrece como una figura para tal tratamiento. De esta manera, nos vemos conducidos 
nuevamente a distinguir entre sus reflexiones y el modo en que las despliega, para poder dar cuenta de tal perspectiva, otorgándole una mayor sistematicidad.

Específicamente, el desarrollo de la cuestión de la mismidad del Dasein en la analítica en torno a $S u Z$, dio cuenta del carácter proyectivo, de su ineludible caída en el Uno y de su posibilidad de recuperación, entre otras cosas, de un modo simétrico al propio pensar y decir de Heidegger, quien por la vía de la tradición metafísica se propone colaborar para su torsión, en vistas a la transición hacia un nuevo comienzo para el pensar y una relación apropiada con el ser.

Para seguir argumentando en base a estas interpretaciones, dedicaremos este capítulo a un análisis y vinculación especifica del tratamiento del lenguaje de/en Heidegger, con el objeto de precisar relaciones entre tal perspectiva, la consideración de la ipseidad y la alteridad, y su propio despliegue discursivo. En esa línea, primero retomaremos con mayor especificación, la perspectiva explícita sobre el lenguaje en la década de 1920 que se cristaliza en $S u Z$, poniendo de relieve su crítica a la recepción moderna del Logos (entendido como razón), su consideración del carácter originario de la comprensión (Verstehen) e interpretación (Auslegung) y la distinción respectiva entre Lenguaje (Sprache) y Habla (Rede), considerando a éste último como existenciario del Dasein. Luego, desarrollaremos sus consideraciones del lenguaje como casa del ser, en trabajos posteriores a 1930, donde deja de lado los tratamientos existenciales de la analítica anterior para abordar de lleno los aspectos formales y ontológicos, en camino a una aprehensión intuitiva del Decir originario, evidenciando que el énfasis y la perspectiva también en estos tratamientos comienza a posicionarse desde el Ereignis y los ámbitos co-originarios respectivos ${ }^{357}$.

En segundo lugar propondremos una puntualización de la modalidad discursiva y enunciativa de Heidegger, a partir de los seminarios y escritos considerados anteriormente lo cual, sin pretensiones de exhaustividad, nos permitirá delimitar con mayor precisión su modo y tratamiento de términos, relaciones, campos semánticos, modulaciones y resonancias, en vistas a su propuesta transicional hacia un nuevo pensar y decir del ser de la cual, como vimos, tan solo puede co-participar de modo lateral, en el marco de una historia del ser que acontece más allá de los marcos de una conciencia rectora.

Finalmente, retomaremos las consideraciones sobre la ipseidad con el objeto de cotejar con tales desarrollos, para especificar y respaldar esta distinción de la mismidad mediada en y por el

\footnotetext{
${ }^{357}$ Específicamente, en estos dos tramos de análisis de su perspectiva sobre el lenguaje, nos detendremos en los siguientes trabajos: Ontologie. Hermeneutik der Factizität (1923) (OHF); Einführung in die phänomenologische Forschung (1923-4) (EPhF); Logik. Die Frage nach der Wahrheit (1925-6)(LFW); Sein und Zeit(1927a)(SuZ); Die Grundprobleme der Phänomenologie(1927b)(DGPh) ; Beiträge zur Philosophie (Vom Ereignis) (1936-8)(BPE); Vorträge und Aufsätze (1936-53)(VA); Brief über den Humanismus (1946)(BH);Unterwegs zur Sprache (1950-1959) (US)y Überlieferte Sprache und technische Sprache(1962b)(UStS), entre otros.
} 
lenguaje, figurando tanto en el pensamiento de nuestro autor, como en su modulación discursiva. Comencemos, entonces, con nuestro recorrido por las reflexiones y elaboraciones respectivas.

\section{1.- El lenguaje en la época de $S u Z$.}

Alrededor de su publicación de $S u Z$, Heidegger desarrolla la noción de Habla como modo originario de apertura que pertenece a la estructura del Dasein. Sus trabajos después de 1930 radicalizan los resultados de aquellas elaboraciones, orientándose a la esencia del lenguaje como ámbito originario respecto a las relaciones entre el Dasein y el ser. En este desplazamiento se torna necesario precisar cuál es el estatuto de la inscripción del lenguaje en la estructura del Dasein, para dar cuenta de tal radicalización posterior.

En efecto, en las elaboraciones del ciclo de SuZ insiste en la tematización y reconsideración de la recepción del Logos por la tradición metafísica moderna, la cual desplazó su significación originaria donde pronunciaba simultáneamente el nombre para ser y decir. Dicho término es asimilado por nuestro autor al ser, al tiempo que se articula en el existir del Dasein. En esta línea de significación, al subrayar que el Habla es constitutivo del existir, la apertura determinante del ser del Dasein se manifiesta como su correlato originario. Con ello presenta las primeras líneas que anticipan la consideración de la subordinación del lenguaje humano al Decir originario del ser.

Con estos elementos, en parte, despliega la siguiente etapa de sus elaboraciones: el lenguaje entendido como casa del ser en la que mora el Dasein. Desde aquí, reencontramos el énfasis que establece respecto a la consideración Dasein-ser, pues se desplaza del hombre al lenguaje: aquél puede hablar porque es oyente del silencioso decir del ser .Desde aquí, su interés recaerá en la poesía, en tanto modalidad de pensamiento y del decir, donde resuena aquél lenguaje originario, en el que el ser se deja decir más apropiadamente.

De esta manera, el lenguaje es entendido como una función de apertura que posibilita la verdad (comprendida como des-ocultamiento del ser), en el marco del vinculo entre hombre y ser. Es por ello que podemos distinguir que la consideración de la analítica también apunta a su relación con el ser más que a su existir óntico, de modo tal que abordar la constitución ontológica del Dasein implica ineludiblemente dar cuenta de su condición de hablante. En este marco, la formalización creciente de sus análisis, con prioridad en los ámbitos ontológicos originarios pueden comprenderse no solo como una profundización de sus elaboraciones, sino también como el resultado y la consecuencia de la propia relación del discurso de Heidegger en el camino a la pregunta por el ser, 
que lo exhortan a profundizar tales perspectivas. Abordemos pormenorizadamente estas interpretaciones, considerando el entramado complejo en el que se articulan la comprensión, interpretación, el sentido y las significaciones frente a la perspectiva instrumental del lenguaje, de la tradición metafísica, la cual se caracteriza por una reducción al enunciado o lenguaje lógicoproposicional.

\section{1.-a.- Hacia un ámbito antepredicativo.}

Estos primeros abordajes de la relación del lenguaje con el ser toman como punto de partida la herencia temática respectiva ${ }^{358}$ para luego enfatizar la preeminencia el tratamiento del Dasein en su apertura originaria, debido a su reformulación de la fenomenología y la facticidad como su punto de partida. Desde allí, la importancia de recuperar la noción griega de Logos lo conduce a entender como derivado el carácter lógico- gramatical del lenguaje/discurso (Sprache) respecto al fenómeno originario de apertura del Habla $(\text { Rede })^{359}$.

Desde estos trabajos tematiza el lenguaje desde su función de apertura de mundo en diálogo con la tradición que deriva de Humboldt, Hamann y Herder ${ }^{360}$. Puntualmente, tal distinción la realiza a partir de tres modos de apertura co-originarios: el encontrarse (Befindlichkeit), el comprender y el Habla. Precisamente en este contexto es donde recupera el sentido originario de Logos, destacando aquello que hace de la existencia el lugar del sentido, pero desligándolo de la estructura meramente proposicional, al aplicarlo al ámbito antepredicativo y prereflexivo, en el cual se fundan los modos de relación con el ente (DGPh: 319[273]). Esta distinción de planos, como veremos, se torna relevante al momento de cotejar la propia relación de Heidegger con el lenguaje en su discurso.

\footnotetext{
${ }^{358}$ Véase, por ejemplo, el trabajo de habilitación en KBS: 189-410. Allí encontramos un abordaje de la consideración metafísica sobre el lenguaje en su vínculo con el ser de la doctrina de la significación en Duns Scoto.

${ }^{359}$ Tal distinción, se halla expuesta en SuZ: 148-68[172-90] .En los sucesivos trabajos, Heidegger también utiliza el término para referirse al lenguaje en forma general (incluyendo la dimensión originaria), distinguiéndolo de su dimensión fonética y enunciativa. A continuación, cuando utilicemos el término lenguaje en consonancia con el Habla, aclararemos el término entre paréntesis; cuando lo hagamos en su dimensión lógico-proposicional derivada, será sin aclaración respectiva. Para la traducción de Rede por Habla (y no por discurso) seguimos aquí las distinciones en Adrian (2009):140 s.

${ }_{360}$ A este respecto , por ejemplo , véase Humboldt (1990):52-9;66;74-89;272s.;Herder(1982):149-165;174-95;196-207; 369-421 (Cf. Hamann,1994:36-44).
} 


\section{1. a.I- La perspectiva instrumental de la tradición metafísica}

Hemos visto que plantea la cuestión del sentido del ser, a partir de su articulación enunciativa y de su comprensión e interpretación, desde lo cual subraya una mutua pertenencia de ser y lenguaje $\mathrm{j}^{361}$. Ya desde sus primeros trabajos, rechaza las consideraciones del ser tal como aparecen en la fenomenología de Husserl, donde es comprendido de un modo atemporal y estático. Asimismo, se contrapone a la tradicional reducción al ámbito de lo proposicional, donde se cristalizó la identificación de verdad y proposición, considerándose a esta última como la sede de la articulación del sentido y a la verdad como determinada a partir la adecuación entre proposición(o juicio) y cosa (LFW: 8-11[17-9]).

Frente a ello, su búsqueda se encamina al horizonte más originario de la esencia del lenguaje, pues entiende que aquella comprensión tradicional dificultó u obstaculizó su aprehensión, bajo el supuesto de distinción entre un estrato ideal y otro real del ser, aún en el pensamiento de Husserl $^{362}$, el cual condujo a considerar el lenguaje como instrumento o medio para la nivelación de tales estratos (Ibíd.: 57-62[54-8]).

A partir de los resultados de su recorrido, el lenguaje se revela más bien en su carácter de apertura de mundo, pues participa previamente de la constitución del ente. Así , nuevamente encontramos una operación del pensar de Heidegger : el rechazo de toda reducción metafísica a la presencia ( en este caso, el enunciado o proposición) en pos de fenómenos más originaros que remiten a su esencia o verdad, evidenciándose como condición de posibilidad de aquellas. Despleguemos tal operación.

\footnotetext{
361 En detalle: el ser se despliega en /por el lenguaje, al tiempo que éste abre a la manifestación de los entes al mundo desde sus nexos de significatividad, lo cual requiere la donación del ser. En este marco, un intérprete desarrolla la consideración no metafísica de la cercanía (Nähe) como la modalidad especifica de esta co-pertenencia ser-lenguaje (y de la pertenencia mutua en general en todas las elaboraciones de Heidegger), significando con ello una mutua apropiación de lo diferente, en el contexto de una relación acontecimental donde ambos se pertenecen, véase Rocha de la Torre (2007):76-84.Cf. US: 118 s. [113-5]. Estos análisis profundizan la consideración del estatuto acontecimental en los desarrollos de nuestro autor, lo cual supone no solo una reelaboración del concepto de relación (Bezug), respecto a la perspectiva causal o dialéctica de la tradición metafísica, sino también una orientación y modulación general del pensar.

${ }^{362}$ No obstante, sus elaboraciones plantean una clara continuidad con la perspectiva respectiva en la fenomenología de su maestro, en lo que respecta a la independencia del sentido (Sinn) de la dimensión lingüística, aunque Husserl lo articule desde el paradigma perceptivo. Para un análisis comparativo al respecto , en el marco de discusiones actuales , véase Bedoya Rodas(2014b):237-42
} 


\section{1. a.II- Una aprehensión originaria del Logos.}

En efecto, en estas elaboraciones parte del factum del sentido en relación con la comprensión, priorizando un análisis de la deriva metafísica del término Logos, entendiéndolo como aquel que hace del Dasein el lugar del sentido ${ }^{363}$. En una mirada retrospectiva, Heidegger distingue tal prioridad debido a que sus intentos para referirse al lenguaje develaron la carencia de las palabras adecuadas y correlativas con una experiencia primaria del mismo ${ }^{364}$.

La consideración de aquella acepción originaria es retomada en $S u Z$, al momento de abordar estructuras tales como el comprender, la interpretación y el enunciado. En este contexto interpreta al lenguaje en su carácter desocultador, apuntando así a un modelo de verdad prerreflexiva: Logos implica relación con el ser, pues remite a un hablar que hace patente, descubriendo de inmediato el ente y al Dasein, respecto al cual la síntesis predicativa y el discurso enunciativo son estructuras derivadas (SuZ: 32-4[55-7]; 159-61[182-5]) $)^{365}$.

Específicamente, aborda dicho término como fue entendido en el pensamiento presocrático, remitiéndose a la significación original de Légein como un decir desde y donde las cosas se muestran, asociado con un colocar que recoge algo presente, al tiempo que se recoge en sí. A partir de esta significación, en el comienzo del pensamiento griego experimentaron el decir y hablar como légein, en referencia al dejar estar y reunir lo que se desoculta y se pone como presente. En esta experiencia, se manifiesta la dinámica de develamiento, presencia y ocultamiento o retracción que coinciden con una experiencia del ser y del ente, apartándose de la tradicional reducción a la mera presencia (Ibíd.: 219-26[239-46]) ${ }^{366}$. Así entendido, es precisamente en el lenguaje donde se da la verdad originaria y la experiencia del ser, tornándose innecesario distinguir, en el campo semántico de este término, el lenguaje de la razón (en su remisión a lo objetual y a la conciencia) o su dimensión fónica, tal como ocurrió en la recepción metafísica moderna ${ }^{367}$. A partir de aquí se encamina a la consideración de un ámbito antepredicativo que es coextensivo a esta significación originaria.

\footnotetext{
${ }^{363}$ Específicamente, sostiene:"Sentido es aquello en lo que se muestra la comprensibilidad de algo. Sentido es lo articulable en la apertura comprensora (...) el sentido debe ser concebido como la estructura existencial-formal de la aperturidad que es propia del comprender. El sentido es un existencial del Dasein, y no una propiedad que adhiera al ente, que esté 'detrás' de él o que se cierna en alguna parte como 'región intermedia'" (SuZ: 151[175]) Con ello subraya un desplazamiento desde el supuesto de una dimensión ideal del sentido, aun vigente en la fenomenología de Husserl, hacia su articulación irreductible en la facticidad de la vida.

${ }^{364}$ Véase, US: 94-6[91-3].

${ }^{365} \mathrm{Cf}$. Con sus análisis en torno a la verdad vinculada al Logos como proposición, en LFW: 143-94. [119-58.].

${ }^{366}$ Cf. Ibíd. : 191-5[156-9].

${ }^{367}$ En próximos apartados, retomaremos la consideración heideggeriana del Logos, frente al énfasis puesto en la modernidad en su aspecto fónico.
} 


\section{1. a.III.- Originariedad y desvíos de la comprensión.}

En este contexto, elabora un análisis de la estructura del comprender en su carácter de originariedad. Si la primaria desocultacion del Logos hace posible la síntesis proposicional, entonces puede darse Habla/lenguaje (Rede) sin la mediación del discurso/lenguaje enunciativo (Sprache), es decir, la intuición respectiva puede no ser explicita proposicionalmente, situándose en aquél ámbito originario. Aquí, como en el caso anterior, Heidegger desarrolla una aprehensión intuitivo-dinámica, sin reducirse al plano proposicional o judicativo.

En este marco, distingue ámbitos antepredicativos correlacionados según su carácter de mayor originariedad : primero, la comprensión (Verstehen) ; luego, la interpretación (Auslegung) como articulación de una comprensión ya abierta y finalmente, el Habla como expresión o explicitación de una interpretación. Solo a partir de la apertura de estos planos originarios, el enunciado puede mostrar, determinar y comunicar aquella explicitación. De este modo, no solo destaca el carácter derivado del enunciado y la proposición, sino también especifica su operación de modalización del ente que determina y comunica. Desarrollemos estas relaciones derivadas en el marco de la analítica en $S u Z$.

En primer lugar, distingue que antes de cualquier enunciación de lo que un ente es, ya lo comprendemos de algún modo en su ser. Tal comprensión se da o abre previamente a toda tematización específica o reflexiva del ente en cuestión. Más aún, en la facticidad, el trato con las cosas, con sí mismo y con los otros Dasein pone de manifiesto que ya se halla abierta una comprensión respectiva la cual, o bien permanece velada, o bien olvidada. Es en este marco en el que se inscribe su tentativa de retomar la pregunta por el sentido del ser, con atención a la diferencia ontológica, pues puede darse , por ejemplo, una comprensión previa que es propia del ser del ente , pero figurando en la comprensión del ser de los otros Dasein . Por estas consideraciones y desvíos, entiende necesario explicitarla en una articulación conceptual, para clarificarla y transitarla desde este carácter ya dado en el trato circunspecto del Dasein (Ibid.:143-8[166-72]).

En segundo lugar, destaca la interpretación como ámbito de elaboración de las posibilidades proyectadas y abiertas en el comprender. Este carácter derivado y correlativo le permite subrayar que la interpretación, al fundarse siempre en un haber previo (Vorhabe), como trasfondo en el cual 
se dan maneras sedimentadas y previas de entender (Vorgriff) y ver (Vorsicht), subyace estructuralmente a toda visión inmediata de los entes (Ibíd.: 148s. [172s]) ${ }^{368}$.

Por la vía de esta diferenciación, reconoce que la interpretación cotidiana en la que ya estamos inmersos evidencia elementos $\mathrm{u}$ orientaciones tradicionales que ocultan, desfiguran o enmascaran la comprensión inmediata de la situación. Es precisamente el suelo fáctico de la vida y el carácter originario de la comprensión la piedra de toque a partir de la cual Heidegger puede distinguir tales inadecuaciones.

Por ello, apela metodológicamente a un desmontaje (Abbau) o destrucción de tal interpretación en su ensamblaje articulado, para develar así la comprensión originaria ${ }^{369}$. En detalle : procede apropiándose conceptualmente de aquella comprensión ya abierta, a partir de una interpretación de la cotidianidad del Dasein, desmontando elementos y conceptos de la tradición que desplazan tal originariedad de la experiencia fáctica ${ }^{370}$. Este procedimiento lo refiere como una clarificación de la situación hermenéutica, pues permite revelar presupuestos que siempre-ya rigen en la interpretación cotidiana, suponiendo así que no hay interpretación pura y originaria inicial que se muestre exenta de ello, o de un modo más general, que la alteridad irreductible de la cotidianidad es el punto de partida ineludible de la facticidad. Así, apropiándose del horizonte ya dado de sentido, la tarea hermenéutica se aplica luego a desmontar los conceptos en el precomprensión respectiva retomando su origen.

En tercer lugar, distingue el Habla como el ámbito de explicitación de una interpretación y como dimensión previa a toda operación comunicativa o de expresión. Así, el sobre-qué del Habla ya se encuentra orientado desde una perspectiva y comprensión, es decir, la explicitación es siempre derivada de una comprensión abierta que incluye el sobre-qué y lo dicho específicamente en cuanto tal (Ibid.:162s. [185s.].

En el marco de estas dimensiones antepredicativas y la tarea de desmontaje en la analítica , especifica que el comprender es un inmediato contacto con el ente del cual derivan las dimensiones

\footnotetext{
${ }^{368}$ Con más detalle , Heidegger distingue una triple estructura de la interpretación: a) la manera de entender previa (Vorgriff), es decir, aquella con la que contamos primariamente en nuestras interpretaciones cotidianas; b) el haber previo (Vorhabe), el cual remite al horizonte de sentido ya dado que permite una aprehensión súbita de la situación y de los entes ( que no podemos enunciar de forma completa) y c) la manera previa de ver (Vorsicht), aquella que recorta lo dado en el haber previo en el marco de una interpretabilidad, de modo tal que se articula con las anteriores en el trato circunspecto del Dasein. Véase, OHF: 14-9[32-8] y SuZ: 150-2[173-5].

${ }^{369}$ Por medio de la cual también investiga el origen de las categorías .En este marco, sostiene que dentro de la fenomenología no es suficiente referirse solo a un entregarse a las cosas, pues esta todo cargado con prejuicios. El ir a las cosas mismas requiere así un desarrollo del ver y una investigación fundamental (EPhF: 275[274]) dirigida a la historia del origen de las categorías tradicionales, que no es otra cosa que la historia del lenguaje en su dimensión enunciativa.

${ }^{370}$ En este marco, Adrian distingue una continuidad parcial con la fenomenología de Husserl, respecto del concepto de reducción y la actitud natural, con este modo heideggeriano de cancelar los presupuestos de la tradición. Véase, Adrian (2009):68.
} 
de explicación (Erklärung) (que permite el desarrollo y explicitación del comprender) y el enunciado (Aussage), sustituyendo con esto el modelo perceptivo paradigmático de las filosofías de la conciencia. Estas vivencias e interpretaciones se expresan en estructuras significativas, al tiempo que atraviesan toda nuestra cotidianidad. Así, la interpretación pone de manifiesto lo ya dado de las estructuras significativas del mundo, es decir, elabora de un modo más específico aquello yasiempre-abierto en la comprensión.

En suma, de un modo sucinto podemos distinguir los siguientes pliegues en su originariedad, a partir de aquellas distinciones: el enunciado articula una determinación del Habla sobre tal o cual interpretación, la que elabora una comprensión ya abierta. Desde aquí, el carácter derivado de los enunciados le permite contraponerse a las respectivas elaboraciones tradicionales ${ }^{371}$.

\section{1. a. IV.- Consideraciones sobre los enunciados.}

En efecto, en estas elaboraciones Heidegger desarrolla una crítica a la perspectiva tradicional del enunciado o la proposición como lugar de la verdad .Como vimos, siempre se haya abierta una estructura formal más originaria que el enunciado: la comprensión, interpretación y el Habla son anteriores en el acceso al ente, circunscribiendo el ámbito donde se sitúa originariamente la dinámica de la verdad. Más aún, el enunciado es una relación con el ente caracterizada por una tendencia a modalizar su entendimiento respectivo, lo cual le permite a nuestro autor distinguir en este estrato la orientación tradicional al cálculo y la dominación en las relaciones del hombre con el ente. Especifiquemos estas puntualizaciones.

En aquél ámbito antepredicativo, el sentido queda inscripto en la facticidad sin suponer ya un estrato de idealidad o atemporalidad, pues se articula con la existencialidad del Dasein a quién la interpretación le pertenece como estructura (Ibíd.: 160[183]). Es por ello que Heidegger subraya que el Dasein es en sí mismo significante: vive en/desde un entramado de significaciones y se puede expresar como tal, por medio de proposiciones o enunciados (LFW: 150-3[125-7]).

Desde estas elaboraciones en torno a la significación, Heidegger distingue la estructuracomo (Als Struktur) que regula la articulación entre la interpretación y el comprender. Asimismo, destaca que al enunciado manifiesta una dependencia y derivación de la interpretación (SuZ: 154 [177]). Con ello, nuestro autor pone en evidencia un saber previo que ya se halla implícito en toda determinación proposicional o enunciativa.

\footnotetext{
${ }^{371}$ Para los desarrollos respectivos, véase SuZ: 154-68[177-90].
} 
Más en detalle: la estructura-como subyace a la proposición y está en la base de la significación, al tiempo que marca el ámbito desde donde se da el sentido de un ente. Ello se debe a que remite a un saber previo y modo primario de apertura al ente, el cual se inscribe en la familiaridad del ocuparse (Besorge) en el trato de la circunspección (Umsicht) del ser-en-el-mundo. En otras palabras, esta estructura orienta la apertura del mundo para que los entes se den en el trato circunspecto del Dasein. Así, siendo anterior a toda tematización determinada, por ejemplo, permite distinguir que el para-qué ( Wozu) de los entes da cuenta de un significado en relación al uso que le damos. Esta estructura primaria del ámbito significativo se inscribe en el trato circunspecto, por el cual el Dasein interpreta algo como algo (Etwas als Etwas), permitiendo reconocer un saber antepredicativo implícito en esta familiaridad con lo que lo rodea. En suma, el para-qué (del ente a la mano) explicitado en la comprensión, tiene tal estructura primaria del algo en cuanto algo (Ibíd.: 149s. [172s.]) $)^{372}$.

Por su parte, el enunciado se determina cuando nivela la interpretación primaria y la comprensión ya abierta, desde tres dimensiones: 1)la indicación (Aufzeigung) del ente que se habla, en referencia a un descubrimiento del ente desde sí mismo en lo ya abierto de la comprensión, es decir , una patentización inmediata donde aún no se afirma o niega, en el marco de una relación inmediata con la estructura-como; 2) la predicación (Prädikation) que se fundamenta en la primera, la cual hace referencia a las determinaciones y pone en evidencia que la estructura del juicio implica una modificación de la estructura-como : orienta la patentización desde tal o cual perspectiva, reduciendo su contenido a mostrarse en tal determinación y, 3) la comunicación , la cual supone la estructura del ser-con al expresar lo patentizado(indicación) y determinado (predicación) del ente, abriendo así un acceso común a este. Es precisamente en esta dimensión comunicativa donde Heidegger da cuenta de la palabra escrita o hablada (Ibid.:154-6[178-80]).

Así, el enunciado deriva de la interpretación desde el siguiente proceso: el ente en el haber previo se manifiesta primariamente como útil. Al determinarse enunciativamente se produce un desplazamiento en tal haber previo, modificándose el "en cuanto" ( $A l s)$ del ente en la interpretación, es decir, se determina como estando de tal o cual modo en su estar-ahí (Ibíd.: 61s. [87s.]; 158[181]; $218[238])^{373}$. Estas especificaciones, nos permiten subrayar algunas consecuencias.

Por un lado, el pasaje de la indicación a la predicación, desprende al ente del conjunto de remisiones en el trato circunspecto del ser-en-el-mundo del Dasein, al punto que deja de

\footnotetext{
${ }^{372}$ Respecto al análisis del ser del ente en el mundo circundante y como útil, véase Ibíd. :67-72[94-9])

${ }^{373}$ Desde aquí, destacamos otras distinciones desarrolladas en SuZ: a) cuando la interpretación comprende algo como algo, en una proposición que se inscribe en un horizonte de significatividad de la interpretación circunspecta, Heidegger lo denomina en cuanto o cómo hermenéutico (hermeneutisches Als), destacando su carácter más originario; b) Cuando el enunciado derivado de ello expresa y modaliza ese algo, es lo que denomina en cuanto o cómo enunciativo o apofántico (apophantisches Als) (SuZ: 158[181]).
} 
comparecer como útil. Ello implica que el enunciado judicativo, en su desplazamiento respecto a la patentización o momento apofántico de manifestación del ente, ya no puede ser inscripto en el marco que entiende la verdad como adecuación a la cosa. Esto se debe a que tal desplazamiento es correlativo a cierta separación del ente en su remisión del trato circunspecto del Dasein, lo cual indica una modificación de la estructura interpretativa. La estructura-como así modalizada, permite a Heidegger señalar la instrumentalización tradicional del Logos, es decir, la asimilación del ente al cálculo y la dominación como consecuencia de aquella separación de su constelación remisional donde originariamente se hace patente e inteligible.

De esta manera, si la estructura apofántica de la manifestación del ente es anterior a la proposición, entonces esta no puede ser el ámbito de la verdad. Desde estos análisis, el Logos se desprende de la estructura proposicional y remite a la dimensión antepredicativa, de la cual derivan los diversos modos de relación con el ente.

Por otro lado, la injerencia directa del Dasein en el lenguaje articulado y las significaciones es más bien mínima, respecto al potencial del ámbito de excedencia antepredicativo, incluso tal ímpetu centralista puede conllevar a una obturación del mismo. Esto es posible con el descuido o desestimación del horizonte que se abre al encaminarse a esta dimensión la cual, por su carácter dinámico, entramado, indeterminado, simultáneo y donante, orienta hacia un campo relacional más vasto que los rincones cerrados del ámbito proposicional.

Ante este estrecho margen Heidegger se vale, por ejemplo, de una modalidad singular para expresar conceptualmente tales comprensiones de la vida fáctica, afines a la diferencia ontológica y la modalidad enunciativa que ello requiere: el concepto metodológico de la indicación formal (formale Anzeige $)^{374}$.

Estos conceptos se caracterizan por un dinamismo y vacuidad que le permiten la explicitación fenomenológica de la hermenéutica adecuada a la facticidad. Es decir, posibilitan objetivar la vida sin descuidar su constitución específica ni reducirla a una mirada teoréticacientífica, de un modo provisorio y en el marco de un análisis dinámico. La operación respectiva, en línea con el desmontaje anteriormente descripto, toma como punto de partida enunciados en su estrato semántico cotidiano y ya abierto, remitiéndolos a su contexto enunciativo o tradición en la que se inscriben. Desde ello, distingue y deslinda sentidos y comprensiones que se desplazaron o desfiguraron de las originarias, operación que revela su carácter formal.

Con ello, insiste en un camino al horizonte de significación originario de términos o conceptos, también desde la esfera proposicional, al proponer una genuina conceptualización de la

\footnotetext{
${ }^{374}$ Un desarrollo diacrónico del tratamiento respectivo, se articula en la siguiente serie: PhAA; PRL; PhIA; GbM
} 
facticidad de la vida, aunque sin plantearlo desde una conciencia rectora que impulsa o manipula conceptos o significaciones, sino a partir del llamado de aquel abismo originario e inagotable que permite poner en evidencia el carácter contingente y desfigurante de las determinaciones conceptuales tradicionalmente sedimentadas.

\section{1. b.- EI Habla en su reserva.}

Como vimos, las dilucidaciones en torno al Habla remiten a una dimensión que articula aquella comprensión del mundo ya siempre abierta en el ser-en-el-mundo la cual se evidencia como condición ontológica para la posibilitación del lenguaje enunciativo ${ }^{375}$.

El todo referencial de los nexos de significatividad en los que se manifiestan los entes, es articulado por esta dimensión del lenguaje ${ }^{376}$, poniendo en evidencia así un ámbito donde el ser acontece. Tal ámbito originario se articula también con la estructura del ser-con: da cuenta de un mundo compartido desde tal horizonte de significatividad. Así, esta estructura no solo se pone de manifiesto desde el ámbito enunciativo, sino que primariamente lo hace desde esta dimensión de significación, lo cual se halla también implícito en la consideración de las habladurías ${ }^{377}$, a partir del análisis de la cotidianidad del Uno ${ }^{378}$.

\footnotetext{
${ }^{375}$ El lenguaje es así uno de los modos en que se le da forma al Habla, en un sentido articulado:’la exteriorización del Habla es el lenguaje" (Ibíd.: 161[184]), sostiene Heidegger.Este carácter derivado le otorga accidentalidad y contingencia, por tanto, lo inscribe en dinámicas no clausurables. En este marco, el juicio es una forma derivada del comprender, como primer procesamiento al que se somete al ente.

${ }^{376}$ Heidegger destaca también los componentes dialógicos, comunicativos y expresivos del Habla. Por eso incluye los fenómenos del escuchar (Hören) y callar (Schweigen) como modos de ser del lenguaje discursivo, en lo cual nos detendremos en próximos apartados.

377 Como vimos, la habladuría es el modo de ser del lenguaje en la vida cotidiana, caracterizada por la falta de apropiación originaria del sobre qué, donde tan solo se dice lo que se oye. Precisamente aquí se funda su dominio, pues incluye la fuerza impersonal del nadie, modalidad que nuestro autor también encuentra en la ciencia de su época, con su tendencia creciente a un pensamiento verbal entregado al poder de determinados conceptos. Desde esta modalidad emerge la indeterminación o vacio de los significados y el lenguaje pasa a ser un tono o un mero sonido. Precisamente esta distinción conduce a nuestro autor a la pregunta por la esencia del lenguaje (BZ: 29 s. [41 s.]). Asimismo, esto permite remitir al lenguaje el ámbito de contingencias y alteraciones, mientras el Habla es condición de posibilidad de apertura (significante) del mundo, por lo cual el hiato o diferencia posible entre el lenguaje enunciativo y la dimensión del Habla queda enmarcado en un contexto históricamente limitado.

${ }^{378}$ Desde esta línea, Adrian destaca dos dimensiones procesuales y no dicotómicas en el análisis heideggeriano de las habladurías en la época de SuZ. Por un lado el potencial de la comunicación de otorgar una comprensión sobre tal significatividad mas allá de la experiencia individual, pero también, por otro , la posibilidad de deformación u ocultamiento de tal horizonte originario que regula la cotidiana interpretación del mundo. Por ello, distingue un sentido activo y otro pasivo de las habladurías: el primero, remite a la posibilidad de asumir propiamente el decir y, el segundo, a la comprensión e interpretación de las significaciones ya dadas y supuestas en todo acto comunicacional que se hallan en estrecha vinculación con la consideración originaria del Habla. Desde allí propone distinguir el correlato necesario entre una comprensión originaria junto a una comprensión de término medio, no necesariamente en un sentido peyorativo o dicotómica, pero que Heidegger entiende como sobrepasando la comprensión originaria, desde lo cual subraya : "Y si bien es cierto que la comprensión media es un rasgo esencial de la apertura del Dasein, la comprensión
} 
Así, este ámbito previo a la expresión se halla implicado en el alumbramiento del mundo. Precisamente por ello, Heidegger entiende la falsedad como un modo derivado de la verdad, es decir, un desvío de este alumbramiento antepredicativo. El decir del Habla no crea al ente pero es la condición para asirlo significativamente, es decir, su función apofántica es condición de posibilidad del contacto simbólicamente estructurado con el mundo circundante.

Con estas distinciones y aprehensiones, la esencia del lenguaje (Rede) como Logos, es pensada desde la esencia del ser y su ámbito. Con ello, el lenguaje entendido de un modo general, remite a una función de carácter ontológico para establecer contacto con el ente, como armazón formal que articula la posibilidad del sentido, es decir, uno de los modos de apertura del Dasein pero sin carácter instrumental: Heidegger no connota con ello que el existente humano tiene lenguaje, sino que lo es formalmente, en tanto constituido de estructuras significativas que suponen el sentido ${ }^{379}$.

En suma, en estas elaboraciones Heidegger muestra la conexión interna con la comprensión y la inteligibilidad de lo ente, enfatizando con ello la función apofántica del Habla para el develamiento de lo que es, previa a toda operación comunicativa y expresiva, de modo tal que el enunciado predicativo se evidencia derivado del ámbito antepredicativo en dos niveles: primariamente, al fundarse en la apertura de la comprensión; luego, al derivarse de la interpretación que articula tal comprensión ${ }^{380}$. Por su parte, la inteligibilidad significativa del ser-en-el-mundo que articula aquella comprensión abierta, se revela co-originaria respecto al ser-con, es decir,

genuina requiere además del desarrollo de nuevas formas de "interrogación y discusión” que rompan con la autoridad anónima del estado público de interpretado. El error del Dasein consiste en tomar la comprensión media como un punto final y no como un simple punto de partida. El hecho de que el Dasein comparta un lenguaje común no le impide alcanzar una relación primordial con los entes y con su propio ser.'Véase Adrian (2011b):18-25. Cf. Lafont (2005):516 ss.

${ }^{379}$ Bertorello propone una argumentación en torno a una teoría semántica en Heidegger, a partir de la distinción de una posible teoría de la enunciación. Circunscribe en esta perspectiva los supuestos respecto a las condiciones de producción del sentido en $S u Z$, los cuales se enmarcan en el análisis de la mismidad co-presente en toda secuencia enunciativa del Dasein. En el contexto de tales interpretaciones, destaca: "El punto de vista genético en Heidegger es el de la degeneración y recuperación del sentido. La lógica de la derivación es un supuesto en la obra fundamental de Heidegger (...) La lectura atenta de estas Vorlesungen arroja como resultado una lista de expresiones que usa profusamente y que tienen una significación inequívocamente genética. Entre ellas menciono las siguientes: Genesis (génesis), Genealogie (genealogía), Ursprung (origen), Quelle (fuente), Herkunft (procedencia), Ableitung (derivación) y Abkunft (descendencia). Todas ellas describen un proceso que nace en un origen y, a medida que se aleja, se transforma. La pregunta que plantea esta descripción es la siguiente: ¿qué es lo que se transforma en el proceso de derivación? La respuesta de Heidegger es la siguiente: lo que se transforma es el sentido (...) En la medida en que esta lógica remite siempre al origen del sentido, y desde allí traza su genealogía, es una lógica de las condiciones de producción del sentido (...) La producción del sentido no alude ni a procesos bio-psicológicos, ni a procesos sociales. El sentido surge, por el contrario, de un yo histórico que vive aquí y ahora en el mundo de sus preocupaciones" véase Bertorello (2006):35 ss. A nuestro entender la comprensión del Dasein como yo histórico o sujeto axiológico desvían estas interpretaciones de las elaboraciones dinámicas en los análisis de Heidegger. Sin embargo, la distinción de nexos entre una teoría de la enunciación y las consideraciones de la mismidad, articula una misma orientación con nuestros desarrollos e hipótesis.

${ }^{380}$ Un intérprete traza aquí una continuidad y desplazamiento de una misma tentativa en Husserl en lo que respecta al origen del enunciado predicativo, en Vigo (2014):114 s. 
implica un ámbito previo de sentidos compartidos y de co-participación, en el marco de la apertura de la comprensión, tal y como lo manifiesta en la analítica existenciaria del estado de caída, en tanto figuración de esta imbricación originaria entre Dasein-alteridad-lenguaje. Ahora bien, ¿de qué manera nuestro autor elabora las dinámicas o los desplazamientos en los procesos de enunciación y de significación?

\section{1. b. I- El carácter inagotable del ámbito prelingüístico: límites y horizontes.}

Pues bien, la comprensión del ser no implica necesariamente hacernos aún un concepto respectivo, debido a este primario desenvolvimiento en un ámbito preconceptual y pre-científico ${ }^{381}$. Por ello, el carácter dinámico de la apertura del ser, en su esquiva oscilación entre desocultamientoocultamiento, no solo supone que su aprehensión en la palabra no puede agotar su fuente y reserva, sino también que todo comportamiento respecto al ente implica ya una proyección que trasciende hacia este horizonte, desde el cual la filosofía tradicionalmente ha tratado de poner en conceptos expresos el ser que previamente comprendemos. Este momento derivado, al determinarlo conceptualmente desde la metodología propuesta, queda reinterpretado, tomando forma conceptual la comprensión del ser, aunque preservando su localización previa e inagotable (EP: 319[332]).

A partir de las consideraciones en torno a esta articulación, el lenguaje lógico gramatical en su carácter y función derivada, permite distinguir un hiato respecto al $\mathrm{Habla}^{382}$, es decir, una diferencia, una distancia que cancela la posibilidad de una cobertura o saturación completa. Tal distinción impacta en la propia operación de enunciación de Heidegger y tratamiento posterior del lenguaje, donde el dar cuenta de un Decir originario que no puede agotar un decir enunciativo, figura en su propio camino del pensar y decir: las paradas articuladas son siempre provisionales y dinámicas, incluso con la implementación de términos cuyos campos de significación se evidencian dinámicos, oscilantes y de conexiones múltiples.

Asimismo, la distinción entre estas dos dimensiones o estratos, permiten dar cuenta por un lado, del carácter irrebasable del Habla con la consecuente inefabilidad de la semántica respectiva, lo cual cancela todo intento de objetivación o tratamiento racional directo y, por otro, circunscribir

\footnotetext{
${ }^{381}$ De un modo similar a lo que hemos visto en la perspectiva de su maestro, Heidegger ilustra con el ejemplo del cuchillo, del cual comprendemos primariamente su función antes de su utilización efectiva. En este contexto, destaca que el conocimiento científico y sus conceptos se encuentra comprendida de antemano y de un modo la naturaleza (EP: $192-5[205-8])$.

${ }^{382}$ Este carácter derivado del lenguaje le permite a Heidegger dar cuenta de ciertas derivas de la tradición metafísica. En especial, destaca que al considerarse eminente el lenguaje, crecer el conocimiento conceptual y la diferenciación de significados, el Logos se tornó representante del ente, siendo el pensamiento científico una de sus consecuencias (Ibíd. $387[410 \mathrm{~s}$.$] ).$
} 
el ámbito de los desplazamientos y variaciones a su dimensión enunciativa pues, si la fuenteabismo es inagotable, no determinable ni representable, entonces la explicitación proposicional potencialmente es contingente y móvil ${ }^{383}$. Estas consideraciones permiten profundizar su perspectiva respecto al carácter dinámico del lenguaje (Rede).

Específicamente, la relevancia de esta distinción de la figura de irrebasabilidad (Nichthintergehbarkeit), expuesta en $S u Z$, reside en que cancela el distanciamiento objetivante por la vía reflexiva, la cual parece suponer una desestimación de las vías racionales para el saber (del lenguaje y del mundo), al menos en sus pretensiones de definitibilidad, con sus consecuencias respectivas en el plano epistemológico. Entendemos que tal desestimación se halla en consonancia con el carácter situado del ser-en-el-mundo del Dasein, con sus respectivos ámbitos co-originarios y simultáneos, que ponen un coto a toda pretensión centralista y acabada de la metafísica.

Más aun, si los conceptos de la tradición son acuñados por la comprensión de lo ya develado, cada época del ser se configura también a partir de un no darse, del retraerse y ocultarse del ser, que es el correlato de tal develamiento. Precisamente en ello reside su carácter inagotable, donde el pensamiento humano se posiciona como un modo de respuesta a la apelación que proviene de este retraimiento inscripto en tal dinámica epocal. Esto también señala su límite: el salto del pensamiento solo puede llegar hasta la figura del ser que impera en una época determinada ${ }^{384}$.

Finalmente, este carácter procesual e histórico de la verdad y del ser, en relación a la doble operación de y en la apertura (que oscila entre manifestación y ocultamiento), nos invita a precisar en tales dinámicas relacionales y temporales en el Habla, la dimensión futura, especialmente en lo que respecta a los procesos de significación, es decir: ¿cuál es el estatuto o la modalidad de aprehensión que propone para este carácter de excedencia e inagotabilidad? ¿Y cuáles son las

\footnotetext{
${ }^{383}$ En esta línea, sostiene una intérprete respecto de: “...el carácter determinante de la apertura lingüística del mundo, propia de cada lenguaje histórico. La imposibilidad de distanciarse de ella, de objetivarla y, de este modo, hacerla transparente (o dejarla fuera de funcionamiento al robarle su carácter previo) es el precio que una perspectiva como ésta tiene que pagar por romper con las ilusiones de la filosofía trascendental "(Lafont ,1993:79). Por medio de esta interpretación pone énfasis en que la irrebasabilidad de tal apertura es un derivado de una modalización del pensar y el decir en el campo de la tradición desde la que se articula.

${ }^{384}$ En un análisis a este respecto, un autor destaca que aquí el pensar parte del pensamiento acumulado, al tiempo que encuentra elementos para pensar lo impensado, y agrega: "Parece, así, que en la hermenéutica de la historia del ser, con su opción por lo absolutamente otro, y con su perspectiva de totalidad, se introduce una cierta clausura del horizonte interpretativo, una cierta exclusión de toda otra posibilidad de comprensión. Cualquier intento de interpretar un pensamiento que no resulte acorde con el dictamen de la historia del ser tiende a ser de antemano condenado como aún prisionero del pensar representativo de la metafísica, cuyo radio de acción es tan extenso como la misma filosofía ¿Es esta una consecuencia inevitable de la idea de 'historia del ser'? ¿ No es posible conciliar la hondura interpretativa de las bases ontológicas de nuestra época, que la historia del ser proporciona, con análisis discrepantes, que rebelen posibilidades positivas en las filosofías que en ella conviven?" Rodríguez García (1993):205.Entendemos que esta interpretación no distingue los planos del comprender, la interpretación y el horizonte epocal de la historia del ser, por lo cual termina desplazando el ámbito de las dinámicas del lenguaje en el pensamiento heideggeriano, al horizonte irrebasable. Sin embargo, al denunciar una pretensión de trascendentalidad en la significación entrecomillada, manifiesta y supone implícitamente la distinción de planos.
} 
condiciones de producción conceptual y de significación desde dicho ámbito? Retomemos entonces, algunos nexos, a partir de la consideración del sentido.

\section{1. b.II.-- En torno al carácter dinámico de las significaciones.}

En ese contexto, para desplegar un análisis de la significatividad (Bedeutsamkeit) debemos retomar nexos con los ámbitos originarios y antepredicativos descriptos ${ }^{385}$. En líneas generales, aquella bidimensionalidad es aquí coextensiva: Heidegger también distingue un entramado de significaciones primarias/originarias y otro derivado/nivelado en el ámbito enunciativo.

Específicamente, analiza la estructura autoremisiva del Dasein, en el encontrarse circunspecto desde su ser-en-el-mundo. Como vimos, desde allí el comprender revela un campo entramado de remisión, donde el significar designa el carácter respeccional del mismo. De esta manera, el ente se abre desde el significar, modalidad por la cual remite a otros entes en el trato de la ocupación del Dasein. En definitiva, la significación (Bedeutung), en su carácter ontológico primario, remite a un entramado de cosas en el seno de la facticidad (SuZ: 151[174 s.], con lo cual pierde toda nota de a-temporalidad e idealidad.

De esta manera, Heidegger pone énfasis en que la relación con el mundo se abre a partir de la comprensión de nexos significativos que articulan la facticidad, donde el lenguaje permite el advenimiento de los entes a la significación. Si el Dasein se encuentra primariamente entre significaciones, entonces las derivaciones y supuestos del modelo perceptivo del paradigma sujetoobjeto son aquí incompatibles.

Así, aquellas significaciones remiten las unas a las otras en la trama holística y relacional de la significatividad, la cual es ontológicamente anterior a la manifestación de los entes .Los significados (Bedeutungen) se articulan en una comprensión, con su respectivo orden de originariedad: primero lo ya develado (en un nexo de referencias no reconocido), segundo, la articulación en palabras (LFW: 149-51[124-6]. Esto permite evidenciar el supuesto de irreductibilidad del pensamiento al lenguaje ${ }^{386}$, que es condición para el desarrollo de consideraciones sobre el carácter dinámico y variable de las significaciones.

\footnotetext{
${ }^{385}$ Véase SuZ: 87 s. [113-115].

${ }^{386}$ Inscripto en este marco distintivo, esboza en sus elaboraciones de juventud una aproximación a partir de la tentativa (luego abandonada) de una ciencia preteorética originaria. Específicamente, subraya que mientras viviendo en un mundo circundante estoy rodeado de significados, todo mundea (welten) estando "yo" inmerso en ese mundear. Con tal expresión designa la manera en que la estructura significativa de la realidad nos sale al encuentro .Por su parte , lo teorético siempre remite a elementos anteriores, en un comportamiento tal me dirijo hacia algo pero "yo", al tiempo
} 
Por otra parte, estos significados articulados en la comprensión se enmarcan en un horizonte compartido. Es decir, si la comunicación implica participar de la misma relación de comprensión, entonces los partícipes ya comprenden el modo de ser del ente del que hablan, al proyectarlo en el mismo horizonte de significatividad (DGPh: 397[336 s.]). Tal proyección implica una comprensión pre-conceptual y preontológica del ser, la cual se haya abierta en la base de un mundo con esta inteligibilidad compartida ${ }^{387}$.

Este tratamiento del sentido compartido y las significaciones en el mundo común también le permite distinguir un sesgo para plantear movilidad o variación en su campo respectivo. Ello figura en las consideraciones de la estructura del ser-con y de la posibilidad del Dasein auténtico de asumir propiamente la tradición, que pueden ser elaboradas a partir de distinguir estas dimensiones antepredicativas, al permitir circunscribir un ámbito de excedencia, multiplicidad e inagotabilidad respecto a la dimensión proposicional. En pocas palabras: tal distinción supone que el proceso de significación y comprensión, epocalmente compartido en la estructura cooriginaria del ser-en-elmundo, se enmarca en una perspectiva no clausurable del lenguaje ${ }^{388}$.

Ello se debe a que la articulación enunciativa o proposicional, al mismo tiempo que se determina como una cierta nivelación de estos ámbitos originarios, revela por ello su contingencia constitutiva, su carácter provisional y móvil, al poner de manifiesto los caracteres furtivos de no fundamento, indeterminación, multiplicidad y simultaneidad del ámbito que la condiciona.

Ahora bien, del mismo modo que con las consideraciones de la ipseidad, la alteridad o la pregunta por el ser, estas elaboraciones sobre el lenguaje se ven en parte desplazadas o radicalizadas en su elaboraciones de madurez, por medio de un desplazamiento del énfasis o perspectiva que parte desde de las estructuras del Dasein, hacia un enfoque desde el ser y el carácter acontecimental

que no vivo en contacto con tal elemento mundano: lo teorético deja de mundear ,de modo que des-significa el significado . Desde aquí, sostiene que la expresión verbal es originariamente vivida y experimentada o bien en un sentido premundano (que puede ser vivido, independiente de su carácter mundano) o en un sentido mundano. Las funciones significativas premundanas y mundanas acompañan la vivencia misma. En este marco destaca la importancia de la dimensión preteorética y prerreflexiva hacia una filosofía auténtica genuina no afectada de teoría y libre de prejuicios del pasado.Véase, por ejemplo, BP: 73-94[88-114].

387 Desde este aspecto Gadamer desarrolla la consideración de la autoridad (ética) de la tradición en su hermenéutica filosófica en su obra de 1960. Respecto a esta continuidad y distinción con Heidegger cfr. Lafont (1993):70 y ss.

${ }^{388}$ A partir de esta perspectiva no clausurable ligada a la variabilidad de la interpretación, Vattimo propone un análisis sobre la verdad epocal de la subjetividad, respecto a su crisis junto a la noción de sujeto, inscribiéndola en un horizonte de época como modo de rebelarse histórico de tal perspectiva, lo cual se evidencia como figuración práctica de estas distinciones de Heidegger. Destaca que el telón de fondo de la precomprensión son las expectativas, la memoria y el lenguaje, únicos elementos sobre los cuales puede profundizar un pensador de época. En este sentido, sigue ciertas precomprensiones rectoras en el marco de las concepciones en torno a la subjetividad, en el horizonte de la experiencia histórica en la que se halla inscripto, que implica cierta modalidad de "actuar" en este marco. Allí, destaca que los pensamientos de Heidegger y Nietzsche se encuentran entre los sedimentos comprensivos de mayor relevancia., en una transición hacia una humanidad posmetafísica capaz de no estar ya sujeta. Véase Vattimo (1991): 115-117; 139.Siguiendo esta vía, entendemos que la transición que implica la elaboración respecto al Dasein se orienta a tal deposición de la sujeción, aunque en el marco de un develamiento del complejo múltiple y relacional en el que puede aprehenderse. 
del Ereignis. Como veremos a continuación, tales desplazamientos son correlativos con la discursividad y la enunciación de nuestro autor, las cuales se ven moduladas alusiva y metafóricamente, de un modo no lineal ni progresivo, con un lenguaje que abre y ensancha un campo por fuera de su función representativa o referencial ${ }^{389}$.

\section{2.- Tras la esencia del lenguaje como casa del ser.}

En efecto, en las elaboraciones a partir de 1930 Heidegger desplaza aquel énfasis desde la función de sentido del lenguaje (Rede) hacia a la consideración de la verdad como desocultamiento $^{390}$. En esta línea, vimos que busca apartarse de todas las notas antropológicas que puedan aún asociarse desde la analítica, poniendo el enfoque especialmente en la relación del lenguaje y el ser, donde el hombre solo es considerado como un ámbito donde aquella relación resuena, como singular portador del lenguaje.

Dicha consideración del papel lateral y subsidiario, se desliga de toda perspectiva instrumental del lenguaje de orientación platónica : para nuestro autor no es el hombre quien se vale del Habla, sino que ésta se vale del hombre como cauce epocal del Decir (die Sage) del ser ${ }^{391}$.Si la

\footnotetext{
${ }^{389}$ Rorty también destaca que estas consideraciones de Heidegger, en confluencia con las de Derrida y de la filosofía analítica del lenguaje (Quine, Putnam y Davison) han puesto de relieve el carácter no referencial del lenguaje con su consecuente remisión infinita, tal como ilustra con claridad con este conjunto de sintagmas :'Considérense las oraciones como cadenas de marcas y ruidos que emiten los organismos (...)Considérense las creencias , deseos e intenciones ...como entidades que se postulan para ayudar a predecir la conducta de estos organismos. Ahora pensemos que esos organismos evolucionan gradualmente en virtud de producir cadenas cada vez más largas y complejas(...) Ahora pensemos en nosotros como ejemplos de estos organismos altamente evolucionados, cuyas máximas esperanzas y más profundos temores resultan posibles, entre otras cosas por nuestra capacidad de producir las cadenas peculiares que producimos. A continuación pensemos en las cuatro oraciones que preceden a ésta como nuevos ejemplos de cadenas de este tipo. En penúltimo lugar, pensemos en las cinco oraciones que preceden a ésta como el bosquejo de una casa del ser rediseñada, una nueva morada para nosotros, pastores del ser. Por último, considérense las seis últimas oraciones como un nuevo ejemplo del juego de significantes, un ejemplo más de la forma en que el sentido es indefinidamente alterable mediante la recontextualización de signos" (Rorty ,1993:21). En este singular pasaje no solo se muestra una propuesta o mención, sino también evidencia lo no-dicho mediante una relación modal del lenguaje, que torna de relevancia la atención puesta en la articulación discursiva. Por un lado, entendemos que tal recontextualización se inscribe en la perspectiva heideggeriana, de modo tal que Rorty opera aquí aplicándola al propio discurso de Heidegger. Con ello se revelan ciertos sintagmas o significaciones de nuestro autor que parecen aún sesgadas con pretensiones trascendentales. Por otro lado, distinguimos que Rorty elimina la dimensión del sentido en sus elaboraciones, priorizando el comportamiento y los aspectos pragmáticos. A diferencia de ello, Heidegger enmarca el sentido en una proyección ontológica.

${ }^{390}$ Como vimos, la verdad como desocultamiento está presente en SuZ en correlación con la interpretación del enunciado en su dimensión apofántica, especialmente en SuZ: 154-60[177-83]; 219-30[239-50].

${ }^{391}$ A continuación, escribiremos Decir, cuando la manifestación remita al ámbito antepredicativo y originario del habla, y decir, cuando hagamos referencia a una articulación en lenguaje enunciativo y derivado de aquella. Respecto a estas distinciones, especifica nuestro autor:"...die Sage, Decir. Significa el decir, lo que el decir dice y lo que está por decir
} 
historia del ser se caracteriza no solo por un abrirse comprensivo e interpretativo determinado, sino también por una modalidad de articulación en el lenguaje, el hombre es el ámbito donde estas dinámicas temporales se despliegan ,aunque siendo la guarda, la entrega, la intermediación y el desvío, algunos de los modos en que participa en ellas.

Desde sus trabajos/conferencias reunidos en Unterwegs zur Sprache (1950-1959) (US) ,entre otros , logra abordar la consideración del lenguaje de un modo más apropiado , absolutizando la función de apertura del mundo, extremando la primacía del significado respecto a la referencia, o mejor, su carácter de condición respecto a un mundo significativamente interrelacionado, aunque ahora encaminándose por medio de la pregunta por su esencia : la consideración del lenguaje como casa del ser en vínculos con la relevancia de la poesía, voz en la que resuena el lenguaje originario (Ursprache), y las dinámicas relacionales con el lenguaje, ocupan la centralidad del análisis.

Con nuestros siguientes desarrollos nos proponemos interpretar y distinguir posibles continuidades y desplazamientos de las elaboraciones anteriores, las cuales le permitieron despejar los ámbitos formales originarios en el camino de la pregunta por el ser. Sostenemos aquí que tal resultado es precisamente lo que motiva una radicalización del énfasis hacia las dinámicas en relación con el lenguaje (Rede), por medio de un desplazamiento modal de su discurso, articulado a través de términos y conceptos correlativos.

\section{2. a.- De las limitaciones del decir a la alteridad del silencio}

Especialmente desde 1936, Heidegger desarrolla aquella aprehensión del ámbito originario y antepredicativo desde la consideración del Ereignis, profundizando así el campo de aprehensión interrelacional $^{392}$.

(...) ¿qué significa 'decir'? Presumiblemente lo mismo que mostrar en el sentido de: dejar aparecer y dejar relucir, pero en el modo de 'señar" (US: 137 [131 s.])

${ }^{392}$ Por ello puede plantearse una continuidad intensiva en el camino, tal como destaca esta lectura y análisis: "que la radicalización del pensamiento heideggeriano no es otra que la radicalización de las preguntas que lo guían, sobre todo, en dirección de la más adecuada formulación de la pregunta fundamental por el sentido del ser". Y más adelante , especifica : "Las diferencias, si bien son también profundas, pueden considerarse diferencias que resultan de una profundización del planteo o de una mayor discriminación analítica al interior de la tesis señalada y no constituyen, a nuestro entender, un cambio de posición (...)En los Beiträge zur Philosophie, la conjunción que se hace visible en_la palabra "mundo" no es solo la bidimensional entre Dasein y el plexo de relaciones remisionales de los entes al que este se conforma, sino la de las cuatro dimensiones indisponibles de cielo, tierra, divinos y mortales. No se trata solo del Dasein del caso, se trata de "los mortales"; no se trata solo del Dasein y los entes que le salen al encuentro, sino del modo en que en aquello que sale al encuentro se reúnen una multiplicidad de dimensiones cuya confluencia hace que esto salga así al encuentro. La palabra del Dasein es convocada a co-responder al modo en que, en lo que sale al encuentro, se reúnen esas múltiples dimensiones; es convocada a hacer resonar en el esto como esto en que resulte su articulación, el eco de las dimensiones que jamás podrán ser suficientemente recogidas en la palabra. El carácter pático del origen de la significación lingüística, ya presente en Ser y tiempo, es elevado en los Beiträge a una formulación más 
En este marco, desarrolla elaboraciones en torno a la Cuaternidad (Geviert) de cielo-tierradivinos-mortales como otra modalidad de hacer referencia a esta dimensión originaria, pero destacando con mayor precisión la articulación entramada y acontecimental que le es inherente, lo cual le permite poner en mayor evidencia el carácter de co-participe del Dasein , bajo la modalidad plural de los mortales, es decir, aquí considerando simultáneamente su estructura proyectiva de ser-para-la-muerte y el carácter co-originario del ser-con ${ }^{393}$.

Destaca la resonancia de un Decir que impulsa desde tal dimensión interrelacional, a partir de la cual puede avizorarse el horizonte para el otro comienzo del pensar. Incluso el propio decir (sagen) enunciativo permite un despliegue de aquel Decir originario que desoculta, muestra (Zeigen) y llama ,solo si el Dasein se entrega en una pertenencia que participa y responde, respecto a este potencial advenimiento y mostración, cuya apropiación (Ereignen) se dona y dinamiza desde el Ereignis, en su carácter disruptivo e incalculable (US:245-7[231-4]) ${ }^{394}$.

Como se evidencia aquí, la cuestión del pensar del otro inicio también se topa con una problemática del ámbito del lenguaje: no hay dominio de respuesta como fondo para el preguntar respectivo. Esto implica que no logra remitir a una referencia como un esto, determinable y estática, sino más bien a una dirección que va develando históricamente aquello que se dinamiza en el vaivén desocultamiento-ocultamiento. Por ello, precisamente este camino implica un pensar no representativo, al tiempo que demanda una modalidad alusiva no-referencial del decir y una posición de enunciación correlativa.

La tensión radica en que el lenguaje enunciativo no permite decir la verdad del ser, pues la superficie desde la que se desplaza solo permite dar cuenta de la presencia en su manifestación actual. Por ello, Heidegger insiste en el carácter proliferante de aquél ámbito primario: todo Decir

elocuente" (Leconte ,2015:273-8). En esta misma línea, distinguimos que las reelaboraciones en torno al Dasein y la Ipseidad se inscriben en esta radicalización de la perspectiva relacional correlativa a la consideración del lenguaje.

${ }^{393}$ Asimismo, aquella significación de interrelación señala el abismo como no-fundamento, también comprendido en las elaboraciones de la Lichtung. Con más detalle: esta cuádruple dimensión le permite poner mayor énfasis en la reunión, la copertenencia mutua, la diferencia, la multiplicidad y el diferimiento irreductible, que abordado de un modo holístico cancela todo posible fundamento o determinación causal. A este respecto véase, por ejemplo, las distinciones que realiza en relación al lenguaje enunciativo, a partir del análisis de un poema de Georg Trakl, en US: 19-29 [20-8].Cf. EHD: $170[188]$.

${ }^{394}$ De esta manera, la distinción ontológica del Decir, cataliza las tesis de Heidegger respecto al lenguaje proposicionalenunciativo, el sentido y la verdad. En este marco, un analista especifica: "éste no se identifica con el decir cotidiano del hombre, que se desgasta en el rumor, en lo infundado e indigno de ser creído, y que se expresa en sonidos articulados portadores de significado. Un recurso al origen del término en alemán aclara la situación: Sagen proviene de Sagan, que significa mostrar (zeigen), dejar-aparecer (erscheinen lassen), dejar ver y oír. Pero el dejar-acontecer del lenguaje como Decir no trae a la luz verdades absolutas, libres de toda duda y oscuridad. Funda, por el contrario, aquello que simultáneamente viene a presencia y se oculta. Con ello no solamente se reconoce la naturaleza ambigua, inconclusa, temporal, y multívoca de las palabras, sino la misma esencia de la verdad. (...) El Decir considerado como dejar es la condición de posibilidad para el surgimiento de lo que hace presencia a través de la palabra. Con él todo acontece como fenómeno de sentido, pues su razón de ser consiste en traer (fundar) las cosas al significado y no solamente en designar con nombres los objetos del mundo (...) Lo que trae el dejar-aparecer del Decir no son presencias en sentido absoluto, sino fenómenos de origen lingüístico" Rocha de la Torre (2005):10s. 
viene del ser y habla su verdad (BPE: 79[78]). En este sentido, no es apropiado hablar sobre el lenguaje (Rede) sino del lenguaje, es decir, de él y desde él, sin apelar a un punto de partida subjetivista, para no obturar esta dinámica de fluidez no clausurable. Esta conduce a un resultado paradójico: si bien no puede decirse enunciativa e inmediatamente el sentido del ser o la esencia del lenguaje, ni construir un sistema definitivo al respecto, no queda imposibilitada una articulación dinámica. Esta se muestra necesaria en el camino epocal de tal decir (Ibíd.: 85 s. [82 s.]), que permite una experiencia del ocultamiento donante, que es abismo y no fundado ${ }^{395}$.De todos modos esta articulación, sea verbal o escrita, es solo secundaria, pues la región originaria da prioridad a los silencios: le es más apropiado un Decir que se articularía auténticamente desde un callar, como preludio para aquel discurrir del lenguaje.

Con esto, Heidegger articula la diferencia de fondo que se halla en todos los estratos de su perspectiva: el ser como lo otro del ente y la diferencia como vía de acceso a lo originario. Por ello podemos subrayar que la modificación o desplazamiento del código en el enunciado no puede venir del mismo código sino desde una relación con su alteridad liminar, en este caso, el silencio $(\text { Schweigen })^{396}$. En esta relación dinámica entre lenguaje y su límite se da la función fundante y desfundante: la palabra autentica (echtes Wort) que resuena en el silencio (US: 251 ss. [237 ss.].

En esa marcha, el esfuerzo del hombre es entendido a-biográficamente, pues se articula más bien con un preguntar del primer inicio, caracterizado por traer el ser en el ente en su verdad ${ }^{397}$. El tránsito de esta puesta en camino da cuenta de una singular experiencia con similitudes modales respecto del tratamiento anterior de la ipseidad: despliega una dinámica donde se torna desconocida cada parada del mismo, cuya falta de consistencia sustancial desplaza el énfasis desde un pensar individual o centrado en la figura primaria del hombre, hacia una singularidad del decir y del pensar, cuyas paradas locales se articulan de un modo u otro, pero sin perder su sesgo no clausurable y abismático.

\footnotetext{
395 Eugenio Trias analiza esta consideración heideggeriana del fin de la fundamentación metafísica, dando cuenta de este fundamento-abismo cuyo arché es la falta en ser y el thelos es la muerte como límite irrebasable de toda posibilidad. Este intérprete propone una articulación con una ontología de la muerte de Dios, pues la elaboración de Heidegger cancela toda concepción de fundamentos purificados de aspectos temporales, contingentes y finitos, a partir de lo cual subraya : “ ...esta finitud afecta radicalmente al ser, que es pensado en radical e intrínseca vinculación con la nada, toda vez que no es ya el ser sin tiempo de la ontoteología postplatonica, sino el ser-tiempo cuyo carácter fundamental, en el sentido del fundamento antes explicitado, fundamento-abismo, despide el ente como presencia , la cual presencia tiene en ese ser fundamental eso desde donde se constituye como tal presencia" Trías (1983) : 22. En este marco, reconocemos una misma estructura entre esta comprensión temporal del ser y las elaboraciones sobre el lenguaje.

${ }^{396}$ Una intérprete desarrolla un paralelo y continuidad de este tratamiento del silencio y los desarrollos en torno a tal dimensión en la analítica de SuZ y su obra temprana, especialmente en el análisis del llamado de la conciencia , la relación entre angustia e insignificatividad y el carácter liminar de la muerte, en Martínez Matías (2008):115-34.

${ }^{397}$ En este sentido, subraya que SuZ representa una escala pequeña en el decir del ser (BPE: 85 s. [83]).
} 
Es precisamente aquí donde la diferencia ontológica le permite distinguir que el ente es y el ser se despliega. Este carácter dinámico también se proyecta en el lenguaje que lo articula y supone la dimensión temporal como condición de tal despliegue. En este contexto, distingue que el modo tradicional de preguntar por el ser se movilizó desde la pregunta guía por el ser del ente. Desde $S u Z$, nuestro autor se inscribe en un tránsito que va de tal orientación a lo que denomina como la pregunta de fondo, la cual pone aquel énfasis en el ser en su diferencia, como desfondado abismo o carente de suelo, es decir, ya no llevado a un suelo para ser explicado (como en el caso del ente y aquella modalidad del preguntar) en una clara modalización y oposición del pensar de tipo representativo, aunque sin un abandono definitivo de aquella orientación, tal como explicita en este pasaje :

"Que el ser se despliegue de este modo en términos de fondo en su despliegue esencial, indica su singularidad y soberanía (...) El ser como lo más digno de pregunta no conoce, en sí, ninguna pregunta. La pregunta-guía, desarrollada en su ensambladura, permite conocer en cada caso una posición fundamental con respecto al ente como tal, es decir, una posición del (hombre) que pregunta sobre un fondo que no puede ser fundado como tal, ni en absoluto sabido desde la pregunta-guía, pero que es traído a lo abierto mediante la pregunta de fondo" (Ibid.:77[76]).

De esta manera, Heidegger destaca el vaivén correlativo en las dinámicas del lenguaje, donde se pone de manifiesto una lucha entre lo que se muestra y lo que se oculta, entre lo decible y lo indecible, lucha en la cual acontece la verdad. Entendemos que en ellas los términos no se destruyen entre sí , sino que se necesitan, no en un sentido dialéctico sino mas bien en/desde el marco de una dinámica relacional-acontecimental que cancela la posibilidad de unilateralizar sus momentos o suponer una posible saturación semántica ${ }^{398}$. El tránsito hacia otro lenguaje y pensar puede dar cuenta de la fuente de ocultamiento desde donde emana ${ }^{399}$.

\footnotetext{
${ }^{398}$ Tal y como también lo articula en su análisis de la obra de arte. En este trabajo Heidegger analiza en una obra de Van Gogh la dinámica de lo visible y lo invisible, la tensión entre mundo, como lo que emerge de la obra y tierra, lo que se oculta. Por medio del análisis propone poner de manifiesto la apertura del ser del ente, el desocultamiento, la Aletehia. Véase Hw: 29-65[28-56].

${ }^{399}$ A este respecto y en referencia al campo semántico en el que se inscriben estas dinámicas relacionales, uno de sus discípulos subraya:”...esta verdad no puede ser pensada como historia porque la historia en su distinción con respecto a la naturaleza o con respecto al llamado ser ideal, solo nombra uno de los ámbitos del ente ;pero este ámbito , precisamente con su epocalidad solo puede ser sacado al lenguaje desde la esencia de la verdad, del desvelar(Entbergen) sobre el fundamento del ocultar (Verbergens), como algo derivado. Así, Heidegger da también un nombre propio a aquello que él intenta pensar como lo hasta ahora no pensado: despejamiento (Lichtung) como despejamiento del ocultarse (Sichverbergens). Pero este despejamiento no es pensado desde la metafísica de la luz (Licht) sino desde la apertura en el bosque, lo abierto en medio de un bosque que se cierra a sí mismo" (Pöggeler, 1984a:145). Distinguimos en este análisis e interpretación, que el contexto de significación impacta semánticamente en el término destacado.
} 
De modo sumario, el otro inicio del pensar no es definible enunciativa o conceptualmente: la emergencia de variados nombres para designarlo son pruebas de su riqueza y extrañeza abismática. Este pensar no se expresa en la proposición, designa más bien otro decir que no es sistemático ni vinculado a la concepción de la verdad como certeza. Por ello, entendemos de relevancia en su camino desde $S u Z$, el distinguir que la verdad del ser llega al lenguaje junto al pensar, evitando la cristalización en expresiones precipitadas ${ }^{400}$. En esta trayectoria, al permitir libertad en el ensamble de sus articulaciones, aquél ámbito tampoco es racionalizable, sino más apropiado a un decir y pensar poético que poco se vincula con la modalidad de la filosofía tal y como fue articulada desde el horizonte de la cientificidad.

Si para el pensar representativo todo se convierte en ente y se omite el ocultamiento, entonces el pensar y decir del ser debe modularse de un modo singular. Nuestro autor destaca que su decir originario no se limita al mero decir de nombres, ni su hablar refiere al lenguaje de las palabras (VA: 246[188]). Esta distinción permite un diálogo ilimitado donde pliegue y despliegue permanecen ocultos, diferenciándose así de aquél pensar que se basa en garantías para alcanzar metas previstas. Tal diálogo circunscribe relacionalmente la posición respectiva del Dasein.

\section{2. b.- Posiciones mediadas por el Decir.}

Hemos visto que la esencia del lenguaje revela un desplegarse significativamente sin reducirse a la relación significante-significado o entre signo y cosa. El Decir que le es inherente se revela como acontecimental, pues emerge desde el seno de las dinámicas e interrelaciones y no a partir de un fundamento previo. No obstante, necesariamente lo hace como expresión y actividad del hombre, pero de un modo singular en relación al silencio de tal ámbito originario (US: 27-9[28 S.].

Más en detalle: Heidegger subraya que el hombre es aquel ser que, diciendo, hace que yazca lo que viene a su presencia. Pero hemos visto que este hacer se separa de su carga semántica antropocéntrica: todo decir precisa ya del ámbito del desocultamiento, de modo tal que la participación del hombre más que a un producir remite a un permitir o prestarse como ámbito para ello, solo a partir de una escucha previa del Decir: donde ya reina este desocultamiento es posible

\footnotetext{
${ }^{400}$ En este marco , Heidegger inscribe el acto de retirar el desarrollo de "Tiempo y ser" de la parte final de $S u Z$, el cual no se dio a la imprenta pues entendió que el pensar no fue capaz de expresar ese giro con un decir de suficiente alcance, dificultad que reside inexorablemente en el lenguaje de la metafísica con el que cuenta (BH:327 s.[270])
} 
que algo se vuelva decible, aun más, este develarse conmina a una urgencia que un pensar relativo al otro comienzo debe atender (WM:443[358]).

En tal reinado, la enunciación potencialmente puede expresar la significatividad del Ereignis, desde aquella multiple co determinación de la Cuaternidad, que se dona y abre en el ente $^{401}$.Y precisamente en el marco de esta relación, es donde subraya el requerimiento del Dasein para manifestarse, bajo condición de modalizar tal articulación : abriéndose comprensivamente a lo que se escucha, para no desfigurar o enmascarar esta potencia de significatividad originaria, lo cual solo es posible con un corresponder previo a partir de una mutua dependencia (US:243-5[229-31]) .

Así, el envío en el Habla es del ser al hombre. Correlativa a este envío es la disposición de entrega y escucha, ateniéndose a lo designado al modo de un ponerse en camino, y no con un dirigirse a él ocasionalmente (variación más bien asociada a una perspectiva voluntarista). Heidegger recurre en varios trabajos a la imagen del rayo para ilustrar intuitivamente esta dinámica y posicionamiento modal, que figura en su comprensión del Logos: su repentino fulgor pone todo lo presente bajo su luz, como una posada que recoge y liga, al tiempo que abre el horizonte de lo que se oculta desde sus contornos fugaces. La visibilidad de tal destello, solo es posible en un emplazamiento del hombre en la tempestad del ser (VA: 214[164]), es decir, en el marco relacional acontecimental.

\section{2. b.I.- La dimensión de lo insonoro.}

Ahora bien, desde esta perspectiva retoma el desvío moderno de la significación originaria del Logos, con el objeto de abordar tales dinámicas en torno el aspecto sonoro del lenguaje, profundizando así su desplazamiento de los marcos proposicionales y representativos del lenguaje.

Distingue que en la tradición metafísica se entendió el lenguaje como una articulación fonética (phoné) y de significación (semainein), al poner en primer lugar la dimensión expresiva $^{402}$.Estas consecuencias en la comprensión del término, reciben el contrapeso del pensar transicional de Heidegger, quien distingue que la palabra del otro pensar es siempre provisional,

\footnotetext{
${ }^{401}$ Con ello destaca la necesariedad del decir enunciativo, en tanto punto de partida ineludible para estos análisis, lo cual evidencia ciertas continuidades con los planteamientos tradicionales. Para un análisis de tales continuidades y desplazamientos del decir enunciativo del Ereignis o acontecimiento del ser, de Aristóteles a Heidegger, véase Rubín (2012):34-9

${ }^{402}$ Frente a esto, en estas elaboraciones sostiene que con Heráclito se pensó fugazmente el lenguaje a partir del ser, al entender Logos como el ser del ente. Asimismo, el pensamiento de Parménides entendió que pensar y ser son recíprocos, estableciendo una continuidad entre el pensar, lo pensado y el lenguaje (entendido como lo expresado, lo hablado).De este modo, subraya la región del pensamiento presocrático como localización de un pensar originario del ser: allí localiza el primer inicio de tal pensar. Cf. EM: 10-3[22-6]; 73-88 [92-109]; 96-149 [118-76].
} 
sin autor ni atractivo, más bien pobre en imágenes puesto que se orienta a la profundidad del enigma de lo que se retrae ${ }^{403}$ (Ibid.:220[169]). En este sentido, el lenguaje se manifiesta como señor del hombre, con una mismidad a la medida de tal habitar (Ibíd.: 141[109]).

Específicamente, aquella reducción al aspecto expresivo se remonta a los análisis de Aristóteles, quien recabó en el fenómeno fónico del hablar, cuya relación sígnica con los estados del alma se explicaron desde el carácter fisiológico de formación de sonidos, en cuyo trasfondo la comprensión de la Ousia como presencia comanda la interpretación. Frente a ello, Heidegger destaca la sonoridad que emerge a partir del Decir donde se cumple el dejar-aparecer el mundo en las cosas, de modo tal que la voz no queda reducida a un hecho fisiológico, sino que remite a una resonancia en el hablar con su origen en el decir desde el $\operatorname{Logos}^{404}$.

Así, entiende que al oír palabras escuchamos la voz de lo hablado, que habita en el ámbito originario desde el cual nos habla. De este ámbito que nos envía la palabra, oculto y aún no pensado, se revela esta como tal y, separado de aquel, deviene un lenguaje desarraigado, como el caso de las habladurías. Por ello es preciso atender el Decir en las palabras, un decir que señala aquél ámbito o fuente originaria. Esto le permite subrayar que la palabra sonante y proferida por el ser humano siempre regresa a lo insonoro, recibiendo su determinación desde allí y modalizando con ello su habitar.

En efecto, tal modulación del hombre en la relación, es profundizada en el contexto semántico de sintagmas como el lenguaje es la casa del ser (BH: 313[259]), buscando señalar con ello la esencia del lenguaje y haciendo referencia a la morada en la cual habita el hombre, inscripta en el tránsito hacia el otro inicio. Más detenidamente, la expresión casa del ser no parece remitir a un concepto del lenguaje ni se reduce a una forma metafórica del pensar, sino que alude a un modo de dejar la palabra al lenguaje (Rede) mismo, donde la palabra deviene seña (Wink) y deja de comprenderse como signo (US:106-13[102-8]) ${ }^{405}$.Al referir la esencia del lenguaje a este señalar profundiza su desplazamiento de la modalidad metafísica de referencia, de modo tal que le

\footnotetext{
${ }^{403}$ En este contexto subraya que ante el silencio del lenguaje queda tan solo lo que mientan las palabras, que invitan a una escucha de tal silencio (VA: 142 s. [109]).

${ }^{404}$ Sin descartar los aspectos físicos y sensibles del lenguaje, es decir, la voz y lo escrito, insiste en no reducirlos a fenómenos del aparato de de fonación o corpóreos, sino que busca despejar el ámbito esencial de tal vocalizar y sonar. Para ello, en línea con el desplazamiento desde la analítica del Dasein hasta estas elaboraciones, circunscribe su análisis desde la perspectiva de los ámbitos originarios y formales, cuyo alcance se hallaría limitado desde aquella perspectiva antropológica o instrumental del lenguaje.

${ }^{405}$ En la publicación de su diálogo "inquisidor" con un japonés, indaga en torno al término apropiado para la esencia del lenguaje, poniendo énfasis en la esterilidad de los esfuerzos voluntarios y denotativos en la significación que se ciñen el ámbito enunciativo del lenguaje. Pues para nombrar la esencia del lenguaje es necesaria una "palabra" que no tenga nada de lingüístico (como si ha ocurrido con el término lenguaje), una suerte de seña que apunte hacia ella, al tiempo que sugiera que de ella nos viene (asociada al gesto-Gebärde- y distinguida de los signos y cifras- Zeichen und Chiffern- , caracteres propios de la tradición metafísica). Véase US: 102 ss. [98 ss.]
} 
permitan centrarse en las señas del mensaje y terciarizar a los hombres como los respectivos mensajeros $^{406}$.

Desde allí destaca que son los pensadores y los poetas las figuras respectivas para aquellos mensajeros y guardianes de tal morada. Para ello deben liberar al lenguaje de las limitaciones de la gramática tradicional y la interpretación técnica del pensar, obteniendo un orden más originario y un tratamiento apropiado ${ }^{407}$.

\section{2. b.II.- Horizontes para un lenguaje no tecnificado.}

Ahora bien, la decadencia del lenguaje que representa la modalidad técnica, se cristaliza en manifestaciones comunicacionales que se proponen extender la objetivación de lo que es, como modo de acceso uniforme de todos a todo. Con ello se despliega una devastación del lenguaje en su carácter originario, que es correlativa a la amenaza hacia la esencia del hombre con su consecuente apertura de lo ente en la objetivación incondicionada. Tal decadencia se articula con el dominio de la metafísica moderna de la subjetividad ${ }^{408}$ y se contrapone al modo de entrega del hombre en otra relación con el ser, como sostiene en este pasaje:

"La metafísica se cierra al sencillo hecho esencial de que el hombre solo se presenta en su esencia en la medida en que es interpelado por el ser. Solo por esa llamada 'ha' encontrado el hombre dónde habita su esencia. Solo por ese habitar 'tiene' el 'lenguaje' a modo de morada que preserva el carácter extático de su esencia. Estar en el claro del ser es lo que denomino ex-sistencia del hombre.A estar en el claro del ser es a lo que yo llamo la ex-sistencia (Ek-sistenz) del hombre” (BH: 323-324[267])

\footnotetext{
${ }^{406}$ No obstante insiste en el carácter transicional de tal señalamiento, por el cual comprende su labor como un estar en camino (unterwegs) a la esencia del lenguaje.

407 A este respecto, sostiene:'Si el hombre quiere volver a encontrarse alguna vez en la vecindad del ser, tiene que aprender previamente a existir prescindiendo de nombres. Tiene que reconocer en la misma medida tanto la seducción la seducción de la opinión pública como la impotencia de lo privado. Antes de hablar, el hombre debe dejarse interpelar de nuevo por el ser, con el peligro de que, bajo este reclamo, él tenga poco o raras veces algo que decir". (BH:.319[263])

${ }^{408}$ En este contexto se articula la producción fonal de signos en el lenguaje de la técnica, respecto a lo cual sostiene : "...son las posibilidades técnicas de las maquinas las que prescriben como el lenguaje puede y debe ser todavía lenguaje. Forma y carácter del lenguaje se determinan conforme a las posibilidades técnicas de la producción formal de signos (...) La forma del lenguaje viene determinada por la técnica (...) Pero aún así las tareas lingüísticas vendrían de antemano y por principio ligadas a la máquina, que en todas partes exige la univocidad de los signos y de las secuencias de signos. De ahí que por principio una poesía sea algo que no puede programarse” (UStS: 24 s. [13]).
} 
Este carácter extático remite a un modo de estar dentro y fuera del claro del ser, correlativo al lenguaje originario como advenimiento del ser, que aclara y oculta. Es decir, el hombre, al hablar, dice lo que oye del Decir originario: su palabra sonora es derivada de aquella palabra silenciosa ${ }^{409}$, lo cual permite subrayar el carácter ineludiblemente relacional del hombre respecto al ser y al lenguaje. En este marco, la ley del pensar no es la de la lógica, sino consecuencia de tal Decir del ser. Por ello entiende necesario meditar qué hay que decir acerca del ser y cómo hay que decirlo, no en el sentido del cálculo y la planificación, sino mediante una rigurosidad en la reflexión, el cuidado y la parquedad de las palabras.

Así, tal decir marca la proximidad que conduce a la poesía, en un dejar aparecer que es simultáneamente luminoso y ocultador (WS: 191[181]). Precisamente desde allí, se articula el decir poético en relación con aquél cuádruple ámbito que remite a la relación de todas las relaciones.

El lenguaje no tecnificado respectivo conserva y guarda hacia nuevas posibilidades al lenguaje ya hablado, al contener y donar lo inhablado, de modo que lo salvador de la decadencia del lenguaje se halla en su misterio inherente, aquél que pone en la proximidad de lo no dicho y de lo inefable. Precisamente esto modaliza a su respectivo partenaire u ámbito de resonancia:"el hombre es empleado para decir de nuevo el mundo desde el lenguaje así mantenido, haciendo de este modo que salga a la luz, que salga a brillar y verse lo todavía no visto. Éste es el oficio del poeta” (UStS: 27[15]). Examinemos brevemente esta figura del poeta desde sus consideraciones y relaciones con esta modalidad en transición respecto al lenguaje del mundo de la técnica.

\section{2. b.III- Hacia un decir y pensar poético.}

Para nuestro autor, el pensar poético y su decir, ponen al poeta en el habitar correlativo al pensar del otro inicio. Esto se debe a que la poesía permite aquel despliegue del desocultamientoocultamiento del ser, haciendo acontecer el espacio abierto donde lo ente brilla y resuena (Hw: 60[52]). Estima la poesía como lugar privilegiado entre las artes, puesto que instala lo nuevo por medio del lenguaje. $Y$ en este marco, Hölderlin es una figura paradigmática ${ }^{410}$.

En efecto, si el ser es el instituirse de las aperturas originarias, los eventos inaugurales tienen su sede en la poesía, es decir, esta tiene un alcance ontológicamente fundante. Ello no debe

\footnotetext{
${ }^{409}$ La palabra silenciosa y el decir vocante derivado remite a la co-pertenencia del Ereignis: aquel es un decir que corresponde como eco (Gegensage) del decir originario .Por el contrario, la enunciación que oculta u omite este ámbito originario, remite a la co-pertenecia con el ser del mundo de la técnica y la tradición metafísica.

${ }^{410}$ Sugiere que Holderlin le proporciono los impulsos decisivos, cuyos poemas fueron como un terremoto para sus tiempos de estudiante (WS: 172[163]).
} 
comprenderse desde los imperativos voluntaristas de la metafísica de la subjetividad: tales eventos remiten a una relación y no a un obrar directo. En este marco entiende la condición del poeta en términos de riesgo, cuya función es poner al mundo de la experiencia en mediación con lo sagrado, con su apertura total. En este sentido, el poeta funda, siempre al límite con el abismo del proceso de fundamentación-desfundamentación (y no en el marco de una práctica en la lengua del bien decir), a partir de una experiencia que transita con/desde el Habla. El lenguaje poético cumple así una función inaugural, de modo tal que también funciona como ocaso propio de y en el lenguaje, pues revela la capacidad de embestir contra sus propios límites ${ }^{411}$.

En este tratamiento, distingue que el arte cumple un rol fundamental en un mundo cada vez más tecnificado donde lo sagrado se ha retirado y el cálculo planetario de la técnica moderna se reduce a contar hechos, descuidando así las palabras en su potencial ${ }^{412}$. Retomando el verso de Holderlin: “¿Para qué poetas en tiempos menesterosos?”, nuestro autor inscribe la necesidad en su determinación para evocar lo sagrado y su recuerdo en un mundo desencantado ${ }^{413}$. En este sentido, la posibilidad de salvación del hombre es habitar poéticamente sobre la tierra, desde una función eminente, articulado con la consideración del Ethos originario, tal como caracteriza en este fragmento:

"Esos que son un soplo más arriesgados se arriesgan en el lenguaje. Son esos decidores que dicen más. Porque ese soplo más al que se arriesgan, no es solo un decir en general, sino que tal soplo es otro soplo, otro decir distinto al decir humano. El otro soplo no pretende tal o cual objeto, sino que se trata de un soplo por nada (...) Expresan lo callado (...) Los más arriesgados son los que quieren más, desde el momento en que quieren de otra manera que la autoimposición intencional de la objetivación del mundo (...) Los poetas del género de esos más arriesgados se encuentran en camino hacia la huella de lo sagrado, porque experimentan como tal la falta de salvación.” (Hw: 293 s. [236-238])

\footnotetext{
${ }^{411}$ En este marco Vattimo, tomando conceptos de Lacan, sostiene que la consideración heideggeriana de la poesía como ocaso del lenguaje, suspende la vigencia de lo simbólico y los espejismos de lo imaginario, cargando positivamente el arte (Vattimo, 1992:84). Con ello, busca desligar la perspectiva de Heidegger de las imputaciones de priorización o imperialismo del significante que ha recibido en las recepciones posteriores, inscribiéndose así en las polémicas contra los centralismos jerárquicos en las teorías del lenguaje, en auge desde finales del siglo XX, tal como veremos en el próximo capítulo.

${ }_{412}$ Para un desarrollo e interpretación de estas elaboraciones sobre la técnica en su carácter amenazante y el sitial del poeta como contrapunto semántico de la metafísica del sujeto y el mundo de la técnica, véase Carrera Aizpitarte (2014):32-40.

${ }^{413}$ En este marco de la re definición del lenguaje sostiene que solo desde la verdad del ser puede plantearse la existencia de lo sagrado, donde puede plantearse la esencia de la divinidad. Y desde allí puede ser pensado y dicho lo que debe nombrar la palabra "dios", es decir, bajo la condición de redefinir el lenguaje desde otra relación con el ser. Véase BH: $351[287]$.
} 
Con esta modalización del decir, Heidegger destaca las dos figuras apropiadas y vecinas para este camino del pensar, el pensador y el poeta: mientras el primero dice el ser, el poeta nombra lo sagrado, es decir, alude a ese ámbito dinámico vedado para un lenguaje técnico y un pensar representativo. En tránsito hacia aquél pensar que retoma el fundamento olvidado por la metafísica, entiende que en la cotidianidad moramos en el lenguaje de un modo impoético (VA: 197[151]), frente al habitar del poeta que está abierto a lo insospechado que resuena en su decir. Para Heidegger la experiencia en camino hacia la esencia del lenguaje, requiere la confluencia de ambos, como el modo más adecuado de relación.

En este contexto, destaca que la localización del lenguaje y del ser no es representable , pues ella dona lugares en que se hace manifiesto el desocultamiento y lo presente ${ }^{414}$.Y ante la exhortación de la urgencia que proviene de aquella fuente abismática sumida en el olvido , obstruida por un pensar y un lenguaje técnico, la morada de la existencia humana es su propia palabra (WS:149[143]), de modo tal que hacer una experiencia respectiva no puede asociarse a la mera adquisición de conocimientos, sino mas bien remite al abandono de las habitualidades de nuestra comprensión, siguiendo la indicación de aquellos caminos que ya existen y que el pensar debe retomar .

Encontramos aquí, la misma estructura mediada y relacional que vimos en el capítulo anterior, lo cual permite entender al pensador y al poeta como figuras de la ipseidad desde el lenguaje. Asimismo, tales distinciones nuevamente suponen dos tesis complementarias de Heidegger, esta vez respecto al lenguaje : a) las superficies del lenguaje son el único escenario donde se articula este camino del pensar, con un carácter lábil, dinámico, provisional debido al Decir que le antecede ; b) solo a partir de las articulaciones en modos determinados, puede abrirse una manifestación o resonancia esquiva y fugaz de aquel ámbito originario, a través de los sesgos o grietas implícitas en el carácter contingente y provisional de la palabra proferida ${ }^{415}$.

Por ello insiste en que es aquel ámbito pre-subjetivo y pre-lingüístico aquello que dinamiza el Habla y el que permite resaltar la figura del poeta como capaz de llevar poéticamente su experiencia, en cuyo poema queda nombrado el sitial donde debe articularse la renuncia, en una experiencia que solo puede ser alusiva y por resonancia, a partir de una inadecuación irreductible, tal como connota en este pasaje:

\footnotetext{
${ }^{414}$ En este sentido el pensar respectivo puede considerarse como topológico o localizador, el cual utiliza el lenguaje de manera meditada, de modo tal que permita dar cuenta de nuestra inserción en una región del acontecer de la verdad del ser. Para un análisis de la consideración topológica del pensar en torno al ser y la esencia del lenguaje, véase Pöggeler (1993):338-361.

${ }^{415}$ Aquí pueden establecerse resonancias con la consideración del ser-para-la-muerte de la analítica: ¿no es acaso el asumir la palabra en su límite más propio, su declinar y frágil contingencia, lo que permite una relación propia con el ámbito originario del Habla?
} 
"Pero ¿dónde habla el habla como tal habla? Habla curiosamente allí donde no encontramos la palabra adecuada, cuando algo nos concierne, nos arrastra, nos oprime o nos anima. Dejamos entonces lo que tenemos en mente en lo inhablado y vivimos, sin apenas reparar en ello, unos instantes en los que el habla misma nos ha rozado fugazmente y desde lejos con su esencia”. (Ibid.:151[145])

No obstante la figura del poeta también debe ser interpretada, teniendo como base semántica algunas imágenes tradicionales respectivas, en el marco de la comprensión metafísica y su relación con el lenguaje: los poetas entendidos como aquellos que buscaban las palabras para sus experiencias interiores, cuyo dilema pone el énfasis en la relación subjetiva entre palabra y pensamiento. Frente a ello, nuestro autor propone entenderlo como aquel que se ubica en lo interdicto, único ámbito posible desde donde debe brotar la profundidad de aquello inefable y el abismo desde donde se da el ser a la palabra. Desde tal posición, la palabra auténtica resultante, en relación con aquella palabra originaria (Ur-wort), permite que advenga la dinámica originaria que abre las posibilidades de significación, preservando su riqueza inagotable (US: 209-16[199-205]) ${ }^{416 .}$

De este modo la experiencia del tránsito en un dirigirse hacia, articula un camino que no remite a un eso de llegada, sino que pone el énfasis en la dirección y el camino mismo. En este sentido el decir del ser se despliega desde las articulaciones sedimentadas en el lenguaje, en una suerte de vibración dinámica desde el Habla y su Decir ${ }^{417}$. Este escenario abismático originario, impacta y modula el pensar y el decir, incluso la posición y el habitar del existente humano que le son correlativos. En otras palabras: el pensar, desde los enredos de un habla insuficiente, se encamina hacia esta región donde el pensamiento inicial tiene su morada, es decir, en su vecindad

\footnotetext{
416 En este sentido, un intérprete subraya: "Heidegger enfatiza el carácter ontológico de la voz poética (...) En consecuencia, el ser ya no es considerado como una entidad independiente del acontecer lingüístico, sino como un fruto de éste. Sin embargo, esta relación no debe ser entendida en términos de causa y efecto, productor y producto, pues con ello se estaría postulando la disolución de la realidad bajo el imperio de la palabra. Debe quedar claro que la crítica a la concepción realista del ser no se transforma en una posición absolutista del lenguaje” Rocha de la Torre (2005):14 s. Entendemos que no es posible interpretar esta posición absolutista, debido a la diferencia y alteridad irreductible que también atraviesa la distinción entre lenguaje y Habla.

${ }^{417}$ Rorty sigue algunas proyecciones de esta articulación al distinguir que el Ser es aquello de lo que tratan los vocabularios finales, por lo cual entiende que seríamos, en tanto existentes, tan solo las palabras que utilizamos, un temprano verso en el poema del ser, y que solo una perspectiva metafísica pretendería que somos algo más que ello. Por ello interpreta en una dimensión no clausurable un sentido normativo en Heidegger, que se halla velado en la consideración de la primordialidad de una comprensión del ser respecto a otra. Dicha dimensión facilita captar su propia contingencia frente a una modalidad relacional metafísica con el lenguaje, como especifica en este fragmento: “ A medida que se sigue la lista de palabras que expresan 'ser' en occidente, se comprueba que las personas que utilizan aquellas palabras cada vez son menos capaces de escuchar sus propias palabras, cada vez más irreflexivas-donde 'irreflexivas' significa algo como ‘incapaces de imaginar alternativas a ellas mismas'”'(Rorty 1993:70)
} 
con la poesía. Y precisamente en esta vecindad, el pensamiento confía en un dejarse decir de lo que se oculta, en aquello que es hablado ${ }^{418}$.

Reencontramos aquí el recurso a la modalizacion a partir de una alteridad ineludible del lenguaje: en el pensar poético no se manifiesta una renuncia a la palabra, sino más bien a su relación tradicional con la cosa (que tradicionalmente está representada con los componentes mismos en esta relación). Con ello logra despejarse el carácter no clausurable de la palabra, que encuentra en el poeta su mejor guardián, remitiéndose a la palabra originaria y considerando que no puede asirse aquella palabra por la cual adviene la palabra determinada ${ }^{419}$.En lugar de aquel planteo tradicional, Heidegger lo expresa de un modo dinámico : la palabra originaria es donante .Con ello, subraya que una referencia a la esencia de la palabra no puede decir que es sino que ella $d a$ (es gibt), o bien, que no es algo dado, sino que da el ser en su decir (simultáneamente desocultando-ocultando), aspecto dinámico que también resuena en el callar, la alusión y la metáfora $^{420}$.

\section{2. b. IV. La pregunta por la mismidad en su dinámica de tránsito.}

En la misma línea, considerando que la ipseidad figura en la ejecución del propio pensamiento de Heidegger, distinguimos que las elaboraciones sobre la mismidad en los Beiträge destacan su relación mediada con el Ereignis y el punto de partida ineludible desde las articulaciones o determinaciones ya dadas. Allí desarrolla estas consideraciones a partir del hombre

\footnotetext{
418 Respecto a lo cual, agrega: “...la verdadera actitud de pensar no es plantear preguntas; sino prestar oído al consentimiento de aquello que debe ponerse en cuestión (...) Hace algún tiempo al final de una conferencia titulada `La pregunta por la técnica', se dijo: 'Pues preguntar es la devoción del pensar' Devoción se entiende aquí en el antiguo sentido de: obediencia, en este caso a lo que el pensamiento tiene por pensar. Es de las experiencias estimulantes del pensamiento, que a veces no logra comprender del todo las nuevas visiones que acaba de alcanzar y que no las satisface en su justa medida" (US: 165[157]).

419 En estas expresiones, aparentemente tautológicas o contradictorias, los términos repetidos remiten a las dos dimensiones: en el primer caso al ámbito de la palabra originaria, que resuena en lo dicho y, en el segundo, a la palabra proferida, necesaria para poner en manifiesto aquella.

${ }^{420}$ En este marco se inscribe la crítica de Badiou sobre la tesis heideggeriana de la relación entre filosofía y poesía. Sostiene que Heidegger, al no valorar el recurso platónico al matema (que organiza la distancia entre filosofía y poesía, pero manteniendo la relación) restauro la autoridad sagrada de la dicción poética cuyo origen es presocrático, de modo tal que "profetiza en vano una reactivación de lo sagrado en el apareamiento indescifrable del decir de los poetas y del pensar de los pensadores". Frente a lo cual sostiene: "cuando la situación está saturada por su propia norma, cuando el cálculo es inscrito sin descanso, cuando no hay vacio entre saber y prever, entonces es preciso poéticamente estar listo a salir fuera de sí mismo. Pues la nominación de un acontecimiento, en el sentido en que hablo, suplementacion indecidible, debe ser nombrada para advenir a un ser-fiel, esto es a una verdad; esta nominación es siempre poética. Para nombrar un suplemento, un azar, un incalculable, es preciso apoyarse en el vacio del sentido, en la ausencia de las significaciones establecidas, con peligro de la lengua. Es necesario entonces poetizar, y el nombre poético del acontecimiento es lo que nos lanza fuera de nosotros mismos, a través del cerco en llamas de las previsiones" (Badiou, 1999: 4 s.). Con esta concepción de lo poético este intérprete se propone reinscribir el término en una teoría del lenguaje no trascendental, con el énfasis puesto en su dimensión no clausurable, señalando una insuficiencia respectiva en los desarrollos de Heidegger. A nuestro entender tal tentativa no es más que una radicalización de la perspectiva de base de nuestro autor.
} 
en el mundo de la técnica, aunque contraponiéndose a todo culto antropológico por el yo, la conciencia, la personalidad o la cultura, pues entiende que la mismidad implica una copertenencia con el ser.

En efecto, subraya que el sí mismo se origina en un dejar ser fundamento por parte del hombre (BPE: 33[43]).En el parágrafo donde desplaza la pregunta por el quién hacia la pregunta por el quiénes somos (retomando de este modo el carácter constelado del ser-con de las elaboraciones de juventud) destaca que la mismidad se apropia en el pertenecer a la verdad del ser, por fuera de todas las tentativas de certeza y distinción propias de la esfera del ego. En línea con aquella caracterización del poeta y el pensador, la meditación, la pertenencia y el dejar ser permiten el advenimiento de lo otro, del hombre venidero, en un pensar inicial que no se expresa en la proposición. Un preguntar que no puede concebirse si no es mediado en una relación con el ser realizado en el Ereignis (BPE: 48-54[55-9]).

En este contexto de mediación, la meditación en torno al sí mismo debe sustraerse del cálculo, sin tomar al hombre como algo dado a la mano, fundándose desde la verdad del ser. Aquí nuestro autor reconoce sus elaboraciones de la época de SuZ como una primera mitad de este camino de meditación (Ibíd.: 67-9[68-70]; 319-21[259-61]).

En suma, tanto el decir y el pensar poético, como esta reelaboración de la pregunta por la mismidad, requieren de un tránsito por las determinaciones y articulaciones ya dadas, en un marco relacional de mediación que se evidencia como irreductible.

Ahora bien ¿es posible distinguir aspectos de este camino del decir y la mismidad en la propia manifestación discursiva que articula el pensamiento de Heidegger? ¿Puede este pensamiento inscribirse como una figura correlativa al tránsito del pensar y decir poético?

\section{3.-La modalización discursiva de Heidegger.}

Como vemos, estas consideraciones requieren no solo una modulación del pensar y el decir, sino una re-consideración de la relación con el lenguaje, en lo que respecta a la respectiva participación. El nivel de abstracción que implican la aprehensión de estos ámbitos pre-ontológicos y pre-subjetivos, procesuales, no clausurables, impactan ineludiblemente en la posición de enunciación, tal y como figura en los nombres que utiliza sucesivamente nuestro autor: hombre, 
Dasein, pensador, poeta, mortales, etc. Es decir, posiciones y temples capaces de soportar torsiones, desplazamientos, giros, saltos, umbrales de espera y co-relaciones simultáneas. Asimismo, demanda un tono discursivo singular, con notas que remiten a la correlación entre tales dimensiones del decir, a partir de variadas orientaciones ${ }^{421}$.Precisamente desde este marco podemos cotejar parte del propio discurrir discursivo de Heidegger, aunque sin intención exhaustiva.

En efecto, el despliegue enunciativo de nuestro autor, a lo largo de sus cursos, seminarios y escritos se caracteriza de un modo procesual y dinámico, en íntima correlatividad con las consideraciones del carácter proyectivo del Dasein, en su mismidad e ipseidad propia y en su irreductible alteridad ${ }^{422}$. El uso de términos que se constituyen en la propia operación discursiva, la modalidad alusiva y metafórica, el desplazamiento de significaciones y vinculaciones en los campos semánticos ,la puesta en tensión y al límite dentro de ellos, el carácter provisorio de énfasis y perspectivas como condición para el despejamiento de ámbitos originarios en el Habla , entre otras cuestiones, dan cuenta de la modalidad singular del discurso de Heidegger ${ }^{423}$ que bien puede entenderse como su propia figura de la ipseidad proyectada en el lenguaje , única localización topológica posible luego de la desustancialización y temporeidad a la que arribaron sus elaboraciones de la década de 1920.

En primer lugar, podemos examinar el tratamiento específico de términos y su articulación sintáctica , que interpretamos como modo de dar cuenta implícitamente de su perspectiva en torno a la relación con el lenguaje enunciativo y proposicional, los cuales permiten la confluencia de notas de provisionalidad (en vistas al horizonte inagotable del ser el cual, por su índole abismática ,

\footnotetext{
${ }^{421}$ En este sentido la experiencia de los diferentes traductores de Heidegger pueden ofrecer elementos para las distinciones respectivas. Por ejemplo, Jiménez Redondo comenta: "Traducir a Heidegger tiene varios problemas. Uno de ellos es que hay que conseguir hablar claro, pero a la vez, lo que se dice, aparte de claro, tiene que ser denso, retorcido, atormentado. Si no, no es Heidegger; y además hay que hablar muy engoladamente, en tono muy profesoral". Jiménez Redondo (2015):100. Por su parte, Steiner distingue cierta arbitrariedad en la frecuentación etimológica de términos y conceptos, en Steiner (1989):26.

${ }^{422}$ En el contexto de SuZ, Gaos caracteriza su enunciación a partir de tres formas de proceder: a) Poner en tensión y al límite expresiones, sustantivando categorías, conjunciones, etc. de su propia lengua; b) utilizar en sentido etimológico expresiones cuyo empleo cotidiano se halle desplazado de tales significaciones; c) realizar juegos de palabras, por ejemplo, plantear nuevas relaciones entre formas y significaciones cotidianas. Desde allí , sostiene : "La filosofía de Heidegger es una filosofía característicamente filológica o lingüística, en el sentido de que sus filosofemas consisten en considerable proporción en hacer explícito el sentido que se encuentra implícito en las expresiones de lenguas determinadas, la alemana, la griega, y en hacerlo explícito no sólo por medio de otras expresiones que lo enuncien, sino de preferencia haciendo resaltar la forma de aquellas mismas expresiones y el sentido anejo a esta forma" Véase Gaos (1996)8-10. Cf. Adrian (2011c):90.

${ }^{423}$ A este respecto, Gadamer distingue ciertas limitaciones irrebasables en tal modalización asociativa del lenguaje:"No hay lenguajes privados. Heidegger piensa y escribe en alemán. Es cierto que las libertades que se toma con las posibilidades del alemán, las que busca y encuentra para articular su pensamiento, es inusualmente grande. Pero sigue manteniéndose dentro de los límites de su lengua materna. Se limita casi por completo al campo semántico y sus efectos sintácticos inmediatos. Esta es la libertad que propiamente descubre: la de los significados que las palabras tiene habitualmente, del sentido que obtienen del contexto. Pero también se atreve a desligarse del contexto mismo que las palabras tienen en los textos de pensadores y poetas, y a menudo recarga el sentido lateral no pensado de una palabra y lo convierte en sentido contrario para dar palabras a su pensamiento"(Gadamer ,2002:227)
} 
dinámica y temporal, no permite una clausura por parte de la palabra proferida) y necesariedad ( pues, de un modo análogo a la alegoría del rayo, precisa de tales determinaciones provisionales para que resuene la región del Habla, del ser y del claro, desde su esquivo ocultamiento). A modo de ejemplo podemos seguir el despliegue de términos tales como Dasein y Ereignis, los cuales se co-producen en su propia marcha y articulación en el discurso, es decir, al hablar de ellos en simultáneo con el modo en que lo hace ${ }^{424}$. De este modo, distinguimos una dimensión significativa procesual que requiere del discurso para su despliegue. En parte se debe a que el horizonte al que se dirige tal discurrir no es calculable ni determinable, sino que se manifiesta más bien en el tránsito del lenguaje, desde su propia superficie ${ }^{425}$.

Por ello Heidegger insiste en que tales términos son más bien conductores o palabras-guía (Leitwort) para el pensar, las cuales permiten, gracias a su carácter dinámico no clausurable, trazar vías y despliegues desde puntos de apoyo, señalando y preservando ámbitos de alteridad radical implícitos en tal diferimiento. Se sirve de ello para apartarse de toda absolutización de la filosofía de la conciencia con sus notas voluntaristas, las cuales se presentan como garantes y motoras de las dinámicas en cuestión. $\mathrm{Y}$ precisamente en este sentido es donde podemos articular una interpretación de la mismidad del Dasein a partir de su despliegue en el lenguaje: ese tránsito, propio del carácter proyectivo del Dasein, que recibe del ser y el Habla su exhortación, se inscribe en el lenguaje como ámbito donde es posible un habitar respectivo, en cuya proyección simultáneamente se constituye. En este marco, referirse a un primer y segundo Heidegger, respecto a su desarrollo discursivo, solo es posible en el contexto de cierto recorte de un campo temático, por el cual se requiera establecer aquella discontinuidad como contraste. Fuera de ello, entendemos que sus vaivenes y transformaciones forman parte de una continuidad-diversidad productiva, tal y como puede considerarse con la tematización del Dasein en la analítica de 1920 y su posterior abandono de punto de enfoque: este paso requiere necesariamente del anterior.

Por otra parte, la relación con las significaciones reviste cierta singularidad. En textos como Gelassenheit (1959), por ejemplo, nuestro autor opera apoyándose en significados originales de términos o componentes de ciertas palabras, relevantes para su camino del pensar. A partir de ello, vuelve a cotejar las interpretaciones en su recepción en la tradición metafísica, resaltando su

\footnotetext{
${ }^{424}$ En este sentido, Santiesteban acuña para esta modalidad de articulación la nominación de discursos pragmáticopoiéticos. Véase Santiesteban (2009):149; 169.

${ }^{425}$ Contraria a esta modulación, un pensar representativo y un lenguaje técnico se despliegan hacia metas determinadas, bajo el influjo de la certeza con sus promesas de consistencia, totalización y determinación definitiva. En este marco, el lenguaje es entendido como un medio que se extiende hacia tales metas y no una superficie de emergencia. Asimismo, ello supone un plano trascendente regulatorio que bien puede corresponder a una subjetividad trascendental o a cierta concepción de la verdad como adecuación al ente cierto.
} 
carácter de desvío o desplazamiento, con el objeto de despejar el suelo móvil originario ${ }^{426}$. Asimismo, la articulación posterior de tales términos permite acuñar una nueva significación, en lugar de la anterior, que se propone recubrir dinámicas ya pensadas y olvidadas ${ }^{427}$. Esta nueva significación, al modificar o ampliar el campo semántico y asociativo en la que se inscribe, le permiten desplazarse desde términos que no pertenecen al uso común en la lengua alemana ${ }^{428}$.

Esta relación con los enunciados y términos responden a las exigencias de su propia búsqueda. El tránsito del significado usual al originario, para luego desplazarse de un modo nuevo, responde a la comprensión de dinámicas acontecimentales en el lenguaje, es decir, aquellas que se dan, que no se producen por voluntad, sino que solo es posible colaborar con un despejar y preservar su carácter proliferante. Por ello, no es posible una resonancia con una atención puesta a lo meramente proposicional, dimensión del lenguaje que no es desechada sino tan solo considerada como punto de partida ${ }^{429}$.

Por lo anterior, Heidegger se ha mostrado resistente a la modalidad estática de utilización académica de sus términos acuñados, desde donde se convierten en meros clisés o bien reciben una modulación que retrae su potencial dinámico y procesual, más afín con un pensar y decir de la tradición metafísica, científica y el lenguaje técnico ${ }^{430}$. Por ello, más que apresurarse en construir terminología, brega por un camino del pensar que puede transformarse y transformar aquello hacia lo cual se dirige la marcha.

\footnotetext{
${ }^{426}$ Una muestra específica de ello puede hallarse en la lista de conceptos que desplaza de su vertiente tradicional, en la lista elaborada en Kisiel (1995):410-510.

${ }^{427}$ En este marco , Gadamer distingue que el concepto nunca se desliza por completo del campo semántico en el que posee todo su significado , de modo tal que desplazarlo del todo implica un vaciamiento de sentido (Gadamer,1992:353)

${ }^{428}$ Un caso ilustrativo es el término Gelassenheit, el cual simultáneamente condensa, desplaza y altera el campo asociativo de las significaciones compartidas (en relación al verbo lassen- dejar, soltar, ceder-), en la articulación común de la lengua, pero sin descartar tales significados sino tan solo cambiando su relación. De este modo, tal palabra se convierte en un testimonio del carácter productivo inmanente a esta modalidad de relación en el lenguaje.

${ }^{429} \mathrm{Al}$ respecto enfatiza la necesidad de aceptar lo dicho como el punto de apoyo para el meditar (ZuS: 29[303]). Otro ejemplo para ello es la palabra conductora de su pensamiento desde 1936: Ereignis, que remite a un mutuo apropiarse, por lo cual Heidegger se sirve de este bajo la modalidad de escritura con y sin guiones. En un caso, para resaltar el campo asociativo y semántico, en el otro para que el término opere como conductor en el camino del pensar, el cual remite a un ámbito supremo que torna imposible ponerlo ante nosotros en un enunciado pues no es, no se da, sino que acaece apropiadoramente. (Ibid.:26-8[298-303]).

${ }^{430}$ En este marco, Heidegger no obstruye los desplazamientos en su propia terminología (la disuelve, relativiza, redefine o abandona) incluso, se manifiesta contrario a la tendencia a "heideggizar" el lenguaje por parte de sus alumnos. Véase Jiménez Redondo (2001):462 .En esta misma línea, sostiene nuestro autor:”La mirada a las dificultades del lenguaje debería ponernos en guardia para no convertir en moneda corriente el lenguaje del pensar ahora intentado, construyendo con demasiado apresuramiento una terminología, así como para no hablar ya mañana sobre la resolución en lugar de dedicar todos los esfuerzos a la penetración de nuestro pensar en lo ya expuesto. Pues lo expuesto fue dicho en un seminario. Y un seminario es, como ya lo indica la palabra, un lugar y una ocasión de arrojar aquí y allá una semilla, de dispersar un germen de meditación que tal vez algún día se abra a su manera y fructifique"(ID:79[157]). Con estos distingos señala la necesaria modalización que implica una lectura e interpretaciones de su obra. Entendemos que diversas críticas posteriores se han realizado desde una comprensión opuesta a la que nuestro autor desarrolla en su obra.
} 
Finalmente, la matriz del pensamiento de nuestro autor, es decir, su modulación y orientación semántico-comprensiva, evidencia disposiciones jerárquicas, tal y como figuran en los contrastes y oposiciones de propiedad/impropiedad; mismidad/uno mismo; lenguaje técnico/tradicional; originario/derivado; Habla/lenguaje; pensamiento griego /metafísico, entre otros. Entendemos que, en parte, esto es una de las consecuencias de la distinción binaria en su ontología, que se articula correlativamente a la consideración de la diferencia ontológica. En efecto, la distinción de planos o ámbitos ontológicamente primarios, le permiten distinguir desvíos, desplazamientos, olvidos, propiedades e impropiedades, derivas, superposiciones, etc., cuyo estatuto parece sesgado por una orientación selectiva e incluso valorativa derivada de tal jerarquización. Esta tendencia axiológica no se manifiesta en los contenidos de su enunciación (pues Heidegger rechaza explícitamente el concepto de valor) ${ }^{431}$ sino más bien en su modulación, en la orientación comprensiva que subyace a su discurso. Aun con esta posible interpretación, la disyunción inclusiva con la que presenta los contrastes, el carácter de correlatividad de tales ámbitos y el funcionamiento holístico en sus elaboraciones, nos permiten sostener que tales distinciones son condiciones necesarias para esta matriz, pero no suficientes.

En efecto, los énfasis selectivos y de superioridad, las prioridades y los peligros que se inscriben o resuenan semánticamente en el uso de términos como ser, sagrado, salvación, propiedad, autenticidad, arraigo, entre otros , parecen continuar con una modulación que ya se halla presente en la matriz del pensamiento metafísico, tradicional y representativo, propio de la filosofía de la conciencia con su carácter centralista y horizontal .No obstante, junto a los sedimentos cristalizados en la cultura e historia de su lengua materna, bien puede ello entenderse como una manifestación y figuración de la irrebasabilidad del ser-con y del lenguaje, cuyo despliegue se encuentra ante los límites infranqueables de una alteridad originaria que insiste en el seno de su dinámica. A partir de sus distinciones originarias del lenguaje, entendemos que este abismo y diferencia inmanente no es simbolizable, lo cual se evidencia como otra de las condiciones para distinguir la dimensión no clausurable del lenguaje.

En el contexto de tal distinción, la articulación provisoria y en tránsito de su pensamiento lo conducen a reevaluar el campo semántico metafísico en el que se inscriben comprensiones , interpretaciones, enunciados y términos, después de alcanzar cierto despejamiento del mismo, por medio de puestas al límite, tensiones y reorientaciones de nexos de significación, es decir : solo a partir de un trabajo de tránsito en dicho campo y sus resultados respectivos, es posible avizorar horizontes de articulación más amplios. En este sentido, entendemos que una investigación en torno

\footnotetext{
${ }^{431}$ Véase, por ejemplo, N II: 23-112[33-108].
} 
a estas elaboraciones difícilmente tenga un desarrollo pertinente si se reduce a un conjunto de enunciaciones determinadas o segmentos discursivos locales. Más aun, el despliegue discursivo de Heidegger es en sí mismo una experiencia y, como tal, puede ser abordada propiamente atendiendo su devenir, lo cual desdibuja la posibilidad de alcanzar una aprehensión acabada de la misma.

Precisamente por estas caracterizaciones interpretamos que el devenir discursivo de Heidegger es una figura de su ipseidad propia, pues remite término a término con el despliegue teórico elaborado en sus trabajos de juventud. Con mayor precisión: sostenemos que su experiencia y desarrollo del discurso pueden distinguirse como una continuidad y desarrollo práctico de una teoría de la ipseidad que ya está inscripta en sus trabajos tempranos ${ }^{432}$. Ahora bien, algunas puntualizaciones de este recorrido pueden ofrecer elementos para cotejar tales distinciones del discurso de Heidegger.

\section{4.- Vínculos entre discurso e ipseidad.}

En sus escritos alrededor de la publicación de $S u Z$ las vías fundamentales que hemos seguido para nuestro trabajo residen en la consideración del Logos, la distinción entre Habla y lenguaje enunciativo o proposicional y la consideración de las significaciones que permiten distinguir el ámbito de la comprensión y la interpretación. Este empalme de planos o ámbitos supone la posibilidad de desplazamientos y torsiones en las significaciones compartidas por el Dasein, así como también opera como respaldo de su método de destrucción fenomenológica de categorías, conceptos e interpretaciones de la tradición metafísica.

La consideración de la significación originaria y la experiencia del pensar presocrática circunscriben un ámbito móvil y no clausurable para su camino del pensar, en pos de repensar aquellas dinámicas que han caído en el olvido y la desviación moderna. Pero tal movilidad no es reductible a tal o cual articulación en el lenguaje, pues precisamente lo que pone de manifiesto aquella distinción es el carácter provisorio, precario y móvil del plano predicativo. Más bien, el carácter de fuente y reserva inagotable de la dimensión originaria del lenguaje, debido a su indeterminación, simultaneidad, multiplicidad y relacionalidad acontecimental, es lo que permite plantear dinámicas en la significación, cuyo impulso es inherente a su propio ámbito, no identificable con una capacidad o potencia del Dasein, es decir, hay una dinámica del ser que se

${ }^{432}$ De un modo más general, incluso puede pensarse desde aquí que la Khere, con sus cambios de enfoques y perspectivas, también se halla inscripta proyectivamente en sus primeras elaboraciones. 
cristaliza en significaciones, de modo tal que el Dasein participa de ella como trasmisor y ejecutor. Aun así, al entender el Habla como existenciario del Dasein orienta y limita sus elaboraciones, pues modula una inscripción del pensar bajo la égida metafísica que entiende al existente humano como centro de los análisis.

Las limitaciones con las que tropieza residen principalmente en el acceso a los campos formales originarios cuyo enfoque solo parece especificado desde el Dasein. La consideración en SuZ de la mismidad propia, su recuperación de la caída en el Uno, la proyección en tanto ipseidad aun llevan las notas antropocéntricas de las cuales busca apartarse. Entre otras resonancias, tal perspectiva deja colegir un funcionamiento holístico y simultáneo en el entramado estructural de la analítica de 1927, que desde cierta articulación remite a un orden o principio de conexión ligado a la figura central del existente humano.

Es por ello que el desplazamiento hacia un análisis desde la perspectiva del Ereignis, el Habla y la esencia del lenguaje a partir de sus elaboraciones de 1930, abre tal campo de resonancias, asociaciones e intuiciones, en desmedro no solo de toda alusión a determinaciones para dar cuenta de sus dinámicas, sino también de un lenguaje en su función referencial o representativa $^{433}$. De todos modos, es precisamente desde el resultado de la analítica del Dasein, en el marco de sus indagaciones en torno a la mismidad, referencia provisora desde donde logra avizorar y alcanzar el límite y umbral semántico que le permite abrir y retomar el trayecto, planteando un cambio de enfoque. En tal contexto ¿de qué modo seguir refiriéndose a este carácter proyectivo, inesencial, temporal e inconsistente sino desde la propia figuración en el lenguaje?

En efecto, encontramos en sus elaboraciones posteriores a 1930 que la tematización desde y en el lenguaje lo conducen a una modificación de la relación con su dimensión enunciativa: términos, campos semánticos, sintaxis, modalidades alcanzan ciertos umbrales y desplazamientos como producción del propio despliegue del mismo. De un modo análogo, la tarea que se propone Heidegger se articula en el lenguaje heredado y marcha término a término con el carácter proyectivo del Dasein: el camino modifica las estaciones y la posición de enunciación, acorde con una ipseidad propia del existente humano que no se determina de un modo definitivo. Tal y como ocurre con términos y palabras, el propio proyectar del pensar y el decir, modifica en su tránsito a todos sus co-partícipes. Es por ello que la tematización del Dasein y el hombre en estas

\footnotetext{
${ }^{433}$ En conversaciones personales, Oscar Esquisabel se pregunta: ¿cómo es posible un lenguaje significativo, pero no referencial o representativo, sin caer en la materialidad del significante? Entiende que ello sólo es posible a través de una metafísica del lenguaje (más allá de la determinación lingüística), la cual tiene que ser especulativa. Cf. Sus desarrollos en torno a la metafísica del lenguaje en Gadamer, donde distingue una herencia del espíritu hegeliano: en ese marco, el lenguaje es entendido como "autoexposición del ser", es decir, en el lenguaje el ser ,como horizonte de horizontes de sentido, se desdobla y se expone a sí mismo. A ello, contrapone la necesidad de reinstalar el carácter elaborador y creador de la subjetividad individual, aunque sin enmarcarla desde la comprensión moderna, en Esquisabel (2003):79-88.
} 
elaboraciones, radicalizan el modo de inscripción relacional, abandonando definitivamente toda perspectiva particular, aislada o parcial. La consistencia móvil y provisoria del lenguaje, su carácter no clausurable debido a la índole abismática del ser y el Habla, desde cuya fuente inagotable se impulsan las dinámicas, se manifiesta simétrica al poder-ser del Dasein, cuya mismidad propia encuentra en el lenguaje su habitar respectivo.

Asimismo, las relaciones acontecimentales entre el decir enunciativo y el Decir originario, considerando al pensador o poeta como las figuras apropiadas para tal vínculo, proyectan de un modo simétrico la dinámica estructural desplegada en sus trabajos de juventud. Por un lado, en sus trabajos de la época de SuZ, tanto el pliegue de la ipseidad propia a partir de la caída, como la consideración del uno-mismo en su transición desde la cotidianidad del Dasein(es decir, en mediaciones con aquello que los limita), se manifiestan como figuraciones de esas dinámicas donde el decir enunciativo es tomado como punto de partida ineludible para el despliegue de un Decir originario. Por otro, en sus trabajos de madurez, la co-pertenecia Dasein-ser con su ipseidad mediada, reitera aquella operación de puesta en tensión del propio campo relacional, para que desde allí pueda desplegarse y proliferar el ámbito originario en su reserva no clausurable.

En este mismo sentido, las consideraciones del silencio o lo insonoro que hemos desarrollado, manifiestan continuidades estructurales respecto a las funciones liminares que la muerte o la angustia tienen en la analítica existenciaria: estas puestas al límite permiten plantear totalizaciones de un campo de análisis determinado y dar cuenta de dinámicas proliferantes a partir de una diferencia originaria ${ }^{434}$.

De esta manera podemos distinguir dos etapas articuladas en la tematización y tratamiento de la mismidad e ipseidad en el pensamiento de Heidegger: primero desde la analítica del Dasein, en un tránsito que despeja los resabios sustancialistas y cósicos de interpretaciones de la tradición metafísica, para dar cuenta de su indeterminación proyectiva y consistencia relativa. Luego, un abordaje alusivo, indirecto y no tematizado, que encuentra en el lenguaje la superficie de despliegue y producción. Desde aquí, el impulso del proyectarse perderá todas las notas aún asociadas a la conciencia o voluntad vigentes en su analítica anterior, para dejar lugar al carácter donante y acontecimental en el marco de las experiencias de y en el lenguaje. Desde aquí, entendemos que el propio discurrir del pensamiento de Heidegger señala el ámbito en el que nuestro autor continua desplegando el tratamiento respectivo.

\footnotetext{
${ }^{434}$ Como por ejemplo: en la época de $S u Z$, la autenticidad del Dasein se dinamiza a partir de el carácter de límite del ser-para-la-muerte ; en sus trabajos de madurez, la proliferación de lo que se oculta o lo indecible, se abre a partir de la puesta en tensión con el decir y lo que se muestra.
} 
Finalmente, la consideración del carácter irrebasable del ser-con y la alteridad, encuentra su epítome en esta articulación de la mismidad desde el lenguaje, en la remisión a dicha región de alteridad radical e ineludible que se manifiesta en la palabra originaria y en la modulación del pensar que desde ella se impulsa y articula: una alteridad inmanente e ineluctable del decir , por cuya diferencia necesaria emergen las dinámicas productivas y no clausurables del lenguaje enunciativo, que se basan, a nuestro entender, en la imposibilidad de una simbolización y determinación respectiva, lo cual frustra todo intento de conjura o expulsión de este sesgo del ámbito del lenguaje .

En este marco podemos inscribir y asociar las consideraciones biográficas de Heidegger que mencionamos en el capítulo anterior: su asilamiento en la Selva negra como ámbito exclusivo de trabajo, su silencio inmediatamente posterior a su afiliación política de 1933, sus consideraciones sobre la acción directa, la transformación y el cambio, su intención expresa de resaltar el camino del pensar por sobre los énfasis puestos en el autor o su propia persona, etc. , las cuales evidencian notas en consonancia con estas perspectivas analizadas.

Ahora bien, en diferentes contextos de recepción contemporánea de su pensamiento podemos encontrar resonancias de estas elaboraciones, así como también críticas y continuidades. En especial, la recepción francesa en la línea de Ricoeur, Foucault, Deleuze , Derrida , Nancy y Lacan, manifiestan explícita e implícitamente tales proyecciones del complejo articulado entre ipseidad-alteridad-lenguaje, en el marco de las consideraciones modales del pensamiento y el lenguaje en lo que respecta a su carácter no clausurable. Como en el caso de Heidegger, esto los conduce a redefinir la modalidad de enunciación de modo tal que se distancie radicalmente de la matriz representativa, tanto del pensamiento científico como de las filosofías de la conciencia y la subjetividad.

En el próximo capítulo nos dedicaremos a distinguir algunas de las proyecciones mencionadas en perspectivas contemporáneas, deteniéndonos especialmente en su manifiesto impacto en el pensamiento de dichos autores, atendiendo variaciones, continuidades y rupturas. 
"Una literatura difiere de otra, ulterior o anterior, menos por el texto que por la manera de ser leída: si me fuera otorgado leer cualquier página actual-ésta, por ejemplo- como la leerán en el año 2.000, yo sabría cómo será la literatura del año 2.000."

(Jorge Luis Borges, Otras inquisiciones)

\section{Capitulo 8. Proyecciones, continuidades y rupturas en el pensamiento contemporáneo.}

Nuestro recorrido por el pensamiento de Heidegger en lo que respecta a la ipseidad, la alteridad, la tematización singular del existente humano y la consideración del lenguaje, en su uso y mención, en el horizonte epocal de la relación con la pregunta por el ser, nos invita a indagar en algunas de sus proyecciones y resonancias en el pensamiento filosófico contemporáneo, principalmente debido a dos motivos. Por un lado, dado que numerosos autores han continuado, tematizado o analizado algunos de estos puntos, en vista de tensiones, omisiones y en el marco de los sedimentos del estado de interpretación de la obra heideggeriana, sobre similares bases comprensivas, se torna necesario cotejar el estatuto de tales continuidades. Por otro lado, las 
perspectivas filosóficas sobre la ipseidad y alteridad, con sus figuraciones en las consideraciones de la identidad, la subjetividad y el lenguaje, se hallan en las bases de numerosos debates contemporáneos en diversos campos : los análisis del discurso, las perspectivas de género, las teorías políticas, el psicoanálisis, la ética, las teorías de la comunicación, etc., donde también puede evidenciarse una proyección de estas elaboraciones, articuladas con recepciones o apropiaciones posteriores. Por ello, dedicaremos este último capítulo a un análisis y breve comparación de algunas de estas recepciones, en el marco de los tres ejes abordados, con el objeto de dar cuenta del impacto e influjo que tiene y ha tenido nuestro autor en el pensamiento del siglo XX, así como también, de circunscribir posibles horizontes ya abiertos para continuar con los diálogos y discusiones respectivas.

Uno de los hilos conductores en estas recepciones es el énfasis puesto en la dimensión no clausurable del lenguaje (entendido en su aspecto lógico gramatical) y en la diversidad de las semióticas, colocando el aspecto pragmático en un lugar fundamental en lo referente a las relaciones con el prójimo y la ipseidad. Estos enfoques se insertan en la tradición de la crítica a la consideración instrumental de la función del lenguaje, dicha tradición encuentra en la perspectiva del lenguaje como apertura del mundo y las distinciones del primer periodo del pensamiento de Heidegger, un claro antecedente.

En este marco, la noción de tradición y sus relaciones con la dimensión abierta del lenguaje ocupan un lugar destacado en estas proyecciones inmediatas. Entendemos que este es uno de los principales puntos en discusión con el tratamiento transicional del lenguaje y su respectiva ontología. El enfoque respectivo del segundo Wittgenstein (1953), Deleuze (1968/1980) y Derrida (1967/1968) entre otros, pueden considerarse claros ejemplos del lugar que ocupa tal dimensión en el lenguaje y las teorías de la significación. La cuestión de fondo remite por un lado a la ontología respecto a una génesis del sentido y, por otro, a la consideración de la temporalidad, en diálogo con las elaboraciones en la etapa de $S u Z$. Tales perspectivas confluyen en el supuesto de la necesaria correlatividad entre ipseidad y lenguaje, así como también en la atención puesta en la articulación discursiva como modo de diálogo crítico con la propia tradición. El carácter ineludible de tal vínculo, la irrebasabilidad del ser-con, la tematización del lenguaje y la alteridad de un modo cada vez más radical, son algunos de las continuidades con el pensamiento de nuestro autor.

Ahora bien, la circunscripción y el corte en el inagotable corpus teórico de estas discusiones, así como también la elección de autores y textos respectivos, responden aquí a una triple consideración. En primer lugar, seguiremos la vía de pensamientos y textos tempranos en la recepción heideggeriana y sus reapropiaciones, relevantes para un diálogo en el campo de investigaciones en el que nos articulamos, dado que responden a intereses, temas y perspectivas que 
actualmente se desarrollan en nuestra región, desde diversas áreas y campos temáticos. En segundo lugar, buscamos atender tensiones y continuidades tempranas en el marco del triple eje que, como vimos, se encuentra fuertemente articulado: ipseidad-alteridad-lenguaje. Ello nos permitirá circunscribir un horizonte para plantear continuidades posibles en el marco de esta constelación. Por último, nuestro interés se orienta a la indagación de la recepción y articulación de las concepciones de Heidegger en el seno de diferentes mundos lingüísticos, es decir, en dilucidar la cuestión de la traductibilidad y apropiación del pensamiento de Heidegger, en el contexto histórico y social que se abre a partir de las articulaciones singulares en diversas lenguas y comprensiones, con el objeto de contar con elementos que nos permitan interpretar posibles relaciones en lo que respecta a énfasis, acentos y relevancias determinadas. Por ello, además de abordar trazos de estas resonancias en la recepción europea, indagaremos influencias en la filosofía analítica anglosajona, así como también la recepción latinoamericana, aunque sin pretensiones de exhaustividad.

Específicamente, presentaremos algunas discusiones que encontramos principalmente en trabajos de Tugendhat, Vattimo, Derrida, Gadamer, Ricoeur, Levinas, Astrada, Walton y Presas, entre otros. En el caso del pensador alemán de escuela analítica, nos remitiremos a sus análisis lingüísticos sobre la autodeterminación, para dar cuenta de algunas discusiones sobre la cuestión de la racionalidad y la deliberación, en el marco de la autodeterminación como figura de la ipseidad desde el pensamiento de Heidegger, buscando contrastar las consideraciones del lenguaje que se hallan en sus bases. Junto a Vattimo, Derrida y Gadamer, abordaremos brevemente estas recepciones europeas en torno a los vínculos entre lenguaje y política, poniendo de manifiesto enfoques diversos en torno a las mediaciones de la alteridad. Luego, indagaremos por un lado, las consideraciones de Levinas respecto a su perspectiva ética y metafísica de la relación ipseidadalteridad y por otro, las elaboraciones de la identidad en la obra de Ricoeur en los que respecta a su inescindible vinculo con el lenguaje y la narratividad, en el marco de un debate con la perspectiva ontológica del ser-con heideggeriano y las relaciones generales con el ser.

Finalmente, nos centraremos en algunos de los recorridos latinoamericanos, especialmente en un conjunto de recepciones en nuestra región de la mano de Astrada, Kusch, Presas y Walton, atendiendo consideraciones estéticas, lingüísticas y políticas que estos pensadores realizan del pensamiento heideggeriano. Tales consideraciones evidencian un desplazamiento gradual del énfasis puesto en el sujeto cultural hacia la consideración primaria del lenguaje.

La problematización con la que nos orientaremos se articula en las siguientes preguntas: a) ¿en qué medida pueden distinguirse continuidades, resonancias, rupturas o reelaboraciones en estas recepciones y discusiones?; b) ¿son legítimos los análisis y criticas manifiestas, respecto al despliegue del pensamiento de Heidegger?; c) ¿qué enfoques sobre el lenguaje y/o la ontología se 
hallan supuestos en las reapropiaciones y derivas de estos tratamientos? Finalmente d) ¿cuáles son los horizontes de diálogo y problematización que pueden distinguirse a partir de estas proyecciones y análisis?

Por la vía de estas cuestiones, nos proponemos clarificar estos ámbitos discursivos, de modo tal que evidencien el sesgo de apertura y continuidad inagotable que caracteriza estos caminos del pensar. Comencemos entonces, con la recepción de Ernst Tugendhat.

\section{1.- La consideración de la autodeterminación y la mismidad desde la perspectiva analítica de Tugendhat.}

Este filósofo alemán ha desarrollado trabajos de filosofía analítica y ética, en torno al comportamiento consigo mismo (Sichzusichverhalten), a partir del abordaje que se llevó a cabo en diversas líneas de pensamiento contemporáneo: Mead, Wittgenstein y especialmente Heidegger, su docente en Friburgo, en lo que respecta a sus consideraciones del mantenimiento de sí. En ese marco, interpreta que nuestro autor "no pudo entender la estructura de la libertad humana, y la consecuencia de esto fue, primero, que vio la necesidad de elegir solo en conexión con el ser-propio y, segundo, que no entendió que la libertad está siempre conectada con la pregunta por razones” (Tugendhat 2002:189). Desde este posicionamiento crítico, desplegó un análisis desde una consideración del lenguaje que manifiesta simultáneamente tensiones, continuidades y rupturas con los supuestos de Heidegger.

En líneas generales, encontramos trabajos de Tugendhat donde interpreta la torsión de la metafísica como determinación lingüística, abriendo una tentativa para semantizar la ontología y disolver lingüísticamente el problema del $\mathrm{Ser}^{435}$, para luego orientarse a la problematización de cuestiones éticas, en el marco de una reelaboración de las perspectivas contemporáneas de la antropología filosófica (Tugendhat 2007:39-47). Estas temáticas se articulan mediante un sistemático análisis y aclaración de términos o expresiones en su articulación discursiva.

A continuación, a partir de algunas especificaciones sobre su perspectiva del lenguaje, abordaremos sus análisis críticos respecto al mantenimiento de sí en las elaboraciones en torno a $\mathrm{SuZ}$, con el objeto no solo de cotejar el alcance de estas críticas en el contexto del pensamiento de

\footnotetext{
${ }^{435}$ En torno a esta distinción, en su relación con el pensamiento de Heidegger, véase un análisis en Zabala (2005):621 SS.
} 
Heidegger, sino también para dar cuenta de énfasis y derivas en la recepción contemporánea que articula ipseidad, ética y filosofía práctica.

\section{1. a.- Una metodología desde el lenguaje proposicional.}

Específicamente, Tugendhat entiende que los hechos se abren en un nexo de significaciones, aunque distingue en particular que la verdad se pone de manifiesto solo en el ámbito proposicional. Desde este supuesto, evalúa las elaboraciones de Heidegger, manteniéndolas rigurosamente en el plano lingüístico, en el marco de una tentativa que rechaza toda huella de irracionalismo, tal y como la efectivizó en sus trabajos críticos de finales de la década de 1960, respecto del concepto de verdad tanto en Heidegger como en Husserl $\underline{436}$.

Desde este punto de partida, la piedra de toque de sus análisis es el horizonte de comprensión epocal en el que se inscriben enunciados y discursos, rechazando la tematización del ámbito antepredicativo. No obstante, puede encontrarse cierta ambigüedad en sus abordajes respecto a las consideraciones sobre la posibilidad de ampliar los límites del comprender (Bonet, 2015:102s.).

En efecto, tal ampliación se basa en una confianza en la razón y la capacidad reflexivadeliberativa humana, lo que permite abrir el potencial del lenguaje proposicional, apartándose así del recurso a la intuición que atribuye a los recorridos de Husserl y Heidegger ${ }^{437}$. La comprensión asimilada al campo lingüístico, delimita una labor que consiste en clarificar y evidenciar lo ya comprendido, en el horizonte de la dimensión intersubjetiva y comunicacional que entiende irreductible $e^{438}$.

Esta circunscripción al uso de términos y conceptos, sus reglas gramaticales y de comunicación en el que se articulan, lo conducen a reconocer el carácter limitado y no clausurable del lenguaje con el que se cuenta, incluyendo un rechazo de todo metalenguaje y posición trascendental por fuera de las cadenas comprensivo-comunicacionales contextuales e históricas. El

\footnotetext{
${ }^{436}$ Las argumentaciones de Tugendhat respecto de la comprensión heideggeriana de verdad, se basan en la distinción de una dicotomía o valoración, que no figura como tal en el planteamiento de Heidegger, reduciendo así la complejidad dinámica con la que nuestro autor desarrolla sus análisis. En este sentido, un intérprete desarrolla este contrapunto , reconociendo también que no hay en Heidegger una descalificación implícita en el supuesto del carácter derivado del lenguaje proposicional, sino una clarificación en sus fundamentos sin descuidar las correlaciones entre ambas dimensiones, véase Doro(2010):84-103.

${ }^{437}$ Para su valoración de las ventajas del lenguaje proposicional para sus análisis, véase Tugendhat (2007): $42 \mathrm{~s}$.

${ }^{438}$ En este marco, un intérprete especifica : "Tugendhat es sin más un nominalista que trata de llevar la filosofía hacia un reconocimiento lingüístico de la comprensión "(Zabala ,2005:623).
} 
entramado remisional de tales cadenas es la vía de acceso para este horizonte comunicacional intersubjetivo.

Sus diferentes tentativas de construcción de lenguajes artificiales y uso de conceptos operatorios, se encuadran en este intento de recorrer tal entramado para dar cuenta de reglas de uso de conceptos o términos, sin reducirse al campo semántico-comprensivo de análisis. Esta metodología permite visibilizar su comprensión de base: el pensamiento es un hecho lingüístico susceptible de ampliar sus fronteras si se aboca al uso adecuado del lenguaje, colocando el carácter pragmático y racional en el centro de sus consideraciones.

Ahora bien, si la conciencia se refiere a proposiciones y significaciones desde los cuales es posible dar cuenta de objetos y hechos, entonces se torna ineludible su carácter mediado. Desde aquí plantea un giro respecto al camino de Husserl, pues entiende que la conciencia intencional implica correlativamente una conciencia proposicional. Esto supone también que la alteridad pertenece a la constitución proposicional de la conciencia, debido al carácter implícito de un horizonte intersubjetivo en las reglas de uso de expresiones con las que se mediatiza la autoremisión (Tugendhat ,2007:40). Veamos como figuran estas perspectivas, en el marco de sus consideraciones específicas respecto de la teoría heideggeriana del sí-mismo ${ }^{439}$.

\section{1. b.- El comportamiento práctico en el marco de un sentido constatable del ser.}

En su trabajo de 1979 parte desde la fenomenología husserliana para distinguir la tematización de la conciencia de algo como proposicional, con el objeto de subrayar que la autoconciencia es un estado consciente solo cuando se articula lingüísticamente (Tugendhat 1993:22). En este marco, indaga en el ámbito de significación de los términos autoconciencia, comportamiento consigo mismo, reflexión, etc., distinguiendo desde allí dos fenómenos: la autoconciencia epistémica (que se expresa en proposiciones con el yo) y el comportarse práctico consigo mismo, que usualmente utiliza oraciones intencionales ${ }^{440}$. Precisamente aquí inscribe el análisis respectivo de Heidegger, en el marco de su singular distinción sobre el sentido del ser.

\footnotetext{
439 Nos detendremos especialmente en tres de sus trabajos en torno a la mismidad, el yo y la autodeterminación: Autoconciencia y autodeterminación. Una interpretación lingüístico-analítica (1993[1979]); Problemas (2002) y Antropología como filosofia primera (2007).

${ }^{440}$ Asimismo, para la tematización de la autoconciencia y la relación consigo mismo reconoce tres modelos ontológicos y teorico-epistemologios: el de la sustancia, de raigambre aristotélica; el de la relación sujeto-objeto (que repercute en un tratamiento objetivante de si) y aquel cuyo supuesto de que todo saber empírico inmediato debe basarse en la percepción. Desde allí, distingue que la teoría tradicional de la autoconciencia, alemana e inglesa, se mueve dentro de estos tres modelos, cuyo aparato categorial fue destruido por Heidegger y Wittgenstein, quienes se levantaron contra la
} 
En primer lugar, reconoce que el análisis de Heidegger del fenómeno de la relación consigo mismo permite abandonar la consideración de la autoconciencia, para descubrir la estructura de tal comportamiento práctico (Ibíd.: 30). Distingue allí que la cuestión del soy aparece con otro significado que en la referencia al es. Es decir, al decir soy, Heidegger subraya que no me relaciono contemplativamente con mi ser como algo que está a la vista (Vorhandenes) sino que me comporto con él en la forma de preocuparme por mí, como el ser que he de ser, lo cual vimos que se encuadra en el carácter proyectivo del Dasein. Tugendhat interpreta que este "haber de ser" solo puede tratarse si el que pregunta plantea un enunciado práctico respecto al ser que ha de ser en el próximo momento, es decir, si quiere acabar con él o seguir realizándolo. Ello le permite destacar que somos entes que solo son en la medida en que se comportan con la realización de la vida que en cada momento les espera. Para Tugendhat, este comportarse respecto a sí, no se refiere a representación alguna ni a una conciencia de algo, sino a la necesidad de posicionarse enunciativamente al respecto, tal y como lo define en este pasaje:

"Consiste en que podemos decir 'si' o 'no'. Las personas no son seres que existen de manera meramente fáctica, sino que existen de tal manera que toman posición implícitamente al respecto de su existir, afirmándolo o negándolo" (Ibid.:30).

Luego, analiza desde aquí la relación práctica consigo mismo que implica una articulación con aquello que Heidegger llamó primero preocupación por sí mismo (Selbstbekümmerung), en referencia a la relación con el propio ser y el existir, y luego, cuidado (Sorge). Distingue que si el propio ser es el objeto último de preocupación, la pregunta filosófica por dicha relación práctica ha de interesarse por la estructura de lo que es relevante en cada caso, es decir, no por sí mismo solamente, sino también, por Dios, por el Ser, los otros o la sociedad ${ }^{441}$.

En esta línea inscribe el fenómeno de autodeterminación (Selbstbestimmung) el cual implica la posibilidad de tomar distancia de nuestros deseos, roles situacionales y normas por las que nos guiamos, preguntándonos ¿quién soy yo mismo en todo esto? ¿Qué es lo que yo mismo quiero? , cuya condición es suponer previamente un concepto de comportamiento consigo mismo. Aquello

concepción tradicional del comprender, entendido como una relación con objetos, y de la apertura, referida a un mero ver o contemplar (Tugendhat 1993: 28).

${ }^{441}$ Entiende que esta última, se ha criticado el tradicional recurso a la autoconciencia, y especifica: “...la única perspectiva desde la que estamos inclinados hoy a cuestionar la relevancia de la relación práctica consigo mismo es, sin dudas, la social. Y esta es ciertamente la perspectiva desde la que fácilmente hoy puede parecer anticuada, en sentido práctico, toda la temática de la autoconciencia" (Ibid.:38).Entendemos que esta interpretación se inscribe en los énfasis contemporáneos puestos en la alteridad en el seno de estas dinámicas de la mismidad, tal como veremos en este capítulo. 
con lo que se relaciona una persona en un remitirse a sí, no es ella como entidad ni sus maneras de comportamiento y acciones o determinaciones, sino con el despliegue de su existencia.

Como vemos, sus análisis y desarrollos ponen un énfasis en la dimensión óntica del mantenimiento de sí heideggeriano. Precisamente por ello, sus críticas se apoyan en una base analítica diferenciándose del método descriptivo de Heidegger el cual, al carecer de un criterio de prueba, tiene por consecuencia pensamientos limitados a tesis intuitivas no demostrables, que torna relevante un examen lingüístico-analítico respectivo.

Finalmente, articula su diferencia metodológica en uno de los resultados de los análisis de SuZ: el Dasein ha de ser su ser en su estar arrojado (Geworfenheit). Desde este carácter proyectivo distingue una mezcla de posibilidad e inevitabilidad, que se hallan unidas en el terreno práctico. En efecto, toda elección se manifiesta determinada por esos dos momentos correlativos: a) encontrarse en una determinada situación práctica, que remite al momento de inevitable facticidad, b) lo cual nunca excluye un campo de juego de posibilidades acerca de la manera como quiero realizar mi ser, al tiempo que se impone ineludiblemente su realización. En este marco, especifica que el sentido de ser es diferente cuando se da como lo que se ha de realizar (sentido práctico), que cuando es constatado teóricamente y expresado en toda oración aseverativa (sentido de estar a la vista): en un caso lo halla analíticamente fuerte, en el otro, débil ${ }^{442}$.

Pues bien, Tugendhat sigue la vía de la pregunta práctica, relacionada con aquella tesis fuerte del ser, distinguiendo que el sentido de estar a la vista no es el único posible, sino más bien derivado respecto al poder-ser. Precisamente ello caracteriza su crítica central a la concepción de Heidegger, en su rechazo a la modalidad de sustancia con propiedades para comprender al Dasein o al sujeto de predicados. A este respecto, sostiene:

"Por lo visto, creía que un ente no podía ser sino lo uno o lo otro, que solo podía ser concebido como estando a la vista o como ente en el modo de ser de la existencia, del haber de ser. Si queremos aprovechar la oportunidad de apropiarnos productivamente las nuevas intuiciones de Heidegger tememos que liberarlas de esas excentricidades enojosas. Si un hombre no fuera algo que está a la vista, constatable, no existiría en absoluto" (Ibid.:146).

Es decir, le imputa una comprensión errónea sobre la base de un uso reducido del sentido del ser, que entiende no válido para el análisis. Sostiene que la tesis de la diferencia de sentido del

\footnotetext{
${ }^{442}$ Tal debilidad analítica reside en su independencia del hablante y en su susceptibilidad de ser verdaderas o falsas, por lo cual este autor encuentra inviable la pretensión de verdad en la utilización del sentido de ser. En esta línea, Tugendhat hace un intento de entender de una manera intersubjetivamente comprobable lo que Heidegger quiere decir con ser. Incluso, al no seguir método analítico y proceder evocativamente, afirma que el proceder de Heidegger termina siendo dogmático (Ibíd., pg.158).
} 
poder-ser y el estar a la vista son controlables, es decir, susceptibles de un análisis lingüístico, pues se puede mostrar las formas de oraciones no aseverativas en las que se expresan (oraciones imperativas o intencionales, dependientes del hablante). En cambio, la tesis de Heidegger del ser a la vista en relación al sentido originario y propio del ser, conducen fuera del lenguaje al momento de ser constatadas, lo que entiende como inviable para un análisis riguroso ${ }^{443}$.

\section{1. c.- La deliberación.}

En este marco aborda la consideración de la deliberación, en cuya operación debe distinguirse lo que es previamente dado en la situación práctica, haciendo posible la acción, de lo que depende de ella e implica una posición a tomar. Es decir, en la consideración práctica se trata de establecer, por deliberación, qué posición tomo ante mis inclinaciones. La pregunta sobre lo que yo quiero no presupone un yo-núcleo, sino una remisión proyectiva a cómo quiero yo ser.

Desde aquí, entiende que el concepto de proyecto en Heidegger presupone que el hombre se da a sí mismo una concepción de vida, lo cual implica que esta concepción tiene que ser establecida de una u otra manera pues, si no tenemos fines volitivos dados, el carácter arrojado del Dasein inevitablemente se topa con concepciones de la vida establecidas por la sociedad históricamente variables. Por ello, tematizar nuestro ser en tal contexto implica necesariamente hacerlo como una pregunta práctica, como deliberación. Especificación que le permite criticar la falta de desarrollo respectivo en las elaboraciones de SuZ, junto a la ausencia de toda figuración del término deliberar entre sus páginas ${ }^{444}$

No obstante, a partir de la distinción heideggeriana de la caída, reconoce que tal deliberación primariamente no puede establecerse en el modo de la autodeterminación, pues suele orientarse por puntos de vista tradicionales. La condición para que el deliberar tome la forma de una pregunta práctica, reside en que la comprensión del propio ser se revele inscripta en un campo de

\footnotetext{
${ }^{443}$ Para un análisis detallado de esta distinción en el proceso y articulación del pensamiento de Heidegger los campos de utilización de la palabra ser, Véase, Ibid.:142-144. No obstante, interpreta que la tematización de los estados de ánimo en $\mathrm{SuZ}$ son modos de autoconciencia-del comportarse consigo mismo-, aspecto que se manifiesta susceptible del control analítico, por lo cual la considera como un verdadero y fructífero descubrimiento en su analítica ( Ibíd. , pg. 166).

${ }^{444}$ A lo cual agrega otra interpretación sobre los términos utilizados:’La deliberación presupone autonomía. Tambien para Heidegger la autonomía es lo contrario del 'Uno', pero para él la autonomía es un mero acto de elegir, no una deliberación, y esto me parece ser la razón por la cual tenía que recurrir en su discusión del 'uno' a la palabra 'auténtico' (echt), que dejó sin explicación”'(Tugendhat,2002:190)
} 
juego de posibilidades, de modo tal que el sentido del comportarse consigo mismo pueda entenderse como una modalidad de autodeterminación.

Así, distingue el límite más relevante en la concepción heideggeriana de autodeterminación: expulsa el sentido de deliberación en la relación reflexiva consigo mismo, en línea con la ausencia de una consideración acerca de la reflexión. Tugendhat interpreta que la cuestión de fondo en tales omisiones, reside en la ausencia del concepto de lo bueno en $S u Z$, cuya necesariedad reside en que plantear la pregunta práctica, implícitamente supone la pregunta ¿Qué es bueno?, implicando preferencias en base de razones objetivas (Ibid.:187).

En el marco de un proceso sucesivo, especifica que tales razones se despliegan hasta un punto culminante donde ya no podemos justificar objetivamente una decisión, de modo tal ésta se constituye necesariamente sobre la base del querer, respecto a inmediatos deseos o inclinaciones. Incluso destaca que si este querer se apoyase en razones, la voluntad perdería su peso y ya no sería la propia decisión ${ }^{445}$. Encontramos aquí el carácter liminar y correlativo de la dimensión irracional (el deseo o querer) en su comprensión sobre la deliberación racional. Pero aun con ello, rechaza toda nota de esta dimensión en la perspectiva heideggeriana, especialmente en el marco de su comprensión del concepto de verdad.

\section{1. d- La imputación de irracionalidad.}

Efectivamente : sostiene que la ausencia de la deliberación y de justificación de afirmaciones evaluativas y normativas en Heidegger tiene su origen en su concepto de verdad (Tugendhat 1993:188), pues caracteriza la decisión como verdad autentica, quitándole la base a la deliberación objetiva previa a la decisión y separándola de la pregunta por la verdad (al entender la decisión como verdad).

Frente a ello, insiste en que una elección que no se lleva a cabo en un horizonte de razones es una decisión en la que se deja al azar la elección, incluso para la elección autentica o propia distinguida por Heidegger es necesaria una pauta, un criterio, como expresa en este fragmento:

\footnotetext{
${ }^{445}$ En su teoría posterior de la deliberación racional, elabora de un modo más especifico la consideración del deseo y los criterios de elección entre deseos, que implica una decisión dentro del ámbito de la deliberación, en una dimensión de profundidad de razones que entiende como faltantes en los desarrollos de Heidegger, y agrega:'Pienso que aquí llegamos a un nivel donde no hay una distinción clara entre razón y decisión. La última razón de cómo quiero o debo entenderme a mí mismo la tengo que decidir por mismo. Parece que esto también explica por qué esta pregunta práctica más fundamental se puede poner igualmente en la forma : ¿Cómo quiero vivir?' y ‘¿cómo debo vivir?'”( Tugendhat ,2002:197 s.)
} 
"Hace ya rato que nos es claro que el Dasein no tiene un criterio material en algo como su 'sí mismo', que pudiera simplemente aplicar a las posibilidades, y que en general no se puede hablar de un criterio material. Bajo criterio solo puede entenderse aquí el cómo, la manera como en el elegir auténtico se aborda la posibilidad, la dirección en que se pregunta por ella. El único criterio que da Heidegger es la confrontación con la muerte y esta es una condición necesaria. Pero ies suficiente?” (Ibíd.: 190).

Así, como el Dasein no tiene una razón que justifique la elección de una y no de otra de las posibilidades históricamente dadas, se trataría en $S u Z$ de una elección irracional, distinguiendo que cuando la voluntad no se apoya en razones ya no es la toma de posición de un sí-mismo, es decir, no es posible concebir allí una ipseidad, aún cuando le sea irreductible reducirse a razones, tal como explicita:

"La característica de la elección que se puede denominar autodeterminación es que realizamos la elección en la forma de un querer racional. La elección no se puede entender como autodeterminación cuando se niega su carácter volitivo irreductible, cuando se cree poder reducirlo a racionalidad. Pero tampoco cuando, como Heidegger lo hace, se niega que tiene que poderse apoyar en una razón, que se fundamenta en la pregunta por la verdad, aun cuando no puede identificarse con ella" (Ibíd.: 191).

Estas consideraciones lo conducen a plantear una interpretación biográfico-histórica de Heidegger: su concepto de verdad y elección desracionalizados, junto con una comprensión de la autodeterminación que resulta afín a ellos, se han cristalizado en sus vinculaciones con el nazismo. De este modo, Tugendhat articula tal situación biográfica como correlato de la comprensión y articulación lingüística de su pensamiento.

\section{1. e.- Acerca de la pertinencia de las críticas.}

Entendemos que la comprensión conceptual y el énfasis puesto por este autor en el lenguaje en su aspecto solo gramatical, circunscribe la diferencia de base en este análisis analítico del comportarse consigo mismo respecto a las elaboraciones de Heidegger, aun cuando la orientación metódica y de análisis regresivo de términos o expresiones se hallen en clara continuidad con el despliegue respectivo de nuestro autor. 
Puede distinguirse con claridad que el análisis crítico que plantea se aparta de una articulación apropiada a los planteamientos de $S u Z$ : no solo remite únicamente al ámbito óntico de la ipseidad y el comportamiento de sí , perdiendo así el marco relacional con la pregunta por el ser que guía aquella obra (y establece un ámbito determinado para la analítica existenciaria), sino que rechaza de plano algunas de las comprensiones e interpretaciones de las que dependen tales análisis : la verdad y la distinción entre lenguaje y Habla.

Esto último se torna fundamental al momento de comprender el alcance de sus críticas en torno a la opacidad de términos o expresiones de Heidegger. Interpretamos que con ello no solo pierde de vista la operación diferencial que propone Heidegger al momento de las distinciones de los modos de ser, sino que también revelan un carácter secundario: aquellas elaboraciones se manifiestan como un medio para desplegar su perspectiva propia ${ }^{446}$.

Así, lo que este pensador comprende desde una disyunción exclusiva en Heidegger, parece no ser más que una proyección de su propia perspectiva. Es decir, Heidegger no descarta el potencial de variabilidad del lenguaje predicativo, sino que plantea un horizonte no lingüístico como condición, que se proyecta en un incremento del potencial de desplazamiento de la comprensión, el lenguaje y el pensar. Para ello, destaca la inmanencia de un sesgo irreductible, una inadecuación o diferimiento originario, que Tugendhat se empeña en excluir ${ }^{447}$.

No obstante, sus planteamientos dan cuenta de una vía para el análisis de la mismidad y la ipseidad, cuyos derivados pueden articularse con la tradición anglosajona con una fuerte influencia del pensamiento de Wittgenstein. En esta vía, como vimos, la perspectiva que enfatiza la elección y la deliberación racional, las consideraciones o análisis pragmáticos, articuladas en el marco de los debates políticos propios de las democracias contemporáneas ${ }^{448}$, poco pueden pretender un diálogo con el pensamiento de Heidegger, que no sea al modo de diferencia de fondo entre perspectivas.

\footnotetext{
${ }^{446}$ Tal y como afirma en este pasaje: "Mi propósito no ha sido presentar fielmente a Heidegger, sino sacar de su pensar lo que necesitamos para nuestra problemática objetiva. Y hasta donde lo veo, el planteamiento de Heidegger es el único que permite una aclaración estructuralmente impecable del comportarse consigo mismo, en general, y de la autodeterminación, en especial."(Tugendhat ,1993:189).

${ }^{447}$ Incluso, su consideración de una conciencia en su carácter proposicional se evidencia sin tal sesgo constitutivo :¿no es acaso lo que de Freud a Lacan se articula como inconsciente?

${ }^{448}$ Tales debates históricos-contextuales, desde una vertiente pragmática, podemos encontrarlos en la recepción heideggeriana de Rorty, quien elabora una articulación con la consideración de la narratividad de sí y la deliberación , tal y como lo explicita en este pasaje :"Las narrativas históricas sobre movimientos sociales e intelectuales constituyen el mejor instrumento que nos es dado utilizar para habérnoslas con nosotros mismos, pues semejantes narrativas sugieren vocabularios de deliberación moral en los cuales plasmar una narrativa coherente acerca de nuestra vida individual (...)las narrativas que le ayudan a uno a identificarse con movimientos comunitarios generan la sensación de ser una máquina engranada en una máquina mayor. Esta es una sensación que vale la pena. Pues ayuda a reconciliar la sensación de contingencia y la moralidad existencialista con un sentido romántico de grandeza. Nos ayuda a constatar que la mejor manera de habérnosla con nosotros mismos es habérnoslas con algo más -una forma mecanicista de decir que solo el que pierda su alma la salvará” (Rorty ,1993:.228). Re-encontramos aquí las resonancias relacionales de las elaboraciones heideggerianas. Veremos a continuación diversas figuraciones de esta disolución en la esfera individual ,ante el encuentro con el ámbito comunitario.
} 
Más aun si enumerásemos los presupuestos y términos que ligan este análisis con los de la metafísica de la subjetividad.

De esta manera, más que una articulación forzada, una continuidad falaz o una ruptura auténtica, tal vez pueda plantearse esta contraposición sobre el comportamiento respecto a sí en Tugendhat y el mantenimiento de sí en Heidegger, como figuras discursivas de alteridad, en el marco de la tradición filosófica que aborda la auto-remisión del existente humano ${ }^{449}$.

Sin embargo, es posible encontrar abordajes sobre los aspectos prácticos de la ipseidad, a partir del análisis y reelaboración de nociones respectivas, sin la desestimación de tal sesgo o diferencia constitutivo. A nuestro entender estas cuestiones no fueron desarrolladas por Heidegger, debido al horizonte y programa de base en sus indagaciones, lo cual no supone necesariamente un rechazo implícito a toda tentativa de elaborarlas. En los próximos apartados desarrollaremos en contraste algunos diálogos en continuidad con aquellas perspectivas de nuestro autor.

\section{2.- Perspectivas sobre la mediación alteridad-ipseidad en la recepción europea.}

La década de 1960 en Francia puede distinguirse por un giro a la ética y la política en el pensamiento filosófico ${ }^{450}$. Desde allí se ha desplegado un movimiento donde la filosofía práctica se renovó, involucrando a diversos campos del pensar filosófico. En nuestra región, numerosas interpretaciones del pensamiento de Heidegger se han presentado mediatizadas por tales lecturas y desplazamientos.

Especialmente destacamos aquellas que abordan la diferencia ontológica y la consideración del lenguaje en el marco de las críticas al denominado imperialismo del significante, como uno de los frentes derivados de las perspectivas estructuralistas de mediados del siglo XX. En líneas generales, estas críticas orbitan en torno a la consideración del carácter abierto del lenguaje y a la distinción entre el pensamiento de lo Mismo y de lo Otro, como modalidades del pensar que obstruyen o favorecen las dinámicas/multiplicidades, respectivamente. Mientras en el primer caso,

\footnotetext{
${ }^{449}$ En el mismo sentido, respecto a estos desarrollos de la cuestión de la identidad personal, Blanco Ilari distingue que el abordaje de este intérprete de los modos de aprehender y comprender la cuestión de la totalidad de una vida son insuficientes en relación con la consideración que realiza del campo práctico de las acciones. En este sentido, entiende que su concepto de identidad personal tal vez pueda complementarse adecuadamente con el concepto narrativista de cuño ricoeuriano .Véase, Blanco Ilari (2005):6.

${ }^{450}$ Para una descripción específica de estos cambios en el pensamiento luego del auge del estructuralismo, véase Conesa (2008):304-6.
} 
se conjura la diferencia alrededor del fundamento, telos ( $\tau \dot{\lambda} \lambda \mathrm{o})$, sentido o significante que no se desplaza, encadena o sustituye con ningún otro; en el segundo, en cambio, la apertura hacia la alteridad y la multiplicidad se ve favorecida por un pensar no jerarquizante que se aparta de la búsqueda del origen, el fundamento o el fin, con el objeto de preservar su carácter proliferante y dinámica no calculable. A continuación abordemos este contexto comprensivo en tres de sus recepciones y lecturas contemporáneas, con la intención de dar cuenta de la creciente radicalidad que va orientando los tratamientos posheideggerianos de la relación alteridad-ipseidad.

\section{2. a La alteridad del dialogo y la tradición en las elaboraciones de Gadamer.}

Este discípulo de Heidegger, retoma la consideración de las sedimentaciones intersubjetivas implícitas en la distinción del horizonte histórico de la comprensión. Articulado por la vía del lenguaje, desarrolla su perspectiva en torno al carácter histórico y dialógico de dicho horizonte, asimilado a la puesta en valor de la tradición. En sus ya clásicas obras en diálogo con su maestro ${ }^{451}$, destaca la estructura de la temporalidad como determinación ontológica de la subjetividad en $S u Z$, lo que impacta en la misma comprensión del ser, que Heidegger entiende como tiempo (Gadamer, 1991a:322s.). Ello pone de manifiesto el carácter contextual de toda significación, es decir, el sesgo temporal y de alteridad en el seno del lenguaje. Desde aquí profundiza las consideraciones de la mediación y codeterminación entre el Dasein (como intérprete situado) y la tradición (como horizonte de comprensión), para las cuales el modelo del texto le permitirá encuadrarlas en la dimensión dialógico-racional del lenguaje $\mathrm{e}^{452}$.

Específicamente, considera que la conciencia hermenéutica es conminada a una receptividad y apertura respecto a la alteridad del texto/tradición. En tal dinámica de disposición, que proyecta la lógica del último Heidegger, esta conciencia debe ser capaz de salir de sí, en una apertura hacia la alteridad implicada en esta dinámica ${ }^{453}$.Sin embargo, considerando que en estas elaboraciones la tradición se distingue como horizonte y también texto, cuyo sentido siempre es el mismo aunque

\footnotetext{
${ }^{451}$ En especial, analizaremos e interpretaremos los siguientes trabajos de Gadamer: Verdad y Método I (1991 a); La actualidad de lo bello (1991 b); Verdad y método II (1992) y Los caminos de Heidegger (2002).

${ }^{452}$ Aquí seguimos la siguiente interpretación de continuidad :"...la base común de la hermenéutica filosófica de Gadamer y la 'hermenéutica de la facticidad' de Heidegger, es , sin duda , el intento de corresponder la finitud de la existencia humana (y con ello la finitud de la razón humana) al ideal de una razón absoluta propio de la Ilustración" (Lafont 1993:89)

${ }^{453}$ Para una continuidad entre el pensamiento rememorante del ser (Andenken) es decir, el ser pensado como envío y don en las elaboraciones de madurez de Heidegger, y la consideración dinámica y hermenéutica de la tradición en Gadamer, véase González Valerio(2003):89 ss.
} 
acaezca de un modo diferente y parcial en cada interpretación ${ }^{454}$ ¿de qué manera puede ser entendida también como alteridad?

Pues bien, la tradición en la perspectiva de Gadamer se caracteriza como textualidad histórica y contingente, por lo tanto no cumplida ni clausurada, pues su despliegue se efectiviza en el marco dinámico de una fusión de horizontes: toda interpretación se abre desde un horizonte históricamente determinado, en un proceso de integración de la tradición por la vía de la comprensión. Así, desde el contexto situacional presente, la interpretación se implica en otro horizonte histórico, cuya nivelación supone una singular fusión con sus desplazamientos respectivos. Es precisamente este aspecto dinámico y no clausurable, lo que permite distinguir el carácter de alteridad en la mediación con una tradición que simultáneamente nos constituye e interpela.

Más en detalle: el intérprete se abre a la situación histórica de la tradición que busca interpretar, incluyendo y fusionando necesariamente su propio horizonte comprensivo en tal desplazamiento. En cada fusión de horizontes, el acercamiento abre una vía de continuidad diversa y variable históricamente: por un lado, impacta en distintas interpretaciones de la tradición y, por otro, en una relación a sí del intérprete que se modifica correlativamente ${ }^{455}$. De esta manera, la tradición en su carácter normativo ${ }^{456}$, requiere una escucha que no la deja intacta, abriéndose en una dinámica no clausurable desde el horizonte de la interpretación actual, tal y como ocurre con su partenaire dialógico (Gadamer, 1991 b: 54).

Esto le permite subrayar el carácter situacional, histórico y experiencial de la comprensión, en lo que denomina historia efectual, la cual se despliega en una dinámica que parte del cuestionamiento de los (ineludibles) prejuicios del intérprete (por medio de una afección del pasado de la tradición), al tiempo que actualiza los elementos tradicionales con la nueva situación. Ello es

\footnotetext{
${ }^{454}$ En sus análisis de esta perspectiva del lenguaje, Esquisabel desarrolla consideraciones sobre el carácter especulativo del sentido del texto, lo cual articula (de manera dialógica) la hermenéutica de Gadamer con la dialéctica hegeliana, en Esquisabel (2009):269s. En este contexto de análisis, destaca que el carácter no clausurable del horizonte de sentido, en el diálogo con la tradición, constituye una diferencia fundamental con la dialéctica especulativa de Hegel, en Esquisabel (2003):81.

${ }^{455}$ Tales dinámicas respecto a la modalización en el lenguaje pueden ilustrarse en este pasaje, en el marco de su crítica a la dialéctica hegeliana: "El sentido es sentido direccional' he afirmado alguna vez, y Heidegger utilizó durante cierto tiempo un arcaísmo ortográfico escribiendo la palabra Sein como Seyn para subrayar su carácter verbal. De modo análogo debe verse mi intento de eliminar el lastre de la ontología de la sustancia partiendo de la conversación y del lenguaje común en ella buscado y que en ella se forma, en el que la lógica de pregunta y respuesta resulta determinante. Ella abre una dimensión de entendimiento que trasciende los esquemas fijados lingüísticamente y, por tanto, la síntesis omnicomprensiva en el sentido de la autocomprensión monológica de la dialéctica"( Gadamer, 1992:357). En el contexto de estas cuestiones, Esquisabel destaca que la dialéctica hermenéutica de Gadamer oscila (en tensión) entre la puesta en relevancia de un diálogo trasformador e innovador y la consideración del autodespliegue del sentido del texto de la tradición, ya dado pero no totalizable en interpretaciones determinadas (Esquisabel, 2009:261-8).

${ }^{456}$ Tal carácter normativo manifiesta una orientación ética : remite a un acuerdo que subyace a la tradición de pertenencia , como fuente de entendimiento y solidaridad común de un grupo (Gadamer, 1991a:437 s.)
} 
lo que entiende como aplicación: la comprensión se desplaza en cada situación, en un proceso de reacomodamiento-aplicación (Ibíd.:379 s.).

Con este enfoque relacional entre intérprete y tradición, se aparta de las orientaciones rígidas del pensar, en una apertura hacia desvíos o giros no calculables ni clausurables, en franca continuidad con la perspectiva de su maestro, tal y como sostiene en este pasaje:

"El hecho de que nos movamos en un mundo lingüístico y de que nos insertemos en nuestro mundo a través de la experiencia lingüísticamente preformada no nos priva en absoluto de la posibilidad de crítica. Al contrario, se le abre la posibilidad de superar nuestras convenciones y todas nuestras experiencias preesquematizadas al aceptar un nuevo examen crítico y unas nuevas experiencias en diálogo con otros, con los disidentes. En el fondo, el tema de nuestro mundo sigue siendo el que fue desde el comienzo : la conformación lingüística en convenciones en normas sociales que implican siempre el mundo de experiencia humana en el que nos vemos precisados a utilizar nuestra capacidad de juicio, es decir, nuestra capacidad de afrontar críticamente todas las convenciones. Esta capacidad de juicio es en realidad producto de la virtualidad lingüística de nuestra razón, y ésta no se ve obstaculizada por el lenguaje" (Gadamer ,1992:199) 457

Ahora bien, tal enfoque relacional incrementa las dimensiones de la alteridad. Por un lado, distinguimos la apertura y reconocimiento a la alteridad de la tradición en su reserva y, por otro, la de una conciencia hermenéutica que deviene otra de sí en el marco de este dialogo y fusión de horizontes. Asimismo, la mediación del sí-mismo intérprete se revela finalmente atravesada/desplazada por este diálogo, en el marco intersubjetivo del lenguaje.

La comprensión como experiencia evidencia aquí un margen de variabilidad al problematizarse desde el encuentro entre horizontes comprensivos y situaciones determinadas. Tal dinámica de inadecuaciones y nuevos acuerdos, supone la puesta en valor de la reflexión como potencial para la producción de estos ensambles y ensanchamientos históricos. Ello supone una doble distancia: entre tradición y situación y entre tradición e intérprete. Entendemos que es tal distancia el referente gadameriano para la alteridad como condición para todo diálogo posible.

En suma, en estas elaboraciones, la intersubjetividad se distingue como un ámbito irreductible desde el cual pensar la dinámica relacional (entre intérprete-tradición) que permite la variabilidad del horizonte comprensivo. Asimismo, el pliegue reflexivo, el diálogo y el acuerdo son condiciones para las aplicaciones y los reacomodamientos implicados en dicha variabilidad. En el

\footnotetext{
${ }^{457}$ Y más adelante, define en tal contexto al lenguaje en su carácter no clausurable: “....el verdadero malentendido en la cuestión de la linguisticidad de nuestra comprensión es un malentendido sobre el lenguaje, como si éste fuese un inventario contingente de palabras y frases, de conceptos, opiniones y modos de ver. El lenguaje es en realidad la única palabra cuya virtualidad nos abre la posibilidad incesante de seguir hablando y conversando y la libertad de decirse y dejarse decir. El lenguaje no es una convencionalidad reelaborada ni el lastre de los esquemas previos que nos aplastan, sino la fuerza generativa y creadora capaz de fluidificar una y otra vez ese material."(Gadamer 1992:.201)
} 
marco de este enfoque, entendemos que el nexo de significaciones en el horizonte comprensivo queda circunscripto al campo del lenguaje enunciativo, es decir, sin desarrollar un análisis de la indeterminación o desfundamentación del ámbito originario del Habla, tal y como figura en las elaboraciones de Heidegger en torno al lenguaje ${ }^{458}$.

De esta manera, Gadamer despliega su perspectiva sobre el lenguaje y la comprensión, ciñendo sus abordajes a las dinámicas entre el horizonte de sentido y los nexos de significación de la situación fáctica, es decir, tomando como punto de partida estratos que se articulan con una dimensión lingüística intersubjetiva originaria, que entiende como fuente y reserva de las dinámicas históricas del lenguaje. Con ello, reelabora de un modo singular las consideraciones sobre la dimensión antepredicativa del lenguaje que Heidegger distinguió en los desplazamientos entre la comprensión, la interpretación y el Habla.

\section{2. b.- Vattimo y la ipseidad en el horizonte efectivo de un nuevo acontecer del Ser.}

Por su parte, las lecturas e interpretaciones que Gianni Vattimo ha desarrollado sobre el pensamiento de Heidegger, en particular sobre la codeterminación entre Dasein-Ser en la dinámica del don y la respectiva mediación de ipseidad-alteridad, plantean un enfoque que se aparta gradualmente de la recepción dialógico-reflexiva de Gadamer ${ }^{459}$.

En efecto, sus primeras elaboraciones se orientan hacia el desarrollo de aquella perspectiva dialógica y de alteridad, para desplazarse hacia la radicalización de la puesta en valor de un pensamiento del conflicto, en una singular confluencia entre las perspectivas de Heidegger y Nietzsche. Esta reelaboración de su orientación se efectúa sobre el eje de una pregunta que atraviesa toda su obra: ¿cómo pensar activamente la transformación y desplazamiento efectivo de la actual época del ser? O bien, ¿de qué modo involucrarse para la promoción de un nuevo acontecimiento del ser? Desde este trasfondo articula sus consideraciones sobre la fundamentación, la mismidad, la alteridad y el lenguaje.

\footnotetext{
${ }^{458}$ Un intérprete propone una elaboración del contrapunto en las concepciones del lenguaje en Gadamer y Heidegger , especialmente a partir de una orientación al monólogo en este último frente a la vertiente dialógica gadameriana, en Herrera de la Fuente (2005):22-4. A nuestro entender, la distinción remite más bien a las dimensiones del lenguaje que reconocen, desde la cual inscriben sus orientaciones respectivas.

${ }^{459}$ A continuación, circunscribiremos nuestros análisis a un conjunto determinado de sus escritos, en el marco de tales lecturas de la obra de Heidegger: Más allá del sujeto. Nietzsche, Heidegger y la hermenéutica (1992); Las aventuras de la diferencia (1998); Diálogo con Nietzsche (2002) y sus conferencias agrupadas en Esperando a los bárbaros (2014).
} 
Por un lado, a partir de un contraste en las discusiones contemporáneas en torno al pensamiento de la fundamentación, se posiciona contra las perspectivas que interpretan la obra de Heidegger en cuanto inscripta en el marco del imperialismo del significante y el pensamiento de lo Mismo. Desde este posicionamiento, destaca la función del silencio en su mediación entre el ser y el lenguaje, como una figura de la diferencia con la que articula, en general, todas las relaciones aparentemente binarias o jerárquicas en la obra heideggeriana (Vattimo ,1992:72-77) ${ }^{460}$.

Asimismo, establece algunas distinciones en la recepción francesa: en primer lugar, respecto de las perspectivas que destacan la ausencia del ser como huella (como en el caso de los desarrollos de Lacan y Derrida), reconoce una fuerte nostalgia residual por la presencia, que las coloca en una suerte de transición hacia el pensamiento de lo Otro, aunque sin un desplazamiento considerable de la tradición metafísica. En segundo lugar, destaca el pensamiento de Deleuze por su tentativa de liberar la multiplicidad y el simulacro de la referencia tradicional al origen. En el marco de estos contrastes, sostiene que Heidegger no abandona la intención de un acceso a un ámbito originario, pues la dinámica fundamentación-desfundamentación no implica una renuncia definitiva. Es decir, lo inscribe en un pensar que persevera formalmente en tal referencia, pero con un desplazamiento radical en la consideración del referente correlativo. Es precisamente esta ambigua determinación la que torna susceptible de críticas tal tentativa heideggeriana.

Por otra parte, desarrolla una ontología del don para la relación Dasein-Ser, a partir de la dinámica de la copertenencia desarrollada en los trabajos de madurez de Heidegger, pero mediante una articulación con el concepto respectivo en el pensamiento de Bataille, el cual remite a un gasto desinteresado, que provoca una reciprocidad de escala mayor. En tal comprensión del intercambio, los partenaires de la donación se ven traspasados en sus propios límites para participar de la dinámica. Con ello, Vattimo no solo destaca una bivalencia en esta dinámica, por su aspecto receptivo-activo, sino también enfatiza la mediación relacional en su potencial para la desustancialización de los partícipes. Es decir, circunscribe el papel activo y transformador en esta dinámica del don, a la posibilidad distorsionante en la recepción del don del pasado ${ }^{461}$, junto a la ruptura o disolución del límite de los co-participes ${ }^{462}$.

\footnotetext{
${ }^{460}$ Distingue otras de estas figuras en $\mathrm{SuZ}$ : en la relación del Dasein con el ser, para su trato con los entes o con su serpara-la-muerte, para la asunción de sus posibles, por ejemplo. Este intérprete subraya el carácter de fundamentacióndesfundamentación que se manifiesta en estas topologías relacionales, en su vinculo con abismos siempre fértiles y donantes, precisamente por su determinación abisal (Véase, Vattimo, 1998:172 s.). En este marco, la vinculación de la obra de Heidegger con el pensamiento de lo Mismo sería inviable. Como veremos, la referencia crítica aquí, remite a la recepción de Derrida.

${ }^{461}$ En este sentido precisamente es donde articula con la noción de don o gasto en Bataille, pues esta modalidad de intercambio pre capitalista, presupone una provocación dirigida al otro al establecerse sobre la base de la autoinmolación de la riqueza, es decir, supone una afrenta en su dinámica. Véase, Bataille (1987):25-44

462 Operación que entiende implícita en la Verwindung de Heidegger, respecto a la metafísica.
} 
Desde aquí, podemos distinguir una comprensión implícita de la ipseidad que se halla ligada a su frontera de disolución. En este sentido, incluye a Nietzsche como interlocutor para pensar la noción de yo o identidad, entendida como modo provisorio de alcanzar un equilibrio entre las fuerzas en conflicto en el Selbst ${ }^{463}$. Es decir, distingue una pluralidad que atraviesa y excede todo semblante humano, por lo cual se torna más apropiado pensar el sí mismo por fuera de los términos positivos o determinados. Más aun, la disolución del sujeto, la cual Vattimo considera implícita en la elaboración del Übermensch nietzscheano y en la perspectiva de Heidegger respecto a la técnica, la inscribe en el marco de discusiones contemporáneas en torno a las relaciones entre poder y subjetivación (Vattimo ,2002:241-9). Entiende que tal consideración sobre la subjetividad, asumiendo la contingencia y limitación en toda determinación, es una condición ineludible para la apertura a una experiencia de la pluralidad del mundo, es decir, para la alteridad (Ibid.:205).

Finalmente, esta orientación disolutoria respecto a la subjetividad y la ipseidad, se cristaliza de un modo radical en sus últimos trabajos, por medio de un desplazamiento desde aquél carácter dialógico-dinámico del don, hacia un pensamiento del conflicto. En efecto, en sus conferencias del año 2014, encontramos un intento de liberar el potencial transformador que reconoce en el pensamiento de Heidegger, poniendo un énfasis singular en el papel activo y lateral del existente humano: a partir de sus consideraciones políticas en torno a la escucha del silencio de los vencidos históricos, en el horizonte para una posible transformación, Vattimo destaca que sin una toma de partido efectiva, el Ser no podrá acontecer en el horizonte transicional de la época contemporánea. En particular, esta toma de partido se articula a partir de un pensamiento del conflicto, es decir, un pensar capaz de poner en tensión la situación y su horizonte comprensivo epocal ${ }^{464}$.

Ahora bien, desde estas breves puntualizaciones de la recepción vattimiana, distinguimos continuidades y tensiones con la perspectiva de Heidegger, en especial, aquellas que articulan de un modo singular el ímpetu implícito de la época de $S u Z$, con los desarrollos relacionales y mediados respecto al Dasein en sus trabajos de madurez.

En efecto, Vattimo considera la relación Dasein-Ser desde su frontera liminar, es decir, en el umbral y desplazamiento del acontecimiento e irrupción de la alteridad, donde el carácter proyectivo y no sustancial del existente humano es ligado al campo de lo otro, en una dinámica de apertura y disolución, lo cual desarrolla y continúa las últimas elaboraciones de Heidegger. Aún así, esta consideración relacional y disolutoria de la subjetividad e ipseidad, en vista de la apertura de una pluralidad que excede toda determinación subjetiva, también subraya la necesidad de un

\footnotetext{
${ }^{463}$ Para un análisis e interpretación de la consideración de la identidad en Vattimo bajo el modelo de la experiencia hermenéutica, véase Leiro (2016):111-121.

${ }^{464}$ Véase, Vattimo (2014): 45-73.
} 
posicionamiento activo y efectivo para la promoción de un nuevo acontecimiento epocal del ser. En esta línea, interpretamos que la perspectiva política y situacional en la que Vattimo se inscribe y reconoce, es aquella que motiva este encuadre o énfasis del rol activo del existente humano, no solo respecto a las posiciones subjetivas, sino también para las transformaciones históricas y del pensar.

De un modo general, esta recepción e interpretación se enmarca en un amplio campo de discusiones contemporáneas en torno a los procesos de subjetivación, la identidad y la ipseidad, las cuales presentan análisis vinculados con la filosofía práctica, los agenciamientos políticos y las perspectivas de género, entre otras cuestiones ${ }^{465}$. En este contexto, podemos reconocer un diálogo singular con las elaboraciones de Heidegger : por un lado, mediante el reensamble de los desarrollos y comprensiones respecto al Dasein ; por otro, como en el caso de Vattimo, a través del despliegue de interpretaciones respectivas, ligadas y orientadas a las propias situaciones sociohistóricas $^{466}$.

\section{2. c.- Relaciones entre lo indecidible y el por-venir en el pensamiento de Derrida.}

Ahora bien, a nuestro entender aquella concepción disolvente de la subjetividad e ipseidad, hallan un tratamiento en la obra de Jacques Derrida, que manifiesta una consistente continuación de los caminos del pensar de Heidegger. Sus trabajos profundizan la caracterización dinámica y liminar del lenguaje y el pensar, radicalizando no solo las perspectivas contemporáneas en torno a la apertura al otro como alteridad, sino también la tentativa transicional del pensamiento de nuestro autor, aplicándola a su mismo discurso.

Tomando distancia de las perspectivas del diálogo, a las que entiende como modos racionales de reducción de lo Otro a lo Mismo, piensa la alteridad desde la no-relación lo cual le permite, en línea con el pensamiento de Lacan y Blanchot, inscribir las dinámicas mediadas por

\footnotetext{
${ }^{465}$ Estas discusiones y elaboraciones pueden encontrarse, por ejemplo, en desarrollos de Gilles Deleuze. A partir de los trabajos de este pensador francés, tomamos el concepto de agenciamiento, no solo por su énfasis puesto en la praxis colectiva por sobre las perspectivas que parten del sujeto, sino también en consideración de su inescindible vínculo con las políticas enunciativas y discursivas. Al respecto, véase Deleuze (1980[2012]):513ss.

466 En este sentido, entendemos que los enfoques políticos de Vattimo (en lo que algunas interpretaciones recientes denominan como la izquierda heideggeriana) pueden vincularse a una interpretación singular, en el marco general de un pensamiento transicional, paralelo al efectuado por Heidegger con el NS, en la década de 1930. El mismo pensador italiano en su trabajo de 2014 proporciona elementos para pensar esta continuidad.
} 
fuera de estas limitaciones de la apropiación ${ }^{467}$. En consonancia con la destrucción heideggeriana, esta perspectiva se articula con una operación deconstructiva en el lenguaje, abordando sedimentaciones lingüísticas y comprensivas, para evidenciar sus estrategias para conjurar un diferimiento originario, a través de la imposición en el tejido textual de jerarquías, centralismos y pretensiones unitarias del pensar, tal y como ejemplifica con sus análisis de aspectos marginales en las obras de Husserl y Heidegger. Abordaremos brevemente algunos de ellos, para evidenciar no solo su modalidad de análisis discursivo en el marco de su perspectiva sobre el lenguaje, sino también la orientación para los análisis de la ipseidad y la alteridad que propone, con el objeto de distinguir su radicalidad respecto a las recepciones anteriormente analizadas, así como también los lazos de continuidad con la tentativa heideggeriana ${ }^{468}$.

Para ello, en primer lugar tomemos su abordaje de la variación en el uso semántico del concepto alemán Geist (espíritu) en diferentes tramos discursivos de Heidegger, lo cual connota su perspectiva política en la consideración del lenguaje ${ }^{469}$. En efecto, con el desarrollo de esta distinción, Derrida se opone a la interpretación ortodoxa de las implicancias de la participación política de Heidegger, a partir del contraste deconstructivo de la función del término Geist en el $\S$ 10 de $S u Z$ y en el discurso del rectorado. Mientras en el primer caso, el término se hallaba enmarcado en el campo semántico de la metafísica de la subjetividad, junto a hombre , yo , sujeto , etc. ; en 1933 , en cambio, la valoración central de la espiritualidad supondría una estrategia : utilizarla en oposición al racismo biológico y la celebración de las fuerzas naturales , con lo cual termina dando una versión al movimiento del Führer desde la valoración del espíritu. Derrida interpreta que esta ética espiritualista fue meramente provisional y estuvo motivada por consideraciones estratégicas, debido a su utilizaciones posteriores, tanto en sus cursos sobre Nietzsche, como en sus trabajos de la década de $1950^{470}$.

Sin embargo, sostiene que aun en tal estrategia el término se inscribe en el marco de una antropología cristiana o metafísica del alma y el sujeto. Es decir, al reinscribir Geist, manteniendo la

\footnotetext{
${ }^{467}$ Desde aquí también se posiciona en un diálogo con los denominados pensadores de la comunidad, entre cuyos exponentes podemos encontrar, entre otros, a Nancy, Blanchot, Bataille y Esposito. En estas perspectivas, se despliegan reelaboraciones en el pensar y los enunciados en torno a las relaciones colectivas, que se contraponen al concepto de relación en su carga metafísico tradicional. La comunidad ya no es comprendida en términos de identidad, común unidad o lazo (lo cual se halla fuertemente ligado al campo semántico de lo Mismo), sino en término de diferencia, de distancia, de no relación, como por ejemplo algunas discusiones respecto a la comunidad de los que no tienen comunidad (Blanchot ,2002: passim.).

${ }^{468}$ Para ello, nos remitiremos a las perspectivas y deconstrucciones derrideanas del pensamiento de Heidegger y Husserl, principalmente desarrolladas en los siguientes volúmenes: La escritura y la diferencia (1989 [1967a]); De la gramatología (2012 [1967b]); La voz y el fenómeno (1995 [1967c]); Del espíritu. Heidegger y la pregunta (1989[1987]); La bestia y el soberano (2010-1[2001-3]) y Márgenes de la filosofía (2013[1972]).

${ }^{469}$ Para una comparación de las perspectivas del lenguaje, como estrategias políticas de enunciación, en la obra de Heidegger y Derrida, véase Butierrez (2016):41-61

${ }^{470}$ Allí, destaca la oposición de Heidegger en los textos de Trakl, pasando de gestig (lo espiritual platónico) a geistlich (lo sagrado), el cual ya no manifiesta una determinación metafísica del espíritu.
} 
unilateralidad de la subjetividad en su voluntarismo, queda en complicidad con el nazismo y sin poder controlar las derivaciones y alcances de tal estrategia: esencializa al hombre; reintroduce la consideración de la "caída espiritual de occidente"; levanta la necesidad de desplegar nuevas fuerzas espirituales. En pocas palabras: por una estrategia semántica en el marco del antisemitismo, termina fortaleciendo la matriz de la metafísica del sujeto, que Derrida entiende como piedra angular del pensar totalitario y subyacente al antisemitismo. Como vemos, estas consideraciones sobre el lenguaje manifiestan una clara continuidad con los supuestos de la tentativa destructiva de Heidegger.

En este marco, Derrida considera que los valores del sujeto y el humanismo vigentes en la actualidad, también son virtualmente cómplices de los valores que pretenden denunciar, dado el campo semántico y su orientación de significación no tematizado, tal y como denuncia en este fragmento:

\begin{abstract}
"La presión de este programa (la presión que ejerce sobre aquellos que lo asumen, el programa de una operación al nazismo que se expresa por referencia a la `subjetividad') continua siendo muy fuerte , domina la mayor parte de los discursos que hoy se oponen-y continuarán haciéndolo por mucho tiempo- al racismo , al totalitarismo , al nazismo, al fascismo , etc., y se oponen en nombre del espíritu y hasta de la libertad del espíritu, en nombre de una axiomática -por ejemplo, la de la democracia o la de los `derechos humanos' que, directa o indirectamente, remite a esta metafísica de la subjetividad. Todas las trampas de la estrategia demarcadora pertenecen a este mismo programa, sea cual fuere el lugar que uno ocupe en él. Solo se puede elegir entre las aterradoras contaminaciones que asigna. Aun cuando no todas las complicidades sean equivalentes, son irreductibles" (Derrida ,1989b [1987]:31) ${ }^{471}$
\end{abstract}

A partir de esta continuidad, se torna relevante cotejar el estatuto de su perspectiva en torno a la ipseidad en sus relaciones con la alteridad. Podemos hallar algunas aproximaciones en sus deconstrucciones de la fenomenología de la autoafección y sobre la comprensión moderna de lo humano. Por un lado, en sus trabajos de 1967, desarrolla un tratamiento de la auto-remisión,

\footnotetext{
${ }^{471}$ Encontramos un contrapunto relevante sobre Derrida y Heidegger en trabajos de Ferry y Renault, que se inscriben en la misma tendencia a la consideración del lenguaje para dar cuenta de las articulaciones y orientaciones del pensamiento. En efecto, a partir de aquellos análisis derrideanos , destacan que la lógica de la modernidad, en el marco de la teleología humanista, es más relevante para las discusiones contemporáneas que la controversia política del caso Heidegger, subrayando la inevitabilidad de la articulación del ser-con en el ámbito del lenguaje, tal y como puede observarse en este pasaje :"...las reacciones son tanto más vivas cuando se tiene en cuenta el compromiso nazi de Heidegger, con su tenor especifico y con toda su amplitud, que sería de rigor preguntarse si esta dimensión esencial de su pensamiento-que fue cuestionar la modernidad- no estaba relacionada con la manera en que este pensamiento atribuía al nacionalsocialismo 'una grandeza y una verdad interna“”’( Ferry- Renault ,2001:.83) . De esta manera, sugieren la preformación del lenguaje en la orientación crítica de Heidegger. Sin embargo, también subrayan cierta continuidad:"Al menos habrá indicado una senda, por la cual, por supuesto, cada uno sabrá si quiere avanzar aún más lejos que Heidegger, en el sentido de lo que él descubrió. Y por esa senda, felizmente, llegó Derrida....” (Ibíd.: 78).
} 
distinguiendo una distancia infranqueable en el retorno del sí mismo para la auto-afección, en el contexto de los desarrollos husserlianos. El vínculo entre distancia y la temporalidad del ahora, que es la que supone Husserl para dicho fenómeno, evidencia una demora irreductible que Derrida liga a una hetero-afección, es decir, un pasaje necesario por la alteridad que cancela toda posibilidad de cobertura plena en el pliegue de la conciencia en su auto-remisión, y también cualquier pretensión implícita de unidad soberana. De este modo, el pliegue del sí-mismo y la alteridad se caracterizan por un cierre imposible.

En este mismo sentido, en su seminario La bestia y el soberano, desarrolla consideraciones sobre lo humano como una noción indecidible, es decir, no definida ni definible. Para ello, deconstruye parte del campo semántico en torno al sujeto soberano de la tradición metafísica. En tal contexto, pone en valor la estructura temporal del por-venir (á venir) como la más apropiada para pensar una dimensión de alteridad radical, incalculable e indefinible, en relación a las posiciones subjetivas y la ipseidad. Específicamente, reconoce que en toda constitución subjetiva primariamente se abre una ausencia o diferimiento radical, condición irrebasable de toda constitución, de modo tal que las relaciones con lo otro, solo pueden intentarse por medio de suplementos o prótesis ${ }^{472}$ y no por una vía reflexivo-dialógica.

Por ello, la aprehensión de la alteridad del otro debe insinuarse siempre por-venir, es decir, sin el carácter de presencia o inmediación que la reduciría a la esfera de la mismidad ${ }^{473}$. En esta perspectiva, la interrupción, el espaciamiento irreductible, la lógica del suplemento y la unidad imposible, son algunas de las notas para las figuraciones de la dinámica de la ipseidad, vinculadas a lo indecible preoriginario y con ello, articuladas en una tentativa de radicalizar el pensar en torno a una dimensión no simbolizable del lenguaje, dándole continuidad y despliegue a las consideraciones del ámbito originario y antepredicativo en Heidegger.

Aún más: esta tentativa es radicalizada a partir de su noción de Gramme o Différance, que desarrolla a partir de su concepto de texto y escritura. Con ella, señala el juego de diferencias con remisiones que cancelan toda comprensión de elementos que estén presentes en sí mismos, pues remiten indefinidamente a otro elemento, el cual también se halla diferido respecto a sí mismo ${ }^{474}$.

\footnotetext{
${ }^{472}$ Ello responde a una lógica singular en el pensamiento de Derrida, con la cual no solo desplaza la oposición metafísica adentro-afuera (como en el caso de la ipseidad, cuya verdad solo se despliega en el afuera de la alteridad), sino que rechaza el carácter derivado del suplemento, para pensar en una operatoria donde el elemento adicionado (otredad) permite el funcionamiento primario del elemento anterior (ipseidad). Puede encontrarse uno de sus primeros desarrollos de esta lógica del suplemento, a partir de su análisis deconstructivo de textos de Rousseau, en Derrida (2012[1967 b]):181-208.

${ }^{473}$ Hemos visto que estas tensiones fueron evidenciadas por Heidegger en sus análisis de la intersubjetividad en Husserl. Aquí Derrida, despliega ese camino del pensar, profundizándolo por medio de la deconstrucción, al tiempo que discute con la teoría del rostro en Levinas, la cual supone preeminencia del ahora y el tiempo presente en su desarrollo.

${ }^{474}$ De esta manera la Différance es estructurante, anterior y originaria respecto a todo valor, sujeto o sentido y permite remisiones no clausurables. Todo código semiótico y lengua son así efectos de esta diferencia irreductible. Véase
} 
En tanto huella (trace), no se trataría aquí de una oposición entre presencia y ausencia, sino de algo más arcaico, anterior a ello, incluso que la diferencia ontológica misma: un simulacro de presencia, un exceso y dislocación en un continuo borrarse de lo que podría mantenerlo en presencia, que ineludiblemente se inscribe en el mismo texto metafísico ${ }^{475}$.

En suma, ambos pensadores coinciden en los intentos de desplazamiento respecto a la metafísica de la subjetividad y en la atención puesta en el lenguaje como ineludible dimensión sesgada por su respectiva gramática y léxico ${ }^{476}$. Continuando la senda heideggeriana, busca evidenciar los enredos insuficientemente atendidos en la articulación del pensar de Heidegger que lo aprisionan aún más en la tradición metafísica, como el caso de la jerarquía y axiología en su programa, las cuales se hallan implícitas en el uso de ciertas palabras (como pobreza, privación, auténtico, etc.), o en flexiones del pensamiento (como la oposición originario/derivado que sigue siendo metafísica), que entiende como consecuencias derivadas de estrategias, comprensiones y articulaciones en el lenguaje (Derrida 2013:98-102). Con ello, libra sus batallas teóricas frente a la preeminencia de aquello que denomina significante trascendental, en referencia a la ilusión metafísica tradicional que se presenta al pensamiento, al momento de considerar y comprender un significado que logre solo remitirse a sí mismo, es decir, con aparente independencia de la lengua, del sistema de significantes o del contexto, que lo debilitaría en su remisión indefinida ${ }^{477}$. A nuestro entender, este es una de las distinciones que derivan de la relación y experiencia de Heidegger con el lenguaje, que aquí Derrida se apropia metodológicamente.

Derrida, (2013 [1972]):39-62 y (2014) :53-67. Según nuestra interpretación esto liga sus elaboraciones a la modalidad del pensar heideggeriano, sin residuos de una nostalgia de presencia.

${ }^{475}$ En este sentido entiende que la différance no es un valor nominal sino más bien un innombrable como condición de posibilidad de efectos nominales. Más bien, toda determinación o nombre entiende que es siempre de orden metafísico y este exceso es el que permite las dinámicas propias. En este marco contrapone e inscribe lo que denomina como la esperanza heideggeriana en su búsqueda de la palabra única y el nombre único (Derrida ,2013 [1972]: 61 s.). El tipo de deconstrucción que realiza Heidegger, este autor la inscribe en una modalidad que comporta determinados riesgos : "Intentar la salida y la deconstrucción sin cambiar el terreno, repitiendo lo implícito de los conceptos fundadores y de la problemática original, utilizando contra el edificio los instrumentos o las piedras disponibles en la casa, es decir , también en la lengua . El riesgo aquí es confirmar, consolidar, o relevar sin cesar en una profundidad siempre más segura aquello mismo que se pretende deconstruir. La explicitación continua hacia la apertura corre el riesgo de hundirse en el autismo del cierre" (Ibid.:173). No obstante destaca, junto a la otra modalidad de cambiar continuamente el terreno de la lengua (propia del pensamiento deleuziano), la estrategia consistente en entrelazar y combinar las dos modalidades, en textos con múltiples estilos .

${ }^{476}$ Desde aquí podemos compartir la sentencia de otro intérprete contemporáneo, quien interpreta que posmodernidad y deconstrucción son meras notas al pie de SuZ (Steiner, 1999: 38).

${ }^{477}$ Por ejemplo, sostiene que la consideración del sentido del ser heideggeriano bien puede interpretarse no como significante trascendental sino como huella significante determinada, derivada respecto de una diferencia. (Derrida,2012[1967 b] :.25 ss.)Como en este caso, la operación derrideana consiste en reinscribir las articulaciones de Heidegger al sistema de significaciones de la lengua cancelando toda pretensión de exterioridad que pueda sugerirse correlativamente de alguna de sus articulaciones metafóricas. 


\section{3.- Hacia una heterología ética en la consideración metafísica del sí-mismo en Levinas.}

En este apartado, abordaremos la recepción de Emmanuel Levinas, la cual se halla implícita en gran parte de las perspectivas anteriores. En líneas generales, este pensador realiza sus interpretaciones tomando como punto de partida el carácter inseparable de las perspectivas filosóficas, el horizonte comprensivo implícito y las formas de vida. En este marco , su lectura crítica de la obra de Heidegger se posiciona a partir de las implicancias y connotaciones políticas que distingue en sus trabajos, pues encuentra inscripciones efectivas de aspiraciones $u$ orientaciones relacionadas al $\mathrm{NS}^{478}$.En este sentido, el desarrollo de tales críticas apuntan a evidenciar la comprensión subyacente en los desarrollos filosóficos de Heidegger, poniendo especial atención al descuido y desplazamiento del tratamiento de las cuestiones éticas al ámbito ontológico, tal y como distingue en la analítica de la época de $\mathrm{SuZ}^{479}$.

Entre sus trabajos vinculados a la cuestión de la relación ipseidad-alteridad, hallamos las elaboraciones sobre la comprensión y el ser-en-el-mundo de la obra de Heidegger, que despliega detalladamente en su libro de 1971. Allí, busca dar cuenta de un ámbito de irreductible alteridad en la articulación de la cotidianidad del Dasein, tal y como se propone también con sus críticas a la conciencia intencional husserliana, en su matriz objetivante y representacionista limitada al ámbito reflexivo $^{480}$.

En su lectura crítica, interpreta que abordar la existencia como ser-en-el-mundo implica ciertas consecuencias: debido a la irreductibilidad de este complejo que no se agota en una mera conciencia, ningún acto de existencia humana puede ser puro en las relaciones con y en el mundo, sino que deja huellas, se encuentra con derivados y relaciones que exceden todo manipular calculador. Precisamente desde aquí, la interpretación que articula manifiesta su contrapunto con los desarrollos de Heidegger, especialmente respecto a la tematización de la mundaneidad del mundo.

A continuación analizaremos este contrapunto, en el marco de su teoría del rostro y la noción de recurrencia, con el objeto de evidenciar su énfasis ético en las consideraciones sobre las

\footnotetext{
${ }^{478}$ En este marco, un analista sostiene: "Para Levinas, la filosofía de Heidegger es la clara expresión de un paganismo, que ignora las exigencias esenciales de la ética, y no puede oponer ninguna resistencia a las brutalidades nazis, sino que más bien las promueve" (Peperzak, 2011:153) Incluso, el desarrollo de un contrapunto permite interpretar que su trabajo en Totalidad e infinito, puede ser leido como un anti-Ser y tiempo (Ibíd.:151).

479 Por ello nos detendremos en el análisis de sus siguientes trabajos: Entre nosotros. Ensayos para pensar el otro (2001); Totalidad e infinito (1971[2002]) y De otro modo de ser o más allá de la esencia (2003)

${ }^{480}$ En línea con nuestro autor, sostiene que el error de Husserl fue privilegiar los actos objetivantes y actuales de la reflexión. Retoma así las consideraciones sobre la conciencia no reflexiva en relación a un saber esquivo de lo profundo e insondable, en el marco de un intento singular de descentramiento de la intencionalidad, desde una perspectiva ética. Véase, Levinas (2001): 151-60; 170-4.
} 
mediaciones de la ipseidad, cuyo carácter metafísico le confiere una singular radicalidad y externalidad, que lo enmarca también en una manifiesta discusión con la perspectiva derrideana.

\section{3. a.- Críticas a $S u Z$.}

En sus análisis de las elaboraciones sobre la técnica, subraya una tendencia al egoísmo en Heidegger, quien por denunciar la soberanía de los poderes técnicos del hombre, se ve llevado a exaltar los poderes pretécnicos de la posesión ${ }^{481}$, cuestión que ya se manifestó en la analítica existenciaria, al considerar el trato con los útiles como punto de partida (Levinas, 2002:70).

En detalle: distingue que en $S u Z$ omite consideraciones relevantes sobre el goce y el habitar en la estructura del ser-en-el-mundo, debido a su intención de contraponerse a la perspectiva moderna, lo cual orientó su abordaje hacia el campo de la instrumentalidad en las relaciones con los entes $^{482}$. Frente a ello, Levinas reconoce formas anteriores al marco instrumental moderno, a partir de lo que denomina elemento, el cual designa un estrato de profundidad siempre esquiva en la relación con los entes ,es decir, un sesgo de alteridad irreductible que se halla implícita en la facticidad y el trato en el entorno(Levinas 2002 :151;159-61). Al reconocer este sesgo también implícito en las relaciones del Dasein con los otros, mediante una separación irreductible que hace del otro una dimensión inasimilable, se aparta de toda subsunción a la esfera de lo propio heredada de la fenomenología tradicional. Por ello, más que distinguirse por el diálogo, esta relación se caracteriza por una radical asimetría, que hace del otro algo no subsumible en totalidad alguna.

Si en la analítica, comprender el ser de lo particular implica situarse más allá de este mediante una relación con lo universal, en el caso de la relación con el otro, en cambio, la comprensión respectiva la desborda, puesto que este otro, además de contar también como ente, nos afecta e interviene en las dinámicas del ámbito de lo propio y la mismidad. Más aún, remarca que la estructura del estar-con-el-otro implica un invocar al otro, un dirigirse por la palabra que se torna inseparable de la comprensión. Y precisamente al hablarle, olvidamos necesariamente la referencia al ser universal que encarna, para atenernos al ente particular que es (Ibid.:18 s.). De este modo, la relación con el otro no es meramente ontología, ni es reductible a la representación, sino más bien, es invocación y plegaria. En este sentido, subraya que el prójimo solo es accesible en cuanto rostro

\footnotetext{
${ }^{481}$ Puede encontrarse aquí un modo de proceder crítico análogo al de Derrida, que manifiesta un supuesto compartido sobre el lenguaje: sea por estrategia o por denuncia, las modalidades de articulación en el lenguaje prefiguran las vías del discurso y el discurrir del pensar. Supuesto que ambos pensadores comparten con Heidegger.

${ }^{482}$ Un análisis e interpretación sobre esta orientación semántica (derivada de tal contraposición) que critica Levinas, puede encontrarse en Sabrovsky, 2011:56 ss.
} 
(Antlitz), es decir, en cuanto otro particular irreductible a lo universal y al cual jamás puedo poseerlo como ente de mi propiedad ${ }^{483}$.

Precisamente en esta línea distingue que la analítica heideggeriana subordina la relación con el otro a la relación con el ser en general, subsumiéndola en una ontología que rechaza elaboraciones de la dimensión ético-práctica. Por el contrario, Levinas propone una ética del otro irreductible, es decir, una relación no alérgica con la alteridad, que no busque conjurarla o esquivarla. De esta manera, para este pensador la comprensión del ser en general no puede dominar la relación con el otro, sino que ésta domina a aquella, es decir, inscribe la comprensión en el marco preontológico de una relación ${ }^{484}$.

Interpreta que la analítica de $\mathrm{SuZ}$ deriva en una sacralización del mundo, tal y como figura en la dinámica de la autenticidad, la cual no presenta trazas de un retorno del yo o mediación con los otros, sino que sigue la vía de la inscripción instrumental en el mundo. Ello se debe a que la salida del Uno parece disolver la relación con los demás, sin encuentro con un rostro, sino tan solo condicionada por el ser-en-el- mundo: la Fürsorge se ejerce en un mundo en el que los otros alrededor de las cosas, se reducen a ser lo que hacen (Levinas ,2001:239). Frente a ello, el discurso acerca del rostro en el que insiste este pensador, se propone quebrar el ser-ahí meramente preocupado por su ser-en-el-mundo atravesado por la instrumentalidad. Una ética del sacrificio se revela, antes o más allá de la ontología, como una responsabilidad respecto al otro, que implica el desinterés y prioridad del otro por sobre mí. Como vemos, estas elaboraciones bien pueden articularse con la tradición fenomenológica contemporánea en un amplio dialogo que incluye a Ricoeur, Heidegger, Merleau Ponty, Henry, Derrida, Gadamer y Marion, entre otros.

\section{3. b.- Un pensar de lo Mismo; un pensar de lo Otro.}

\footnotetext{
${ }^{483}$ Debido a este carácter evasivo, autónomo y de una distancia infranqueable, entiende que el intentar poseerlo es un modo de negarlo parcialmente. Por ello afirma que el otro es el único ente al que puedo querer matar, pues su negación solo puede intentarse como total. En cambio, la relación cara a cara supone no poder matar (Levinas ,2001:21 s.): matarlo es captarlo en la apertura del ser en general, sin encontrarme con su rostro. A diferencia de la cosa, cuya relación de comprensión se establece a partir de la totalidad que les otorga significación, la relación con el rostro es relación con el ente como puro ente, relación con una profundidad más que un horizonte: esto es lo que subyace, en sus trabajos, al énfasis puesto en la desnudez del rostro.

${ }^{484}$ Así se aparta de la perspectiva heideggeriana de la prioridad por lo ontológico en el análisis de la existencia y la relación con el prójimo. Entiende que esta es la relación última del ser, más aún : sostiene que la ontología supone la metafísica (Levinas 2002:71)
} 
En sus críticas a la fenomenología trascendental, sostiene que la tentativa tradicional de reducir lo otro a la esfera del yo o sujeto, impide que se manifieste como tal. En este marco, distingue que la relación del sujeto con la representación del objeto es una relación de lo Mismo (Selben) (mismidad del yo en cada caso idéntica) con lo Otro, donde este es comprendido como mero reverso de la identidad del sujeto cognoscente, tal y como lo distingue en la noción husserliana de reducción.

Asimismo, inscribe el pensamiento de Heidegger en la misma tradición y orientación: mientras su obra se aboca a lo otro del ente que permite la posibilidad de entendimiento y el pensar, Levinas se dirige interrogativamente al Otro, al prójimo, el otro Dasein que se halla fuera del alcance de la comprensión y más allá del ser como lo universal.

Aun así, en ambos casos el impulso del pensar proviene no ya de un pensante voluntario sino de lo otro del pensar: o bien el Ser como otro que exhorta al hombre, o bien es el Otro-prójimo sin más, que lo solicita. Mientras el paso atrás de Heidegger va en busca de la verdad epocal del ser frente al decir y el pensar orientado al ente, Levinas, por su parte, experimenta el pensar como perturbado e interrumpido mediante la responsabilidad del otro, la diferencia ética , más allá del ser y de la ontología. Esto figura también en su consideración tanto de una racionalidad no teórica ${ }^{485}$, como de un enfoque sobre el lenguaje que incluye tal dimensión inasimilable ${ }^{486}$.

Para este pensador la donación histórica del ser, en la que insiste Heidegger, remite al ser que la ontología en sus distintas épocas reúne y compara como una totalidad, dirigido luego a un pensar nivelador: el pensar totalitario de la identidad. En esta remisión, el yo y el pensar del ser que de aquí parte, o bien abarca todo lo ente para buscarse a sí mismo, o bien para abandonar todo o fundirse en él (desapareciendo el ente objetivo y el yo). A esta remisión histórica, Levinas contrapone el infinito de la alteridad inasimilable a una totalidad.

No obstante, comparte con Heidegger la crítica al pensamiento de la subjetividad con vistas a la pretensión de apoderamiento y de totalización, bajo la cual el sujeto junto con sus objetos se vuelve indiscernible. No inscripto en un humanismo del sujeto como fin en sí mismo, insiste en el lugar del hombre en su recurso a la ciencia y la técnica. Subraya que la diferencia ontológica, como intento de ruptura con el pensar de la identidad universal, no logra su cometido si no se tensiona por la referencia ética al otro, que lleva rostro y nombre, significando desde la absoluta exterioridad.

\footnotetext{
${ }^{485}$ En referencia a una racionalidad ética que no subsume la alteridad tal y como evidencia el despliegue de la racionalidad teorico-cientifica. Para un desarrollo sobre esta racionalidad en relación con la ética y la alteridad ,véase Conesa (2008):309-11

${ }^{486}$ En este enfoque distingue entre lo Dicho y el Decir (le Dit et le Dire), con evidente resonancias heideggerianas. Mientras lo Dicho remite a la comunicación intersubjetiva, el Decir no se reduce a este, ni de él derivado. Implica un estrato de excedencia, en la misma línea que la distinción heideggeriana del Habla. Esta dimensión evidencia un espacio de intersubjetividad originario, designando la apertura al Otro (Levinas, 2003: 48-51; 97-104). Para un análisis sobre la perspectiva ética del lenguaje en Levinas, Véase Palacio (2013):141-52.
} 


\section{3. c. La ipseidad ética.}

A diferencia de Heidegger, entiende que no hablan en primer lugar los poetas ni dioses, sino que lo sagrado habla a través de los hombres, mediante el sujeto, pero afectado del otro, un sujeto en marcha en busca inacabada del otro, sin llegada ni plenificacion posible. Así, el rostro del otro no es ningún fenómeno del yo, sino del prójimo. Es un fenómeno del no-fenómeno, que arranca toda fenomenalidad con sus diferenciaciones epocales, que llama al sujeto a la responsabilidad más allá de toda presencia, de su capacidad de poder decir o hacer algo nuevo.

Las consideraciones acerca de la mismidad se hallan implícitas en esta apuesta ética de Levinas. En este marco, la autonomía del sujeto debe volcarse en heteronomía, donde la subjetividad logre darse cuenta del puente a su mismidad que experimenta mediante el otro, al ponerse en evidencia la necesidad de recursos más allá de su poder. Tan solo así recibe sentido la subjetividad y lo que produce de significativo: el sentido no brota de la relación ontológica, sino de la relación ética, mediante el otro y las relaciones del mundo.

De esta manera, la ipseidad se aborda en una singular dinámica con esta alteridad radical, abandonando toda perspectiva de autosuficiencia o autonomía en la remisión a sí, en vistas de un ámbito de excedencia que quiebra sus límites, los del saber, el conocimiento y el lenguaje. Esta relación con lo otro le imposibilita un retorno a si pleno, al tiempo que abre al compromiso y la responsabilidad por el otro. Por ello, podemos reconocer aquí una hétero-constitución de la ipseidad $^{487}$, donde la persona se articula en el marco de una dinámica bivalente de pasividadactividad, entre la venida incalculable del otro y la responsabilidad a él dirigida. En este marco, el acceso al sí mismo solo es posible por el camino de una diferencia que no solo es su condición, sino que también se le revela como infinitamente exterior, al punto de verse ineludiblemente absorto en una situación ética : la irrupción del prójimo en tanto rostro implica el fin de la dominación sobre el otro y la reducción a lo Mismo, en el marco de una ética anterior ontológicamente e independiente

${ }^{487}$ Puede encontrarse un análisis al respecto , donde un intérprete distingue esta consideración como condición anfibológica de la persona humana, en Ordieres (2015):31-8 
de toda iniciativa y poder individual (Levinas, 2002:211).Por ello, la mismidad solo es experimentable mediante el otro, tal y como especifica con la noción de recurrencia.

\section{3. d.-La noción de recurrencia como expulsión de sí.}

Finalmente, dos aspectos de sus elaboraciones manifiestan continuidad con los tratamientos de Heidegger aquí considerados. Por un lado, la consideración de lo inmemorial, en el marco de la responsabilidad por el otro. Específicamente, en su concepción de la temporalidad sostiene un tiempo irreductible a presencia, irrepresentable, inmemorial y significado sin haber sido presente, a partir de la responsabilidad para el otro desde aquello que denomina como lo otro del ser (Levinas, 2003: 45 s.; 55-59) ${ }^{488}$. Tal responsabilidad es anterior a todo comienzo, pre-original y ajena a la voluntad.

De este modo tal relación ética introduce un tiempo diacrónico: un pasado más antiguo que todo presente y aun no manifiesto, una anterioridad previa a toda anterioridad representable, un pasado irrecuperable por el recuerdo y un futuro no agotable por el porvenir. Respecto al prójimo, su pasado es irrepresentable para uno, además de tener como futuro la obligación respecto al otro como orden inaudita. Por ello, la anterioridad ética de un pasado inmemorial nos compromete con una responsabilidad sin comienzo.

En este marco, remite en la subjetividad al abandono de toda generalidad que correlativamente conlleve la imposibilidad de descargarse de la responsabilidad del otro. Esto se inscribe en la dinámica de lo que denomina substitución (en referencia a la alteridad del prójimo que reside en el lugar del Yo), que irradia en su consideración de la mismidad e identidad humana.

En efecto, elabora una noción de recurrencia donde se evidencia que la conciencia y el saber de sí no agota la noción de subjetividad. El sí-mismo es un término en recurrencia, es decir, más allá o antes de la conciencia y del ser que esta tematiza. La responsabilidad anterior al compromiso da lugar a una recurrencia irrenunciable del sí-mismo en el sujeto, una remisión a sí mismo que

\footnotetext{
488 Ámbito que este autor logra reconocer como huella, cuando especifica su accesibilidad : "El movimiento que marcha ‘más allá” pierde su propia significación, se torna inmanencia en el momento en que el logos interpela el más allá, lo cerca , lo presenta y lo expone, mientras que su atenerse a la proximidad es absoluta exterioridad, sin medida común con el presente, no compaginable con él, siempre algo ya pasado sobre el cual el presente va con retraso , algo por encima del 'ahora' que esta exterioridad inquieta u obsesiona" (Levinas , 2003:165). Vemos aquí , en un pensar que se aparta de la metafísica de la presencia, una tentativa de pensar no jerarquizante, que subrepticiamente conmuta el término anterioridad por exterioridad, en tanto inconmensurabilidad respecto a la conciencia como huella esquiva , que remite a nuestra relación con el prójimo.
} 
impide mantenerse allí. En otras palabras, implica un estar en sí como exilio bajo el efecto de una expulsión, desbordado por aquella exigencia irrecusable del otro (Ibíd.: 168) ${ }^{489}$.

Precisamente por ello, insiste en que el sí-mismo en su recurrencia no puede hacerse, como si fuese una esencia que se repliega sobre sí misma, voluntaria e intencional, sino que está hecho de la pasividad absoluta en su dinámica con la alteridad ${ }^{490}$.

Con esto, Levinas da cuenta de una dinámica paradójica en la ipseidad, con su lógica de oxímoron, al distinguir en su constitución la permanencia de una pérdida de sí mismo, desde una insistente inquietud y ansiedad ${ }^{491}$ que emerge de la inminencia de una elección ineludible, tal como explicita en este fragmento:

"El Sí mismo se hipostasia de otro modo; se anuda como imposible de desatar en una responsabilidad para con los otros. Intriga an-árquica porque no es el reverso de alguna libertad, de algún compromiso libre adquirido en el presente o en un pasado memorable, tampoco una alienación de esclavo, a pesar de la gestación del otro en el mismo que significa tal responsabilidad para con el otro. En la exposición a las heridas y a los ultrajes, en el sentir de la responsabilidad, el sí mismo queda provocado como irremplazable, como llamado a los otros sin posible dimensión y, de este modo, como encarnado para ofrecerse, para sufrir y para dar y, así, uno y único en conjunto dentro de la pasividad, sin disponer de nada que le permitiese no ceder a la provocación" (Ibíd.: 171 s.)

En suma, al igual que el ámbito de lo inmemorial, tal recurrencia es previa a toda autoremisión de la conciencia en identificación, pues es anterior a la distinción de momentos que pueden ofrecerse en una síntesis: retrocede más acá de sí misma, señalando aquella alteridad irreductible. Desde estas elaboraciones, los diálogos en relación a los primeros tramos del pensar de Heidegger, se establecen en el énfasis radical puesto en la oscilación y dinámica inexorable de la

\footnotetext{
${ }^{489}$ Y especifica: "La ipseidad dentro de su pasividad sin arjé de la identidad es rehén. El término yo significa heme aquí, respondiendo de todo y de todos. La responsabilidad para con los otros no ha sido un retorno sobre sí mismo, sino una crispación exasperada, que los límites de la identidad no pueden retener. La recurrencia se hace identidad haciendo estallar los límites de la identidad, el principio del ser en mi, el intolerable reposo en sí de la definición" (Ibíd.:183). A partir de estas consideraciones Walton desarrolla paralelos en los procedimientos fenomenológicos en Levinas y Husserl, poniendo de relieve su consideración singular del ámbito de lo originario : entiende que Levinas se inscribe en la oscilación entre intencionalidad y alteridad en la tradición fenomenológica, que refleja el movimiento de hacer/padecer que Husserl coloco en el centro de su análisis, cuando mostro que el yo es simultáneamente centro de irradiación de actos y polo de incidencia de afecciones. Distingue que con Levinas se radicaliza el polo de afección, pero parece olvidar el polo correlativo, enfatizando la responsabilidad como estructura esencial, primera y fundamental de la subjetividad, de modo que estamos coordinados con el otro de manera pre-original e inmemorial, con anterioridad a todo comienzo (Walton 2010:134).

${ }^{490}$ Lo cual, en su posicionamiento frente a los desarrollos respectivos de Hegel, Husserl y Sartre , lo conduce a distinguir: "Presentar el nudo de la ipseidad en el nudo directo de la esencia sobre el modelo de la intencionalidad del para sí o como la abertura de la reflexión sobre sí misma, es poner una nueva ipseidad detrás de la que se quería reducir"'(Levinas 2003:171)

${ }^{491}$ Distingue la ansiedad de la recurrencia del sí mismo frente a la angustia del ser-para-la-muerte heideggeriano, por su carácter ineludible. (Ibíd. :175)
} 
alteridad en la ipseidad, que impactan también en la ontología de ruptura que propone ${ }^{492}$. La radicalidad metafísica con la que es pensada aquí la dimensión ética de lo otro es correlativa a un enfoque disolutorio de la ipseidad en su relación de alteridad irreductible. Como en el caso de Derrida, la orientación respectiva apunta al carácter liminar y disgregatorio en las mediaciones con la alteridad en su comprensión radical: si en este pensador, ello es condición para la apertura al porvenir, en el caso de Levinas, es condición (pre) ontológica para la constitución paradójica de la ipseidad.

Ahora bien, un diálogo en contrapunto, orientado más bien a cierta consistencia de la ipseidad, especialmente en torno a la consideración del mantenimiento de sí heideggeriano, puede articularse a partir de las elaboraciones respectivas de Paul Ricoeur.

\section{4.- Análisis posheideggerianos de la identidad: Paul Ricoeur y la hermenéutica de sí.}

En efecto, una continuidad crítica puede encontrarse en sus consideraciones de la identidad, con la distinción de su carácter narrativo, en línea con la estructura del poder-ser y carácter arrojado del Dasein en SuZ. Tomando distancia de algunos supuestos de Strawson, Parfit y Tugendhat de la filosofía analítica, este pensador parte del supuesto heideggeriano por el cual las significaciones además de lingüísticas , corresponden también a determinados modos de ser (Ricoeur ,1990:349) .Sus escritos se ponen en diálogo con diversos tramos del pensamiento contemporáneo, entre los cuales se hallan aquellas elaboraciones de Levinas, en especial respecto a su teoría del rostro y la omisión de la cuestión de la estima de sí en las relaciones con la alteridad. En este contexto, las motivaciones éticas también orientan parte de sus búsquedas e inquisiciones ${ }^{493}$.

\footnotetext{
492 Respecto a las comparaciones posibles entre ambos pensadores, un intérprete concluye con sesgos heideggerianos:"Así son ambos planteamientos del pensar y movimientos del pensar junto con sus respectivas rupturas...no fáciles de comparar en uno con el otro. A pesar de sus semejanzas estructurales no se pueden unificar mediante correcciones, rectificaciones, críticas mutuas y en dado caso aclaraciones de malentendidos y mediante un plan de adaptaciones interpretativas; pero se empujan mutuamente en la puesta en cuestión y precariedad que puede mover más profundamente que la respuesta que acucia a lo concluyente" (Halder ,2006:62). Este fragmento con su modalidad para pensar el diálogo en filosofía, nos muestra las resonancias que tienen las elaboraciones de Heidegger en los modos contemporáneos de plantear y leer relaciones diacrónicas entre perspectivas.

${ }^{493}$ Incluso la orientan con ciertos compromisos manifiestos, como en este excurso:"Los 10 estudios que componen esta obra suponen pasar por alto, de modo consciente y decidido, las convicciones que me sujetan a la fe bíblica. No pretendo que, en el plano profundo de las motivaciones, estas convicciones no hayan influido en el interés que tengo por tal o cual problema, e incluso en el conjunto de la problemática de si "(Ricoeur ,1990: XXXVIII)
} 
Apartándose de la mención al sujeto en sus trabajos, por su ligazón semántica con la centralidad tradicional del yo, se refiere al existente humano a partir de la autocomprensión de sí. Ello le permite poner un énfasis mayor en las interpretaciones narrativas y prácticas que han sedimentado esta consideración de sí, es decir, en su carácter irreductiblemente mediado ${ }^{494}$.

De este modo, la vía reflexiva y las mediaciones en el lenguaje son prioritarias frente a la consideración de inmediatez en la posición del sí. En este contexto se despliegan algunas de sus diferencias con Levinas: mediante la noción de proximidad, destaca la co-presencia de la alteridad en la constitución de la ipseidad, suponiendo que el sí mismo ya se halla manifiesto primariamente al momento de las relaciones de reciprocidad. En cambio, vimos que Levinas al destacar la externalidad radical del Otro y el carácter metafísico de las dinámicas respectivas, supone que la ipseidad se manifiesta de un modo derivado de dicha dinámica originaria ${ }^{495}$. A continuación analizaremos el estatuto del sí mismo en Ricoeur, para dar cuenta de las notas dinámicas y proyectivas en continuidad con la perspectiva heideggeriana y en discusión con aquella recepción ${ }^{496}$

\section{4. a.- La distinción de identidad.}

Para su elaboración respectiva, parte de la disociación de dos significaciones del término latino identidad, como idem e ipse. En el primer caso encuentra una remisión a la permanencia en el tiempo, opuesto a lo diferente, cambiante y variable. En el segundo, se inscribe en un campo semántico que no supone afirmación sobre un núcleo no cambiante de la personalidad. Desde aquí destaca una sinonimia parcial entre mismo e idéntico, en su diferencia con el término mismidad (Gleichheit) que es sinónimo de identidad-idem y opuesto a ipseidad (Selbstheit) que se articula con la identidad -ipse. En este último caso, se pone en juego una dialéctica entre ipseidad y mismidad, en el marco de la relación entre el sí mismo y el otro distinto de sí, donde la alteridad puede ser constitutiva en un grado tan íntimo que no se puede pensar en una sin la otra (Ibíd.: XIV).

\footnotetext{
${ }^{494}$ A este respecto sostiene: "sólo nos comprendemos mediante el gran rodeo de los signos de la humanidad depositados en las obras culturales" (Ricoeur, 2001: 109).Este es uno de los aspectos que distinguen estos abordajes de una perspectiva meramente fenomenológica: mientras esta se circunscribe a la inmediatez de la intuición, la hermenéutica incluye la mediación de la interpretación como la vía de acceso a los fenómenos considerados.

${ }^{495}$ Para un contrapunto detallado entre ambos pensadores, en el marco de las críticas a las consideraciones metafísicas de Levinas, véase Sánchez Hernández (2013): 114-31. Cf. Derrida (1989a [1967 a]): 107-2010.

${ }^{496}$ En este apartado, nuestros textos de referencia para el análisis y comparación, especialmente serán: Si mismo como otro (1990); Tiempo y narración (1998) y Del texto a la acción. Ensayos de hermenéutica II (2001).
} 
En línea con los análisis heideggerianos, la hermenéutica de sí no es igual a la filosofía del cogito: decir sí mismo no es decir yo, el cual o bien se pone o es destituido. El sí está implicado reflexivamente en operaciones cuyo análisis preceden al retorno hacia sí mismo, el cual se opone a la inmediatez del yo soy y a la ambición de colocarlo como último fundamento (Ibíd.: XXXI). Desde esta consideración, la hermenéutica se entrega a la historicidad de la interrogación, el rodeo del análisis por las mediaciones culturales y del lenguaje impone el modo indirecto y fragmentario de todo retorno a sí.

Como queda manifiesto, para esta distinción de la identidad también se apoya en el horizonte originario de la temporalidad como condición indispensable para pensar su modalización singular: entiende que la persona de la que se habla tienen su propia historia, de modo tal que la identidad personal solo puede articularse en la dimensión temporal de la existencia humana (Ibid.:107).Desde aquí articula lo que denomina como identidad narrativa la cual, a diferencia de las perspectivas anteriores, pone un mayor énfasis en los márgenes de constancia en las elaboraciones sobre la ipseidad.

\section{4. b.- La consideración del mantenimiento de sí.}

Para el desarrollo de aquella noción, que ha elaborado desde sus trabajos de $1985^{497}$, parte de la tesis heideggeriana que la comprensión de sí es interpretación, de modo tal que la narración puede ofrecer una mediación privilegiada, al valerse tanto de la historia como de la ficción, entrecruzando estilo historiográfico-biográfico y novelesco, por medio de lo cual aquella puede ser desarrollada.

Asimismo, articula la mismidad como un concepto relacional que remite: a la identidad numérica, en tanta unicidad; a la identidad cualitativa, en tanta sustitución sin pérdida semántica y a la dimensión temporal, como continuidad ininterrumpida en los estadios de un mismo individuo.

\footnotetext{
${ }^{497}$ Allí introduce el concepto de identidad narrativa, de la siguiente manera:’El frágil vástago, fruto de la unión de la historia y de la ficción, es la asignación a un individuo o a una comunidad de una identidad especifica que podemos llamar su identidad narrativa. El termino `identidad “ es tomado aquí en el sentido de una categoría de la práctica. Decir la identidad de un individuo o de una comunidad es responder a la pregunta ¿Quién ha hecho esta acción? ¿quién es su agente, su autor? (...) ¿Qué justifica que se tenga al sujeto de la acción, así designado por su nombre, como el mismo a lo largo de una vida que se extiende desde el nacimiento hasta la muerte? La respuesta solo puede ser narrativa. Responder a la pregunta ‘¿Quién?’ como lo había dicho con toda energía Hannah Arendt, es contar la historia de una vida. La historia narrativa dice el quién de la acción. Por lo tanto, la propia identidad del quien no es más que una identidad narrativa” (Ricoeur ,1998:997 s.). Con ello, la cuestión de la ipseidad en su estructura temporal, se sustraería del dilema de lo Mismo y lo Otro. A partir de estas definiciones vía Arendt, nos reencontramos con las elaboraciones heideggerianas de la estructura temporal de la ipseidad dinámica del Dasein, especialmente respecto a la cuestión del quién en el $\S 25$ de SuZ.
} 
Ahora bien, si el tiempo es factor de desemejanza y diferencia, entonces la amenaza implícita en esta acepción de la identidad solo se detiene si se parte de un principio de permanencia en el tiempo. Ricoeur reconoce dos modelos de tal permanencia que disponemos al hablar de nosotros mismos: el carácter y la palabra dada.

Mientras la permanencia del carácter oculta la diferencia del idem y el ipse, la fidelidad de si en el mantener la palabra dada, por su parte , marca distancia extrema entre la permanencia de sí y la del mismo. Por ello, la identidad narrativa puede intervenir en la constitución conceptual de la identidad personal como término medio entre el polo del carácter (como tendencia a coincidir el idem y el ipse) y el polo del mantenimiento de si (donde ipseidad se libera de la mismidad).

Específicamente: el carácter remite a signos distintivos que permiten designar de nuevo a un individuo, en el conjunto de sus disposiciones duraderas. Tal disposición esta sesgada en la dimensión temporal y se vincula a la costumbre. Este autor sostiene que si bien la costumbre proporciona una historia del carácter, también recubre y opaca la innovación que le ha precedido recubriendo el ipse por el idem, es decir, su sesgo dinámico. Pero la dialéctica de innovación y sedimentación del proceso de identificación, implícita en su temporalidad irreductible, evidencian que el carácter tiene una historia que se halla contraída. Precisamente lo que la sedimentación del carácter ha contraído, la narración puede volver a desplegarlo (Ibid.:113-7).

El otro modelo de permanencia en el tiempo, la palabra dada y mantenida, expresa un mantenerse a sí que solo se inscribe en el quién, cuya perseveracion característica la pone en sintonía con el tratamiento de Heidegger, aunque sin limitarse a la resolución frente a la muerte .Y esto es así porque Ricoeur articula el mantenerse a sí, en el caso del cumplimiento de la promesa como desafío al tiempo. Allí se abre un intervalo de sentido que hay que llenar por la mediación en el orden de la temporalidad, modalizando la ipseidad que se mantiene frente a lo circunstancial o lo emocional: punto crucial que también entiende como propicio para la noción de identidad narrativa donde el ipse se articula con la identidad sin el apoyo del idem.

\section{4. c.- La ipseidad en la hermenéutica del texto y la narración de sí.}


Ahora bien, si la comprensión de sí, sigue la vía de su mediatización en el lenguaje, entonces no puede darse como acabada ${ }^{498}$.En este camino, Ricoeur recurre al modelo del texto en las relaciones de interpretación, estableciendo paralelos y articulaciones entre la hermenéutica de sí y su teoría narrativa.

Por una parte, entiende que el texto abre un espacio donde es posible circunscribir un tránsito hermenéutico, donde las relaciones entre vida y narración dan cuenta de una unidad móvil de sentido: como en el caso del lector que refigura el texto, también formamos parte de una temporalidad histórica donde de cierto modo escribimos y somos escritos por ella.

Da cuenta de ello por medio de la noción de apropiación (en línea con la consideración gadameriana de la aplicación), la cual permite explicitar no solo la superación implícita de la relación texto-intérprete, sino también el rol que el texto cumple en la autocomprensión del lector. En este sentido, a partir de las implicancias en la comprensión de sí, texto y obra pueden considerarse como nuevas formas de apertura y extensión del ser-en-el-mundo.

De modo correlativo, Ricoeur destaca el momento de desapropiación en el acto de exponerse al texto, por el cual el lector ve en parte limitada sus pretensiones arbitrarias frente a él. Este momento circunscribe una suspensión de la posición del lector, a favor de otro sí mismo fíccional y con mayor alcance, de modo que la desapropiación de sí en el encuentro con el texto se torna correlativa a la expansión de sus límites (Ricoeur, 2001:105-10). Así apropiación-desapropiación caracterizan la dinámica de la ipseidad que Ricoeur distingue en la hermenéutica del texto ${ }^{499}$.

Por otra parte, la narración de sí permite determinar, articular y clarificar la experiencia temporal. Es decir, el relato confiere unidad de sentido al superar su heterogeneidad por la integración sintética en la trama narrativa, al tiempo que la operación narrativa supone un concepto de identidad dinámica. La historia de una vida es refigurada constantemente por todas las historias verídicas o de ficción que el sujeto cuenta sobre sí mismo, que hace de la propia vida un tejido de historias narradas ${ }^{500}$.

Frente a la ambición de certeza auto fundadora del cogito, opone la atestación en la base del crédito y la confianza, donde el existente se reconoce como agente y paciente: un decir sí, un mantener la palabra que se sostiene desde la superficie del lenguaje, en el actuar y el narrar. En esta

\footnotetext{
${ }^{498}$ Es decir, en estas elaboraciones la identidad narrativa no agota la ipseidad, pues para la comprensión de si queda pendiente siempre una hermenéutica de lenguajes y acciones, en textos, signos y hechos culturales. De este modo, rechaza la posibilidad de una ontología acabada en los análisis respectivos, en estrecha conexión con el carácter no clausurable de la ipseidad resultante de la analítica de Heidegger.

${ }_{499}$ Para un análisis comparativo de estas consideraciones de la identidad, frente a la perspectiva de dislocación en Derrida, véase Vergalito(2005):20-4

${ }^{500}$ Por ello, sostiene que el psicoanálisis constituye un laboratorio muy instructivo para la indagación filosófica sobre la noción de identidad narrativa, en lo que respecta a la posibilidad de rectificar el sentido de relatos previos de sí, desde donde el sujeto se reconoce (Ricoeur, 1998:999).
} 
línea, toma de $S u Z$ resonancias con esta hermenéutica de la ipseidad: interpreta el término conciencia moral (Gewissen) con el significado primario de atestación (Bezeugung).

Específicamente, la atestación es para Ricoeur una modalidad que responde a una singular lógica de anhelo o intento de comprenderse como unidad (de una vida) en el despliegue de la ipseidad, lo cual no puede comprenderse bajo el modelo teorético de la certeza objetiva. El paradigma con que piensa esta modalidad es el de la promesa, por el cual el sí da cuenta, al prójimo y a sí mismo, de una permanencia en el mundo y el tiempo. Pero en este caso, esta testificación incluye la alteridad, un sí que se manifiesta como otro, pues se enmarca en un acto donde compromete su existencia y su proyecto, ante la conminación del prójimo. De este modo, el mantenimiento de sí y la unidad propuesta, no solo implican un compromiso en relación al otro y a sí, sino también dan cuenta de que la unidad de la atestación no es definitiva, al requerir implícitamente del despliegue de una experiencia y de las mediaciones de la narratividad.

Desde estas elaboraciones insiste en distinguir que la alteridad pertenece a la constitución ontológica de la ipseidad, en su despliegue y devenir. Esta alteridad se pone en evidencia a partir de tres experiencias de pasividad: la del cuerpo propio, mediadora entre sí y el mundo; la de lo extraño, en referencia al otro distinto de uno y finalmente, la relación de sí consigo mismo, a partir de la conciencia como Gewissen, donde articula la consideración de la atestación. Distingamos brevemente estas consideraciones de la alteridad

\section{4. d.- La irrupción de la alteridad.}

Como vimos en los primeros capítulos, la consideración del cuerpo por parte de Husserl se apoya en su doble incidencia: el cuerpo propio pertenece al reino de las cosas y al de sí. Esto se halla articulado con la distinción husserliana entre carne (Leib) y cuerpo (Körper) que retoma Ricoeur, al sostener que la analítica del ser-en-el mundo ofrece un ámbito para la ontología de la carne, al romper con la problemática de la constitución basada en la intencionalidad de la conciencia, aunque distingue que Heidegger finalmente no desplego tal ontología ${ }^{501}$.

Ricoeur subraya que la ipseidad implica una alteridad propia cuyo soporte es la carne. La ontología de la carne remite a la encarnación del yo soy y la mediación práctica del ser-en-el-mundo que somos en cada caso, ambigüedad que permitiría indicar el carácter contingente o aspecto pasivo

\footnotetext{
${ }^{501}$ Sostiene que posiblemente la priorización de la temporalidad por parte de Heidegger, produjo la falta de desarrollo de una ontología de la carne en SuZ (Ibid.:364).
} 
inherente al humor o los deseos, por ejemplo. En este contexto, entiende que el estado de arrojado puede servir para investigar el sí como carne: el proyecto arrojado es sellado por la encarnación como alteridad primera.

Por su parte, la consideración heideggeriana de la conciencia como Gewissen abre un ámbito para una forma original de dialéctica entre ipseidad y alteridad. Recordemos que en $S u Z$ distingue la alteridad en la conciencia, desde donde el sí mismo es capaz de retomarse en el anonimato del Uno: logra desprenderse con la llamada $(R u f)$, con la cual explicita el rasgo de extrañeza que sobreviene a la conciencia, proveniente de su condición de arrojada. Así, el momento de alteridad propio del fenómeno de la conciencia es ser conminado por aquella voz.

En este marco, Ricoeur interpreta que la conciencia, como respuesta a tal invocación , implica que las posibilidades mas propias del Dasein son originalmente estructuradas por el optativo del bien-virtud, que gobierna el imperativo del respeto y alcanza la convicción del juicio moral en situación, lo que designa en última instancia a un sujeto ético en el ámbito del existente humano. Frente a ello, distingue que Heidegger rebaja la alteridad de la llamada al extrañamiento y la nulidad del ser-yecto, reduciendo la alteridad de la conciencia a la alteridad englobadora del seren-el-mundo. Tales limitaciones dan cuenta del escaso desarrollo que tiene la cuestión del otro como alteridad en SuZ.

Por el contrario, para este pensador la alteridad correspondiente a la pasividad de la conciencia, queda ligada a la atestación como testificación del devenir de sí: este es afectado según el modo de ser-conminado, articulado en una unidad que incluye la conminación venida del otro y la atestación de sí, es decir, la alteridad en la ipseidad. Desde aquí toma distancia de la teoría del rostro de Levinas, la cual conduce a lo que denomina como la aporía del Otro: si tal alteridad es insituable, entonces la fuente de conminación parece carente de referencia posible (Ricoeur, 1990: 397).

En suma, estas consideraciones de la alteridad toman distancia de la egología husserliana, en un acercamiento calculado con la heterología de Levinas, sin rechazar la dimensión gnoseológica del sentido de aquella perspectiva. Asimismo, se articula en línea con Heidegger, al pensar la hermenéutica de sí desde la relación entre atestación y conciencia. No obstante, discrepa respecto a su modo de pensar la dinámica de alteridad en la conciencia, pues interpreta que por medio del cuidado y la solicitud (Fürsorge) remite al otro como extraño de sí, donde la atestación del poderser de la conciencia queda fuera de toda posible interpretación ética, dado el origen y el contenido vacuo y silente del llamamiento. Para Ricoeur, en cambio, la alteridad no deriva de la ipseidad, más bien la conciencia puede testimoniarla, a partir de la unidad entre conminación y atestación. Al conciliar palabra y acción en la atestación, se sitúa a partir de otra ontología donde la pasividad de 
la interpelación del sí-mismo se entrelaza con la alteridad. Así, la alteridad del otro y la del símismo coexisten en la conciencia sin confundirse, por medio de un gesto que este pensador desdobla en solicitud y promesa ${ }^{502}$. No obstante, no descuida el carácter originariamente anterior de la temporalidad, evitando así re-inscribirse en la metafísica de la subjetividad, tal y como específica en este pasaje:

“...no se dirá que el elogio de la narración de nuevo ha dado vida solapadamente a la pretensión del sujeto constituyente de dominar el sentido...tampoco se dirá que el reconocimiento de los límites de la narración, correlativo del conocimiento del misterio del tiempo, ha alimentado el oscurantismo; el misterio del tiempo no equivale a un entredicho que pesa sobre el lenguaje; suscita, mas bien, la exigencia de pensar mas y de decir de otro modo. Si esto es así , hay que proseguir hasta su término el movimiento de retorno, y sostener que la reafirmación de la conciencia histórica en los límites de su validez requiere a su vez la búsqueda , por parte del individuo y de las comunidades a las que pertenece, de su identidad narrativa respectiva" ( Ricoeur ,1998:1036 s.)

Como hemos visto, en este breve recorrido por recepciones y reelaboraciones del pensamiento de Heidegger, las discusiones sobre el estatuto de la relación dinámica entre ipseidad y alteridad, ponen énfasis en su exterioridad radical o en su carácter constitutivo-constituyente, a partir de la consideración no sustancial, dinámica y proyectiva de la ipseidad, cuyos límites se evidencian y abren en la ineludible irrupción de la alteridad. En este marco, distinguimos diferentes perspectivas en torno a esta relación y mediación: o bien enfatizando los caracteres disolventes y dislocadores que produce el encuentro con la alteridad, o bien destacando márgenes de mantenimiento y unidad experiencial en la ipseidad (con su carácter dinámico y no clausurable) en el acontecer de la alteridad. Desde ambos enfoques, podemos encontrar continuidades en diversas discusiones contemporáneas en el campo de la filosofía práctica, la ética y la política, en su inexorable ligazón con el lenguaje.

Asimismo, el marco relacional en el que estas recepciones comprenden el sí-mismo se caracteriza con las mismas notas de inconsistencia y variabilidad que en las elaboraciones de Heidegger, lo que permite plantear un retorno a sí dinámico y con una potencia liberada, en el marco de consideraciones en torno a la identidad y los procesos de subjetivación. Son precisamente estas orientaciones las que forman parte y mediatizan algunas recepciones y diálogos con la obra de Heidegger en nuestra región. Para terminar con nuestro recorrido, proponemos breves puntualizaciones al respecto.

\footnotetext{
${ }^{502}$ Es decir, analiza el fenómeno de la promesa junto a la solicitud heideggeriana, para dar cuenta de tal coexistencia en la conciencia de la alteridad del otro y la del sí mismo.
} 


\section{5.- Ipseidad, interculturalidad y lenguaje como primeras orientaciones en la recepción regional.}

Los estudios sobre el pensamiento de Heidegger en nuestra región, fueron retomados por pensadores vinculados a la corriente fenomenológica ${ }^{503}$. En el caso de la recepción de la fenomenología en Argentina, luego del auge académico de la corriente positivista, tuvo como principales exponentes, en la década de 1920, a Carlos Astrada, Francisco Romero y Luis Juan Guerrero, entre otros. A partir de 1970, esta corriente fue cediendo terreno al existencialismo, la filosofía crítica, la filosofía analítica, para finalmente abrirse hacia los estudios sobre lenguaje, ética y política contemporáneos. Sin embargo, pensadores como Mario Presas, Héctor Mandrioni, Ricardo Maliandi, Carmen Balzer, Roberto Walton y Edgardo Albizu, entre otros, continuaron profundizando a partir de aquellos caminos del pensar. En particular siguieron la fenomenología trascendental de Husserl, extendiéndose también al pensamiento de Scheler, Hartmann y Heidegger.

En general, una historia esta recepción puede separarse en dos grandes etapas: un pensamiento anterior y otro posterior a la denominada Kehre heideggeriana. Entre las obras más comentadas en dichos períodos se destaca por un lado, una referencia casi exclusiva a $S u Z$ a partir de 1930 y, por otro, desde la publicación de Brief über den Humanismus (1946), los análisis donde predomina la problemática ontológica. Por esta vía, desde mediados del siglo pasado, esta perspectiva logra afianzar sus fundamentos: la concepción del lenguaje como casa del ser junto al acento puesto en la ontología hermenéutica de sus últimos escritos, consolidan esta segunda etapa

\footnotetext{
${ }^{503}$ Entendemos necesario distinguir la cuestión de la recepción local de la obra de Heidegger en las temáticas aquí consideradas, para circunscribir en nuestro trabajo el diálogo desde el cual parte. En especial, si atendemos algunas interpretaciones de tal recepción que pueden limitar tal ámbito de diálogo en el estado de interpretación respectivo. Pensamos, por ejemplo, en el caso de Apel quien distingue una influencia de Heidegger en línea anglosajona hacia Escandinavia y otra franco-alemana que va hacia Europa del sur y Latinoamérica. En este marco , respecto a sus desarrollos de la metafísica de la técnica , sentencia:"Esta interna coyuntura del pensamiento heideggeriano, junto con la pretensión de un estilo frecuentemente apenas tolerable, parece tanto repugnar a los anglosajones y escandinavos, en el fondo creyentes en el progreso, como por otra parte favorece de modo manifiesto a un cierto resentimiento humanístico de las culturas latinas contra el predominio de la civilización técnica” ( Apel, 1967 :111 s.). Como veremos, las elaboraciones y asociaciones en relación a la cuestión de la era de la técnica, forman parte de la recepción local de un modo diverso.
} 
de interpretación y crítica enmarcada en los caminos de la filosofía hermenéutica, la filosofía analítica, la filosofía de la liberación, las confluencias con el marxismo, etc. A partir de aquella primera etapa de las interpretaciones y análisis se han desarrollado numerosos debates en torno a las conexiones entre fenomenología, ipseidad, alteridad y lenguaje.

En primer lugar, ligados con la tradición fenomenológica, podemos encontrar análisis que ponen el acento en continuidades y diferencias teóricas entre Husserl y Heidegger. Específicamente, distinguimos trabajos que abordan e interpretan la reducción fenomenológica del yo trascendental desprendida de la facticidad, frente al análisis del sí mismo en Heidegger, el cual permanece imbricado en la facticidad del ser-en-el-mundo del Dasein (Walton, 2001/ 2009; Xolocotzi, 2004/2008). Por otra parte, algunos autores se han centrado en desplegar las consideraciones en torno a la temporalidad del sí mismo a partir de su inacabamiento y su apertura en el horizonte de sus posibilidades (Presas, 2009). Los desarrollos y elaboraciones de estas recepciones pueden distinguirse por los acentos puestos en sus abordajes.

\section{5. a.- El énfasis puesto en la identidad y el sujeto cultural.}

Las discusiones en torno a la identidad latinoamericana y sobre la colonización, a mediados del siglo pasado, llevaron a tomar las consideraciones de SuZ en una matriz relacionada con la identidad y los modos de ser en su carácter situacional, que derivaron entre otras cuestiones, en la formación en México del grupo Hiperion, con Luis Villoro y Emilio Uranga entre sus integrantes, donde se desarrollaron trabajos en torno al análisis ontológico del ser de lo mexicano, es decir, en la delimitación de un campo propio de la identidad cultural por la vía de la reflexión filosófica ${ }^{504}$.

En el mismo sentido, en nuestro país los análisis con sesgo existencialista y nacionalista han tenido como exponentes a Carlos Astrada (quien fuera alumno de Heidegger hasta 1930) ${ }^{505} \mathrm{y}$ Kusch, así como las interpretaciones americanistas de la inculturación de Cullen, Dussel, Scannone (ambos en la corriente de la filosofía de la liberación) ${ }^{506}$, entre otros. En el primer caso, evitando

\footnotetext{
${ }^{504}$ Esta vertiente puede encuadrarse en lo que Cortés-Boussac reconoce como las tres líneas de la recepción americana de Heidegger: aquellas que siguen una lectura de su obra, las que exponen críticamente su pensamiento y aquellas evolutivas que toman elaboraciones de Heidegger para asimilarlas a propios recorridos del pensar, como en este caso. Véase Cortes-Boussac (2006):3ss. Cf. Martínez Garnica (2006):102 ss.

${ }^{505}$ Un detallado itinerario de la experiencia de Carlos Astrada como alumno de Heidegger en el periodo anterior a la primera guerra mundial, puede encontrarse en David (1999):70 ss.

${ }^{506}$ Para una especificación histórica de las perspectivas de la inculturación en América Latina, en las dinámicas entre identidad y alteridad desde las recepciones de la fenomenológica y el pensamiento heideggeriano, véase el trabajo de Scannone (2005):63-69.
} 
ataduras a modelos europeos de interpretación y en el marco de dos etapas de sus elaboraciones ( una de línea existencialista e impronta heideggeriana y otra, de vertiente hegeliano-marxista ), interpreta antropológica y críticamente el Dasein heideggeriano, desde lo que distingue como su libertad vacía en relación a su mismidad, pues entiende que carece de un querer determinado respecto a sí mismo, lo cual lo conduce a perder su ipseidad en una existencia apátrida (Astrada, 1952:103 s.) Frente a ello este autor defiende un sesgo existencialista, a partir del reconocimiento de su versión singular y alternativa en la tentativa de Heidegger: una libertad que remita a un retorno a sí como realidad y potencia efectiva, por medio de un querer decisorio que hace retornar al Dasein a su ipseidad, la cual se vincula a cierta fidelidad destinal en relación con su ser (Astrada ,2007:37) ${ }^{507}$. Así, buscando fundamentar al Dasein en la praxis social articulada comunitariamente, distingue el problema de la praxis en SuZ, donde el Dasein no logra una transformación de su situación quedando encapsulado en la existencia propia como único desplazamiento posible (Astrada ,1952: 94-7.). Por esta vertiente, y con influencias de Scheler y Hartmann, continúan algunas elaboraciones de Francisco Romero y Rafael Virasoro, entre otros.

En el caso de Rodolfo Kusch encontramos indicios de una filosofía latinoamericana que aborda la mismidad a partir del encuentro con el otro, en la búsqueda del sujeto cultural americano, mestizo e indígena, en articulación de algunos tramos del pensamiento de Heidegger, Levinas, Ricoeur y Scheler. En sus trabajos, especialmente en la década de $1960^{508}$, elabora la cuestión de la búsqueda de la ipseidad por medio del encuentro intercultural con el prójimo. Alrededor de ese período interpretó las elaboraciones de Heidegger en torno a $S u Z$, desde la necesidad de la filosofía de arraigar en la cultura de su tierra y en su situacionalidad, desde una ética de la alteridad con su impacto en el sí-mismo, atendiendo a los sujetos populares, marginales e indigentes de las instituciones. En línea con Levinas y Ricoeur, entiende que solo en dirección hacia el otro se da el encuentro con su ipseidad, especialmente en el excluido en su radicalidad ontológica. Intuitivamente sostiene, a partir de su experiencia por países latinoamericanos, que el impacto subjetivo en tal recorrido se debe a que llevamos adentro, muy escondido, eso mismo que lleva el indio (Kusch ,1975:15).En esta línea , interpreta el existenciario heideggeriano de ser-en-el-mundo a partir del término estar, ausente en lengua alemana para su distinción semántica con ser, de modo tal que mientras allí se concibe al Dasein como ser-ahí, Kusch distingue el estar-ahí como estructura existencial, en el marco de lo que defiende como decisión cultural latinoamericana

\footnotetext{
${ }^{507}$ En otros escritos insiste en la fidelidad de un retorno a las fuentes absolutas que sellan la relación entre la existencia y su tierra. Véase , Astrada(1964):68 s.

${ }^{508}$ Nos referimos a El pensamiento indígena y popular en América (1977) y América profunda (1975).
} 
(Kusch ,1973:575-579). Así, desarrollo sus trabajos en el horizonte de una filosofía antropológica americana, a partir de esta apropiación del pensamiento heideggeriano en torno a $S u Z^{509}$.

\section{5. b.- El énfasis puesto en el lenguaje.}

En segundo lugar, en referencia a la identidad y la ipseidad en $S u Z$, podemos encontrar análisis en lengua castellana que hacen hincapié en tres áreas fundamentales : 1) Los análisis de las figuras de la identidad y la ipseidad contrastando y vinculando las posiciones de Heidegger , Ricoeur , Henry , Zubiri y Levinas en lo que respecta al mantenimiento de sí y a la temporalidad como propias de la ipseidad ( Presas , 2009 ; Naishtat , 2007 ; Walton , 2001) ; 2) Diferentes análisis del lenguaje en Heidegger vinculados a la comprensión y la ipseidad del Dasein, entre ellos : acerca de la comprensión de sí implícita en toda mismidad y la necesidad de una mediación discursiva a partir de la distinción entre dimensión excéntrica de la ipseidad (propia de la identidad discursiva, que implica darse razones ) y la dimensión céntrica ( referencial e imbuida en el mundo, propia de la identidad desde la narración de acciones) ( Sáez Rueda , 1998 ; Castellanos , 2006;Duran Rojas ,2015); en relación a los cambios en los contextos de significación en $S u Z$ y la relevancia de los contextos de significados en común ( Fuenmayor, 1994;Cataldo Sanguinetti,2013) ; en torno al sentido en tanto carácter pre-predicativo de la comprensión del ente ( Rodríguez Suarez , 2005;Bedoya Rodas,2014 b) y en la consideración de una teoría del discurso y el lenguaje a lo largo de su obra ( Rocha de la Torre ,2005;Martinez Matías ,2008) 3) Finalmente , en línea con Tugendhat, encontramos las críticas de irracionalismo en el pensamiento de Heidegger que proponen partir del análisis del mantenimiento-de-sí en $S u Z$, para elaborar una síntesis entre mismidad e ipseidad a través del concepto de identidad narrativa o desarrollar una teoría de la elección racional (Ferrer Santos, 1999/2001), así como también la consideración de algunas discusiones éticas y de los estudios vinculados al nexo ipseidad-lenguaje en nuestra región

\footnotetext{
${ }^{509}$ Para un análisis de las reelaboraciones de Kusch en torno a la inautenticidad y el pensamiento de la técnica en Heidegger, situadas en el horizonte de tal filosofía antropológica, véase Rogna (2013):200-9.
} 
(Blancollari,2011/2016; Davila,2004; Muñoz,2010;Burlando,2015; Adrian, 2011b /2012, entre otros).

En este contexto, un conjunto de estas elaboraciones pueden oficiar de muestra acerca de la recepción de la cuestión de la ipseidad con el énfasis puesto en la consideración del lenguaje. Por un lado, Roberto Walton desarrolla trabajos en torno a la fenomenología contemporánea especialmente recuperando la presencia de las elaboraciones tardías de Husserl en el pensamiento de Heidegger y atendiendo vertientes que pasan por Levinas, Henry y Marion, entre otros. En este marco, abordó la consideración husserliana del yo, distinguiendo diversas figuras de la identidad en la fenomenología post-husserliana (Walton 2001:9-49). Allí, retoma la consideración del mantenimiento de sí en SuZ, que opera como contracara de la pérdida del sí-mismo en el Uno, desde lo cual distingue su modalización singular resaltando el contrapunto semántico de las elaboraciones de Heidegger, tal como en este fragmento:

“El Dasein es su sí-mismo en cada caso solo existiendo, y, por tanto, solo a través de la existencia se puede dar cuenta de la constancia o mantenimiento del sí-mismo (Ständigkeit des Selbst) (...) Tenemos pues una serie de oposiciones. A la perduración y mismidad de un yo-sustancia como continuo estar ahí de algo, se contrapone el mantenimiento de sí de la ipseidad de un sí-mismo. En lugar de la mismidad de un subjectum que nos sale al encuentro como el mismo (ein Selbiges) en medio de la multiplicidad de las vivencias, el Dasein se caracteriza por una ipseidad que es determinada por su manera de existir. El temor de que esto implica una evaporación o disolución del núcleo del Dasein solo puede ser albergado si se considera que el Dasein tiene el modo de ser de lo que está ahí ante los ojos, es decir, del subjectum” (Ibíd.: 14-15)

Desde aquí, subraya la tesis de una herencia husserliana de la reducción trascendental en esta noción de sí-mismo articulada en la consideración de la voz de la conciencia en $S u Z$, cuyo llamado y apelado coinciden en el sí-mismo de cada uno. Incluso, sostiene que la interpretación del yo en Husserl por parte de Heidegger no es acertada e incluso, coinciden en demasía. Walton interpreta que la modificación del sí-mismo supone un polo en torno al cual giran las modificaciones o donde se reabsorbe la recuperación de sí ${ }^{510}$. De esta manera, destaca que Heidegger, por su acervo en la crítica al yo como sustancia, descuida ciertos fenómenos en torno al mantenimiento de sí del polo-yo que si ha desarrollado Husserl, en sus elaboraciones de las habitualidades y los intereses, en el marco de la fenomenología genética de su último período (Ibid.:18-27).

\footnotetext{
${ }^{510} \mathrm{Y}$ especifica: "Toda modificación es modificación de algo en algo, y, si no tiene lugar sobre un sustrato, este proceso al menos debe estar relacionado con un punto común, es decir, un yo y su auto percatación que mantenga abierta la posibilidad del nexo entre lo anterior y lo posterior. Porque debe haber alguna referencia de la modificación a lo modificado para que sea posible hablar de modificación en un sentido u otro" (Walton,2001:26).Las relaciones entre fenomenología y lenguaje se vuelven aquí evidentes.
} 
Por su parte, Mario Presas junto a sus abordajes de la obra de Ortega y Gasset, Marcel, Henry, Husserl, Levinas y Ricoeur, retoma en diversos trabajos la consideración del poder-ser y la ipseidad del Dasein en articulación con la noción de identidad narrativa, que trae a la filosofía en vecindad con la experiencia estética. Interpreta que el siglo pasado, desde el punto de vista filosófico, estuvo fascinado por el enigma del tiempo, por el descubrimiento de la existencia como temporalidad. Retomando la crítica de Ricoeur respecto a Heidegger, subraya que este abordó en su analítica de un modo directo la existencia, sin atender el rodeo por símbolos, instituciones , memoria, etc. (Presas , 2005: 105), al tiempo que reconoce que el relato y la metáfora es el modo más apropiado en que el existente humano se da cuenta de su propia temporalidad e historicidad ${ }^{511}$ (Presas ,1993:99 s.), encontrando allí la única vía para comprenderse a sí mismo al aprehender su vida como narración de su propia historia, confluencia que queda manifiesta en este fragmento :

“...la acción de contar, sobre todo si se manifiesta en una obra literaria de ficción, es una suerte de laboratorio experimental, que reproduce y anticipa las opciones de la existencia real y de este modo predispone para la decisión moral. Asimismo, sirve de modelo para la identidad propia, entendida no como la estabilidad de un carácter o la constancia de un ser sustancial, sino más bien como ese modo de existir que se sostiene en el ser en virtud de la fidelidad" (Presas 2009: 152).

Tal fidelidad en la que se sostiene la existencia, enmarcan sus interpretaciones en consideraciones éticas que lo ponen en diálogo con las elaboraciones de Levinas y Ricoeur. En esta línea distingue entre mismidad, aferrada al pasado y la memoria (bajo el acecho ineluctable del olvido) e ipseidad, la cual anticipa el futuro como si ya fuera, siendo la traición su única potencial derrota. Por ello, desde una perspectiva ética, define al hombre como ser de palabra, mediante un análisis de la promesa de cuño ricoeuriano, que permite figurar el mantenimiento de sí a través de un acto aún no realizado," el cual es ciertamente un habito, pero un hábito suave, silencioso, que dice sin más 'yo estoy aquí”, es la fidelidad entre amigos” (Ibid.:164).

Desde este conjunto de trabajos y recorridos se articulan una serie de elaboraciones recientes e investigaciones en curso, que continúan con los desarrollos de la cuestión de las aspectos narrativos en la identidad personal en el pensamiento de Ricoeur, Tugendhat, MacIntyre , Parfit, entre otros ( Ferrari , 2002/2013 ;Blanco Ilari , 2005/2016) ; la consideración del problema de la corporalidad (Solas 2013 ; Di Pego 2008; Prosperi 2015;Johnson,2016) , la tematización del lenguaje poético, la cuestión de la técnica y el discurso como figura de ipseidad (Carrera Aizpitarte

\footnotetext{
${ }^{511}$ En otro texto, a propósito de las lecciones de Heidegger del año 1923, sostiene: “...la hermenéutica es un constitutivo del existir, la existencia es hermenéutica y la filosofía es la explicitación de esa interpretación de lo fáctico en que consiste el ser del hombre" (Presas ,2009:93).Con esta interpretación articula singularmente la noción heideggeriana de interpretación (como desarrollo de la comprensión) con la labor de la filosofía.
} 
,2012/2014/2015; Bertorello 2006/2008; Butierrez,2016), las cuales se vinculan explícitamente con el pensamiento de Heidegger.

Precisamente por la senda de estos recorridos, interpretaciones e inquietudes, se configura el presente trabajo en el marco dialógico de tal tradición local, con la intención de contribuir con los análisis contemporáneos de las figuras no sustancialistas de la identidad personal e ipseidad desde la perspectiva del lenguaje, de tal manera que permita reconocer espacios para renovar planteamientos, sentidos e interpretaciones.

"El idioma es un ordenamiento eficaz de esa enigmática abundancia del mundo. Lo que nombramos sustantivo no es sino abreviatura de adjetivos y su falaz probabilidad, muchas veces. En lugar de contar frío, filoso, hiriente, inquebrantable, brillador, puntiagudo, enunciamos puñal, en sustitución de ausencia de sol y progresión de sombra, decimos que anochece. Nadie negará que esta nomenclatura sea un grandioso alivio de nuestra cotidianidad. Pero su fin es tercamente práctico: es un prolijo mapa que nos orienta por las apariencias, es un santo y seña utilísimo que nuestra fantasía merecerá olvidar alguna vez".

(Jorge Luis Borges, Inquisiciones)

\section{Conclusiones}


En este trabajo de investigación hemos examinado las elaboraciones filosóficas de Martin Heidegger en lo que respecta a su teoría de la mismidad e ipseidad, en vinculación con sus consideraciones de la alteridad y el lenguaje, distinguiendo derivaciones ontológicas y orientaciones éticas. En líneas generales, buscamos alcanzar una mayor comprensión de estas cuestiones en el pensamiento de nuestro autor, distinguiendo su incidencia en elaboraciones e investigaciones posteriores, de tal modo que permita no solo establecer marcos para desarrollar interpretaciones , continuidades y sentidos, sino también circunscribir un ámbito teórico en diálogo abierto con las elaboraciones tradicionales, en lo que respecta a los enfoques y prácticas contemporáneas con referencias a la condición humana, las perspectivas políticas de la identificación y la subjetivación, entre otras.

El trabajo pormenorizado y atento de Martin Heidegger en sus investigaciones en torno al existente humano en la vía de la pregunta por el ser, especialmente a partir de $S u Z$ con su reelaboración del método fenomenológico, junto a la investigación conceptual y comprensiva de los sedimentos semánticos y conceptuales de la modernidad y la tradición occidental en general, tornan a su obra un punto de partida ineludible para una indagación contemporánea acerca de la condición humana.

En este marco, esta investigación se ha articulado con la relevancia que ha tenido en las últimas décadas los abordajes filosóficos del lenguaje por lo cual, situar aquellas investigaciones desde estos enfoques, lo hemos considerado como un paso necesario. En este sentido, debido al entramado holístico y complejo de los análisis y perspectiva sobre el lenguaje de nuestro autor , hemos recorrido varias veces y desde diversos enfoques las mismas constelaciones de su analítica, para dar cuenta de fronteras, tensiones, desplazamientos laterales en su pensamiento y discurso, en lo que respecta a la cuestión de la racionalidad, la ética, el lenguaje poético-literario, el pensar no representativo por fuera del enfoque de la fundamentación, etc.

Atendiendo el estado de las interpretaciones de su obra, retomamos las investigaciones e interpretaciones en torno a sus conceptos de identidad e ipseidad, considerando también las sistematizaciones de Ricoeur en sus figuraciones narrativas y de alteridad, entre otras. Desde aquí argumentamos que los desarrollos de Heidegger, tanto explícitos como implícitos a lo largo de su obra, constituyen las bases filosóficas y discursivas para los análisis posteriores, es decir, son precursores de tales elaboraciones contemporáneas, las cuales pueden entenderse como proyecciones, continuidades y diálogos con tales bases. 
En efecto, hemos investigado alrededor de tales conceptos y términos en su obra, centrándonos específicamente en sus consideraciones filosóficas en torno al Dasein, a partir de sus elaboraciones articuladas de un modo sistemático y múltiple en cursos y escritos fundamentales de la década de 1920. Asimismo, procuramos articular tales elaboraciones con sus interlocutores más relevantes: por un lado con su maestro Husserl y por otro, dando cuenta de influencias y proyecciones en los tratamientos contemporáneos sobre estos aspectos de la existencia humana. Desde allí, examinamos sus principales perspectivas en torno a la pregunta por el ser, las consideraciones sobre el pensar, el lenguaje y el discurso, sobre las consideraciones en torno a los otros y a sus aportes para una transición en la orientación del pensar filosófico de segunda mitad del siglo pasado, que entendemos fundamentales para los replanteamientos en las investigaciones y análisis contemporáneos.

En una orientación general situamos y caracterizamos los fundamentos y variaciones de la consideración del rol del Dasein: en general, desde el trasfondo de su indagación ontológica y en el marco de la tradición fenomenológica, en particular, en el desarrollo teórico de su pensamiento en lo que respecta a la constitución de la ipseidad. A partir de allí, nos propusimos vincular dichos fundamentos con la perspectiva acerca de la relación Dasein-Ser en sus siguientes elaboraciones. Con ello buscamos contribuir por un lado, con la delimitación y sistematización de los conceptos abordados a las interpretaciones contemporáneas en los debates en torno a la obra heideggeriana, respecto a los vínculos entre ipseidad, intersubjetividad y lenguaje y por otro, dentro del escenario de las críticas a la metafísica y a la modernidad, con los replanteamientos de las filosofías del sujeto.

Desde ello nos propusimos los siguientes objetivos específicos : a) Determinar y relacionar, a partir de vinculaciones con la fenomenología de Husserl y algunos pensadores tradicionales, la cuestión de la identidad personal y la constitución de la ipseidad en la época de $S u Z$, junto al despliegue de los conceptos de lenguaje, racionalidad y alteridad, así como también el uso y función del concepto Ser en el nexo ipseidad-lenguaje-ética, en los trayectos fundamentales del pensamiento de Heidegger ; b) Determinar los alcances y límites de tales abordajes y sus posibles vinculaciones con el lenguaje, para distinguir condiciones de posibilidad de continuidades en determinados debates contemporáneos ; c) Contribuir con: I) La delimitación y especificación conceptual dentro de la obra de Heidegger para arrojar mayor claridad a las críticas y debates en torno a tales análisis, de tal modo que permita un fluir de las interpretaciones ; II) los análisis contemporáneos de las figuras no sustancialistas de la identidad personal e ipseidad, desde la perspectiva del lenguaje, de tal manera que permita reconocer espacios para renovar planteamientos y sentidos. En especial, insertar y articular dicha contribución con las principales investigaciones 
sobre de la obra de Heidegger y sobre los nexos entre ipseidad-lenguaje en nuestra región en los últimos años.

Por estas vías propusimos una sistematización de su enfoque sobre el existente humano, entendido como desplazamiento teórico y transición respecto de las elaboraciones modernas en torno a la autoconciencia, el cogito y el sujeto trascendental .Este resultado, en el marco de los ejes ipseidad-alteridad-lenguaje que organizaron nuestro recorrido, fue alcanzado y argumentado a través de las siguientes hipótesis : 1) Desde la distinción y especificación de una teoría del lenguaje y de la ipseidad en la obra de Heidegger circunscribimos, en sus primeros trabajos, un criterio regulador para las modificaciones posibles en la comprensión de sí , la búsqueda de planos ontológicos más originarios, el cual supone un entramado de significaciones caracterizado por pliegues, intersticios, tensiones y fallas, de modo tal que rechaza una significación plenificable, trascendental o clausurable. Sostenemos que esta caracterización del campo semántico y el entramado de significaciones es una condición de posibilidad para la pliegue de la ipseidad y su modo auténtico , así como también para la producción de distorsiones /modificaciones del sentido y de la comprensión del ser y de sí mismo, en el acceso a planos cada vez más originarios, característica que este autor mantendrá tanto en el desarrollo de su pensamiento de su etapa posterior, como también en la matriz de su propio estilo filosófico. No obstante , la alteridad constitutiva e irreductible del lenguaje y el discurso desde el que enuncia, evidencian sesgos que lo mantienen aún en el campo semántico moderno, incluso con la puesta en evidencia de cierta orientación semántica, jerárquica o axiológica, dada o bien por un conjunto de significaciones que modulan dicho campo, o bien por la matriz, modalidad del pensamiento o concepción aún trascendental en su teoría de la significación ; 2) Partiendo de sus consideraciones de la comprensión del ser en la estructura del Dasein y de su carácter ante-predicativo, consideramos que el ámbito del lenguaje, la mediación discursiva y la interpretación son elementos para el escenario apropiado desde el cual poder desplegar la asunción de la propia ipseidad, razón por la cual no es posible comprenderla como una alternativa entre opuestos, sino como una dinámica de pliegue variable, manifestándose así correlativa a la significación y comprensión del Dasein. Como segunda hipótesis postulamos tres argumentos articulados: En primer lugar que el sentido y el decir poético-literario necesariamente deben ocupar un lugar relevante en la consideración postmetafísica de la co-pertenencia del Dasein y el ser, no solo para las elaboraciones de nuestro autor, sino también para las articulaciones filosóficas posheideggerianas sobre la condición humana. En segundo lugar, a partir de aquel carácter mediado, relacional y dinámico de la ipseidad por la vía del lenguaje, interpretamos que en sus posturas de antes de 1930 ya están contenidos, potencialmente, los desarrollos posteriores, de modo tal que el despliegue del discurso de Heidegger puede 
entenderse como una figura correlativa, derivada de los resultados obtenidos en la analítica de 1920. La tercera argumentación consiste en sostener que una complementación con el abordaje de las relaciones entre el proceso de significación, la intersubjetividad y la tradición, desde la cual se da cuenta del carácter originario y no derivado del ser-con en la estructura del Dasein, permite extraer posibles consecuencias tanto éticas como políticas de y en el discurso del autor ; 3) Considerando el despliegue discursivo de Heidegger, su modalización y tratamiento respectivo, en vinculación con sus enunciados respectivos, sostenemos como tercera hipótesis que cada período de alguna manera fuerza o conlleva necesariamente una reelaboración posterior, de modo tal que las limitaciones halladas en la analítica de $S u Z$, la tematización centralista del Dasein, las tensiones con la fenomenología husserliana, los sesgos metafísicos que atraviesan todas sus articulaciones y la insuficiencia de lenguaje que se evidencia en su recorrido, entre otras, operan retrospectivamente como condiciones de posibilidad para la dinámica de transición que evidencia su pensamiento en el siglo XX, la cual no sería posible si no llevase al límite las tensiones del campo semántico en el que se inscribe. En este marco consideramos probable distinguir una tensión irrebasable y constitutiva en las constelación ipseidad/alteridad y lenguaje/alteridad, particularmente en tres tramos en el análisis de Heidegger: I) en el campo semántico, respecto a la significación del Dasein ,así como también en la consideración opuesta del significar y las significaciones en el das Man (rígidas e inflexibles) y en el Dasein propio (contingentes, no clausurables ni plenas); II) en su elaboración teórica, enfoque y articulación discursiva , respecto al ámbito para retorno a sí y a la dinámica del uno-mismo (en su posible pliegue como sí-mismo), el cual debe evitar recaer en comprensiones sustancialistas o cósicas del ser entendido como presencia; III) en sus elaboraciones de madurez, respecto a las consideraciones del Habla y el Decir en sus irreductibles mediaciones con el Dasein , con lo cual se propone radicalizar la puesta en cuestión y Destruktion de la conceptualización de la metafísica moderna y su lógica subyacente. Entendemos que dicha tensión irreductible precondiciona las orientaciones de recepciones e interpretaciones ulteriores de su obra.

A continuación desplegaremos de un modo breve los diferentes argumentos y resultados del análisis interpretativo con los que propusimos respaldar tales hipótesis, en el marco de los objetivos expuestos. Por medio de estas puntualizaciones proponemos dar cuenta de los aspectos más relevantes de nuestro recorrido, buscando una clara sistematicidad en las conclusiones y resultados obtenidos en la investigación. Esto permitirá delimitar un ámbito para sugerir, plantear y avizorar otras vías e hipótesis para investigaciones futuras en lo que respecta a estas temáticas en sus múltiples conexiones, así como también para evaluar la pertinencia de las interpretaciones respecto a la obra heideggeriana y a las indagaciones respecto al discurso filosófico en sus tensiones constitutivas. 
Los primeros capítulos fueron abordajes preliminares para situar por un lado, la reelaboración del método fenomenológico y, por otro, la perspectiva en torno al existente humano allí enmarcada, por parte de nuestro autor. En efecto, en el capítulo 1 hemos planteado un recorrido por la reelaboración que propone Heidegger confrontándola con algunos de los puntos principales de la propuesta de su maestro Husserl. En línea con nuestro primer objetivo e hipótesis, evaluamos la validez de este método para las investigaciones contemporáneas de la existencia o condición humana, por sobre enfoques psicologistas o cientificistas. Distinguimos que la atención puesta a las sedimentaciones del lenguaje y el sentido tornan eficaz esta metodología, frente al método científico que aborda este campo temático sin poner en cuestión el lenguaje categorial de partida, limitando con ello su alcance.

Precisamente aquello es lo que torna dinámico y variable el despliegue y comprensión inherente al método. Nuestras interpretaciones fueron hechas atendiendo el ámbito del lenguaje sobre el que se basan algunos de los desplazamientos entre ambas perspectivas, distinguiendo conceptos y sentidos tradicionales que son puestos en tensión o al límite por nuestro autor. En este marco, hemos argumentado que el tratamiento del lenguaje que realiza cancela la posibilidad de interpretar sus elaboraciones de forma acabada, pues su recorrido se manifiesta al modo de una ejecución que se efectiviza en tránsito, es decir, como una experiencia. Y tal recorrido fenomenológico confluye en SuZ. Nuestros argumentos se apoyaron en el reconocimiento de una co-extensión de la articulación lingüística de Heidegger y ciertos aspectos modales de su pensamiento que manifiesta en ordenamientos y jerarquías.

Por un lado, el análisis fenomenológico de la conciencia intencional de Husserl permitió evidenciar estructuras múltiples y correlativas que se apartan de enfoques dualistas tradicionales. Vimos que las criticas de Heidegger al carácter estático de sus reducciones, en desmedro del horizonte temporal de base, responden más bien a las primeras elaboraciones de Husserl, pero no a sus trabajos de madurez. Tales críticas se dirigen al horizonte de cientificidad subyacente a su metodología que impactan en la utilización de categorías sustancialistas o cósicas para las investigaciones de la conciencia. En tal orientación, la conciencia es comprendida desde su carácter universal, estableciendo con ello una continuidad no discutida con la perspectiva cartesiana, en la vía de la preocupación por la certeza como lo propio del desarrollo de la ciencia. Asimismo, su énfasis puesto en la vertiente teórico-reflexiva para tematizar la conciencia originaria, debido al horizonte de cientificidad hacia el que despliega su método, nos permitió distinguir que mientras sus análisis se limitan a tales reducciones teoréticas de la conciencia , Heidegger, por su parte , propone partir del ámbito prerreflexivo, con el objeto de atender las implicancias factuales de 
aquella conciencia originaria, reelaborando en este sentido la orientación del método de su maestro. Desde aquí, desarrollamos sus consideraciones sobre el concepto de intencionalidad, el cual se halla bajo la comprensión tradicional del ser como presencia, desatendiendo la vida en su facticidad y en conexión de significatividad con el mundo. Puesta en su carácter factual, Heidegger busca retomar al carácter situacional y temporal de la misma, que aquel sesgo universal del horizonte de Husserl obstaculizaba. Distinguimos que la vía que usa para ello remite al lenguaje: la interpretación permite apropiarse de lo comprendido, explicitarlo y desarrollarlo.

El modo en que Heidegger lleva a cabo esta labor consiste en no permitir que el haber previo (Vorhabe), es decir, el horizonte y trasfondo en el marco del cual se dan maneras sedimentadas de ver y entender, sea dado por el trato y la experiencia en lo cotidiano, movimiento que lo remite a dichos elementos pre-teoréticos. Refundada en la comprensión, la fenomenología deviene, con ello, hermenéutica. Reconocimos que es precisamente esta puesta al límite de la herencia conceptual y semántica, lo que tiene como corolario un desplazamiento de enfoque en el tratamiento de la existencia humana en el horizonte de la indagación ontológica: por la vía de la denominada destrucción, entiende que a Husserl se le cuela una dirección de la mirada, guiada por categorías que no son acordes al ser de la conciencia. Tal distinción nos permitió evidenciar el supuesto de un diferimiento entre lo conceptual y lo preconceptual como condición para circunscribirla, el cual mantendrá a lo largo de sus elaboraciones tempranas.

Por otra parte, el análisis de la facticidad, como vía para la indagación por el ser del ente y en la pregunta por el sentido del ser en general, nos permitieron evidenciar su pertinencia para el análisis, al atender ámbitos de anterioridad para la constitución de conceptos y sentidos sedimentados, que implican una transición respecto al método de su maestro . Desde allí reelabora fenomenológicamente el concepto de fenómeno, desde donde circunscribe la necesidad de explicitar aquello que inmediatamente no se muestra en los fenómenos, quedando oculto y constituyendo su sentido: el ser del ente. A partir de este objeto de investigación, que orienta reflexivamente el método hacia sus propias cristalizaciones lingüísticas, pudimos circunscribir sus análisis por fuera del sesgo de presencia de la metafísica tradicional, de modo tal que, para señalar aquello que permanece oculto, entiende primario hacer una adecuada presentación del ente, por la vía de un acceso que se corresponda a su propia condición.

Desde estos desarrollos, destacamos que partir del análisis de la facticidad es lo que le permite poner en primacía un saber hacer respecto al lenguaje y visibilizar ámbitos originarios o adecuados a la investigación realizada, desde los cuales pueda luego aprehenderlos conceptualmente, es decir, acceder a las remisiones de significado en que se da preteoréticamente la 
vida fáctica, en un modo de acceso que busca apartarse del ámbito reflexivo-teorético de su maestro , para desarrollarse en un estrato hermenéutico-comprensivo.

Ello se debe a que el punto de partida es el comprender, específicamente, la precomprensión del ser en la que ya siempre nos hallamos y permanece oculta, la cual es correlativa a una terminología y conceptualidad que se halla sedimentada en una ontología tradicional. En este contexto, sostuvimos que la pregunta por el ser, la tematización del lenguaje y del Dasein, se tornan coextensivas desde estas reelaboraciones.

Nuestro abordaje evidenció el modo lingüístico en que Heidegger presenta los resultados de sus investigaciones, en una modalidad móvil enmarcada en el proceso de acceso a ámbitos más originarios, desde donde irá abandonando o desplazando puntos de acceso, comprensiones y conceptualizaciones retrospectivamente provisorias. Ello nos condujo a interpretar que desde este enfoque, la modalizacion del tratamiento del existente humano implica correlativamente una modalizacion del tratamiento del lenguaje. Por ello, el método fenomenológico le resulta luego contingente respecto al camino de la pregunta por el ser, cuya función, según sostuvo en 1963, fue más bien la dinamización del pensar que las cristalizaciones del sentido y el lenguaje tienden a obturar, lo cual permite circunscribir en sus enunciaciones el carácter de tránsito en su abordaje fenomenológico.

No obstante, el tratamiento atento respecto al sentido y al lenguaje heredado se halla en ambas perspectivas, tanto la de Husserl como la de Heidegger, lo cual figura como una muestra del carácter dinámico del método. Más aún, en el marco de las discusiones sobre la ruptura o continuidad de las elaboraciones de Heidegger respecto a las de su maestro, argumentamos que el método fenomenológico en sí mismo supone, debido a su desplazamiento por la vía del lenguaje , una reelaboración posterior e incluso, su consecuente abandono, puesto que cada resultado de su investigación va evidenciando la necesidad correlativa de revisar el tratamiento que se lleva a cabo mediante el propio lenguaje en el que se articula el método, es decir, direccionando el método hacia el propio discurso o enunciación, develando así el carácter emergente, situacional y relacional de significaciones y sentidos.

En el capítulo 2, vimos que estas consideraciones modales respecto al lenguaje fueron retomadas en el modo en que Heidegger afronta los términos tradicionales de hombre, sujeto o yo, en el marco de su reelaboración del término Dasein hacia una significación dinámica, cuya comprensión y sentido ontológico de base la enmarcan en el carácter irreductible de la ligazón Dasein-facticidad, con su respectivo entramado de estructuras simultáneas. Desde allí, distinguimos una bidimensionalidad en tensión entre su carácter fáctico y su constitución entramada. 
Luego, abordamos sus iniciales desarrollos en torno a la ciencia originaria o preteorética de la vida, en su camino para la elaboración de una metodología no universalista y objetivante para la aprehensión del Dasein, en vistas a su intención de poner de manifiesto estructuras originarias, en el marco de su programa de una ontología fundamental. Vimos que la modalidad resultante se caracteriza por una movilidad que la aparta de todo intento de aprehensión cientificista que apunte a lo presente o sustancial. Analizamos desde aquí las relaciones de simetría entre la orientación del método y el carácter móvil de la significación del Dasein que excede lo concreto espacial, temporal e individual.

En el despliegue de su reelaboración, seguimos las diferenciaciones que establece en su análisis enfocado a la comprensión subyacente de la terminología tradicional que se remontan a una tradición desde la ousía griega, desde la cual se comprende el ser como presencia. La tematización de la conciencia se vio así atravesada por un uso categorial cósico y sustancialista que condujo a una comprensión universalista de la conciencia desprendida de su facticidad e historia. Con el sentido en que usa el término Dasein, Heidegger específica existenciales, modalidades de ser y estructuras propias que le permiten apartarse de aquellos sedimentos semánticos y campos conceptuales. Estas indagaciones nos revelaron horizontes no clausurables, determinando al Dasein en su carácter inesencial y proyectivo. Vimos con ello, el rechazo a estructuras aisladas o universales del hombre y la conciencia. No obstante argumentamos, en línea con los análisis de Gadamer, que aquí se halla sometido dentro de la comprensión tradicional de la metafísica, a partir de un conjunto de rémoras con las que se topa en sus desarrollos. La razón de ello la reconocimos en parte en la necesidad de establecer sus articulaciones desde las cadenas de significación a las que se opone o busca deslazar. Esto deriva en una modalizacion y orientación de su pensamiento, sesgado por los interlocutores con los que debate y el campo semántico en el que se inserta, los cuales predeterminan los horizontes de desplazamientos y orientaciones semánticas. Los obstáculos condicionan sus análisis y programa general, al tiempo que limitan sus intentos de superar las limitaciones teórico-comprensivas de un pensamiento tradicional caduco.

Argumentamos que una prueba de ello es el carácter de fundamento que subyace a la tematización preeminente del Dasein para su analítica de la década de 1920, el cual aún es entendido como punto de partida para desplazamientos y reelaboraciones. Si bien Heidegger cambia la modalidad de dicha (pre) eminencia, conserva el modo de asociación moderna: por allí se empieza y desde allí se elaboran las significaciones y los desplazamientos del pensar. Con ello, conserva notas propias de los supuestos que remiten al sujeto trascendental, manifestándose como una versión hermenéutica de la pregunta moderna por el sujeto. Desde aquí colegimos que el 
margen posible para la transición implícita en la propuesta heideggeriana, se halla prefijado por el campo de lenguaje en el que se inscribe.

No obstante, el supuesto de un diferimiento de fondo y el olvido del ser, le permiten un margen de variabilidad respecto a tal campo: la piedra de toque ya no será la reducción al sentido, como en la metodología de su maestro, sino una delimitación del sentido en vistas al ámbito sustraído por un olvido en la tradición occidental. Asimismo, tales limitaciones revelan para Heidegger la necesidad de un cambio de enfoque para su recorrido.

La estrategia conceptual que empezó a esbozar en SuZ y sus cursos inmediatamente posteriores, fue vincular al Dasein términos que logren connotar procesos y movimientos, más afines al carácter de poder-ser en el horizonte de la temporalidad que al ámbito categorial de lo cósico, demostrando con ello que no podría desplegar su potencialidad propio, si previamente no establece giros y desplazamientos en la propia articulación conceptual de lo que se expone. En este marco, especificamos que la emergencia del Dasein en sus análisis es uno de los corolarios de su articulación en el lenguaje, debido al marco conceptual y el contexto de discusión de los campos en los que se inserta.

Por otra parte, el análisis desde la facticidad del Dasein como resultado de la previa aclaración de su modo de ser como existencia, puso de manifiesto estructuras complejas y dinámicas como el ser-en-el-mundo, que revelan la estructura del cuidado como elemento fundamental, en el horizonte de la temporeidad como la estructura unitaria que permite una totalización ontológica de la analítica del Dasein. Con el examen de algunas de sus estructuras fundamentales, pudimos cotejar el carácter situado y situacional del Dasein, revelando el entramado complejo de tal situación, lo que le permite abandonar comprensiones aisladas o segregacionistas propias de las perspectivas anteriores.Es precisamente en este sentido, donde distinguimos que la tensión y doble dimensión en sus elaboraciones son ineludibles, al momento de presentar este vaivén significante y comprensivo que se desprende de un cambio de sentido ontológico, como una transición respecto a la conceptualización moderna, que busca desplazar los ejes de la discusión y argumentación metafísica . Aun así, subrayamos nuestras diferencias respecto a todo posicionamiento crítico frente a estas tensiones, que suponga la posibilidad de una modalidad de aprehensión o significación plena o que pudiese lograr una ruptura radical y definitiva con la tradición con la que discute. En este sentido, argumentamos la relevancia de intentar proyectar los resultados de las elaboraciones de nuestro autor, en las propias modalidades de lectura e interpretación de su obra, pues ello no solo supone un despliegue y desarrollo de tales resultados, sino también implica la posibilidad de una experiencia aprehensiva desde ellos. 
En los siguientes dos capítulos, examinamos e interpretamos por la vía del lenguaje y el discurso , el tratamiento explicito que realiza en torno al concepto de ipseidad en sus vínculos con la alteridad, tanto a nivel general como en relación al otro Dasein co-existente, en cursos y trabajos fundamentales de la década de 1920. En efecto, en el capítulo 3, abordamos de lleno las modalidades de la mismidad del Dasein: el modo cotidiano de uno-mismo y el modo propio del símismo. Por medio de una proyección de su ser-para-la-muerte, la voz de la conciencia y la angustia como temple fundamental, Heidegger explicita estructuras no voluntarias desde las cuales el Dasein puede modificar su auto-comprensión de un modo propio.

Específicamente, considerando los supuestos de su concepción no clausurable y no objetivante del lenguaje, articulada en simultáneo con el carácter proyectivo del sí-mismo del Dasein, analizamos sus desarrollos en torno a la tendencia a la cristalización de las significaciones, que nuestro autor reconoce como movimiento propio de la existencia cotidiana que experimenta el entorno como cósico y acabado, condensándolo luego a-temáticamente en conceptos y significaciones. Distinguimos que desde tal cotidianidad de significaciones Heidegger modaliza, por oposición, sus elaboraciones y articulaciones. Más aún: destacamos que esta operación en el discurso de nuestro autor manifiesta una figuración o transferencia semántico-discursiva de sus respectivas consideraciones del Uno en su encubrimiento del sí mismo propio.

Sin embargo, distinguimos que tal encubrimiento no alude a un contenido oculto, alternativo y superador sino, más bien, a la falta de contenido o consistencia definitiva y a la ausencia de significaciones últimas, lo cual nos permitió reconocer una tensión y diferimiento de fondo que correlativamente atraviesa la mismidad del Dasein a partir de la cotidianidad. En la misma línea, tal diferimiento y dimensionalidad nos permitió referirnos a pliegues en lugar de alternativas entre modalidades de la mismidad, tomando distancia de algunas recepciones críticas de estas elaboraciones. Las consideraciones del lenguaje en la caída en el Uno nos permitieron argumentar que la existencia auténtica puede entenderse como una especie de mella/grieta modal que es inherente al Uno en la cotidianidad, es decir, reconociendo también aquí su carácter irrebasable. Destacamos que desde allí, la modalizacion atraviesa el complejo dinámico y simultáneo de las estructuras del Dasein: relaciones con los entes, con los otros Dasein, con las significaciones y consigo mismo, lo cual pone en tensión las estructuras de su cotidianidad y des-cubren una dimensión contingente, dinámica, no clausurable ni plenificable.

Asimismo, hemos hecho explícitas algunas tensiones que se siguen de tal retorno a sí, las cuales develan el eje paradigmático de las perspectivas de la conciencia y el sujeto trascendental, en tanto figuraciones o resonancias de un polo-yo como sede de tal retorno. Estas tensiones prefiguran el énfasis relacional del siguiente período de sus elaboraciones. En aquel sentido, la autenticidad 
alcanzada en la propiedad de sí puede sugerir en primera instancia, una posibilidad de superación definitiva de las determinaciones situacionales y de alteridad.

La distinción de sus elaboraciones y las articulaciones en su discurso, nos llevaron a desplazar la atención a este ámbito, lo que nos permitió revelar probables imprecisiones en las recepciones e interpretaciones contemporáneas de su obra que destacan de un modo deficitario la discontinuidad o desplazamiento en su discurso. Por el contrario, entendemos que los desplazamientos modales para la mismidad del Dasein son correlativos a su propia no sustancialidad y la del lenguaje. Es decir, vimos que la caracterización dinámica de términos, conceptos y expresiones, acompaña los análisis del lenguaje de la tradición y las articulaciones que realiza, por medio de una reapropiación proyectiva de la tradición.

Ello nos ha llevado a distinguir, en el marco de nuestra segunda hipótesis, una teoría de la ipseidad explícita en este período, donde el entramado de significaciones en el que se halla inscripto el ser-en-el-mundo se manifiesta como condición de posibilidad para la asunción del sí-mismo propio, como también para desplazamientos comprensivos y de sentido. Por ello, argumentamos que en tal teoría, la mediación discursiva y de la interpretación opera como el escenario apropiado para este proceso de la constitución de la ipseidad. No obstante, vimos que la tensión del intento de transición de la metafísica no logra disolverse en estas elaboraciones, pues se halla relacionada con la alteridad desde la que realiza el pliegue discursivo para una posible transición. La dinamización y énfasis en el carácter no clausurable del lenguaje lo entendemos como un correlato de estas indagaciones, que buscan sortear inmovilizaciones conceptuales y terminológicas: las significaciones son desplazables en un carácter proyectivo, de un modo correlativo a la mismidad del Dasein en su analítica. Los supuestos que hemos reconocido en esta reconstrucción son la irrebasabilidad semántica y aquella alteridad irreductible.

En el capítulo 4, hemos cotejado la reducción al ego puro de Husserl en su análisis fenomenológico de la intersubjetividad, en contraste con el análisis desde el ser-con como punto de partida de abordajes de Heidegger. Aquí vimos que la alteridad se encuentra inserta en la misma ipseidad, sin necesidad de postular una armonía preestablecida entre co-existentes, apartándose así del marco conceptual de la identidad en sus vínculos con el yo y el sujeto.

Los análisis del ser-con de finales de la década de 1920, parten de la condición respectiva y luego, del estar en medio de los entes y los otros Dasein. En este marco, distinguimos las tensiones emergentes de tomar como punto de partida el estar-a-la-mano en su consideración retroactiva del prójimo, entendido como un medirse con este, delimitando con ello una instancia primaria a ser suprimida o superada. 
Desde aquí, desarrollamos algunas de las consecuencias o derivados de la ipseidad y la alteridad a partir de sus estructuras fundamentales. El punto donde detuvimos el análisis es en la consideración de la consistencia y mantenimiento de sí, que desarrolla de un modo correlativo al carácter proyectivo, temporal e insustancial del Dasein, lo que nos condujo a poner de manifiesto un conjunto de tensiones por las resonancias semánticas evidentemente opuestas. En este contexto, argumentamos que las elaboraciones en torno a las visones del mundo desde donde Heidegger inscribe la reelaboración u orientación de la filosofía, pueden entenderse como una bisagra hacia su cambio de enfoque, en el marco de los escollos que lo condujo la perspectiva del Dasein.

En lo que respecta a la consideración de la intersubjetividad desde los análisis de Husserl nos detuvimos especialmente en sus Meditaciones cartesianas. Vimos que si bien este pensador halla las huellas del otro en la esfera de la propiedad del ego puro, de un modo irreductible como en el caso de Heidegger, aun así no supera el dualismo moderno, bajo el yugo de pretensión de fundamentación absoluta. Ello se debe a que la alteridad queda ligada al ámbito de lo propio. Asimismo, el abordaje de la consideración de la comunidad, nos permitió evidenciar que las remisiones a escalas mayores de relaciones entre mónadas, también presenta una articulación por la vía de la analogía o semejanza, la cual, en última instancia, se mantiene ligada a la esfera primordial del ego y el campo comprensivo que le es correlativo. Si bien la consideración del carácter no apodíctico de estas experiencias de alteridad, supone en Husserl una distancia u opacidad irreductible e inherente en el conocimiento relacional con el otro o la comunidad, aun así distinguimos la orientación de su descripción hacia un horizonte que supone una supresión de tensiones y conflictividades inherentes a las relaciones intersubjetivas, tensión que interpretamos derivada del propio método de análisis y su punto de partida.

De esta manera, reconocimos que el sentido y las significaciones, junto el formalismo de tal armonía son el marco de la correlación intersubjetiva en dichos análisis, con un énfasis limitado a la dimensión gnoseológica, es decir, ligado a la consideración del conocimiento común y la comunidad de pertenencia de habla, aspectos de la intersubjetividad estrechamente ligados a la orientación cientificista de sus análisis fenomenológicos. Frente a ello, la partida desde la facticidad en Heidegger invierte el orden de exposición: parte desde la alteridad de base, para el acceso a la mismidad e ipseidad, lo cual distinguimos como su intento de superación de los abordajes respectivos de su maestro.

Vimos que su remisión al Dasein supone una alteridad de partida, un diferimiento o distancia que abre la alternativa entre una reflexividad propia o impropia pues, como al mismo tiempo es ser-con, debe determinarse el auténtico ser en convivencia, cuyo pliegue o modalización repercute correlativamente en toda su constelación co-originaria. En sus consideraciones sobre la 
identidad, Heidegger destaca que la propiedad del sí-mismo es tan solo una modalizacion de la impropiedad, característica que inscribe esta flexión teórica en el horizonte irreductible la alteridad co-originaria. No obstante reconocimos resonancias tradicionales, ligadas al horizonte de los imperativos de auto-fundación de la conciencia.

En efecto, distinguimos la coexistencia de dimensiones y ambigüedades semánticas y terminológicas que derivan de esta metodología que realiza la analítica desde el Dasein en su cotidianidad, tal y como se manifiesta en la metodología de Husserl, cuando halla las huellas de alteridad desde la esfera primordial del ego .En ambos casos, se debe a un modo de articulación y orientación del análisis ligados a la comprensión y tematización moderna del sujeto.

Advirtiendo estas limitaciones, nuestro autor va desplazando sus análisis hacia campos discursivos o perspectivas, como es el caso de las visiones del mundo ante la falta de sostén o consistencia de la existencia, las cuales pueden comprenderse como figuraciones de la mismidad desde la perspectiva de la dimensión co-originaria del ser-con : parte del mito, la cosmovisión científica y la filosofía, desde cuyos desvíos respectivos emergen la centralidad y antropologización del hombre y la eminencia transversal de la comprensión del ser como presencia. Por esta vía retoma la eminencia de la pregunta por el ser, cambiando los puntos de apoyo que eran frecuentes en su analítica. Así, desde el Dasein en su preeminencia, Heidegger desplaza su enfoque a los ámbitos de alteridad, como por ejemplo, tales visiones del mundo.

En los dos capítulos siguientes, hemos propuesto un recorrido por trabajos posteriores a 1930, los cuales entendemos que son relevantes para nuestra investigación temática de la obra de Heidegger. Específicamente, en el capítulo 5 nos abocamos a circunscribir el estatuto del carácter mediado de la ipseidad, a partir de sus consideraciones respecto al ser y al pensar, en sus dinámicas de co- determinación con el Dasein. Atendiendo la superficie de sus enunciaciones, distinguimos que el desplazamiento de enfoque tiene al decir poético como modalidad pertinente. Prueba de ello, es el carácter no sustancial, proyectivo y no representacional que evidencia el despliegue de tal discurso .En línea con los dichos de Heidegger, argumentamos acerca de una singular continuidad dinámica entre ambos períodos de sus elaboraciones, abandonando con ello las segmentaciones estancas y lineales de su obra que proponen determinadas interpretaciones y recepciones de la misma. Tal y como buscamos articular en los anteriores capítulos, entendemos que estos escritos y seminarios demandan lecturas holísticas y ensambladas, atendiendo relaciones, asociaciones y resonancias semánticas, no necesariamente de un modo lineal. En estas constelaciones relacionales pudimos circunscribir la función del Dasein en las diversas modalidades de co-pertenencia epocal con el ser. 
En efecto, detallamos el desplazamiento del énfasis en el enfoque de Heidegger : de establecerse desde la perspectiva del ser ( buscando desplazarse de la comprensión tradicional del ser como fundamento del ente), abordando la dirección que va del ser (en su donación) al Dasein, finalmente se consolida en la relación inescindible de Ser-Dasein, es decir, en su pertenencia recíproca. Esto le permite enfocar su análisis en el darse, en el manifestarse del ser del ente en su singular movilidad de desocultamiento y retracción, abriendo una perspectiva en torno a la historia del ser. Así, vimos que considera al Dasein como el que descubre y preserva tal manifestación, destacando su carácter pasivo y receptivo, aspecto que no obtuvo un suficiente tratamiento anterior debido al enfoque y articulación desde el Dasein en la analítica de SuZ. Destacamos algunas variaciones terminológicas en su discurso que proyectan este desplazamiento: de superación a torsión de la metafísica; del recurso al método al de camino, donde la mención del encuentro le permite indicar un parámetro relacional-simultáneo, ya no unilateral o externo.

En el marco de nuestra hipótesis interpretativa de que la modalizacion del lenguaje de estos años incluye implícitamente la comprensión y conceptualización precedente, hemos explicitado otros desplazamientos correlativos que entendemos relevantes, por ejemplo, los abordajes en torno al Uno y la caída en su giro a la consideración de la técnica moderna y su pensar respectivo, que reconocemos como consecuencia de un cambio de enfoque, a partir de los resultados de la analítica de 1920.

Asimismo, para plantear una transición al otro pensar del ser, evaluamos su consideración del salto y el paso atrás, como modos de desplazamientos dinámicos y en diferimiento desde/en el pensar, contrapuestos a modalidades o praxis desde el sesgo representacionista moderno. En tales entre-lugares, nuestro autor supone un claro o apertura originaria como base abismática de fondo, desde donde se articula la co-pertenencia epocal de hombre y ser, apartándose con ello de una base representacionalista o sustancial para su ontología. Sin embargo, también aquí la caracterización es dinámica: especifica que es por la presencia, es decir, por la vía de lo manifiesto del fenómeno, desde donde es posible acceder a la experiencia histórica del ser, irrebasable pero distinguible por el pensar.

De este modo, Heidegger desarrolla sus especificaciones intuitivas para tales ámbitos intermedios, al tiempo que da cuenta de articulaciones y modalizaciones gramaticales correlativas a ello. Por este camino, delimitamos su perspectiva que abandona la orientación del fundamento, distinguiendo una oscilación de fundamentación-desfundamentación irreductible. Con ello, la representación y la presencia pierden su preeminencia, en vistas a un pensar oscilante y no clausurable. Con una lógica de base sustractiva y dinámica delimita la transición respectiva, donde 
los recorridos despliegan puntos de llegada que tornan (retroactivamente) necesarios los momentos previos a tal despliegue.

En este marco, buscamos dar cuenta del estatuto de esta modalidad relacional en los estratos coextensivos: claro-ser-Dasein-ente. Destacamos una lógica singular de aprehensión : solo a partir de lo que se manifiesta como presente es posible esbozar una aprehensión parcial del ser en su ocultamiento inmediato, pues es precisamente lo que se sustrae u oculta lo que constituye aquello que se manifiesta o se presenta, consistiéndolo por el mismo movimiento de sustracción u ocultarse. Dar cuenta intuitivamente de esta dinámica del ocultarse-darse y del carácter epocal de tal consistir, caracteriza el programa de esta etapa de su perspectiva en torno al ser. Interpretamos que por ello enfatiza el aspecto relacional de la misma : el ámbito a circunscribir en su fugacidad requiere de esta singular relación entre los partenaires, sin reducirse a uno de ellos ni a determinación alguna, excluyendo puntos de partida externos o anteriores a la relación. Esta lógica entramada, sustractiva, oscilante, esquiva, diferenciante y sin fundamento atraviesa estas elaboraciones del carácter mediado de la ipseidad.

Asimismo, hemos desarrollado la creciente relevancia de la consideración de los temples anímicos, que despliega frente al auge voluntarista del pensamiento de la metafísica del sujeto. Desde allí, examinamos las notas que configuran al Dasein como guardián del ser frente al sujeto rector y central de la modernidad. A partir de la consideración del pensamiento de Nietzsche como expresión de la metafísica consumada, Heidegger analiza la época de la técnica donde la manipulación del ente se torna lo eminente, convirtiendo la naturaleza en un ámbito objetual susceptible de cálculo y planificación, lo cual conduce a un aumento de la exigencia de regulación sobre ella. Frente a esta orientación, el Dasein deja ser a lo ente, por la vía de la meditación como otra modalidad relacional, lo cual abre un horizonte de transición para otra época del ser y el pensar respectivo: si en el primer caso, la Ge-stell es el modo de co-pertenencia de la técnica, el Ereignis, en cambio, señala una modalidad originaria de co-pertenencia, en un retroceso del mundo técnico y su manipulación característica.

Con énfasis puesto en el carácter situado y relacional, el hombre, el Dasein y el Da-sein son nombres para estos ámbitos derivados y en diferimiento. En este marco, la ipseidad deviene acontecimental e histórica en una dependencia que la analítica de 1920 no permitió distinguir con precisión. Como pastor del ser, el hombre es entendido en su función de entrega, por medio de la guarda y meditación que le permite señalar aquello que se retira sin quedar ya limitado a la mera presencia, en un horizonte dinámico y no clausurable , que entendemos afín a la dinámica del pensar que articula el discurso de Heidegger. Así, reconocimos que ello lo conduce a plantear la cuestión liminar del decir y del discurso el cual, mientras se despliega, requiere cuestionarse a sí 
mismo. Interpretamos que esto oficia como una prueba de la necesariedad del paso por la mismidad sustancial del mundo de la técnica (coincidente con ciertas modalidades de enfoque en la analítica de 1920) para que, en tensión dentro del mismo campo semántico, puedan distinguirse y señalarse horizontes, umbrales o fronteras.

Por ello, insistimos en nuestra consideración sobre el carácter inapropiado de un planteo interpretativo y posicionamiento crítico reducido solo a rupturas y discontinuidades entre los periodos de sus elaboraciones. En lugar de ello, entendemos apropiado a su enfoque, destacar superposiciones y desplazamientos necesarios de pliegues del pensar, en el acceso a límites en sus perspectivas, pues la base desde la que se posiciona Heidegger es discursivo-dinámica y no sustancial-estática. Ello también oficia de respaldo para nuestra tercera hipótesis: la oposición al campo semántico de la tradición y el develamiento de ámbitos originarios repercuten en la modalidad del pensar o el decir y solo desde allí es posible plantear o distinguir desplazamientos posibles. Vemos nuevamente así que el propio trayecto modifica el recorrido, modalizando en cada tramo la relación con el lenguaje. Esto no remite para nuestro autor a los actos voluntarios de un sujeto de enunciación, sino a determinaciones epocales, provenientes del ser y de aquel claro originario. El resultado de este abordaje complejo e interrelacionado arroja luz sobre un modo pertinente de abordar la cuestión de la ipseidad, es decir, de un modo inescindible con sus vínculos con la alteridad y el lenguaje.

Para profundizar nuestras argumentaciones e interpretaciones en ese sentido, en el capítulo 6 examinamos las consideraciones sobre praxis, ética originaria y Ethos en sus elaboraciones de madurez. Distinguimos y argumentamos que el tratamiento de la ipseidad en este período se halla implícito en los movimientos del discurso de este autor, en su proyecto y modalización relacional en la pregunta por el ser, tal y como figura en sus caracterizaciones del otro pensar. Específicamente, dimos cuenta de la orientación teórica que despliega en torno a la praxis, la voluntad, la transformación y el cambio por la vía mediada de una co-intervención humana, poniendo énfasis en las reservas que nuestro autor manifiesta ante los imperativos prácticos que entiende anclados en la metafísica de la subjetividad y sus presupuestos. Por ello, cotejamos la posible homogeneidad del discurso respecto a su enunciación teórica, al menos en lo que respecta a los temas y conceptos que aquí analizamos.

En este marco, partiendo de la intensa polémica que aún sigue suscitando su implicancia política y posterior silencio sobre ello, entendimos necesario comenzar por un abordaje de sus discursos en la época de su participación en el Nacionalsocialismo (NS), que dieron cuenta de la dimensión política de su pensamiento en lo que respecta al rol o papel histórico del Dasein. Realizamos este análisis en vista de los desarrollos posteriores donde rechaza todo centralismo 
histórico del existente humano, en lo que respecta las modificaciones de las relaciones epocales con el ser, la modalizacion del pensamiento y las relaciones instrumentales con el lenguaje. De este modo, argumentamos que tales discursos oficiaron como una muestra de los vínculos entre el discurso de Heidegger y su posición de enunciación. La pasividad con la que concibe al Dasein y la consideración de las disposiciones afectivas lo aparta de los enfoques de filosofías prácticas o de filosofías del sujeto en general.

En efecto, reconocimos un mismo campo semántico en sus discursos del 1933-34, en el que figuran el carácter situacional y complejo del ser-en-el-mundo del Dasein, la estratificación jerárquica del pensar, etc. Su silencio posterior al respecto lo articulamos en parte con sus elaboraciones sobre el carácter situado, relacional, derivado y lateral de la praxis y la voluntad del Dasein. La búsqueda de un medio adecuado para circunscribir el otro comienzo del pensar fueron, en palabras de Heidegger, motivos para alinearse y desalinearse con la orientación política del NS. Sus disculpas medidas, su aislamiento posterior y su énfasis en deshacer la relevancia de la figura de autor, los interpretamos como correlatos de una perspectiva y una relación consigo mismo y con la época que marchan de la mano con sus elaboraciones. La voluntad se alinea aquí con la orientación de los discursos y las políticas.

En el mismo contexto, planteamos un recorrido breve por la recepción de la reciente publicación de sus Schwarze Hefte, en el marco de los debates actuales en torno al posible correlato entre sus posicionamientos/convicciones políticas y el propio campo semántico y perspectiva en sus elaboraciones filosóficas, donde destacamos las críticas que apuntan a relaciones entre comprensión , lenguaje y praxis, al momento de comprender tales convicciones y decisiones en la vida de Heidegger, lo cual requiere también de la dilucidación del suelo discursivo y enunciativo que desarrolla.

En el marco de sus elaboraciones filosóficas, el énfasis puesto en lo situacional y relacional, implican un desplazamiento de los análisis tradicionales de la praxis, los cuales se han caracterizado por unilateralizar o reducir las dinámicas históricas a uno de los co-partícipes de ellas. El deshacimiento, la entrega, la preservación de la alteridad en el entorno, en sí y en la época, son algunas de las notas de estas disposiciones para el Dasein en el umbral de transición hacia una nueva época del pensar. En este marco, la disposición voluntaria solo es entendida por Heidegger como relevante en un momento de transición para el abandono ulterior: una voluntad que se autoremite al posicionamiento respecto a la praxis y la centralidad del hombre en el mundo. Aquí, la decisión implícita no supone una elección ni acto del hombre, sino que se inserta en una disyuntiva epocal: o bien pertenecer al ser o bien abandonarse en lo ente en el marco de la historia del ser, cuya base es el desarraigo en que el hombre contemporáneo se encuentra. Notamos aquí la manifestación 
de la modalidad diferida y superpuesta de orientaciones tradicionales, como otra muestra de la alteridad constitutiva de su discurso.

Asimismo, hemos recorrido su rechazo de la ética como doctrina de la acción, la cual se ve acompañada por una confianza en el pensar y la interpretación como ámbitos pertinentes para abordar cambios o desplazamientos, no ya desde la acción segregada o directa del existente humano. Su consideración del Ethos originario como modo humilde de relación del hombre con el ser y de habitar originario como ser-en-el-mundo, contrapuesto a la orientación de este como señor del ente (propio del mundo de la técnica), implica una nueva relación del hombre con el ente en su totalidad a lo cual apunta el pensar heideggeriano. Junto a ello, distinguimos las figuraciones de la alteridad que se manifiestan no tanto en sus elaboraciones sobre los otros Dasein y las relaciones humanas, sino en los marcos del pensar que nuestro autor articula: el otro comienzo, Ethos, el olvido del ser, el ser, la muerte, etc., dando así a la alteridad un estatuto ontológico y originario.

Desde estas flexiones en su teoría circunscribimos el momento discursivo en que el papel del hombre en las dinámicas deja de entenderse como determinante. La mismidad revela una codependencia dinámica. Aun así, vimos que el desplazamiento relacional requiere una posición correlativa del hombre, que se enmarca en la bidimensionalidad de actividad-pasividad que Heidegger destaca en los roles respectivos del Dasein. Argumentamos que ello también otorga factibilidad a la interpretación de la ipseidad en esta etapa de sus elaboraciones necesariamente mediada por el lenguaje, puesto que se manifiesta correlativa al abandono de asociaciones externas , duales o aisladas, y de puntos de apoyo con resonancias sustancialistas : de tales apoyos, el más pertinente como ámbito topológico es la superficie móvil del lenguaje, la cual, al igual que el Dasein , se proyecta en un horizonte no clausurable hasta el encuentro bien sea con la muerte, bien sea con el silencio.

Reconocimos nuevamente aquí que el pensamiento de nuestro autor prefigura la orientación de una modalidad para la interpretación o análisis crítico de su obra, la cual necesariamente debe tomar en consideración el lenguaje o pensamiento al que se opone como una disyunción inclusiva (tal como hicieron él y Husserl), es decir, como punto de partida diferido irreductible para un despliegue o abandono posterior. Sugerimos, en línea derrideana, que un rechazo de ello corre el riesgo de derivar en una asunción velada del mismo lenguaje o campo semántico, en un nivel de mayor profundidad. En otras palabras, un posicionamiento crítico frente a sus elaboraciones pone en evidencia los supuestos de una teoría subyacente del lenguaje los cuales, en caso de que mantengan la misma orientación, deben abordar dicha perspectiva asumiendo ineludiblemente su alteridad de base, inscripta en sus sedimentos de lenguaje. Una negación o expulsión de la misma, sin una tematización suficientemente desarrollada, posiblemente implique un desplazamiento de 
aquellos supuestos, es decir, un corrimiento de las notas de consistencia o determinación cósica desde las consideraciones teóricas hacia enunciados o posiciones de enunciación, figurando en pretensiones de totalización o de carácter definitivo en el discurso. Entendemos que un rechazo de esa índole solo puede sostenerse en defensa de una consistencia supuesta. Por el contrario, una tentativa por eludir tal consistencia caracteriza la discursividad heideggeriana.

Ahora bien, este recorrido temático nos condujo a sistematizar y vincular las consideraciones del lenguaje en esta obra, por lo cual en el capítulo 7 nos abocamos a desarrollar la perspectiva de Heidegger en línea con su empleo discursivo. Examinamos sus elaboraciones de la década de 1920 , a partir de las críticas a la recepción moderna del Logos griego, en el marco de su distinción del ámbito originario del lenguaje que le permite no tomar como punto de partida los enunciados y las proposiciones, sino esta apertura originaria, la cual entendemos como una flexión teórica fundamental para dar cuenta de desplazamientos y transformaciones en el campo semántico y para subrayar el carácter inesencial y no clausurable del lenguaje, afín a la perspectiva teórica que resulta de sus investigaciones.

En efecto, desarrollamos su perspectiva que considera el entramado complejo en el que se articulan la comprensión, interpretación, el Habla, los enunciados, el sentido y las significaciones, frente a la perspectiva instrumental del lenguaje de la tradición metafísica, la cual se caracteriza por una reducción al enunciado o lenguaje lógico-proposicional. Reencontramos aquí una operación del pensar de Heidegger: el rechazo de toda reducción metafísica a la apariencia y presencia (en este caso, el enunciado) en pos de fenómenos más originaros que remiten a su esencia o verdad, evidenciándose como condición de posibilidad de aquella.

Cotejamos que el tratamiento sintáctico, gramático, conceptual y semántico de su discurso evidencian nuevamente una puesta en tensión del lenguaje heredado, con lo cual Heidegger se propone abrir campos originarios, umbrales y fronteras, desde y en el mismo campo tradicional, lo cual marcha en consonancia con sus elaboraciones en torno a la filosofía de la acción o la praxis : tales desplazamientos tienen su sede en el lenguaje, en el marco de la historia del ser, de cuyo resultado el existente humano co-participa tan solo de un modo lateral.

Allí planeta la esencia del lenguaje como Logos en su función antepredicativa y prerreflexiva, es decir, como apertura de mundo, la cual prefigura el modo de contacto con el mundo en torno. En este marco, entiende formalmente al Dasein como un complejo de estructuras significativas y de sentido. Aquí se establece un ensamblaje originario entre Dasein, alteridad y lenguaje que señalan el carácter derivado del enunciado y la posición de enunciación. El punto irrebasable para nuestro autor es el acceso a la figura de una época del ser, más allá del cual no es posible avanzar. Asimismo, vimos que las significaciones y sentidos compartidos permiten dar 
cuenta de la co-originariedad de ser-con y lenguaje en su carácter no clausurable, cuyo diferimiento respecto al Habla permite pensar no solo los desplazamientos, sino los puntos de torsión u obstrucción de tales diferimientos en sus manifestaciones primarias en la cotidianidad.

En este marco, especificar sus dilucidaciones en torno al Habla implica remitirse a una dimensión que articula aquella comprensión del mundo ya siempre abierta en el ser-en-el-mundo, la cual se evidencia como condición ontológica para la posibilitación del lenguaje enunciativo. Desarrollamos su perspectiva en torno al sentido, el cual se inscribe en la facticidad sin suponer ya un estrato de idealidad o atemporalidad, pues se articula con la existencialidad del Dasein, destacando que éste es en sí mismo significante: desde una comprensión e interpretación ya abiertas, vive en/desde un entramado de significaciones y se puede expresar como tal, por medio de proposiciones o enunciados. Su propuesta de transitar un camino al horizonte de significación originario de términos o conceptos, también desde la esfera proposicional, no supone una conciencia rectora que impulsa o manipula conceptos o significaciones, sino el impulso dado por un llamado de aquel abismo originario inagotable, que es precisamente el que permite poner en evidencia el carácter contingente de las determinaciones conceptuales tradicionalmente sedimentadas, a partir de los caracteres furtivos de no fundamento, indeterminación , multiplicidad y simultaneidad con que Heidegger lo distingue.

Luego de 1930 examinamos el énfasis puesto en el lenguaje entendido como casa del ser, donde nuestro autor busca apartarse de las notas antropocéntricas de sus anteriores elaboraciones, a partir de un enfoque orientado a las relaciones entre lenguaje y ser, donde el hombre es comprendido como ámbito de resonancia de tal relación. Interpretamos allí que la distinción de ámbitos originarios y su despejamiento, fueron condición para las orientaciones respectivas en este periodo, en lo que respecta al desplazamiento de los énfasis puestos y la retematizacion del carácter temporal del lenguaje.

Desarrollamos su elaboración intuitiva de la resonancia de un Decir que impulsa desde tal dimensión interrelacional, a partir de la cual puede avizorarse un horizonte para el otro comienzo del pensar. Incluso el propio decir enunciativo permite un despliegue de aquel Decir originario que desoculta, muestra y llama, solo si el Dasein se entrega en una pertenencia que participa y responde. Reconocimos que tal Decir se revela como acontecimental, pues emerge desde el seno de las dinámicas e interrelaciones y no a partir de un fundamento previo. Incluso, las consideraciones del silencio o lo insonoro nos permitieron establecer continuidades respecto a aquellas funciones liminares que la muerte o la angustia manifiestan en las dinámicas de la analítica existenciaria.

El otro inicio del pensar, que Heidegger señala en su transición, se aparta de una aprehensión enunciativa determinada. En este ámbito no racionalizable, nuestro autor destaca la 
eminencia del pensar y decir poético-literario como lo más propicio para ello. En este marco la función del hombre es de guardián y vigía de esta morada, liberándolo de los estrechos cotos de la gramática en su sedimentación metafísica. La decadencia del lenguaje tal y como se manifiesta en la era de la técnica, simultáneamente opera como un ámbito desde el cual surge aquello salvador de los peligros consecuentes de tal decadencia. Reconocimos nuevamente los diferimientos de planos o dimensiones, que aquí supone en el umbral del pensar representativo, los cuales, con su debida puesta en tensión, permiten la emergencia de un pliegue de fondo que los desplaza.

Desde estas consideraciones reforzamos argumentalmente nuestra interpretación de que una investigación en torno a estas elaboraciones difícilmente tenga un desarrollo pertinente si se reduce a un conjunto de enunciaciones determinadas o segmentos discursivos locales. Más aun, si consideramos el despliegue discursivo de Heidegger como una experiencia, la cual puede ser abordada propiamente solo atendiendo su devenir, cancelando así la posibilidad de alcanzar una aprehensión acabada de la misma. Precisamente desde aquí argumentamos nuestra tesis: es posible distinguir su experiencia del discurso como una continuidad y desarrollo práctico de su teoría de la ipseidad, la cual remite término a término con el despliegue teórico elaborado en sus trabajos de juventud.

En este marco, también hemos analizado e interpretado algunas características del discurrir enunciativo de nuestro autor. Ofrecimos argumentos para nuestra segunda hipótesis: la tematización que realiza impacta y modula su enunciación así como también la posición respectiva en el discurso. Con términos procesuales y dinámicos, su discurso no tiene una determinación definitiva a lo largo de las paradas de sus elaboraciones. El doble carácter de provisionalidad y necesariedad para los desplazamientos posteriores manifiestan el aspecto productor de tal transito en el lenguaje. La dimensión de significación se inserta así en un despliegue que la efectiviza, con horizontes no previamente fijados, sino más bien emergentes de/en la misma marcha.

La ampliación de campos semánticos o asociativos le permite proponer recorridos desde nuevas significaciones o relaciones dentro de la lengua heredada. Esta relación con el lenguaje vimos que es correlativa a su malestar respecto al uso academicista y sustancialista de sus términos, acuñaciones y resultados de investigación, que responde más bien a una relación con el lenguaje afín al pensamiento técnico y a los presupuestos de la metafísica de la subjetividad.

Tambien retomamos la matriz jerárquica y axiológica que se evidencia en el uso de binarismos, términos de sus elaboraciones o en flexiones de su pensar. Interpretamos que esto se debe a una modalizacion o matriz del pensamiento como signo de alteridad constitutiva del lenguaje y el pensar de partida, lo cual figura en la orientación semántica de sus elaboraciones por la vía de una modalización o conjunto de significaciones que direcciona tal orientación. 
En este marco, distinguimos que tal alteridad originaria del lenguaje se manifiesta como no susceptible de aprehensión enunciativa directa. A partir de este sesgo emergen las dinámicas productivas y no clausurables del lenguaje enunciativo, que se basan, a nuestro entender, en la imposibilidad de una simbolización y determinación respectiva, lo cual frustra todo intento de conjura o expulsión de este sesgo del ámbito del lenguaje. Ello conduce a nuestro autor a redefinir la modalidad de enunciación diferenciándola radicalmente de la matriz representativa, tanto del pensamiento científico como de las filosofías de la conciencia y la subjetividad. Desde aquí pudimos circunscribir con claridad dos etapas continuadas del tratamiento heideggeriano de la ipseidad: el primero, bajo los sesgos de la metafísica; el segundo, con un abordaje lateral, figurando implícitamente en su discurso.

Finalmente, con el objeto de respaldar argumentalmente la necesariedad que en este enfoque manifiestan las etapas anteriores, en su tránsito o desplazamiento a las posteriores, por tratarse de una dinámica que se actualiza en el lenguaje, entendimos necesario examinar ciertas continuidades, resonancias y críticas en la sucesiva recepción posterior de estas elaboraciones de Heidegger. Por ello, en el capítulo 8 hemos examinado algunos desarrollos contemporáneos sobre las teorías del lenguaje, las relaciones entre ipseidad y alteridad, las consideraciones éticas y los aspectos pragmáticos que se oponen a la tradición de la perspectiva del aspecto instrumental del lenguaje, como algunas de tales resonancias de aquellas elaboraciones, sea de modo indirecto o bien de modo directo, junto el empalme con diversos aspectos poco desarrollados o tematizados por nuestro autor.

En efecto, argumentamos en torno a la necesidad de articular entre ipseidad, alteridad y lenguaje en trabajos de Gadamer, Vattimo, Derrida Tugendhat, Levinas y la respectiva recepción regional principalmente de la mano de Walton y Presas, entre otros. Los análisis lingüísticos sobre la autodeterminación en la vertiente analítica nos permitieron poner en evidencia el impacto que tiene las consideraciones de fondo sobre el lenguaje. Las consideraciones inexorables sobre el sercon y la creciente radicalidad con la que se enfoca la consideración de la alteridad en estas dinámicas relacionales, han tenido desarrollos y contraposiciones en la recepción europea que nos permitieron visibilizar desplazamientos en los tratamientos ontológicos o énfasis en nuestra constelación temática. En nuestra región, delimitamos la inscripción del presente trabajo en los sedimentos de interpretación con un énfasis puesto en el lenguaje, en continuidad con las primeras recepciones centradas en la consideración del sujeto cultural como base del abordaje de la obra heideggeriana. Como veremos, estos recorridos nos ofrecen elementos para circunscribir horizontes de posibles abordajes e investigaciones en el marco de la dimensión pragmática y no clausurable del lenguaje, que incumben no solo a perspectivas filosóficas, sino también psicoanalíticas, antropológicas, entre otras, en sus aspectos metodológicos y lingüístico-comprensivos. 
Por un lado, vimos que el abordaje de Tugendhat del mantenimiento de sí en SuZ, evidenció solo una articulación óntica y descuidó de las bases fenomenológicas y ontológicas de estos trabajos. Destacamos que las tesis críticas de este autor se remiten al concepto de verdad, la irracionalidad en la cuestión de la elección y el concepto de autodeterminación, los cuales entiende afines a las elecciones políticas de Heidegger. Asimismo, interpreta como innecesario su rechazo a la modalidad de sustancia con propiedades para comprender al Dasein, distinguiendo su tesis del ser como inconstatable dentro del ámbito del lenguaje proposicional. El resultado es un claro desvío del programa de nuestro autor, incluso en sus imputaciones de irracionalismo, en descuido del carácter procesual del lenguaje heideggeriano. A nuestro entender, los supuestos de base, en lo que respecta al concepto de sujeto y a las teorías del lenguaje, se oponen a tal perspectiva, lo que inscribe sus desarrollos por fuera de un diálogo legítimo con sus elaboraciones.

Frente a ello, distinguimos que Heidegger no descarta el potencial de variabilidad del lenguaje predicativo, sino que plantea un horizonte no lingüístico como condición, que se proyecta en un incremento del potencial de variabilidad y desplazamiento de la comprensión, el lenguaje y el pensar, destacando allí la inmanencia de un sesgo irreductible, una inadecuación o diferimiento originario, que Tugendhat se empeña en excluir. En este contexto, reconocimos que la diferencia de perspectiva respecto a Heidegger señala una vía que conduce a trabajos de Wittgenstein y la escuela analítica anglosajona de mediados del siglo pasado.

En tal sentido, reconocimos la relación de alteridad que propone con la obra en cuestión, es decir, la operación de límite o tensor con estos desarrollos. En la actualidad pueden hallarse abordajes sobre los aspectos prácticos de la ipseidad, a partir del análisis y reelaboración de nociones respectivas, sin la desestimación de tal sesgo o diferencia constitutivo. A nuestro entender, estas cuestiones no fueron desarrolladas por Heidegger, debido al horizonte y programa de base en sus indagaciones, lo cual no supone necesariamente un rechazo implícito a toda tentativa de elaborarlas.

Frente a ello, las recepciones que siguen los presupuestos de nuestro autor continúan con la exploración de la dimensión no clausurable del lenguaje y las relaciones no sustancialistas con el lenguaje. En este marco las críticas al imperialismo del significante y al significante trascendental que se hallan en elaboraciones de Deleuze, Derrida, Vattimo e incluso Foucault, pueden inscribirse entre ellas. El paso hacia un pensar no jerárquico, que se aparta de todo arjé y thelos, abre el carácter proliferante y múltiple del pensar, buscando el abandono definitivo de la orientación semántica de las articulaciones de nuestro autor.

En este contexto de recepciones, la hermenéutica filosófica de Gadamer nos permitió distinguir los aspectos intersubjetivos en los análisis del lenguaje y de la dinámica relacional entre 
intérprete-tradición, lo cual implica atender los sedimentos tradicionales y culturales que se hallan en las bases de las relaciones con el lenguaje, en su carácter de alteridad. Desarrollamos diferenciaciones respecto a Heidegger, distinguiendo su perspectiva circunscripta al horizonte de sentido, los nexos de significación y el horizonte comprensivo de la situación fáctica, es decir , estratos que se articulan con una dimensión lingüística intersubjetiva, la cual supone como ámbito originario, fuente y reserva de las dinámicas históricas del lenguaje, en tanto reelaboración de la indeterminación o desfundamentación del ámbito originario del Habla que plantea nuestro autor.

Los análisis e interpretaciones respectivas de Vattimo, nos permitieron puntualizar el despliegue de un enfoque que se aparta gradualmente de la recepción dialógico-reflexiva de Gadamer, hacia la radicalización de una puesta en valor del pensamiento del conflicto, en base a una tentativa de desplegar el potencial transformador en el pensamiento de Heidegger. Lo que motiva tal despliegue reside en su interés en torno a una participación en la promoción de un nuevo acontecimiento epocal del Ser, lo cual lo conduce a enfatizar los aspectos activos en las dinámicas de co-relación del Dasein. Analizamos sus aproximaciones o figuraciones de cuestiones relativas a la ipseidad en el umbral y desplazamiento del acontecimiento de la alteridad, donde su carácter proyectivo es ligado a este campo, en una dinámica de apertura y disolución que simultáneamente requiere de una determinación activa y efectiva. En este marco, interpretamos algunas relaciones entre tales énfasis y adecuaciones de las elaboraciones heideggerianas, en función de ligazones contextuales con la propia situación socio-histórica del pensador italiano.

Reconocimos que aquella concepción disolutoria de la subjetividad e ipseidad, hallan un tratamiento en la obra de Jacques Derrida, que manifiesta una consistente continuación y ensanchamiento de los caminos del pensar de Heidegger. Específicamente, vimos que sus trabajos profundizan la caracterización dinámico-liminar del lenguaje y el pensar, radicalizando no solo las perspectivas contemporáneas en torno a la apertura a lo Otro como alteridad, sino también la tentativa transicional del pensamiento de nuestro autor, aplicándola a su mismo discurso.

A partir de su abordaje de la alteridad desde la no-relación, desarrollamos el modo de apartarse de las perspectivas dialógicas, a partir de uno de sus supuestos más relevantes: en toda constitución subjetiva primariamente se abre una ausencia o diferimiento radical, que es condición irrebasable de toda constitución, de modo tal que las relaciones con el sí-mismo y con lo otro, solo pueden intentarse por medio de suplementos. Estas relaciones solo pueden insinuarse en la modalidad de por-venir, es decir, sin el carácter de presencia o inmediación que la reduciría a la esfera de la mismidad. Interpretamos que su enfoque responde a una tentativa para radicalizar el pensar en torno a una dimensión no simbolizable del lenguaje, dándole con ello continuidad y despliegue a las consideraciones del ámbito antepredicativo en Heidegger. En este sentido, 
especificamos resonancias respectivas en la deconstrucción derrideana y su concepto de Différance, atendiendo sus críticas a flexiones de lenguaje en el pensamiento de nuestro autor, lo cual reconocemos como una figura del pliegue que este camino del pensar ejerce retroactivamente sobre sus estadios anteriores.

Por otra parte, hemos recorrido algunas puntualizaciones de la recepción levinasiana. Vimos que con su teoría del rostro, Levinas rechaza la consideración ontológica y universal del otro para situarla en una singularidad y alteridad radical. En esta propuesta ética, interpreta que el análisis heideggeriano reduce y limita el campo inexorable del prójimo al ámbito del ser y lo universal, donde la autenticidad y propiedad de retorno de la caída del Uno, deja al prójimo atrás y sin relevancia en una sacralización del mundo. Nuestra interpretación inscribió el análisis de Levinas en el marco de un despliegue parcial del discurso heideggeriano.

En sus desarrollos la alteridad en el lenguaje se ve distinguida como una interrupción, un diferimiento y alteridad que subyace al propio decir de Levinas. Ello se evidencia en la descripción del fenómeno de la recurrencia el cual remite a un exilio de sí mismo insuperable y paradójicamente constituyente, una tensión inherente, una expulsión en el seno de la mismidad, que unifica permanencia y pérdida sin posibilidad de superación. Este fenómeno de fenómenos es anterior y condición de toda ipseidad. Desde allí, reconocimos una heteroconstitución de la ipseidad, donde la persona se articula en el marco de una dinámica bivalente de pasividad-actividad, entre la venida incalculable del otro y la responsabilidad a él dirigida. Distinguimos que la radicalidad metafísica con la que es pensada aquí la dimensión ética de lo otro es correlativa a un enfoque disolutorio de la ipseidad en su relación de alteridad irreductible, dándole un carácter metafísico y pre-ontológico que lo distingue de la radicalidad propuesta por Derrida.

Como contrapunto, desarrollamos algunas elaboraciones de Ricoeur, a partir de su noción de identidad narrativa. En una suerte de entrelugar entre los desarrollos de Heidegger y Levinas, vimos que este pensador desarrolla una investigación que no desalienta las posiciones éticas, al tiempo que se orienta hacia los márgenes de consistencia de la ipseidad en su sitial en el lenguaje. Retomando la idea que la comprensión de si es interpretación, desplegamos su abordaje en torno a la narración como mediación privilegiada del sí-mismo en el lenguaje, en un modo parcial y dinámico de mantenimiento de sí, que supone un concepto de identidad dinámica. Desde nuestras interpretaciones, argumentamos que esta posición extrema y desarrolla los abordajes de Heidegger sobre el carácter mediado de la ipseidad en el lenguaje. Reconocimos que para poder pensar sin contradicción la alteridad del otro en la conciencia y en la ética, Ricoeur distingue entre solicitud y promesa, diferenciándose de las notas de extrañamiento que Heidegger le confiere a este fenómeno. Desde allí hemos visto que sus análisis de la atestación, la palabra y la acción le permiten 
desarrollar un planteamiento ético por la vía de la palabra mantenida en la promesa, donde la alteridad del otro y la del sí-mismo coexisten en la conciencia sin confundirse. Esta orientación se revela coextensiva con sus elaboraciones sobre la hermenéutica de sí en confluencia con su teoría del texto, en sus dinámicas de apropiación-desapropiación. A diferencia del devenir de la ipseidad ética levinasiana, en su carácter derivado, su enfoque destaca la co-presencia de la alteridad en la constitución de la ipseidad, suponiendo que el sí mismo ya se halla manifiesto al momento de tales relaciones.

En definitiva, con el contraste entre estas recepciones europeas, nos propusimos dar cuenta del estatuto de la relación dinámica entre ipseidad y alteridad en el pensamiento contemporáneo. Ellas coinciden en su tentativa de dar cuenta del carácter no sustancial, dinámico y proyectivo de la ipseidad, cuyos límites se evidencian y abren en la ineludible irrupción de la alteridad, poniendo énfasis singulares o bien en aspectos disolutorios, o bien en los márgenes de constancia dinámica, lo cual les permite desarrollar reelaboraciones en el campo de la filosofía práctica, ética y política, en su inexorable ligazón con el lenguaje. Asimismo, el marco relacional en la que se comprende el símismo se caracteriza por las mismas notas de inconsistencia y variabilidad, lo que les permite plantear un retorno a sí dinámico y con una potencia liberada, en el marco de las consideraciones en torno a la identidad y los procesos de subjetivación.

Por último, vimos que estas elaboraciones han oficiado como mediatizadoras de la recepción heideggeriana en nuestra región. Entre las primeras apropiaciones respectivas hemos distinguido un abordaje con el énfasis puesto en el sujeto cultural en la primera mitad del siglo pasado, en exponentes como Kusch y Astrada. Los análisis marcadamente existencialistas, culturales y situacionales se tornan eminentes en esta época, destacando el encuentro intercultural con el otro, en el marco del auge del marxismo y las perspectivas anticolonialistas. Posteriormente, las interpretaciones evidenciaron un énfasis mayormente puesto en el lenguaje, tal y como hemos visto con ciertos trabajos de Walton y Presas. En el primer caso, los análisis son realizados en una continuidad y diálogo con la fenomenología husserliana, en claro rechazo a la interpretación rupturista de ambas elaboraciones. Por su parte, Presas sigue en ciertos trabajos la vía narrativa de la ipseidad, en continuidad con la fenomenología husserliana, para destacar al hombre como ser de palabra, en su dimensión proyectiva e ineludiblemente ética. Vimos que estas vertientes se cruzan, en mayor o menor medida, en las investigaciones y elaboraciones actuales de nuestra región. En este contexto de recepciones, lecturas e interpretaciones, hemos articulado el desarrollo de estos capítulos, buscando también una inscripción en una tradición lo cual entendemos ahora, como una condición ineludible para toda apertura posible de las interpretaciones o análisis de esta obra y sus caminos del pensar. 
Para finalizar podemos distinguir algunas vías y puntualizaciones generales para posibles investigaciones o desarrollos respectivos. En primer lugar, atendiendo cuestiones metodológicas respecto a las interpretaciones de la obra de Heidegger, la atención puesta a : a) el correlato enunciación-enunciado , b) la alteridad irreductible en la base del lenguaje y c) la distinción entre las manifestaciones explícitas de las connotaciones implícitas de sus tratamientos, pueden hallar un pertinente despliegue y profundización en el abordaje de diversas conceptualizaciones de su obra , permitiendo delimitar y distinguir con mayor precisión pliegues o tensiones modales y discursivas que las orientan, incluso examinando sus vínculos con desarrollos modernos y tradicionales . Entendemos que por esta vía no solo se puede proporcionar una creciente claridad de los alcances y límites del programa heideggeriano, sino también ella permite operar como condición para el desarrollo de una reelaboración contemporánea del pensar respectivo, la cual requiere de tal develamiento para su despliegue.

Específicamente , un recorrido interpretativo en torno a sus elaboraciones de la afectividad, la comunidad, el deseo y las figuras de alteridad no suficientemente tematizadas en tanto tales, como por ejemplo la corporeidad, la animalidad, el horizonte del porvenir del pensar, el silencio, incluso en su inscripción implícita en el devenir-camino de su método de análisis ( articulado en diálogo con recepciones y reelaboraciones contemporáneas), puede permitir una profundización de estos planteamientos en las constelaciones implícitas de su teoría de la ipseidad.

Por otra parte, si la modalidad de interpretación y lectura que se desprende de la propia experiencia del pensar de Heidegger, se caracteriza por su movilidad dinámica y por una aprehensión con cierto tono holístico, entonces tanto el abordaje de temas o relaciones en su obra, como en problematizaciones contemporáneas afines a las cuestiones de identidad, procesos de subjetivación , alteridad, lenguaje , comunicación y tecnología , pueden ampliar su perspectiva a partir de una modalidad de aprehensión y del pensar que mantenga en constante revisión : sus períodos estáticos y dinámicos, sus segregaciones o ensambles conceptuales, las relaciones consteladas entre su despliegue temporal, el contexto situacional de significación , la comprensión y los conceptos respectivos, entre otros.

En segundo lugar, considerando las recepciones y continuidades contemporáneas, los abordajes de los discursos teóricos respectivos también requieren un examen atento de sus bases lingüísticas y semánticas, en lo que respecta a las relaciones entre las tematizaciones a las que remiten y las relaciones con el lenguaje que evidencian. En este marco, entendemos relevante cotejar la modalidad discursiva en correlato con el campo de estudio, simultáneamente a toda investigación de contenido. Tal examen puede ofrecer elementos para distinguir: en general, su 
potencial transicional $\mathrm{y}$ dinámico para el pensamiento contemporáneo $\mathrm{y}$, en particular, las conceptualizaciones y significaciones que evidencien pretensiones de aislamiento, externalidad, totalización o clausura del campo semántico en tales discursos y elaboraciones.

Asimismo, tales requerimientos pueden permitir reconocer condiciones más adecuadas para las modalidades de investigación que busquen llevar a cabo tal empresa. En este sentido, los abordajes interdisciplinares y colectivos, que logren articular diversas orientaciones discursivas y de enunciación, pueden ofrecer un mayor alcance y pertinencia al respecto.

Finalmente, en el marco de los debates contemporáneos en torno a los agenciamientos identitarios y de género, así como también de los análisis críticos sobre los procesos y prácticas políticas de subjetivación y sujeción, un examen que no desatienda la alteridad inmanente del discurso desde el que se enuncia y de los vínculos dinámicos con la posición de enunciación y de la narratividad, junto al abordaje contextual-situacional de las prácticas respectivas, probablemente permita dinamizar la comprensión de los procesos políticos y sociales de ipseidad, en el marco de agenciamientos que se articulan en los umbrales de aquellas tradiciones obstinadas en conjurar la alteridad, el diferimiento y la multiplicidad de los cuales, tales tradiciones ,también forman parte. A modo de ejemplo, proponemos dos articulaciones posibles:

Por un lado, abordar pormenorizadamente los análisis, supuestos y la práctica implícita en la obra de Derrida, considerándolos en el marco de una experiencia del pensar y partiendo de una hipótesis de continuidad y profundización con nuestros recorridos, puede permitir abrir horizontes para tal dinamización comprensiva, correlativa con dichos agenciamientos.

Por otro, algunas discusiones contemporáneas en el psicoanálisis, atendiendo su metodología y perspectiva sobre el lenguaje en el complejo ipseidad-alteridad, pueden proporcionar elementos de apertura para estas dilucidaciones del campo de las cuestiones referidas a la condición humana en sus relaciones ineludibles con lo Otro. En especial, a partir de una articulación con estos recorridos, evaluando una posible continuidad y/o ruptura con el método fenomenológico y sus horizontes respectivos, así como también entre la modalidad experiencial singular de tal práctica y aquella que se despliega implícitamente en el discurso y el pensar de Heidegger .

Con estas perspectivas, el recorrido del pensamiento de Heidegger que hemos analizado, revela una vez más su carácter polifónico, en un diálogo que se avizora como interminable. 


\section{Referencias Bibliográficas}

\section{A.-De Heidegger}

- HEIDEGGER, Gesamtausgabe (GA), Frankfurt a. M., Editor Principal: Wilhelm-Friedrich von Herrmann. Varios editores para diferentes volúmenes de la serie. Fráncfort del Meno: Vittorio Klostermann. Edición: De 1975 al presente. 102 volúmenes proyectados. Aproximadamente 96 volúmenes publicados hasta la fecha.

- HEIDEGGER, Briefausgabe (BA), Friburgo/Munich: Alber, Eds: Alfred Denker y Holger Zaborowski, Edición: 2010 al presente.45 volúmenes proyectados. Aproximadamente 10 volúmenes ya publicados.

- (1910-1976) Aus der Erfahrung des Denkens, ed. H. Heidegger. 2002[T.C. :Experiencias del pensar (1910-1976), Madrid, Abada,2014, trad. :Francisco de Lara] (GA13) 
- (1913), Die Lehre vom Urteil im Psychologismus. Ein kritisch-positiver Beitrag zur Logik, in Frühe Schriften (1912-1916), ed. F.-W. von Herrmann, 1978 (GA 1)

- (1915), Die Kategorien und Bedeutungslehre des Duns Scotus, in Frühe Schriften (19121916), ed. F.-W. von Herrmann, 1978 (GA 1)

- (1919), Zur Bestimmung der Philosophie. 1. Die Idee der Philosophie und das Weltanschauungsproblem (Kriegsnotsemester 1919), ed. B. Heimbüchel, 1999[T.C.: La idea de la filosofía y el problema de la concepción del mundo, Barcelona, Herder, 2005, Trad: Jesús Adrian Escudero] (GA 56/57)

- (1919-1920), Grundprobleme der Phänomenologie (Winter semester 1919/20), ed. H.-H. Gander, 1992(GA 58)

- (1919-1921), Anmerkungen zu Karl Jaspers »Psychologie der Weltanschauungen«, in Wegmarken (1919-1961), ed. F.-W. von Herrmann, 2004[T.C.: Anotaciones a la Psicología de las visones del mundo de Karl Jaspers, en Hitos, Madrid, Alianza, 2007, trad.: Helena Cortés y Arturo Leyte] (GA 9)

- (1919-1961), Wegmarken[Trad. castellana, Hitos, Madrid, Alianza, 2007, trad.: Helena Cortés y Arturo Leyte] (GA 9)

- (1920), Phänomenologie der Anschauung und des Ausdrucks. Theorie der philosophischen Begriffsbildung (Summer semester 1920), ed. C. Strube, 1993 (GA 59)

- (1920-1921), Phänomenologie des religiösen Lebens. 1. Einleitung in die Phänomenologie der Religion (Semestre d'hiver 1920/21), ed. M. Jung et T. Regehly,1995 [ T.C.: Introducción a la fenomenología de la religión, Madrid,Siruela,2005,Trad.: Jorge Uscatescu] (GA 60)

- (1921-1922), Phänomenologische Interpretationen zu Aristoteles zu Ontologie (Anzeige der hermeneutischen Situation) (summer semester 1922), ed. G. Neumann, 2005. [T.C.: Interpretaciones fenomenológicas sobre Aristóteles. Indicación de la situación hermenéutica (Informe Natorp), Madrid, Trotta, 2002, Trad: Jesús Adrian Escudero] (GA62)

- (1923) Ontologie. Hermeneutik der Factizität. [Trad. cast. Ontología. Hermenéutica de la facticidad, Madrid, Alianza, 2008] (GA 63)

- (1923-1924), Einführung in die phänomenologische Forschung (Winter semester 1923/24), ed. F.-W. von Herrmann[T. C. : Introducción a la investigación fenomenológica, Madrid, Síntesis, 2014, Trad. : Juan José García Norro] (GA 17)

- (1924), Der Begriff der Zeit, ed. F.-W. von Herrmann, 2004[Trad. cast. El concepto de tiempo ,Herder, Barcelona , 2008] (GA64)

- (1925), Wilhelm Diltheys Forschungsarbeit und der gegenwärtige Kampft um eine historische Weltanschauung (Kasseler Vorträge 1925), Nachschrift von Walter Bröcker. In: 
Dilthey-Jahrbuch für Philosophie und Geschichte der Geisteswissenschaften, Bd. 8/1992-1993 (pp. 143-180) [T.C. : El trabajo de investigación de Wilhelm Dilthey y la actual lucha por una concepción histórica del mundo (Conferencias de Kassel,1925), en Tiempo e historia , Madrid, Trotta ,2009 (pp.39 ss.), Trad. : Jesús Adrian Escudero] (GA80)

- (1925-6), Logik. Die Frage nach der Wahrheit (Winter semester 1925/26), ed. W. Biemel, 1995 [T.C.: Lógica. La pregunta por la verdad, Alianza Editorial, Madrid, 2004, trad. J. A. Ciria] (GA 21)

- (1926),Die Grundbegriffe der antiken Philosophie(Sommersemester 1926) Ed.: Franz-Karl Blust, 2004.[TC.: Conceptos fundamentales de la filosofia antigua, Waldhuter Editores, Buenos Aires, 2014, trad.: Germán Jiménez] (GA 22)

- (1927a), Sein und Zeit (Trad. cast. Ser y Tiempo, Santiago, Ed. Universitaria de Chile, 1997 , Trad. J.E. Rivera ; Ser y tiempo , Buenos Aires , FCE , 2000 , trad. J. Gaos) (GA 2)

- (1927b), Die Grundprobleme der Phänomenologie [T.C:: Los problemas fundamentales de la fenomenología, Madrid, Trotta, 2000] (GA 24)

- (1928), Metaphysische Anfangsgründe der Logik im Ausgang von Leibniz (Summer semester 1928), ed. K. Held, 1990[T.C.: Principios metafísicos de la lógica, Madrid, Sintesis, 2014,trad.:Juan José García Norro] (GA 26)

- (1928-1929), Einleitung in die Philosophie (Winter semester 1928/29), ed. O. Saame et I. Saame-Speidel, 2001 [T.C. :Introducción a la filosofía, Madrid, Cátedra,2001, Trad.: Manuel Jiménez Redondo] (GA 27)

- (1929a), Kant und das Problem der Metaphysik [Trad. cast. : Kant y el problema de la metafisica, México, FCE, 1996) (GA, 3)

- (1929b), Vom Wesen des Grundes, in Wegmarken (1919-1961), ed. F.-W. von Herrmann, 2004[T.C.: De la esencia del fundamento , en Hitos , Madrid, Alianza, 2007, trad.: Helena Cortés y Arturo Leyte] (GA 9)

- (1929c), Was ist Metaphysik? , in Wegmarken (1919-1961), ed. F.-W. von Herrmann, 2004, [Trad cast.: ¿Qué es metafisica?, en Hitos, Madrid, Alianza, 2007 trad.: Helena Cortés y Arturo Leyte] (GA 9)

- (1929-30), Die Grundbegriffe der Metaphysik. Welt - Endlichkeit - Einsamkeit (Winter semester 1929/30), ed. F.-W. von Herrmann, 2004 [T.C.: Los conceptos fundamentales de la metafísica. Mundo, finitud, soledad, t, Alianza Editorial, Madrid, 2007, Trad. J. A. Ciria Cosculluela] (GA 29/30)

- (1930a), Vom Wesen der menschlichen Freiheit. Einleitung in die Philosophie (GA 31).

- (1930b), Vom Wesen der Wahrheit, in Wegmarken (1919-1961), ed. F.-W. von Herrmann, 2004[T. C.: De la esencia de la verdad, en Hitos, Madrid, Alianza, 2007 trad.: Helena Cortés y Arturo Leyte] (GA 9) 
- (1931-1938), Überlegungen II-VI (Schwarze Hefte 1931-1938), Vittorio Klostermann, Frankfurt am Main, Ed. de Peter Trawny, 2014 [T.C.: Cuadernos negros, (1931-1938). Reflexiones II-VI, Ed. Trotta, Madrid, 2015, Trad.: Alberto Ciria] (GA 94)

- (1933), Die Selbstbehauptung der deutschen Universität (27 May. 1933) en Reden und andere Zeugnisse eines Lebensweges (1910-1976), ed. H. Heidegger, Frankfurt a. M., 2000, pp.107-17. [T.C.: La autoafirmación de la Universidad Alemana. El Rectorado 1933-1934. Madrid , Tecnos , 1996 , Trad. Ramón Rodríguez] (GA 16)

- (1933), Discursos y alocuciones recogidos por SCHNEEBERGER, Guido (1962) Nachlese zu Heidegger. Dokumente zu seinem Leben und Denken, Berna.

• (1934-1935), Hölderlins Hymnen “Germanien” und “Der Rhein”(GA 39)

- (1935), Einführung in die Metaphysik [Trad. castellana : Introducción a la metafísica, Barcelona, Gedisa , 2003 , Trad. Angela Ackermann Pilári ] (GA 40)

- (1936-1938), Beiträge zur Philosophie (Vom Ereignis) [T.C.: Aportes a la filosofía. Acerca del Evento, Buenos Aires, Biblos, 2006, Trad. Dina V. Picotti] (GA 65)

- (1936-1939), Nietzsche I, ed. B. Schillbach, 1996 [T.C.: Nietzsche I, Barcelona, Destino, 2000, Trad.J.L. Vermal] (GA 6.1)

- (1936-1946), Holzwege, Frankfurt a. M., Vittorio Klostermann, 1957 [T.C.: Caminos de bosque, Madrid, Alianza, 1996, Trad.: Helena Cortés y Arturo Leyte] (GA 5)

- (1936-1953), Vorträge und Aufsätze [Trad. castellana Conferencias y artículos, Ediciones del Serbal, Barcelona, 2001. T.C.: Eustaquio Barjau ] (GA 7)

- (1936-1968), Erläuterungen zu Hölderlins Dichtung [T.C.: Aclaraciones a la poesía de Hölderlin, Madrid, Alianza, 2005, Trad. Helena Cortés y Arturo Leyte] (GA 4)

- (1937-1938), Grundfragen der Philosophie. Ausgewählte "Probleme" der "Logik" (Winter semester 1937/38), ed. F.-W. von Herrmann, 1992.[T.C. : Preguntas fundamentales de la filosofía. 'Problemas' escogidos de la 'lógica', Departamento de filosofía de la Universidad de Chile ,2006, Trad.: Pablo Sandoval Villarroel] (GA 45)

- (1938-1939a), Besinnung[T.C.: Meditación, Buenos Aires, Biblos, 2006, Dina V. Picotti ] (GA 66)

- (1938-1939b), Hegel: 1. Die Negativität [T.C.: Hegel. La Negatividad. Una Confrontación con Hegel Desde el Planteo de la Negatividad (1938-1941). Dilucidación de la 'Introducción' a la Fenomenología del Espíritu de Hegel (1942). Buenos Aires: Almagesto. 2000. Trad. D. Picotti.] ( GA 68)

- (1938-1939c), Überlegungen VII-XI (Schwarze Hefte 1938/39), ed. P. Trawny, 2014 (GA 95) 
- (1939-1941), Überlegungen XII-XV (Schwarze Hefte 1939-1941), ed. P. Trawny, 2014 (GA 96)

- (1939-1946), Nietzsche II ed. B. Schillbach, 1997 [T.C.: Nietzsche II, Barcelona, Destino, 2000, Trad.J.L. Vermal] (GA 6.2)

- (1941-1942a), Hölderlin Hymne “Andenken”(GA 52)

- (1941-1942b), Das Ereignis, ed. F.-W. von Herrmann, 2009(GA71).

- (1942), Hölderlin Hymne “Der Ister” (GA 53)

- (1942-3), Parménides (Winter semester 1942/43), ed. M. S. Frings, 1992.[T.C.: Parménides, Madrid, Akal,2005,Trad.:Carlos Másmela] (GA54)

- (1943-1944), Heraklit. 1. Der Anfang des abendländischen Denkens (Summer semester 1943) / 2. Logik. Heraklits Lehre vom Logos (Summer semester 1944), ed. M. S. Frings, 1994, [T.C.: Heráclito, Ed. El hilo de Ariadna, Buenos Aires, 2012.Trad. de Carlos Másmela] (GA 55)

- (1944-1945), Zur Erörterung der Gelassenheit. Aus einem Feldweggespräch über das Denken, in Aus der Erfahrung des Denkens (1910-1976), 2002, pp57-74[T. C.: Debate en torno al lugar de la serenidad (de un dialogo sobre el pensamiento en un camino de campo), en Serenidad, Barcelona, Ed. Del Cerbal, 1994, pp.31-82, trad. Yves Zimmerman] (GA 13)

- (1945a), Der Rektorat 1933/34. Tatsachen und Gedanken, en Reden und andere Zeugnisse eines Lebensweges (1910-1976), ed. H. Heidegger, Frankfurt a. M., 2000, pp.373-94. [Trad. castellana: La autoafirmación de la Universidad Alemana. El Rectorado 1933-1934. Madrid, Tecnos , 1996 , Trad. Ramón Rodríguez] (GA 16)

- (1945b), Die Armut, en Heidegger Studies, vol. 10, 1994 [Trad. Castellana: La Pobreza, Buenos Aires, Amorrortu, 2006. Trad. . Irene Agoff].

- (1946), Brief über den Humanismus, in Wegmarken (1919-1961), ed. F.-W. von Herrmann, 2004[T. C.: Carta sobre el 'humanismo', en Hitos, Madrid, Alianza, 2007 trad.: Helena Cortés y Arturo Leyte] (GA 9)

- (1947), Aus der Erfahrung des Denkens, in Aus der Erfahrung des Denkens (1910-1976), ed. H. Heidegger. 2002, pp.75-86 [T.C.: Desde la experiencia del pensar. Debajo y a través de los altos abetos, Bs. As., Vortice,2014,trad.:Claudio Cesar Calabrese] (GA13)

- (1950-1959), Unterwegs zur Sprache [T. C.: De camino al Habla, Barcelona, Serbal, 2002 , trad. Ives Zimmermann] (GA 12)

- (1951-1952), Was heisst Denken? [T.C.: Qué significa pensar?, Ed. Nova, Buenos Aires, 1964. Trad. Haraldo Kahnemann.] (GA 8)

- (1953), Die Frage nach der Technik, in Vorträge und Aufsätze (1936-1953), ed. F.-W. von Herrmann, 2000 [T.C.: Conferencias y artículos, Ediciones del Serbal, Barcelona, 2001. Trad. Eustaquio Barjau] (GA 7) 
- (1954a), Wissenschaft und Besinnung, in Vorträge und Aufsätze (1936-1953), ed. F.-W. von Herrmann, 2000(GA 7)

- (1954b), Aletheia (Heraklit, Fragment 16), in Vorträge und Aufsätze (1936-1953), ed. F.W. von Herrmann, 2000(GA 7)

- (1955), Was ist das - die Philosophie? in Identität und Differenz (1955-1957), ed. F.-W. von Herrmann, 2006, pp. 7-26 [ T. C. : ¿Qué es la filosofía?, Barcelona, Herder, 2004, Trad. : Jesús Adrian escudero] (GA11)

- (1955-1956), Der Satz vom Grund ed. P. Jaeger, 1997 [T. C. La proposición del fundamento, Barcelona, Serbal,2003] (GA10)

- (1955-1957), Identität und Differenz [T. C.: Identidad y diferencia, Barcelona, Anthropos,2008. trad. Helena Cortes y Arturo Leyte ] (GA 11)

- (1957-1958), Das Wesen der Sprache, in Unterwegs zur Sprache (1950-1959), ed. F.-W. von Herrmann, 1985,pp.147-204 [ T.C.: La esencia del habla, en De camino al Habla, Barcelona, Serbal, 2002,pp.141-194] (GA 12)

- (1959), Gelassenheit, Pfullingen [DE]: Günther Neske, 1959, in Reden und andere Zeugnisse eines Lebensweges (1910-1976), ed. H. Heidegger, 2000, pp.517-29[T. C.: Serenidad, Barcelona, Ed. Del Cerbal, 1994. trad. Yves Zimmermann ] (GA16)

- (1959-69), Zollikoner Seminare [ T. C. : Seminarios de Zollikon, Barcelona, Herder, 2014, trad.: Ángel Xolocotzi Yáñez] (GA 89)

- (1962a), Zeit und Sein, in Zur Sache des Denkens, pp.5-30[Trad. castellana, Tiempo y ser, en Filosofía, Ciencia y técnica, Editorial universitaria, Santiago de Chile, 1997, pp.273-304, Trad.: Francisco Soler] (GA 14)

- (1962b), Überlieferte Sprache und technische Sprache (Vortrag auf dem Lehrgang für Gewerbeschullehrer auf der Comburg 18. Juli 1962), prevista para Vorträge (1915-1967), publicada en Switzerland: Erker-Verlag, ed. H. Heidegger, St. Gallen 1989 [T. C.: Lenguaje tradicional y lenguaje técnico, Trad.: Manuel Jiménez Redondo, Recuperado el 20/02/17 de: https://docs.google.com/file/d/0Bx6x9vlHlfTONzEyZjExNDItMmY0Mi00Zjg3LThmYmM tMDhkZGMxN2JmMDNj/edit?hl=en] (GA80)

- (1963), Mein Weg in die Phänomenologie, in Zur Sache des Denkens[T.C.: Tiempo y ser, Madrid, Tecnos, 2000, trad.: Manuel Garrido] (GA 14)

- (1962-1964), Zur Sache des Denkens, ed. F.-W. von Herrmann, 2007 (GA 14)

- (1966), Spiegel-Gesprächt mit Martin Heidegger, in Reden und andere Zeugnisse eines Lebensweges (1910-1976), ed. H. Heidegger, 2000, pp.652-63. [T.C.: Política, Técnica y filosofía (entrevista de Der Spiegel) , en Revista de la Universidad Nacional , 1969, pp. 4370, Trad.: Fredy Téllez y Elviera Bobach y en La autoafirmación de la Universidad Alemana, Madrid, Tecnos , 1996 pp. 51 ss., Trad. Ramón Rodríguez ] (GA 16) 
- (2005), Mein liebes Seelchen! Briefe Martin Heideggers an seine Frau Elfride, ed. Gertrud Heidegger, Munich: Deutsche Verlags-Anstalt[T. C.: ";Alma mía!': cartas de Martin Heidegger a su mujer Elfride, 1915-1970, Manantial, Bs. As. Trad.: Sebastian Sfriso] (Briefausgabe-BA- 1.2)

- HEIDEGGER, Martin y JASPERS, Karl (1920-1963), Briefwechsel 1920-1963, Vitoria Klostermann, Frankfurt a. M. / R. Piper, München, 1990. , Ed.: Walter Biemel y Hans Saner [T.C.: Correspondencia (1920-1963), Madrid, Síntesis, 2003. Trad. : Juan José García Norro] (BA II.2)

- HEIDEGGER, Martin y ARENDT, Hannah, Briefe 1925-1975 (Briefwechsel mit Hannah Arendt), U. Ludz (ed.). Fráncfort del Meno: Klostermann, 1998 [T. C.: Correspondencia (1925-1975) y otros documentos de los legados, editorial Herder, Barcelona , 2000] (BA II.24 )

- HEIDEGGER, Martin y RICKERT, Heinrich (2002), Briefe 1912-1933. Fráncfort del Meno: Klostermann (BA- II.16).

\section{b.- De Husserl:}

- HUSSERL, Edmund (1952[1913]), Ideen zur einer reinen Phänomenologie und phänomenologischen Philosophie II: Phänomenologische Untersuchungen zur Konstitution. Ed. Marly Biemel. La Haya, Netherlands: Martinus Nijhoff [T.C.: Ideas relativas a una fenomenología pura y a una filosofía fenomenológica II : Investigaciones fenomenológicas sobre la constitución, México, FCE,2003, Trad: Zirión, Antonio] [Husserliana (Hua) 4]

- (1954[1936]), Die Krisis der europäischen Wissenschaften und die transzendentale Phänomenologie, Herausg. V. W. Biemel, La Haya, Martinus Nijhoff [T.C.: La crisis de las ciencias europeas y la fenomenología trascendental, Bs. As. Prometeo, 2008, trad. Julia Iribarne] (Hua 6)

- (1956 [1923-4]), Erste Philosophie (1923/4). Erste Teil: Kritische Ideengeschichte. [First philosophy (1923/24). First part: the critical history of ideas.] Ed. Rudolf Boehm. La Haya, ,Martinus Nijhoff.(Hua 7) 
- (1959 [1923-4]), Erste Philosophie (1923/4). Zweiter Teil: Theorie der phänomenologischen Reduktion. [First philosophy (1923/24). Second part: theory of phenomenological reduction.].La Haya, ,Martinus Nijhoff.(Hua 8)

- (1968[1925]), Phänomenologische Psychologie .Vorlesungen Somersemester 1925, Herausg. V. W. Biemel, La Haya, Martinus Nijhoff (Hua 9).

- (1973[1931]), Cartesianische Meditationen und Pariser Vorträge, Ed. S. Strasser. La Haya, Netherlands: Martinus Nijhoff [T.C.: Meditaciones Cartesianas, Madrid, Ediciones Paulinas, 1979, Trad. : Mario Presas] (Hua 1)

- (1974[1929]), Formale und Transzendentale Logik. Versuch einer Kritik der Logischen Vernunft, Saale, Niemeyer. [T.C.: Lógica Formal y Lógica Trascendental. Ensayo de una Crítica de la Razón lógica,UNAM,2009, trad.: Luis Villoro] (Hua 17)

- (1975 [1900-1901]), Logische Untersuchungen. I. Prolegomena zur reinen Logik, Ed. E. Holenstein. La Haya, Netherlands: Martinus Nijhoff [T. C.: Investigaciones lógicas I, Alianza, Bs. As. 1985, Trad: Morente-Gaos] (Hua 18)

- (1984 [1900-1901]), Logische Untersuchungen. II. Untersuchungen zur Phänomenologie und Theorie der Erkenntnis, Ed. Ursula Panzer, La Haya, Netherlands: Martinus Nijhoff[T. C.: Investigaciones lógicas II, Alianza, Bs. As. 1985, and Trad: Morente-Gaos] (Hua 19)

- (1988 [1913]), Ideen zu einer reinen Phänomenologie und phänomenologischen Philosophie I: Allgemeine Einfuhrung in die reine Phänomenologie, 2. Halbband: Ergänzende Texte, Ed. Karl Schuhmann. La Haya, Netherlands: Martinus Nijhoff, (1912--1929) [T.C.: Ideas relativas a una fenomenología pura y una filosofia fenomenológica, México, FCE, 1949, Trad.: José Gaos] (Hua 3-2)

- (1990[1925]) , Der Encyclopcedia Britannica Artikel, im Phänomenologische Psychologie, Vorlesungen Sommersemester 1925, ed. de Walter Biemel Martinus Nijhoff, La Haya, 1968 [T.C.: El artículo de la Encyclopaedia Británica, México , UNAM, Trad.: Antonio Ziron ] (Hua 9)

- (1994) Briefwechsel. Vol. III: Die Freiburger Schule, Dordrecht/Boston/Londres.

- $\quad$ (2008 [1916-37]) Die Lebenswelt. Auslegungen der vorgegebenen Welt und ihrer Konstitution. Texte aus dem Nachlass (1916-1937) Ed. Rochus Sowa. New York: Springer (Hua 39)

- (2014[1893-1917]) Zur Phänomenologie des inneren Zeitbewusstseins (1893-1917). Hrsg. von Rudolf Boehm. Nachdruck der 2. verb. Auflage. 1969. [ T.C.: Fenomenología de la conciencia inmanente del tiempo, Bs. As. , Prometeo ] (Hua 10) 


\section{c.- Diálogos y resonancias respecto a cuestiones consideradas en Heidegger.}

- AA.VV (1990-1991), Zur philosophischen Aktualität Heideggers, Frankfurt a. M., Vittorio Klostermann, Tomo I: Philosophie und Politik, Tomo II: Im Gespräch der Zeit.

- AA. VV. (1991), Heidegger la voz de tiempos sombríos, Barcelona, Serbal.

- ACEVEDO, Jorge (1999), Heidegger y la época técnica, Santiago, Editorial Universitaria de Chile.

- ADORNO, Theodor W. (1971), Dialéctica negativa, Madrid, Taurus.

- ADORNO, Theodor W. (1983) Terminología filosófica I, Madrid, Taurus. Trad.: Ricardo Sánchez Ortiz de Urbina.

- ADORNO, Theodor W. (1984), La ideología como lenguaje (La jerga de la autenticidad), Madrid, Taurus.

- ADORNO, Theodor W. y HORKHEIMER, Max (1987), Dialéctica del Iluminismo, Buenos Aires, Sudamericana.

- ADORNO, Theodor W. (2005), Dialéctica negativa. La jerga de la autenticidad, Madrid, Akal.

- ADRIAN, Jesús (2009), El lenguaje de Heidegger. Diccionario filosófico 1912-1927, Barcelona, Herder.

- ADRIAN, Jesús (2010a), Heidegger y la genealogía de la pregunta por el ser. Una introducción temática y sistemática de su obra temprana, Barcelona, Herder, pp. 426-525.

- ADRIAN, Jesús (2010b), Ser y tiempo y el imperativo de una estética de la existencia: el Dasein como una obra de arte, en Revista de Humanidades, N. 21, Junio, pp.9-29.

- ADRIAN, Jesús (2011a), El joven Heidegger y los postulados de los prepuestos metodológicos de la fenomenología hermenéutica, en Thémata. Revista de Filosofía, 44, pp. 212-230.

- ADRIAN, Jesús (2011b), Heidegger, lector de la retórica aristotélica, en Diánoia, vol. 56, N. 66, Mayo: pp. 3-29.

- ADRIAN, Jesús (2011c), Traducir a Heidegger, en Investigaciones Fenomenológicas, n. 8, pp. 89-95.

- ADRIAN, Jesús (2012), "Ser y tiempo”: ¿una ética del cuidado?, en Aurora, N. 13, pp.74-9.

- AESCHIMANN, Erick, (2013), Cahiers noirs: vers une nouvelle affaire Heidegger, en Le Nouvel Observateur (7/12/13), Recuperado el 15/01/17 de: http://tempsreel.nouvelobs.com/culture/20131206.OBS8603/cahiers-noirs-vers-une-nouvelleaffaire-heidegger.html. 
- AgUt I MARTINEZ, Vincent (2001), Para una teoría personalista de la acción, en Rev. Recerca, N. 31, pp.109-121.

- AltWEGG, Jürg (2013), Antisemitismus bei Heidegger. Ein Debakel für Frankreichs Philosophie en Frankfurter Allgermeine Zeischrift ( 13/12/2013), Recuperado el 15/01/17 de: http://www.faz.net/aktuell/feuilleton/buecher/themen/antisemitismus-beiheidegger-ein-debakelfuer-frankreichs-philosophie-12710158.html

- ANDERS, Günther, ARENDT, Hannah, JONAS, Hans, LÖWITH, Karl, STRAUSS, Leo (2008), Sobre Heidegger. Cinco voces judias, Buenos Aires, Manantial.

- APEL, Karl-Otto (1967), “Wittgenstein y Heidegger, la pregunta por el sentido del ser y la sospecha de falta de sentido en la metafísica”, en Diánoia, México, pp. 111-148.

- APEL, Karl-Otto, (1976[1985]) La transformación de la filosofía, Madrid, Taurus.

- ARENDT, Hannah. (1970), Martin Heidegger, octogenario, en Revista de Occidente, N. 84, Madrid, pp.255-271.

- ARENDT, Hannah. (1993), La condición humana, Barcelona, Paidós.

- ARRESE IGOR, Héctor (2011), La ética de la autenticidad en ser y tiempo, en Eidos: Revista de Filosofía de la Universidad del Norte, núm. 15, julio-diciembre, pp. 118-141.

- ASTRADA, Carlos (1933), Heidegger y Marx, En Cursos y Conferencias, Buenos Aires: Año II $\mathrm{N}^{\mathrm{o}} 10$, Abril.

- ASTRADA, Carlos (1952), La revolución existencialista. Hacia un humanismo de la libertad, La Plata: Nuevo Destino.

- ASTRADA, Carlos (1964), El mito gaucho, Bs. As., Cruz del sur.

- ASTRADA, Carlos (1970), La dialéctica en la filosofía de Hegel. Buenos Aires: Kairós.

- ASTRADA, Carlos (2007), Tierra y figura, Bs. As. , Ed. Las Cuarenta.

- AURENQUE, Diana (2016), Martin Heidegger y Los cuadernos negros: más que la mera reactivación de un mero debate, en Alpha, N.42, Osorno, Julio, pp.235-51.

- AZPIUNZA, Jaime (2001), El significado (en castellano) del "Dasein" heideggeriano, en Er: Revista de filosofía, N. 29, pp.71-100.

- BADIOU, Alain (1982[2009]), Teoría del sujeto, Buenos Aires, Prometeo.

- BADIOU, Alain (1988), El ser y el acontecimiento, Bs. As., Manantial.

- BADIOU, Alain (1999), El estatuto filosófico del poema después de Heidegger, en Imago Agenda, n.29, Mayo, Trad.: Carlos Torres. 
- BADIOU, Alain (2007), Manifiesto por la filosofia, Buenos Aires, Nueva visión.

- BASSO, Leticia (2014), Aportes para una interpretación de la estructura del Dasein de acuerdo a su carácter bidimensional, en Areté, Vol. 26, N.2, pp.273-93.

- BATAILLE, Georges (1987), La parte maldita, Barcelona, Icaria Editorial.

- BEDOYA RODAS, Carlos (2014a), Ruina y recuperación de la vida: La hermenéutica en el joven Heidegger, en Universitas Philosophica Vol. 31, N. 62, pp.95-112, Recuperado el 15/01/17,de:

http://revistas.javeriana.edu.co/index.php/vniphilosophica/article/viewFile/10646/8813

- BEDOYA RODAS, Carlos (2014b), El sentido y su origen. Esbozos de una relación de continuidad entre Husserl y Heidegger, en Anuario Colombiano de fenomenología Vol. VIII, Medellín, pp.231-244.

- BERCIANO, Modesto (1991a),El evento (Ereignis) como concepto fundamental de la filosofía de Heidegger, en Acercamiento a la obra de Martin Heidegger, Actas de la sociedad castellanoleonesa de filosofía, Salamanca, pp.91-118.

- BERCIANO, Modesto (1991b), Superación de la metafisica de Martin Heidegger, España, Universidad de Oviedo publicaciones.

- BERCIANO, Modesto (1992), ¿Qué es realmente el “Dasein” en la filosofía de Heidegger?, en Thémata, N.10, pp.435-50.

- BERCIANO, Modesto (2001), La revolución filosófica de Martin Heidegger, Madrid, Biblioteca Nueva.

- BERCIANO, Modesto (2002), Ereignis: La clave del pensamiento de Heidegger, en Thémata. Revista de Filosofía, N.28., pp.47-69.

- BERTORELlO, Adrian (2006), La filosofía de Heidegger como una teoría del sujeto de la enunciación, en Revista LSD (Lenguaje, sujeto, discurso) N. 3, diciembre, pp.36-44.

- BERTORELLO, Adrian (2008) El límite del lenguaje. La filosofía de Heidegger como Teoría de la enunciación, Buenos Aires, Biblos.

- BeRTORELlO, Adrian (2011), La estructura semántica del dasein en Sein und Zeit de M. Heidegger, en Horizontes filosóficos: revista de filosofía, humanidades y ciencias sociales, N. 1, pp.11-21.

- BEUCHOT, M. (2003), Hermenéutica analógica y del umbral, Salamanca, Ed.San Esteban.

- BIEMEL, Walter (1950), Le concept du monde chez Heidegger, París, Vrin.

- BIEMEL, Walter (1968), Husserl. Cuadernos de Royaumont, Buenos Aires, Paidos. 
- BLANCHOT, Maurice (2002), La comunidad inconfesable, Madrid, Arena.

- BLANCO ILARI, Juan (2005), Totalidad de una vida y pregunta práctica fundamental: en torno a la noción de identidad personal en Ernst Tugendhat[en línea] V Jornadas de Investigación en Filosofía, 9-11/12/2004,en Revista de filosofía y teoría política, Anexo 2005, Recuperado el 15/01/17

http://www.memoria.fahce.unlp.edu.ar/trab_eventos/ev.68/ev.68.pdf

- BLANCO ILARI, Juan (2011) Aspectos narrativos de la identidad personal ,Revista Tópicos; Lugar: Santa Fe ; Año: 2011 p. 1 - 32

- BLANCO ILARI, Juan (2016), Significatividad y mundo en los escritos del joven Heidegger, Conjetura, Caxias do Sul; vol. 21 p. $27-57$.

- BOEDER, H. (2003), El límite de la modernidad y el legado de Heidegger, Buenos Aires, Quadratta.

- BONET, José (2015), La antropología como filosofia primera, después de Tugendhat, en Daimon. Revista Internacional de Filosofía, nº 66, pp. 95-108.

- BOSS, Medard (1963), Psychoanalysis and Daseinsanalysis (L. B. Lefebre, Trans.), New York, Basic Books.

- BOSS, Medard (1979), Existential Foundations of Medicine and Psychology (S Conway, Trans.), Nueva York, Jason Aronson.

- BOURDIEU, Pierre (1988), La ontología política de Martín Heidegger, Barcelona, Paidós.

- BROGAN, Walter (1990), Heidegger and Aristotle. Dasein and the Question of Practical Life, Crisis in Continental Philosophy. Eds. Arleen Dallerry y Charles Scott. Albany: State University of New York Press, pp. 137-146.

- BUREN, John (1994), The Young Heidegger. Rumor of the Hidden King. Bloomington/ Indianápolis: Indiana University Press, Bloomington/Indianápolis.

- BURLANDO, Giannina (2015), Un análisis interno del dasein ontológico de Heidegger: críticas externas de Edith Stein, en Mirabilia: Revista Eletrônica de História Antiga e Medieval, $N^{o}$. 20, (Art, Criticism and Mysticism), pp.365-82.

- BUTIERREZ, Luis (2016), Los conspiradores del lenguaje. Políticas y estrategias del discurso en las elaboraciones de Heidegger y Derrida, en Revista Diferencia(s), año 3, N. 2, Noviembre, pp.41-61.

- CALLE ZAPATA, Mauricio (2016), Martin Heidegger y el intento por pensar la esencia de la técnica como una reorientación en el ethos. Revista Perseitas, 4(1), pp. 41-61.

- CARAVEDO DURAN, Joan (2014), El “motivo cartesiano” en Heidegger y Husserl: salida de la familiaridad y encuentro con el sí-mismo anónimo, en Factótum, N. 11, pp.67-80. 
- CARDINALli, Ida (2015), Heidegger: o estudo dos fenômenos humanos baseados na existência humana como ser-aí (Dasein), en revista Psicologia USP, V. 26, N. 2, pp. 249-58.

- CARrera AizPitarte, Luciana (2012) Parente, Diego. Del órgano al artefacto. Acerca de la dimensión biocultural de la técnica. La Plata: Edulp, 2010, 257 pp. , reseña en Revista de Filosofia y Teoría Política (43):133-136.

- CARRERA AIZPITARTE, Luciana (2014), La crítica de Heidegger a la noción de sujeto: un análisis a partir de la incidencia de su reflexión sobre la técnica y el lenguaje. EN: Karczmarczyk, Pedro, comp. El sujeto en cuestión: Abordajes contemporáneos La Plata: Universidad Nacional de La Plata. Facultad de Humanidades y Ciencias de la Educación, pp.1442.

- CARRERA AIZPITARTE, Luciana (2015), El giro práctico en la búsqueda del fundamento: Interpretaciones a partir de la hermenéutica filosófica de Martin Heidegger, en X Jornadas de Investigación en Filosofía, 19 al 21 de agosto, Ensenada, Argentina.

- CARRASCO PIRARD, Eduardo (1996), Heidegger y la ética, en Revista de filosofía N. 47, pp.73-87, Facultad de filosofía y humanidades, Universidad de Chile.

- CASTELLANOS, Rafael (2006), Hermeneútica y deconstrucción, Rev. Ideas y valores n. 130, Bogotá, Colombia.

- CATAldo SANGUINETTI, Gustavo (2013), Existencia e historicidad. El problema de la identidad en Martin Heidegger, en Ideas y valores, V. 62, N. 153, diciembre, pp. 31-44.

- CEREZO GALAN, Pedro (1984), La voluntad de la aventura. Aproximamiento crítico al pensamiento de Ortega y Gasset, Barcelona, Ariel.

- CEREZO GALAN, Pedro (1997),Metafísica, técnica y humanismo, en Heidegger o el final de la filosofía, Cordon y Rodríguez (comp), Ed. Complutense, Madrid, pp.59ss

- CHAPELLE, Albert (1962), L'ontologie phénoménologique de Heidegger. Un commentaire de «Sein und Zeit», París, Éditions Universitaires.

- CHILLON LORENZO, José (2016), Heidegger y lo insondable del pensar, en LOGOS. Anales del Seminario de Metafísica, Vol. 49, pp. 21-42

- CHIODI, Pietro (1952), L'ultimo Heidegger, Torino, Taylor.

- CONESA, Dolores (2008), Una ampliación ética de la racionalidad teórica, en Pensamiento y Cultura, V. 11-2, diciembre, pp. 303-12.

- COLL, Josep (1990), La intersubjetividad en Heidegger, en Taula, n.13-14, pp.191-207.

- CORTES-BOUSSAC, Andrea (2006), Heidegger-en-Latinoamérica, en Civilizar. Ciencias Sociales y Humanas, N. 10, junio, pp. 1-28. 
- CORTES-BOUSSAC, Andrea (2007), La Cuestión Hombre-Tecnología: Dasein-en-las Redes de las Nuevas Tecnologías, en Civilizar. Ciencias Sociales y Humanas, V. 7, N. 12, enero-junio, pp. 125-139.

- COURTINE, Jean-François (1990), Heidegger et la phenomenology, Vrin, Paris.

- COURTINE, Jean-François (ed.) (1996), Heidegger 1919-1929. De l’herméneutique de la facticité à la métaphysique du Dasein. París: J. Vrin.

- CRUZ VÉLEZ, Danilo (1970), Filosofía sin supuestos. De Husserl a Heidegger, Buenos Aires, Sudamericana.

- CRUZ VÉLEZ, Danilo (1989), El mito del rey filósofo. Platón, Marx, Heidegger, Bogotá, Planeta.

- DAMASIO Antonio (1995), Descartes' Error. Emotion, Reason and the Human Brain, New York: Avon Books.

- DASTUR, Françoise (2015), La ipseidad: Su importancia en la psicopatología, en Universitas Philosophica, Vol. 32(N. 64), pp. 251-266, ,Recuperado el 15/03/17 en línea: http://dx.doi.org/10.11144/Javeriana.uph32-64.iipp

- DAVID, Guillermo (1999), Carlos Astrada: La larga marcha de la filosofía argentina, en Nombres. Revista de filosofía, año 9, N.13-4, septiembre, Córdoba, pp.67-84.

- DAVIDSON, Donald (1990), De la verdad y de la interpretación. Fundamentales contribuciones a la filosofia del lenguaje, Barcelona, Gedisa.

- DAVILA, Amilcar (2004), Hacia una ontología de la comunidad a partir de Heidegger, en Intuición Revista de filosofía, Vol. 1, N. 1, pp.116-36.

- DE WAELEHENS, Alphonse (1952), La filosofía de Martin Heidegger, Madrid, Consejo Superior de Investigaciones Científicas.

- DILTHEY, W. (1944), El mundo histórico, México, F.C.E.

- DI PEGO, Anabela (2008), Violencia(s) y politica(s). Algunas notas en torno del debate "no matarás", V Jornadas de Sociología de la UNLP, 10, 11 y 12 de diciembre, La Plata, Argentina.

- DORO, Marcelo (2010), Pertinência e alcance da crítica de Tugendhat ao conceito heideggeriano de verdade, en Guairacá (Unicentro) n.26, N. 1, pp.81-104.

- DREYFUS, Hubert L. (2002), Ser-en-el-mundo. Comentarios a la división I de "Ser y tiempo», Santiago de Chile, Ed. Cuatro Vientos.

- DUMMETT, Michael (1991), the Logical Basis of Metaphysics, Cambridge, Mass., Harvard UP. 
- DUQUE, Félix (1993), “Los últimos años de Heidegger”, en PÖGGELER (1990)

- DUQUE, Félix (2002), Los humores de Heidegger (teoría de las tonalidades afectivas), en Atiliano Domínguez (coord.), Vida, pasión y razón en grandes filósofos, Cuenca, Ediciones de la Universidad de Castilla-La Mancha, pp. 323-353.

- DURAN ROJAS, Cristóbal (2015), La auto-afección del otro: Heidegger y el tiempo que demora el sí-mismo, en Revista de Filosofía, Vol.71, pp.53-64.

- ESPERON, Juan Pablo (2016), Heidegger, Deleuze y la diferencia. Aportes para pensar la irrupción de la novedad, en AISTHESIS, N 59, Chile, pp.143-156.

- ESTIÚ, Emilio (1964), "De la vida a la existencia en la filosofía contemporánea", UNLP. FAHCE. Instituto de Filosofía.

- FARÍAS, Víctor (1998[1987]), Heidegger y el nazismo, Santiago de Chile, FCE.

- FARÍAS, Víctor (2010), Heidegger y su herencia: los Neonazis, el neofascismo y el Fundamentalismo Islámico, Madrid, Tecnos.

- FAYE, Emanuel (2009), Heidegger. La introducción del nazismo en la filosofía. En torno a los seminarios inéditos de 1933-1935, Madrid, Akal.

- FERNANDEZ BEITES, Pilar (2009), Ambigüedad en Ser y tiempo: imposibilidad de la existencia propia, en Cuadernos de filosofia latinoamericana, Vol. 30, N. 101, pp.31-57.

- FERRER SANTOS, Urbano (1999), Sobre la identidad de la persona y otras identidades, Thémata, N. 22, pp. 105-112.

- FERRER SANTOS, Urbano (2001) De la autodeterminación del existente a la aceptación del ser en la Analitica existencial heideggeriana, Investigaciones fenomenológicas, $\mathrm{N}^{\mathrm{o}} 3$, SEFEUNED, Madrid, 2001, pp. 179-193.

- FERRY, L., Y RENAUT, A. (2001), Heidegger y los modernos, Buenos Aires, Paidós.

- FIDALGO BENAYAS, Leónides (2013), Ontología del hombre y deconstrucción: Heidegger, Sartre / Derrida, Sloterdijk, en Eikasia, septiembre, pp.105-27.

- FILIPPI, Silvana (2006), Heidegger, la metafísica y el pensamiento posmoderno, en Enfoques, Vol. 18, N.1-2, pp.51-90.

- FUENMAYOR, Ramsés (1994), Modernidad y autenticidad: el no ser siendo de lo moderno, Rev. . Actual n. 28, Universidad de Los Andes, Venezuela.

- GAOS, José (1996), Introducción a El ser y el tiempo de Martin Heidegger, México, FCE. 
- GARCES FERRER, Rocío (2015), Facticidad, afectividad e intencionalidad: la hipótesis hermenéutica del 'New Heidegger'", en Differenz. Revista internacional de estudios heideggerianos y sus derivas contemporáneas, $\mathrm{n}^{\circ} 1$, julio, pp. 47-56.

- GARCIA MARTIN, José (2009), Ser singular, ser social: la invectiva a la alteridad categórica en los Diarios de S.A. Kierkegaard, en Metafísica y persona. Revista sobre filosofía, conocimiento y vida, N.2, Julio-diciembre, pp. 221-32.

- GARRIDO MATURANO, Ángel (1999), El abismo y el tiempo. Elucidación de la noción de abismo y de temporalidad en los Beiträge zur Philosophie de Martin Heidegger, Revista Venezolana de Filosofía N. 36-37, pp. 163-191.

- GARRIDO PERIÑAN, Juan José (2014), Aperturidad e iluminación: el Dasein como ente iluminado. Aportaciones a Sein und Zeit de Martin Heidegger bajo el horizonte del claro del ser, en Eikasia revista de filosofía, diciembre, pp. 205-16.

- GETHMAN-SIEFERT, Annemarie y PÖGGELER, Otto [eds.] (1988), Heidegger und die praktische Philosophie, Frankfurt.

- GIRALT, Paul (1995), ¿ ¿Cómo volver a dar un sentido a la palabra 'Humanismo'?’; Revista de filosofía de México, V.28, N.82.pp.:1-35.

- GOICOCHEA, David (2003), "Heidegger-The Taoists-Kierkegaard”, en Journal of Chinese Philosophy, 30:1, 81-97.

- GONZALEZ, Antonio (2004), Ereignis y actualidad, en Gracia, Diego (Ed.), Desde Zubiri (Col. Filosofía hoy, N.32), Ed. Comares, Granada, pp.103-92.

- GONZALEZ VALERIO, María A. (2003), Rememoración y tradición: La hermenéutica entre Heidegger y Gadamer, en Signos Filosóficos, N. 10, julio-diciembre, México, pp. 87-102.

- GUIGNON, Charles (2000), Philosophy and authenticity: Heidegger's Search for a Ground for Philosophizing, Essays in honor of Hubert L. Dreyfus: Heidegger, authenticity, and modernity Vol. 1, ed. Wrathall-Malpass, Cambridge: MIT Press. pp-79-101.

- GRAHAM, Archie (2000), Art, Language, and Truth in Heidegger's Radical Zen, Journal of Chinese Philosophy 27:4, pp. 503-543.

- GREISCH, Jean (1994a), Ontologie et temporalité: Esquisse d'une interprétation intégrale de Sein und Zeit, Paris, PUF.

- GREISCH, Jean (1994b), Le phénomène de la chair: un «ratage» de Sein und Zeit. En Floviral, G. (Ed.), Dimensions de l'exister. Etudes de anthropologie philosophique, vol. 40. (pp. 154177). Paris: Éditions Peeters.

- GRONDIN, Jean (2008). ¿Qué es la hermenéutica? Barcelona, Herder. 
- GRONDIN, Jean (2011). El paso de la hermenéutica de Heidegger a Gadamer, De Lara, F. (Ed.). Entre fenomenología y hermenéutica. Franco Volpi In Memoriam. México: Plaza y Valdés. (pp. 139-163).

- GROUSSER, Florian (2011), Revolutionen denken. Heidegger und das Politische 1919-1969. München: Verlag Beck, pp. 66-98.

- GUARIGLIA, Osvaldo (2004), Continuidad y ruptura con la tradición ética aristotélica en Sein und Zeit, Revista Latinoamericana de filosofía, n.30.

- GUIGNON, Charles (1990), Philosophy after Wittgenstein and Heidegger, Philosophy and Phenomenological Research, vol. 50, No 4, pp. 649-672

- HABERMAS, Jürgen (1984), Perfiles filosófico-políticos, Madrid, Taurus.

- HABERMAS, Jürgen (1985), El discurso filosófico de la modernidad, Madrid, Taurus.

- HABERMAS, Jürgen (1987), Teoría de la acción comunicativa, Madrid, Taurus.

- HABERMAS, Jürgen (1989), "Heidegger, Werk und Weltanschauung", Prólogo a la edición alemana de FARIAS (1987).

- HABERMAS, Jürgen (1990), El pensamiento postmetafisico, Madrid, Taurus.

- HALDER, Alois (2006), Heidegger y Levinas, uno en la pregunta del otro, en Revista La lámpara de Diógenes, N.2-3, pp.56-68.

- HAAR, Michel (1990), Heidegger et l'essence de l' homme, Grenoble: Jérôme Millon.

- HEGEL, Georg Wilhelm Friedrich (1807[2007]), Fenomenología del espíritu México, FCE.

- HERRERA DE LA FUENTE, Carlos (2005), Habla o lenguaje en Heidegger y Gadamer, en Contribuciones desde Coatepec, N. 9, julio-diciembre, México, pp. 11-24.

- HERRMANN, F-W. von (1985), Subjekt und Dasein. Interpretationen zu "Sein und Zeit", Frankfurt am Main, Vittorio Klostermann.

- HERRMANN, F-W. von (1990), Wege und Methode. Zur hermeneutischen Phänomenologie des seinsgeschichtlichen Denkens, Frankfurt am Main, Vittorio Klostermann.

- HERRMANN, Friedrich Wilhelm von (1991) Heideggers "Grundprobleme der Phänomenologie". Zur "Zweiten Hälfte" von "Sein und Zeit", Frankfurt am Main, Vittorio Klostermann. (T.C.: La segunda mitad de Ser y Tiempo. Sobre los problemas fundamentales de la Fenomenología de Heidegger, Madrid, Trotta, 1997).

- HERRMANN, Friedrich Wilhelm von (1994), Wege ins Ereignis. Zu Heideggers "Beiträge zur Philosophie”, Frankfurt am Main, Vittorio Klostermann. 
- HERRMANN, Friedrich Wilhelm von (1997), Die „,Beitrāge zur Philosophie” als hermeneutischer Schlüssel zum Spātwerk Heideggers, en Heidegger neu gelesen, ed. Markus Happel, Würzburg: Königshausen und Neumann.

- HERRMANN, F-W. von (2000), Hermeneutik und Reflexion. Der Begriff der Phänomenologie bei Heidegger und Husserl, Frankfurt am Main, Vittorio Klostermann.

- $\quad$ HERRMANN, F-W. von (2002), Sein und Zeit und das Dasein, en Enrahonar, N.34, pp.47-57.

- HOFFMAN, Piotr, (2002): Heidegger and the Problem of Idealism en Dreyfus \& Wrathall ed.: Heidegger reexamined / Vol. II: Truth, Realism and The History of Being. New York \& London: Routledge; pp. 319-327.

- HOLZAPFEL, Cristóbal (2000), Aventura ética, Hacia una ética originaria, Lom Ediciones Facultad de filosofía y humanidades, Universidad de Chile.

- JANKE, Wolfgang (1995), Mito y Poesía en la crisis Modernidad/Posmodernidad. Postontología, Buenos Aires, La Marca.

- JASPERS, Karl (1978[1990]), Notas sobre Heidegger, Barcelona, Grijalbo.

- JIMENEZ REDONDO, Manuel (2001), Epilogo del traductor, en Heidegger, Introducción a la filosofia, Madrid, Cátedra, pp.437-69.

- JIMENEZ REDONDO, Manuel (2015) Mis experiencias como traductor de Fichte, Hegel, Heidegger y Habermas, En: Domínguez Rey, A y Alonso Martos, A. (Eds.) (2015). O Soño transparente da lingua, Espiral Maior, p. 83-104.

- JOHNSON, Felipe (2010). Der Weg zum Leib. Methodische Besinnungen zu einer Ontologie der Leiblichkeit anhand des Denkens Martin Heideggers. Würtzburg: Königshausen \& Neumann.

- JOHNSON, Felipe (2011), El cuerpo como posibilidad de la vida: el modo de despliegue del mundo concreto, en Revista ALPHA, n 33. (pp. 115-130). Osorno: Universidad de Los Lagos.

- JOHNSON, Felipe (2016), La exclusión del cuerpo en Sein und Zeit y la negación de una fenomenología del cuerpo en el pensamiento de Heidegger, en Rev. Pensamiento, V. 72, N. 270, pp.131-145.

- KELKEL, Arion L (1980), La légende d l’ être. Langage ET poésie chez Heidegger, J. Vrin, Paris.

- KISIEL, Theodore (1995), The génesis of Heidegger"s Being and time, University of California Press, Berkeley, Los Angeles, London.

- KUSCH, Rodolfo (1973), El 'estar-siendo' como estructura existencial y decisión cultural Americana, en II Congreso Nacional de filosofemas, Actas II, Sudamericana, Córdoba. 
- KUSCH, Rodolfo (1975), América profunda, Bs As, Bonum.

- KUSCH, Rodolfo (1977), El pensamiento indígena y popular en América, Bs. As ,Hachette.

- KUSCH, Rodolfo (1978), Esbozo de una antropología filosófica Americana, Bs. As., Castañeda.

- LANDGREBE, Ludwig (1968), El camino de la fenomenología, Buenos Aires, Sudamericana.

- LANDGREBE, Ludwig (1975), Fenomenología e historia, Caracas, Monte Ávila.

- LANDGREBE, Ludwig (1982), Faktizität und Individuation. Hamburg, Felix Meiner

- LARRAÍN IBAÑEZ, Jorge (1996), Modernidad, razón e identidad en América Latina, Buenos Aires, Andrés Bello.

- LECONTE, Mariana (2015): El habla habla. El Heidegger del pensar onto-histórico y la pregunta por el origen de la significación lingüistica, en Areté. Revista de Filosofía, Vol. 27, $\mathrm{N}^{\circ} 2$, pp. 267-278.

- LEIRO, Daniel M. (2016), Debate sobre la identidad. Hacia una caracterización del 'Selbst'en el pensamiento de Nietzsche desde la perspectiva de Gianni Vattimo, en Revista de Filosofía, V. 72, pp.:109-121.

- LEON,E. (2009), El giro hermenéutico de la fenomenológica en Martín Heidegger, en Polis , Vol. 8 , n. 22 , Recuperado el 15/01/17 de: http://polis.revues.org/2690

- LEVINAS, Emanuel, (1971[2002]) Totalidad e infinito, Salamanca, Ed. Sígueme.

- LEVINAS, Emanuel (2000), Ética e infinito, Madrid, Machado.

- LEVINAS, Emanuel (2001), Entre nosotros. Ensayos para pensar en otro, Valencia, Pre-textos, trad.: José Luis Pardo.

- LEVINAS, Emanuel, (2003) De otro modo que ser o Mas allá de la esencia, Salamanca, Ed. Sígueme.

- LlORENTE, Jaime (2013), La política del acontecimiento. El "Nacionalismo privado" de Heidegger como totemismo ontológico, en Isegoria. Revista de Filosofía Moral y Política, N. ${ }^{o}$ 49, julio-diciembre, pp. 629-648, Recuperado el 15/01/17: http://dx.doi.org/10.3989/isegoria.2013.049.15

- LUCKACS, Georg (1959), El asalto a la razón, la trayectoria del irracionalismo desde Schelling hasta Hitler, México, FCE.

- LÖWITH, Karl (1968), El sentido de la historia, Madrid, Aguilar.

- LÖWITH, Karl (1984), Heidegger, pensador de un tiempo indigente, Buenos Aires, FCE. 
- LUCKNER, Andreas (2001), Wie es ist, selbst zu sein. Zum Begriff der Eigentlichkeit, en Rentsch (comp.), Martin Heidegger. Sein und Zeit, Berlín, Akademie Verlag, pp.149-68.

- LYOTARD, Jean-François (1995), Heidegger y “los judios”, Buenos Aires, La Marca.

- MACINTYRE, Alasdair (1981[2001]), Tras la virtud, Barcelona, Crítica.

- MACINTYRE, Alasdair (2006), Ética y política, Ensayos escogidos II, Ed. Nuevo Inicio, Granada.

- MALIANDI, Ricardo (1993), Dejar la Posmodernidad. La ética frente al irracionalismo actual, Buenos Aires, Almagesto.

- MARCUSE, Herbert (1991), Herbert Marcuse and Martin Heidegger: An Exchange of Letters, in New German Critique No. 53, Spring - Summer, Duke University Press, pp.28-32. [T.C.: Dos cartas inéditas de Marcuse a Heidegger sobre el nazismo, en Dialéctica N. 20,1988, México, pp.113-116).

- MARION, Jean-Luc (1990), El interpelado, en: Taula, Quaderns de pensement, No. 13-14. Palma de Mayorca, pp. 87-97, Trad. Juan Luis Vermal.

- MARION, Jean-Luc. (2012), Reducción y donación. Investigaciones acerca de Husserl, Heidegger y la fenomenología, Bs. As., Prometeo.

- MARTINEZ GARNICA, Armando (2006), Crónica de la recepción de Heidegger en Hispanoamérica, en Revista de Santander, N.1, Marzo, Bucaramanga, Universidad industrial de Santander, pp.102-25.

- MARTINEZ MATIAS, Paloma (2008), Hablar en silencio, decir lo indecible. Una aproximación a la cuestión de los límites del lenguaje en la obra temprana de Martin Heidegger, en Diánoia, vol. 53, n. 61: pp. 111-147.

- MCINTYRE, Ronald (1986), Husserl and Representational Theory of Mind, Topoi, 5, pp. 101113.

- MOLINUEVO, José Luis, (1998), El espacio político del arte. Arte e historia en Heidegger, Madrid, Tecnos.

- MÖRCHEN, Hermann (1980), Macht und Herrschaft im Denken von Heidegger und Adorno, Stuttart, Klett-Cotta.

- MUller, M. (1961), Crisis de la metafísica, Buenos Aires, Sur.

- MUÑOZ, Iban (2010), Anotaciones sobre una posible fundamentación de la ética en Ser y tiempo de Martin Heidegger, en Revista Praxis filosófica, N. 31, Julio-diciembre, pp.99-108.

- MUÑZ PEREZ, Enrique (2015), Trascendencia, mundo y libertad en el entorno de Ser y Tiempo de Martín Heidegger, en Veritas, N.32, marzo, pp. 95-110. 
- NAISHTAT, Francisco (2004), Problemas filosóficos en la acción individual y colectiva, Una perspectiva pragmática, Buenos Aires, Prometeo.

- NAISHTAT, Francisco (2007), Del Ipse existencial al Ipse narrativo. Fronteras y pasajes entre la fenomenología ontológica de Sartre y la fenomenología hermeneútica de Ricoeur, Revista de filosofía y teoría política.

- NANCY, Jean Luc (2001), La comunidad desobrada, Madrid, Arena Libros.

- NANCY, Jean Luc (2003), La creación del mundo y la mundialización, Barcelona, Paidos Ibérica.

- NANCY, Jean Luc (2014),Heidegger y nosotros, en Reflexiones marginales, N. 24, Recuperado el 15/02/17 de: http://reflexionesmarginales.com/3.0/heidegger-y-nosotros/

- NESKE, Günther y KETTERING, Emil [eds.] (1988), Antwort. Martin Heidegger im Gespräch, Pfullingen.

- NIETZSCHE, Friedrich (1967), Obras completas, Buenos Aires, Aguilar.

- NOLTE, Ernst (1998), Heidegger: Política e historia en su vida y pensamiento, Madrid, Tecnos.

- OLASAGASTI, Manuel (1967), Introducción a Heidegger, Madrid, Ed. Revista de occidente.

- OLIVÉ, León (comp.) (1988), Racionalidad. Ensayos sobre la racionalidad en ética y política, ciencia y tecnología, México, Siglo XXI.

- ORDIERES, Alejandro (2015), La conformación de la persona como relación asimétrica en Emanuel Levinas, en En-claves del Pensamiento, vol. IX, núm. 18, julio-diciembre, pp. 13-39.

- ORDOÑEZ GARCIA, José (2014), Heidegger y la noción de preciencia (Vorwissenschaft) como propedéutica existencial. (Parte 1: El afecto del tiempo), en Estud. Filos, N. 50, diciembre, pp.155-69.

- ORR, James (2014): Being and Timelessness Edith Stein's Critique of Heideggerian Temporality, Modern Theology, 30/1.

- ORTeGA Y GASSET, José (1983a), Adán en el Paraíso, en Obras completas, Madrid, Alianza ; Revista de Occidente

- ORTEGA Y GASSET, José (1983b), Meditaciones del Quijote, en Obras completas, Madrid, Alianza ; Revista de Occidente

- ORTEGA Y GASSET, José (1983 c [1951-1954]), Pasado y porvenir del hombre actual, en Obras completas, Madrid, Alianza; Revista de Occidente. 
- OSSWALD, Andrés (2014), Afección y mundo en los Manuscritos-C de Edmund Husserl, en Revista de Filosofia, 39, pp. 101-119.

- OTT, Hugo (1992), Martin Heidegger. En camino hacia su biografía, Madrid, Alianza.

- OTTO, Rudolph (1917), Das Heilige. Über das Irrationale in der Idee des Götlichen und Sein Verhältnis zum Rationalen. Traducción castellana: Lo sagrado, Buenos Aires, Claridad, 2008.

- PALACIO, Marta (2013), La posición de Levinas en el giro hermenéutico: el lenguaje como ético, en Arete, revisto de filosofía, V.25, N.1, pp.133-52.

- $\quad$ PARFIT, Dereck (1984), Razones y personas, Visor/Antonio Machado, Madrid, 2005.

- PARFIT, Dereck (2004), Personas, racionalidad y tiempo, Madrid, Síntesis.

- PEPERZAK, Adriaan (2011), Algunas Tesis para la crítica de Emmanuel Levinas a Heidegger, en Signos Filosóficos, vol. XIII, núm. 25, enero-junio, pp. 151-168

- PHILPSE, Henry (1998), Heidegger's Philosophy of Being-A Critical Interpretation, Princeton University Press, Princeton.

- PINTOS PEÑARANDA, María Luz (1982), Aspectos de la constitución del yo en la fenomenología heideggeriana, en Ágora: Papeles de filosofía, N.2, pp.109-120.

- PRESAS, Mario (1970) Un diálogo con Heidegger, Folia humanística, Barcelona/España, Vol. VIII, N 88. Reeditado con variantes en Revista de Filosofía, La Plata, N²2 (1970), pp. 90-96.

- PRESAS, Mario (1971) Filosofía e historia de la filosofía en Heidegger, Man and World, Vol. 4, $\mathrm{N}^{\circ} 3$, pp. 294-312.

- PRESAS, Mario (1980) Jaspers contra Heidegger, Criterio, Buenos Aires, Año LIII, N 1838 , pp. 357-359. Reproducido en El café literario, Bogotá, N 9 (1979), pp. 13-16.

- PRESAS, Mario (1982) De Heidegger a Husserl, Manuscrito, Universidade Estadual de Campinas/Brasil, Vol. V, N², pp. 104-116.

- PRESAS, Mario (1983) La experiencia del otro, Escritos de Filosofía, Buenos Aires, N¹2, pp. 47-51

- PRESAS, Mario (1984) Acerca del programa de la fenomenología, Revista latinoamericana de Filosofia, Vol. X, № 3 (Nov.), pp.255-267. Reimpreso en Universidad Nacional de Tucumán, Homenaje al Prof. Dr. Carlos Cossio, Tomo I, San Miguel de Tucumán, 1989, pp. 90-105.

- PRESAS, Mario (1985) Ortega: el abandono de la fenomenología, Escritos de filosofía, Buenos Aires, $\mathrm{N}^{\circ}$ 15/16, (enero-dic. 1985. Impreso en 1988), pp. 83-105.

- PRESAS, Mario (1987), Heidegger, crítico de Husserl, Diálogos, n. 49. 
- PRESAS, Mario (1992) Jaspers y Heidegger en la Alemania de 1933, Diálogos, Universidad de Puerto Rico, $N^{\circ} 60$ (julio), pp.165-185

- PRESAS, Mario (1992) La vergüenza de Heidegger, La Nación, Bs. As., 19 de enero de 1992.

- $\quad$ PRESAS, Mario (1993), Ficción y verdad, en Endoxa N.2, UNED, Madrid, pp.97-112.

- PRESAS, Mario (2002), Arte y ensimismamiento, en Revista de Filosofía y Teoría Política, UNLP, $n^{\circ} 34$, pp. 11-22.

- PRESAS, Mario (2005), Ser hasta la muerte: Notas in memoriam de Paul Ricoeur (1913-2005), en Revista de Filosofía y Teoría Política n. 36, Universidad Nacional de La Plata, pp. 105-109

- PRESAS, Mario (2009), Del ser a la palabra, Buenos Aires, Biblos.

- PROSPERI, German (2015), Vientres que hablan: Ventriloquia y subjetividad en la historia occidental La Plata: Universidad Nacional de La Plata. Facultad de Humanidades y Ciencias de la Educación.

- PÖGGELER, Otto (ed.) (1970), Heidegger. Perspektiven zur Deutung seines Werkes, Köln/Berlin, and Kiepenheuer \& Witsch.

- PÖGGELER, Otto (1984a), Heidegger y Hölderlin, en Filosofía y política en Heidegger, Barcelona, Alfa , pp.129-49

- PÖGGELER, Otto (1984b), Die Frage nach der Kunst, Freiburg/München, Karl Alber.

- PÖGGELER, Otto (1993), El camino del pensar de Martin Heidegger, $3^{\circ}$ edición ampliada, Madrid, Alianza [Trad. Félix Duque].

- RABANAQUE, Luis Román (1998), Alteridad, cinestesia, tiempo, en Escritos de filosofia N. 33-34, pp.91-107.

- RABANAQUE, Luis Román (2013), Naturaleza, cuerpo, cultura, en Actas del XV. Congreso Nacional de Filosofía AFRA (EDUNTREF).

- ROCHA DE LA TORRE, Alfredo (2005), Más allá de las palabras: El lenguaje en la filosofía de Heidegger, en Revista de Filosofía, V. 23, N49, Chile, pp.5-27.

- ROCHA DE LA TORRE, Alfredo (2007), El concepto de cercanía en Martin Heidegger, en Eidos: Revista de Filosofía de la Universidad del Norte, núm. 7, Colombia, pp. 48-86.

- ROCHA DE LA TORRE, Alfredo (ed.) (2009a), Martin Heidegger. La experiencia del camino, Barranquilla, Ediciones de la Universidad del Norte, Primera parte: Ser y Tiempo y su entorno.

- $\quad$ ROCHA DE LA TORRE, Alfredo (ed.) (2009b), Op. cit., Segunda Parte: Heidegger después de la Kehre, y Cuarta Parte: Lenguaje, arte y poesía. 
- ROCKMORE, Tom (1992), Heidegger's Nazism and Philosophy, Berkeley: University of California Press, Recuperado el 15/02/17 de: http://publishing.cdlib.org/ucpressebooks/view?docId=ft6q2nb3wh\&brand=ucpress.

- RODRIGUEZ SUAREZ, Luisa P. (2005), Diferencia ontológica y constitución del sentido en Heidegger, Revista de humanidades n.11, Universidad de Zaragoza.

- RODRIGUEZ GARCIA, Ramón (1993), Historia del ser y filosofía de la subjetividad, en Navarro Cordon y Rodríguez (comps) Heidegger o el final de la filosofía, Ed. Complutense, Madrid, pp.191-205.

- RODRIGUEZ GARCIA, Ramón (1997). La transformación hermenéutica de la fenomenología. Una interpretación de la obra temprana de Heidegger. Madrid, Tecnos.

- RODRIGUEZ GARCIA, Ramón (2012). La indicación formal y su uso en Ser y tiempo. Rodríguez, R. \& Cazzanelli, S. (Eds.). Lenguaje y categorías en la hermenéutica filosófica. Madrid, Biblioteca Nueva. (pp. 157-176).

- ROEHE, Marcelo \& DUTRA, Elza (2014), Dasein, o entendimento de Heidegger sobre o modo de ser humano. Avances en Psicología Latinoamericana, V. 32(1), pp. 105-113.

- ROGNA, Juan E. (2013), La filosofía antropológica americana de Rodolfo Kusch como alternativa real frente al mandato cultural de la tecnocracia, en Nuevo Itinerario. Revista digital de filosofía, V. 8, N.8, Chaco, pp.197-209.

- $\quad$ RORTY, Richard (1980), Philosophy and the Mirror of Nature, Oxford, Blackwell, 1986.

- RORTY, Richard (1993), Escritos filosóficos II. Ensayos sobre Heidegger y otros pensadores contemporáneos, Barcelona, Paidós.

- RORTY, Richard. (1996), Objetividad, relativismo y verdad, Barcelona, Paidós.

- RORTY, Richard (2000), Verdad y progreso, escritos filosóficos 3, Barcelona, Paidós.

- RORTY, Richard (2001), Contingencia, ironía y solidaridad, Barcelona, Paidós.

- ROSSI, Luis (2004), "La política en su sentido más alto: los supuestos políticos y metodológicos de la interpretación heideggeriana de Hölderlin", en Revista Latinoamericana de Filosofía, vol. XXX, No 1, pp. 97-124.

- ROSSI, María José y MUÑIZ, Marcelo (2012), Hermenéuticas de la intersubjetividad en Hegel y Husserl, en Revista Eletrônica Estudos Hegelianos Ano 9, nº 16, Junio, pp. 67-93.

- RUBIN, Abraham (2012), Heidegger desgarrado. El papel de la diferencia en la concepción de Ereignis, en Revista de Filosofía, V. 37, N. 2 (2012), pp. 31-54, Recuperado el 15/02/17 de : http://dx.doi.org/10.5209/rev_RESF.2012.v37.n2.41067

- RUBIO, Roberto (2003), La relevancia de la praxis en la ontología del Dasein, en Areté. Revista de Filosofía, V. XV, N. 2, pp. 303-323. 
- SCANNONE, Juan Carlos (2005), Religion y nuevo pensamiento: hacia una filosofía de la religión para nuestro tiempo de América latina, Anthropos, México, Universidad Autónoma Metropolitana, Iztapalapa.

- SABROVSKY, Eduardo (2011), La crítica de Lévinas a Heidegger en Totalidad e infinito, en Ideas y Valores, vol. 60, núm. 145, abril, pp. 55-68.

- SAEZ RUEDA, L (1995), Facticidad y excentricidad de la razón, en VVAA, Discurso y realidad, Madrid, Trotta.

- SAEZ RUEDA, L (1998), Dimensiones de la ipseidad, Rev. . de filosofía n. 16, Universidad de Granada.

- SAFRANSKI, R. (1994[2003]), Un maestro de Alemania. Heidegger y su tiempo, Barcelona, Tusquets.

- SANCHEZ HERNANDEZ, Francisco (2013), Estima de sí y alteridad. Una reflexión a partir de Paul Ricoeur y de Emmanuel Levinas, en Franciscanum V. 55, N.160, julio - diciembre, pp.111-33.

- SANTIESTEBAN, Luis (2005), Heidegger: la relación de su pensar con la antropología, en Signos Filosóficos, V. 7, N. 13, enero-junio, pp. 73-103.

- SANTIESTEBAN, Luis (2007), Heidegger: el pensar del ser y el último dios, en Signos Filosóficos, v. 9, n. 17, enero-junio, (México), pp. 9-30.

- SANTIESTEBAN, Luis (2009), Heidegger y la ética, México, Editorial Aldus.

- SARTRE, Jean Paul (1968[1936]), La trascendencia del ego, Buenos Aires, Caldén.

- SARTRE, Jean Paul (1970[1960]), Crítica de la razón dialéctica, Precedida de Cuestiones de método, Buenos Aires, Losada.

- SARTRE, Jean Paul (1972[1943]), El ser y la nada, Ensayo de ontología fenomenológica, Buenos Aires, Losada.

- SARTRE, Jean Paul (1982[1945-1949]), El existencialismo es un humanismo, Buenos Aires, Ediciones del 80.

- SCHÜLZ, Walter (1970), Über den philosophiegeschichtlichen Ort M. Heideggers, en O. Pöggeler, Heidegger, Köln-Berlín, Kiepenheur \& Witsch.

- SCHOLZ, Oliver R. (2001), Verstehen und Rationalität, Frankfurt a. M., Vittorio Klostermann.

- SCHÖFER, Erasmus (1962), Die Sprache Heideggers. Neske: Pfullingen. 
- SCHÜMANN, Reiner (1983), ¿Qué hacer en el fin de la metafísica?, en Cahier de l'Herne, N.46 (Heidegger), pp.354-68, Paris. [Trad. :Diego Tatián]

- SlugA, Hans (1993), Heidegger's Crisis: Philosophy and Politics in Nazi Germany ,Cambridge: Harvard University Press,

- SOBREVILLA, David (1986), Repensando la tradición occidental. Filosofía, historia y arte en el pensamiento alemán, Lima, Amaru.

- SOLAS, Silvia (2013), Subjetividad, corporalidad y percepción en la filosofía de MerleauPonty. EN: Solas, Silvia; Oller, Carlos; Ferrari, Luján, coordinadores. Introducción a la filosofia: Argumentación filosófica, lectura académica La Plata: EDULP.

- STEIN, Edith (1962): Martin Heideggers Existentialphilosophie, en Edith Stein Welt und Person, Edith Stein Werke 6, Louvain: Éditions Nauwelaerts.

- STEIN, Edith (1989) On the Problem of Empathy. Washington, C.S Publications.

- STEINER, George (1993), Otra vez Heidegger, en Nombres. Revista de filosofía, N. 3, septiembre, pp.15-27.

- STEINER, George (1999), Heidegger, México, FCE.

- TAMINIAUX, Jacques (1991), Heidegger and the Project of Fundamental Ontology. Albany: State University of New York Press, pp.111-143.

- TAMINIAUX, Jacques (1992), La herencia husserliana en la noción heideggeriana de Selbst, en Rosemary Rizo- Patrón de Lerner: El pensamiento de Husserl en la reflexión filosófica contemporánea, Lima, Pontificia Universidad Católica del Perú/Instituto Riva Agüero.

- TAYLOR, Charles (1994), La Ética de la autenticidad, Barcelona, Paidós.

- TAYLOR, Charles (1996), Fuentes del yo. La construcción de la identidad moderna, .Barcelona, Paidós.

- THEUNISSEN, Michael (1965), Der Andere: Studien zur Sozialontologie der Gegenwart, Berlin, De Gruyter.

- THEUNISSEN, Michael (1993), Der Begriff Verzweiflung. Korrekturen an Kierkegaard, Frankfurt, Suhrkamp.

- $\quad$ THOMÄ, Dieter (1990), Die Zeit des Selbst und die Zeit danach. Zur Kritik der Textgeschichte Martin Heideggers 1910-1976, Suhrkamp, Frankfurt.

- THURNHER, Rainer (2004), Las Ideas de Husserl y Ser y tempo de Heidegger, en Anuario filosófico, 37/2 (pp.429-455), Recuperado el 15/02/17 de : http://dadun.unav.edu/bitstream/10171/4534/1/12.\%20Thurner.pdf 
- TOWARNICKI, Fréderic y PALNIER Jean Michel (1970[1969]), Conversación con Heidegger (tomado de L'Express $n^{\circ}$ 954, 20-26 de octubre 1969), en Revista Ideas y valores, N. 35-37, Bogotá, Universidad Nacional, pp.87-96, trad.: J. Díaz Báez, Recuperado el 15/02/17 de: http://www.bdigital.unal.edu.co/30301/1/29089-104478-1-PB.pdf).

- TRAWNY, Peter (2014), Eine neue Dimension, en Zeit online (2/01/2014), Recuperado el 15/02/17 de: http://www.zeit.de/2014/01/heidegger-schwarze-hefte-herausgeber-peter-trawny

- TRAWNY, Peter (2014b), Heidegger und der Mythos der judischen Weltverschwörung. Frankfurt a/M: Vittorio Klostermann.

- TRAWNEY, Peter, GUIMARÃES, Soraya (2014), Un segundo comienzo. Diálogo con el editor de los Cuadernos Negros de Martin Heidegger, en HYBRIS. Revista de Filosofía, V. $5 \mathrm{~N}^{\circ}$ 1, pp. 95-109, Recuperado el 26/02/17 de: http://revistas.cenaltes.cl/index.php/hybris/article/view/42

- TRIAS, Eugenio (1983), Vigencia de Heidegger, en Heidegger Interpretaciones sobre la poesía de Hölderlin, Ariel, Barcelona, pp.8-22.

- TUGENDHAT, Ernst (1970), Der Wahrheitsbegriff bei Husserl und Heidegger, Berlín, Walter de Gruyter.

- TUGENDHAT, Ernst (1993[1979]), Autoconciencia y autodeterminación, Una interpretación lingüistico-analítica, Madrid, FCE.

- TUGENDHAT, Ernst (1994), La pregunta de Heidegger por el ser, en Revista de Filosofía, 3 época, v.7, núm. 11 (Madrid), pp. 3-26.

- TUGENDHAT, Ernst (1998), Ser-verdad-acción, Ensayos filosóficos, Barcelona, Gedisa.

- TUGENDHAT, Ernst (2002), Problemas, Barcelona, Gedisa.

- TUGENDHAT, Ernst (2004[1997]), Egocentricidad y mística, Un estudio antropológico, Barcelona, Gedisa.

- TUGENDHAT, Ernst (2007), Antropología como filosofía primera, en Thémata. Revista de filosofía, N.39, pp.:39-47.

- VAN BUREN, John (1994). The Young Heidegger. Rumor of the Hidden King. Bloomington: Indiana University Press.

- VATTIMO, Gianni (1971[2006]), Introducción a Heidegger, México, Gedisa.

- VATTIMO, Gianni (1985), El fin de la modernidad. Nihilismo y hermenéutica en la cultura posmoderna, Barcelona, Planeta-Agostini.

- VATtiMO, Gianni (1989), La sociedad transparente, Barcelona, Paidós.

- VATTIMO, Gianni (1991), La ética de la interpretación, Barcelona, Paidos. 
- VATtimo, Gianni (1992), Más allá del sujeto. Nietzsche, Heidegger y la hermeneútica, Barcelona, Paidós.

- VAttimo, Gianni (1998), Las aventuras de la diferencia. Pensar después de Nietzsche y Heidegger, Barcelona, Península.

- VATTIMO, Gianni (2002), Diálogo con Nietzsche. Ensayos 1969-2000, Barcelona, Paidós Ibérica.

- VATtimO, Gianni (2014), Esperando a los bárbaros. Buenos Aires, Fedun.

- VATtimo, Gianni y ROVATTI, Pier Aldo (2002), El pensamiento débil, Madrid, Cátedra.

- VARElA, F. J., THOMPSON, E. y ROSCH, E. (1991): The Embodied Mind: Cognitive Science and Human Experience. Cambridge: MIT Press.

- VELEZ LOPEZ, German (2009) Peso de la existencia y dificultad hermenéutica en la génesis del pensamiento de Heidegger, en Co-herencia, V. 6, N. 10, enero-junio, pp. 113-124.

- VERAZA TONDA, Pablo (2016), El pensar del Ereignis de Heidegger como otra fenomenología. Método e inicio del camino, en Franciscanum. Revista de las ciencias del espíritu, V.58, N. 165, enero-junio, pp. 89-116.

- VERGALITO, Esteban (2005), ¿Ricoeur vs. Derrida?: hacia una aproximación entre Hermenéutica y Deconstrucción, en El Pensadero. Revista de Filosofía, № 1, Bs. As., junio, pp. 19-24.

- VIGO, Alejandro (2003), Verdad, libertad y trascendencia en Heidegger. La radicalización de un motivo central de Sein und Zeit en los escritos de los años 1929-30. En P. Brickle (Ed.), La filosofía como pasión. Homenaje a Jorge Eduardo Rivera Cruchaga en su 75 cumpleaños. Madrid: Trotta, pp.143-90.

- VIGO, Alejandro (2006), La recuperación crítica de la pregunta por el ser en Heidegger, en Signos Filosóficos, V. 8, N.15, enero-junio, pp. 65-104.

- VIGO, Alejandro (2008), Temporalidad y trascendencia, La concepción heideggeriana de la trascendencia del Dasein en Sein und Zeit, en Arqueología y aleteiología y otros estudios heideggerianos. Buenos Aires: ed. Biblos; pp. 39-58.

- VIGO, Alejandro (2014), Heidegger y el origen del enunciado predicativo (Sein und Zeit, §33), en: Vigo, A., Arqueología y aleteiología y otros estudios heideggerianos, Buenos Aires: Biblos, pp.95-128.

- VILLAROEL, Raúl (2006) Heidegger y la filosofía práctica, ser y tiempo como un palimpsesto Revista de filosofía [Santiago de Chile], n. 62, pp.81-99.

- VOLPI, Franco (1994), La existencia como praxis. Las raíces aristotélicas de la terminología de Ser y Tiempo, en Gianni Vattimo (compilador), Hermenéutica y racionalidad, Barcelona, Buenos Aires, etc.; Grupo Editorial Norma. 
- VOLPI, Franco (1996), ¿Es aún posible una ética? Heidegger y la filosofía práctica, Seminarios de filosofía N. 9, pp. 45-73, Recuperado el 20/02/17 de: http://www.konvergencias.net/volpi.htm

- VOLPI, Franco (2006a), Ser y tiempo: semejanzas con la Ética Nicomaquea, en Signos filosóficos, V. VIII, N. 16, julio-diciembre, pp.127-47.

- VOLPI, Franco (2006b), La maravilla de las maravillas: que el ente es. Wittgenstein, Heidegger y la superación "ético-práctica" de la metafísica, en Tópicos, Revista de Filosofía, núm. 30, 2006, pp. 197-231.

- VOLPI, Franco (2008), Goodbye, Heidegger! Mi introducción censurada a los Beiträge Zur Philosophie, en Fenomenología y hermenéutica. Actas del I Congreso Internacional De Fenomenología y hermenéutica, pp. 43-63.

- VOLPI, Franco (2012), Heidegger y Aristoteles, Bs. As., FCE.

- WALDENFELS, Bernhard (1997), De Husserl a Derrida. Introducción a la fenomenología Barcelona, Paidós.

- WALTON, Roberto (1992), Las figuras de la identidad personal en la fenomenología, en Arete, Vol. 4, N. 2, pp.415-41.

- WALTON, Roberto (1993), Husserl. Mundo, conciencia y temporalidad., Buenos Aires, Almagesto.

- WALTON, Roberto (2001), La subjetividad como respuesta y centramiento. Multiplicidad y unidad en las figuras del yo, Rev. Naturaleza humana, V. 3 N.1, Sao Paulo, pp. 9-49.

- WALTON, Roberto (2009), Fenomenología y reflexión sobre el tiempo, la historia, la generatividad y la intersubjetividad, en: Cuaderno de trabajo del V Coloquio Latinoamericano de Fenomenología, Morelia: Coordinación en México del Círculo Latinoamericano de Fenomenología, pp. 46-67.

- WALTON, Roberto (2010), El giro teológico como retorno a los orígenes: la fenomenología de la excedencia, en Rev. Pensamiento y cultura, N.13-2, Diciembre, Colombia, pp.127-140.

- WALTON, Roberto (2012), El "viraje" en los "Beiträge" de M. Heidegger y en los manuscritos $C$ de E. Husserl, en Investigaciones Fenomenológicas, N. 9, pp. 89-115.

- WELTON Donn (2001), The Other Husserl: The Horizons of Transcendental Phenomenology. Bloomington: Indiana University Press.

- WELTON Donn (2003), The New Husserl. A Critical Reader. Bloomington: Indiana University Press. 
- WOLIN, Richard (1990), the politics of being: the political thought of Martin Heidegger, New York, Columbia University, Press.

- WOLIN, Richard (1993), the Heidegger Controversy: A Critical Reader, New York, Columbia University, Press.

- XOLOCOTZI YAÑEZ, Ángel (2004), Fenomenología de la vida fáctica. Heidegger y su camino a Ser y tiempo., México, Universidad Iberoamericana, Plaza y Valdés.

- XOLOCOTZI YAÑEZ, Ángel (2007a), Subjetividad radical y comprensión afectiva. El rompimiento de la representación en Rickert, Dilthey, Husserl y Heidegger, México, Universidad Iberoamericana, Plaza y Valdés.

- XOLOCOTZI YAÑEZ, Ángel (2007b), Martin Heidegger, el hombre. Entrevista con Hermann Heidegger ,en La jornada semanal, N.638, Recuperado el 15/02/17 de http://www.jornada.unam.mx/2007/05/27/sem-angel.html

- XOLOCOTZI YAÑEZ, Ángel (2008), Dos décadas de una atormentada relación: Martin Heidegger y Edmund Husserl 1909-1929, en Contribuciones desde Coatepec n. 15, UNAM, México, pp. 11-37, Recuperado el 15/02/17 de: http://www.redalyc.org/pdf/281/28101501.pdf.

- XOLOCOTZI YAÑEZ, Ángel (2009a). Facetas Heideggerianas. México: Benemérita Universidad Autónoma de Puebla.

- XOLOCOTZI YAÑEZ, Ángel (2009b). La «Escuela» friburguesa de Heidegger. En M. Cepeda \& R. Arango (eds.). Amistad y alteridad. Homenaje a Carlos B. Gutiérrez (493-502). Bogotá: Universidad de los Andes.

- XOlOCOTZI YAÑEZ, A. y TAMAYO, Luis (2012), Los demonios de Heidegger. Eros y manía en el maestro de la Selva Negra, Madrid, Trotta

- XOLOCOTZI YAÑEZ, Ángel (2013), Heidegger y el Nacionalsocialismo. Una crónica (19261936), Madrid, Plaza y Valdés-BUAP.

- XOlOCOTZI YAÑEZ, Ángel (2014), Filosofia, politica y poder: los Cuadernos negros, de Heidegger, en Jornada semanal (20/7/2014), Recuperado el 15/02/17 de: http://www.jornada.unam.mx/2014/07/20/sem-angel.html

- XOlOCOTZI, Ángel y HUERTA, Vanesa (2014), De camino a una hermeneútica de la afectividad, en Revista interdisciplinaria de filosofía y psicología, Vol. 9, N.31, pp. 3-9.

- YOUNG, Julian (1997), Heidegger philosophy Nazism, Cambridge: Harvard University Press.

- ZABALA, Santiago (2005), ¿Qué significa pensar tras el giro lingüístico? La filosofía de Ernst Tugendhat, en Endoxa Series Filosóficas, n. ${ }^{\circ} 20$. Madrid, pp.- 619-637.

- ZABOROWSKI, Holger (2010), Eine Frage von Irre und Schuld? Martin Heidegger und der Nationalsozialismus. Frankfurt am Main: Fischer, pp. 414-420. 
- ZAHAVI, Dan (2003a), How to investigate subjectivity: Natorp and Heidegger on reflection, Continental Philosophy, N.36, pp. 155-176.

- ZAHAVI, Dan (2003b), Inner Time-Consciousness and Pre-reflective Self-awareness, en Welton, D. (ed.): The New Husserl. A Critical Reader. Bloomington: Indiana University Press, pp. $157-80$

- ZAHAVI Dan (2005), Subjectivity and Selfhood. Investigating the first-person Perspective, Massachusetts, MIT press.

- ZAHAVI, Dan, OVERGAARD Soren y SCHWARZ Thomas (eds.) (2003), Den unge Heidegger, Copenhague: Akademisk Forlag

- ZIZEK, Slavoj (2001), El espinoso sujeto. El centro ausente de la ontología política, ed. Paidós, Buenos Aires.

- ZIZEK, Slavoj (2009), Sobre la violencia. Seis reflexiones marginales, Bs. As., Paidós.

- ZIZEK, Slavoj y otros (2010), El prójimo. Tres indagaciones en teología política, Buenos Aires, Amorrortu.

- ZUBIRI, X. (1986), Sobre el hombre, Madrid, Editorial Alianza.

- ZUBIRI, X. (1999), El hombre y la verdad., Madrid, Editorial Alianza

\section{d.- Sobre Filosofía del lenguaje, Fenomenología, Semiótica y Hermenéutica.}

- AGAMBEN, Giorgio (2003), El lenguaje y la muerte, un seminario sobre el lugar de la negatividad, Valencia, Pre-textos.

- AGÍS VILLAVERDE, Marcelino (1997), Metáfora y filosofía. En torno al debate Ricoeur y Derrida, en Aranzueque, G. (ed.), Horizontes del relato. Lecturas y conversaciones con Paul Ricoeur, Madrid, Cuaderno Gris.

- ANKERSMIT, Frank (2004), Historia y tropología. Ascenso y caída de la metáfora, México, Fondo de cultura económica. 
- BARTHES, Roland (1986), El placer del texto en Lección inaugural de la cátedra de Semiología literaria del Colegge de France, México, SXXI.

- BEUCHOT, Mauricio (2003), Hermenéutica analógica y del umbral, Salamanca, San Esteban.

- $\quad$ BLACK, Max (1966), Modelos y metáforas, Madrid, Tecnos.

- BOZAL, Valeriano (1987), Las imágenes y las cosas, Madrid, Visor.

- BRUNER, Jerome (1996), Realidad mental y mundos posibles. Los actos de la imaginación que dan sentido a la experiencia, Barcelona, Gedisa.

- CARLSON, Sacha (2014), Reducción monadológica y reducción fenomenológica: El problema de la reducción en Husserl y en Richir (pp.241-256), en Eikasia N. 57 Julio, Recuperado el 15/02/17 de: http://www.revistadefilosofia.org/57-15.pdf

- CROWELL, Steven G. (2001). Husserl, Heidegger and the Space of Meaning. Illinois: Northwestern University Press.

- DELEUZE, Gilles (1980[2012]), Mil mesetas. Capitalismo y esquizofrenia, Madrid, Pre-textos.

- DELEUZE, Gilles (1968[2005]), Lógica del sentido, Barcelona, Paidos Ibérica.

- DERRIDA, Jacques (1989a [1967a]), La escritura y la diferencia, Barcelona, Anthropos.

- DERRIDA, Jacques (1989b [1987]), Del espíritu. Heidegger y la pregunta, Valencia, Pre textos, Tambien disponible en la versión digital de la Escuela de Filosofía de la universidad de Arcis, Recuperado el 15/02/17 de : www.mercaba.org/SANLUIS/Filosofia/autores/Contempor\%C3\%A1nea/Derrida/Del\%20espirit u.pdf

- DERRIDA, Jacques (1993), La desconstrucción en las fronteras de la filosofía, La retirada de la metáfora, Barcelona, Paidós.

- DERRIDA, Jacques (1994), Políticas de la amistad, Seguido de El oído de Heidegger, Madrid, Trotta.

- DERRIDA, Jacques (1995[1967c]), La voz y el fenómeno, Madrid, Pre-textos.

- DERRIDA, Jacques (1996), El monolingüismo del otro. La prótesis de origen, Buenos Aires, Manantial.

- DERRIDA, Jacques (1997), Como no hablar, y otros textos, Barcelona, Proyecto A.

- DERRIDA, Jacques (2010), Seminario La bestia y el soberano. Volumen 1 (2001-2), Buenos Aires, Manantial.

- DERRIDA, Jacques (2011), Seminario La bestia y el soberano. Volumen 2 (2002-3), Buenos Aires, Manantial. 
- DERRIDA, Jacques (2012 [1967b]), De la gramatología, Madrid, SXXI.

- DERRIDA, Jacques (2013[1972]), Márgenes de la filosofía, Madrid, Cátedra.

- DERRIDA, Jacques (2014), Posiciones, Valencia, Pre-textos.

- DESCOUMBES, Vincent (1998), Lo mismo y lo otro, Cuarenta y cinco años de filosofia francesa [1933-1978], Madrid, Cátedra.

- ECO, Umberto (1979), Obra abierta, Barcelona, Ariel.

- ECO, Umberto (1985), Tratado de semiótica general, Barcelona, Lumen.

- ESQUISABEL, Oscar M. (2003), “Lenguaje, acontecimiento y ser: la metafísica del lenguaje en H-G Gadamer", Cuadernos del Sur, No31-32, pp. 65-89.

- ESQUISABEL, Oscar M (2004), Experiencia, juego y lenguaje en Revista Latinoamericana de Filosofía, 30 (2), pp. :347-359.

- ESQUISABEL, Oscar M. (2009), Dialéctica y hermenéutica, en Ricardo Maliandi (comp.), Actas de las Jornadas Nacionales de Ética. Conflictividad. Buenos Aires, Academia Nacional de Ciencias de Buenos Aires-UCES, pp. 259-270.

- ESQUISABEL, Oscar M. (2016), Leibniz y la hermenéutica: perspectivismo y fusión de horizontes, Revista Dissertatio de filosofía, Vol.3, pp.35-72.

- FERRARI, Lujan (2003), El concepto de identidad narrativa según Paul Ricoeur, tesis de licenciatura, $U N L P$.

- FERRARI, Lujan (2013), La noción de "identidad personal" en el Tratado de la Naturaleza Humana de David Hume. EN: Solas, Silvia; Oller, Carlos; Ferrari, Luján (coord.) Introducción a la filosofía: Argumentación filosófica, lectura académica La Plata: EDULP.

- FREGE, Gottlob (1974), Escritos lógico-semánticos, Madrid, Tecnos.

- $\quad$ FREGE, Gottlob (1991), La búsqueda del significado, Madrid, Tecnos.

- GADAMER, Hans-Georg (1991a), Verdad y Método. Fundamentos de una hermenéutica filosófica, Salamanca, Sígueme [4ºd.] [Trads. Ana Agud Aparicio y Rafael de Agapito].

- GADAMER, Hans-Georg (1991b), La actualidad de lo bello. El arte como juego, símbolo y fiesta, Barcelona, Paidós Ibérica.

- GADAMER, Hans-Georg (1992), Verdad y Método II, Salamanca, Sígueme [Trad. Manuel Olasagasti].

- GADAMER, Hans-Georg (1993), Poema y diálogo, Barcelona, Gedisa. 
- GADAMER, Hans-Georg (2002), Los caminos de Heidegger, Barcelona, Herder [Trad. Ángela Ackerman Pilári].

- GENDE, Carlos (2003), Las condiciones de posibilidad para la interpretación de textos en la teoría de Paul Ricoeur, tesis doctoral, UNLP.

- GOODMAN, Nelson (1990), Maneras de hacer mundos, Madrid, Visor.

- HACKING, Ian (1979), ¿Por qué el lenguaje importa a la filosofía?, Buenos Aires, Sudamericana.

- HAMANN, Johann G. (1994), La metacrítica sobre el purismo de la razón pura, en VV.AA. ¿Qué es ilustración? Tecnos, Madrid, pp. 36-44.

- HERDER, Johann G. von (1982), Ensayo sobre el origen del lenguaje, en Obra selecta, Madrid, Alfaguara, pp. 131-232.

- HUMBOLDT, Wilhelm von (1990), Sobre la diversidad de la estructura del lenguaje humano y su influencia sobre el desarrollo espiritual de la humanidad, Barcelona, Anthropos.

- HERRERA LIMA, M. (1998), Teorías de la interpretación. Ensayos sobre filosofía arte y literatura, México, UNAM.

- HINTIKKA, Jaakko (1979), Saber y creer: Una introducción a la lógica de las dos nociones, Madrid, Tecnos.

- HINTIKKA, Jaakko (1997), Lingua Universalis vs. Calculus Ratiocinator: An Ultimate Presupposition of Twentieth-Century Philosophy, Dordrecht, Kluwer Academia Publishers.

- IRIBARNE, Julia (1988), La intersubjetividad en Husserl. Bosquejo de una teoría, Buenos Aires: Carlos Lohle.

- ISER, Wolfgang (1987) El proceso de lectura. un enfoque fenomenológico en Mayoral, J. A., Estética de la percepción, Madrid, Arco.

- JAUSS, Hans R., (1992), Experiencia estética y hermenéutica literaria, Buenos Aires, Taurus.

- KARCZMARCZYK, Pedro (2007a), Gadamer: aplicación y comprensión, La Plata, Edulp.

- KARCZMARCZYK, Pedro (2007 b), Reglas y conciencia de las reglas: Significado, ontología y escepticismo, tesis doctoral n. 278, UNLP.

- KNUUTTILA, Simo y HINTIKKA, Jaakko (eds.) (1986), the Logic of Being. Historical Studies, Dordrecht, Reidel.

- KRIPKE, Saúl (1978), Identidad y necesidad, Traducción de Margarita Valdés, Cuadernos de Crítica \#7, UNAM. 
- KRIPKE, Saúl (1995), El nombrar y la necesidad, Traducción de Margarita Valdés, UNAM.

- KUSCH, Martin (1989), Language as Calculus vs. Language as Universal Medium. A Study in Husserl, Heidegger and Gadamer, Dordrecht, Kluwer Academia Publishers.

- KUSCH, Martin (1997), "Husserl and Heidegger on Meaning”, en HINTIKKA, Jaakko (1997), pp. 240-268.

- LAFONT, Cristina (1993), La razón como lenguaje. Una revisión del 'giro lingüístico' en la filosofia del lenguaje alemana, Madrid, Visor.

- LAFONT, Cristina (1997), Lenguaje y apertura del mundo, el giro lingüístico de la hermenéutica de Heidegger, Madrid, Alianza.

- LAFONT, Cristina (2005), Was Heidegger an Externalist? En Inquiry: An Interdisciplinary Journal of Philosophy, vol. 48, no. 6, pp. 507-532.

- $\quad$ LAKOFF, G. y JOHNSON, M. (1980), Metáforas de la vida cotidiana, Madrid, Cátedra.

- LEVI-STRAUSS, Claude (1987), Antropología estructural, Barcelona, Paidós.

- LORDA, Andrés Simón (2001) La experiencia de la alteridad en la fenomenología trascendental. Madrid: Caparros editores

- MONASTERIOS, Elizabeth (1998), "Poesía y Filosofia: el aporte de Paul Ricoeur al estudio de la metáfora", en Valdés, M. y otros, Con Paul Ricoeur: indagaciones hermenéuticas, Caracas, Monte Ávila.

- OÑATE Y ZUBÍA, Teresa, GARCÍA SANTOS, Cristina y QUINTANA PAZ, Miguel (eds.) (2005), Hans-Georg Gadamer: Ontología estética y hermenéutica, Madrid, Dykinson.

- PATOČJA, Jan (1988 [1975]), Ensayos heréticos sobre filosofía de la historia, Barcelona, Península.

- PATOČJA, Jan (1991), Kommentar zum «Spiegel»-Interview mit Marti Heidegger, en Die Bewegung der menschlichen Existenz, Ed. K. Nellen, J. Němec y I. Srubar, Stuttgart: KlettCotta.

- PERELMAN, Chaim (1997), El imperio retórico. Retórica y argumentación, Barcelona, Norma.

- PINKER, Steven (2007), El mundo de las palabras. Una introducción a la naturaleza humana, Buenos Aires, Paidós.

- POSADA VARELA, Pablo (2015), ¿Consonancia o distancia? La confrontación HusserlHeidegger en torno al a priori de correlación fenomenológico, en Eikasia n.64 Mayo, pp. 2352, Recuperado el 15/02/17 de: http://www.revistadefilosofia.org/64-02.pdf. 
- RICHIR, Marc (1992), Méditations Phénoménologiques. Phénoménologie et phénoménologie du langage, Grenoble, Jérôme Millon.

- RICHIR, Marc (2001), Phénoménologie en esquisses. Grenoble: Editions Jérôme Millon.

- RICHIR, Marc (2012), Sintesis pasiva y temporalización/especialización, Acta fenomenológica Latinoamericana, Volumen IV, Circulo Latinoamericano de fenomenología, Lima, págs. 665692, Recuperado el 15/02/17 de http://www.clafen.org/AFL/V4/665-692_DOC_Richir.pdf

- RICOEUR, Paul (1976[1995]), Teoría de la interpretación. Discurso y excedente de sentido, México, Siglo XXI.

- RICOEUR, Paul (1990), Sí mismo como otro, México, SXXI.

- RICOEUR, Paul (1998), Tiempo y narración I, II Y III, México, SXXI.

- RICOEUR, Paul (2001), Del texto a la acción. Ensayos de hermenéutica II, Buenos Aires, FCE.

- RICOEUR, Paul (2003), El conflicto de las interpretaciones. Ensayos de hermenéutica, Buenos Aires, Fondo de cultura económica.

- RICOEUR, Paul (2004), Caminos del reconocimiento, tres estudios, Madrid, Trotta.

- RICOEUR, Paul (2006), La vida: un relato en busca de narrador, Ágora, Santiago de Compostela, 25, 2.

- RODRIGUEZ PEREYRA, Gonzalo (1993), Kripke y las descripciones rígidas, Revista latinoamericana de filosofía, n.19.

- RORTY, Richard (1990), El giro lingüistico. Dificultades metafilosóficas de la filosofía lingüistica, Barcelona, Paidós.

- SAUSSURE, FERDINAND de (1945), Curso de lingüística general, Buenos Aires, Losada.

- SZILASI, Wilhelm (1959), Introducción a la filosofía de Husserl, Bs. As. , Amorrortu.

- STEINER George (1982), Lenguaje y silencio. Ensayos sobre la literatura, el lenguaje y lo inhumano, Barcelona, Gedisa.

- TODOROV, Tzvetan (1992), Simbolismo e interpretación, Caracas, Monte Ávila, 1992.

- TODOROV, Tzvetan (1993), Teorías del símbolo, Caracas, Monte Ávila.

- WHEELWRIGHT, Philip (1979), Metáfora y realidad, Madrid, Espasa-Calpe.

- WiTtGENSTEIN, Ludwig (1972), Tractatus logico-philosophicus, Madrid, Alianza. 
- WITTGENSTEIN, Ludwig (2002), Investigaciones filosóficas, Barcelona, Crítica.

- XIRAU, Joaquín (1966), La filosofía de Husserl, Bs. As., Troquel. 
